\begin{tabular}{|c|c|}
\hline Pobreza y desigualdad : en América Latina y el Caribe & Titulo \\
\hline Gaitán, Flavio - Autor/a & Autor(es) \\
\hline Calvi, Gabriel - Autor/a & \\
\hline Ocampo Meneses, Heidy Paola - Autor/a & \\
\hline Viáfara López, Carlos Augusto - Autor/a & \\
\hline Boniolo, Paula - Autor/a & \\
\hline Boniolo, Paula - Compilador/a o Editor/a & \\
\hline Otero, María Pía - Autor/a & \\
\hline Otero, María Pía - Compilador/a o Editor/a & \\
\hline Di Virgilio, María Mercedes - Autor/a & \\
\hline Di Virgilio, María Mercedes - Compilador/a o Editor/a & \\
\hline Hernández Chávez, Mónica L. - Autor/a & \\
\hline Sánchez, Jhon Antón - Autor/a & \\
\hline Antequera D., Nelson - Autor/a & \\
\hline Blanco, Osvaldo - Autor/a & \\
\hline Scala, Lorena M. - Autor/a & \\
\hline Martínez Alonso, Gleidys - Autor/a & \\
\hline Buenos Aires & Lugar \\
\hline CLACSO & Editorial/Editor \\
\hline 2011 & Fecha \\
\hline CLACSO-CROP & Colección \\
\hline Exclusión social; Estratificación social; Distribución del ingreso; Desigualdad; & Temas \\
\hline Pobreza; Políticas públicas; Educación; Estrategias de reducción de la pobreza; & \\
\hline América Latina; Caribe; & \\
\hline Libro & Tipo de documento \\
\hline $\begin{array}{l}\text { http://bibliotecavirtual.clacso.org.ar/clacso/clacso-crop/20120521095917/DiVirgilio-Ote } \\
\text { ro-Boniolo-2010.pdf }\end{array}$ & URL \\
\hline $\begin{array}{l}\text { Reconocimiento-No comercial-Sin obras derivadas } 2.0 \text { Genérica } \\
\text { http://creativecommons.org/licenses/by-nc-nd/2.0/deed.es }\end{array}$ & Licencia \\
\hline
\end{tabular}

Segui buscando en la Red de Bibliotecas Virtuales de CLACSO http://biblioteca.clacso.edu.ar

Consejo Latinoamericano de Ciencias Sociales (CLACSO)

Conselho Latino-americano de Ciências Sociais (CLACSO)

Latin American Council of Social Sciences (CLACSO)

www.clacso.edu.ar

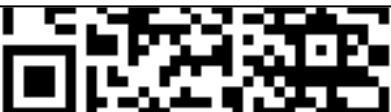

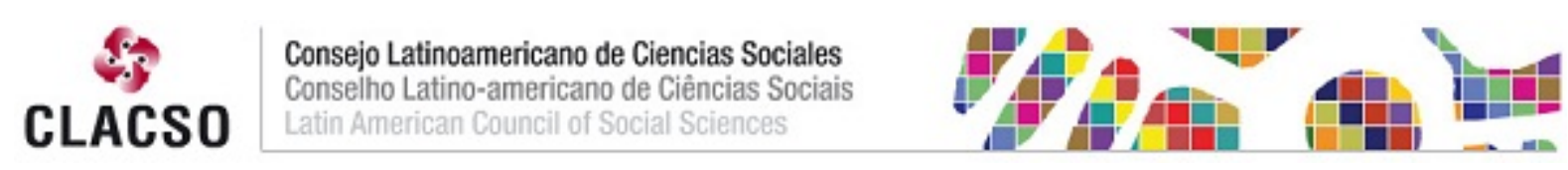




\title{
POBREZA Y DESIGUALDAD EN AmÉriCA LATINA Y El CARIBE
}

\author{
María Mercedes Di Virgilio, \\ María Pía Otero y PaUla Boniolo \\ [COORDINADORAS]
}


Pobreza y desigualdad en América Latina y el Caribe / María Pía Otero ... [et.al.]. - 1a ed. -

Buenos Aires : Consejo Latinoamericano de Ciencias Sociales CLACSO, 2010.

348 p. ; 16x26 cm. - (CLACSO-CROP / Alberto Cimadamore)

ISBN 978-987-1543-61-8

1. Sociología. 2. Ciencias Políticas. I. María Pía Otero CDD 301

Otros descriptores asignados por la Biblioteca virtual de CLACSO: Pobreza / Desigualdad / Desigualdad social / Exclusión social / Estratificación social / Política social / Distribución del ingreso / Estrategias de reducción de la pobreza / América Latina / Caribe 
La Colección CLACSO-CROP tiene como objetivo principal difundir investigaciones originales y de alta calidad sobre la temática de la pobreza. La colección incluye los resultados de las actividades que se realizan en el marco del Programa CLACSO-CROP de Estudios sobre Pobreza en América Latina y el Caribe (becas, seminarios internacionales y otros proyectos especiales), así como investigaciones relacionadas con esta problemática que realizan miembros de la red CLACSO-CROP y que son aprobadas por evaluaciones académicas externas. 
CLACSO

\section{Secretario Ejecutivo}

Emir Sader

\section{Comité Directivo [Miembros Titulares]}

Julio César Gambina

Fundación de Investigaciones Sociales y Políticas

(FISyP), Argentina

Luis Tapia

Posgrado Multidisciplinario en Ciencias del Desarrollo (CIDES),

Universidad Mayor de San Andrés (UMSA), Bolivia

José Vicente Tavares

Programa de Pós-Graduação em Sociologia, Instituto de Filosofia e Ciências Humanas (IFCH), Universidade Federal do Rio Grande do Sul (UFRGS), Brasil

\section{Carmen Caamaño Morúa}

Instituto de Investigaciones Sociales (IIS), Universidad de Costa Rica (UCR), Costa Rica

Jesús Redondo Rojo

Departamento de Psicología (DP), Facultad de Ciencias Sociales (FACSO), Universidad de Chile (UC), Chile

Gabriel Misas Arango

Instituto de Estudios Políticos y Relaciones Internacionales (IEPRI), Universidad Nacional de Colombia (UNAL), Colombia

\section{Suzy Castor Pierre-Charles}

Centre de Recherche et de Formation Économique et Sociale pour le Développement (CRESFED), Haití

Francisco Luciano Concheiro Bórquez

Centro Universitario de Ciencias Sociales y

Humanidades (CUCSH), Universidad de Guadalajara (UDG), México

\section{CRPP}

\section{Director}

Hans Egil Offerdal

\section{Comité Científico}

Thomas Pogge

Chair of CROP Scientific Committee

Leitner Professor / Philosophy and International Affairs Yale University, USA

Julio Boltvinik

Professor / Centro de Estudios Sociológicos, El Colegio de México, México

\section{Atilio Boron}

Professor / Programa Latinoamericano de Educación a Distancia en Ciencias Sociales (PLED), Argentina

Jean Comaroff

Professor / Department of Anthropology, University of Chicago, USA

Bob Deacon

Professor / Department of Sociological Studies University of Sheffield, UK

\section{Shahida El Baz}

Dr. / The National Center for Social and Criminological Research (NCSCR), Egypt

\section{Sara Hossain}

Lawyer / Supreme Court, Bangladesh

\section{Asunción Lera St. Clair}

Professor / Department of Sociology, University of Bergen, Norway

Karen 0'brien

Professor / Department of Sociology and Human Geography, University of Oslo, Norway

Adebayo Olukoshi

Director / United Nations African Institute for Economic Development and Planning (IDEP), Senegal

\section{Isabel Ortiz}

Associate Director / UNICEF

Shahra Razavi

Research Co-ordinator / United Nations Research Institute for Social Development (UNRISD)

\section{CROP}

\section{CLACSO}

Consejo Latinoamericano de Ciencias Sociales Conselho Latino-americano de Ciências Sociais

Av. Callao 875, piso $4^{\circ} \mathrm{G}$

C1023AAB, Buenos Aires, Argentina

Tel. (54 11) 48116588 / 48142301 - Fax (54 11) 48128459

$<$ www.clacso.org >

$<$ clacso-crop@clacso.edu.ar>

\section{Comparative Research Programme on Poverty}

P.O. Box 7800

N-5020 Bergen, Noruega

Tel. 4755589744

$<$ www.crop.org>

$<$ crop@uib.no> 


\title{
POBREZA Y DESIGUALDAD EN AmÉrica LATINA Y EL CARIBE
}

\author{
María Mercedes Di Virgilio, \\ María Pía Otero y Paula Boniolo \\ [COORDINADORAS]
}

\author{
Carlos Augusto Viáfara lópez \\ Heidy Paola Ocampo Meneses \\ Gabriel CALVI \\ Flavio Gaitán \\ Mónica L. HernáNdez Chávez \\ JHON ANTÓN SÁNCHEZ \\ NeLSON ANTEQUeRA D. \\ Osvaldo Blanco \\ LORENA M. SCALA \\ GLEIDYs MARTÍNEZ ALONSO
}

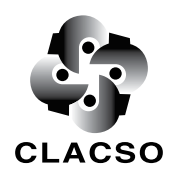


Editor Responsable Emir Sader, Secretario Ejecutivo de CLACSO

Coordinador Académico Pablo Gentili, Secretario Ejecutivo Adjunto de CLACSO

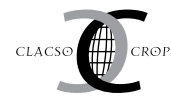

\section{Colección CLACSO-CROP}

Directores de la colección Alberto Cimadamore y Hans Egil Offerdal

Coordinación Fabiana Werthein

Asistente Santiago Kosiner

Área de Producción Editorial y Contenidos Web de CLACSO

Responsable editorial Lucas Sablich

Director de arte Marcelo Giardino

Responsable de contenidos web Juan Acerbi

Webmaster Sebastián Higa

Logística Silvio Nioi Varg

Producción Fluxus estudio

Arte de tapa Ignacio Solveyra

Impresión Gráfica Laf SRL

\section{CLACSO}

Consejo Latinoamericano de Ciencias Sociales - Conselho Latino-americano de Ciências Sociais

Av. Callao 875 Piso $3^{\circ}$ E I C1023AAB Ciudad de Buenos Aires, Argentina

Tel. [54 11] 48116588 I Fax [54 11] 48128459 I <clacso@clacso.edu.ar> I <www.clacso.org>

\section{Primera edición en español}

Pobreza y desigualdad en América Latina y el Caribe

(Buenos Aires: CLACSO, mayo de 2011)

ISBN 978-987-1543-61-8

(C) Consejo Latinoamericano de Ciencias Sociales

Queda hecho el depósito que establece la Ley 11723

Patrocinado por la Agencia Noruega de Cooperación para el Desarrollo Norad

No se permite la reproducción total o parcial de este libro, ni su almacenamiento en un sistema informático, ni su transmisión en cualquier forma o por cualquier medio electrónico, mecánico, fotocopia u otros métodos, sin el permiso previo del editor.

Este libro está disponible en texto completo en la Red de Bibliotecas Virtuales de CLACSO $<$ www.biblioteca.clacso.edu.ar $>$

La responsabilidad por las opiniones expresadas en los libros, artículos, estudios y otras colaboraciones incumbe exclusivamente a los autores firmantes, y su publicación no necesariamente refleja los puntos de vista de la Secretaría Ejecutiva de CLACSO. 


\section{ÍNDICE}

Pobreza y desigualdad en AMÉRICA LATINA Y EL

CARIBE: INTRODUCCIÓN A UN PROBLEMA COMPLEJO

María Pía Otero, María Mercedes Di Virgilio

Y PAULA BONIOLO

EFECTOS DEL CAMBIO ESTRUCTURAL EN LAS

OPORTUNIDADES EDUCATIVAS Y OCUPACIONALES EN LA

CiUdad de CAli, Colombia

CARLos Augusto Viáfara López

RECORRIDOS Y CAUSALIDADES DE LA DESIGUALDAD EN

EL INGRESO LABORAL EN AMÉRICA LATINA: ANÁLISIS

COMPARADO DE LOS CASOS ECUATORIANO Y NICARAGÜENSE

HeIDY PaOla OCAMPo MenESES

LAS METAMORFOSIS DE LA DESIGUALDAD DE INGRESOS EN

LA ARgENTINA (1974-2005)

GABRIEL CALVI 
CRECiMiento, DESiguALdAd Y POBREZA EN EL

CAPITALISMO PERIFÉRICO: ANÁLISIS DE LOS PAÍSES

LATINOAMERICANOS

Flavio GAITÁn

EXCLUSIÓN LABORAL Y EMIGRACIÓN EN EL SALVADOR:

EFECTOS DE LAS REMESAS FAMILIARES SOBRE LA SITUACIÓN DE POBREZA DE LOS HOGARES DURANTE EL PERÍODO 1990-2004

MóniCA L. HeRnáNDEZ Chávez

EXCLUSIÓN, POBREZA Y DISCRIMINACIÓN RACIAL EN LOS AFROECUATORIANOS: LAS RESPUESTAS DESDE SUS ORGANIZACIONES SOCIALES JHON ANTÓN SÁNCHEZ

EL SISTEMA DE ORGANIZACIÓN ORIGINARIO Y EL CICLO AGRÍCOLA-COMERCIAL-LABORAL COMO ESTRATEGIAS DE RESISTENCIA A LA POBREZA EN EL CONTEXTO DE LA MUNICIPALIZACIÓN. El CASO DE LAS COMUNIDADES INDÍGENAS DEL AYLLU KIRKYAWI (BOLIVIA)

Nelson ANTEQUERA D.

MICROCRÉDITO Y EMPRENDIMIENTO EN CHILE. UN ANÁLISIS DESDE LA IDEOLOGÍA Y EL ANÁLISIS DE DISCURSO Osvaldo Blanco

TRABAJO, POBREZA Y POLÍTICAS SOCIALES DE EMPLEO. Un ACERCamiento a los EMPRENdimientos del Plan DE DesarRollo local y Economía Social MaNos a la ObRa EN LA PROVINCIA DE MENDOZA

LORENA M. SCALA

INTER(DES)CONEXIONES DEL ESTADO Y LA SOCIEDAD CIVIL EN LAS POLÍTICAS Y ESTRATEGIAS DE SUPERACIÓN DE LA POBREZA EN CUBA

GLEIDYS MARTÍNEZ ALONSO 


\title{
Pobreza y desigualdad en América latina y el Caribe
}

\author{
INTRODUCCIÓN A UN PROBLEMA COMPLEJO
}

\author{
María Pía Otero, María Mercedes \\ Di Virgilio y Paula Boniolo*
}

TODAS LAS SOCIEDADES COMPLEJAS se caracterizan, en diferentes grados, por la desigualdad en la distribución de las recompensas materiales y simbólicas socialmente generadas. El término estratificación social describe las estructuras sistemáticas de la desigualdad. Tanto las sociedades tradicionales como preindustriales justificaban su desigualdad a partir de cierto orden divino o natural. En contraposición a esta idea, durante el siglo XVII se argumentó que las personas nacen iguales en virtud de su humanidad y, por ende, debe buscarse una explicación a las causas persistentes de la desigualdad social (Crompton, 1994). Las desigualdades sociales no son naturales, sino por el contrario, la resultante de un proceso de construcción sociocultural. Numerosos autores buscaron dar respuesta a estos interrogantes: ¿cómo se pueden explicar y justificar las desigualdades en las sociedades? ¿Cuáles son las dimensiones que están por detrás de la estratificación social y que sostienen y reproducen estas desigualdades? Podemos imaginar un recorrido teórico comenzando con los clásicos de la sociología -Marx, Weber, Parsons, entre otros- y sus relecturas contemporáneas, seguidos por autores como Bourdieu o Giddens y reconociendo los aportes de autores latinoamericanos como Germa-

* CONICET-Instituo de Investigación Gino Germani/Universidad de Buenos Aires. 
ni, Florestán Fernández y González Casanovas, para nombrar sólo a algunos de los tantos referentes. Estos autores intentaron dar respuestas, desde múltiples teorías, en diferentes sociedades y momentos históricos, al problema de la desigualdad y la estratificación social.

América Latina y el Caribe ha sido desde la colonia un continente marcado por profundas desigualdades sociales y político-económicas.

La persistencia de estas desigualdades ha sido un rasgo característico de su devenir histórico, pese a los esfuerzos que se han emprendido, a través de políticas públicas de combate contra las formas más extremas de desigualdad (Salas, 2004).

La desigualdad social y la pobreza son los principales problemas que enfrenta históricamente la región:

En 1990, el 46\% de los latinoamericanos vivían en la pobreza y cerca de la mitad de ellos eran indigentes carentes de recursos para satisfacer necesidades fundamentales. Así, en 1990 había 195 millones de pobres en América Latina, mientras se registraban 76 millones más que en 1970 (O’Donnell, 1999).

Actualmente, según los datos de CEPAL ${ }^{1}$, América Latina y el Caribe continúa siendo la región más desigual del mundo en términos de la distribución de ingresos y de activos como tierra, capital, salud, educación y tecnología. Las estimaciones más recientes para los países de América Latina, correspondientes al año 2007, muestran que la incidencia de la pobreza alcanza un 34,1\% (184 millones de personas pobres) de la población de la región. De este porcentaje las personas que viven en condiciones de pobreza extrema o indigencia representan un 12,6\% (68 millones de indigentes). A pesar de ello, el panorama actual parece ser más alentador del que se presentaba en el año 2002, en el que históricamente las mediciones registraron el mayor número de pobres (221 millones de pobres y 97 millones de personas indigentes) (CEPAL, 2008).

A pesar de los avances que muestran las mediciones, el porcentaje de latinoamericanos que vive en condiciones de privación es muy elevado. Si bien este ha descendido 14 puntos porcentuales desde inicios de la década del noventa, aun queda un largo camino por recorrer. Los

1 La CEPAL clasifica como "pobre" a una persona cuando el ingreso por habitante de su hogar es inferior al valor de la "línea de pobreza" o monto mínimo necesario que le permitiría satisfacer sus necesidades esenciales. En el caso de la indigencia, la línea utilizada refleja únicamente el costo de satisfacer las necesidades de alimentación (CEPAL, 2008). 
países que más disminuyeron la pobreza, según las cifras del 2007, fueron Bolivia y Brasil, en donde los descensos excedieron los tres puntos porcentuales por año, seguidos de Honduras, Paraguay y Venezuela en donde superaron los 2 puntos porcentuales por año. Los mayores avances registrados en los índices de pobreza e indigencia en los países de América Latina en el periodo 2002-2007 se deben al incremento en los ingresos medios de los hogares. Sin embargo, la participación de los efectos del crecimiento económico en los países de la región ha sido heterogénea y en varios de ellos las reducciones de los índices de pobreza tienen por principal factor explicativo la mejor distribución de los ingresos antes que mejores niveles de crecimiento.

El mercado de trabajo en América Latina presenta elevadas tasas de desempleo entre los pobres, las mujeres y los jóvenes. Aunque los datos de CEPAL (2008: 25) muestran que las tasas de desempleo en el decil más pobre de los hogares bajaron del $30,2 \%$ al $23,8 \%$ en el periodo 2002-2006, la brecha con el decil más rico aún supera los 20 puntos porcentuales. Esta reducción en el desempleo urbano no ha modificado las diferencias entre hombres y mujeres, manteniéndose elevadas en el caso de las mujeres. En el caso de los jóvenes, el desempleo mostró una disminución pronunciada entre 2002 y 2006, pero aún continúa siendo superior al de otros grupos etáreos. Asimismo, los datos ponen en evidencia la existencia de situaciones de precariedad laboral extendidas: puestos de trabajos insertos en sectores de baja productividad, mala calidad, bajas remuneraciones y caracterizados por la inestabilidad laboral y la falta de acceso a los sistemas de seguridad social.

Los datos de la CEPAL nos acercan al panorama de las carencias materiales que sufren muchos latinoamericanos. Sin embargo, la pobreza es un problema social complejo que abarca otras dimensiones que superan la dimensión material para la reproducción de la vida cotidiana. A continuación expondremos los enfoques que en la actualidad contribuyen a la conceptualización, definición y medición de la pobreza (PNUD, 2000). Cada uno de ellos recupera diferentes dimensiones del fenómeno y constituyen un buen punto de partida para dar cuenta de sus complejidades.

En primer enfoque se pregunta: ¿qué y cuánto poseen? Este enfoque asocia el problema de la pobreza a la carencia, escasez y privación. Es decir, a la imposibilidad de las personas para acceder a un conjunto de bienes y servicios materiales que les permitan satisfacer sus necesidades fundamentales. Su objetivo se limita a identificar las personas y grupos poblaciones que sufren una o más carencias, apuntando a cuantificar en forma directa, a través del índice de las Necesidades Básicas Insatisfechas (NBI). El NBI pone énfasis en el 
consumo. Por otro lado, está la Línea de Pobreza (LP), que pone el acento en la insuficiencia de ingreso para la satisfacción de las necesidades. Algunas limitaciones de este enfoque radican en que sólo tiene en cuenta la dimensión económica y que excluye las dimensiones no materiales, como la dimensión social. El concepto de necesidades básicas se refiere a lo requerido por una comunidad para su sobrevivencia. Este concepto plantea dificultades a la hora de definir el "conjunto de necesidades", en el momento de escoger y caracterizar esos bienes y servicios considerados como básicos. Asimismo, el ingreso resulta ser un indicador indirecto que no habla de las condiciones de vida de las personas. Una de las críticas a este enfoque es que la forma de medir la pobreza no tiene en cuenta una mirada integral que tenga como horizonte las desigualdades y la equidad y justicia como valores subyacentes a la sociedad. En este sentido, la medición encierra un concepto que reduce la pobreza al cálculo del ingreso o a las necesidades básicas insatisfechas y no da cuenta de la distribución total del ingreso y del nivel de riqueza que dispone la sociedad. Es decir, no pone en relación al todo, y no piensa la pobreza de forma dinámica y relacional. La medición del NBI apunta a políticas que intentan aliviar la pobreza mediante la provisión de bienes, y en este sentido apunta a la elaboración de políticas sociales sectoriales (vivienda, salud, etcétera). La medición de la línea de pobreza conduce a políticas económicas de empleo e ingresos.

El segundo enfoque se focaliza en la pregunta: ¿quiénes son excluidos y de qué son excluidos? Este enfoque liga la pobreza a la exclusión social y la entiende como un problema multidimensional en el que se consideran las carencias de ingreso, empleo, vivienda, salud, educación, seguridad. Este enfoque considera la pobreza como un proceso en el que es importante el rol que juegan las instituciones. Una de sus ventajas es que apunta a que las políticas consideren las prioridades locales y las nociones de integración, donde los derechos son fundamentales. Una de las críticas que se le hace a este enfoque es la falta de indicadores mensurables y la dificultad para diferenciar grupos. Su medición solo muestra una privación de largo alcance y de carácter crónico, y pierde de vista los alcances a corto plazo.

Por último, el tercer enfoque es el de Amartya Sen, quien se interroga: ¿quién puede hacer qué? Este enfoque plantea una visión integral de la problemática de la pobreza entendida como carencia y privación de capacidades. Esta concepción parte de la precariedad de las dotaciones iniciales que poseen las personas y que les impiden el ejercicio efectivo de sus derechos, por lo que se traducen en una baja calidad de vida. Estas dotaciones de recursos hacen referencia a los recursos que son el punto de partida para poner en acción sus capa- 
cidades y contemplan los bienes y servicios mercantiles y no mercantiles. Este enfoque avanza en la explicación de las causas e incorpora las implicaciones de política públicas. Es dinámico y contempla el carácter intergeneracional, incorporando la desigualdad y la inequidad en su medición, ya que permite conocer la brecha entre pobres y no pobres, así como la distribución entre los pobres. Asimismo, incorpora una variedad de conceptos que permiten distinguir grupos; así distingue entre pobreza: absoluta, relativa, coyuntural y estructural. El Índice de Desarrollo Humano, el Índice de Condiciones de Vida y el Índice de Sen son formas de medición que avanzan en esta dirección. La política se orienta hacia garantizar el ejercicio efectivo de los derechos fundamentales que permite diferenciar los grupos de pobres y por tanto se pueden identificar las políticas más apropiadas para erradicar cada uno de ellos. El enfoque analítico lleva a un cuestionamiento del orden social que requiere de reformas estructurales y coyunturales para combatir la pobreza, haciendo énfasis en las políticas primarias de redistribución del ingreso.

En este marco, entendemos la pobreza como un problema multidimensional relacionado con un proceso de escasez de recursos económicos, sociales, culturales, institucionales y políticos que afecta a gran parte de personas en el mundo y particularmente a muchos latinoamericanos. En nuestra región la pobreza se vincula con la inestabilidad, la informalidad, los bajos salarios y la precariedad de las condiciones de inserción en el mercado de trabajo (Ziccardi, 2008: 11). Para poder ir más allá de la mera descripción, es preciso comprender a la pobreza no como algo individual que atañe a las personas -tanto si hablamos de causas como de consecuencias- sino entenderla como un fenómeno social a partir de una mirada relacional que integra, en el proceso social, el interjuego entre las condiciones materiales, las instituciones, las reglas de juego -formales e informales- que rigen las relaciones sociales y las acciones colectivas y culturales de los actores sociales que están involucrados en él.

Asimismo, un concepto más integral de pobreza implica explicitar las consecuencias políticas que subyacen a las diferentes concepciones de la pobreza y a sus mediciones. Una conceptualización compleja del fenómeno debería permitirnos aprehender integralmente sus características e incorporar analíticamente los factores que están en su origen y dinámica, así como hacer evidentes las implicancias que la definición y la medición tienen en la orientación de las políticas para su erradicación. Para poder combatir la pobreza y la desigualdad en la región es necesario contar con estudios que contemplen una mirada multidimensional desde diferentes enfoques y metodología. Al mismo tiempo es necesaria una mirada aguda sobre los problemas 
sociales que contribuya a repensar, desde una perspectiva académica y también política, el tema de la desigualdad social en la región. La reflexión basada en enfoques críticos que tengan en cuenta no sólo la descripción, sino también la comprensión y el diagnóstico de la situación, resulta fundamental a fin de brindar insumos que permitan diseñar políticas tendientes a accionar colectivamente sobre nuestro continente. Los artículos contenidos en este libro colaboran en este recorrido.

\section{EXPLICACIONES ESTRUCTURALES DE}

\section{LA POBREZA Y LA DESIGUALDAD}

El trabajo de Viáfara López, a partir del modelo teórico de logro de status (Blau y Duncan, 1967), analiza los cambios y continuidades en la transmisión intergeneracional de ventajas educacionales y ocupacionales con datos secundarios de una encuesta sobre estratificación social y movilidad realizada en la Ciudad de Cali, Colombia, en 1998. Concluye que la expansión educativa observada en las últimas décadas no ha sido suficiente para garantizar una ampliación de las oportunidades educativas y ocupacionales a los grupos sociales históricamente desaventajados, ya sea por rasgos étnico-raciales como por el origen socioeconómico. En su estudio, el autor corrobora que el estatus socioeconómico de la familia de origen, lejos de menguar su influencia, tiene un peso significativo sobre las oportunidades educativas de los hijos ${ }^{2}$. Asimismo, cuando se analizan los factores que explican los destinos ocupacionales, advierte que la educación tiene un peso mayor que el origen social. El proceso de estratificación social también se ve influenciado por variables como el color de la piel y el sexo, que contribuyen con la explicación de buena parte de las desigualdades en los logros ligadas al origen social. En este sentido, el trabajo permite observar cómo las mujeres negras tienen menos oportunidades por su color de piel que los hombres negros, aunque también están en desventaja. Las razones de esta falta de oportunidades se asocian preponderantemente con su origen social y con una menor educación. En este sentido, el trabajo contribuye al conocimiento de cómo influyen la raza y el estatus socioeconómico (a través de los logros educacionales) sobre la inserción en ciertas posiciones socio-ocupacionales dentro de la estructura social. Aun cuando se ha

2 El compendio de estudios de Shavit y Blossfeld (1993) presenta una vasta evidencia empírica sobre trece países que pone en cuestión las predicciones acerca de que en el transcurso del desarrollo industrial el efecto de los recursos familiares sobre los logros educacionales y socioeconómicos de los hijos disminuye (Parsons, 1971; Blau y Duncan, 1967). A pesar de la modernización observada a lo largo del siglo XX, las desigualdades no han disminuido sino que se han mantenido relativamente estables. 
extendido la educación y se ha modernizado en parte la economía, estos cambios no han sido suficientes para atenuar las desigualdades preexistentes entre los distintos grupos sociales sino que, por el contrario, se ha reforzado la pertenencia a cierto grupo étnico-racial como factor que profundiza las desigualdades en las oportunidades educacionales y ocupacionales.

En un estudio acerca de los procesos que determinan la desigualdad en los ingresos laborales en Nicaragua y en Ecuador, se toma a la educación como uno de los ejes de análisis en la explicación de la brecha en los ingresos. A partir de la teoría económica del capital humano (Becker, 1964) que postula que la existencia de diferentes niveles de inversión en educación explica la desigualdad de ingresos - esto es, que a mayor educación, mayor nivel de ingresos de las personas $^{3}-$, Ocampo Meneses observa para Ecuador y Nicaragua que la educación constituye un medio importante para disminuir la brecha

3 Los postulados fundamentales de la teoría del capital humano (Becker, 1964; síntesis en Schultz, 1983) son: 1) La educación puede ser considerada como otra forma de capital físico, es decir, como una inversión que proporciona una tasa de rentabilidad determinada. 2) Existe una relación positiva entre el desarrollo económico y las tasas de escolarización de todos los niveles educativos. El factor educación consigue explicar la gran diferencia de renta nacional y los niveles salariales entre los países del norte y del sur en el continente americano. El modelo de Mincer (1974), a su vez, permite explicar la relación positiva entre años de estudio y los ingresos, lo que es reflejo de los efectos de la educación sobre la productividad. La teoría se apoya en la invariable cadena entre inversión educativa-más productividad-mejor remuneración. Se asumen los siguientes supuestos: la relación positiva entre educación y productividad del trabajo; la determinación del salario en base a la productividad y, consecuentemente, en base a la calificación del trabajador. 3) Los individuos están en disposición de conocer el rendimiento que pueden obtener de su inversión educativa; de este modo el individuo se convierte en capitalista porque puede invertir en sí mismo (en su propia formación). Sus conocimientos y habilidades tienen un valor económico que puede intercambiarse por un salario en el mercado de trabajo. Así se difumina la frontera entre capital y trabajo y la desigualdad social puede llegar a ser explicada como el resultado lógico del aprovechamiento individual de las oportunidades o, incluso, como la expresión de distintos sistemas de preferencias individuales. 4) La educación no sólo es beneficiosa desde el punto de vista del avance tecnológico y del crecimiento económico. La inversión en educación tiene importantes efectos redistributivos. Al tratarse de una inversión financiada casi en su totalidad por el sector público y por tratarse de un servicio universalista, las rentas más elevadas contribuyen en mayor medida a la financiación de la educación produciéndose de este modo un impacto redistributivo del gasto público en este terreno. En este argumento se apoya el discurso igualitarista que incorpora la teoría del capital humano y cuyo efecto es enormemente efectivo en pleno desarrollo material e ideológico de los estados de bienestar. Sin embargo, la constatación de la persistencia de mecanismos selectivos que mantienen elevada la correlación positiva entre origen social y nivel de instrucción cuestionará en el mediano plazo la validez de este argumento. 
de ingresos, pero no la única ${ }^{4}$. La autora plantea que en la ampliación de la desigualdad DE la distribución de los ingresos laborales desempeñan un papel decisivo los factores económicos relacionados con las empresas tales como la rama de actividad económica y el tamaño de la empresa; factores geográficos como la región donde trabaja el individuo; e individuales como la edad y el género. En este sentido, se dirige la mirada hacia el empleo para comprender el acceso al mercado de trabajo y el nivel de remuneración ${ }^{5}$, esto es, no es la capacidad intelectual ni los años de educación lo que puede explicar las diferencias salariales sino el propio funcionamiento del mercado de trabajo. El ritmo de crecimiento de la remuneración del trabajo no se corresponde con el ritmo de crecimiento de los niveles educativos. Esto se conecta con las teorías de la segmentación del mercado de trabajo (Edwards et al., 1975) cuya tesis central consiste en que la determinación del salario dependerá del segmento en que se halle el trabajador. Además, no es la educación lo que permite explicar las diferencias salariales sino atributos como el sexo, la raza o los hábitos. Se puede interpretar con estas teorías que los individuos inviertan en educación como "estrategia defensiva", para evitar quedarse con los trabajos de baja calificación, mal remunerados e inestables. Este estudio, basado en datos secundarios provenientes de encuestas de condiciones de vida para el período 1990-2003, plantea la necesidad de revisar los supuestos de la teoría del capital humano ya que resultan insuficientes para explicar las desigualdades persistentes en la distribución de los ingresos y señala la necesidad de incorporar al análisis características estructurales económicas y del funcionamiento del mercado de trabajo que condicionan fuertemente dicho proceso distributivo.

\section{Pobreza y desigualdad en los ingresos}

El estudio de Calvi, plantea un análisis socio-histórico de la evolución de los patrones distributivos en la Argentina durante las últimas tres décadas (1974 y 2005), identificando ciclos de desigualdad marcados por transformaciones y crisis en la economía local y del mercado de trabajo, y mostrando una profundización y transformación de la desigualdad distributiva. En este sentido, el patrón distributivo de la sociedad argentina presenta cambios cuantitativos y cualitativos a lo largo de los últimos años, desarrollados en forma escalonada en distintas etapas mediadas por fuertes procesos regresivos (crisis distributivas)

4 La brecha entre niveles educativos se hace cada vez mas amplia sobre todo entre los niveles secundario y universitario.

5 Este planteo coincide con una de las primeras críticas a la teoría del capital humano, planteada por el economista norteamericano Thurow (1972). 
asociados a las últimas grandes crisis de la economía local. Los mayores niveles de inequidad a lo largo de estas décadas se escalonan estableciendo un umbral más alto de deterioro de la desigualdad distributiva en cada nuevo ciclo. A su vez, los momentos de crisis distributivas dan lugar a la modificación de alguno de los factores causales de la desigualdad y por lo tanto asume características que la distinguen del patrón de desigualdad vigente hasta entonces. El autor concluye señalando la complejidad del patrón distributivo actual, en el cual no basta con observar un crecimiento económico para alterar significativamente los niveles de inequidad, esto es, la recuperación económica no es suficiente sino que quienes diseñan las políticas públicas tendrán que valerse del conocimiento de este escenario y plantear alternativas que contemplen las nuevas condiciones de la desigualdad.

Junto con la probada persistencia de la desigualdad en Latinoamérica, aun en contextos de crecimiento económico, la pobreza ha sido también un tema de trabajo central en estas investigaciones. La identificación de cuáles son sus causas principales y qué mecanismos histórico-económicos y geo-políticos la vuelven un problema acuciante en esta región es el propósito del trabajo de Gaitán. La conclusión más saliente de este trabajo es la persistencia de un núcleo duro de pobreza asociado a una alta desigualdad en la distribución del producto social (particularmente en los países de ingreso medio y medioalto). La experiencia en América Latina muestra que la pobreza puede mantenerse e incluso aumentar, mostrando una mayor sensibilidad al nivel de inequidad de la distribución de ingresos que a las tasas de crecimiento económico. De aquí que el autor plantee la necesidad de conectar la atención de la pobreza junto con las políticas que apuntan a disminuir las desigualdades socioeconómicas. Durante la década de los noventa, en la cual los países implementaron reformas estructurales de la economía, se produce un aumento significativo de la desigualdad y no han redundado en una reducción significativa de la pobreza, esto es, el crecimiento económico experimentado por distintos países de la región no ha reportado beneficios sociales al conjunto de la población.

\section{Pobreza, Desigualdad Y El Dilema de las REMESAS}

Las políticas de reforma del Estado y de cambios en la estructura productiva y en el mercado de trabajo a partir de los años noventa en El Salvador con su consecuente retracción de la demanda de empleo constituyen el contexto histórico en el cual se desarrolla el trabajo de Hernández Chávez acerca de la importancia de las remesas familiares en atenuar la pobreza de los hogares, en el período 1990-2004, postulando que la exclusión laboral es una de las razones principales 
de la emigración transnacional. Este trabajo constituye un ejemplo contundente para visualizar el impacto de las transformaciones impulsadas por las políticas de corte neoliberal en la mayoría de los países latinoamericanos que produjeron un aumento de la precariedad laboral y del desempleo y que, a su vez, condujeron a una profundización de los niveles de pobreza en estas sociedades. El caso de El Salvador es llamativo respecto de las consecuencias de este proceso, ya que la más significativa fue la emigración a otros países por razones económicas $^{6}$, sobre todo de sectores de población desempleada con baja calificación y en situación de pobreza. La emigración de estos trabajadores excluidos del mercado laboral produjo un primer efecto global de reducción de los niveles de pobreza del país. Como resultado de este aumento de la emigración laboral se originó un incremento del ingreso total del país vía las remesas familiares, las cuales posibilitaron una mejora de las condiciones de vida de las familias más pobres y concomitantemente una disminución de los niveles de pobreza de la población. Ahora bien, la pregunta que emerge de este estudio es si la emigración y los ingresos a través de las remesas familiares constituyen la solución deseada para disminuir los niveles de pobreza por ingresos en la región. En principio la autora apunta una contradicción que se plantea a los gobiernos actuales que proponen mejorar las condiciones laborales y, de este modo, dar solución a una de las causas que generan la emigración, y la importancia que asume para la economía del país el producto de dicha emigración: las remesas. Asimismo, el estudio plantea que el destino que los hogares le dan a sus ingresos vía las remesas familiares no mejoran las capacidades de estas familias, esto es, se observa que la utilización de las remesas se orienta al consumo y muy escasamente a la educación y el cuidado de la salud que redundarían en una mayor permanencia de los beneficios que estos ingresos pueden significar para las familias.

\section{Pobreza, DeSigualdad y ETNia}

Una de las cuestiones que los trabajos reseñados hasta aquí ponen en evidencia son las múltiples relaciones que existen entre el origen étnico y las situaciones de pobreza que enfrentan hombres y mujeres en los países de la región. El trabajo de Antón Sánchez se focaliza en la situación de la población de origen afro residente en el Ecuador. Tal como señala Rangel (2006), en América Latina, como consecuencia de la conquista, el colonialismo y la inmigración, coexiste una realidad

6 Vale tener en cuenta que en El Salvador la importancia de las remesas en el ingreso del país data de mucho tiempo atrás. Aquí lo que se argumenta es que la contracción de la demanda de trabajo estimuló la emigración económica (antes política). 
sociodemográfica muy compleja. Actualmente, los afrodescendientes representan por lo menos el 30\% de la población regional y el 5\% de la población del Ecuador y entre ellos, la amplísima mayoría se encuentra en situación de pobreza estructural. Tal y como ocurre en otras partes de la región, los afroecuatorianos conviven con múltiples desigualdades asociadas a su posición socio-étnica: desigualdades en el acceso a las oportunidades educativas, en el acceso a la salud, a la vivienda y, también, al empleo ${ }^{7}$. En ese marco y desde fines de la década del noventa, los afroecuatorianos, en tanto actores sociales y políticos, se integran en procesos de movilización social y reivindicación de derechos. Tal y como lo muestra el trabajo de Antón Sánchez la pobreza, la discriminación racial y la exclusión social constituyen los temas clave de la agenda de las organizaciones afroecuatorianas y son los que han motorizado su accionar en los últimos quince años. Desde la perspectiva de los líderes de dichas organizaciones, en el Ecuador se han logrado avances en materia de política pública a favor de los afroecuatorianos; sin embargo, las medidas aún no son suficientes. Una de las cuestiones que señalan los líderes de la comunidad afro es que muchas de las acciones que se han emprendido para enfrentar la pobreza entre los afroecuatorianos no han tenido en cuenta que las desigualdades y las variadas formas de exclusión a las que se ven expuestos son las huellas que los históricos procesos de esclavización dejan ver en la sociedad contemporánea. La larga historia de la esclavización los ha despojado de recursos y ha impactado, también, en sus posibilidades organizativas. En este marco, los esfuerzos de la política pública deben orientarse a: (1) propiciar la redistribución del gasto social con miras a mejorar las oportunidades de los afroecuatorianos y a realizar una mayor inversión en capital humano; (2) generar estructuras de gestión que contribuyan a desmontar los mecanismos propios de la mentalidad colonial, y (3) facilitar el acceso de estos grupos al crédito productivo.

La relación entre pobreza, etnia y políticas públicas constituye el eje de indagación del trabajo de Antequera. El autor, con base en el

7 "Los afrodescendientes como grupo social viven situaciones diferenciadas en sus países. Por ejemplo, en las naciones caribeñas de habla inglesa ellos son mayoría y participan activamente en la política con alto grado de autodeterminación, autonomía y control del territorio, como es el caso de Belice con los negros anglófonos (PNUD, 2003). En otros países, existen tantos grupos con escasa conciencia étnica como minorías con identidad bien definida. Esta distinción es importante, porque lleva a que ellos presenten condiciones socioeconómicas diferenciadas [...] lo que significa que, aunque de manera general las poblaciones afrodescendientes se ubiquen mayoritariamente en los estratos socioeconómicos más bajos, hay países en los cuales sus indicadores son incluso mejores que los del resto de la población" (Rangel, 2006: 63). 
análisis de las articulaciones entre la economía de los ayllus bolivianos y la dinámica participativa impulsada por la Ley de Participación Municipal (1994), da cuenta de los impactos de una política pública en las situaciones de desigualdad social con las que conviven las comunidades campesinas. La investigación muestra con claridad cómo dichas articulares, de carácter más bien formal, han tenido escasos impactos a nivel de sus condiciones de vida. Los signos visibles de la implementación de Ley en las comunidades del ayllu Kirkyawi se observan en la ejecución de pequeñas obras de infraestructura y equipamiento; a pesar de eso los impactos en las economías familiares han sido escasos. El proceso de municipalización, en la letra de la ley, reconoce a las organizaciones existentes en las comunidades campesinas y prevé su incorporación a la lógica municipal. Sin embargo, en la práctica, su puesta en marcha supuso el desarrollo ad hoc de formas colectivas que les permitieran a las comunidades articularse efectivamente con el Estado. En el ayllu Kirkyawi esa forma es el sindicato campesino. El sindicato se constituyó como una entidad que permite el diálogo con las estructuras municipales sin alterar la organización interna de las comunidades. La emergencia de colectivos ad hoc a la implementación de la política pública pone en evidencia que la municipalización, lejos de reconocer las dinámicas organizativas existentes, sigue su propia lógica obligando a las comunidades a adaptar sus sistemas organizativos a la misma. Las políticas públicas ignoran la dinámica económica y organizativa de las comunidades poniendo en evidencia, una vez más, que el Estado boliviano se ha considerado ajeno al ayllu. Lamentablemente, tal y como señala Antequera, la municipalización no parece haber logrado revertir esta situación.

Las políticas públicas que incorporan componentes participativos tienen una larga tradición en América Latina. La participación en programas públicos fue considerada centralmente como mecanismo de interacción entre los beneficiarios y los efectores (básicamente públicos). En ese marco, se han desarrollado procesos muy heterogéneos de variada calidad. En algunos escenarios, los programas se han constituido en ofertas de oportunidades circunscriptas de participación y en otros, en cambio, se han orientado a facilitar la emergencia de áreas de igualdad (no necesariamente permanentes). La noción de área de igualdad refiere a las potencialidades de los procesos participativos para intervenir sobre la estructura y sobre los valores de un sistema de intereses (Pizzorno, 1976). Cuando ello ocurre, el resultado es un proceso que podríamos llamar de formación de áreas de igualdad. En un contexto en el que predominan intereses desiguales y heterogéneos, el desafío de la municipalización se orienta a la formación de áreas de igualdad. Para ello, parece ser necesario revisar las formas de 
interacción entre las comunidades y las estructuras municipales a fin de que las prácticas participativas no constituyan esfuerzos aislados sino que se articulen horizontalmente y sistemáticamente con la dimensión institucional.

\section{POBREZA, DESIGUALDAD Y PROGRAMAS SOCIALES PARA MICROEMPRENDEDORES}

Tal y como lo muestra el trabajo de Blanco, las nociones de microempresa y emprendimiento se acuñan en las últimas décadas para dar cuenta de nuevos dispositivos de lucha contra la pobreza. La nueva semántica de los términos supone redefiniciones en el papel de las instituciones y, por sobre todo, en el del propio sujeto-pobre. Si bien dichas redefiniciones se relacionan con la reorientación conceptual de la política social (Sottoli, 2000); en la práctica, su puesta en marcha descansa sobre el supuesto de la existencias de unas instituciones oferentes que prestan sus servicios microcrediticios y de una masa cada vez. más amplia de clientes o microempresas que acceden al sistema. En tanto dispositivos de lucha contra la pobreza, estos han mostrado tener eficacia discursiva, aun cuando queda pendiente una evaluación de su eficacia real. La efectividad del emprendimiento y del microcrédito se sustenta en su capacidad de racionalización de prácticas sociales en las que instituciones y sujetos presentan a sí mismos una explicación de su quehacer que es tanto lógicamente congruente como éticamente aceptable. Tal y como señala Blanco, "esta racionalización legitima al discurso del emprendimiento, convirtiéndose así en orientaciones, valores y prescripciones para la acción de los agentes". Parafraseando a Althusser, el autor sostiene que para instituciones como las estudiadas, los microempresarios son siempre-ya emprendedores; en este supuesto reside la efectividad de la interpelación ideológica. "De esta forma, la efectividad del discurso del emprendimiento tiene menos relación con la capacidad economicista a potenciar externamente que con el aspecto interno, vivido, práctico y valorativo en relación a la forma en que las personas/ instituciones ven imaginariamente la realidad social".

El trabajo de Scala completa la fotografía que presenta el de Blanco. La autora analiza la implementación del Plan Nacional Manos a la Obra, en la provincia de Mendoza (Argentina) e indaga las formas de organización de los emprendimientos socioproductivos que recibieron apoyo económico de la iniciativa estatal. Luego de la crisis de la Convertibilidad, el Estado argentino parece dar un giro en su retirada de la promoción del desarrollo local. De hecho, en agosto de 2003, el Ministerio de Desarrollo Social de la Nación lanza el Plan Nacional de Desarrollo Local y Economía Social "Manos a la Obra". La 
implementación del Plan y la orientación de la cartera de programas sociales hacia el desarrollo ponen en el centro de la escena a la generación de colectivos de trabajo. El Plan Nacional de Desarrollo Local y Economía Social reconoce la necesidad de que el Estado se constituya en articulador de las políticas y que promueva la consolidación de los vínculos entre las organizaciones gubernamentales y de la sociedad civil en función de contribuir con el desarrollo de emprendimientos de la economía social orientados hacia el desarrollo local ${ }^{8}$. En el contexto del Plan, se jerarquiza el rol del Estado como promotor de políticas concertadas orientadas al desarrollo de las sociedades locales.

Sin embargo, si se tiene en cuenta la historia reciente de la última década en la Argentina, no necesariamente los gobiernos locales han acumulado capacidades para el desarrollo de esta estratégica función. Es decir, la transformación de los gobiernos locales en espacios efectivos de gestión de políticas públicas dependió básicamente de sus capacidades para reorganizar sus recursos y estructura en pos de ello, sin que necesariamente exista una intencionalidad explícitamente orientada a tal efecto. Asimismo, cuando lograron constituirse en espacios locales de gestión, las políticas públicas locales fueron las políticas del gobierno local, en las que los actores económicos y sociales tuvieron escasa implicación. El Plan supone un nuevo rol para los gobiernos locales y para las organizaciones sociales, en la medida en que los convoca a formar parte de espacios asociativos articuladores de políticas sociales y generadores de proyectos productivos. Esta iniciativa significa un cambio en las reglas de juego (expresado, entre otras en el replanteo de programas para integrarlos en ejes acotados de políticas, ${ }^{9}$ en la promoción de vínculos entre actores gubernamentales y de la sociedad) y también en las representaciones a las que se apela e insiste en fortalecer (la necesidad de fundar otra economía centrada en el trabajo, nuevas formas de construcción de legitimidad, otra forma de concebir la acción de gobierno, por señalar las más difundidas). En este contexto y dadas estas orientaciones, la generación de espacios locales de gestión pública participativa orientados al desarrollo local es un desafío que requiere de una estrategia específica que la promueva, apoye y sostenga con la finalidad de recuperar la capacidad de intervención del poder público (en los distintos niveles) en tanto regulador de la vida social. Sin embargo, los entramados locales no necesariamente están en condiciones de avanzar en procesos de este

8 En la perspectiva del Plan, economía social y desarrollo local son conceptos que se relacionan estrechamente.

9 Los programas existentes están integrados en tres ejes: Producción Solidaria, Redes y Seguridad Alimentaria. 
tipo, ni aquellos que han avanzado sostenidamente encuentran un camino exento de problemas (Chiara y Di Virgilio, 2006).

Las huellas de esta historia reciente, tal y como lo muestra Scala, se dejan ver en los alcances que ha tenido la implementación del Plan en la Provincia de Mendoza. Si bien el Plan busca rescatar los valores relacionados con el trabajo asociativo y comunitario, en la práctica promueve la construcción de un otro sujeto -un sujeto microempresario- guiado por una lógica eminentemente capitalista. En este marco, lejos de plantearse la recuperación de racionalidades alternativas, se expanden los valores económicos dominantes a las formas organizativas que las familias de menores ingresos generan para dar respuesta a sus necesidades de sobrevivencia. Si bien el Plan visibiliza en el espacio público las distintas experiencias organizativas que estas familias desarrollan para mitigar los efectos de su exclusión del mercado de trabajo, propicia una creciente mercantilización de vínculos y estrategias de supervivencia que escapaban al cálculo racional y a la lógica del mercado. El Plan se propone como una iniciativa de apoyo a las experiencias de trabajo informal y a la economía de subsistencia, pero en la práctica no parece haber logrado la inclusión efectiva de los emprendimientos a la economía local.

\section{Corolario PARA PENSAR LA POBREZA Y LA DESIGUALDAD}

Finalmente, el trabajo de Martínez Alonso nos invita a reflexionar sobre cómo, en este derrotero, se resuelve la relación entre el Estado y la sociedad. Centrada en el caso cubano, la autora analiza cómo se articulan iniciativas estatales y de la sociedad en la lucha contra la pobreza, focalizándose en la indagación de las estrategias que estado y sociedad ponen en marcha para tales fines. Martínez Alonso sostiene que en Cuba, "ni el Estado cubano, ni las estrategias de la sociedad civil estudiadas se reconocen explícitamente como políticas de reducción de pobreza, sino que incluyen la superación de esta condición dentro de una estrategia más amplia de transformación social". La reticencia de los líderes sociales a hablar y a trabajar explícitamente contra la pobreza y a partir de un enfoque de políticas de pobreza facilita la articulación con el Estado cubano que es el actor hegemónico en la transformación social. A pesar de ello, las experiencias encuentran su límite en carencias económicas devenidas de la centralización de recursos. En el contexto cubano, muy a pesar de la voluntad política, las iniciativas del Estado, las estrategias de la sociedad, las articulaciones y metodologías de intervención para la superación no han logrado aún poner coto a las situaciones de pobreza. Desde el punto de vista institucional, políticas y estrategias funcionan, según muestra la autora, en franca desconexión, contribuyendo a la dispersión de 
esfuerzos. En este marco, tal y como lo señala uno de los entrevistados de Martínez Alonso,

... un Estado fuerte [...] corre el peligro de ignorar o no tomar en cuenta la capacidad que tienen instituciones de menor tamaño para complementar a estos esfuerzos del [propio] estado, o coadyuvar en estrategias trazadas por el estado, en su implementación [...] porque tienen capacidades para ello.

A pesar de sus limitaciones, en el contexto cubano, la revalorización y el potenciamiento de espacios microsociales de gestión de políticas sociales, parece ser una condición de posibilidad para dar respuesta a las necesidades de la población en su contexto más próximo y a sus situaciones sentidas de la pobreza.

\section{Bibliografía}

Becker, G. S. 1964 Human Capital (Nueva York: National Bureau of Economic Research).

Blau, P. y Duncan, O. D. 1967 The American Occupational Structure (Nueva York: Wiley).

CEPAL 2008 "Pobreza, Exclusión social y desigualdad distributiva" en Panorama Social de América Latina (Chile: CEPAL).

Chiara, M. y Di Virgilio, M. M. 2006 "Notas sobre las relaciones entre políticas sociales orientadas hacia el desarrollo y su institucionalidad" en Revista Conciencia Social, N 7 (Córdoba: Escuela de Trabajo Social, Universidad Nacional de Córdoba).

Crompton, R. 1994 Clase y Estratificación. Una introducción a los debates actuales (Madrid: Tecnos).

Edwards, R. C., Reich, M. y Gordon, D. M. 1975 Labor Market Segmentation (Lexington, Mass: Heath).

Mincer, J. 1974 Schooling, Experience and Earnings (Nueva York: National Bureau of Economic Research).

O’Donnell, G. 1999 “Pobreza y desigualdad en América Latina. Algunas reflexiones políticas” en Tokman, V. E. y O’Donnell, G. (comps.) Pobreza y Desigualdad en América Latina (Buenos Aires: Paidós).

Parsons, T. 1971 [1951] “El sistema social” en Revista de Occidente.

Pizzorno, A. 1976 "Introducción al estudio de la participación política" en Pizzorno; Kaplan y Castells Participación y cambio social en la problemática contemporánea. (Buenos Aires: Ed. SIAP).

PNUD 2000 "Investigaciones sobre desarrollo en Colombia" en Cuadernos del PNUD-MPS (Colombia: PNUD). 
Rangel, M. 2006 “La población afrodescendiente en América Latina y los Objetivos de Desarrollo del Milenio. Un examen exploratorio en países seleccionados utilizando información censal" en Del Popolo, F. y Ávila, M. (comps.) Pueblos indígenas y afrodescendientes de América Latina y el Caribe: información sociodemográfica para políticas y programas (Santiago de Chile: CEPAL).

Salas, M. M. 2004 "Desigualdad social ¿Nuevos enfoques, viejos dilemas?" en Cuaderno de Ciencias Sociales (Costa Rica: FLACSO) $\mathrm{N}^{\circ} 131$.

Shavit, Y. y Blossfeld, H. P. (eds.) 1993 Persistent inequality (Boulder: Westview Press).

Sottoli, S. 2000 "La política social en América Latina bajo el signo de la economía de mercado y la democracia" en Revista Mexicana de Sociología (México: Instituto de Investigaciones Sociales).

Thurow, L. 1983 [1972] "Educación e igualdad económica” en Educación y Sociedad, Vol. 2.

Ziccardi, A. (comp.) 2008 Procesos de urbanización de la pobreza y nuevas formas de exclusión social (Colombia: CLACSO). 



\section{Carlos Augusto Viáfara López}

\section{EFECTOS DEL CAMBIO ESTRUCTURAL EN LAS OPORTUNIDADES EDUCATIVAS \\ Y OCUPACIONALES EN LA CIUDAD DE CAli, Colombia}

\section{INTRODUCCIÓN}

En la segunda mitad del siglo XX Colombia, como varios países en América Latina, experimentó fuertes cambios en el ámbito económico, social y demográfico. Desde los años cincuenta hasta la década del setenta Colombia tuvo altas tasas de crecimiento, debido a la implantación del modelo de sustitución de importaciones, la participación activa del Estado en la planeación y ejecución del desarrollo y al éxito de la economía cafetera. Este buen desempeño de la economía derivó en un incremento en los niveles de educación, y una mayor inserción en ocupaciones de alta calificación en la industria y en el naciente sector de servicios.

Con el agotamiento del modelo de desarrollo basado en la sustitución de importaciones, la caída en los precios internacionales del café, la crisis de la deuda externa a principios de los ochenta y la adopción de políticas de estabilización y ajuste estructural, la tasa de crecimiento de la economía colombiana comienza a caer drásticamente; lo que resultó en la década de los noventa en el peor desempeño en la segunda mitad del siglo anterior. A estos efectos, es muy probable que aunque continúe el mejoramiento educativo y ocupacional, el impacto del cambio estructural implique una disminución con relación a la cohorte anterior, además, acompañado de una ma-

* Profesor del departamento de economía de la Universidad del Valle (Cali, Colombia), e investigador del Centro de Investigaciones y Documentación Socioeconómica (CIDSE) de dicha universidad. 
yor inequidad en indicadores sociodemográficos, de pobreza y distribución del ingreso. ${ }^{1}$

Pese a la importancia del tema, en Colombia son pocas las investigaciones que tratan de indagar sobre las consecuencias de tales transformaciones en el proceso de estratificación social. Del mismo modo, son escasas las investigaciones que involucran el color de la piel y el sexo como un factor clave en los resultados en el proceso de estratificación social.

En este sentido las preguntas que intenta resolver esta investigación son las siguientes: 1) ¿Cómo influye el cambio estructural en la economía en los determinantes de las oportunidades educativas y ocupacionales en la ciudad de Cali? 2) ¿Hasta qué punto el color de la piel y su interacción con el sexo constituyen un factor de desigualdad en el proceso de estratificación social a través de las distintas cohortes? 3) Si existen desigualdades, ¿`se deben estas al estatus socioeconómico familiar, la condición migratoria, las credenciales educativas?, ¿o acaso pueden ser explicadas por el color de la piel y sexo?

\section{OBjetivos}

En esta investigación propongo analizar el efecto del color de la piel y su interacción con el sexo en el proceso de estratificación social en tres aspectos: la salida de la escuela, el logro educativo y el estatus socioocupacional. El primer objetivo será indagar sobre la existencia y magnitud de las desigualdades en el proceso de estratificación social con base en el color de la piel y el sexo a través de las distintas cohortes. El segundo objetivo será dilucidar si estas desigualdades son producto de los efectos del estatus socioeconómico familiar, la condición migratoria, las credenciales educativas de los individuos, o si por el contrario son el resultado de la discriminación por el color de la piel y sexo. La discriminación es considerada aquí como la ausencia de igualdad de resultados en el logro de estatus socioeconómico para individuos de similares orígenes sociales y credenciales educativas (Schiller, 1971: 263).

El argumento central contempla tres aspectos: 1) Ser negro/a implicaría inferiores resultados en la salida de la escuela, el logro educativo y el estatus socio-ocupacional observado en el último empleo. 2) Tales resultados no solo se determinarían por los orígenes sociales según el capital escolar del padre, la condición migratoria y el nivel educativo alcanzado, sino también por la discriminación por el color de la piel y el sexo combinados. 3) A pesar de un mejoramiento en las

1 Un muy buen resumen de los impactos en la estructura social de las políticas de estabilización y ajuste estructural en la región se encuentra en Edwards (1995), Stalling y Perés (2000), Katzman (2002) y Roberts (2002). 
oportunidades educativas y ocupacionales a escala societal, el efecto del cambio estructural implica una ampliación de las desigualdades en el proceso de estratificación social según el color de la piel y sexo.

\section{Metodología}

\section{Datos}

Los datos provienen de la Encuesta de movilidad, urbanización e identidades de las poblaciones afrocolombianas realizada en Cali en el segundo trimestre de 1998. Para un individuo mayor de 18 años de edad seleccionado en cada hogar, la encuesta recolecta los datos anuales de la biografía residencial, educativa, laboral y familiar completa. La muestra biográfica incluye 1880 individuos (43\% negros; 22\% mulatos; $0,59 \%$ indígenas; $13 \%$ mestizos; $18 \%$ blancos; el resto, $0,21 \%$, son otros o no se informa el color de la piel).

A continuación se describen las variables incluidas en el análisis.

Cohorte para las decisiones de educación e inserción ocupacional: Con esta variable se quiere captar y controlar la influencia del cambio estructural en la economía en el proceso de estratificación y movilidad social en la ciudad de Cali. Se construyen dos tipos de cohortes: a) cohortes para las decisiones educativas $=$ año de nacimiento +6 años para la primera salida de la escuela, $y$, año de nacimiento +11 años en el modelo de logro educativo; b) cohortes para las decisiones laborales = año de entrada al mercado laboral. Se codifica como 0 "1906-1972" y 1 “1973-1998".

Color de la piel: esta caracterización se apoya en la observación llevada a cabo por el encuestador con un relativo grado de arbitrariedad, de rasgos fenotípicos negros, mulatos, blancos, mestizos. Se codifica como 0 para los negros, 1 para los mulatos y 2 para los blancos o mestizos.

Sexo: Se codifica como 0 para las mujeres y 1 para los hombres

Estatus socioeconómico familiar: el estatus socioeconómico familiar es medido por el máximo nivel educativo alcanzado por el padre. Se codifica como 1 "Primaria incompleta y menos", 2 "primaria completa", 3 "secundaria completa o incompleta" y 4 "superior".

Condición migratoria: las diferencias entre los nacidos en la ciudad de Cali y los migrantes son captadas por esta variable. Tal como el estatus socioeconómico familiar, constituye una variable proxy al origen social de los individuos. Se codifica como 0 para los "migrantes" y 1 para los "nativos de Cali".

Logro educativo: el logro educativo se incluye como una variable que mide las capacidades, conocimientos, competencias y cualificaciones de los individuos. Corresponde al máximo nivel educativo al- 
canzado por el individuo. Se codifica como 1 "Primaria incompleta y menos", 2 "primaria completa", 3 "secundaria completa o incompleta" y 4 "superior".

Estatus socio-ocupacional: esta variable mide el logro ocupacional en la última ocupación. Se codifica como: 1 "manuales bajos", 2 "manuales altos" y 3 "no manuales". La figura 1-1 muestra el esquema de la clasificación ocupacional a utilizar.

Figura 1-1

Clasificación 0cupacional

$\begin{array}{cl}\text { No Manuales } & \begin{array}{c}\text { Alta } \\ \text { Calificación } \\ \begin{array}{c}\text { Baja } \\ \text { Calificación }\end{array} \\ \text { Alta } \\ \text { Calificación } \\ \text { Manuales }\end{array} \quad\left\{\begin{array}{l}\text { Profesionales; técnicos y trabajadores afines. } \\ \text { Gerentes y propietarios } \\ \text { Calificación } \\ \text { en ventas y control de trabajadores }\end{array}\right. \\ \text { Artesanos y operarios calificados. Capataces, } \\ \text { administradores y propietarios agrícolas }\end{array}$

\section{Estrategia analítica}

El eje de investigación es el modelo de Blau y Duncan (1967: 163205). La importancia de este modelo es que permite cuantificar la importancia conjunta de los orígenes sociales y el logro individual en el proceso de estratificación social entre grupos sociales diferenciados por el color de la piel. En esta investigación considero el proceso de estratificación social en dos grandes componentes: las oportunidades educativas y el estatus socio-ocupacional alcanzado (ver Ganzeboom et al., 2000; Solís, 2005). Primero, se estima el efecto del color de la piel y su interacción con el sexo frente a los efectos del estatus socioeconómico familiar y la condición migratoria en el logro educativo. Después, se examina la influencia del color de la piel y su interacción con el sexo frente a los efectos del estatus socioeconómico familiar, la condición migratoria y el logro educativo en el estatus socio-ocupacional de lo individuos. La figura 1-2 muestra el esquema a seguir. 
Figura 1-2.

Esquema de Análisis. Modelo simplificado de logro de estatus de Blau y Duncan

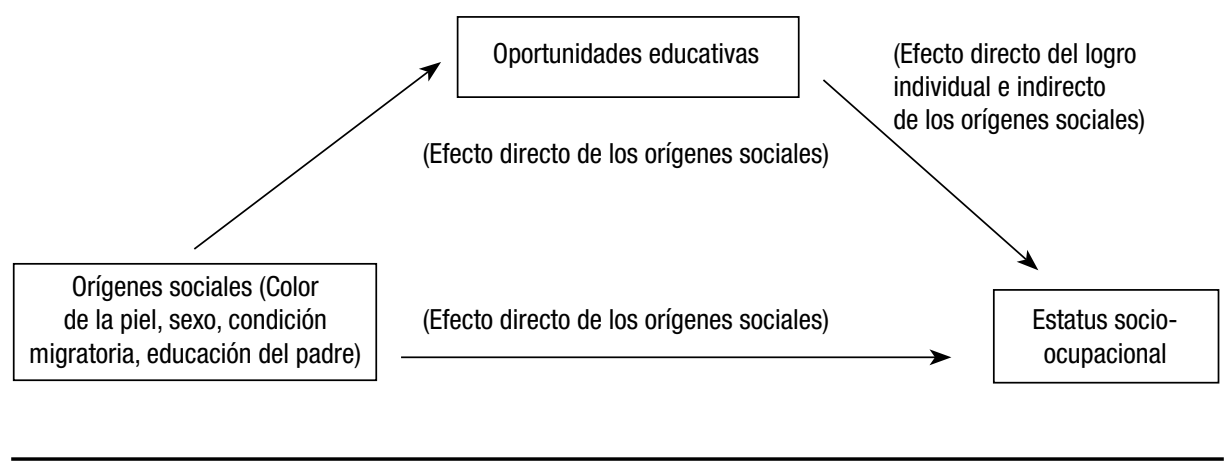

Esquema adaptado de Blau y Duncan (1967: 170).

\section{Herramientas técnicas}

En el desarrollo del esquema de análisis se utilizaran estadísticas descriptivas y modelos logísticos ordenados. La importancia de los modelos logísticos ordenados es que permiten valorar de forma correcta la influencia del color de la piel, controlando otros factores asociados en el proceso de estratificación social.

La regresión logística ordenada tiene la característica de que la variable dependiente es ordinal y politómica; es decir, resultados "más altos" se asocian con valores más altos de la variable dependiente. Las variables independientes pueden ser continuas o categóricas. La variable dependiente $Y$ puede tomar $\mathrm{k}+1$ valores codificados como 0 , $1,2, \ldots . . \mathrm{k}$. La probabilidad de que un resultado sea igual a $\mathrm{k}$ dado el vector x, de $\Phi$ variables independientes, se puede representar como:

$$
\operatorname{Pr}[Y=k / x]=\phi_{k} x
$$

Específicamente el modelo de momios proporcionales compara la probabilidad de que la variable dependiente sea igual o más pequeña, $\mathrm{Y} \leq \mathrm{k}$, a la probabilidad de que $\mathrm{Y}>\mathrm{k}$ (ver Hosmer y Lemeshow, 2000)

$$
\begin{gathered}
c_{k}(x)=\ln \left[\frac{p(Y \leq k / x)}{P(Y>k / x)}\right] \\
c_{k}(x)=\ln \left[\frac{\phi_{0}(x)+\phi_{1}(x)+\ldots+\phi_{k}(x)}{\phi_{k+1}(x)+\phi_{k+2}(x)+\ldots+\phi_{k}(x)}\right]
\end{gathered}
$$




$$
c_{k}(x)=\tau_{k}-x^{\prime} \beta
$$

El parámetro $\beta_{\mathrm{k}}$, representado en "momios proporcionales" mide el efecto de la variable independiente, $\mathrm{x}_{\mathrm{k}}$, o sus diferentes categorías, sobre la probabilidad de alcanzar un mayor valor de la variable dependiente.

A continuación describo el contenido de esta investigación. En la sección dos presento una revisión sucinta de los principales aspectos conceptuales, teóricos y metodológicos considerados en los estudios de estratificación social; una revisión de los estudios más importantes sobre estratificación y movilidad social llevados a cabo en Colombia. En la sección tres me intereso en el efecto del estatus socioeconómico familiar, la condición migratoria, y el color de la piel y su interacción con el sexo en la desigualdad en las oportunidades educativas según cohortes en las cuales los individuos tomaron sus decisiones educativas. En la sección cuatro busco explicar cómo el estatus socioeconómico familiar, la condición migratoria y el color de la piel y su interacción con el sexo se interrelacionan con el logro educativo para influenciar el estatus socio-ocupacional en la última ocupación. En la sección cinco se realiza una discusión sobre los hallazgos encontrados en esta investigación.

\section{ESTAdo DEL ARTE}

El logro educativo y el logro ocupacional han sido temas centrales en la sociología y la economía laboral, dada su importancia para entender las dinámicas de estratificación social y la forma como el cambio estructural y tecnológico afecta a ciertos grupos sociales (Blau y Duncan, 1967: 2). A este respecto se distinguen tres generaciones en los estudios de estratificación y movilidad social. La primera generación surge con la teoría liberal en la cual sobresalen los estudios de Lipset y Bendix y Lipset y Zatterberg en la década de los cincuenta y principios de los sesenta (ver Ganzeboom et al., 1991; Grusky, 1994). Ganzeboom et al. (1989: 5) comentan que el interés de estos estudios fue valorar la hipótesis de fluidez social común en todos los países industriales de occidente a partir de las comparaciones de tablas de movilidad ocupacional. La razón para explicar una fluidez social ascendente se fundamenta en la movilidad desde ocupaciones manuales hacia ocupaciones no manuales como resultado del proceso de industrialización, en especial cuando las tasas de fecundidad de los trabajadores no manuales son más reducidas que las de los trabajadores manuales.

La segunda generación se interesa por el proceso de movilidad individual (proceso de logro de estatus). En el proceso de logro de 
estatus el objetivo es valorar la contribución de cada uno de los factores determinantes en logro ocupacional a escala individual. Blau y Duncan (1967) son los principales exponentes de esta teoría. En su estudio pionero para los Estados Unidos en la década de los sesenta establecen que el proceso de logro de status está determinado por variables que pueden agruparse en dos categorías: adscriptivas y de logro individual Entre las primeras se encuentran las variables asociadas a los orígenes sociales: nivel educativo del padre, ocupación del padre, característica étnica y característica migratoria. Las segundas son el nivel educativo alcanzado por los individuos y la primera experiencia en el mercado laboral. A partir de esta primera contribución existe un importante debate en la importancia de las variables adscriptivas frente a las variables de logro individual como determinantes fundamentales del proceso de estratificación y movilidad social (ver Sewell, Haller y Portes, 1969; Hauser y Featherman, 1977; Ganzeboom et al., 2000).

La tercera generación surge en la década de los setenta. Esta se funda en la hipótesis de Featherman, Jones y Hauser (FJH Hipótesis), que sustenta que la movilidad social en las naciones industrializadas no solo responde a cambios estructurales a escala societal en las posiciones ocupacionales, sino también en la forma cómo los cambios en las posiciones ocupacionales afectan a los diferentes grupos sociales (Ganzeboom et al., 1989: 6). Esta generación también se destacó por los avances metodológicos que van más allá de la comparación de simples tablas de movilidad, e introducen en la medición de la movilidad social modelos multivariados con variables discretas y posteriormente los modelos log-lineales; estos últimos con la ventaja de que permiten separar la movilidad absoluta de la movilidad relativa (ver Grusky y Hauser, 1984; Erikson y Goldthorpe, 1985).

No obstante que los estudios de estratificación social fueron muy populares en América Latina en la década de los cincuenta y sesenta (veáse al respecto Filgueira, 2001), en Colombia son recientes los intentos por tratar de investigar las dinámicas de estratificación y movilidad social. Uno de los primeros trabajos fue el de Nina y Grillo (2000), quienes efectuaron una investigación sobre la movilidad intergeneracional educativa, ocupacional y de ingresos en Colombia. Después Behrman, Gaviria y Székely (2001) realizaron un análisis de la movilidad intergeneracional educativa y ocupacional en Colombia, Brasil, México, Perú y los Estados Unidos, estudio novedoso por su carácter comparativo entre países. Gaviria (2002) realizó una ampliación al estudio de Behrman, Gaviria y Székely (2001). Cartagena (2004) efectuó un estudio sobre la movilidad educativa entre gene- 
raciones en Colombia entre 1915 y 2003. Por último, Tenjo (2004) hace un análisis de la movilidad educativa intergeneracional en Colombia. Un rasgo común de estos estudios es que basan el análisis de la movilidad intergeneracional educativa y ocupacional a partir del uso de tablas de movilidad (con excepción del estudio de Tenjo, 2004), lo cual reduce el análisis de la estratificación social a los efectos directos del estatus socioeconómico familiar de padres a hijos. No obstante la importancia de esta aproximación para entender las dinámicas de estratificación social, esta no permite "desentrañar" el proceso, lo cual implica considerar la importancia conjunta de los orígenes sociales y de las características de logro individual en el proceso de estratificación social. A nivel general, los resultados de estos estudios muestran que a pesar del continuo mejoramiento educativo, en las últimas décadas el proceso parece haberse estancado como resultado de los efectos del cambio estructural en la economía que induce a una reducción de la movilidad social a escala societal. Las clases sociales más pobres y los migrantes reiteradamente muestran las mayores inequidades en el proceso de estratificación social. También se pudo corroborar que en Cali la movilidad social es más restringida, aunque los estudios no indagan cuáles son los grupos más perjudicados en el proceso.

Otro aspecto característico de estos estudios en Colombia es la ausencia de incorporación de diferencias con base en el color de la piel de los individuos, en contraste con los estudios realizados principalmente en los Estados Unidos. Una excepción lo constituyen los estudios recientes de Viáfara (2005a y 2005b) para la ciudad de Cali, en los cuales se encuentra un efecto diferencial según el color de la piel y sexo en el proceso de estratificación social. Barbary y Estacio (2005), utilizando un modelo no paramétrico de curso de vida, encuentran diferencias significativas que limitan la movilidad social de las mujeres negras educadas en Cali. Urrea, Viáfara y Ramírez (2005) realizan un estudio donde miden el efecto del logro socio-ocupacional en las probabilidades de estar en una situación de pobreza o miseria para grupos étnico-raciales versus no étnico-raciales al nivel nacional, urbano y rural. Para terminar, Viáfara y Urrea (2006) en un estudio para tres ciudades colombianas encuentran que los diferenciales en el proceso de estratificación social para los individuos afrocolombianos se producen por efectos de la discriminación por raza y género.

\section{LA MOVILIDAD EDUCATIVA}

El efecto positivo del logro educativo sobre el logro ocupacional ha sido bien documentado en los estudios de estratificación social, así 
como en los estudios de inversión en capital humano (ver Blau y Duncan, 1967; Becker, 1983). La dotación de mejores credenciales educativas constituye una ventaja para la inserción en el mercado de trabajo, en especial, en el acceso a las ocupaciones de mayor estatus en las cuales se supone existe una mayor competencia. Lo anterior es de especial importancia debido a la tendencia a la especialización de las actividades productivas y el cambio sectorial en la economía, lo cual incrementa la demanda de mano de obra altamente calificada y hace del logro educativo un aspecto fundamental en la colocación en el mercado de trabajo (Solís, 2005).

La influencia de los orígenes sociales podría ser determinante en la consecución del logro educativo. Bowles (1973) ha distinguido tres formas de la transmisión intergeneracional de estatus socioeconómico: la primera se refiere a las desigualdades en las oportunidades de educación; la segunda explicación enfatiza que las aspiraciones, características de personalidad y valores de los individuos son fuertemente afectados por las características de la familia y modelos culturales dominantes en la sociedad; por último se destaca en la transmisión intergeneracional de las habilidades intelectuales de padres a hijos.

Además del efecto significativo del estatus socioeconómico familiar en el logro educativo, el color de la piel podría ser un factor determinante de la estratificación social. Es probable que en presencia de discriminación, a igual estatus socioeconómico familiar, los individuos del grupo discriminado (quienes probablemente tienen que realizar mayores sacrificios en la adquisición de credenciales educativas), tengan menores estímulos para alcanzar altos niveles de educación, debido a que el mercado laboral no valora igual sus credenciales educativas que las de otros individuos (ver Blau y Duncan, 1967: capítulo 6).

Así, pues, es probable que las personas negras enfrenten mayores impedimentos en sus oportunidades educativas: los resultantes de sus orígenes sociales y los asociados con el color de la piel. Esto se hace más significativo en sociedades donde no existen políticas universalistas de acceso y calidad de la educación, haciendo que el logro educativo se convierta en un rasgo distintivo de las desigualdades en la estructura de oportunidades.

\section{CARACTERísticas Del LOGRo edUCATIVo}

\section{El mejoramiento educativo a través de las cohortes}

En el Cuadro 3-1 se presenta la distribución por nivel de escolaridad de los individuos pertenecientes a la primera y segunda cohorte 
en las cuales los individuos tomaron sus decisiones de educación. Se advierte que en la primera cohorte aproximadamente el 54,6\% había alcanzado a lo más educación primaria completa. También cabría destacar el bajo porcentaje de individuos quienes obtuvieron una educación universitaria: 7,9\%. Este panorama tiene un cambio importante para la cohorte más joven: en esta cohorte el porcentaje de individuos que había alcanzado a lo más educación primaria incompleta se reduce sustancialmente (de 31,7\% a 5,7\%). Esta reducción significativa en los individuos con menor educación se ve reflejado en el incremento en el porcentaje de individuos que alcanzaron secundaria completa o incompleta (de $37,5 \%$ a $60,7 \%$ ) y educación universitaria (de $7,9 \%$ a $19,4 \%$ ).

Estos resultados revelan el mejoramiento en los niveles educativos en la ciudad para la cohorte más joven. No obstante se observa un incremento en el número de personas que no terminaron la educación secundaria, lo cual muestra la presencia de un "cuello de botella" en el acceso a la educación superior (Solís, 2005). Es posible que esto este asociado a los efectos del cambio tecnológico que reduce la utilización del factor trabajo e induce un descenso en la tasa de retornos a la educación, lo cual provoca que los individuos o las familias cambien sus decisiones de educación (Cartagena, 2004). También se podría atribuir a la incapacidad del Estado colombiano para garantizar un incremento substancial en el porcentaje de individuos que acceden a la educación superior, a través de mecanismos de financiación (becas condonables) para los individuos con menor estatus socioeconómico familiar, y que produce un estancamiento en el mejoramiento educativo.

Cuadro 3-1.

Distribución por nivel educativo de dos cohortes de los mayores de 20 años residentes en Cali en 1998 (casos ponderados)

\begin{tabular}{c|c:c:c}
\hline Nivel educativo & $1912-1972$ & $1973-1998$ & Total \\
\hline Primaria incompleta y menos & 31,7 & 5,7 & 18,2 \\
\hline Primaria completa & 23,0 & 14,3 & 18,5 \\
\hline Secundaria & 37,5 & 60,7 & 49,5 \\
\hline Superior & 7,9 & 19,4 & 13,8 \\
\hline Total & 100,0 & 100,0 & 100,0 \\
\hline Casos & 823 & 887 & 1710 \\
\hline
\end{tabular}

Fuente: Cálculos propios con base en la Encuesta de movilidad, urbanización e identidades de las poblaciones afrocolombianas realizada en Cali en el segundo trimestre de 1998. 


\section{Diferencias en el logro educativo}

No obstante el mejoramiento en los niveles de educación a través de las cohortes es probable que este oculte desigualdades en el logro educativo. Es posible observar estas diferencias al elaborar tablas de los niveles de escolaridad para los miembros de cada una de las cohortes según ciertas características sociodemográficas consideradas en este estudio como el sexo (Cuadro 3-2) y el color de la piel (Cuadro 3-3), las cuales son el objetivo fundamental de esta investigación.

El Cuadro 3-2 muestra los cambios en el nivel educativo por sexo. A nivel general, se observa que el mejoramiento en los niveles de educación a través de las cohortes observado en la sección anterior se produce independiente del sexo de los individuos. Por ejemplo, los diferenciales más fuertes entre hombres y mujeres en la cohorte más joven se producen en el nivel educativo de primaria incompleta donde estos alcanzan aproximadamente 4 puntos porcentuales en contra de las mujeres. No obstante los hombres muestran una ligera mayor proporción entre los individuos que habían alcanzado primaria incompleta y menos. Las desigualdades son más reducidas en los otros niveles de educación.

\section{Cuadro 3-2.}

Distribución por nivel educativo de dos cohortes de los mayores de 20 años residentes en Cali en 1998, según sexo (casos ponderados)

\begin{tabular}{|c|c|c|c|}
\hline a) Mujeres & & & \\
\hline Nivel educativo & $1912-1972$ & 1973-1998 & Total \\
\hline Primaria incompleta y menos & 29,8 & 5,0 & 17,1 \\
\hline Primaria completa & 25,6 & 15,9 & 20,6 \\
\hline Secundaria & 40,0 & 60,3 & 50,4 \\
\hline Superior & 4,6 & 18,8 & 11,9 \\
\hline Total & 100,0 & 100,0 & 100,0 \\
\hline Casos & 476 & 502 & 978 \\
\hline \multicolumn{4}{|l|}{ b) Hombres } \\
\hline Nivel educativo & 1912-1972 & 1973-1998 & Total \\
\hline Primaria incompleta y menos & 34,2 & 6,6 & 19,7 \\
\hline Primaria completa & 19,3 & 12,0 & 15,5 \\
\hline Secundaria & 34,0 & 61,2 & 48,3 \\
\hline Superior & 12,5 & 20,2 & 16,6 \\
\hline Total & 100,0 & 100,0 & 100,0 \\
\hline Casos & 348 & 384 & 732 \\
\hline
\end{tabular}

Fuente: Cálculos propios con base en la Encuesta de movilidad, urbanización e identidades de las poblaciones afrocolombianas realizada en Cali en el segundo trimestre de 1998. 
Por otro lado, y lo más importante para los objetivos de este estudio, el Cuadro 3-3 enseña las diferencias en el nivel educativo de acuerdo al color de la piel de los individuos según cohortes. En la primera cohorte el porcentaje de individuos negros que habían alcanzado a lo más educación primaria completa en relación a los mulatos y blancos o mestizos era $(67,8 \%$, frente a $52,0 \%$ y $52,8 \%$, respectivamente). Este porcentaje se reduce para los individuos negros en las cohorte más joven, al igual que para los mulatos y blancos o mestizos (34,4\%, frente a $25,5 \%$ y $15,5 \%$, respectivamente). Este resultado insinuaría movilidad social ascendente para los individuos negros en promedio. No obstante, al observar los diferenciales frente a los blancos o mestizos, en especial, se aprecia un incremento en las desigualdades: mientras que en la primera cohorte los individuos negros tenían una sobreparticipación de 15,0 puntos porcentuales, esta se incrementa a 18,9 puntos porcentuales para la cohorte más joven.

En conexión a lo anterior, los diferenciales se han incrementado el acceso a la educación universitaria. En la primera cohorte, el porcentaje de individuos negros que habían alcanzado educación primaria universitaria en relación a los mulatos y blancos o mestizos era $3,7 \%$, frente a $7,4 \%$ y $8,6 \%$, respectivamente; es decir, una diferencia de 3,7 y 4,7 puntos porcentuales frente a los mulatos y blancos y mestizos respectivamente. Para la cohorte más joven tanto los individuos negros como los mulatos y blancos y mestizos mejoran sus niveles de educación $(8,6 \%$, frente a $19,2 \%$ y $22,1 \%$, respectivamente), pero los diferenciales se incrementan: 10,5 y 13,5 puntos porcentuales cuando se les compra con los mulatos y blancos o mestizos, respectivamente.

\section{Cuadro 3-3.}

Distribución por nivel educativo de dos cohortes de los mayores de 20 años residentes en Cali en 1998, según el color de la piel (casos ponderados)

\begin{tabular}{c|c|c|c}
\hline \multicolumn{3}{|c}{ a) Negros/as } \\
\hline Nivel educativo & $1912-1972$ & $1973-1998$ & Total \\
\hline Primaria incompleta y menos & 47,0 & 16,4 & 28,6 \\
\hline Primaria completa & 20,8 & 18,0 & 19,1 \\
\hline Secundaria & 28,5 & 57,0 & 45,7 \\
\hline Superior & 3,7 & 8,7 & 6,7 \\
\hline Total & 100,0 & 100,0 & 100,0 \\
\hline Casos & 301 & 459 & 760 \\
\hline
\end{tabular}




\begin{tabular}{|c|c|c|c|}
\hline \multicolumn{4}{|c|}{ b) Mulatos } \\
\hline Nivel educativo & 1912-1972 & 1973-1998 & Total \\
\hline Primaria incompleta y menos & 24,4 & 6,5 & 14,0 \\
\hline Primaria completa & 27,5 & 19,1 & 22,6 \\
\hline Secundaria & 40,7 & 55,3 & 49,2 \\
\hline Superior & 7,4 & 19,2 & 14,3 \\
\hline Total & 100,0 & 100,0 & 100,0 \\
\hline Casos & 162 & 227 & 389 \\
\hline \multicolumn{4}{|c|}{ b) Blancos o mestizos } \\
\hline Nivel educativo & $1912-1972$ & 1973-1998 & Total \\
\hline Primaria incompleta y menos & 29,9 & 2,9 & 16,6 \\
\hline Primaria completa & 22,8 & 12,6 & 17,8 \\
\hline Secundaria & 38,6 & 62,4 & 50,4 \\
\hline Superior & 8,6 & 22,1 & 15,3 \\
\hline Total & 100,0 & 100,0 & 100,0 \\
\hline Casos & 285 & 276 & 561 \\
\hline
\end{tabular}

Fuente: Cálculos propios con base en la Encuesta de movilidad, urbanización e identidades de las poblaciones afrocolombianas realizada en Cali en el segundo trimestre de 1998.

Estos resultados muestran la importancia del color de la piel en el logro educativo. No obstante el mejoramiento de los niveles de educación a escala societal, las oportunidades de movilidad entre grupos raciales es reducida. Los resultados aquí encontrados confirman las tendencias observadas en varios países de América Latina, aunque los resultados son novedosos en torno a las desigualdades según el color de la piel (ver Nina y Grillo, 2000; Behrman, Gaviria y Székely, 2001; Gaviria, 2002; Tenjo, 2004; Cortés y Escobar, 2003; Solís, 2005).

\section{DETERMINANTES DEL LOGRO EDUCATIVO}

La sección anterior mostró que las desigualdades en el logro educativo están determinadas por la persistencia de los factores adscriptivos en el proceso de estratificación social. No obstante, las estadísticas descriptivas no permiten saber si las diferencias en el logro educativo según el color de la piel y sexo se producen por el efecto directo del color de la piel, o son producto de los rezagos del estatus socioeconómico familiar y la condición migratoria. Lo anterior, reitero de nuevo, solo se consigue a través de un modelo multivariado que permita valorar de forma adecuada el efecto independiente de cada variable en la probabilidad de alcanzar un nivel educativo más alto, según cohortes. 
A continuación utilizo un modelo de regresión logística ordenada para valorar la probabilidad de que un individuo alcance un nivel educativo más alto al de otro individuo para las distintas cohortes. La variable dependiente es el nivel educativo alcanzado por el individuo, en el cual valores más altos representan mayores niveles de educación. Como variables independientes se incluyen el color de la piel, el sexo, la condición migratoria y la escolaridad del padre.

Especificación del modelo:

$$
\begin{aligned}
\ln \left[\frac{p(Y \leq k)}{P(Y>k)}\right]=\alpha+ & \beta_{1}\left(\text { raza }_{1}\right)+\beta_{2}\left(\text { raza }_{2}\right) \\
& +\beta_{3}(\text { hom bre }) \\
& +\beta_{4}(\text { nativo }) \\
& +\beta_{5}\left(\text { nivelpa }_{2}\right)+\beta_{6}\left(\text { nivelpa }_{3}\right)+\beta_{7}\left(\text { nivelpa }_{4}\right) \\
& +\varepsilon
\end{aligned}
$$

Los resultados del modelo se presentan en el Cuadro 3-4. De estos se puede destacar lo siguiente:

La educación del padre muestra un efecto positivo en la probabilidad de alcanzar un nivel educativo más alto en ambas cohortes, aunque es mayor y más significativo para los individuos que tomaron sus decisiones de educación entre 1973 y 1998. Por ejemplo, en la primera cohorte el efecto de la educación del padre solo era significativo para los hijos con padres que hubiesen alcanzado la primaria completa y la educación superior cuando se los compara con los hijos de padres con primaria incompleta y menos. Los hijos de individuos con padres que hubieran alcanzado la secundaria completa o incompleta sorprendentemente solo mostraban un efecto en la probabilidad de alcanzar un nivel educativo más alto. En la cohorte más joven el efecto de la educación del padre se incrementa en todos los casos y es fuertemente significativo para los hijos de los padres que al menos terminaron la primaria cuando se les compara con los hijos de los padres con primaria incompleta y menos.

La condición migratoria tiene un efecto significativo sobre el logro educativo, aunque disminuye para la segunda cohorte: en ambas cohortes ser nativo de Cali hace más probable alcanzar un nivel educativo más alto. 


\section{Carlos Augusto Viáfara López}

\section{Cuadro 3-4.}

Modelo de logro educativo según cohortes en las cuales los individuos tomaron sus decisiones de educación

\begin{tabular}{|c|c|c|c|c|}
\hline \multirow{3}{*}{$\begin{array}{l}\text { Máximo nivel educativo alcanzado } \\
\text { Variables }\end{array}$} & \multirow{2}{*}{\multicolumn{2}{|c|}{$\begin{array}{c}\text { Modelo Ajustado } \\
1909-1972 \\
\end{array}$}} & \multirow{2}{*}{\multicolumn{2}{|c|}{$\begin{array}{c}\text { Modelo Ajustado } \\
1973-1998 \\
\end{array}$}} \\
\hline & & & & \\
\hline & $\beta$ & $\mathrm{P}>\mathrm{t}$ & $\beta$ & $\mathrm{P}>\mathrm{t}$ \\
\hline \multicolumn{5}{|l|}{ Efectos Principales } \\
\hline \multicolumn{5}{|l|}{ Educación del padre } \\
\hline Primaria incompleta y menos & --- & & --- & \\
\hline Primaria completa & 0,80 & 0,010 & 0,62 & 0,042 \\
\hline Secundaria & 1,14 & 0,310 & 1,24 & 0,006 \\
\hline Superior & 2,57 & 0,049 & 3,46 & 0,000 \\
\hline \multicolumn{5}{|l|}{ Status Migratorio } \\
\hline Migrante & --- & & --- & \\
\hline Nativo & 1,25 & 0,000 & 0,87 & 0,004 \\
\hline \multicolumn{5}{|l|}{ Sexo } \\
\hline Mujer & --- & & --- & \\
\hline Hombre & 0,29 & 0,365 & $-0,11$ & 0,714 \\
\hline \multicolumn{5}{|l|}{ Color de la piel } \\
\hline Negro & --- & & --- & \\
\hline Mulato & 0,48 & 0,068 & 0,40 & 0,119 \\
\hline Blanco o mestizo & 0,38 & 0,170 & 0,68 & 0,006 \\
\hline \multicolumn{5}{|c|}{ Efectos de interacción color de la piel y sexo } \\
\hline \multicolumn{5}{|l|}{ Mujer } \\
\hline Negra & --- & & --- & \\
\hline Mulata & 0,79 & 0,010 & 0,70 & 0,030 \\
\hline Blanca o mestiza & 0,51 & 0,108 & 0,77 & 0,019 \\
\hline \multicolumn{5}{|l|}{ Hombre } \\
\hline Negro & --- & & --- & \\
\hline Mulato & $-0,03$ & 0,926 & 0,06 & 0,866 \\
\hline Blanco o mestizo & 0,23 & 0,588 & 0,54 & 0,104 \\
\hline \multirow[t]{2}{*}{ Numero de observaciones } & & 746 & & 964 \\
\hline & & $F(7,209)$ & & $F(7,225)$ \\
\hline $\mathrm{F}$ & & 6,28 & & 11,16 \\
\hline Prob $>F$ & & 0,000 & & 0,000 \\
\hline
\end{tabular}

Fuente: Cálculos propios con base en la Encuesta de movilidad, urbanización e identidades de las poblaciones afrocolombianas realizada en Cali en el segundo trimestre de 1998. 
El sexo no consiguió tener un efecto diferencial sobre la probabilidad de alcanzar un nivel educativo más alto como ya se preveía desde el análisis descriptivo.

Los efectos del color de la piel muestran un cuadro interesante: en la primera cohorte existe un efecto significativo de ser mulato en relación a ser negro en a probabilidad de alcanzar un nivel educativo más alto: ser mulato hace más probable alcanzar un nivel educativo más alto que ser negro; mientras tanto, el coeficiente de ser blanco relativo a ser negro no tiene un efecto significativo en la probabilidad de alcanzar un nivel educativo más alto. En la segunda cohorte, aun después de controlar por la educación del padre, la condición migratoria y el sexo, las diferencias en el logro educativo según el color de la piel son fuertes y significativas. Ser mulato en relación a ser negro hace más probable alcanzar un nivel educativo más alto; y ser blanco en relación a ser negro igualmente hace más probable alcanzar un nivel educativo más alto, aunque el efecto es mucho más fuerte que para los mulatos.

\section{Interacción de color de la piel y sexo en el logro educativo}

En esta sección se indaga si las diferencias de acuerdo al color de la piel es en el logro educativo se mantienen según sexo. El cálculo de las interacciones según el color de la piel y sexo se presentan la parte inferior del Cuadro 3-4.

Al igual que en el modelo de la salida de la escuela, básicamente, las inequidades de acuerdo al color de la piel en el logro educativo en ambas cohortes se explican por las desigualdades de las mujeres negras en relación a las mulatas y blancas o mestizas. Para las mujeres mulatas y blancas o mestizas es más probable alcanzar un nivel educativo más alto que para las mujeres negras. Es importante resaltar que ser mujer mulata confiere más ventajas en la probabilidad de alcanzar un nivel educativo más alto relativo a las mujeres negras. Para los hombres el efecto del color de la piel no es significativo.

\section{Probabilidades predichas de alcanzar un nivel educativo}

El cálculo de probabilidades en el modelo logístico ordenado se muestra en el Cuadro 3-5. Para los individuos que tomaron sus decisiones de educación en la primera cohorte era más probable alcanzar la secundaria completa o incompleta, seguida por la primaria incompleta y menos, y luego la primaria completa que mostraban una probabilidad similar. En concordancia a lo anterior, obtener un nivel universitario era menos probable con diferencias notables en relación a los niveles educativos señalados con anterioridad. Este panorama, sin embargo, era diferente según el color de la piel y sexo de los individuos: 
las mujeres negras mostraban una sobreconcentración en los niveles educativos inferiores comparadas son sus congéneres. Las mulatas, coherente con los resultados del modelo econométrico, mostraban la mayor probabilidad de alcanzar niveles educativos más altos. Los hombres negros por su parte seguían igual patrón que las mujeres, aunque es importante recordar que los diferenciales de estos con respecto a sus congéneres resultaron ser no significativos en el modelo econométrico.

En la cohorte siguiente se confirma el patrón de sobreconcentración o "cuello de botella" en la educación secundaria incompleta y completa. También se observa una reducción en las probabilidades alcanzar primaria incompleta y menos, y primaria completa, al unísono que se incrementó levemente la probabilidad de obtener un nivel universitario. A tal efecto, aunque las mujeres y hombres negros muestran un mejoramiento con respecto a la cohorte anterior, las desigualdades se hacen más fuertes en relación a sus congéneres, en especial, las desigualdades en relación con las(os) blancas(os) o mestizos(as), mientras que las desigualdades con relación a los mulatos tienden a aminorarse. En ese sentido, los diferenciales en las probabilidades para alcanzar un nivel educativo universitario entre las mujeres negras y mulatas pasan de 5,2 a 6,3 puntos porcentuales, y entre las mujeres negras y blancas o mestizas pasan de 3,8 a 8,2 puntos porcentuales.

Cuadro 3-5

Modelo de logro educativo según cohortes en las cuales los individuos tomaron sus decisiones de educación

\begin{tabular}{|c|c|c|c|c|}
\hline \multicolumn{5}{|c|}{ Probabilidades predichas del nivel educativo alcanzado } \\
\hline Cohorte & Primaria incompleta y menos & Primaria completa & Secundaria & Superior \\
\hline \multicolumn{5}{|c|}{ 1917-1972 } \\
\hline Total & 26,8 & 25,7 & 41,1 & 6,4 \\
\hline \multicolumn{5}{|c|}{ Mujer } \\
\hline Negra & 40,1 & 26,8 & 29,5 & 3,6 \\
\hline Mulata & 20,4 & 23,3 & 47,4 & 8,8 \\
\hline Blanca & 23,8 & 24,8 & 44,1 & 7,4 \\
\hline \multicolumn{5}{|c|}{ Hombre } \\
\hline Negro & 33 & 26,8 & 35,4 & 4,8 \\
\hline Mulato & 16,4 & 20,8 & 51,5 & 11,3 \\
\hline Blanco & 17,9 & 21,8 & 50 & 10,3 \\
\hline
\end{tabular}




\begin{tabular}{c|c|c|c|c}
\hline & \multicolumn{2}{c}{ Probabilidades predichas del nivel educativo alcanzado } & \\
\cline { 1 - 2 } Cohorte & Primaria incompleta y menos & Primaria completa & Secundaria & Superior \\
\hline $\mathbf{1 9 7 3 - 1 9 9 8}$ & & & & \\
\hline Total & 6,9 & 18,7 & 64,9 & 9,5 \\
\hline & & Mujer & & \\
\hline Negra & 11,5 & 26,0 & 56,8 & 5,7 \\
\hline Mulata & 5,4 & 15,6 & 67,0 & 12,0 \\
\hline Blanca & 4,6 & 13,7 & 67,8 & 13,9 \\
\hline & & Hombre & & \\
\hline Negro & 10,4 & 24,5 & 58,7 & 6,3 \\
\hline Mulato & 5,1 & 14,8 & 67,4 & 12,7 \\
\hline Blanco & 4,0 & 12,1 & 68,0 & 15,9 \\
\hline
\end{tabular}

Fuente: Cálculos propios con base en la Encuesta de movilidad, urbanización e identidades de las poblaciones afrocolombianas realizada en Cali en el segundo trimestre de 1998.

Estos resultados sugieren un incremento en la movilidad educativa para los individuos que tomaron sus decisiones de educación en cohorte más joven. Esto se explica por los mayores niveles de urbanización, el descenso en la tasa de crecimiento de la población, el cambio sectorial en la economía y el incremento en la oferta de servicios educativos, no obstante que se observa un estancamiento en los niveles educativos superiores como otros estudios lo han señalado (ver Cartagena, 2004; Solís, 2005). Por otro lado, y lo más importante, para la cohorte más joven, no obstante el mejoramiento a escala societal, las desigualdades entre grupos de acuerdo al color de la piel son más fuertes que para la primera cohorte.

Una explicación para el incremento en las desigualdades educativas entre grupos de acuerdo al color de la piel podría ser atribuido a los efectos de las nuevas modalidades de crecimiento económico que inducen a un mayor riesgo de pobreza para los individuos pertenecientes a los grupos sociales más vulnerables y que se ve representado en un mayor empeoramiento de las condiciones del mercado laboral para estos grupos y que podrían ser muy lesivos en presencia de discriminación por el color de la piel y sexo, de lo cual me ocuparé en la siguiente sección de esta investigación.

\section{LA MOVILIDAD OCUPACIONAL}

Debido a que en la sociedad capitalista los individuos obtienen sus ingresos a partir de la venta de la fuerza de trabajo a las firmas, existen dos mecanismos básicos en la explicación de las desigual- 
dades en el proceso de logro de estatus: el primero, se refiere a las prácticas de reclutamiento, promoción y remuneración por parte de los empleadores; y el segundo, en la forma en la cual tanto la familia como el sistema escolar forman competencias útiles para el sistema productivo entre individuos de diferentes orígenes sociales (Bowles, 1973: 350).

Según Bowles, existen cinco características que los empleadores tienen en cuenta para realizar la selección de sus empleados, lo cual probablemente tenga la intención de legitimar la organización social de la producción: atributos cognitivos, referidos al conocimiento de un oficio; características de personalidad, tales como la iniciativa, personalidad, sumisión, etc.; presentación propia, en la cual se destacan la manera de hablar, de vestir, modelos de identificación semejante y distancia social percibida entre grupos de diferentes posiciones sociales; características adscriptivas como el color de la piel, sexo y edad; y por último el rol de las credenciales educativas.

De las características anteriores parecería que el color de la piel juega un rol importante en la determinación de las demás. El capítulo anterior mostró la influencia significativa del color de la piel y su interacción con el sexo en la formación de credenciales educativas para la población negra en Cali. Además, varios estudios han mostrado que a iguales credenciales educativas, la adscripción de acuerdo al color de la piel induce diferencias en los resultados en el mercado laboral debido estereotipos y prejuicios asociados al color de la piel y al menor capital social de los individuos negros (ver por ejemplo Blau y Duncan, 1967; Schmidt y Strauss, 1975; Wilson et al., 1999).

En esta sección me intereso en la inserción en la estructura ocupacional laboral alcanzada para los individuos que empezaron sus carreras laborales en las cohortes de análisis. Lo importante aquí no es solo observar el efecto del nuevo modelo de acumulación en la estructura ocupacional entre grupos de acuerdo al color de la piel, sino ver los resultados del efecto conjunto de la educación y la inserción en la estructura ocupacional en el proceso de movilidad social o proceso de logro de estatus de Blau y Duncan en la ciudad de Cali. ${ }^{2}$

\section{DESTINOS OCUPACIONALES}

A continuación se presenta una descripción analítica según destinos ocupacionales de algunas variables seleccionadas en ambas cohortes.

2 Raúl Atria (2004: 38) señala a la influencia conjunta de la educación y la inserción en la estructura ocupacional como uno de los temas de emergentes en una agenda actual sobre estratificación y movilidad social en la región. 
El Cuadro 4-1 muestra la distribución según destinos ocupacionales de individuos pertenecientes a ambas cohortes. Así, cabría mencionar en primer término el mejoramiento ocupacional en la ciudad de Cali, el cual se representa en un mayor porcentaje de trabajadores no manuales en la segunda cohorte que para la primera cohorte (39\%, frente a $22,8 \%$, respectivamente). Concomitante a lo anterior, los individuos que iniciaron sus carreras laborales en la cohorte más joven experimentaron una reducción en el porcentaje de trabajadores manuales; cabría destacar el descenso de los trabajadores manuales de alta calificación probablemente empleados en el sector industrial. ${ }^{3}$

\section{Cuadro 4-1}

Distribución por posición socio-ocupacional de dos cohortes de los residentes en Cali en 1998 (casos ponderados)

\begin{tabular}{c|c|c|c}
\hline Logro ocupacional & $\mathbf{1 9 1 2 - 1 9 7 2}$ & $\mathbf{1 9 7 3 - 1 9 9 8}$ & Total \\
\hline Manuales baja calificación & 46,5 & 41,9 & 43,8 \\
\hline Manuales alta calificación & 30,6 & 19,1 & 23,9 \\
\hline No manuales & 22,8 & 39,0 & 32,2 \\
\hline Total & 100,0 & 100,0 & 100,0 \\
\hline Casos & 712 & 990 & 1702 \\
\hline
\end{tabular}

Fuente: Cálculos propios con base en la Encuesta de movilidad, urbanización e identidades de las poblaciones afrocolombianas realizada en Cali en el segundo trimestre de 1998.

Los destinos ocupacionales según sexo y cohortes exhiben el mejoramiento ocupacional para las mujeres frente a los hombres, para los individuos que iniciaron sus carreras laborales en la cohorte más joven en la ciudad de Cali (ver Cuadro 4-2). El mejoramiento ocupacional para las mujeres podría estar asociado a una serie de transformaciones sociodemográficas a finales del siglo anterior que posibilitó la mayor adquisición de credenciales educativas y por consiguiente una mejor inserción en el mercado laboral (ver Flórez, 2000).

3 Estos resultados son concluyentes con el fenómeno de desindustrialización en la ciudad de Cali y en Colombia en general para los que iniciaron sus carreras laborales en la segunda cohorte. Según Echavarría y Villamizar (2006) pese a la reducción en el porcentaje de trabajadores empleados en el sector industrial, en lo que se conoce como el proceso de desindustrialización, el sector industrial colombiano ahora es más moderno y competitivo. Lo anterior quizás tenga efectos en la estructura de oportunidades entre grupos sociales, más adelante volveré sobre este tema. 


\section{Cuadro 4-2}

Distribución por posición socio-ocupacional de dos cohortes de los residentes en Cali en 1998, según sexo (casos ponderados)

\begin{tabular}{|c|c|c|c|}
\hline \multicolumn{4}{|c|}{ a) Mujeres } \\
\hline Logro ocupacional & $1912-1972$ & 1973-1998 & Total \\
\hline Manuales baja calificación & 53,9 & 34,9 & 42,5 \\
\hline Manuales alta calificación & 24,6 & 14,7 & 18,7 \\
\hline No manuales & 21,6 & 50,4 & 38,9 \\
\hline Total & 100,0 & 100,0 & 100,0 \\
\hline Casos & 377 & 567 & 944 \\
\hline \multicolumn{4}{|c|}{ b) Hombres } \\
\hline Logro ocupacional & $1912-1972$ & 1973-1998 & Total \\
\hline Manuales baja calificación & 38,0 & 51,7 & 45,6 \\
\hline Manuales alta calificación & 37,7 & 25,2 & 30,8 \\
\hline No manuales & 24,3 & 23,1 & 23,6 \\
\hline Total & 100,0 & 100,0 & 100,0 \\
\hline Casos & 336 & 422 & 758 \\
\hline
\end{tabular}

Fuente: Cálculos propios con base en la Encuesta de movilidad, urbanización e identidades de las poblaciones afrocolombianas realizada en Cali en el segundo trimestre de 1998.

Los destinos ocupacionales según el color de la piel y cohortes enseñan profundas desigualdades en la estructura de oportunidades ocupacionales, lo cual se ve representado en el incremento en la brecha de logro ocupacional para los individuos negros en la cohorte más joven (ver Cuadro 4-3). Esto probablemente se explica por un reforzamiento de los mecanismos institucionales que producen desigualdades entre grupos sociales en el sistema de estratificación social y que se producen por las características del nuevo modelo de acumulación presentes en la gran mayoría de países en América Latina (Portes y Roberts, 2004). En especial, sería importante aludir al respecto el efecto de las condiciones laborales que probablemente afecten con mayor intensidad a los individuos que tiene que hacer un mayor esfuerzo en la adquisición de credenciales educativas y enfrenten prácticas discriminatorias en el mercado laboral. Por ejemplo, algunos estudios recientes muestran el incremento significativo en el índice de subempleo en Cali en los últimos años, lo cual sugiere que la mayoría de empleos creados en la ciudad son de baja remuneración y muestran la falta de aparejamiento con las competencias y aspiraciones de los individuos. A nivel general, estos empleos se caracterizan por la carencia de protección 
social y de los cuales se obtienen ingresos más bajos e inestables. En este sentido cabe destacar la mayor desventaja para los individuos afrocolombianos, las cuales exhiben una sobreparticipación en este tipo de ocupaciones como lo muestran los resultados.

\section{Cuadro 4-3}

Distribución por posición socio-ocupacional de dos cohortes de los residentes en Cali en 1998, según el color de la piel (casos ponderados)

\begin{tabular}{|c|c|c|c|}
\hline \multicolumn{4}{|c|}{ a) Negros(as) } \\
\hline Logro ocupacional & $1912-1972$ & 1973-1998 & Total \\
\hline Manuales baja calificación & 65,0 & 64,7 & 64,8 \\
\hline Manuales alta calificación & 16,0 & 13,9 & 14,7 \\
\hline No manuales & 19,0 & 21,4 & 20,5 \\
\hline Total & 100,0 & 100,0 & 100,0 \\
\hline Casos & 290 & 479 & 769 \\
\hline \multicolumn{4}{|c|}{ b) Mulatos } \\
\hline Logro ocupacional & $1912-1972$ & $1973-1998$ & Total \\
\hline Manuales baja calificación & 45,0 & 50,4 & 48,1 \\
\hline Manuales alta calificación & 30,4 & 16,9 & 22,5 \\
\hline No manuales & 24,6 & 32,8 & 29,4 \\
\hline Total & 100,0 & 100,0 & 100,0 \\
\hline Casos & 160 & 226 & 386 \\
\hline \multicolumn{4}{|c|}{ c) Blancos o mestizos } \\
\hline Logro ocupacional & $1912-1972$ & 1973-1998 & Total \\
\hline Manuales baja calificación & 43,2 & 35,4 & 38,8 \\
\hline Manuales alta calificación & 33,5 & 20,6 & 26,1 \\
\hline No manuales & 23,3 & 44,0 & 35,1 \\
\hline Total & 100,0 & 100,0 & 100,0 \\
\hline Casos & 234 & 313 & 547 \\
\hline
\end{tabular}

Fuente: Cálculos propios con base en la Encuesta de movilidad, urbanización e identidades de las poblaciones afrocolombianas realizada en Cali en el segundo trimestre de 1998.

En síntesis, las estadísticas descriptivas sugieren un incremento o en el mejor de los casos, el mantenimiento en las desigualdades en los destinos ocupaciones según sexo y color de la piel. No obstante, y siguiendo la estrategia de los capítulos anteriores, las estadísticas descriptivas no permiten observar el efecto neto de cada una de las variables manteniendo las demás constantes. Particularmente inte- 
resa saber si los diferenciales de logro ocupacional según cohortes entre individuos negros y mulatos y blancos o mestizos se producen por las mayores dificultades en la adquisición de credenciales educativas como se observo en los capítulos anteriores, o, si por el contrario, se explican por la discriminación por el color de la piel y sexo.

\section{DETERMINANTES DEL ESTATUS SOCIO-OCUPACIONAL EN EL ÚLTIMO EMPLEO}

A continuación se utiliza de nuevo un modelo de regresión logística multinomial ordenada para valorar la probabilidad de que un individuo obtenga una ocupación de mayor estatus que otro individuo. La variable dependiente es la posición socio-ocupacional del individuo en el último empleo. Como variables independientes se incluyen el color de la piel, el sexo, la condición migratoria, el nivel educativo alcanzado por el individuo y la escolaridad del padre.

Especificación del modelo:

$$
\begin{aligned}
\ln \left[\frac{p(Y \leq k)}{P(Y>k)}\right]=\alpha & +\beta_{1}\left(\text { raza }_{1}\right)+\beta_{2}\left(\text { raza }_{2}\right) \\
& +\beta_{3}\left(\text { hom }_{\text {bre }}\right) \\
& +\beta_{4}(\text { nativo }) \\
& +\beta_{5}\left(\text { nivel }_{2}\right)+\beta_{6}\left(\text { nivel }_{3}\right)+\beta_{7}\left(\text { nivel }_{4}\right) \\
& +\beta_{8}\left(\text { nivelpa }_{2}\right)+\beta_{9}\left(\text { nivelpa }_{3}\right)+\beta_{10}\left(\text { nivelpa }_{4}\right) \\
& +\varepsilon
\end{aligned}
$$

Los resultados del modelo se presentan en el Cuadro 4-4, los cuales permiten resaltar lo siguiente:

El efecto de la educación del padre en la probabilidad de alcanzar una ocupación de mayor estatus es significativo para los individuos cuyos padres alcanzaron educación superior frente a los individuos cuyos padres alcanzaron a lo más educación primaria incompleta y menos en la primera cohorte. En la segunda cohorte, el efecto se hace significativo para los hijos de padres con primaria completa y cualquier nivel de educación secundaria, además mantiene la importancia de tener un padre con educación superior en la probabilidad de alcanzar una ocupación de mayor estatus. Esto sugiere, no obstante que el efecto de tener un padre con educación superior en la probabilidad de 
alcanzar un nivel educativo más alto es mucho mayor en la primera cohorte que en la segunda cohorte, la importancia de la escolaridad del padre en el acceso a ocupaciones de mayor estatus y, por ende el reforzamiento de una estructura de oportunidades sesgada por los orígenes sociales de los individuos.

Por su parte, la educación tiene un efecto preponderantemente positivo. Los coeficientes sugieren que obtener un nivel educativo de secundaría y más, frente a los individuos que alcanzaron a lo más educación primaria incompleta y menos, hace más probable alcanzar una posición socio-ocupacional de mayor estatus, aunque el efecto es mayor en la última cohorte.

El efecto de la condición migratoria no es significativo, lo cual sugeriría que el mercado laboral de Cali no discrimina a los individuos por su región de origen o movilidad espacial.

El efecto del género no es significativo en la primera cohorte, pero en la cohorte más joven ser hombre hace más probable alcanzar una posición socio-ocupacional de mayor estatus. A tal efecto, el resultado sugiere que el mercado laboral de Cali discrimina a las mujeres por su condición sexual independiente de sus credenciales educativas, estatus socioeconómico familiar, color de la piel y condición migratoria.

En último lugar, el efecto del color de la piel manifiesta que ser negro hace menos probable alcanzar una posición socio-ocupacional de mayor estatus frente a los mulatos y blancos o mestizos en ambas cohortes (el coeficiente para los mulatos no es significativo en la segunda cohorte). En ese mismo sentido, se observa una disminución en el efecto y significancia del coeficiente asociado a los individuos mulatos frente a los negros, mientras que el coeficiente asociado a los blancos o mestizos incrementa su efecto y significancia estadística en el tiempo. Este resultado es de suma importancia en la comprensión de las desigualdades entre grupos de acuerdo al color de la piel, y muestra que a pesar del efecto preponderante de la educación, seguido por la educación del padre y el sexo, a igual nivel educativo estatus socioeconómico familiar y sexo, los individuos negros se insertan en ocupaciones de bajo estatus socioocupacional, lo cual podría ser interpretado como discriminación por el color de la piel. 


\section{Carlos Augusto Viáfara López}

\section{Cuadro 4-4}

Modelo de logro socio-ocupacional según cohortes en las cuales los individuos ingresaron al mercado laboral

\begin{tabular}{|c|c|c|c|c|}
\hline \multirow{2}{*}{ Logro socio-ocupacional } & \multicolumn{2}{|c|}{ Modelo Ajustado } & \multicolumn{2}{|c|}{ Modelo Ajustado } \\
\hline & \multicolumn{2}{|c|}{ 1909-1972 } & \multicolumn{2}{|c|}{ 1973-1998 } \\
\hline Variables & $\beta$ & $\mathrm{P}>\mathrm{t}$ & $\beta$ & $\mathrm{P}>\mathrm{t}$ \\
\hline \multicolumn{5}{|l|}{ Efectos principales } \\
\hline \multicolumn{5}{|l|}{ Educación del padre } \\
\hline Primaria incompleta y menos & --- & & --- & \\
\hline Primaria completa & 0,52 & 0,160 & 0,46 & 0,093 \\
\hline Secundaria & 0,38 & 0,391 & 0,85 & 0,061 \\
\hline Superior & 2,60 & 0,000 & 1,80 & 0,018 \\
\hline \multicolumn{5}{|l|}{ Educación del Ego } \\
\hline Primaria incompleta y menos & --- & & --- & \\
\hline Primaria completa & $-0,11$ & 0,790 & 0,52 & 0,432 \\
\hline Secundaria & 1,42 & 0,001 & 1,81 & 0,001 \\
\hline Superior & 1,35 & 0,049 & 3,55 & 0,000 \\
\hline \multicolumn{5}{|l|}{ Status Migratorio } \\
\hline Migrante & --- & & --- & \\
\hline Nativo & $-0,40$ & 0,233 & 0,11 & 0,711 \\
\hline \multicolumn{5}{|l|}{ Sexo } \\
\hline Mujer & --- & & --- & - \\
\hline Hombre & 0,48 & 0,152 & 1,13 & 0,000 \\
\hline \multicolumn{5}{|l|}{ Color de la piel } \\
\hline Negro & --- & & --- & \\
\hline Mulato & 0,76 & 0,006 & 0,36 & 0,107 \\
\hline Blanco o mestizo & 0,51 & 0,037 & 0,86 & 0,000 \\
\hline \multicolumn{5}{|l|}{ Efectos de interacción color de la piel y sexo } \\
\hline \multicolumn{5}{|l|}{ Mujer } \\
\hline Negra & --- & & --- & \\
\hline Mulata & 1,02 & 0,010 & 0,83 & 0,007 \\
\hline Blanca o mestiza & 0,29 & 0,431 & 1,46 & 0,000 \\
\hline \multicolumn{5}{|l|}{ Hombre } \\
\hline Negro & --- & & --- & \\
\hline Mulato & 0,30 & 0,401 & $-0,25$ & 0,375 \\
\hline Blanco o mestizo & 0,74 & 0,077 & 0,11 & 0,684 \\
\hline \multirow[t]{2}{*}{ Numero de observaciones } & & 694 & & 1008 \\
\hline & & $\mathrm{F}(10,211)$ & & $\mathrm{F}(10,222)$ \\
\hline $\mathrm{F}$ & & 5,79 & & 9,56 \\
\hline Prob $>F$ & & 0,0000 & & 0,0000 \\
\hline
\end{tabular}

Fuente: Cálculos propios con base en la Encuesta de movilidad, urbanización e identidades de las poblaciones afrocolombianas realizada en Cali en el segundo trimestre de 1998. 


\section{INTERACCIÓN DE COLOR DE LA PIEL Y SEXO EN EL LOGRO OCUPACIONAL}

Ahora, y al igual que en las secciones anteriores, se trata de indagar si las inequidades ocupaciones para los individuos negros frente a los mulatos y blancos o mestizos se mantienen para los mujeres y hombres en las cohortes de análisis.

Las interacciones entre color de la piel y sexo se muestran en la parte inferior del Cuadro 4-4. Entre las mujeres el efecto del color de la piel es muy revelador en ambas cohortes. Ser mujer negra hace más probable alcanzar una ocupación de menor estatus frente a las mulatas y blancas o mestizas (aunque el coeficiente de las mujeres blancas no es significativo en la primera cohorte). Además, y similar a los resultados anteriores, las inequidades tienden a incrementarse para las mujeres negras que ingresaron al mercado de trabajo en la cohorte más joven.

Por otra parte, entre los hombres el efecto del color de la piel solo es significativo cuando se compara a los hombres negros y blancos en la primera cohorte. Esto sugiere que los hombres negros enfrentan inequidades ocupacionales frente a los blancos o mestizos que no se explican por el color de la piel y que podrían ser atribuibles a sus bajos niveles de educación o por tener padres más pobres o por su condición migratoria.

\section{Probabilidades predichas de alCANZAR UNA OCUPACión}

El cálculo de probabilidades según el color de la piel y sexo para alcanzar una ocupación específica se muestran en el Cuadro 4-5. Los resultados corroboran las mayores probabilidades en ambas cohortes de los individuos negros de alcanzar una ocupación manual de baja calificación. En correspondencia, las probabilidades de alcanzar una ocupación manual de alta calificación y, sobre todo, una ocupación no manual es muy inferior para las mujeres y hombres negros.

A este respecto, es importe anotar que además de las mayores probabilidades que tienen los individuos negros de ser empujados al fondo de la estructura ocupacional, los diferenciales frente a los mulatos y blancos o mestizos (cambios discretos) se incrementan entre cohortes, lo cual confirma la ampliación de la brecha de logro ocupacional entre grupos de acuerdo al color de la piel en la cohorte más joven. Por ejemplo, los diferenciales en las probabilidades para alcanzar una ocupación no manual entre las mujeres negras y las mulatas pasan de 8,2 a 17,1 puntos porcentuales, y entre las mujeres negras y blancas o mestizas pasan de 15,2 a 24,2 puntos porcentuales. 


\section{Cuadro 4-5}

Modelo de logro socio-ocupacional según cohortes en las cuales los individuos ingresaron al mercado laboral

\begin{tabular}{|c|c|c|c|}
\hline \multicolumn{4}{|c|}{ Probabilidades predichas del estatus socio-ocupacional alcanzado } \\
\hline Cohorte & Manuales baja calificación & Manuales alta calificación & No manuales \\
\hline 1917-197 & & & \\
\hline Total & 44,0 & 35,3 & 20,8 \\
\hline \multicolumn{4}{|c|}{ Mujer } \\
\hline Negra & 59,9 & 28,0 & 12,1 \\
\hline Mulata & 35,4 & 37,3 & 27,3 \\
\hline Blanca & 44,3 & 35,1 & 20,5 \\
\hline \multicolumn{4}{|c|}{ Hombre } \\
\hline Negro & 46,8 & 34,2 & 18,9 \\
\hline Mulato & 26,2 & 37,1 & 36,7 \\
\hline Blanco & 33,0 & 37,5 & 29,5 \\
\hline \multicolumn{4}{|c|}{ 1973-1998 } \\
\hline Total & 59,4 & 21,6 & 18,9 \\
\hline \multicolumn{4}{|c|}{ Mujer } \\
\hline Negra & 63,6 & 20,0 & 16,4 \\
\hline Mulata & 40,4 & 26,0 & 33,5 \\
\hline Blanca & 33,3 & 26,0 & 40,6 \\
\hline \multicolumn{4}{|c|}{ Hombre } \\
\hline Negro & 82,7 & 10,6 & 6,7 \\
\hline Mulato & 69,3 & 17,5 & 13,2 \\
\hline Blanco & 59,2 & 21,7 & 19,1 \\
\hline
\end{tabular}

Fuente: Cálculos propios con base en la Encuesta de movilidad, urbanización e identidades de las poblaciones afrocolombianas realizada en Cali en el segundo trimestre de 1998.

En resumen, estos resultados sugieren el mayor efecto de la educación, la educación del padre, el sexo y el color de la piel en la determinación del estatus socio-ocupacional de los individuos. Según el color de la piel y sexo, las mujeres negras enfrentan grandes desigualdades ocupacionales, mientras que los efectos para los hombres negros no son tan significativos. Esto muestra que las desigualdades en las oportunidades ocupacionales según el color de la piel son reforzadas por la condición de género. A iguales niveles educativos y orígenes sociales, el color de la piel y el sexo fijarían fuertemente la ubicación de los individuos en la estructura ocupacional, lo cual sugiere una "doble desventaja” para las mujeres negras: ser negras y ser mujeres. 
También se advierte una estructura de clases bien marcada entre las mujeres, y determinada por el color de la piel. Mientras las mujeres blancas y mulatas ocupan puestos de cuello blanco, un gran porcentaje de mujeres negras son confinadas al empleo doméstico y servicios de baja calificación. Esto, reitero, se produce a iguales orígenes sociales y niveles de educación, lo cual constituye una buena evidencia de que las mujeres negras en Cali sufren los efectos combinados de la discriminación por el color de la piel y sexo, la cual es reforzada para las mujeres negras que iniciaron sus carreras laborales en la cohorte más joven.

\section{Comentarios FinAles}

Las ideas que han guiado la investigación sobre estratificación y movilidad social son las tesis de modernización y la tesis de intervención política (Ganzeboom et al., 2000: 12). La tesis de modernización señala que el efecto directo de los orígenes sociales va ser cada vez más reducido en el proceso de logro de estatus, lo que produciría una reducción en las inequidades sociales. Por su parte, la tesis de intervención política está fundamentada en la inclusión del Estado en el proceso de estratificación social a través de la universalización de las políticas públicas.

Sea como fuere debe señalarse que los resultados encontrados en esta investigación ponen a prueba tales hipótesis. Estos sugieren que a pesar del mejoramiento educativo y ocupacional a "escala societal", las desigualdades entre grupos étnico-raciales no se han reducido como se esperaría. Más bien estas tienden a incrementarse en la ciudad de Cali. Esto muestra que la expansión del sistema educativo y la modernización del aparato productivo en la última cohorte inducen un reforzamiento de la dimensión de clase social en la estructura ocupacional y, desde aquí, en la estructura social (Atria, 2004: 38-40).

En este sentido esta investigación corrobora en parte las premisas establecidas por Blau y Duncan (1967: 163-205). Por un lado, se corrobora la importancia significativa de los orígenes sociales, en especial el estatus socioeconómico familiar, en las oportunidades educativas. Un buen antecedente familiar suele estar asociado con mayores recursos materiales que pueden garantizar éxito en las carreras educativas de los individuos e influir en las aspiraciones, características de personalidad, valores y en la transmisión de las habilidades intelectuales de padres a hijos (Bowles, 1973). No obstante cabría señalar que este efecto es mayor en la última cohorte, lo cual probablemente se explica por el aumento de las desigualdades en las remuneraciones entre trabajadores de baja y alta calificación inducidos por el proceso de globalización (ver López, 2001; Feliciano, 2001). A lo anterior se suma 
el cambio en el énfasis de la política social, que provocó una mayor segmentación educativa y con ello la mayor preponderancia de los orígenes sociales para brindar la continuidad y calidad en la educación de los hijos. Por otro lado el efecto del logro educativo es más importante que el de los orígenes sociales en el estatus socio-ocupacional.

Se podría pensar entonces que debido a los orígenes sociales y niveles de educación inferiores para los individuos negros, el resultado normal del proceso de estratificación, en ausencia de políticas universalistas de acceso y calidad de la educación, se manifestaría en una mayor probabilidad de abandonar la escuela a temprana edad, alcanzar menores logros educativos y obtener un menor estatus socioocupacional. De tal forma, tales resultados podrían ser atribuidos al efecto de un círculo de pobreza debido a los rezagos en el estatus socioeconómico familiar, condición migratoria, nivel de escolaridad y probablemente a los modelos culturales que tales situaciones suelen reproducir.

Sin embargo, de los orígenes sociales, el color de la piel y su interacción con el sexo revelaron un efecto significativo en todas las etapas del proceso de estratificación. Esto sugiere la presencia de un "círculo vicioso" o "desventajas acumulativas" para los individuos negros, que no están asociadas a sus orígenes sociales, ni al logro individual, sino a la presencia de mecanismos institucionales que inducen a inequidades en la estructura de oportunidades, los cuales podrían estar fundados en la discriminación por el color de la piel.

En efecto, en Cali, la inequidad de oportunidades esta determinada por el color de la piel, aunque estos datos solo permitieron corroborarlo de manera categórica para las mujeres. Mientras que las desventajas de los hombres negros se asocian mayormente a sus orígenes sociales y logros educativos inferiores.

Referido al efecto conjunto de la educación y el trabajo en la estructura de oportunidades Raúl Atria (2004: 38-40) ha señalado lo siguiente:

"En general estos dos factores están positivamente relacionados con la movilidad social ascendente, pero actúan también como mecanismos de reproducción de las desigualdades en el perfil de la estratificación social [...]. Estaríamos por tanto en presencia de una estructura de oportunidades sesgada en favor de quienes ya están en posesión de un activo social sea por las mejores oportunidades de trabajo que capturan dado el activo laboral que ya posee su grupo generacional familiar, o por el mejor acceso que tienen a una escolaridad prolongada dado el capital cultural que ya posee el grupo familiar del cual provienen." 
Este efecto, según Atria, podría inducir la perpetuación y ampliación en las desigualdades debido a la presencia de discriminación en la estructura de oportunidades. Según Atria este efecto es comúnmente conocido como el "Efecto Mateo", y fue inicialmente formulado por Robert K. Merton. ${ }^{4}$ Para Merton "los procesos de auto-selección individual y de selección social institucionalizada, interactúan y afectan las probabilidades sucesivas de acceso a la estructura de oportunidades" (Merton, 1996a: Cap.13, 160. Citado por Atria, 2004: 39). En relación a su estudio de publicaciones científicas en el cual aquellos quienes desarrollan un temprano liderazgo tienden incrementarlo en el tiempo en detrimento de aquellos que quedan en desventaja inicial, Merton señala que:

“[...] los sistemas de recompensas, asignación de recursos y selección social operan para crear y mantener una estructura de clase por medio de la provisión de una distribución estratificada de oportunidades entre los científicos para incrementar su rol de investigadores. La acumulación diferencial de las ventajas opera de tal manera que, parafraseando a los evangelistas Mateo, Marcos y Lucas, 'al que tiene, se le dará más, y tendrá de sobra; pero al que no tiene, hasta lo poco que tiene se le quitará'." (Merton, 1996b: 320. Citado por Atria, 2004: 39)

Ahora bien, el modelo de Blau y Duncan y las teoría liberales sobre estratificación social (ver Ganzemboom et al., 1991) establecen como hipótesis una reducción a través del tiempo de las desigualdades entre grupos social en el proceso de estratificación social como resultado de la universalización de las políticas públicas. Los hallazgos de esta investigación muestran que el efecto del cambio sectorial en la economía, urbanización y el incremento en la oferta en los servicios educativos, posibilitaron una mayor permanencia en el sistema escolar y por ende un incremento en los niveles educativos a través del tiempo, además un mejoramiento en el estatus socio-ocupacional en la ciudad. No obstante la movilidad social a escala societal, este resultado se produce en presencia de mayores desigualdades entre grupos sociales. Esto podría ser explicado por la presencia de vaivenes reiterados en la economía que inducen a una inestabilidad en los ingresos familiares y con ello un mayor riesgo de abandonar los estudios a temprana edad, obtener menores logros educativos e insertarse en ocupaciones de bajo estatus para los grupos más vulnerables, en especial los individuos negros que podrían verse afectados por varios ejes de desigualdad social. La mayor

4 George Farkas (2002) utiliza este efecto para señalar el proceso de desventajas acumulativas en el sistema educativo para los individuos negros en los Estados Unidos. 
inestabilidad en los ingresos familiares para los individuos negros se explicarían por la presencia de menores retornos a la educación (cuando se miden en términos de logro ocupacional), lo que derivaría posiblemente para estos hogares una inadecuación de ingresos para generar capacidades mínimamente aceptables (Sen y Foster, 2003), en comparación con los que tienen similar estatus socioeconómico familiar. En una economía de mercado esto significa que las familias negras de clase media, en especial, no pueden disfrutar de la misma calidad en el acceso a la salud, educación y ubicación de las viviendas en la ciudad, en comparación con los blancos y mestizos que tienen similar estatus socioeconómico familiar. Esto probablemente afecte la igualdad de resultados en el proceso de estratificación entre el color de la piel para individuos con similar estatus socioeconómico familiar. También es factible que aunque los individuos negros obtengan iguales ingresos, vivan en los mismos barrios de los blancos o estudien en los mismos colegios, se enfrenten a un aislamiento por parte de sus vecinos y compañeros de clases debido a los prejuicios por el color de la piel, lo cual podría inducir al aislamiento relacional y una falta de capital social similar al de la población negra de los barrios pobres de la ciudad. Estas características se hacen más fuertes en la última cohorte debido a la mayor segmentación del mercado laboral que induce una mayor segmentación social en los países de América Latina (ver Roberts, 2002).

Por último, el efecto significativo de la educación del padre en el acceso a ocupaciones de mayor estatus, no obstante el efecto preponderante de la educación, muestra la importancia del estatus socioeconómico familiar en el proceso de logro de estatus, lo cual refuerza aún más el efecto de desventajas acumulativas o "efecto mateo" para los individuos negros en la ciudad de Cali, que como se dijo más arriba se ven afectados por varios ejes de desigualdad social. El avivamiento de los prejuicios de los trabajadores y empleadores con relación a los individuos negros, en especial las mujeres, se hace más visible en períodos de inestabilidad económica como los que enfrentaron los individuos en la segunda cohorte en la ciudad de Cali, aunado a el cambio tecnológico en la economía que induce que los individuos que tienen mayores facilidades para acceder a mejores credenciales educativas sean los primeros en ser contratados en el sector productivo moderno, empujando a los grupos más vulnerables a las ocupaciones más precarias, además de los ya tradicionales prejuicios en torno al acceso en ocupaciones de mando y dirección (ver Wilson et al., 1999)

\section{Bibliografía}

Anker, Richard 1998 Gender and jobs: sex segregation of occupation in the world (Ginebra: OIT). 
Atria, Raúl 2004 "Estructura ocupacional, estructura social y clases sociales" en Serie Políticas Sociales (Santiago de Chile: CEPAL, División de Desarrollo Social) No 96.

Barbary, Olivier y Estacio, Alexander 2005 "Desigualdad socio-racial frente a la movilidad laboral en Cali" en Pobreza, exclusión social y discriminación étnico-racial en América Latina y el Caribe (Cali: CIDSE / UNIVALLE, CLACSO, CROP).

Becker, Gary 1983 "Inversión en capital humano e ingresos" en Toharia, Luis El mercado de trabajo: teoría y aplicaciones: lecturas seleccionadas (Madrid: Alianza Editorial).

Behrman, R. Jere; Gaviria, Alejandro y Székely, Miguel 2001 "Intergenerational mobility in Latin America" en Fedesarrollo Working Papers Series. Documentos de Trabajo. (Bogotá) № 25, abril.

Blau, Peter y Otis, D. Duncan 1967 The american occupational structure (Nueva York: Wiley).

Bowles, Samuel 1973 "Understanding unequal economic opportunity" en The American Economic Review (Chicago) Vol. 63, No 2.

Cartagena Pizarro, Catherine 2004 "Movilidad intergeneracional en Colombia”. Tesis para optar al título de Magíster en Teoría y Política Económica de la Universidad Nacional de Colombia, Bogotá DC, agosto.

Cortés, Fernando y Escobar, Agustín 2003 "Movilidad social intergeneracional en los años de la reforma económica: un estudio del México urbano" en Revista de la CEPAL (México DF: CEPAL) No 85.

Dannefer, Dale 2003 "Toward a global geography of the life course: challenges of late modernity for life course theory" en Mortimer, Jeylan T. y Shanahan, Michael J. (eds.) Handbook of the Life Course (Nueva York: Kluwer Academic / Plenum Publisher).

Echavarría, J. J. y Villamizar, M. 2006 "El proceso colombiano de desindustrialización" en Borradores Semanales de Economía (Bogotá: Banco de la República) No 361.

Edwards, Sebastian 1995 Crisis and Reform in Latin America: from Despair to Hope (Washington DC: World Bank).

Encuesta Cidse, Ird, Conciencias 1998 "Movilidad, urbanización e identidades de las poblaciones afrocolombianas" (Cali) mayojunio.

Erikson, R. y Goldthorpe, J. H. 1985 “Are American Rates of Social Mobility Social Exceptionally High? New Evidence on the Old Question" en European Sociological Review (Londres) Vol. 1, $\mathrm{N}^{\circ}$ 1.

Farkas, George 2002 "Racial Disparities and Discrimination in Education: what do we know, how do we know it, and what do we need to know?", paper preparado para el taller "Measuring Misparities 
in Education", Division of Behavioral and Social Sciences and Education, Committee on National Statistics, National Research Council, Washington DC, julio.

Feliciano Zadia, M. 2001 "Workers and Trade Liberalization: The Impact of Trade Reforms in Mexico on Wages and Employment" en Industrial and Labor Relations Review (Cornell: Cornell University Press) Vol. 55, $\mathrm{N}^{\mathrm{o}} 1$.

Filgueira, Carlos 2001 "La actualidad de viejas temáticas: sobre los estudios de clase, estratificación y movilidad social en América Latina" en Serie de Politicas Sociales (Santiago de Chile: CEPAL) No 51.

Flórez, Carmen E. 2000 Las transformaciones sociodemográficas en Colombia durante el siglo XX (Bogotá: Banco de La República y Tercer Mundo Editores).

Ganzeboom, Harry; Luijkx, Ruud y Treiman, Donald J. 1989 "Intergeneracional Class mobility in comparative perspective" en $R e$ search in Social Stratification and Mobility (Amsterdam: Elsevier) Vol. 8 .

Ganzeboom, Harry; Treiman, Donald J. y Wout, C. Ultee 1991 "Comparative Intergenerational Stratification Research: Three Generations and Beyond" en Annual Review of Sociology (Palo Alto, CA: Annual Reviews) Vol. 17.

Ganzeboom, Harry; Kramberger, Antón y Nieuwbeerta, Paul 2000 "The Parental Effect on Education and Occupational Attainment in Slovenia during the $20^{\text {th }}$ Century" en Druzboslovne Razprave (Liubliana) Vol. XVI, N ${ }^{\circ} 32-33$.

Gaviria, Alejandro 2002 Los que suben y los que bajan. Educación y movilidad social en Colombia (Bogotá: Editorial Alfaomega).

Grusky, David y Hauser, R. M. 1984 "Comparative social mobility revisited: models of convergence and divergence in 16 countries" en American Sociological Review (Washington DC: American Sociological Association) Vol. 49.

Grusky, David 1994 "The Contours of Social Stratification” en Grusky, David (ed.) Social Stratification: Class, Race, and Gender in Sociological Perspective (Boulder: Westview Press).

Hauser, Robert M. y Featherman, David L. 1977 The Process of Stratification: Trends and Analyses (Nueva York: Academic Press).

Helg, Aline 1987 La educación en Colombia 1918-1957: una historia social (Bogotá: Ensayos sobre Colombia y América Latina. Servicio de Estudios del BBVA).

Hosmer, David y Lemeshow, Stanley 2000 Applied Logistic Regressión (Hoboken: John Wiley \& Sons Inc.).

Hurtado, Teodora 2005 "La utilización de los servicios de salud en Colombia con énfasis en la condición étnica-racial” en Identidades y 
movilidades, las sociedades regionales frente a los nuevos contextos políticos y migratorios. Una comparación entre México y Colombia. Proyecto CONACYT 40147 s. (México DF: Ediciones Ciesas / Ird / Icanh, Documentos $\mathrm{N}^{\circ}$ 5).

Infante, Ricardo; Martínez, Daniel y Tokman, Víctor E. 1999 “América Latina: la calidad de los nuevos empleos en los noventa" en Infante, Ricardo (ed.) La calidad del empleo (Lima: OIT).

Kaztman, Rubén 2002 "Convergencias y divergencias: exploración sobre los efectos de las nuevas modalidades de crecimiento sobre la estructura social de cuatro áreas metropolitanas en América Latina" en Kaztman, Rubén y Wormald, Guillermo Trabajo y Ciudadanía. Los cambiantes rostros de la integración y exclusión social en cuatro áreas metropolitanas de América Latina (Montevideo: Cebra).

López-Acevedo, Gladiz 2001 "Evolution of Earnings, Rates and Returns to Education in México" en Policy Research Working Paper (Washington DC: World Bank) N 2691.

Medina, Carlos Alberto 2002 "Oferta laboral en Colombia de acuerdo al Color de la Piel" en Documento CEDE (Bogotá: Universidad de los Andes).

Merton, Robert 1996a "Opportunity structure" en Sztompka, Piotr (ed.) Robert K. Merton on Social Structure and Science (Chicago: The University of Chicago Press).

Merton, Robert 1996b "The Matthew effect II" en Sztompka, Piotr (ed.) Robert K. Merton on Social Structure and Science (Chicago: The University of Chicago Press).

Nina, Esteban y Grillo, Santiago 2000 “Educación, movilidad social y trampa de la pobreza" en Coyuntura Social (Bogotá: Fedesarrollo) $\mathrm{N}^{\circ} 22$.

Portes, Alejandro y Roberts, Bryan 2004 "The Free Market City: Latin American Urbanization in the Years of Neoliberal Adjustment". Ponencia presentada en el Seminario Latin American Urbanization at the End of the 20th Century, Center for Latin American Social Policy, CLASPO, Universidad de Austin en Texas, Texas, 5 y 6 de marzo.

Portilla, D. A. 2003 "Mercado laboral y discriminación racial: una aproximación para Cali” en Documento Cede 2003-14 (Bogotá: Universidad de Los Andes).

Roberts, Bryan 2002 "Los nuevos modelos de crecimiento y sus desafíos para los derechos sociales y la política social" en Kaztman, Rubén y Wormald, Guillermo Trabajo y Ciudadanía. Los cambiantes rostros de la integración y exclusión social en cuatro áreas metropolitanas de América Latina (Montevideo: Cebra). 
Rueda, José Olinto 1993 “Población y poblamiento” en Colombia Pacífico (Bogotá: Universidad Nacional De Colombia) Tomo II.

Schiller Bradley, R. 1971 "Class discrimination vs. racial discrimination" en The Review of Economics and Statistics (Cambridge, MA: MIT Press) Vol. 53, No 3, agosto.

Schmidt, Peter y Strauss, Robert P. 1975 "The Prediction of Occupation Using Multiple Logit Models" en International Economic Review (Pennsylvania) Vol. 16, $\mathrm{N}^{\circ} 2$.

Sen, Amartya y Foster, James 2003 "Espacio, capacidad y desigualdad" en Boltvinik, Julio (coord.) "Pobreza: desarrollos conceptuales y metodológicos" en Comercio Exterior (México DF) Vol. 53, $\mathrm{N}^{\circ}$, mayo.

Sewell, William H.; Haller, Archibald O. y Portes, Alejandro 1969 "The Educational and Early Occupational Attainment Process" en American Sociological Review (Washington DC: American Sociological Association) Vol. 34, $\mathrm{N}^{\circ}$ 1, febrero.

Solís, Patricio 2005 "Cambio estructural y movilidad ocupacional en Monterrey, México” en Revista Estudios Sociológicos (México: El Colegio de México).

Stallings, Bárbara y Pérez, Wilson 2000 Crecimiento, empleo y equidad. El impacto de las reformas económicas en América Latina y el Caribe (México: CEPAL / FCE).

Tenjo, Jaime 2004 "Educación y movilidad social en Colombia" en Documento (Bogotá: Facultad de Ciencias Sociales y Económicas, Universidad Javeriana) $\mathrm{N}^{\circ} 13$.

Urrea, Fernando y Ortiz, Carlos Humberto 1999 "Patrones sociodemográficos, pobreza y mercado laboral en Cali". Documento de trabajo para el Banco Mundial, noviembre, Cali.

Urrea, Fernando et al. 2000 "Cambios en el mercado de trabajo de Cali (Colombia). Reestructuración económica y social del empleo de la población negra en la década del 90: un análisis de segregación socio-racial a partir de las transformaciones más recientes del mercado de trabajo" en Relaciones interraciales, sociabilidades masculinas juveniles y segregación laboral de la población afrocolombiana en Cali (Cali: CIDSE-IRD / Universidad del Valle) Documento de trabajo $\mathrm{N}^{\circ} 49$.

Urrea, Fernando 2000 "Relaciones interraciales y clases en la construcción de ciudadanía: el caso de Cali (Colombia)" en Relaciones interraciales, sociabilidades masculinas juveniles y segregación laboral de la población afrocolombiana en Cali (Cali: CIDSE-IRD / Universidad del Valle) Documento de trabajo $\mathrm{N}^{\circ} 49$.

Urrea, Fernando; Viáfara, Carlos y Ramírez, Héctor Fabio 2002 "Perfiles sociodemográficos de la población afrocolombiana en con- 
textos urbano-regionales del país a comienzos del siglo XXI" en Anuario de Investigaciones (Cali: CIDSE / Universidad del Valle).

Urrea, Fernando; Viáfara, Carlos y Ramírez, Héctor Fabio 2005 "Pobreza y grupos étnicos en Colombia: análisis de sus factores determinantes y lineamientos de políticas para su reducción" en Misión para el Diseño de una Estrategia para la Reducción de la Pobreza y la Desigualdad (Cali: DNP-BID / Grupo de investigación CIDSE-IRD sobre estadísticas étnico-raciales).

Viáfara, Carlos 2005a "Diferencias raciales en las oportunidades educativas y en el estatus ocupacional en el primer empleo en la ciudad de Cali, Colombia”. Tesis para optar por el título de Maestro en Población con especialidad en Mercados de Trabajo, en la Facultad Latinoamericana de Ciencias Sociales (México DF: FLACSO).

Viáfara, Carlos 2005b "Efectos de la raza y el sexo en el logro educativo y estatus ocupacional en el primer empleo en la ciudad de Cali". Ponencia presentada en el Seminario Internacional "Exclusión social y discriminación étnico-racial en América Latina y el Caribe", CIDSE-CLACSO-CROP, 23 a 25 de noviembre, Cali.

Viáfara, Carlos y Urrea, Fernando 2006 "Efectos de la raza y el género en el logro educativo y en estatus socio-ocupacional para tres ciudades colombianas" en Desarrollo y Sociedad (Bogotá: Universidad de los Andes) $\mathrm{N}^{\circ} 58$, segundo semestre.

Wilson, G.; Sakura-Lemessy, I. y West, J. P. 1999 "Reaching the top: Racial differences immobility paths to upper-tier occupations" en Work and Occupations (Los Angeles: Sage) N 26. 


\title{
Heidy Paola Ocampo Meneses*
}

\author{
RECORRIDOS Y CAUSALIDADES \\ DE LA DESIGUALDAD EN EL INGRESO \\ LABORAL EN AMÉRICA LATINA
}

\author{
ANÁLISIS COMPARADO DE LOS CASOS \\ ECUATORIANO Y NICARAGÜENSE ${ }^{* *}$
}

\section{INTRODUCCIÓN}

La desigualdad en los ingresos es uno de los fenómenos sociales que mayor atención ha concitado en América Latina y, en general, en los países con menor desarrollo económico. Desde diversas disciplinas sociales se ha intentado diseñar explicaciones teóricas para dar cuenta de tal hecho y no pocas opciones de políticas públicas se han generado con el fin de paliar tal asimetría. En el campo de la economía uno de los enfoques predominantes para el estudio de esta temática es el que gira alrededor de las ideas provenientes de la teoría del capital humano y del conjunto de premisas aportadas por la tradición del elector racional. En esencia, dicha visión hace explícito que el nivel de inversión en educación es el factor determinante para la presencia de una mayor o menor desigualdad en los ingresos de los individuos. Así,

* Economista (Universidad del Tolima, Colombia). Maestra en Economía (Facultad Latinoamericana de Ciencias Sociales FLACSO - Sede Ecuador) y Magíster (c) en Sociología Económica (Instituto de Altos Estudios Sociales -IDAES-. Universidad Nacional de San Martín. Buenos Aires, Argentina). Investigadora del Centro de Investigaciones de Política y Economía (CIPEC). Comentarios y sugerencias: paolaoca@gmail.com.

** Agradezco los valiosos comentarios de Santiago Basabe Serrano así como también las sugerencias realizadas por los becarios y tutores CLACSO-CROP05. No obstante, cualquier imprecisión es de mi absoluta responsabilidad. 
a mayor nivel de educación de una persona, mayores oportunidades de recibir mejores ingresos (Becker, 1993).

En el presente trabajo se argumenta que, además de los factores individuales señalados por la teoría del capital humano existen otros, de carácter socio-económico, que ejercen influencia en la explicación de la desigualdad en los ingresos laborales. En ese plano, el tamaño de la empresa, la rama de actividad económica y la naturaleza de la vinculación laboral constituyen variables decisivas al efecto. Más aun, el trabajo aquí expuesto demuestra que para los casos analizados tales factores tendrían mayor incidencia que el nivel de educación en la explicación de la desigualdad en los ingresos laborales. Agregar variables de carácter socio-económico a aquellas de orden puramente individual deja entrever, como corolario, la necesidad de plantear refinamientos y ajustes a la teoría del capital humano, fundamentalmente cuando el análisis enfrenta contextos institucionales y políticos como los de América Latina.

En lo de fondo, esta investigación busca identificar los factores que inciden en la desigualdad de los ingresos laborales en dos países de América Latina: Ecuador y Nicaragua. Lo que distingue y torna interesante la comparación de estas unidades de análisis, más allá de su proximidad regional, es la elevada concentración de la desigualdad en el ingreso que presentan. Con base en las argumentaciones presentadas en párrafos precedentes, la hipótesis que se plantea indica que en contextos políticos e institucionales como los observados en América Latina, existen factores socioeconómicos que tendrían mayor influencia que la educación en la explicación de la desigualdad de de los ingresos laborales.

A fin de establecer las posibles correlaciones entre las variables seleccionadas para el estudio se recurrió al método estadístico de análisis econométrico. En este sentido, se toma partido por la ecuación de ingresos minceriana -corregida en cuanto al sesgo por selección a partir del método de estimación de Heckman- para de allí recurrir a la poco utilizada y no por ello menos valiosa metodología de descomposición de Fields. La bondad de tal herramienta radica fundamentalmente en que permite encontrar la contribución específica de cada factor considerado como explicativo de un fenómeno social, aislando la influencia de otros relacionados. La información empírica utilizada para el análisis proviene de las encuestas de condiciones de vida realizadas por los organismos oficiales de Nicaragua y Ecuador en conjunto con Living Standards Measurement Study (LSMS) del Banco Mundial.

Los hallazgos empíricos surgidos del trabajo permiten sostener que si bien la educación constituye un medio importante para dismi- 
nuir la brecha de ingresos existen factores socioeconómicos incorporados alrededor de las variables tamaño de la empresa y rama de actividad económica que desempeñan un papel decisivo en la ampliación de la desigualdad en la distribución de los ingresos laborales. A partir del análisis de los países descritos, la posibilidad de testear dicha hipótesis al resto de países de América Latina ubicados en contextos político institucionales similares es una tarea pendiente.

\section{TEORÍA DEL CAPITAL HUMANO SOBRE LA DESIGUALDAD. Algunas APlicaciones Para NiCARAgUa Y ECUADOR}

Este apartado ofrece una ligera revisión de las bases que fundamentan la teoría del capital humano así como también una breve exposición de críticas provenientes de planteamientos alternativos como los de Amartya Sen. Finalmente se dará una panorámica contextual de los países explorados.

\section{Los “CLÁSICOS” Y LA TEORÍA DEL CAPITAL HUMANO}

La teoría del capital humano no puede considerarse como un constructo "fundacional" sino, por el contrario, como el resultado del refinamiento de visiones ya existentes y que constituyen su origen. En esencia, se argumenta que el tratamiento dado en la teoría económica clásica de Smith (Smith; 1958: 99). y J. S. Mill (1909) al tema de la desigualdad en los ingresos y al de los factores que la determinan es, a través de la teoría del capital humano, retomado y enriquecido. Así, por ejemplo, la consideración del factor educativo como esencial para el crecimiento económico y principal demarcador de las desigualdades sociales, hallado en la tradición del elector racional (Becker, 1993: $5)$, tiene su origen en el pensamiento liberal antes mencionado ${ }^{1}$.

Es en las ideas liberales que la teoría del capital humano hallará la piedra angular de su posterior aporte. Así, apoyándose en las nociones del individualismo metodológico y la defensa de la capacidad de estabilización de las relaciones sociales a través del mercado ${ }^{2}$, la denominada corriente neoclásica ahondará en la particularización de

1 Para los clásicos las habilidades constituían la fuerza más importante en el progreso económico. Si bien la inversión en educación y capacitación implica un alto costo, para A. Smith y J. Stuart Mill este era necesario, ya que sería superado con los beneficios obtenidos por la productividad de los trabajadores. Desde luego, en ambos casos partían del supuesto de que el mercado asignaría eficientemente los recursos entre los actores y, a la par, que la posibilidad de acceso a información de los individuos les permitiría decidir coherentemente entre los oficios y profesiones que mayor lucro o rendimiento les proveerían a futuro.

2 Sobre las temáticas planteadas, los desarrollos teóricos relacionados con los mercados competitivos los hallamos en Smith (2004). 
las características de los individuos como factor desencadenante de la desigualdad en la riqueza. Para ello, este enfoque centra su análisis en la estructura de costos y utilidades marginales de la inversión en capital humano, midiéndolos a través de los ingresos. A la par, insistirá en la importancia que tiene la educación formal para la eficiencia en el desempeño laboral, así como en las implicaciones que de allí se derivan para el "buen gobierno" y el diseño de políticas públicas.

Entre los principales supuestos que tanto Mincer como Becker utilizan en sus desarrollos teóricos sobre el capital humano se encuentran: (i) Todos los individuos tienen idénticas habilidades e iguales oportunidades para participar en cualquier ocupación; (ii) Las ocupaciones son diferentes según sea la capacitación que ellas requieren; y, (iii) Los individuos con diferentes niveles de capacitación son compensados por los costos en los que incurren, por lo que dicha inversión se verá reflejada en el valor presente de sus salarios, según la elección ocupacional realizada.

En síntesis, las implicaciones de las diferencias en la inversión en capital humano para explicar la distribución en el ingreso laboral han sido derivadas de un modelo teórico en el que el proceso de inversión en capacitación depende de la libre elección. Dicho supuesto implica que la inversión efectuada por el individuo en su educación se ve recuperada con los salarios obtenidos a lo largo del periodo de vida. Así, la dispersión en el ingreso para cada grupo está positivamente relacionada con la inversión en capital humano, estableciéndose las diferencias por industria, raza, sexo y tamaño de la ciudad (Mincer, 1958) ${ }^{3}$. Siguiendo esta misma línea, G. Becker (1993: 100) argumenta que la distribución de los ingresos podría ser exactamente la misma que la de las habilidades, siempre que estas se hallen simétricamente distribuidas y la inversión en capital humano sea la misma. Tal afirmación implica un fuerte supuesto clásico según el que los individuos tienen un comportamiento homogéneo, con iguales habilidades y niveles de inversión en educación, según sea el año escolar alcanzado. Bajo estos supuestos es factible realizar un análisis más cercano de la realidad al momento de estimar la distribución en los ingresos laborales y familiares.

Finalmente, para los teóricos del capital humano la distribución de los salarios está afectada por las elecciones de los individuos en cuanto a su comportamiento económico. Así, los modelos del capital

3 Si bien se destaca a Jacob Mincer y Gary Becker como principales exponentes de la teoría del capital humano, es importante tener en cuenta a autores como Ben Portath y J. Heckman, quienes prevalecen por sus valiosos aportes metodológicos. Para mayor información ver Ben Porath (1970) y Heckman (1976). 
humano señalan que las decisiones de los individuos hacia la inversión es un factor clave que explica la posterior heterogeneidad del ingreso laboral. Además, recalcan que el capital humano puede ser incrementado en la medida en que la experiencia laboral progrese, aunque solo hasta un determinado punto de inflexión a partir del que existe una tendencia marginalmente decreciente

\section{La VISIÓn DE AMarTya SEN}

La explicación proporcionada por Amartya Sen (1999) respecto a la desigualdad plantea no solo plantea nuevos aportes en lo teórico sino que proporciona espacios para una relectura de las metodologías hasta ahora en vigencia. En esencia, Sen señala que los teóricos del capital humano al tratar la desigualdad incurren en una distorsión tanto de lo que constituye el objeto real de estudio-fin-como de los mecanismos instrumentales que lo analizan -medios-. De allí que argumente que medir la desigualdad a partir de los ingresos llevaría a mensurar los medios y no el fin en sí mismo, que es la mejora de las condiciones del individuo. Así, al destacar la noción de libertad como consecuencia de la provisión de un conjunto de capacidades entre los actores, Sen concluye que el grado de libertad que tiene el individuo para decidir debe ser observado en base al conjunto de capacidades que tiene para elaborar juicios razonados respecto a los fines que valora.

Además de las críticas de Sen, dentro de la propia literatura del capital humano existe un problema de disparidad en cuanto a la definición declarativa y operativa del concepto eje: la desigualdad, y, como consecuencia de ello, tensiones en cuanto a las herramientas necesarias para su medición. Algunos se concentran en determinar la desigualdad a partir de la observación de las rentas, otros analizan la variación en los niveles de bienestar y existen también los que se focalizan en la ponderación de utilidades ${ }^{4}$ De su lado, Sen agregaría a los que -descritos como libertarios puros-, sin pertenecer a la tradición señalada, se preocupan por valorar el nivel de derechos y libertades individuales en base a la provisión de capacidades.

\section{LA DESIgUALDAD EN AMÉRICA LATINA}

Durante la década de los noventa América Latina mostró un acelerado crecimiento de la desigualdad y la pobreza, al extremo de ser considerada como la región más rezagada del mundo en términos de equidad. Martín Ravallión (2004) en su estudio empírico realizado

4 Sobres los enfoques del tema planteado se puede recurrir, respectivamente a: Smith (1958), Samuelson (1947) y Arrow (1977). 
para América Latina señala que la evidencia hallada sobre la relación entre crecimiento y pobreza absoluta si bien muestra una correlación estrecha, directa y positiva, no implica que se deba concluir que todas las políticas orientadas al crecimiento producen disminución de la desigualdad y la pobreza. Factores endógenos a cada país y los cortes temporales a partir de los que se realice el análisis serían decisivos para marcar las diferencias entre los casos. Por tanto, y para efectos de comparación, resulta conveniente confrontar países con características similares, aunque respetando las especificidades de cada unidad de análisis ${ }^{5}$. A continuación se realiza una breve descripción de las realidades nicaragüense y ecuatoriana de manera que permitan contextualizar el escenario de desigualdad en el que se ven inmersos estos países.

\section{Nicaragua}

Durante los años ochenta Nicaragua inició un periodo de transición a la democracia en el que el denominado "Frente Sandinista" dirigido por Daniel Ortega alcanzó la presidencia de la república en el año 1984. Este periodo fue caracterizado por una fuerte intervención del Estado en la economía, evidenciándose esto en la nacionalización de los bienes de exportación, el control del sistema financiero y la implementación de políticas de reforma agraria. Si bien -en principio- fue considerada importante la aplicación de este tipo de medidas luego de un extenso y virulento periodo de confrontación política interna, seguido de un proceso de descomposición social, las consecuencias económicas se observaron a inicios de la década de los noventa. Prueba de ello es que para es década la economía nicaragüense se vio sumida en una fuerte pérdida de competitividad a nivel de los sectores productivos (Dubcovsky, 1999).

En 1990 el gobierno de la presidenta Violeta Chamorro implementó un programa de estabilización económica para controlar los altos niveles de hiperinflación y gasto público hallados en las cuentas fiscales. Los principales instrumentos de política económica utilizados -fiscales, monetarios y cambiarios-, basados en el control y la disciplina, se encaminaron a la aplicación de reformas para el fomento de las exportaciones dirigidas por el sector privado, a la reducción del gasto en el sector público, a la privatización de algunas entidades estatales, a la liberalización del sector externo y a la reorganización del sistema

5 En una línea más aplicada de la teoría del capital humano, a nivel de América Latina hallamos los trabajos de Berman y Birdsall (2001); Sosa Escudero y Gasparini (2003); Beccaria (1997); Paes de Barros y Mendonça (1997); Mincer (1956); Becker (1972); Fields (1976); Heckman (1978), entre otros. 
financiero (con la creación de una superintendencia de bancos independiente). De esta manera, se logró una recomposición de la economía nicaragüense en los primeros cinco años de la década descrita (CEPAL, 1994). A pesar del éxito que en un primer momento tuvieron las políticas anteriormente señaladas, la continuidad de las mismas se vieron obstaculizadas por acontecimientos externos, los que, más allá de lo contingentes que fueren, dejaron en evidencia la vulnerabilidad de la economía nicaragüense. Los efectos generados en 1998 por el huracán Mitch, que arrasó la producción agrícola y principalmente la del sector cafetero -que representa el producto de mayor importancia en el Producto Interno Bruto-, sumados a la pérdida de dinamismo de la inversión privada y pública, ocasionaron un estancamiento de la economía de ese país (CEPAL, 2002).

\section{Ecuador}

Al igual que la mayoría de los países de América Latina que se acogieron al modelo de Sustitución de Importaciones sin poseer una base industrial, Ecuador no tardó en evidenciar, una década después de la aplicación del modelo en referencia, los efectos de un obeso aparato burocrático, de una decadente industria y de un proceso de ajuste fiscal ocasionado por la contracción en los ingresos nacionales a raíz de la caída en el precio del petróleo, el principal producto de generación de recursos al Producto Interno Bruto de ese país.

Los años noventa estuvieron caracterizados por una mayor tendencia a aminorar la intervención directa del Estado en temas de política social, trasladando esas responsabilidades y competencias a gobiernos locales -municipios cantorales y prefecturas provinciales- y vinculando a las Organizaciones no Gubernamentales (ONG) como entes encargados de identificar y distribuir ayuda a los grupos sociales más vulnerables (Vos, 2000). En esta misma época, el gobierno de Sixto Durán Ballén (1992-1996) diseñó un fuerte programa de estabilización, priorizando el ajuste fiscal. Entre las reformas más destacadas para ese periodo hallamos las relacionadas con el sector financiero, a través de la nueva legislación para el mercado de valores y el sistema bancario; y otras que implicaron el redireccionamiento de los términos de negociación de papeles de deuda pública internacional, a través los acuerdos relacionados a los Bonos Brady (Vos, 2000).

La estabilidad económica lograda en Ecuador a principios de la década de los noventa, sin embargo, se vio obstaculizada -al igual que Nicaragua- por factores externos; entre ellos, la presencia del "Fenómeno del Niño", que en 1993 alteró la producción agrícola del país; la caída de los precios internacionales del petróleo -fundamental para países como Ecuador que depende de aquel en buena parte de su pre- 
supuesto público- y la crisis bancaria de 1999, generada por la pérdida de confianza en el sistema financiero nacional. Todo ello, sumado a otro tipo de factores políticos, condujo a las autoridades monetarias a tomar la drástica medida de asumir, en el año 2000, al dólar norteamericano como la moneda de circulación en el país (Ponce, 2000).

De la misma manera que en Nicaragua, para el caso ecuatoriano es difícil establecer causalidades a priori que permitan relacionar la política macroeconómica con los indicadores sociales, dado que los efectos se ven distorsionados por políticas anteriores. Así, por ejemplo, el proceso de reformas conducentes a la estabilización de los noventa, mostró; de un lado, indicadores económicos positivos, como la disminución de la deuda externa, un crecimiento económico del 3\% y el control de la inflación, mientras que; de otro, presentó indicadores sociales con dos tipos de resultados: (i) en el corto plazo se incrementó el desempleo a la par de que los salarios nominales descendieron abruptamente; y, (ii) en el mediano plazo, entre 1992 y 1997, se registró una mejora en los ingresos reales (Vos, 2000).

Si bien el crecimiento económico para el caso de los dos países en mención es una variable que guarda estrecha relación con la desigualdad, otros indicadores como las crecientes tasas de desempleo, las ocupaciones en sectores de baja productividad y la lenta recuperación de los salarios evidencian que, aun en periodos de estabilidad económica, las estructuras distributivas presenten incrementos. Por tanto, abordar la desigualdad solo como un problema de crecimiento económico es sesgado e insuficiente de manera tal que la búsqueda de otros factores explicativos de la desigualdad en el ingreso laboral se tornan necesarios (CEPAL, 2001, 2004).

\section{Planteamiento teórico y metodología}

Sin desconocer la valía del enfoque presentado por Sen y otras vertientes teóricas que sustentan la desigualdad como un fenómeno que debe ser abordado más allá de la sola cuestión de acceso a oportunidades medibles únicamente con los ingresos e indicadores, la complejidad de mensurar y comparar una diversidad de variables halladas en el entorno -político, social y cultural- lleva a que tomemos partido por un estudio más analítico y por ello con posibilidades de generar resultados más precisos y observables. De otro lado, un abordaje en el que exista un número excesivo de variables explicativas tendería a menoscabar el principio de parsimonia y nos alejaría del objeto de estudio de la presente investigación.

Por ello, en la presente investigación se asume como concepto de desigualdad a las diferencias suscitadas en la distribución de los ingresos entre las personas (Becker y Nigel, 1986). A efectos de opera- 
cionalizar esa noción declarativa, se argumenta que la variable dependiente denominada desigualdad en los ingresos, se la observa mejor a partir de la variación en cuanto a los ingresos laborales percibidos por los agentes. Se recurre a la citada forma de mensurar la desigualdad por diversas razones. De un lado, por ser la que resulta más fácilmente observable; y, de otro, por ser allí donde las desigualdades en el ingreso son más notorias ${ }^{6}$. Así mismo, las variables independientes utilizadas para explicar la desigualdad en los ingresos se encuentran agrupadas por factores a saber: 1) individual y de capital humano, que comprende las variables sexo, edad y nivel educativo; 2) geográfico, que incluye la variable región o ciudad; y, 3) socio-económico, que concentra la rama de actividad económica, tamaño de la empresa y tipo de vinculación laboral.

Todas estas variables se hallan controladas por el efecto del tiempo y los shocks económicos. Sobre la base de la presunción constante en el apartado anterior y considerando la pregunta inicial de trabajo, la presente investigación intentará contrastar la siguiente hipótesis: Los factores socioeconómicos tendrían mayor influencia que la educación en la explicación de la desigualdad de la distribución de de los ingresos laborales tanto en Ecuador como en Nicaragua.

La temporalidad de la investigación estará dada en el periodo comprendido entre 1990-2003, puesto que en ese espacio se pueden hallar más fidedignamente los puntos de comparación, tanto por la información empírica disponible como por la relativa estabilización del régimen democrático observada en esos dos países. Los datos utilizados para el análisis de la desigualdad en el ingreso laboral en el Ecuador fueron obtenidos de las Encuestas de Condiciones de vida (Encuestas de Hogares) tomadas para los años 1995, 1998 y 1999, y de la Encuesta de Gastos para el 2003. Para el caso de Nicaragua las Encuestas de Condiciones de Vida de 1993, 1998, 2001 son la base sustancial del estudio.

Las metodologías utilizadas son dos, a saber: (i) Para la estimación del modelo econométrico se recurre a las técnicas de estimación de Heckman (1979) dado que estas permiten corregir los problemas

6 Una de las principales dificultades al momento de iniciar un trabajo investigativo radica en la definición de los conceptos fundamentales que lo orientan. En el presente caso, la noción de ingresos que sirve como referente para observar la desigualdad se encuentra en dicha circunstancia y la adopción de un criterio específico no está a salvo de críticas, quizá tantas como enfoques para abordar la temática existen. En todo caso, y por razones de acceso a la información como por otras de carácter teórico, se ha adoptado al ingreso laboral como base para el análisis. Varios autores ahondan en los criterios de selección de los ingresos laborales como variable para medir la desigualdad (Duryea y Székely, 1998; Mincer, 1958). 
de sesgo por selección (King, Keohane y Sidney, 2000). que surgen cuando se trabaja con los ingresos laborales; y, (ii) para evaluar específicamente las desigualdades en el ingreso laboral y los factores que la determinan, me apoyo en dos metodologías: a) la Descomposición de Fields (1997) que servirá tanto para determinar la influencia de la educación en la desigualdad como para identificar el peso relativo que tienen las otras variables del modelo que son significativas; y, b) El análisis de varianza de la variable dependiente -ingreso laboral-con las variables independientes -o explicativas- como educación, edad, sexo, entre otras.

\section{ANÁLISIS DE RESULTADOS}

La creciente desigualdad en los ingresos y la inestabilidad económica de los países de América latina son dos de los temas que mayor atención y análisis han concitado durante la década de los noventa. Los resultados aquí obtenidos no solo dejan entrever el comportamiento cíclico de la desigualdad en los ingresos laborales sino también la ampliación de la brecha existente entre los niveles educativos (Ponce, Bedi y Vos, 2003). De otro lado, el poder explicativo de factores socioeconómicos y geográficos respecto a la desigualdad en los ingresos laborales es otro de los aportes que de esta investigación se desprende.

Este apartado consta de tres partes, a saber: (i) el análisis la distribución de los ingresos laborales en Nicaragua; (ii) similar ejercicio realizado para el caso ecuatoriano; y, (iii) un análisis comparado de la desigualdad en la distribución de los ingresos laborales para los dos países. En las dos partes iniciales se hace una descripción detallada de los factores explicativos de la distribución de los ingresos, apoyándonos fundamentalmente en los resultados obtenidos del modelo de regresión tipo Heckman; y, en la tercera, se agrega el análisis comparado de la desigualdad de los ingresos laborales utilizando los resultados obtenidos de la metodología de descomposición de Fields y el análisis de varianza ${ }^{7}$.

\section{LOS INGRESOS LABORALES EN NICARAGUA}

Son tres factores los que nos interesa analizar en el modelo de ingresos: a) individual y de capital humano; b) geográfico; y, c) socio-económico. Cada uno de estos está compuesto por variables específicas,

7 En la descripción de los resultados, se entenderán como variables significativas aquellas cuyo nivel de confianza se encuentre entre el 99\% y 90\%. Así, una variable cuyo valor oscile en este rango indicará que tiene alta capacidad explicativa en la desigualdad de los ingresos laborales. 
a saber: sexo, edad y nivel educativo en el primer caso; región en el segundo; y, rama de actividad económica, tamaño de la empresa y tipo de vinculación laboral en el tercero. Todas las variables expuestas se hallan controladas por el efecto del tiempo y shocks económicos a lo largo del periodo de estudio (ver Cuadro 1)

\section{Factores individuales y de capital humano}

Iniciando por la variable sexo se puede observar que esta tiene un valor significativo en la distribución de los ingresos, pues los varones presentan un ingreso laboral 47\% mayor que el de las mujeres. Si bien solo a partir de dicho resultado no se puede inferir la existencia de discriminación, si se puede sentar un indicio que, junto a otros factores concernientes al mercado laboral, como son la tasa global de subempleo visible e invisible (INEC, Nicaragua, 2001), podrían contribuir a explicar este fenómeno. Además, en la medida que estos indicadores permiten evidenciar la incapacidad del mercado laboral para generar un número suficiente de empleos productivos y de tiempo completo podrían observarse mayores repercusiones si se analiza desde una perspectiva de género.

Por su parte, la edad hasta la que se puede lograr el máximo de ingresos y a partir de la que comienza una fase decreciente o constante es la de 60 años. Esta situación podría tener algún tipo de relación con la ampliación de los diseños normativos en cuanto al límite de edad considerada como productiva en términos de inserción laboral. De hecho, el incremento de los años para la jubilación podría ser una posible explicación de lo aquí expuesto (INEC, Nicaragua, 2001).

De otro lado, el nivel educativo en la distribución en los ingresos continúa siendo una variable muy importante en la distribución de los ingresos, en la medida que mantiene una relación directa y positiva respecto a este fenómeno social. Así, una persona que posee educación secundaria obtendría un ingreso $29 \%$ superior al que conseguiría si tuviera solo primaria o educación formal no terminada ${ }^{8}$. Este valor se quintuplica (150\%) entre personas con nivel superior -universitario y posgradista- frente a personas con nivel primario.

Aunque lo anterior comprueba uno de los postulados de la teoría del capital humano (Becker, 1993) que señala que los retornos educativos siempre van a ser positivos y mayores cuanto mayor sea el nivel de calificación alcanzado; cuando se analiza esta relación, in-

8 Los niveles de educación tomados son tres: nivel primario o educación formal no terminada, nivel de secundaria y nivel superior. Estas son variables dummy que para efectos de la regresión del modelo econométrico toma como base -o referencia para ser comparada- el nivel primario o formal no terminado. 
gresos laborales y educación en diferentes puntos del tiempo se evidencia un deterioro de los ingresos sobre todo en las personas con nivel educativo superior. Ello puede estar relacionado con otros factores, tomados como exógenos para la teoría del capital humano, como el alto incremento de subempleo y de la informalidad, que podrían dar cuenta de dicho fenómeno distributivo. En suma, la evaluación de la distribución de los ingresos considerada solo a partir del nivel de educación resultaría sesgada pues aunque se observa la relación directa entre estas dos variables, los retornos obtenidos por un mayor nivel de educación podrían estar afectados por otros factores, como el socioeconómico según la evidencia empírica aquí hallada.

\section{Factor geográfico}

Este componente, interpretado a través de la variable región, desempeña un papel importante en la distribución en los ingresos pues, cuanto mayor conglomerado económico tiene una región mayores son las oportunidades de trabajo. En el estudio, la región de Managua tiene un efecto positivo en la distribución de los ingresos, de allí se tiene que los ingresos laborales son 29,6\% mayores aquí de los que se pudieran obtener trabajando en la región Atlántica. En sentido contrario, estar ubicado en la región Central o Nueva Segovia implicaría alcanzar ingresos 37\% y 30\% menores, respectivamente, de los que se pudieran alcanzar en la región Atlántica9 . Llama la atención la importancia de la ubicación geográfica para explicar los ingresos, pues estas tres regiones -Managua, Central y Nueva Segovia- abarcan el 36\% de la población en edad de trabajar (INEC, Nicaragua, 2001), y además, porque convoca al estudio de una geografía económica en la que no solo se analice la localización de los factores tierra, trabajo y capital (Krugman, 1991) sino también las transformaciones territoriales que la aplicación de políticas pudieran haber generado en el sector económico y de la población.

\section{Factores socioeconómicos}

En este componente se encuentran: (i) la rama de actividad económica, (ii) el tamaño de la empresa; y, (iii) el tipo de vinculación laboral. Respecto a la primera, laborar en actividades agrícolas implica tener un ingreso menor en $44 \%$ respecto a actividades relacionadas con servicios sociales y comunitarios ${ }^{10}$. Teniendo en cuenta que Nicaragua es

9 La variable región toma como referencia de comparación las Regiones Autónomas del Atlántico.

10 Servicios sociales y comunitarios es la variable que se toma como referencia para comparar todas las ramas de actividad económica. 
un país con una economía re-primarizada ${ }^{11}$, justamente es en estas ramas de actividad, agricultura y minería, donde se ubica la mayor parte de la población económicamente activa: agricultura $(39,2 \%)$, servicios $(21,3 \%)$ e industria manufacturera $(12 \%)(\mathrm{BCN}, 2001)$.

En segundo lugar, el tamaño de la empresa contribuye de manera positiva ( $9 \%$ ) en la mejora de los ingresos laborales, es decir, cuanto mayor sea el tamaño de la empresa los ingresos serán mayores en $9 \%$. Sin embargo, la fragilidad que muestra el sector empresarial nicaragüense, por la representatividad que tienen las micro y pequeñas empresas puesto que comprenden el $87,85 \%$ de los establecimientos y además concentran el 85,3\% del personal ocupado (BCN, 2000), estas influyen para que las brechas de desigualdad se agranden. De tal manera que se evidencia una limitante de parte de la demanda laboral para proveer mejores ingresos laborales (BCN, 2000).

Finalmente, en cuanto al tipo de vinculación laboral -relación de dependencia o no- los resultados arrojan que mantener una relación de dependencia lleva a ganar un $44 \%$ menos de lo que obtienen quienes actúan como independientes. Lo dicho marca la necesidad no solo de poseer un negocio propio sino la capacidad de generar empresas, atento a las precariedades a las que está sometido el trabajador dependiente, ocasionadas entre otras cosas, por el incumplimiento de la normativa laboral por parte de los empleadores y las dificultades que enfrentan los trabajadores para obtener mejores condiciones laborales (CEPAL, 2003).

A fin de corregir el sesgo por selección, se encontró entre los factores que afectan la probabilidad de participar o no en el mercado laboral, que la calidad de jefe de hogar genera una probabilidad mayor respecto al resto de integrantes de la familia para insertarse en el mercado laboral (100\%), seguido del cónyuge con $(78,3 \%)$. Este resultado es interesante ya que implica que existe una necesidad de incrementar los ingresos del hogar y en la mayoría de los casos se relaciona con el incremento de la participación de la mujer -como cónyuge o como jefe- en el mercado laboral. En suma, a pesar de la fuerte influencia de la educación en la distribución de los ingresos, existe un peso fuerte tanto del factor socio-económico como de los relacionados con los factores individuales y de capital humano. Es decir, es el factor socioeconómico tendrían mayor peso que el nivel de factores individuales y de capital humano, como el nivel de educación, en la explicación de la distribución de los ingresos en Nicaragua.

11 El grado de industrialización de la economía, medido como la relación de la proporción entre el valor agregado del sector industrial y el Producto Interno Bruto, refleja una tendencia negativa -al pasar de 20,9\% en 1997 a 18,2\% en 2000-, lo que refleja una incapacidad del sector industrial para transformar los bienes primarios (BCN, 2001). 


\section{Cuadro 1}

Coeficientes del modelo Heckman. Pesos relativos de las variables en la desigualdad de los ingresos laborales

\begin{tabular}{|c|c|c|c|c|c|c|}
\hline & corr $X, Y$ & coeficiente & desv. estándar & sj & $\% s j$ & $\mathbf{z}$ \\
\hline loging & 1 & & 0,5574064 & & & \\
\hline sexo & 0,2933 & 0,391972 & 0,4989791 & 0,102914724 & 10,29147237 & 0,0000 \\
\hline secundaria & 0,1424 & 0,2638337 & 0,4868178 & 0,032812155 & 3,281215511 & 0,0000 \\
\hline superior & 0,541 & 0,9217111 & 0,2889427 & 0,258482924 & 25,84829244 & 0,0000 \\
\hline edad & 0,3201 & 0,0293539 & 14,19677 & 0,239314537 & 23,93145369 & 0,0100 \\
\hline edad 2 & 0,2798 & $-0,0002394$ & 962,1715 & $-0,115625173$ & $-11,56251726$ & 0,1390 \\
\hline Región Segovias & $-0,2614$ & $-0,272989$ & 0,2752775 & 0,035241103 & 3,524110322 & 0,0050 \\
\hline Región oeste & $-0,1702$ & $-0,1385502$ & 0,3687195 & 0,015598788 & 1,559878845 & 0,1430 \\
\hline Managua & 0,4771 & 0,2632077 & 0,492299 & 0,110908545 & 11,09085454 & 0,0040 \\
\hline Región sur & $-0,0564$ & $-0,0291039$ & 0,3537987 & 0,001041873 & 0,10418725 & 0,7560 \\
\hline Región central & $-0,1287$ & $-0,3267747$ & 0,2071656 & 0,015630493 & 1,563049251 & 0,0008 \\
\hline Región norte & $-0,1192$ & 0,1061577 & 0,2579195 & $-0,005855176$ & $-0,58551764$ & 0,3350 \\
\hline agricultura & $-0,3476$ & $-0,3728657$ & 0,3156919 & 0,07340467 & 7,340466994 & 0,0000 \\
\hline minería & 0,0313 & 0,0209703 & 0,1790728 & 0,000210866 & 0,021086605 & 0,9520 \\
\hline manufactura & 0,0351 & $-0,0781287$ & 0,3652461 & $-0,001796931$ & $-0,179693079$ & 0,3790 \\
\hline electricidad & 0,0526 & 0,2270368 & 0,0954608 & 0,002045197 & 0,204519687 & 0,4970 \\
\hline construcción & 0,1347 & 0,05375 & 0,2486625 & 0,003229865 & 0,322986529 & 0,5160 \\
\hline comercio & $-0,0143$ & $-0,0930293$ & 0,3800935 & 0,00090714 & 0,090713993 & 0,1960 \\
\hline transporte & 0,2415 & 0,1500632 & 0,3190475 & 0,020743151 & 2,074315122 & 0,2360 \\
\hline ss. financieros & 0,0701 & $-0,1688356$ & 0,151021 & $-0,00320662$ & $-0,320661954$ & 0,2470 \\
\hline tam. empr. & 0,2992 & 0,0878919 & 1,823861 & 0,086045909 & 8,604590923 & 0,0000 \\
\hline depen. lab. & $-0,1438$ & $-0,3656435$ & 1,823861 & $-0,120477824$ & $-12,04778237$ & 0,0000 \\
\hline d1998 & 0,1007 & $-0,5453337$ & 0,445275 & 0,017338111 & 1,733811065 & 0,0000 \\
\hline d1999 & $-0,0398$ & $-0,6794147$ & 0,4452782 & 0,08586198 & 8,586198032 & 0,0000 \\
\hline d2003 & $-0,1582$ & $-0,7324263$ & 0,4657239 & 0,096811508 & 9,681150788 & 0,0000 \\
\hline
\end{tabular}

Fuente: Encuestas de condiciones de vida 1993,1998, 1999 2003, INEC, Nicaragua.

Elaboración: Propia del autor.

\section{LOS INGRESOS LABORALES EN ECUADOR}

Aplicando la misma metodología que para el caso nicaragüense propongo exponer a continuación los principales resultados de las variables que explican la desigualdad en los ingresos laborales de Ecuador durante el periodo 1990-2003. En este sentido, 
explicaré cada una de las variables contenidas en los factores: individual y de capital humano; geográfico y socio-económico (ver Cuadro 2).

\section{Factores individuales y de capital humano}

La variable sexo si bien mantiene un coeficiente negativo, es decir que las mujeres presentan ingresos laborales menores a los de los hombres no constituye una variable significativa al el momento de explicar la distribución en los ingresos. Aunque es prematuro negar la existencia de discriminación, este resultado, es decir, la capacidad no explicativa de esta variables, puede argumentarse con las altas tasas de subempleo que tiene el Ecuador ya que no solo es síntoma de deterioro de los salarios sino que además bordea por encima del $50 \%$ tanto a hombres como a mujeres.

En cuanto a la variable edad, a diferencia de Nicaragua, a pesar de tener una relación positiva con los ingresos laborales es no significativa. Una explicación a este hecho puede deberse a que la población en edad de trabajar se encuentra proporcionalmente distribuida (SIISE, 2006). Lo dicho, sumado a la poca relevancia de dicha variable en el modelo aplicado, llevaría a suponer que no hay indicios de discriminación por razones de género lo suficientemente considerables en este campo.

Por su parte, la variable nivel de educación muestra una relación directa con los ingresos laborales, así, tener educación secundaria implicaría obtener unos ingresos 32\% mayores que si solo se tuviera educación primaria; más aun, la brecha sería cuatro veces mayor si la persona contara con educación superior. La respuesta dada desde el capital humano ante lo expuesto sería que a un mayor nivel de escolaridad existirá un incremento en la productividad de la mano de obra y con ello mayores ingresos (Mincer, 1958). En primera instancia ello indicaría que la teoría del capital humano ha sido testeada favorablemente, sin embargo, existirían otras variables como actividad económica, el tamaño de la empresa, y el tipo de vinculación laboral, que hacen parte del factor socio-económico, que cobrarían una importancia mayor a la educación.

\section{Factor geográfico}

Para el caso de Ecuador se consideró como variable región a algunas ciudades. En la estimación de la distribución de los ingresos se encontró que estar ubicado en Quito implicaría recibir un ingreso $8,3 \%$ mayor que si se estuviera trabajando en otra ciudad del país. Sin embargo, este valor es no significativo y ello podría deberse a que si bien en Quito se perciben mejores ingresos promedio mensuales 
que en otras ciudades del país -y existe la tasa más baja de desempleo $(8,9 \%)$ y subempleo $(48,9 \%)$ (INEC, Ecuador, 2002)-, estos no distan del promedio nacional por lo que se podría decir que el factor geográfico no tiene significativa capacidad explicativa en la desigualdad de los ingresos.

\section{Factores socioeconómicos}

Tomando como parte de este componente: (i) la rama de actividad económica, (ii) el tamaño de la empresa y (iii) el tipo de vinculación laboral, los resultados muestran que, la rama de actividad tiene una alta capacidad explicativa de la desigualdad de los ingresos laborales. Es interesante el resultado para las diferentes ramas, agricultura, comercio y servicios, la alta significatividad de sus coeficientes, destacan la importancia del sector primario y sectores de baja productividad evidenciando, no solo la fragilidad de la economía con su débil aparato productivo sino también la incapacidad de la demanda laboral para absorber la mano de obra (BCE, 2003).

El componente referido al tamaño de la empresa es significativo aunque negativo, lo que indica que existe un deterioro de las remuneraciones en un $23 \%$ según el tamaño de la empresa. Lo anterior puede deberse a la gran cantidad de fuerza de trabajo que se ocupa en el sector microempresarial, servicios domésticos y trabajadores por cuenta propia, que no solo conforman el sector informal $(56 \%)^{12}$ de la economía sino que además involucran condiciones laborales precarias sujetas -entre otras cosas- a la limitada capacidad económica, técnica y de recurso humano característico de las pequeñas y medianas empresas.

Finalmente, la vinculación laboral no evidenció capacidad explicativa de la desigualdad en los ingresos laborales, puesto que su coeficiente mostró ser negativo y no significativa, es decir, encontrarse en vinculado bajo la figura de dependiente o independiente en el campo laboral no explica la desigualdad en los ingresos. A fin de corregir el sesgo por selección, se encontró entre los factores que afectan la probabilidad de participar o no en el mercado laboral ser cónyuge $(23 \%)$ o ser hijo $(2,5 \%)$ ya que para el primer caso cuanto mayor numero de hijos pequeños tenga el hogar, menor es la probabilidad de participar en el mercado laboral, de la misma manera, ocupar la posición de hijo dentro del hogar reduce la posibilidad de ingresar al mercado laboral mientras este se encuentre en edad de estudiar.

12 Este valor corresponde al empleo urbano del sector informal como porcentaje de la participación en el empleo (OIT, 2004). 


\section{Heidy Paola Ocampo Meneses}

\section{Cuadro 2}

Descomposición de Fields. Pesos relativos de las variables en la desigualdad de los ingresos laborales

\begin{tabular}{|c|c|c|c|c|c|c|}
\hline & corr. $X, Y$ & coeficiente & desv. estándar & sj & $\% \mathbf{s j}$ & $\mathbf{z}$ \\
\hline loging & 1 & & 0,6940496 & & & \\
\hline sexo & $-0,0209$ & $-0,0257341$ & 0,4997853 & 0,000387301 & 0,038730066 & 0,935 \\
\hline secundaria & $-0,0725$ & 0,2810197 & 0,4941904 & $-0,014507032$ & $-1,450703199$ & 0 \\
\hline superior & 0,3113 & 0,8147865 & 0,3792884 & 0,138612373 & 13,86123727 & 0 \\
\hline edad & 0,3031 & 0,021433 & 14,4380400 & 0,135140846 & 13,51408458 & 0,563 \\
\hline edad 2 & 0,2821 & $-0,0001014$ & $1.002,612$ & $-0,0413222$ & $-4,13221996$ & 0,844 \\
\hline ciudad-Quito & 0,0611 & 0,0805939 & 0,3824323 & 0,00271336 & 0,271336013 & 0,296 \\
\hline ciudad-Guayaquil & $-0,0502$ & $-0,00789$ & 0,4505049 & 0,000257093 & 0,025709269 & 0,923 \\
\hline agricultura & $-0,0173$ & 0,3181474 & 0,28529 & $-0,002262384$ & $-0,226238368$ & 0,009 \\
\hline minería & 0,0114 & 0,3051191 & 0,06747 & 0,000338146 & 0,033814638 & 0,117 \\
\hline manufactura & 0,7604 & $-0,0579299$ & 0,35018 & $-0,022225354$ & $-2,222535434$ & 0,481 \\
\hline electricidad & $-0,0118$ & 0,0795901 & 0,06537 & $-8,84615 \mathrm{E}-05$ & $-0,00884615$ & 0,799 \\
\hline construcción & 0,0663 & 0,4752397 & 0,24945 & 0,011324714 & 1,132471419 & 0,121 \\
\hline comercio & 0,0606 & 0,2165089 & 0,47090 & 0,008902055 & 0,89020545 & 0,003 \\
\hline transporte & 0,0747 & 0,3050459 & 0,24039 & 0,007892365 & 0,789236508 & 0,16 \\
\hline ss. Financieros & 0,1457 & 0,4542656 & 0,22339 & 0,021302776 & 2,130277628 & 0 \\
\hline tam. empr. & $-0,7289$ & $-0,21625$ & 1,9481410 & 0,442439553 & 44,24395527 & 0 \\
\hline dep. lab. & $-0,2763$ & $-0,0691892$ & 0,4626399 & 0,012743003 & 1,274300258 & 0,457 \\
\hline cultura & 0,0294 & 0,0857857 & 0,15457 & 0,00056169 & 0,056169031 & 0,635 \\
\hline d1998 & $-0,6007$ & $-0,3143532$ & 0,4247895 & 0,115573638 & 11,55736376 & 0,144 \\
\hline d1999 & $-0,2696$ & $-0,6010487$ & 0,4262796 & 0,099525322 & 9,9525322 & 0,011 \\
\hline d2001 & $-0,1644$ & 0,2849239 & 0,466325 & $-0,031472329$ & $-3,147232911$ & 0,172 \\
\hline
\end{tabular}

Fuente: Encuestas de condiciones de vida 1993,1998, 1999 2003, INEC, Ecuador.

Elaboración: Propia del autor. 
A partir del comportamiento de las variables explicativas de la desigualdad para el caso ecuatoriano, se puede decir que, en lo referido a la distribución en los ingresos existen otros factores que están repercutiendo de manera negativa en los retornos educativos, de manera que lograr un mayor nivel de educación no implica necesariamente que se vayan alcanzar mayores ingresos.

La teoría del capital humano señala al respecto que ello depende de la inversión que los individuos realicen en la educación, lo que supone la existencia de cobertura -dígase escuelas, colegios, universidades- de manera que sea solo elección del individuo el nivel de ingresos que desea obtener. A partir de allí, Becker (1986) incorpora factores familiares para explicar los determinantes de ingresos, sin ahondar en los procesos de reproducción de la desigualdad. En tal sentido, la inversión en la educación si bien es fundamental, no es exógena al modelo sino que además tiene un comportamiento dinámico en la maximización de beneficios. En otras palabras, aunque las expectativas de los padres están encaminadas a mejorar las oportunidades que les permita modificar las estructura social en la que se encuentran, solo aquellos que poseen mayores recursos económicos pueden realizar la inversión necesaria para obtener mayores retornos en la educación vía ingresos (Reimers, 2000). De esta manera, la desigualdad continúa siendo un proceso permanente que va de generación en generación.

En suma, la inversión en el capital humano -dígase alcanzar un mayor nivel de educación- si bien no ha dejado de ser importante para explicar la desigualdad en los ingresos abre la posibilidad a otro tipo de argumentaciones que señalan la existencia de factores que, para el caso ecuatoriano, dan cuenta de dicho fenómeno. Estos serían: (i) la estructura del mercado laboral, que promueve las diferencias entre trabajos calificados y no calificados y que concentra la mano de obra en un sector informal con poca formación de capital humano; y, (ii) las crisis económicas, producidas no solo por la vulnerabilidad del sistema como consecuencia del endeble aparato productivo, sino también por las limitaciones halladas tanto en el capital físico como humano de la economía ecuatoriana.

\section{UN ANÁLISIS COMPARADO DE LA DESIGUALDAD}

Una vez corrido el modelo de regresión y corregido por sesgo de selección con la técnica Heckman, se obtuvieron los coeficientes estimados de las variables independientes en los que, la educación, la edad, la ciudad o región y la rama económica, fueron las variables más significativas para explicar la desigualdad en los ingresos laborales. Aunque la educación continúa siendo una variable influyente y definitoria en 
la desigualdad, para el caso ecuatoriano y nicaragüense se destacaron otras en igual o superior relevancia.

Para profundizar en el análisis de la afirmación anterior, se recurrió al método de descomposición de Fields (Fields, 1997), cuyos resultados señalan que además de las variables mencionadas, los cortes en diferentes periodos de tiempo -la variable dummy de año- constituyen un componente bastante fuerte en la desigualdad en los ingresos (ver Cuadro 3). A partir de allí se puede decir que los ingresos laborales y la desigualdad son sensibles a los shocks económicos; estos factores a los que he llamado externos -identificado por las variables dicotómicas años- tienen un peso relativo de $9,95 \%$ para Ecuador y $20 \%$ para Nicaragua en la desigualdad de los ingresos laborales. En este sentido, podría afirmarse que la inestabilidad de las economías durante la década tuvieron un gran impacto en la explicación de la desigualdad en la distribución de los ingresos laborales.

De otro lado, los factores que he denominados como socioeconómicos tienen gran influencia en la desigualdad de los ingresos laborales. El tamaño de la empresa por su parte, también es un factor que contribuye sustancialmente en la desigualdad de los ingresos, sobre todo en el Ecuador, con un peso relativo de $44,2 \%$. Una explicación puede deberse al impacto que las pequeñas y medianas empresas, que componen el $70 \%$ del sector productivo y además contienen un 38\% del empleo (Vergara, 2005). La debilidad para este sector empresarial radica en la poca articulación entre políticas macroeconómicas y competitividad y la ausencia de implementación de políticas públicas provistas de información previa que permita un diseño más eficiente de las mismas.

Esta situación no es menor pues, lejos de ocupar un papel marginal, se convierte en centro de atención al momento de abordar la desigualdad. Por tanto, a partir de allí se pueden implementar políticas de articulación de redes empresariales de carácter horizontal -v.g. vía generación de centros empresariales-, vertical -v.g. vía programas de desarrollo de proveedores-; y, territorial -v.g. impulsando la articulación de actores de una misma comunidad-. Es en este campo en el que Nicaragua ha venido trabajando a fin de fortalecer el sector empresarial pequeño y mediano, observándose algunos de sus resultados en el menor impacto que esta variable tiene en la desigualdad de los ingresos laborales $(8,6 \%)$ respecto al caso ecuatoriano. 


\section{Cuadro 3}

Descomposición de Fields. Peso de los factores que influyen en la desigualdad de Nicaragua y Ecuador.

\begin{tabular}{|c|c|c|c|c|}
\hline FACTORES / PAÍS & ECUADOR & & NICARAGUA & \\
\hline & $>$ desigualdad & $<$ desigualdad & $>$ desigualdad & $<$ desigualdad \\
\hline Factores individuales & & & 34,22 & \\
\hline Sexo & no significativo & & 10,29 & \\
\hline Edad & no significativo & & 23,93 & \\
\hline Capital humano & 12,41 & & 29,08 & \\
\hline Educación secundaria & & $-1,45$ & 3,28 & \\
\hline Educación superior & 13,86 & & 25,80 & \\
\hline Factores geográficos & & no significativo & 16,18 & \\
\hline Regiones/ciudades & no significativo & & 16,18 & \\
\hline Factores económicos & 47,04 & & 3,90 & \\
\hline Rama económica & 2,79 & $-97,52$ & 7,34 & \\
\hline T. empresa & 44,24 & & 8,60 & \\
\hline Dependencia laboral & no significativo & & & $-12,05$ \\
\hline Externos & 9,95 & & 20,00 & \\
\hline
\end{tabular}

Fuente: Encuestas de condiciones de vida 1995, 1998, 1999, 2001 y Encuestas de Empleo 2003, INEC de Nicaragua e INEC-SIISE de Ecuador.

Elaboración: Propia del autor. Programa STATA y SPSS.

La rama de actividad económica no se puede analizar como un hecho aislado de los factores mencionados anteriormente. Los sectores que mayor desigualdad en los ingresos generan para el caso ecuatoriano son el de servicios $(0,57 \%)$ y el manufacturero $(2,5 \%)$, mientras que para Nicaragua es el sector agrícola, con una tasa de 48,20\%. Esta situación puede estar relacionada no solo con las características de las economías -endeble aparato especializado en productos primariossino también con el nivel educacional de la población.

Para realizar recomendaciones de política es necesario además identificar dónde se concentra la desigualdad; es decir, si esta se da entre grupos o al interior de los mismos. Para ello se recurrió al método de análisis de varianza del logaritmo del ingreso respecto a las variables explicativas -y significativas- utilizadas en el modelo de Heckman. El control de estas variables por el tiempo -la variable dummy de años- presenta una mayor varianza a nivel intra grupo; es decir, los ciclos económicos influyen en la desigualdad de los ingresos. Además, los sucesos económicos y/políticos ocurridos en cada año, surten efectos importantes en la estabilidad económica y, por tanto, en los niveles de 
desigualdad. Sin embargo el efecto entre grupos no es menor y deja entrever los problemas estructurales que tiene cada país.

La desigualdad intra de los niveles de educación y la rama de actividad económica preocupa no solo porque son variables altamente significativas para explicar la desigualdad en los ingresos laborales, sino también porque deja entrever que el problema va más allá de la búsqueda de la cobertura educativa y crecimiento del sector económico. De hecho, solamente considerar los elementos cuantitativos para su medición, dejando de lado aspectos cualitativos, haría pecar al análisis de determinados sesgos. Así, la calidad de la educación constituye un componente fundamental para analizar las causas de las brechas entre individuos que están ubicados en una misma rama de actividad económica, sea por nivel educativo o por sector.

Sin duda, uno de los postulados que fundamenta la teoría del capital humano es la inversión que, erróneamente, se asume homogénea para todos los agentes en el punto de partida; sin embargo, y como se señaló en la discusión teórica, para el caso de países como Ecuador y Nicaragua los niveles de cobertura en educación no son completos. Además, la brecha entre el financiamiento privado y público de la educación acrecienta la desigualdad favoreciendo a quienes poseen mayores recursos económicos. Lamentablemente, el sistema educativo público no da evidencia suficiente para garantizar una cobertura con calidad que permita disminuir las brechas generadas al interior de los grupos, tanto de educación como de posición ocupacional.

En suma, la educación no deja de ser un componente importante en la distribución de los ingresos, sin embargo, para el caso ecuatoriano $y$ nicaragüense, existen otras variables que tienen mayor peso relativo, tal como muestra la descomposición de Fields. Así, factores económicos como la rama de actividad económica, el tamaño de la empresa; factores geográficos como la región donde trabaja el individuo; e individuales como la edad y el género serían de trascendental importancia para explicar la desigualdad en la distribución de los ingresos laborales. Colateralmente, lo enunciado conduce a pensar en que el problema es de orden estructural y, por tanto, requiere una implementación de políticas públicas orientadas a la totalidad de factores antes expuestos.

\section{REFLEXIONES FINALES}

Sumando las particularidades que enfrenta cada uno de los países, el análisis comparado a partir del cuerpo teórico que ofrece la teoría del capital humano permitió evaluar la problemática de la desigualdad en los ingresos de dos países de América latina como Ecuador y Nicaragua, identificando los factores que mayor capacidad tienen para explicar dicho fenómeno. A continuación se sintetizan las ideas 
principales que derivaron de la presente investigación. Comenzando por los factores que intervienen en la desigualdad en los ingresos, el correspondiente al capital humano resultó ser coherente con la teoría, al afirmar que una mayor inversión en la educación contribuye a mejorar los ingresos laborales. Así lo evidenció la descomposición de Fields al señalar la importante contribución de esta variable para disminuir la desigualdad. Sin embargo, la brecha entre niveles educativos se hace cada vez más amplia sobre todo entre los niveles secundario y universitario. Si bien se ha ampliado la cobertura en educación, sus efectos no son perceptibles en el corto y mediano plazo, generando un rezago permanente en el ajuste de la oferta laboral. Lo anterior se puede explicar además con el bajo porcentaje del factor capital humano -obtenido en este estudio- respecto a otros como el económico e individual que duplican su valor en términos de importancia.

En cuanto a los factores económicos, la relevancia que estos tuvieron en la desigualdad de los ingresos deja entrever que para explicar la desigualdad se requiere de un componente adicional. Tal vacío lo podría suplir la demanda laboral, lo que induciría a estimar al fenómeno de la desigualdad como estructural. En ese plano, la oferta laboral se enfrenta a dos problemas: (i) que no logra satisfacer las necesidades o requerimientos de la demanda y (ii) la demanda no tiene capacidad para absorber la mano de obra que se halla en el mercado. Lo anterior podría deberse a la ausencia de información que de manera recurrente se presenta en el mercado laboral, y que impide la canalización entre la mano de obra -calificación de la misma- oferente y la demandante. Todo esto se traduce finalmente en elevadas tasas de subempleo, particularmente subempleo invisible, que refiere a la subocupación por calificación e ingresos inferiores por el trabajo realizado.

De esta manera y sumado a lo anterior, el tamaño de las empresas se convierte en una variable relevante, pues las grandes empresas han tomado como estrategia de competencia reducir costos a través de la disminución del empleo y el consiguiente incremento de salarios. Esto provoca dos efectos: (i) ampliar la brecha salarial entre estas y las micro- empresas; y, (ii) el incremento del empleo en el sector microempresarial -en algunos casos por el reducido tamaño del personal se catalogan como sector informal y de baja productividad- con pocas oportunidades de mejora de las condiciones laborales y presentando signos de precarización laboral.

De otro lado, la actividad económica que prima en ambos países es la agrícola y la de servicios por lo que, combinado con un incremento en el nivel educativo y la existencia de un fuerte sector microempresarial; un aumento de la educación de la oferta laboral no implica que 
exista una demanda sesgada hacia los grupos de mayor calificación sino más bien que la evolución de la oferta laboral no sea compatible con las transformaciones de la demanda. En otras palabras, la expansión del sector microempresarial y de baja productividad sub-ocupa la mano de obra calificada naciente.

Finalmente, ante las conclusiones empíricas anotadas se hace necesario recurrir a la particularidad de cada país para elaborar diagnósticos. De esta forma se pueden observar problemas relacionados con la influencia que la estructura productiva, demográfica y geográfica ejerce sobre en la desigualdad. De otro lado, por ser el capital humano una inversión a largo plazo, su efecto se ve invisibilizado con el recrudecimiento de los factores estructurales mencionados anteriormente. En ese mismo sentido, la decisión de invertir en el capital humano como lo plantea la teoría aquí utilizada pasa a ser un mecanismo necesario pero no suficiente en la disminución de la desigualdad de los ingresos laborales.

El segundo componente de conclusiones a las que quiero hacer alusión corresponde a los supuestos implícitos que subyacen la teoría del capital humano cuya utilidad -sin las debidas acotaciones a la realidad estudiada- pierde alcance para países de América Latina, como los aquí abordados. Por ello, se sugiere no solo una revisión de la teoría sino la búsqueda de un paradigma alternativo que más allá de pensar en un ideario de sociedad permita más bien explicar la realidad latinoamericana.

Uno de los errores que se pueden cometer en el momento de aplicar modelos basados en los supuestos del rational choice es creer que los resultados obtenidos reflejan exactamente la realidad. Me refiero específicamente al supuesto de la información completa con la que contarían los individuos al momento de tomar sus decisiones. Aunque no es propósito en este estudio discutir y cuestionar todos los postulados que sustentan el paradigma del rational choice, sí quisiera resaltar algunos planteamientos que atacan directamente la teoría del capital humano (North, 1995).

En lo relacionado con la educación, la inversión a la cual la teoría hace alusión asume como exógenas las características institucionales de una sociedad. Una de las críticas más fuertes tiene que ver con que las inversiones tanto en capital humano -oferta laboral- como en capital físico -demanda laboral- tienden a ser complementarias. Como se ha demostrado empíricamente para Ecuador y Nicaragua, las imperfecciones del mercado evidenciadas en la formación educativa, la ausencia de información y la fragilidad del sistema productivo, no garantizan que la mayor inversión en capital humano marche de manera sincrónica con el crecimiento de la estructura del capital físico. 
Con lo anterior, el supuesto a través del cual los individuos compensan su inversión en educación con los salarios recibidos se halla violado, al no existir el permanente estado de equilibrio que la teoría presupone. Además, al considerar la teoría del capital humano a dicha imperfección como un hecho aislado y atípico, cuando realmente es una situación frecuente para los países de América Latina, resulta débil en cuanto a su capacidad explicativa, al menos para realidades como las de la región.

Finalmente, una estrategia de investigación para desentrañar aun más en el tema en cuestión podría consistir en la incorporación de variables con contenido más interdisciplinario, que traten de evaluar las causas de la desigualdad en los ingresos laborales al interior de los diferentes niveles educativos. Para ello observar la calidad de la educación y sus diferencias entre el sector público y privado o comparar la posición ocupacional de personas con igual nivel educativo, podrían ser alternativas viables. En definitiva, el análisis de la desigualdad de los ingresos laborales desde la teoría del capital humano da cuenta de los factores -que desde la oferta laboral- influyentes en la explicación de dicho fenómeno, los resultados obtenidos y las características socioeconómicas de cada país, promueven la re-operacionalización de las variables utilizadas por este enfoque a fin de que los datos por ellas capturados, cumplan con el criterio de validez, es decir, que el concepto teórico guarde concordancia con el indicador que lo expresa.

\section{Bibliografía}

Altimir, Oscar y Becaria, Luis 1999 "El mercado de trabajo bajo el nuevo régimen económico para Argentina" en Serie Reformas Económicas (Santiago de Chile: CEPAL) N ${ }^{\circ} 28$.

Arcos, C. Xavier 1997 La desigualdad del consumo en el Ecuador (Cornell: Cornell University / Ediciones Abya-Yala).

Arrow, Keneth 1977 "Extended Sympathy and the Possibility of Social Choice" en American Economic Review (Pittsburg) No 67.

BCE. Banco Central del Ecuador. <http://www.bce.fin.ec/>.

BCN. Banco Central de Nicaragua. <http://www.bcn.gob.ni>.

BCN. Banco Central de Nicaragua 2000 "Censo Económico Urbano" en <http://www.bcn.gob.ni/estadisticas/censo/censo_2000/Informe_Censo_Economico2000.pdf>.

Becker, Gary S. 1993 Human capital (Nueva York: National Bureau of Economic Research).

Becker, Gary S. y Nigel, Tomes 1986 "Human Capital and the Rise and Fall of Families" en Journal of Labor Economics (Chicago: The University of Chicago) $\mathrm{N}^{\circ} 4$ (3). 
Ben Porath, Yoram 1970 "The production of Human Capital and the Life-cycle of Earnings" en Journal of Political Economy (Chicago: Elsevier Science Ltd.) $\mathrm{N}^{\mathrm{o}} 75$.

CEPAL 2002 Panorama social de América Latina y el Caribe 2002 (Santiago de Chile: Naciones Unidas).

CEPAL 2003 Panorama social de América Latina y el Caribe 2003 (Santiago de Chile: Naciones Unidas).

CEPAL 2004 Panorama social de América Latina y el Caribe 2004 (Santiago de Chile: Naciones Unidas).

De Ferrati, David y Perry, Guillermo 2004 "Desigualdad en América Latina. Una ruptura con la historia" en Banco Mundial (Bogotá: Alfaomega Colombiana).

Dubcovsky, Gerardo 1999 "Structural Adjustment Policy Analysis in the Nineties" en The North American Journal of Economic and Finance (California) $\mathrm{N}^{\circ} 10$.

Durkheim, Emile 1967 De la división del trabajo social (Buenos Aires: Editorial Schapire).

Duryea, Suzanne y Székely, Miguel 1998 "Los mercados laborales en América Latina: el argumento de la oferta" en RES Working Papers 4121 (Washington DC: BID).

Fields, Gary 1979 "Descomposing LDC Inequality" en Oxford Economic Paper. New series (Oxford: Oxford University Press) Vol. 1, $\mathrm{N}^{\circ}$ 3.

Fields, Gary 1997 "Wage Floors and Unemployment: a Two-Sector Analysis" en Research in Labor Economics (Chicago: Elsevier Science Ltd.) $\mathrm{N}^{\mathrm{o}} 4$.

Fields, Gary 2003 "Accounting for Income Inequality and its change: A new method, with application to the distribution of earnings in the United States" en Research in Labor Economics (Chicago: Elsevier Science Ltd.) Vol. 22, $\mathrm{N}^{\mathrm{o}} 1$.

Fields, Gary; Leary, J. B. et al. 1998 Education's crucial role in explaining labor income inquality in urban Bolivia (Cambridge, MA: Harvard Institute for International Development. Harvard University).

Fiszbein, Ariel y Psacharopoulos, George 1997 "Tendencias de la desigualdad del ingreso en América Latina en los años ochenta" en Lustig, Nora (comp.) El desafío de la austeridad (México: Fondo de Cultura Económica).

Gindling, T. H. 2003 "La desigualdad en América Central durante los años noventa" en $U M B C$ - Economics Department Working Papers with $\mathrm{N}^{\mathrm{o}}$ 03-109, en <http://www.umbc.edu/economics/> (Acceso: 2003).

Griliches, Zvi 1977 "Estimating the returns to schooling: some econometric problems" en Econometrica (Cleveland) $\mathrm{N}^{\circ} 45$. 
Haimovich, Francisco; Winkler, Hernán y Gasparini, Leonardo 2006 "Distribución del ingreso en América Latina: Explorando las diferencias entre países”. Documento de Trabajo No 34 (La Plata: Centro de Estudios Distributivos, Laborales y Sociales - Universidad Nacional de La Plata).

Heckman, J. J. 1976 “A Life-cycle Model of Earnings, Learning, and Consumption" en Journal of Political Economy (Chicago: Elsevier Science Ltd.) $\mathrm{N}^{\circ} 84$.

Heckman, J. J. 1979 "Sample Selection Bias as a Specification Error" en Econometrica (Cleveland) $\mathrm{N}^{\circ} 471$.

Heckman, J. J. y Smith, J. 1995 "Assessing the Case for Randomized Social Experiments" en Journal of Economic Perspectives (Broadway: AEA) primavera, $\mathrm{N}^{\circ} 92$.

INEC. Instituto Nacional de Estadísticas y Censos de Nicaragua. $<$ www.inec.gov.ni>

INEC. Instituto Nacional de Estadísticas y Censos de Ecuador. <www. inec.gov.ec>

King, Gary; Keohane, Robert O. y Sidney, Verba 2000 El diseño de la investigación social. Inferencia científica en los estudios cualitativos (Madrid: Alianza Editorial).

Krugman, Paul 1991 "Increasing Returns and Economic Geography" en Journal of Political Economy (Chicago: Elsevier Science Ltd.) junio.

Larrea, M. Carlos 2004 Pobreza, dolarización y crisis en el Ecuador (Quito: Abya-Yala).

Londoño, Juan Luis 1997 "Pobreza, desigualdad y formación de capital humano en América Latina, 1950-2025" en Estudios del Banco Mundial sobre América Latina (Washington DC: Banco Mundial).

Martínez, María Eugenia 1997 "El papel de la educación en el pensamiento económico" en Aportes. Revista de la Facultad de Economía de la BUAP (México DF: BUAP) Año 1, No 3 y 4, septiembrediciembre de 1996 y enero-abril de 1997.

Mincer, J. 1958 "Investment in Human Capital and Personal Income Distribution" en Journal of Political Economy (Chicago: Elsevier Science Ltd.) $\mathrm{N}^{\mathrm{o}} 66$.

Mincer, J. 1970 "The distribution of Labor Incomes: A Survey with special Reference to the Human Capital Approach" en Journal Of Economic Literature (Broadway: AEA) $\mathrm{N}^{\circ} 81$.

Mincer, J. y Polachek, S. 1974 "Family Investment in Human Capital: Earnings of Women" en Journal of Political Economy (Chicago: Elsevier Science Ltd.) Vol. 82, $\mathrm{N}^{\circ} 2$.

Morley, Samuel 1997 "El ajuste estructural y los determinantes de la pobreza en América Latina” en Lustig, Nora (comp.) El desafío de la austeridad (México DF: Fondo de Cultura Económica). 
North, Douglas 1995 Instituciones, cambio institucional y desempeño económico (México DF: Fondo de Cultura Económica.

OIT 2004 Panorama Laboral (Montevideo: OIT).

Peters, Guy 2003 "El nuevo institucionalismo" en Teoría institucional en Ciencia Política (Barcelona: Gedisa).

Ponce, J. 2000 Y la madrugada los sorprendió en el poder (Quito: Planeta).

Ponce, J.; Bedi, A. y Vos, R. 2003 “¿Cómo hacer más eficiente el gasto educativo?” en Vos, R. (ed.) ¿Quién se beneficia del gasto social en el Ecuador? (Quito: SIISE-STFS).

Ravallón, Martín 2004 "Competing Concepts of Inequality in the Globalization Debate" en World Bank Research - Policy Research working paper WPS 3243, en <http://www.worldbank.org> (Acceso: 06/08/2004).

Reimers, F. 2000 “¿Pueden aprender los hijos de los pobres en las escuelas de América Latina?” en Revista Mexicana de Investigación Educativa (México DF) enero-junio, Vol. 5, No 9.

Sadoulet, Elisabeth y De Janvry, Alain 1997 "El alivio de la pobreza, la redistribución del ingreso y el crecimiento económico durante el ajuste" en Lustig, Nora (comp.) El desafío de la austeridad (México: Fondo de Cultura Económica).

Samuelson, Paul 1947 Foundations of Economic Analysis (Cambridge, MA: Harvard University Press).

Sen, Amartya 1992 "Inequality Reexamined" (Cambridge, MA: Harvard University Press).

Sen, Amartya 1999 Nuevo examen de la desigualdad (Madrid: Alianza Editorial).

Shorrocks, A. F. 1983 "Inequality Decomposition by Factor Components" en Econometrica (Cleveland) $\mathrm{N}^{\circ} 50$.

SIISE. Sistema Integrado de indicadores Sociales del Ecuador, en $<\mathrm{http}: / / w w w . f r e n t e s o c i a l . g o v . e c / s i i s e / p \_C e n s o \% 202001 / 1 . h t m>$.

Smith, Adam 1958 Investigación sobre la naturaleza y causas de la riqueza de las Naciones (México: Fondo de Cultura Económica).

Smith, Adam 2004 La teoría de los sentimientos morales (Madrid: Alianza Editorial).

Stallings, Bárbara y Peres, Wilson 2000 Crecimiento, empleo y equidad. Impacto de las reformas económicas en América Latina y el Caribe (Santiago de Chile: CEPAL).

Stuart Mill, John 1909 Principles of Political Economy (Londres: W. J. Ashley) 2 vols.

Tokman, Víctor E. 1994 Generación de empleo en un nuevo contexto estructural (Lima: Oficina Regional de la OIT para América Latina y El Caribe). 
Vargas, Oscar-René 1998 Pobreza en Nicaragua: un abismo que se agranda (Managua: Instituto de Investigación y Desarrollo Humanístico de la Univ. Politécnica).

Vergara, M. Sebastián 2005 Pequeñas y medianas empresas en América Latina. División de desarrollo productivo y empresarial (Lima: CEPAL).

Vos, Rob 2000 "Liberalización económica, ajuste, distribución y pobreza en Ecuador, 1988-1999”. Mimeo. Disponible en <www.siise. gov.ec>. 


\title{
Gabriel Calvi*
}

\section{LAS METAMORFOSIS DE LA DESIGUALDAD DE INGRESOS EN LA ARgENTINA (1974-2005)}

\author{
"Lo difuso, lo oscuro, lo incognoscible, \\ escapa a nuestra acción. \\ Cuando no se sabe o se sabe mal cuál es su carácter, \\ no se lo puede cambiar." \\ ÉmILE DuRKheIM, \\ Lecciones de Sociología
}

\section{INTRODUCCIÓN}

La desigualdad es hoy en la Argentina un problema de pública trascendencia. La prolongada crisis económico-social de principios del nuevo milenio ha contribuido a extremar a niveles sin precedentes no solo la incidencia de la pobreza y la indigencia, sino también la concentración del producto social. Sin embargo, y frente a la abundancia de bibliografía que aborda los cambios en la estructura productiva local, contrasta la relativa ausencia de investigaciones dedicadas a explorar los cambios en el patrón distributivo de la sociedad. Ciertamente, algunos trabajos principalmente centrados en las modificaciones del régimen de acumulación local intentan conectar las transformaciones estructurales con los cambios experimentados por los principales indicadores socioeconómicos. Es cierto, también, que otras investigaciones que tienen por tema la dinámica del mercado de trabajo urbano aluden, en sus conclusiones, a los efectos desigualadores que emergen de la nueva configuración del mercado laboral. Sin embargo, en uno u otro caso las conexiones entre ambas dimensiones o bien son bastante generales o bien no van más allá de meras intuiciones. Crecimiento y desarrollo, acumulación y distribu-

* Licenciado en Sociología (UBA) y Ciencia Política (UBA). Magíster en Investigación en Ciencias Sociales (UBA). Docente de la Facultad de Ciencias Sociales (UBA). 
ción, producción y apropiación, todas ellas dualidades co-constitutivas de un ordenamiento social parecen haber devenido campos autónomos y autorreferenciales en lo que al discurso académico se refiere. No obstante su notable relevancia, el fenómeno de la desigualdad sigue siendo, pues, un terreno -parafraseando al autor de las Lecciones- predominantemente difuso, oscuro, y la ineficacia manifiesta de muchas de las políticas orientadas a revertir los elevados niveles de inequidad no es ajena a esta situación.

El principal objetivo de este trabajo es, pues, aportar herramientas que permitan echar luz sobre la evolución de la distribución de los ingresos personales en la Argentina en el marco de las transformaciones experimentadas por la economía en general y el mercado de trabajo en particular durante los últimos treinta años. En otras palabras, detectar aquellas modificaciones en el desempeño económico y socio-laboral que inciden alterando el patrón de desigualdad desde mediados de la década del setenta hasta la actualidad. Evidentemente, los cambios en el desempeño económico-laboral dependen, en última instancia, del impacto -coyuntural o estructural- de las principales opciones de política económica implementadas por los sucesivos gobiernos. Tales modalidades de intervención estatal influyen decisivamente sobre el ritmo y naturaleza del proceso de acumulación, alterando tanto los requerimientos de mano de obra como el peso que las estrategias de valorización de las empresas asignan al consumo interno. Los niveles de desigualdad son la resultante de esta compleja imbricación de factores.

El presente trabajo está organizado en cuatro apartados. En el primero de ellos se describe brevemente la estrategia metodológica empleada en la operacionalización del fenómeno distributivo. Dicha operacionalización, que más adelante daremos en llamar patrón de desigualdad social, asume un lugar central pues de ella depende la posibilidad de establecer algún tipo de nexo relacional entre las transformaciones sociales y los cambios en la desigualdad. En el segundo apartado se describen las tendencias seculares y cíclicas que se observan en la evolución del reparto de los ingresos y se evalúan las posibles causas (macrosociales) que están en el origen de las sucesivas alteraciones del patrón de desigualdad social. Una última sección tiene por objetivo contribuir a sanear la virtual inexistencia de análisis e información estadística comparable sobre la distribución del ingreso para los distintos niveles subnacionales.

\section{BREVES SEÑALIZACIONES SOBRE LA ESTRATEGIA METODOLÓGICA EMPLEADA}

Para dar cuenta del grado de desigualdad de ingresos y su evolución a lo largo del tiempo se ha optado en este trabajo por analizar el origen 
de las tendencias que asume la dispersión del ingreso per cápita familiar mensual (IPCF), indicador generalmente seleccionado como el más relevante para el estudio del bienestar de una población. El IPCF es una medida resumen construida a partir de una serie de características propias de cada hogar: el ingreso mensual de los miembros perceptores y la proporción de miembros perceptores en el hogar. Dos tipos de factores contribuyen, pues, a modificar la desigualdad en su reparto: por un lado, los cambios en la distribución de los ingresos individuales de los perceptores y, por el otro, las modificaciones en las estructuras ocupacionales de los hogares. Por ejemplo, un deterioro de los ingresos individuales que perjudique a los perceptores de los hogares más pobres tendrá como resultado (ceteris paribus) un incremento de la desigualdad del IPCF. Asimismo, un aumento en las tasas de desocupación (o una disminución en las tasas actividad) que afecte fundamentalmente a esos hogares tendrá (ceteris paribus) un impacto similar.

\section{Sintesis gráfica de la metodología}

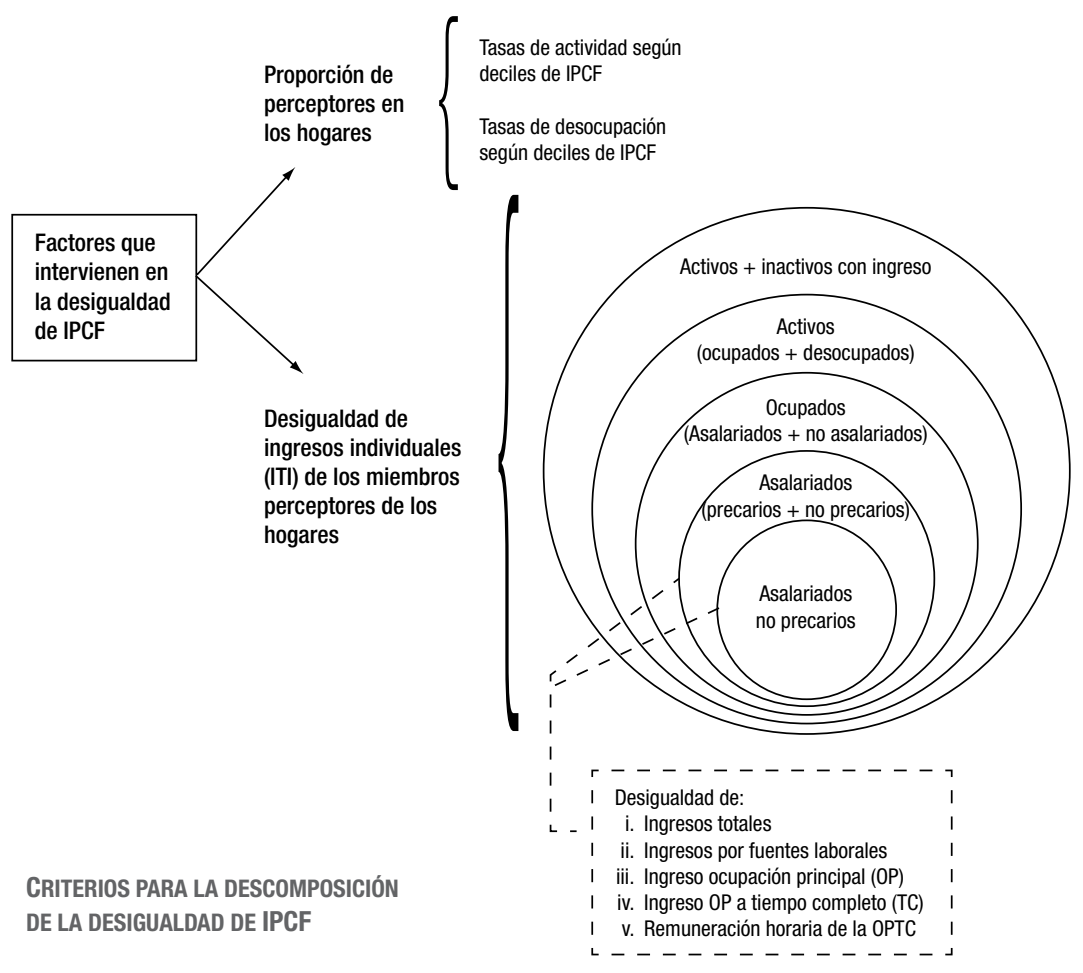


Para analizar los cambios en el reparto de los ingresos individuales -primer factor mencionado- se ha procedido a desglosar el universo de perceptores en distintos subgrupos (categorías): a) los asalariados registrados; b) los asalariados (entre los que se cuentan también los trabajadores precarios) 1; c) los ocupados (que contemplan también a los no asalariados); d) los activos (entre los que quedan incluidos también los desocupados), y e) los activos e inactivos perceptores (entre los que se contabilizan, además, los jubilados, pensionados, rentistas, etc.). Como vemos, cada una de las categorías menos numerosas aquí consideradas queda incluida en las poblaciones de mayor tamaño. De resultas, la diferencia en el grado de desigualdad de ingresos de dos subgrupos puede ser atribuida a la incidencia de la población que queda excluida en el subgrupo menos numeroso. Por ejemplo, la diferencia entre el grado de desigualdad de ingresos de los ocupados y el de los asalariados da cuenta de la incidencia distributiva de los ocupados no asalariados; del mismo modo, la distancia entre el reparto de los activos y el de los ocupados revela el efecto de la población desocupada sobre la distribución de ingresos individuales; etc. Por último, como todas las poblaciones menores están incluidas en la población total, las dispersiones de los ingresos individuales evaluadas son relevantes para explicar lo que ocurre con la desigualdad en la distribución del IPCF.

Para abordar los cambios en el segundo tipo de factores que contribuye a modificar el reparto del IPCF, esto es, las alteraciones en las tasas de actividad y desocupación de los hogares, se han comparado los distintos niveles que alcanzan esas tasas en cada decil de IPCF a lo largo de todo el período estudiado. Así, cuando se observe un deterioro en el reparto del IPCF que no encuentre su origen en la evolución de los ingresos individuales, este comportamiento será explicado por un incremento en la dispersión decílica de las tasas de desocupación y/o por una reducción relativa en las tasas de actividad de los hogares más pobres. Por el contrario, una mejora en la distribución del IPCF que no sea explicada por modificaciones en el reparto de los ingresos individuales encontrará su origen en una caída de la dispersión de las tasas de desocupación y/o en un aumento de los niveles de actividad que mejore la situación relativa de los hogares de menor IPCF.

1 Aunque se trata de un fenómeno complejo, que involucra una multiplicidad de dimensiones y que ha sido objeto de numerosas conceptualizaciones, en este artículo consideramos como trabajadores precarios a aquellos que declaran que no se les realizan los descuentos para el sistema jubilatorio (Beccaria, 2003). Para otras aproximaciones al fenómeno de la precariedad consultar: Pok (1992) y Salvia y Tissera (2000). 
Ahora bien, la medida de la desigualdad, tanto de IPCF como de ingresos individuales, elegida para este trabajo ha sido el coeficiente de Gini. El valor máximo de esta medida (1) representa la mayor concentración de ingresos posible en una determinada población, mientras que el valor mínimo (0) representa la distribución más equitativa. Resta mencionar que la información utilizada en este trabajo fue elaborada a partir de los datos desagregados (y expandidos) de la Encuesta Permanente de Hogares del Instituto Nacional de Estadística y Censos (EPH), para los años 1974 a 2005, contemplando a la población sin ingresos. ${ }^{2}$

\section{Los CAMbios EN EL PATRón distributivo en la ARgentina}

Las transformaciones estructurales operadas desde mediados de la década del setenta en la Argentina no solo contribuyeron a alterar las particularidades y dinámica que habían caracterizado al mercado de trabajo urbano durante la segunda posguerra, sino que estuvieron acompañadas por un deterioro secular del reparto de los ingresos personales. ${ }^{3}$ En este sentido, los datos del Cuadro 3.1 arrojan un resultado categórico: entre 1974 y 2005 el índice de dispersión del ingreso

2 Muchos han señalado las debilidades relativas al registro de ingresos en la EPH: las omisiones y subdeclaraciones subestiman los niveles de desigualdad al concentrarse en sectores de mayor poder adquisitivo. Sin embargo, tal problema no afectaría la comparación interanual mientras la estructura de subregistro y subdeclaración no se modifique significativamente en el tiempo, como ha demostrado el trabajo de Gasparini et al. (2000), "La distribución del ingreso en la Argentina y en la provincia de Buenos Aires”, en Cuadernos de Economía (La Plata) N 49. Un supuesto similar es usado por Altimir et al. (2002), "La distribución del ingreso en Argentina, 19742000", en Revista de la CEPAL (Buenos Aires) $\mathrm{N}^{\circ} 78$, diciembre.

3 Cabe recordar que el estudio de la desigualdad no se agota en el análisis de la distribución personal del ingreso. Una dimensión no menor de este tipo de problemáticas es la relativa a la distribución funcional. Un trabajo reciente ha contribuido a completar la información estadística disponible sobre distribución funcional del ingreso con valiosas estimaciones a nivel nacional (Lindemboim et al., 2005). Las principales tendencias observadas en este trabajo señalan que la distribución funcional del ingreso fue también objeto de serias modificaciones por esos años. Entre las principales conclusiones a las que arriban los autores de tales estimaciones podemos mencionar: a) una fuerte caída de la participación asalariado-cuentapropista en el ingreso nacional durante la década del noventa; b) una consecuente reducción de la participación asalariado-cuentapropista en el consumo privado en ese período, y c) un aumento del consumo capitalista, tendencia que no es sino la contraparte de la escasa envergadura de la inversión privada registrada por esos años (Lindemboim et al., 2006: 86). En contraste con la década del noventa los autores señalan que en el período 1960-1973 "el aumento de la participación de la masa salarial en el producto" habría sido acompañado "por un movimiento en igual sentido de la participación del 'ingreso asalariado' en el consumo privado a costa del realizado por los capitalistas" (Lindemboim et al., 2006: 87). 
per cápita familiar (IPCF) en el Gran Buenos Aires (GBA) se deterioró un 42,7\%; por su parte, la desigualdad en el reparto de los ingresos personales para los principales grupos sociolaborales da cuenta de malogros igualmente significativos (de entre el $43 \%$ y el $31 \%$, según sea el caso). Al observar lo ocurrido en el conjunto de los aglomerados urbanos, si bien con datos que parten del año 1985, también es posible observar una clara tendencia hacia el incremento de la desigualdad: el reparto del IPCF se deteriora un $21,2 \%$ en esos veinte años, mientras que los coeficientes de Gini (CG) para los ingresos de las grandes categorías sociolaborales lo hace entre un $22 \%$ y un $16 \%$.

Resulta interesante, con los datos presentados hasta el momento, destacar el quiebre que se produce en la distribución del ingreso a partir de 1980. Específicamente, si nos concentramos en la desigualdad relativa al IPCF, observamos que si sobre el final de la segunda fase de la ISI el nivel de desigualdad se encontraba en el orden de los 0,35 puntos del CG, desde principios de la década perdida en adelante el guarismo superará sensiblemente el valor de 0,40. A partir de ese momento, se registra un deterioro persistente de la distribución del IPCF: si el promedio del CG en los años ochenta se encontraba -en el GBA- un 24\% por encima del registrado hacia 1974, durante los noventa el indicador será un 35\% superior al del año de referencia y en los primeros cinco años del nuevo milenio el promedio superará en un $49 \%$ el valor registrado en el año base.

\section{Cuadro 1}

Coeficientes de Gini de ingresos familiares (IPCF) y de ingresos individuales

para distintas categorías socio-laborales

GBA y total de aglomerados urbanos, 1974-2005

\begin{tabular}{|c|c|c|c|c|c|c|c|c|c|c|c|c|c|c|}
\hline \multirow{3}{*}{ Onda } & \multicolumn{7}{|c|}{ GBA } & \multicolumn{7}{|c|}{ Total de aglomerados urbanos } \\
\hline & \multirow{2}{*}{ IPCF } & \multirow{2}{*}{$A c+I P$} & \multirow{2}{*}{ Ac } & \multirow{2}{*}{$0 \mathrm{c}$} & \multicolumn{3}{|c|}{ As } & \multirow{2}{*}{ IPCF } & \multirow{2}{*}{$A c+I P$} & \multirow{2}{*}{ Ac } & \multirow{2}{*}{$0 \mathrm{c}$} & \multicolumn{3}{|c|}{ As } \\
\hline & & & & & Total & AsRg & AsPI & & & & & Total & AsRg & AsPI \\
\hline 0ct-74 & 0,356 & 0,388 & 0,369 & 0,348 & 0,328 & 0,299 & - & - & - & - & - & - & - & - \\
\hline 0ct-80 & 0,394 & 0,443 & 0,428 & 0,406 & 0,383 & 0,374 & 0,377 & - & - & - & - & - & - & - \\
\hline 0ct-81 & 0,471 & 0,468 & 0,465 & 0,450 & 0,438 & 0,437 & - & - & - & - & - & - & - & - \\
\hline 0ct-82 & 0,423 & 0,448 & 0,439 & 0,408 & 0,367 & - & 0,356 & - & - & - & - & - & - & - \\
\hline 0ct-84 & 0,431 & 0,452 & 0,426 & 0,397 & 0,370 & - & 0,352 & - & - & - & - & - & - & - \\
\hline 0ct-85 & 0,413 & 0,449 & 0,427 & 0,393 & 0,359 & 0,337 & 0,349 & 0,414 & 0,446 & 0,433 & 0,395 & 0,357 & - & 0,346 \\
\hline 0ct-86 & 0,423 & 0,468 & 0,450 & 0,416 & 0,371 & 0,352 & 0,361 & 0,428 & 0,463 & 0,453 & 0,418 & 0,377 & - & 0,366 \\
\hline 0ct-87 & 0,448 & 0,481 & 0,458 & 0,429 & 0,403 & 0,384 & 0,394 & 0,447 & 0,475 & 0,462 & 0,429 & 0,400 & - & 0,390 \\
\hline 0ct-88 & 0,453 & 0,484 & 0,481 & 0,443 & 0,423 & - & 0,412 & 0,449 & 0,477 & 0,477 & 0,440 & 0,417 & - & 0,404 \\
\hline 0ct-89 & 0,521 & 0,543 & 0,527 & 0,489 & 0,449 & 0,434 & 0,441 & 0,498 & 0,521 & 0,514 & 0,475 & 0,437 & - & 0,429 \\
\hline
\end{tabular}




\section{Gabriel Calvi}

\begin{tabular}{|c|c|c|c|c|c|c|c|c|c|c|c|c|c|c|}
\hline \multirow{3}{*}{ Onda } & \multicolumn{7}{|c|}{ GBA } & \multicolumn{7}{|c|}{ Total de aglomerados urbanos } \\
\hline & \multirow{2}{*}{ IPCF } & \multirow{2}{*}{$A c+I P$} & \multirow{2}{*}{ Ac } & \multirow{2}{*}{$0 c$} & \multicolumn{3}{|c|}{ As } & \multirow{2}{*}{ IPCF } & \multirow{2}{*}{$A c+I P$} & \multirow{2}{*}{ Ac } & \multirow{2}{*}{ Oc } & \multicolumn{3}{|c|}{ As } \\
\hline & & & & & Total & AsRg & AsPI & & & & & Total & AsRg & AsPI \\
\hline 0ct-90 & 0,467 & 0,474 & 464 & 0,426 & 0,392 & - & 380 & 0,454 & 0,463 & 0,460 & 0,422 & 0,389 & - & 0,374 \\
\hline 0ct-91 & 0,404 & 479 & 0,460 & 0,429 & 0,395 & 0,389 & 0,386 & 0,459 & 0,471 & 0,464 & 0,428 & 0,393 & 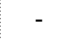 &, 383 \\
\hline 0ct-92 & 0,447 & 79 & 451 & 0,407 & 0,363 & 355 & 353 & 0,456 & 0,479 & 0,465 & 421 & 378 & - & 366 \\
\hline 0ct-93 & 0,448 & 0,490 & 0,470 & 0,413 & 0,375 & 0,362 & 362 & 0,457 & 0,486 & 0,476 & 0,422 & 0,384 & 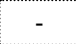 &, 372 \\
\hline 0ct-94 & 0,463 & 0,505 & 0,491 & 0,414 & 0,381 & 0,359 & 0,363 & 0,467 & 0,498 & 0,491 & 0,422 & 0,386 & - & 0,371 \\
\hline 0ct-95 & 0,492 & 0,537 & 0,537 & 0,443 & 0,399 & 376 & 382 & 0,488 & 0,523 & 528 & 0,439 & 0,397 & 0,367 & 380 \\
\hline May-96 & 0487 & 0,528 & 528 & 0 , & 0,388 & 359 & ,363 & 0,486 & 518 & 525 & 433 & 91 & 0,357 & 0,369 \\
\hline 0ct-96 & 495 & 43 & 48 & 442 & 404 & 376 & 373 & 0,494 & 528 & 38 & 442 & 404 & 68 & 377 \\
\hline May-97 & 490 & 539 & 1 & 0 & 5 & 88 & 381 & 91 & 27 & 33 & 15 & 4 & 64 & 0,382 \\
\hline 0ct-97 & 487 & 518 & 516 & 0,427 & 0,395 & 365 & ,366 & 0,490 & 514 &, 517 & 435 & 00 & 0,362 & $0,3 / 5$ \\
\hline May-98 & 0,496 & 0,526 & 525 & 0,449 & 0,402 & 0,373 & 0,371 & 0,496 & 0,518 & 0,522 & 0,451 & 0,406 & 0,370 & 0,378 \\
\hline Oct-98 & 0,507 & 0,526 & 0,526 & 0,456 & 0,415 & 0,376 & 0,386 & 0,504 & 0,517 & 0,521 & 0,455 & 0,416 & 0,371 & 0,390 \\
\hline May-99 & 0,504 & 0,531 & 0,535 & 0,448 & 0,410 & 0,374 & 0,384 & 0,503 & 0,522 & 0,529 & 0,450 & 0,412 & 0,370 & 0,386 \\
\hline Oct-99 & 0,495 & 0,523 & 0,524 & 0,446 & 0,408 & 0,372 & 0,374 & 0,494 & 0,514 & 0,520 & 0,445 & 0,408 & 0,366 & 0,379 \\
\hline May-00 & 0,509 & 0 & 544 & 0 , & 0,424 & 37 & 0 & 0,505 & 26 & 35 & 56 & 19 & 75 & 0393 \\
\hline 0ct-00 & 0,511 & & 0,529 & 0, & 0 & 0,382 & 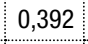 & 0 & 0,524 & 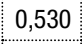 & 3 & 1 & 4 & 0,395 \\
\hline May-01 & 0 & 0 & o & 0 & 0 & 0 & 0 & 0 & 2 & 5 & 3 & 25 & 73 & 0,396 \\
\hline Oct-01 & 0,53 & 44 & 569 & 0 , & 0,440 & 0,390 & 0 & 31 & 43 & 22 & 0 & 437 & 881 & 0,402 \\
\hline May-02 & 0,560 & 0,576 & 0,596 & 0,476 & 0,435 & 0,380 & 0,389 & 0,551 & 0,564 & 0,589 & 0,473 & 0,435 & 0,374 & 0,393 \\
\hline 0ct-02 & 0,542 & 0,564 & 0,582 & 0,499 & 0,463 & 0,382 & 0,413 & 0,533 & 0,548 & 0,571 & 0,490 & 0,456 & 0,372 & 0,407 \\
\hline May-03 & 0,541 & 0,551 & 0,562 & 0,489 & 0,457 & 0,378 & 0,393 & 0,529 & 0,536 & 0,551 & 0,480 & 0,450 & 0,370 & 0,390 \\
\hline || 2003 & 0,557 & 579 & 0,594 & 0,510 & 0,494 & 0,422 & 0,449 & 0,544 & 0,568 & 0,587 & 0,502 &, 484 & 0,401 & 0,438 \\
\hline 12004 & 0,525 & 0,548 & 0,561 & 0,472 & 0,450 & 0,374 & 0,397 & 0,520 & 0,545 & 0,563 & 0,476 & 0,452 & 0,364 & 0,401 \\
\hline II 2004 & 0,518 & 0,540 & 0,555 & 0,472 & 0,445 & 0,332 & 0,367 & 0,511 & 0,535 & 0,551 & 0,473 & 0,449 & 0,337 & 0,379 \\
\hline 12005 & 0,519 & 0,536 & 0,547 & 0,467 & 0,437 & 0,348 & 0,378 & 0,507 & 0,525 & 0,540 & 0,465 & 0,439 & 0,342 & 0,381 \\
\hline II 2005 & 0,508 & 0,523 & 0,530 & 0,462 & 0,432 & 0,341 & 0,372 & 0,502 & 0,517 & 0,527 & 0,463 & 0,435 & 0,334 & 0,378 \\
\hline Var. \% & 42,7 & 34,8 & 43,7 & 32,6 & 31,4 & 14,0 & $-1,5$ & 21,2 & 15,9 & 21,7 & 17,3 & 22,1 & $-8,9$ & 9,3 \\
\hline
\end{tabular}

${ }^{*}$ Referencias: $\mathrm{Ac}+\mathrm{IP}=$ activos e inactivos perceptores; $\mathrm{Ac}=$ activos; $0 \mathrm{c}=$ ocupados; $\mathrm{As}=$ asalariados; $\mathrm{AsRg}=$ asalariados registrados; AsPI = asalariados a jornada completa; var.\% = porcentaje de variación entre extremos.

Fuente: Elaboración propia en base a datos desagregados y expandidos de la EPH tradicional (1974-2003) y continua (2003-2005).

\section{DETRÁS DEL PERSISTENTE DETERIORO DISTRIBUTIVO: LOS CICLOS DE DESIGUALDAD}

Aunque nuestra primera lectura de la información disponible señala con notable simplicidad la magnitud del proceso regresivo experimentado, poco aporta por sí sola a su esclarecimiento. Para aproximarnos a un claro diagnóstico del malogro distributivo argentino debemos 
dejar de lado las tendencias seculares y prestar atención a la evolución de mediano plazo. En este sentido, además de dar cuenta de la tendencia secular, los datos presentados en el Cuadro 1 evidencian el carácter crítico en materia distributiva de los años 1981, 1989, 1995 y 2002: entre octubre de 1980 y octubre de 1981, la desigualdad de IPCF se incrementó un 19\% en el GBA; hacia el mismo mes de 1989, el deterioro interanual del indicador era del 15\% para el GBA y del 11\% para el conjunto de los aglomerados urbanos; entre octubre de 1994 y octubre de 1995 el aumento fue del 6\% en el GBA y 5\% en el conjunto de aglomerados, y entre mayo de 2001 y mayo de 2002, el deterioro del CG fue del orden del $6 \%$ en ambos agrupamientos territoriales.

Estos abruptos saltos en la distribución del IPCF se encuentran estrechamente vinculados a las últimas grandes crisis que experimentó la economía argentina: la desigualdad es, pues, altamente sensible a los deterioros en la coyuntura económica. Pero de los datos también surge que, en general, luego de estos importantes picos redistributivos la desigualdad tiende a atenuarse. Sin embargo, y en esto reside la peculiaridad del caso argentino, las mejoras posteriores a las crisis no incluyen recomposiciones del reparto del IPCF tales que retrotraigan la situación a los niveles precedentes a las mismas y tienden a apuntalar niveles de desigualdad superiores. Es este comportamiento escalonado de la desigualdad de los ingresos el que explica el deterioro de largo plazo: la concentración de los ingresos personales evoluciona por ciclos. El análisis de la desigualdad debe, pues, dar cuenta no solo de las tendencias de su evolución secular, sino también de aquellas singularidades que diferencian a cada una de las etapas en las que -dado el comportamiento escalonado observado- se descompone, así como también de las crisis que median entre ellas.

En lo que sigue, se tomará como referencia temporal la periodización que se desprende de los ciclos de desigualdad señalados anteriormente para intentar dilucidar qué elementos gobiernan el deterioro distributivo en cada etapa así como en las crisis que median entre ellas. En la evaluación del origen de los cambios distributivos prestaremos especial atención al impacto diferencial de distintas $c a$ tegorías sociolaborales sobre el fenómeno distributivo. ${ }^{5}$ Esta forma

4 Los patrones de evolución de la concentración del IPCF medidos con otros coeficientes de dispersión (Theil, Atkinson, Coeficiente de variación) registran tendencias similares (Gasparini et al., 2001). Lo mismo puede decirse -por lo menos para los años noventa- con relación a la evolución de la desigualdad estimada a partir de la distribución por quintiles de ingresos (Salvia y Donza, 2001).

5 Este abordaje se aproximaría en alguna medida a la propuesta de Charles Tilly (2000). En su búsqueda de una explicación sociológica de la desigualdad, el autor enfatiza el componente categorial de las desigualdades persistentes. No obstante las 
de abordar el fenómeno tiene por objeto contribuir a resaltar el carácter social de la desigualdad de ingresos personales: la inequidad de ingresos personales se encuentra determinada, fundamentalmente, por la posición que los individuos ocupan en la estructura sociolaboral y los ingresos que corresponden a esa posición. Los cambios en las condiciones macroestructurales alteran (o perpetúan) la desigualdad en la medida en que modifican (o no) la gravitación de tales categorías macrosociales y/o su capacidad para apropiarse de una parte del producto social.

\section{Gráfico 1}

Evolución del reparto de los ingresos familiares. GBA y total de aglomerados urbanos (1974-2005)

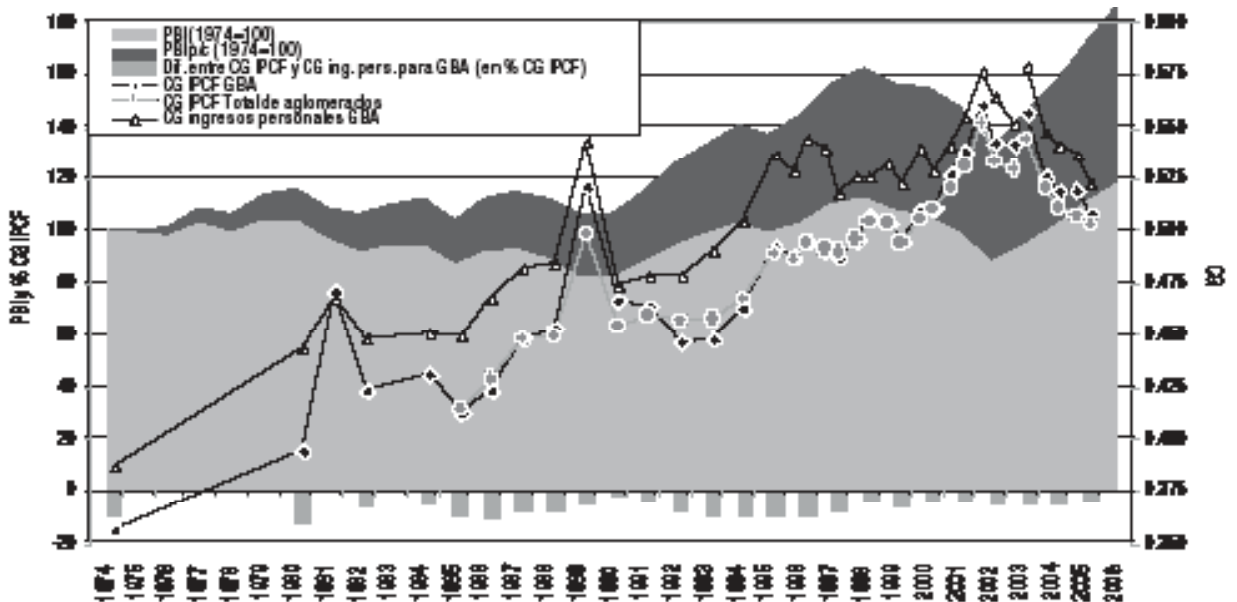

Fuente: Elaboración propia en base a datos desagregados y expandidos de la EPH tradicional (1974-2003) y continua (2003-2005).

Cabe tener presente también que entre la distribución del IPCF -nuestra dimensión a explicar-y las correspondientes a los ingresos personales de las distintas categorías de perceptores existe un hiato (ver Gráfico 1). Una forma de interpretar este hiato -que por momentos se amplía o estrecha- es considerarlo como un indicador de la eficacia relativa que las estrategias de subsistencia de los hoga-

distancias entre las categorías (persistentes) propuestas por Tilly y las aquí sugeridas, el rechazo a explicaciones de corte individualista acerca ambos enfoques. 
res de distintos estratos de ingreso tienen sobre los niveles de desigualdad. Como sabemos, hogares de distintos estratos se insertan en la vida económica en forma diferenciada: las tasas de actividad y desocupación de tales estratos de hogares difieren sustancialmente y varían a lo largo del tiempo en forma no siempre homogénea. Estas variaciones alteran la composición de los hogares e inciden, junto con los cambios en en la gravitación de las distintas categorías sociales, sobre los niveles de equidad. En este sentido, del Gráfico 1 se desprenden una serie de consideraciones: a) en general, los niveles de desigualdad de IPCF son menores a los correspondientes a los ingresos personales de los miembros perceptores; b) el deterioro secular de la dispersión del IPCF (del 43\% en GBA) fue mayor al experimentado por el reparto de los ingresos personales de la categoría sociolaboral de mayor agregación (la concentración de los ingresos de la población de activos e inactivos perceptores aumentó un 35\%); c) en algunas circunstancias -asociadas, en general, a fases recesivas de la economía $(1981,1990)$ - ambas dispersiones ven aproximarse sus valores en forma notable. La primera observación responde a cuestiones meramente estadísticas: el IPCF es una medida resumen que relaciona los ingresos aportados por los miembros perceptores del hogar con la totalidad de miembros del mismo (perceptores y no perceptores), por lo cual su rango de variación es más reducido que el correspondiente a los ingresos individuales de los perceptores. Las restantes consideraciones reflejan peculiaridades del caso argentino: la eficacia relativa de los esfuerzos (estrategias de inserción económica y de apropiación de ingresos) de los hogares más pobres varía con el tiempo y parece haber mermado tendencialmente con el correr de los años; más aun, existen momentos -las coyunturas críticas de 1981 y 1989- en los cuales tal ineficacia se acentúa considerablemente.

Llamaremos patrón de desigualdad social a la operacionalización que utilizaremos para señalar el peso relativo que tanto las distintas categorías sociolaborales -dimensión macrosocial- como las estrategias de los hogares -dimensión microsocial- tienen sobre los niveles de equidad de ingresos. En los próximos apartados describiremos las particularidades del patrón de desigualdad vigente en cada una de las etapas referenciadas, así como las condiciones macroestructurales que están en su origen. Las transformaciones experimentadas por la sociedad argentina a lo largo de los últimos treinta años contribuyeron al malogro distributivo a través de distintos mecanismos: el estudio de la forma de la desigualdad permitirá dar cuenta de cuáles fueron los mecanismos desigualadores que predominaron en cada etapa (ciclo/crisis). 


\section{LAS SUCESIVAS FORMAS DE LA DESIGUALDAD DE INGRESOS}

\section{ESTRATIFICACIÓN SALARIAL Y DESIGUALDAD EN EL PERÍODO DICTATORIAL} Los datos disponibles para el ciclo de desigualdad 1974-1980 -que refieren solamente al $\mathrm{GBA}^{-}{ }^{6}$, señalan un importante incremento de la desigualdad. A pesar de que entre esos años se registró un crecimiento del PBI del orden del 16\%, dicho incremento de la actividad económica no produjo algún tipo de mejora en la dispersión de los ingresos metropolitanos: la distribución del IPCF se deterioró en un $11 \%$ del CG. Es notable, también durante esta etapa, que tal deterioro fue sensiblemente menor al experimentado por la desigualdad de ingresos de la categoría sociolaboral de mayor nivel de agregación (activos e inactivos perceptores), que fue del orden del $25 \%$. En este sentido, distintos indicadores dan cuenta de la mayor eficacia relativa, en términos distributivos, que tuvieron durante esta etapa las estrategias de los hogares de menores recursos: de un lado, mientras que la tasa de actividad para los cinco deciles de mayor IPCF retrocedió en un 5\%, la correspondiente a los deciles más pobres experimentó un leve incremento (del orden del 1\%); del otro, si bien las tasas de desocupación durante esta etapa se encuentran en niveles bajos y sus variaciones no inciden fuertemente sobre la dispersión del IPCF, entre los deciles de menores ingresos el desempleo se redujo 30 puntos porcentuales más que entre los de mayores ingresos. Tales esfuerzos de los sectores de menores ingresos (incremento de la participación económica y reducción de la desocupación) hicieron que el efecto igualador asociado a la estructura de los hogares alcanzara niveles cercanos al -10\% del CG de IPCF en promedio durante esta etapa (Gráfico 2).

6 Por falta de información procesable (bases de datos) los indicadores distributivos correspondientes a los años 1974-1984 refieren solo al GBA. Sin embargo, dada la similitud que desde 1985 es posible observar entre las tendencias distributivas para GBA y para el conjunto de los aglomerados urbanos, no es aventurado suponer que durante el período anterior esa similitud se mantuvo. De este modo, los datos para el GBA referentes a los años 1974-1984 no serían muy distintos de las principales tendencias que sería posible observar de contar con información para el conjunto de los aglomerados urbanos. 
Gráfico 2

Efectos de distintas categorías sociolaborales sobre la desigualdad de ingresos personales (promedios del período)

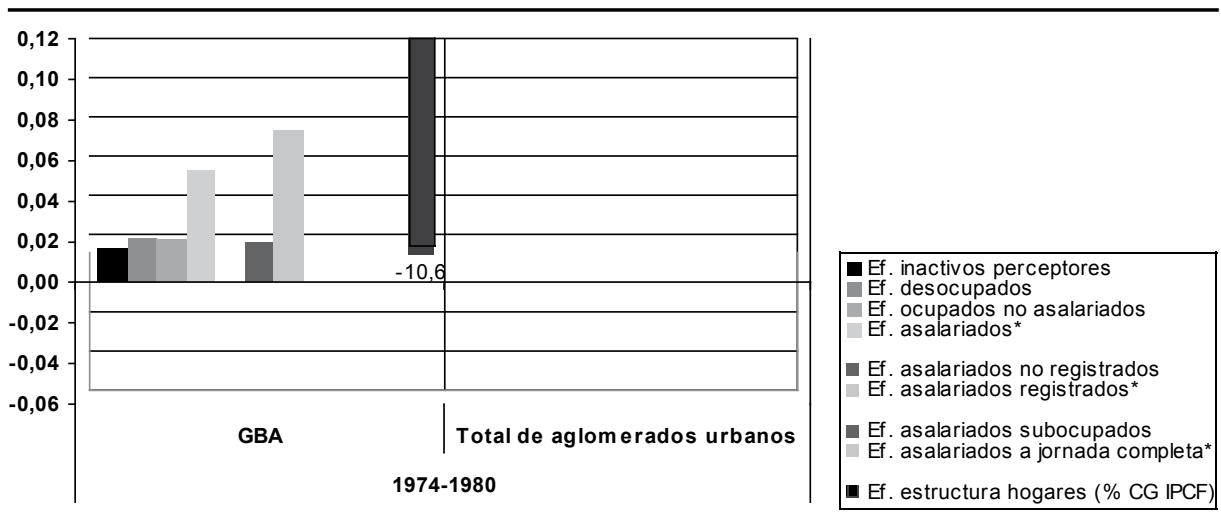

(*) Variaciones absolutas de los CG en cada período.

Fuente: Elaboración propia en base a EPH puntual y continua.

En segundo lugar, el patrón distributivo de esos años parece haber estado fuertemente determinado por la desigualdad de ingresos de los asalariados en general (Gráfico 2): el efecto de esta población explica 0,06 puntos de incremento absoluto del CG entre 1974 y 1980, mientras que el efecto de las restantes categorías de ingresos (inactivos perceptores, desocupados, ocupados no asalariados) se mantuvo en niveles cercanos a los 0,02 puntos del coeficiente en promedio. Sin embargo, no todas las posiciones asalariadas experimentaron el mismo retroceso: mientras que el efecto de las posiciones precarias sobre la desigualdad de los asalariados se mantuvo en niveles bajos ( 0,02 puntos del CG), las ocupaciones asalariadas registradas evidenciaron síntomas de retroceso distributivo cercanos a los 0,08 puntos del CG (Gráfico 2). Estos datos sugieren que la mayor desigualdad de los ingresos individuales estaría asociada principalmente a las variaciones en el reparto de los ingresos totales de la población de los asalariados registrados. Evidencias aportadas por otros autores (Altimir y Beccaria, 2001: 597) indican que fueron, más específicamente, los cambios en las remuneraciones horarias los que impulsaron esta mayor concentración de los ingresos de los asalariados.

Para interpretar el comportamiento del reparto de los ingresos de los asalariados registrados, principal factor que explica la desigualdad en esta etapa, resulta necesario aludir a algunos de los procesos históricos por los que atravesaba el país. Las primeras medidas implementadas durante el autodenominado Proceso de Reorganización Nacional (1976-1983) no se apartaban, en sus efectos, del esquema clásico 
de estabilización característico de la industrialización sustitutiva de importaciones: si bien otras disposiciones ulteriores serían los pilares de un nuevo ordenamiento que transformaría la estructura económica del país, la liberación de precios y el congelamiento salarial de 1976 significaban más una recomposición en las condiciones de funcionamiento del esquema de desarrollo vigente (Damill y Frenkel, 1993). La única modificación sustancial con relación a los planes precedentes fue debida a la virulencia del ajuste salarial operado en esta primera etapa: la escalada de precios -que no pudo ser contenida por esos años- hizo que el poder de compra de los salarios ahora congelados se redujera en un 36\% con relación al año anterior (Altimir et al., 2002). Los mecanismos para operar el fuerte ajuste salarial constituían una opción más que viable en el marco de un régimen de facto en el cual las instancias represivas del Estado cobraron especial vigor: el reemplazo de la negociación colectiva por un control gubernamental de los salarios, la supresión del derecho de huelga y varias reformas al código nacional de trabajo contribuyeron a disciplinar económica y políticamente a los asalariados (Cortés y Marshall, 1991). ${ }^{7}$

En tal contexto y en una coyuntura que se mantuvo cercana al pleno empleo, los asalariados de mayores niveles de calificación se habrían encontrado en mejores condiciones ante sus empleadores para recomponer sus remuneraciones horarias nominales que aquellos asalariados de menores calificaciones, dando lugar a un proceso de estratificación salarial (Altimir y Beccaria, 2001). Como resultado, según datos de la EPH, mientras que el promedio del ingreso total real de los asalariados de mayor nivel de educación (superior completa o incompleta) mejoró un 4,4\% entre 1974 y 1980, el correspondiente a los de menor nivel (primario completo o incompleto) cayó en un 25\% en igual período. Asimismo, el control gubernamental de los salarios habría permitido a los administradores de turno el realizar importantes modificaciones en las remuneraciones relativas por categoría y rama de actividad. Tales modificaciones en los salarios relativos de distintas categorías habrían tenido por resultado una intensificación del proceso de estratificación salarial entre los trabajadores registrados.

\section{LA DESIGUALDAD DE INGRESOS EN LA TRANSICIÓN DEMOCRÁTICA}

En la segunda de las etapa aquí consideradas (1982-1988), el patrón de desigualdad experimenta las siguientes alteraciones (Gráfico 3): a)

7 La suspención de la Ley 14.250 -esporádicamente vigente desde 1953- que establecía los mecanismos institucionales de negociación salarial -convenciones colectivas-, la puesta en vigencia del Decreto Ley 21.307 que le otorgaba al Estado la facultad unilateral de fijar las escalas y niveles de remuneración y las reformas a la Ley de Contrato de Trabajo (20.744) fueron las principales medidas instrumentadas en este sentido (Cortés y Marshall, 1991). 
el efecto igualador asociado a la estructura de los hogares retrocede en comparación con la etapa precedente; b) las poblaciones de desocupados y ocupados no asalariados incrementan levemente su gravitación sobre la inequidad distributiva; c) la desigualdad de los asalariados sigue siendo el principal factor que explica la concentración de los ingresos personales. Con relación al primer punto, aunque los esfuerzos de los hogares de menores ingresos siguen operando un importante efecto igualador (del 7,4\% de reducción del CG de IPCF en el GBA), el mismo se ha reducido considerablemente (un 30\% aproximadamente con relación al ciclo anterior): la mayor incidencia de la desocupación sobre los hogares pobres deterioró en este período la eficacia de las estrategias asociadas a una mayor participación económica de sus miembros.

\section{Gráfico 3}

Efecto de distintas categorías sociolaborales sobre la desigualdad de ingresos personales (promedios del período)

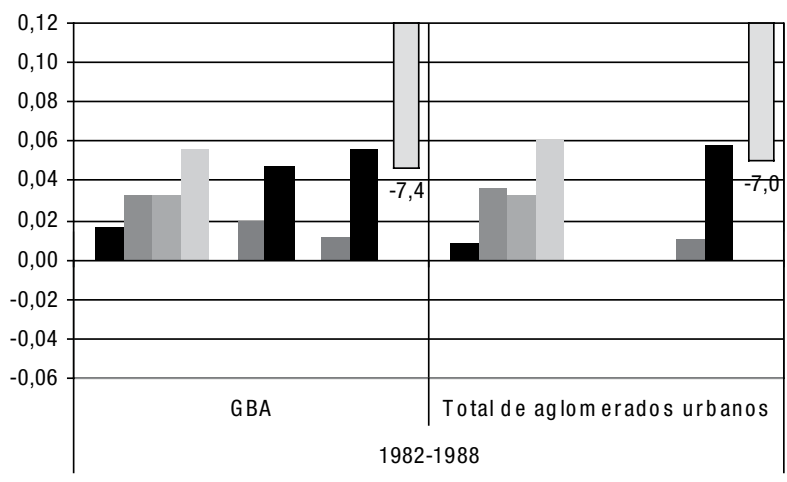

Ef. inactivos perceptores

Ef. desocupados

Ef. ocupados no asalariados

Ef. asalariados*

- Ef. asalariados no registrados

- Ef. asalariados regis trados*

- Ef. asalariados subocupados

- Ef. asalariados a jornada completa*

$\square$ Ef. estructura hogares (\% CG IPCF)

(*) Variaciones absolutas de los CG en cada período.

Fuente: Elaboración propia en base a EPH puntual y continua. La información para el total de aglomerados urbanos data de 1985 en adelante.

En segundo término, el incremento en la gravitación de la desocupación y la ocupación no asalariada sobre los niveles de desigualdad responde a procesos macroestructurales similares. Las transformaciones estructurales operadas por el programa monetario de la última dictadura militar -cuyas principales secuelas no pudieron ser revertidas por el gobierno de la transición democrática (1983-1989)- y el estancamiento crónico del período redujeron la capacidad de absorción de mano de obra de la economía. En este contexto, la tasa de 
desocupación sufrió un incremento superior al 30\%. Ahora bien, si consideramos que el estancamiento económico que caracterizó a la década del ochenta significó una caída del PBI del orden del $1 \%$ anual -esto es, un deterioro superior al $10 \%$ en los diez años- el incremento de la desocupación -del 4,6\% al 6,1\% entre 1982 y 1988-resultó bajo en términos relativos. Esto último se debió a un ajuste tradicional del mercado de trabajo: el efecto sobre el perfil productivo local que produjo el programa económico de 1978 -la apertura comercial y la apreciación cambiaria resultante de la instrumentación del esquema de devaluaciones programadas, configuraron un cambio sustancial en los precios relativos que perjudicó a los pequeños y medianos productores industriales- determinó la traslación de muchos asalariados industriales a actividades independientes. No obstante la inserción en este tipo de actividades por parte de quienes quedaban al margen del empleo asalariado limitó el incremento de las tasas de desocupación, ${ }^{8}$ el carácter refugio de las mismas -dado por su baja productividad relativa- contribuyó a volver más heterogénea la estructura de ingresos del sector del autoempleo, acentuando su incidencia distributiva negativa.

En lo que respecta a la concentración de ingresos de los asalariados, en este ciclo volvieron a ser los trabajadores registrados quienes definieron los niveles de desigualdad. En el contexto inflacionario que sucedió a los primeros y exitosos meses de vigencia del Plan Austral -programa económico diseñado con el objetivo de limitar la inflación inercial a través del control de los principales precios de la economía, entre ellos el salario- ${ }^{9}$ y en el marco del renovado vigor que adquirieron los mecanismos indexatorios, la caída del salario real volvió a ser la norma. Sin embargo, mientras que entre 1974 y 1980 la capacidad de negociación individual de salarios parecía haber contribuido a un proceso de estratificación salarial que favorecía a los asalariados

8 Esta hipótesis es sostenida por varios autores (Giosa Zuazua, 1999; Villarreal 1985; entre otros).

9 Los ajustes salariales seguían, por esos años, atados a disposiciones gubernamentales, pues el gobierno había decidido mantener algunas de las restricciones impuestas durante el gobierno dictatorial -como la suspensión de la negociación colectiva de salarios. Si bien la Ley 23.126, de septiembre de 1984 (Boletín Oficial, $12 / 11 / 84$ ), dispuso que a partir del 3 de noviembre del año siguiente las convenciones colectivas recobrarían íntegramente sus efectos legales conforme su estado anterior a marzo de 1976, el mecanismo institucional de negociación salarial seguiría congelado por la vigencia del Decreto Ley 21.310 hasta principios de 1988, momento en el cual el ya debilitado gobierno radical derogaría la norma de facto. El mantenimiento del Decreto Ley 21.310 resultaría un instrumento fundamental a la hora de implementar el Plan Austral, principal programa de estabilización del período (Cortés y Marshall, 1991). 
con mayores calificaciones, la mayor desigualdad de los ingresos de los asalariados en la segunda mitad de los ochenta responde a otras causas: la caída de las remuneraciones horarias reales en esta etapa afectó por igual a todos los asalariados independientemente de su nivel educativo y las brechas por educación parecen haberse reducido hasta 1988. Tampoco los ingresos por posiciones precarias ni el efecto de la subocupación sobre los salarios parecen haber incidido sobre la mayor concentración que experimentaron los asalariados (Gráfico 3). En primer lugar, el incremento de la desigualdad de los ingresos de esta población pudo haber estado asociado a diferencias salariales por productividad o presentismo, pues distintos decretos permitieron recomposiciones salariales por estos conceptos: ${ }^{10}$ el efecto desigualador asociado a las posiciones asalariadas a jornada completa aporta a esta primera línea de interpretación (ver Gráfico 3). En segundo lugar, especialmente desde principios de 1988 -momento en el que se restablecen los mecanismos institucionales de negociación salarial-, las distintas capacidades de negociación de gremios y sindicatos podrían haber operado alteraciones en la estructura de ingresos de los asalariados registrados que habrían contribuido a aumentar aun más la desigualdad de ingresos en esta población.

\section{LA IRRUPCIÓN DEL DESEMPLEO EN LOS PRIMEROS AÑOS DE LA CONVERTIBILIDAD}

Una segunda oleada de reformas neoliberales, impulsada tempranamente en la década del noventa, tendría como resultado, ya en el primer lustro del decenio -tercer ciclo de desigualdad-, nuevas alteraciones en la forma de la desigualdad (Gráfico 4). Mientras que la eficacia relativa de los esfuerzos de los hogares de menores ingresos siguió mermando, el patrón de desigualdad de los ingresos personales de los miembros perceptores se transformó en forma sustancial: el reparto de los ingresos provistos por el salario, que había definido los niveles de inequidad distributiva en las dos etapas anteriores, cedería su lugar como principal factor desigualador a la desocupación.

La culminación de los dos episodios hiperinflacionarios (1989 y 1990) y la estabilización de los precios internos que siguió a la implementación de un régimen de tipo de cambio convertible (1991) detuvieron la espiral desigualadora -similar en sus efectos aunque diversa en sus causas- que había caracterizado a la dinámica de los ingresos salariales en las etapas anteriores. Prácticamente todos los sectores

10 En materia de salarios se establecieron, a partir del segundo semestre de 1986, procedimientos para permitir el aumento de remuneraciones atados a los niveles de productividad y presentismo (Decretos $1155 / 86$ y $2489 / 86$ ). 
asalariados contribuyeron a esta mejoría: de un lado, los asalariados registrados y los asalariados a jornada completa asistieron a una mejora absoluta en sus niveles de equidad distributiva (de entre 0,03 y 0,02 puntos del CG, respectivamente, entre 1990 y 1994); del otro, el efecto de los ingresos provistos por las posiciones precarias (no registradas) sobre la desigualdad salarial se recompuso considerablemente con relación a los ciclos anteriores. Esto último se debió, en lo fundamental, a que una efímera recomposición del poder de compra de los salarios -que no se prolongó más allá de 1993- fue más intensa entre los trabajadores no registrados, que habrían sufrido con más virulencia la caída del poder adquisitivo en los procesos hiperinflacionarios.

\section{Gráfico 4}

Efectos de distintas categorías sociolaborales sobre la desigualdad de ingresos personales (promedio del período)

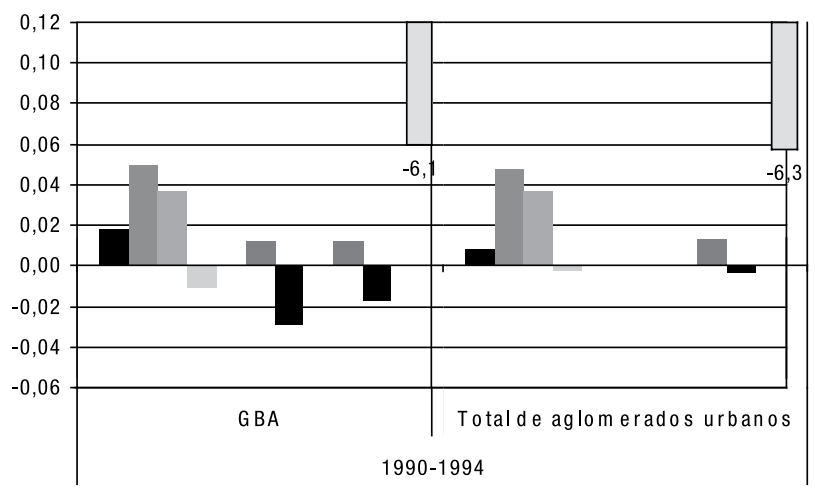

Ef. inactivos perceptores

Ef. desocupados

Ef. ocupados no as alariados

Ef. a s alariados*

Ef. asalariados no registrados

- Ef . a salariados regis trados*

- Ef. a salariados subocupados

Ef. a salariados a jornada comple ta*

DEf. estructura hogares (\% CG IPCF)

(*) Variaciones absolutas de los CG en cada período.

Fuente: Elaboración propia en base a EPH puntual y continua.

A pesar de estas mejoras en el reparto de los salarios, la desigualdad no logró recomponerse a los niveles del decenio anterior debido a uno de los fenómenos que caracterizaron a la etapa neoliberal: la explosión de las tasas de desocupación. En este sentido, los lineamientos básicos instrumentados por la administración justicialista (1989-1999) que sucedió al gobierno de la transición democrática -entre los que se cuentan la reforma del Estado (privatizaciones, restricción del gasto, descentralización de funciones), la desregulación de la economía y la apertura al comercio y a los capitales extranjeros- configuraron un 
escenario particular en el cual la demanda de fuerza de trabajo se vio afectada en múltiples dimensiones.

En primer lugar, en lo que a la estructura del empleo se refiere, a lo largo de esos años la participación del empleo industrial siguió disminuyendo en forma constante, como consecuencia de una retracción absoluta en los puestos de trabajo del sector -que entre 1991 y 2000 había sido del orden del 30\% (Lindemboim, 2003: 79; Schorr, 2002: 27). La apertura económica y el tipo de cambio apreciado hicieron sentir sus efectos combinados en la estructura productiva argentina: de un lado, llevaron al cierre de pequeñas y medianas firmas que no lograron sobrevivir a la competencia internacional; del otro, contribuyeron, a redefinir las estrategias de valorización de las empresas de mayores dimensiones, generando una mayor especialización productiva -principalmente en sectores capital intensivos- y cierta desverticalización de sus estructuras internas (Giosa Zuazua, 1999: 196). Ambos factores contribuyeron a la transformación de empleo formal, o bien directamente en desempleo, o bien en empleo informal. El primer caso es el relativo al impacto del cierre de empresas industriales de menores dimensiones, de la especialización en sectores de capital intensivos -con ventajas comparativas naturales o institucionales (sector automotriz) - y del incremento de los insumos importados en el mix de producción. ${ }^{11}$ El segundo es el referido a la subcontratación de servicios que antes eran provistos al interior de la firma. ${ }^{12}$ Es evidente que tales estrategias de valorización de las empresas industriales tendieron a profundizar el distanciamiento entre crecimiento y nivel de empleo.

Ahora bien, no obstante la ocupación en el sector servicios parece haberse incrementado por esos años -tanto en términos absolutos como relativos-, tal teciarización del empleo esconde otro fenómeno registrado durante los noventa, que contribuyó también al deterioro de la capacidad de absorción de fuerza de trabajo. El incremento en la productividad no solo se verificó en la industria manufacturera-que directamente expulsó mano de obra- sino también en buena parte del sector servicios. En este punto, es destacable el aumento de la relación

11 Según Azpiazu (2000: 11), "en buena parte de las empresas industriales líderes el componente de producción propia de las ventas perdió peso relativo frente a la comercialización de bienes importados complementarios de los que producen o, incluso, sustitutivos de algunas líneas de producción discontinuadas".

12 Con relación a este último punto, según Giosa Zuazua (1999) durante los noventa irrumpe como novedad un sector informal urbano productivo (SIUP), es decir, que forma parte de la lógica de acumulación de las empresas, el cual estaría fundamentalmente dedicado a proveer este tipo de servicios a las empresas de mayores dimensiones. 
producto-empleo en la mayoría de los sectores y ramas de la economía. Según Beccaria (2003: 92), tales mejoras responden a dos fenómenos paralelos: de un lado, en un contexto de atraso tecnológico -como el que signaba a la estructura productiva local a principios de la décadala apertura económica y el tipo de cambio sobrevaluado promovieron la incorporación de capital en vastos sectores de la economía, ${ }^{13}$ del otro, la transferencia de empresas estatales a manos privadas revirtió la baja eficiencia que las caracterizaba durante los años ochenta, ampliándose en este proceso la relación producto-empleo de los sectores en los que las mismas participan.

La resultante de estos procesos, el desempleo magnificado incluso en una etapa caracterizada por la recuperación de la actividad económica (el PBI se expandió a razón de un 7,3\% anual entre 1990 y 1994 y no obstante ello el desempleo duplicó su tasa), signó la historia del reparto de los ingresos en este ciclo de forma categórica: el impacto de la desocupación sobre la desigualdad neutralizó la mejora distributiva experimentada por los ocupados asalariados y sería una carga difícil de revertir en las etapas siguientes.

\section{DESEMPLEO Y SEGMENTACIÓN LABORAL EN EL ORIGEN DE UNA SOCIEDAD DUAL}

En el segundo quinquenio de la década del noventa -cuarto ciclo- una nueva reducción del efecto igualador de los esfuerzos de los hogares de menores recursos (Gráfico 5) y una mayor gravitación (directa e indirecta) de la desocupación caracterizarán al patrón de desigualdad de la Argentina. Las modificaciones en las estructuras familiares de los hogares más pobres (que siguieron arrojando mayores cantidades de trabajadores adicionales al mercado laboral) chocaron con fuertes restricciones del lado de la demanda de fuerza de trabajo: consecuentemente el efecto igualador derivado de la estructura de los hogares se redujo en un 15\% (pasando del $-6,1 \%$ al $-5,4 \%$ del CG de IPCF). Por su parte, no obstante el desempleo volvió a ocupar un lugar privilegiado en la explicación de los niveles de inequidad, su incidencia también parecería haberse hecho sentir en el reparto de otras categorías de perceptores: de un lado, los altos niveles de desocupación habrían afectado el poder de negociación de los asalariados impulsando el empeoramiento en la dispersión de sus remuneraciones; en segundo lugar, la baja absorción de mano de obra habría llevado a muchos activos a aceptar condiciones de empleo de baja calidad y

13 Cabe destacar que los incrementos en la productividad del sector industrial se encuentran menos asociados a este fenómeno que a la destrucción de puestos de trabajo (Schorr, 2002). 
magros ingresos, contribuyendo así al mayor efecto negativo asociado a la precariedad y al subempleo (Gráfico 5).

El balance de esos años permite dar cuenta de las alteraciones observadas en la forma de la desigualdad. A partir de 1998, y luego de la recuperación de los niveles de empleo que siguió a la crisis de mediados de la década (efecto tequila), un cambio en la coyuntura internacional volvió a operar como detonante de una nueva reversión del ciclo económico, que se extendería por cuatro años. Esta prolongada recesión afectó profundamente los niveles de absorción de mano de obra dado el carácter altamente pro-cíclico que las tasas de empleo habían cobrado desde principios de la década: tanto la flexibilización laboral -cristalizada en la Ley de Empleo de 1991 y en las ulteriores reformas a la Ley de Contrato de Trabajo- como la exacerbación de la proporción de asalariados que operan por fuera de los marcos regulatorios vigentes están en el origen de la mayor capacidad -de jure y de facto, respectivamente- que habrían tenido las empresas para ajustar sus requerimientos de fuerza de trabajo a los avatares de la demanda interna. El aumento de la desocupación, que alcanzaría en octubre de 2001 al 18,3\% de la PEA urbana (datos para el conjunto de aglomerados), hizo que el impacto desigualador de esta categoría sociolaboral alcanzara sus niveles más altos en la totalidad del período considerado: el efecto del desempleo sobre los niveles de desigualdad superaría los 0,08 puntos del CG en promedio entre 1996 y 2001.

\section{Gráfico 5}

Efectos de distintas categorías sociolaborales sobre la desigualdad de ingresos personales (promedio del período)

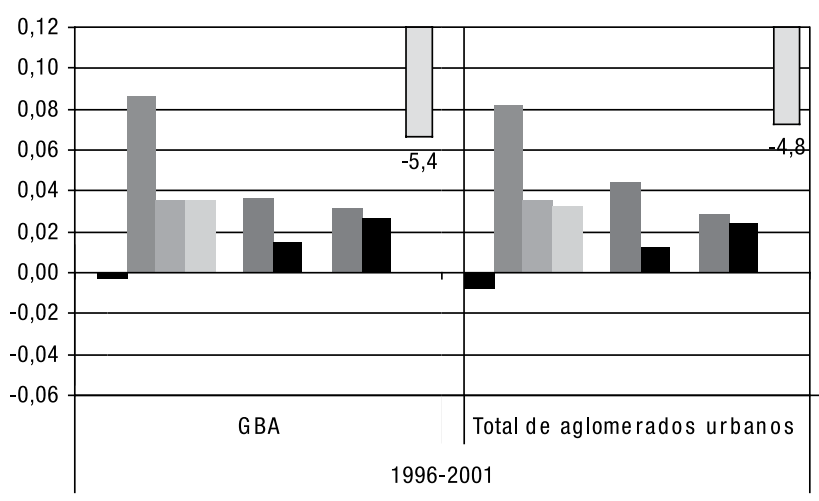

Ef. inactivos perceptores f. desocupados ocupados no as alariados f. as alariados*

Ef. as alariados no registrados - Ef. as alariados registrados*

Ef. as alariados subocupados Ef. as alariados a jornada completa* $\square$ Ef. es tructura hogares ( $\%$ CG IPCF) 
A esta elevada incidencia directa del desempleo sobre el deterioro distributivo debemos agregar la mayor dispersión salarial (Gráfico 5), que -recordemos- en la etapa precedente había mejorado en términos absolutos. La mayor concentración de los ingresos provistos por el salario se intensificó, particularmente, desde el inicio de la fase recesiva de 1998 y el reparto de las remuneraciones horarias parecería haber estado en el origen de esta intensificación. Dado que por esos años la media de los ingresos horarios de los asalariados con mayor nivel educativo (universitario completo e incompleto) se distanció de la de aquellos con menores calificaciones, una primera interpretación (cf. Altimir y Beccaria, 2001) podría llevarnos a asociar este deterioro en el reparto de los asalariados con un renovado proceso de estratificación salarial por devaluación educativa, similar al registrado durante el primer ciclo de desigualdad. Sin embargo, al observar la evolución de la desigualdad de ingresos para distintas categorías de asalariados, esta primera lectura pierde asidero. Por un lado, entre mayo de 1998 y mayo de 2001, el reparto de los ingresos individuales de los asalariados "en blanco" -así como el de sus remuneraciones horarias- no experimenta cambios significativos: de hecho, incluso al evaluar la totalidad del ciclo (1996-2001) la desigualdad de esta población solo da cuenta un incremento de 0,01 puntos del CG (Gráfico 5). Por el contrario, es la incidencia de los asalariados precarios -tanto en la distribución de los ingresos totales como en la correspondiente a las remuneraciones horarias- la que da cuenta de la mayor concentración de los salarios: entre los años 1996 y 2001 el efecto de esta categoría sociolaboral sobre la desigualdad de ingresos personales escaló hasta alcanzar los 0,04 puntos del CG (los valores para GBA y para el conjunto de los aglomerados urbanos son similares). Por su parte, al comparar el aporte a la inequidad realizado por ocupados plenos y subocupados (Gráfico 5) se observa una mayor incidencia relativa de estos últimos. Los altos niveles de desocupación parecen haber contribuido a deteriorar las condiciones de empleo de los asalariados, potenciando tanto los niveles de precariedad como las jornadas laborales reducidas. Así, la hipótesis de la estratificación educativa pierde potencial explicativo ante otra que irrumpe de los datos: la conjunción de los fenómenos señalados -aumento del efecto distributivo de asalariados "en negro" y subocupados y de la disparidad salarial por niveles educativos-son indicadores de un proceso de segmentación laboral incipiente, por el cual los empleos de baja calidad se destinan a aquel sector de la oferta laboral que cuenta con menores calificaciones.

\section{DEVALUACIÓN, INTERVENCIÓN ESTATAL Y DESIGUALDAD EN EL NUEVO ESCENARIO}

En el escenario abierto luego de la devaluación que dio fin a la convertibilidad monetaria -en enero de 2002- la evolución del reparto de 
los ingresos personales ha cambiado de signo: entre octubre de 2002 y el segundo semestre de 2005 los niveles de desigualdad de IPCF han tendido a recomponerse (la mejora del CG entre esos años ha superado el 6,3\% en el GBA y el 5,8\% en el conjunto de aglomerados). Sin embargo, la forma que ha asumido el patrón de desigualdad en el último ciclo parece haber consolidado el carácter dual que el mercado laboral comenzaba a manifestar ya en los últimos años de la década del noventa.

Cabe resaltar que el efecto distributivo de corto plazo de la devaluación no fue para nada positivo. De hecho, dio lugar a la crisis distributiva (mayo de 2002) que culminó el cuarto ciclo de desigualdad. En primer lugar, la devaluación se tradujo -como otrora- en un incremento generalizado de los precios internos que redujo el poder de compra de los salarios y profundizó aun más la recesión que experimentaba la economía desde el año 1998. En estas circunstancias los niveles de subutilización de fuerza de trabajo ascendieron al 40,1\% de la PEA en el conjunto de aglomerados urbanos: a pesar de las restricciones formales impuestas en enero al despido de trabajadores -la Ley de Emergencia Pública y de Reforma del Régimen Cambiario de enero de ese año estableció, además de un nuevo régimen cambiario, un sistema transitorio de doble indemnización para los despidos sin causa justificada- la tasa de desocupación alcanzó en mayo niveles sin precedentes en la historia moderna $(21,5)$ y otro tanto ocurrió con la de subocupación $(18,6)$. En segundo lugar, la modificación en los precios relativos que operó la devaluación implicó una transferencia de ingresos que favoreció fuertemente a los sectores productores de bienes transables y que intentó ser acotada (a los tres meses de efectuada la modificación cambiaria) con retenciones a las exportaciones tradicionales (bienes salario). Finalmente, si bien la devaluación mejoró las cuentas externas, tal mejoría no encontró sus fundamentos, por lo menos en el corto plazo, en algún aumento de las exportaciones no tradicionales sino en una pronunciada reducción de las importaciones por efecto de la intensificación del contexto recesivo (el efectoingreso de la devaluación es el que siguió rigiendo). ${ }^{14}$ En el mediano plazo, en cambio, el incentivo para la sustitución de importaciones -debido a la alteración en el esquema de precios y rentabilidades relativas operada por la devaluación- daría nuevos impulsos a la producción industrial doméstica y la economía volvería a crecer. El final de la prolongada recesión, que había significado una caída del PBI del 5\% anual promedio para los años 1999-2002, se evidenció a partir de

14 Sobre el efecto-ingreso de las devaluaciones en la Argentina ver Diamand (1973). 
2003, y desde entonces hasta 2005 la economía crecería a una razón del $9 \%$ cada año.

Ahora bien, al evaluar tanto la temprana reversión de las tendencias del reparto de los ingresos como la nueva forma del patrón distributivo no es posible hacer caso omiso de otras modalidades de intervención gubernamental con las cuales parece abandonarse el quietismo estatal de los años noventa. Como primer punto, cabe considerar que el gobierno provisional de E. Duhalde (2002-2003) puso en vigencia -desde abril de 2002- un programa social de amplio alcance -con cerca de dos millones de beneficiarios en los primeros meses de su implementación- con el objetivo de garantizar un ingreso mínimo a los jefes y jefas de hogar desocupados con hijos a cargo. Básicamente, el efecto del aún hoy vigente Plan Jefes y Jefas de Hogar (PJJH) incluyó: a) una reducción de los niveles de desempleo, dado que aquellos beneficiarios que realizan contraprestaciones laborales son considerados ocupados por el sistema estadístico de encuestas a hogares; b) un incremento de las tasas de subocupación, debido a que tales contraprestaciones no pueden exceder la 4 horas diarias en su duración; c) un aumento de los niveles de precariedad, pues los destinatarios que realizan la contraprestación laboral no tienen acceso a los beneficios sociales por no participar de una relación salarial convencional; d) un ingreso de 150 pesos -un subsidio que se encuentra muy por debajo de la línea de indigencia- a muchos de los hogares más castigados por la crisis.

Del impacto del PJJH depende, exclusivamente, la mejora en la concentración del IPCF inmediatamente posterior a la crisis: al calcular el CG de octubre de 2002 descontando de los ingresos de los hogares aquellos correspondientes a la asignación del plan, en lugar de registrarse una mejora en la concentración de los ingresos medios de los hogares del 3,3\% -el ejemplo refiere al GBA-, asistiríamos a un deterioro del CG del 0,2\%, que volvería a alcanzar el nivel récord de 0,562 puntos. ${ }^{15}$ Sin embargo, el plan mismo explicaría también una mayor concentración de los ingresos entre los asalariados: entre mayo y octubre de 2002 la desigualdad salarial aumentó entre un 6,5\% y un $4,7 \%$, en el GBA y en el total urbano, respectivamente. La acentuación de la desigualdad en esta población obedecería tanto al impacto de la magra asignación que perciben los beneficiarios del plan, que se encuentra muy por debajo de la media salarial de esos años -superior a los 600 pesos mensuales-, como al hecho de que la contraprestación

15 El ejercicio contrafáctico es presentado solo con fines ilustrativos, pues, de no contar con la asignación provista por el PJJH posiblemente muchos hogares habrían contado con ingresos provenientes de otras fuentes. 
laboral que algunos de ellos realizan lleva a contabilizarlos entre los asalariados -precarios y subocupados- (Calvi y Benza, 2005).

Como segundo punto, con el objeto de compensar en alguna medida el incremento generalizado de los precios, la intervención estatal sobre los niveles de ingreso de los asalariados cobraron un renovado impulso: una política salarial expansiva -pero que, al igual que la doble indemnización, solo impactaría sobre el trabajo registrado- buscó contener el retraso salarial. En este sentido, a la restitución de los haberes de los empleados públicos y los pasivos -recortados durante la gestión De la Rúa (1999-2001)-, sucesivos decretos sumaron, de un lado, incrementos no remunerativos a los asalariados del sector privado y, del otro, aumentos en los niveles del salario mínimo vital y móvil (SMVM): mientras que la política de ingresos de la gestión Duhalde estuvo concentrada en el primero de estos mecanismos de compensación salarial, los incrementos en el salario mínimo vital y móvil comienzan a efectivizarse desde mediados de 2003, caracterizando a la política salarial del nuevo gobierno electo (entre julio de 2003 julio de 2005 el SMVM pasó de $\$ 250$ a $\$ 630) .{ }^{16}$

En materia distributiva, si bien tales modalidades de intervención estatal -las políticas de ingreso- generaron una mejoría en la dispersión de los ingresos de los asalariados "en blanco" -y de los trabajadores retirados- el impacto de esta situación sobre el reparto de los ingresos familiares tendió a ser sensiblemente atenuado por el aumento del efecto de la precariedad. La brecha entre los ingresos de las posiciones asalariadas registradas y las no registradas se exacerbó, producto tanto de la mayor recomposición de los haberes de los primeros como de los altos niveles de precariedad heredados de la etapa anterior (el $45 \%$ del total de los asalariados no tenía descuentos jubilatorios en el segundo semestre de 2005).

La imagen global del patrón de desigualdad durante los primeros años del nuevo milenio refleja claramente las tendencias arriba señaladas (Gráfico 6). Como primera observación, cabe destacar que las estrategias de supervivencia de los hogares de menores ingresos

16 En lo que refiere a la restitución del 13\% de las jubilaciones y los haberes del sector públicos el Decreto 1819 de septiembre de 2002 (Boletín Oficial del 13/09/2002) y la decisión administrativa 8 de enero de 2003 (Boletín Oficial del 30/01/2003) significaron también un pago retroactivo de los montos adeudados por la administración nacional abonado en efectivo (caso de las jubilaciones) o en bonos (caso de los empleados del sector público). En este último caso, buena parte de los empleados públicos habría optado por deshacerse de esos bonos en el mercado financiero durante el año 2003. Con relación a los incrementos salariales cf. Decretos 1273/02, 905/03, referidos a los incrementos no remunerativos, y Decreto 388/03, relativo al incremento del SMVM (Marticorena, 2005). 
poco contribuyeron a la mejora distributiva registrada en esos años: el hecho de que la desocupación se haya reducido con mayor velocidad entre los hogares de mayores ingresos da cuenta de este fenómeno. En este sentido, no obstante los hogares más pobres continuaron incrementando la participación de sus miembros en el mercado de trabajo, las bajas probabilidades de encontrar un empleo neutralizaron este mayor esfuerzo. En segundo lugar, fueron tres las categorías de perceptores que han contribuido a mantener la desigualdad en niveles elevados (0,530 puntos del CG en promedio en el GBA y 0,521 en el conjunto de aglomerados). Si bien la tasa de desocupación se ha reducido progresivamente a lo largo de esos años, el efecto de la falta de trabajo sobre la inequidad ha sido elevado en promedio (cercano a los 0,08 puntos del CG tanto en GBA como en el total urbano). Asimismo, y no obstante el conjunto de los asalariados experimentó una mejora distributiva absoluta (cercana a los 0,03 puntos del CG en GBA y a los 0,02 puntos en el total urbano a lo largo del período), las condiciones de empleo de un segmento de este sector y los niveles de ingreso a estas condiciones atados evitaron que tal mejora fuera más intensa: el efecto de la precariedad superó, en promedio, los 0,08 puntos del CG (tanto en GBA como en el conjunto de aglomerados) y otro tanto ocurrió con el correspondiente a las posiciones a jornada parcial (cuya incidencia regresiva alcanzó los 0,6 puntos del indicador).

\section{Gráfico 6}

Efectos de distintas categorías sociolaborales sobre la desigualdad de ingresos personales (promedio del período)

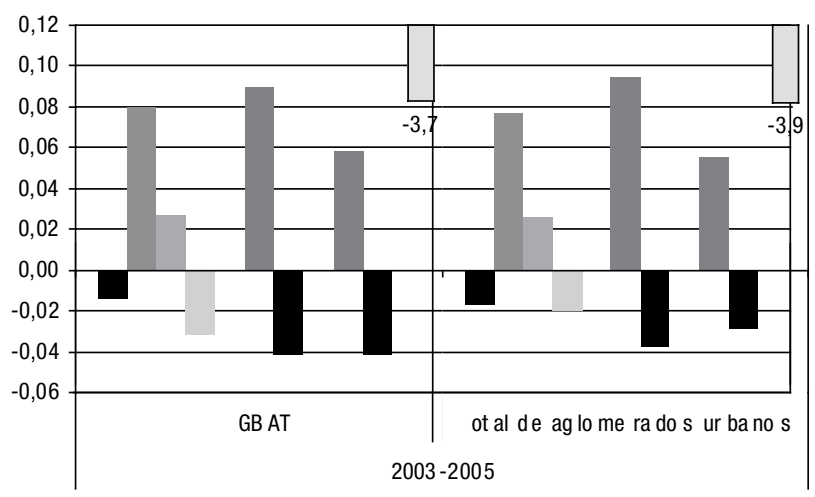

Ef. inac tivo s perceptores
Ef. de so cu pados

Ef. Oc up ad os no as alariados

Ef. as alariados ${ }^{\star}$

Ef. as alariados no registrad os

- Ef. as alariados re gistrado ${ }^{*}$

- Ef. as alariados subo cu pados

- Ef. as alariados a jorn ada completa*

$\square$ Ef. es tructura hogares (\% CG IPCF)

(*) Variaciones absolutas de los CG en cada período.

Fuente: Elaboración propia en base a EPH puntual y continua. 
En resumen, el balance distributivo de los primeros años del modelo post-convertibilidad no es para nada unívoco. De un lado, se ha experimentado entre 2003 y 2005 una significativa recuperación de los niveles de equidad de IPCF. La reactivación del aparato productivo y la mejora en la dinámica del mercado de trabajo, sumadas a una novedosa -en comparación con la década del noventa-combinación de políticas de ingreso y contención social por parte del gobierno, han contribuido a ello. Sin embargo, es posible también encontrar límites a este virtuosismo de los primeros años de vida de la opción del dólar alto: el efecto del desempleo sigue siendo elevado y los correspondientes a la baja calidad del empleo - precariedad y subocupación- se han exacerbado. Más aun, eventuales disminuciones en el impacto de la desocupación parecen estar acompañadas por incrementos en el efecto distributivo negativo de los empleos de baja calidad: la fuerte segmentación del mercado de trabajo parece poner límites estrictos a la recomposición de los niveles de equidad de ingresos.

\section{LAS CRISIS DISTRIBUTIVAS}

De lo expuesto en los apartados anteriores queda claro, en primer lugar, que la evolución de la desigualdad de ingresos personales no depende inmediatamente, salvo contadas excepciones (como en el caso de las políticas de ingreso o de transferencia de ingresos), de las opciones de política impulsadas por las distintas administraciones. Por el contrario, en la generalidad de los casos son los cambios en el modo de funcionamiento de la economía los que, al incidir sobre las principales variables socioeconómicas, alteran el patrón distributivo en el mediano y largo plazo. En este sentido, las opciones de política en general -cambiaria, comercial, monetaria, laboral, etc.- solo afectan a la distribución del ingreso cuando, al modificar el esquema de incentivos de los actores más relevantes, contribuyen a alterar el desempeño de la economía doméstica afectando, eventualmente, las tendencias de los principales indicadores sociales; fundamentalmente los relativos al mercado de trabajo (dimensión macrosocial) y a las estrategias de subsistencia de los hogares de menores recursos (dimensión microsocial). En segundo lugar, las crisis distributivas ocupan un lugar destacado en la dinámica cíclica de la inequidad de ingresos: abren y cierran etapas con patrones de desigualdad disímiles. Como consecuencia, la forma de la desigualdad que predomina en cada una de estas crisis tiene características propias: las crisis distributivas constituyen, en cada caso, la exacerbación de las distintas tendencias que operan sobre el deterioro del reparto de ingresos en cada etapa.

En la Argentina, el aumento de la desigualdad de ingresos personales en tales coyunturas críticas parece deberse a dos causas 
principales: de un lado, a un desigual reparto de la capacidad para recomponer las remuneraciones reales en contextos inflacionarios, si la crisis estuvo acompañada por una modificación de la pauta cambiaria; ${ }^{17}$ del otro, y en momentos en los que existen desequilibrios explícitos en el mercado de trabajo, a deterioros en los niveles empleo -desocupación- o en su calidad -empleos refugio, precariedad o subocupación. La acción de estos dos mecanismos desigualadores no parece haber afectado igualmente a las crisis distributivas de los últimos treinta años.

En la primera de estas crisis (1981) el deterioro del reparto de los ingresos estuvo gobernado por una mayor concentración en los ingresos de los asalariados registrados. En este sentido, si bien la devaluación de ese año desencadenó una reversión del ciclo económico, el relativo equilibrio que caracterizaba al mercado de trabajo en esta etapa hizo que fuera solo el primero de los mecanismos desigualadores el que primó entonces: la diferencial de capacidad para recomponer las remuneraciones reales en contextos inflacionarios y de clausura sindical favoreció ese año, como vimos, a los trabajadores registrados con mayores niveles educativos, intensificando el proceso de estratificación salarial observado durante el segundo quinquenio de los setenta. Con posterioridad a la crisis, una política que apuntaba sencillamente a recomponer los salarios permitió una pronta mejora de los niveles de inequidad durante el año siguiente. ${ }^{18}$

Hacia 1989 la fuerte depreciación de la moneda local, desatada por la renuncia del gobierno de la transición democrática a intervenir en el mercado cambiario, intensificó la fase recesiva registrada desde el año anterior y desencadenó un proceso hiperinflacionario que condujo a un intenso deterioro distributivo. El pico distributivo de ese año se explica por un fuerte incremento en la concentración de ingresos de los ocupados. La particularidad de la crisis hiperinflacionaria residió en la contribución fundamental de asalariados y no asalariados en el deterioro distributivo. A diferencia de lo observado en la crisis

17 Si en un país como la Argentina las alteraciones en el tipo de cambio desencadenan recurrentemente crisis distributivas esto se debe a las particularidades del desequilibrio de la estructura productiva local (Diamand, 1973). Las devaluacionesdepreciaciones, de no estar mediadas por otras herramientas de política económica, inducen a un incremento generalizado en los precios de los bienes transables: de los exportables -en su mayoría bienes salario- en proporción a la devaluación; de los destinados solo al mercado interno en proporción a su componente importado (Braun, 1975). Tal inflación cambiaria deteriora los ingresos reales de la población y abre -o profundiza- procesos recesivos.

18 Esta política salarial expansiva sería denunciada durante la campaña del candidato presidencial de la UCR como expresión de un "pacto militar-sindical". 
de 1981, los ocupados no asalariados -autoempleos- contribuyeron a incrementar el deterioro global: la estructura de ingresos de este sector de los ocupados parece, pues, haberse vuelto más heterogénea a lo largo de la década del ochenta (la mayor incidencia de las actividades refugio, resultante de una economía que había visto deteriorada su capacidad de absorción de mano de obra, está en el origen de este fenómeno). Asimismo, y no obstante las tendencias de corto plazo que explican el pico distributivo, en la comparación con la crisis anterior se observa también un leve incremento relativo del efecto de los desocupados sobre el nivel del coeficiente. Si bien la crisis no incrementó sustancialmente los niveles de desocupación de los años anteriores, la escasa elasticidad producto-empleo que se registró a lo largo de la década fomentó la incidencia de esta población sobre el nivel global de la desigualdad. De resultas, tanto la diferencial capacidad para recomponer ingresos en contextos inflacionarios como los mayores desequilibrios del mercado de trabajo, contribuyeron conjuntamente al pico distributivo. La rápida recuperación de la distribución del ingreso posterior a 1989 se encuentra estrechamente vinculada, pues, tanto a la relativa estabilidad de precios en la que se encontraba la economía argentina hacia fines del noventa, luego de finalizados los dos episodios hiperinflacionarios, como a la recomposición de los niveles de actividad económica.

La crisis distributiva de 1995 no fue acompañada por modificación alguna en la pauta cambiaria -la Ley de Convertibilidad estaba en plena vigencia-, de modo que no encuentra su origen en diferenciales capacidades para ajustar precios o ingresos en contextos inflacionarios. El factor que explica el pico registrado hacia ese año es el impacto de la recesión en un mercado de trabajo deteriorado: la tasa de desempleo se elevó a niveles sin precedentes. En primer lugar, y como resulta autoevidente, la destrucción neta de puestos de trabajo significó un aumento de la cantidad de personas con ingresos cercanos a cero: el efecto de los desocupados sobre los niveles de desigualdad resulta notable cuando se compara su incidencia relativa en las crisis anteriores. En segundo lugar, el alto desempleo contribuyó también a la mayor desigualdad de ingresos al presionar sobre las remuneraciones de los asalariados. Ahora bien, el hecho de que la mayor concentración no se haya generado en un contexto inflacionario -y por tanto, por efecto de la desigual capacidad de recomposición de ingresos- explica la ausencia de una mejora en los niveles de dispersión posteriores a la crisis. La persistencia, con posterioridad a la crisis, de los altos niveles de desocupación y el acentuamiento del deterioro de en la calidad del empleo está en el origen del estancamiento de la elevada concentración de los ingresos en los años siguientes. 
Finalmente, el salto de la desigualdad registrado hacia mayo de 2002 se produce en un contexto de fuerte devaluación del tipo de cambio, al igual que en las crisis de 1981 y 1989. Sin embargo, el mecanismo causal del deterioro distributivo es diferente. De un lado, la devaluación tuvo lugar luego de una prolongada fase recesiva, cosa restringió la demanda interna evitando que la escalada de precios fuera más pronunciada. Del otro, la alteración de la pauta cambiaria estuvo acompañada (si bien tardíamente) por retenciones a las exportaciones de productos tradicionales -bienes salario- lo cual contribuyó a atenuar el incremento generalizado de los precios. Así, en un contexto de baja inflación (en términos comparativos) y de intensa recesión, fue el desempleo, que se incrementó sustancialmente, el que arrastró el deterioro distributivo. La veloz aunque tenue recuperación de los niveles de desigualdad hacia octubre de 2002 se vincula, como quedó demostrado en el apartado anterior, a la implementación de un plan asistencial-compensatorio con el que el gobierno intentó atenuar el descontento social en la crítica situación económica. Finalmente, en comparación con otras crisis distributivas no solo se destaca el peso de los desocupados en la desigualdad de ingresos, sino también el notable crecimiento del efecto distributivo de las posiciones asalariadas precarias resultante de la evolución precedente del patrón de desigualdad.

\section{Principales Características de La desigualdad Regional en LA Argentina}

La diversidad regional que caracteriza a un país como la Argentina nos lleva a preguntarnos en qué medida las tendencias observadas -en el GBA y en el conjunto de los aglomerados urbanos- en materia de desigualdad de ingresos se han manifestado en las distintas latitudes del territorio nacional. En los próximos apartados se realiza un intento -si bien exploratorio- para evaluar las principales alteraciones distributivas tanto a nivel regional como aglomeral, ${ }^{19}$ teniendo en cuenta las distintas etapas (ciclos) en que hemos descompuesto la evolución secular de la concentración de los ingresos personales. Cabe recordar que la disponibilidad de información estadística solo nos permite realizar este tipo de ejercicios desde el año 1985.

19 Dado que las estrategias familiares en ningún momento logran revertir (modificar el signo de) las principales tendencias observadas en el reparto de los ingresos de los miembros perceptores, hemos decidido a los fines de simplificar la exposición ulterior obviar el efecto de la estructura de los hogares sobre la evolución general de la desigualdad, centrando nuestra explicación de tal evolución en los determinantes que refieren al impacto de los distintos agrupamientos categoriales (dimensión macrosocial). 


\section{EVOLUCIÓN REGIONAL DE LA DESIGUALDAD DE INGRESOS personales en la Argentina}

Un elemento que surge al comparar los niveles de desigualdad regional es cierta persistencia en la heterogeneidad entre las distintas zonas del país. De la información suministrada por el Cuadro 2 se desprende que, descontado al GBA -región ya analizada y que en términos comparativos asciende al primer lugar en materia de desigualdad en los albores del nuevo milenio-, en cada una de las etapas que hemos dado en llamar ciclos distributivos, dos de las cinco regiones restantes encabezan recurrentemente el ranking de inequidad: los más altos promedios de concentración del IPCF se registran en las regiones del norte argentino (NEA y NOA). Una lectura de los CG de IPCF para los distintos aglomerados urbanos de cada región verifica la intensidad de las desigualdades entre regiones arriba señalada. En cada una de las etapas los más altos niveles de desigualdad se registran en las localidades norteñas: solo el GBA y la localidad de Concordia, entre los años 1996-2001 y 2002-2005, superan levemente los promedios de desigualdad característicos del territorio septentrional de la Argentina (Cuadro 3). Sin embargo, y a pesar del mantenimiento de tal patrón regional, a lo largo de las últimas dos décadas la evolución de la desigualdad de IPCF en las distintas regiones no ha sido unívoca. En primer lugar, no solo el GBA fue la más afectada en sus niveles de equidad (en un 23\% entre 1985 y 2005), sino que a esta región no le siguió precisamente alguna de las del norte argentino sino, por el contrario, la región Pampeana (19,3\% de deterioro). De las restantes, en las dos décadas aludidas solo una vio deteriorado el reparto de sus ingresos en más de un dígito (el NOA, con un 12,1 $\%)$ mientras que las demás experimentaron incrementos en la desigualdad más moderados.

Asimismo, al analizar la evolución de los indicadores promedio para cada una de las sucesivas etapas otras novedades resaltan. De un lado, el malogro distributivo entre la década del ochenta y los primeros años de la del noventa, segundo en su intensidad relativa-debido esto a la notable recomposición en los niveles de equidad experimentada con posterioridad a los episodios hiperinflacionarios- y del orden del 5,5\% para el conjunto de los aglomerados urbanos, no fue la norma en todas las regiones: aquellas del norte argentino lograron mantenerse en los niveles promedio de desigualdad del quinquenio anterior, mientras que las restantes experimentaron un aumento de los CG de IPCF de entre el 5,4 (GBA) y el 2,1\% (Patagonia). Por su parte, el incremento de la desigualdad promedio entre el primero y el segundo quinquenio de los noventa, el más elevado $(9,4 \%)$ en térmi- 
nos comparativos -circunstancia que no es ajena ni a la ausencia de una etapa de mejoramiento distributivo post crisis ni al impacto de la prolongada recesión que se inicia en 1998-, fue notable en todas las latitudes: no obstante el GBA, el NEA, Cuyo y la Región Pampeana fueron las principales afectadas entre ambas etapas (experimentando un aumento de entre un $10,1 \%$ y un $8,6 \%$ en la concentración del IPCF), las regiones de NOA y Patagonia, menos expuestas al deterioro intercíclico, también fueron seriamente perjudicadas (en un $6,4 \%$ y $4,6 \%$, respectivamente). Finalmente, en la comparación entre los promedios de las últimas dos etapas (segundos noventa y postconvertibilidad) el resultado global, de un 3,7\% de deterioro de la equidad de IPCF, esconde en su seno el comportamiento más diverso observado: mientras que algunas regiones continúan manifestando empeoramientos más o menos pronunciados (GBA, Pampeana, NOA y Patagonia) otras conservan o bien mejoran sus niveles de equidad (Cuyo y NEA, respectivamente).

\section{Cuadro 2}

Media de CG de IPCF para distintas etapas y variaciones porcentuales

Regiones estadísticas, 1985-2005

\begin{tabular}{|c|c|c|c|c|c|c|c|}
\hline Etapa/Onda & GBA & CUY & NEA & NOA & PAM & PAT & Total Aglomerados \\
\hline 1985-1988 (2) & 0,43 & 0,42 & 0,47 & 0,46 & 0,40 & 0,44 & 0,43 \\
\hline 0ct-89 & 0,52 & 0,47 & 0,48 & 0,49 & 0,44 & 0,47 & 0,50 \\
\hline 1990-1994 (3) & 0,46 & 0,43 & 0,47 & 0,46 & 0,42 & 0,45 & 0,46 \\
\hline 0ct-95 & 0,49 & 0,44 & 0,48 & 0,48 & 0,43 & 0,48 & 0,49 \\
\hline 1996-2001 (4) & 0,50 & 0,47 & 0,51 & 0,49 & 0,46 & 0,47 & 0,49 \\
\hline May-02 & 0,56 & 0,51 & 0,55 & 0,52 & 0,51 & 0,52 & 0,55 \\
\hline $2002-2005(5)$ & 0,53 & 0,47 & 0,50 & 0,50 & 0,48 & 0,48 & 0,53 \\
\hline \multicolumn{8}{|c|}{ Variaciones porcentuales } \\
\hline & GBA & CUY & NEA & NOA & PAM & PAT & Total Aglomerados \\
\hline (3)-(2) & 5,4 & 3,0 & 0,0 & $-0,8$ & 4,6 & 2,1 & 5,5 \\
\hline (4)-(3) & 10,1 & 9,7 & 9,9 & 6,4 & 8,6 & 4,6 & 9,4 \\
\hline$(5)-(4)$ & 5,2 & 0,4 & $-2,6$ & 3,0 & 4,8 & 2,1 & 3,7 \\
\hline (0ct-89)-(2) & 20,9 & 11,9 & 2,1 & 6,5 & 10,0 & 6,8 & 16,3 \\
\hline$(0 c t-95)-(3)$ & 6,5 & 2,3 & 2,1 & 4,3 & 2,4 & 6,7 & 6,5 \\
\hline (May-02)-(4) & 12,0 & 8,5 & 7,8 & 6,1 & 10,9 & 10,6 & 12,2 \\
\hline $1985-2005$ & 23,0 & 4,1 & 7,4 & 12,1 & 19,3 & 6,5 & 21,2 \\
\hline
\end{tabular}

Fuente: Elaboración propia en base a EPH. 
La evolución, para los distintos aglomerados urbanos, de la desigualdad de ingresos medios familiares entre las distintas etapas, precisa también lo observado entre las regiones: a) el deterioro distributivo generalizado entre las primeras dos etapas y entre las dos últimas tuvo algunas excepciones, tales como San Juan, Salta, Formosa, Jujuy y La Rioja, en el primer caso, y San Luis, Formosa, Jujuy, Resistencia, La Rioja, Paraná y Posadas, en el segundo; b) entre el primer y segundo quinquenio de los noventa el aumento de la concentración del IPCF fue la norma (Cuadro 3).

Un último aspecto referido a los niveles de concentración del IPCF es el que refiere al impacto en cada una de las regiones de las crisis distributivas que median entre cada etapa. Como se observa en el Cuadro 2, con posterioridad a cada una de las crisis se observa, en todas las regiones, un incremento -o cuando menos estancamiento- de los CG por encima de los promedios de la etapa anterior. Eso señala no solo la relevancia de estas coyunturas como hitos distributivos significativos, sino que también confirma en cada una de las regiones el patrón de comportamiento "escalonado" de la desigualdad, que había sido observado en apartados anteriores para el GBA y para el conjunto de aglomerados urbanos y, por tanto, hace posible evaluar comparativamente los determinantes de la desigualdad en cada una de estas etapas por separado.

\section{Cuadro 3}

Media de CG de IPCF para distintas etapas. Aglomerados urbanos, 1985-2005

\begin{tabular}{|c|c|c|c|c|c|c|c|c|}
\hline \multirow{2}{*}{ REGIÓN } & \multirow{2}{*}{ AGLOMERADO } & \multirow{2}{*}{$\begin{array}{c}\text { Segundo } \\
\text { ciclo } \\
\text { (2) }\end{array}$} & \multirow{2}{*}{$\begin{array}{c}\text { Tercer } \\
\text { ciclo } \\
(3)\end{array}$} & \multirow{2}{*}{$\begin{array}{c}\text { Cuarto } \\
\text { Ciclo } \\
\text { (4) }\end{array}$} & \multirow{2}{*}{$\begin{array}{c}\text { Nuevo } \\
\text { escenario } \\
\text { (5) }\end{array}$} & \multicolumn{3}{|c|}{ Diferencias porcentuales } \\
\hline & & & & & & $(3-2)$ & $(4-3)$ & $(5-4)$ \\
\hline GBA & Gran B.A. & 0,43 & 0,46 & 0,51 & 0,53 & 5,35 & 10,44 & 4,91 \\
\hline \multirow{3}{*}{ CUY } & Mendoza & 0,40 & 0,43 & 0,47 & 0,47 & 7,72 & 9,27 & 0,60 \\
\hline & San Juan & 0,44 & 0,42 & 0,47 & 0,48 & $-5,12$ & 11,93 & 2,46 \\
\hline & San Luis & 0,41 & 0,43 & 0,49 & 0,44 & 4,80 & 14,27 & $-9,96$ \\
\hline \multirow{4}{*}{ NEA } & Corrientes & & 0,46 & 0,49 & 0,50 & & 7,86 & 0,73 \\
\hline & Formosa & 0,47 & 0,46 & 0,51 & 0,47 & $-2,66$ & 12,33 & $-7,95$ \\
\hline & Posadas & & 0,46 & 0,51 & 0,50 & & 11,78 & $-1,40$ \\
\hline & Resistencia & 0,47 & 0,48 & 0,53 & 0,51 & 2,76 & 9,44 & $-3,40$ \\
\hline \multirow{6}{*}{ NOA } & Catamarca & & 0,45 & 0,48 & 0,50 & & 7,18 & 3,73 \\
\hline & Jujuy & 0,48 & 0,48 & 0,50 & 0,48 & $-0,22$ & 6,01 & $-4,00$ \\
\hline & La Rioja & 0,45 & 0,45 & 0,48 & 0,47 & $-0,12$ & 7,90 & $-2,95$ \\
\hline & Salta & 0,46 & 0,44 & 0,49 & 0,52 & $-4,18$ & 12,69 & 4,90 \\
\hline & Sgo. del Estero & & 0,45 & 0,46 & 0,49 & & 3,21 & 6,94 \\
\hline & Tucumán & & 0,46 & 0,48 & 0,50 & & 3,34 & 4,03 \\
\hline
\end{tabular}




\begin{tabular}{|c|c|c|c|c|c|c|c|c|}
\hline \multirow{10}{*}{ PAM } & Bahía Blanca & & 0,42 & 0,44 & 0,47 & & 4,07 & 7,40 \\
\hline & Concordia & & & 0,53 & 0,54 & & & 1,72 \\
\hline & Córdoba & 0,41 & 0,42 & 0,45 & 0,48 & 3,16 & 8,02 & 5,81 \\
\hline & La Plata & 0,37 & 0,40 & 0,45 & 0,47 & 7,48 & 12,84 & 4,87 \\
\hline & Mar del Plata & & & 0,44 & 0,47 & & & 6,22 \\
\hline & Paraná & 0,42 & 0,42 & 0,47 & 0,47 & 0,09 & 11,75 & $-1,49$ \\
\hline & Rosario & 0,40 & 0,42 & 0,45 & 0,46 & 5,12 & 7,73 & 2,70 \\
\hline & Río Cuarto & & & 0,44 & 0,48 & & & 10,15 \\
\hline & Santa Fe & 0,42 & 0,44 & 0,47 & 0,49 & 3,59 & 7,96 & 3,14 \\
\hline & Santa Rosa & & 0,41 & 0,45 & 0,47 & & 11,03 & 5,22 \\
\hline \multirow{4}{*}{ PAT } & $\begin{array}{c}\text { Cdro. } \\
\text { Rivadavia }\end{array}$ & & & 0,47 & 0,48 & & & 3,39 \\
\hline & Neuquén & 0,46 & 0,47 & 0,49 & 0,49 & 2,04 & 4,85 & 0,95 \\
\hline & Río Gallegos & 0,39 & 0,40 & 0,42 & 0,43 & 1,90 & 5,53 & 1,54 \\
\hline & Ushuaia & & 0,42 & 0,44 & 0,46 & & 5,49 & 2,84 \\
\hline
\end{tabular}

Fuente: Elaboración propia en base a EPH.

\section{Principales Determinantes Regionales}

\section{DE LA DESIGUALDAD DE INGRESOS}

Con relación al efecto de los ingresos individuales de distintas categorías poblacionales sobre la desigualdad, los años 1985 a 1988 (segundo ciclo distributivo) estuvieron sensiblemente marcados por la evolución de la concentración de los ingresos de los asalariados a jornada completa. ${ }^{20} \mathrm{El}$ Gráfico 7.A señala que el incremento en la desigualdad de ingresos de esta población experimentado durante esta etapa supera el promedio del efecto explicado por los restantes subgrupos sobre la desigualdad en todas las regiones con excepción de dos: el NEA, donde los altos niveles de desocupación, cercanos al 10\% de la PEA, ${ }^{21}$ explican el mayor impacto distributivo de esta subpoblación; el NOA, donde la desigualdad encuentra su principal origen en el impacto conjunto del desempleo y de los ingresos provistos por ocupaciones no asalariadas. Tales excepciones no reflejan más que la peculiaridad del patrón distributivo de las dos regiones más postergadas de la Argen-

20 Como quedó señalado en apartados anteriores, los datos disponibles sobre precariedad para los años 1985 y 1995 solo refieren al aglomerado GBA.

21 Las tasas de desocupación citadas en este apartado fueron calculadas sobre el universo de las personas de hogares en los que la totalidad de los miembros responden el módulo de ingresos de la EPH (universo al que refieren los cómputos del CG de IPCF). 
tina, en las cuales la escasa dinámica del mercado de trabajo durante los ochenta no solo generó altas tasas de desempleo, sino también una importante gravitación de las actividades de refugio (autoempleos). Entre las restantes regiones: a) Patagonia y GBA presentan patrones distributivos similares, con un elevado peso desigualador de los ingresos provistos por posiciones asalariadas a jornada completa y un efecto relativamente bajo del desempleo y los autoempleos; b) Cuyo y la Región Pampeana, con elevado impacto de los asalariados plenos pero un relativamente mayor peso del desempleo y la subocupación en la explicación de la desigualdad.

Durante el primer quinquenio de los noventa el patrón distributivo se altera en forma considerable. En todas las regiones estadísticas, sin excepción esta vez, el principal determinante de la inequidad de ingresos individuales es el desempleo: el promedio del efecto de esta categoría sobre la desigualdad de los ingresos individuales supera sensiblemente el explicado por las restantes subpoblaciones (Gráfico 7.B). Por supuesto, las peculiaridades regionales persisten: mientras que por esos años en el GBA la dispersión de los salarios mejora, en Cuyo y el NOA la misma experimenta leves deterioros, manteniéndose sin modificaciones sustanciales en el resto de las regiones. Por su parte, el impacto de los ingresos de ocupaciones no asalariadas sobre la desigualdad mantiene niveles similares en todas las regiones, inferiores al asociado al desempleo pero no muy distintos a los del quinquenio anterior. Las transformaciones estructurales impulsadas durante esta etapa configuraron un contexto generalizado de destrucción neta de empleo y, no obstante la estabilidad de precios que contribuyó a sanear la desigualdad salarial, las distintas regiones experimentaron altos niveles de concentración de los ingresos personales por efecto del desempleo. 
Gráficos 7

Promedio de efectos de distintas categorías poblacionales sobre el CG de ingresos individuales.

Regiones estadísticas, 1985-2005

7.A7.B
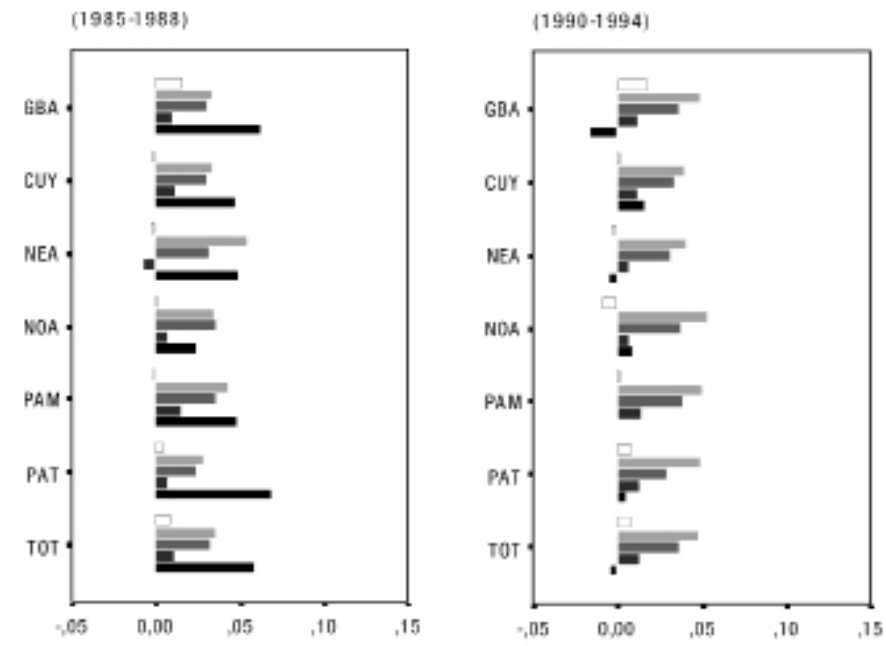

Efecta insetwas

con ingreso

Efecto desempleo

Efecto ocupedos no

a8alariado8

Efecto asalariado

subocupados

- C6 asalariados a

jornada completa*

7.C7.D

$(1996-2001)$

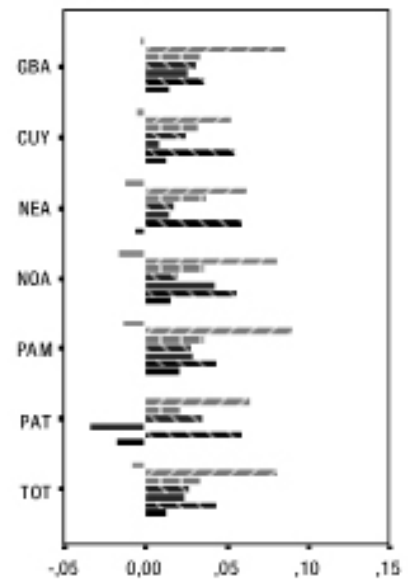

[2002-2005)

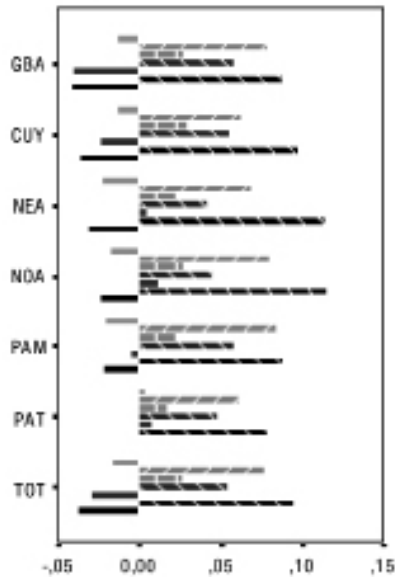

Efecto inactios con ingreso

ZEfecto desemplon

III Efecto deupados no asalariados

Nefacto asalariado

subocupados

C6 ascatirtados a jornada completa*

Defecto asalariados precarios

CG asalariados registradas*

(*) Variaciones absolutas de los CG en cada período.

Fuente: Elaboración propia en base a EPH puntual (ondas octubre 1996-2002) y continua (segundo semestre años 2003-2005). 
Entre 1996 y 2001 los persistentes niveles de desempleo mantienen a esta categoría poblacional a la cabeza de los factores determinantes de la desigualdad de ingresos individuales en todas las regiones estadísticas (Gráfico 7.C). No obstante ello, algunas alteraciones en el patrón de desigualdad son también claramente observables. La desigualdad salarial comienza a marcar nuevamente su impronta distributiva pero bajo manifestaciones novedosas. Aunque en sus mejores formas contractuales -no precarias, por un lado, y a jornada completa, por el otro- los ingresos por salario vuelven a incrementar su incidencia distributiva (en todas las regiones, principalmente en GBA, NOA y Cuyo, menos en Patagonia) y comienzan a registrarse con notable claridad los síntomas de un mercado de trabajo segmentado: tanto los ingresos asociados a posiciones asalariadas "en negro" como aquellos apropiados por los asalariados a jornada parcial tienen un impacto distributivo negativo elevado, a punto tal que en algunas regiones (GBA, Cuyo, NEA y Patagonia) comienzan a superar la desigualdad derivada de las ocupaciones asalariadas de mejor calidad (los casos de la Patagonia y Cuyo son los más destacables en este sentido). El desequilibrio explícito del mercado de trabajo -niveles de desocupación promedio por encima de los dos dígitos en todas las regiones durante este período- producto tanto del perfil productivo consolidado durante los años de la convertibilidad como de la prolongada recesión iniciada hacia 1998, parece haber ejercido una fuerte presión sobre la calidad del empleo, fenómeno que no pudo sino reflejarse -como veremos, aún incipientemente en esta etapa- en el patrón de desigualdad.

\section{Cuadro 4}

Promedio de efectos de algunas categorías poblacionales sobre el CG de ingresos individuales. Aglomerados urbanos, 1985-2005

\begin{tabular}{|c|c|c|c|c|c|c|c|c|c|c|c|}
\hline \multirow{3}{*}{ REGIÓN } & \multirow{3}{*}{ AGLOMERADO } & \multicolumn{4}{|c|}{ Efecto de desocupados } & \multicolumn{2}{|c|}{$\begin{array}{l}\text { Efecto de } \\
\text { precarios }\end{array}$} & \multicolumn{4}{|c|}{ Efecto de subocupados } \\
\hline & & \multicolumn{4}{|c|}{ Etapa } & \multicolumn{2}{|c|}{ Etapa } & \multicolumn{4}{|c|}{ Etapa } \\
\hline & & 2 & 3 & 4 & 5 & 4 & 5 & 2 & 3 & 4 & 5 \\
\hline GBA & GBA & 0,03 & 0,05 & 0,09 & 0,08 & 0,04 & 0,09 & 0,01 & 0,01 & 0,03 & 0,06 \\
\hline \multirow{3}{*}{ CUY } & Mendoza & 0,03 & 0,04 & 0,05 & 0,07 & 0,05 & 0,09 & 0,01 & 0,02 & 0,02 & 0,05 \\
\hline & San Juan & 0,05 & 0,05 & 0,06 & 0,07 & 0,06 & 0,11 & 0,02 & 0,01 & 0,03 & 0,06 \\
\hline & San Luis & 0,03 & 0,04 & 0,06 & 0,05 & 0,05 & 0,10 & 0,01 & 0,01 & 0,03 & 0,04 \\
\hline \multirow{4}{*}{ NEA } & Corrientes & & 0,04 & 0,08 & 0,08 & 0,06 & 0,11 & & 0,00 & 0,02 & 0,04 \\
\hline & Formosa & 0,06 & 0,05 & 0,05 & 0,05 & 0,04 & 0,10 & $-0,02$ & 0,00 & 0,00 & 0,04 \\
\hline & Posadas & & 0,04 & 0,04 & 0,07 & 0,08 & 0,12 & & 0,01 & 0,03 & 0,05 \\
\hline & Resistencia & 0,05 & 0,04 & 0,07 & 0,05 & 0,06 & 0,12 & 0,00 & 0,01 & 0,02 & 0,05 \\
\hline
\end{tabular}


Gabriel Calvi

\begin{tabular}{|c|c|c|c|c|c|c|c|c|c|c|c|}
\hline \multirow{3}{*}{ REGIÓN } & \multirow{3}{*}{ AGLOMERADO } & \multirow{2}{*}{\multicolumn{4}{|c|}{ Efecto de desocupados }} & \multirow{2}{*}{\multicolumn{2}{|c|}{$\begin{array}{c}\text { Efecto de } \\
\text { precarios } \\
\text { Etapa }\end{array}$}} & \multicolumn{4}{|c|}{ Efecto de subocupados } \\
\hline & & & & & & & & \multicolumn{4}{|c|}{ Etapa } \\
\hline & & 2 & 3 & 4 & 5 & 4 & 5 & 2 & 3 & 4 & 5 \\
\hline \multirow{6}{*}{ NOA } & Catamarca & & 0,05 & 0,09 & 0,09 & 0,04 & 0,10 & & 0,01 & 0,01 & 0,05 \\
\hline & Jujuy & 0,04 & 0,03 & 0,08 & 0,08 & 0,06 & 0,11 & 0,01 & 0,00 & 0,01 & 0,03 \\
\hline & La Rioja & 0,03 & 0,05 & 0,06 & 0,07 & 0,04 & 0,10 & 0,01 & 0,01 & 0,03 & 0,07 \\
\hline & Salta & 0,04 & 0,05 & 0,08 & 0,09 & 0,06 & 0,12 & 0,00 & 0,01 & 0,02 & 0,05 \\
\hline & Sgo. del Estero & & 0,03 & 0,06 & 0,07 & 0,08 & 0,15 & & 0,00 & 0,02 & 0,04 \\
\hline & Tucumán & & 0,07 & 0,09 & 0,08 & 0,05 & 0,11 & & 0,01 & 0,03 & 0,05 \\
\hline \multirow{10}{*}{ PAM } & Bahía Blanca & & 0,06 & 0,09 & 0,08 & 0,04 & 0,08 & & 0,03 & 0,03 & 0,05 \\
\hline & Concordia & & & 0,10 & 0,09 & 0,04 & 0,10 & & & 0,02 & 0,05 \\
\hline & Córdoba & 0,04 & 0,03 & 0,07 & 0,08 & 0,05 & 0,09 & 0,02 & 0,01 & 0,03 & 0,05 \\
\hline & La Plata & 0,04 & 0,04 & 0,09 & 0,08 & 0,03 & 0,08 & 0,01 & 0,02 & 0,03 & 0,07 \\
\hline & Mar del Plata & & & 0,09 & 0,09 & 0,05 & 0,08 & & & 0,03 & 0,06 \\
\hline & Paraná & 0,04 & 0,05 & 0,08 & 0,07 & 0,04 & 0,08 & 0,01 & 0,02 & 0,02 & 0,06 \\
\hline & Rosario & 0,05 & 0,06 & 0,11 & 0,10 & 0,04 & 0,09 & 0,02 & 0,01 & 0,03 & 0,06 \\
\hline & Río Cuarto & & & 0,07 & 0,07 & 0,06 & 0,09 & & & 0,03 & 0,06 \\
\hline & Santa Fe & 0,06 & 0,08 & 0,11 & 0,08 & 0,05 & 0,11 & 0,01 & 0,01 & 0,03 & 0,07 \\
\hline & Santa Rosa & & 0,03 & 0,07 & 0,06 & 0,04 & 0,08 & & 0,00 & 0,02 & 0,04 \\
\hline \multirow{4}{*}{ PAT } & Cdoro. Rivadavia & & & 0,07 & 0,07 & 0,05 & 0,08 & & & 0,04 & 0,06 \\
\hline & Neuquén & 0,03 & 0,06 & 0,08 & 0,07 & 0,07 & 0,09 & 0,01 & 0,02 & 0,04 & 0,06 \\
\hline & Río Gallegos & 0,02 & 0,03 & 0,03 & 0,02 & 0,03 & 0,04 & $-0,01$ & 0,00 & 0,02 & 0,01 \\
\hline & Ushuaia & & 0,05 & 0,06 & 0,07 & 0,05 & 0,08 & & 0,01 & 0,04 & 0,05 \\
\hline
\end{tabular}

Fuente: Elaboración propia en base a EPH (ondas octubre años 1985-1988 y 1990-1994, ondas mayo y octubre años 1996-2001, onda octubre 2002, onda mayo 2003, segundo semestre 2003 y primer y segundo semestres 2004-2005).

Durante los últimos cuatro años (2002-2005) el patrón de desigualdad asume su forma más compleja, si bien relativamente más homogénea en la comparación entre regiones (Gráfico 7.D). En todas las regiones estadísticas el desempleo ha perdido su carácter de principal origen de la desigualdad de ingresos individuales (si bien manteniendo una importante gravitación sobre el fenómeno) ante el efecto de los ingresos provistos por posiciones asalariadas precarias. El tercer lugar, no menos significativo, se encuentra relacionado con el impacto sobre la desigualdad ejercido por los ingresos de asalariados subocupados. Precariedad y subocupación se suman al nuevo escenario distributivo caracterizado también por la abrupta mejora (en todas las regiones menos en Patagonia) en la distribución de los salarios de los empleos de calidad. 
Contradicción solo aparente, tal configuración responde -como quedó señalado en otros apartados- a dos novedades asociadas a iniciativas gubernamentales: por un lado, a los altamente positivos efectos sobre los ingresos de los trabajadores "en blanco" de la política de ingresos de los gobiernos que siguieron al fin de la convertibilidad y su contracara de aumento de la brecha salarial entre registrados y no registrados; del otro, peculiar efecto del PJJH en materia distributiva, el cual atenúa el efecto distributivo derivado del desempleo, no obstante lo cual deteriora -por subocupación y precariedad contractual- los ingresos provistos por el salario.

\section{REFLEXIONES FINALES}

A lo largo de este trabajo hemos intentado aportar evidencias empíricas y herramientas de análisis que nos permiten vincular las transformaciones económicas de los últimos treinta años y sus efectos sobre el mercado laboral con los niveles y características que asumió progresivamente el reparto de los ingresos personales en la Argentina. En primer lugar, hemos visto que no solo se ha experimentado en este país un profundo incremento en los niveles de desigualdad, sino también que tal evolución se ha desarrollado en forma escalonada. Detrás del persistente deterioro distributivo se esconden, pues, distintas etapas (que hemos dado en llamar ciclos de desigualdad), mediadas por fuertes procesos regresivos (crisis distributivas) asociados a las últimas grandes crisis de la economía local. Cada una de estas etapas es depositaria de peculiaridades que la distinguen del resto y tiende a consolidar los niveles de desigualdad inmediatamente anteriores a las crisis distributivas que las separan, estableciendo así pisos cada vez más elevados y dando lugar a las tendencias seculares que todos tristemente conocemos. Las crisis constituyen la exacerbación de las principales tendencias que asume la inequidad de ingresos en cada etapa y abren, en general, procesos de transformación en algunos de los componentes que definían al patrón de desigualdad vigente hasta entonces. Así, el patrón distributivo que hoy, en los albores del siglo XXI, caracteriza a la sociedad argentina difiere del que predominaba en la posguerra: es decir, no solo difiere en los niveles de inequidad predominantes, sino también el aquellos factores que explican estos elevados grados de concentración del producto social. El contenido del proceso observado en los últimos treinta años es siempre el mismo: una paulatina disociación entre crecimiento y equidad. Pero la forma de la desigualdad se ha alterado con cada uno de los ciclos.

El origen de las transformaciones que hicieron de la Argentina una sociedad dual nos lleva, en primer lugar, a la tristemente recordada década del setenta. Las principales herramientas con las cuales el 
gobierno de facto tendió a disciplinar económicamente a los sectores populares -la suspensión de las convenciones colectivas y el congelamiento salarial- tuvieron vigencia en el marco de un régimen de alta inflación, e hicieron que el primer ciclo de desigualdad estuviera claramente impulsado por una mayor concentración de los salarios. El deterioro del poder de compra de los salarios fue la norma en esta etapa y el contexto cercano al pleno empleo habría configurado un escenario en el cual aquellos trabajadores de mayores calificaciones lograron atenuar la erosión de sus ingresos reales en mayor medida que a aquellos con menores credenciales educativas, debido ello tanto a un mayor poder de negociación individual como a una política explícita de alteración de las remuneraciones relativas de distintas categorías de empleados. El violento incremento de la desigualdad observado hacia 1981, que encuentra su origen en la intensificación del proceso de estratificación salarial -dados los altos niveles de inflación que siguieron al abandono de la política cambiaria de devaluaciones sucesivas-, fue el emergente de la crisis que dio fin al programa iniciado hacia 1977, que había sumido al país a una alta vulnerabilidad externa mediante opciones de política económica que hicieron de la reforma financiera y la apertura comercial sus principales eslabones.

La recomposición de los niveles de desigualdad que acompañó a los últimos años de la dictadura y los primeros del gobierno de la transición democrática no pudo revertir en su totalidad el malogro distributivo de años anteriores. La destrucción de buena parte del aparato productivo, la gran concentración de capitales, la pesada carga de la deuda pública y los altos niveles de inflación, todos ellos heredados del período militar, conminaron al país al estancamiento crónico y la acentuación de la desigualdad volvió a escena desde mediados de la década. Con un gobierno que progresivamente asumiría como propio el ideario de los principales actores económicos locales y extranjeros, el deterioro distributivo del segundo quinquenio de los ochenta obedecería también a un desigual reparto de los salarios. Sin embargo, la mayor desigualdad salarial no estaría, en esta oportunidad, asociada a diferenciales educativos. Tampoco la subocupación ni la precariedad parecen explicar la mayor concentración de los salarios en esta etapa. En el marco del mantenimiento de algunas de las restricciones a la negociación salarial impuestas por el gobierno de facto, decisiones administrativas -que permitieron ajustes salariales por presentismo o productividad-podrían estar en el origen de esta particular evolución del reparto de los salarios. Desde 1988 la eliminación de las restricciones para negociar colectivamente salarios puede haber aportado alteraciones en igual sentido. El leve pero constante incremento de la desocupación, que afectó principalmente a los hogares más pobres, 
contribuyó también al deterioro distributivo de esos años, dando cuenta de los primeros síntomas de la baja capacidad de absorción de mano de obra que caracterizaría en adelante al modelo económico emergente. Sin embargo, la incidencia de los desocupados sobre el reparto de los ingresos se mantuvo por esos años en niveles moderados: el hecho de que el efecto de esta subpoblación no haya aportado al pico distributivo registrado durante la crisis de 1989 es un indicador de que tal problema no había asumido aún los niveles endémicos que se advertirían en la década siguiente. La mayor concentración de los ingresos personales desencadenada durante la crisis de ese año fue el resultado de la desigual distribución de las capacidades de los ocupados (asalariados y no asalariados) para lidiar con el proceso hiperinflacionario abierto.

Durante el primer quinquenio de los noventa, la Argentina experimentó una segunda y virulenta secuencia de opciones de política de corte neoliberal, signada por la reversión de la injerencia del Estado en la economía. La mirada gubernamental concentró su atención, durante esos años, en el control del gasto, la autorregulación del mercado y los intereses de las fracciones dominantes del establishment, demostrando un nulo reparo ante los amplios sectores de la población que esperaban el "derrame". La explosiva combinación de reformas estructurales y de políticas de estabilización centradas en el anclaje del tipo de cambio extremaron la herencia del período dictatorial: endeudamiento masivo, desindustrialización y extranjerización. Pero en esta oportunidad la progresiva exclusión de vastos sectores de la población de las filas del empleo fue el principal síntoma de una estrategia de crecimiento económico socialmente deficitaria. La baja elasticidad producto-empleo de la economía se intensificó considerablemente y la desocupación entró en escena arrastrando consigo el deterioro distributivo durante los primeros años de la década. Así, la crisis distributiva desatada hacia 1995, en cuyo germen se encuentra la exacerbada vulnerabilidad externa de la economía, estuvo guiada novedosamente por el efecto de la desocupación y, dados los niveles de desempleo, la reaparición de un proceso de concentración de los salarios.

La heteronomía de la política local frente a las arbitrariedades de los organismos financieros internacionales se intensificó con posterioridad al salvataje financiero del FMI de 1995. Opciones de política con un fuerte sesgo fiscalista predominaron desde entonces como último recurso para ganar el favor de los acreedores externos, única y costosa fuente que quedaba entonces para dar liquidez a la economía. Restricción fiscal y endeudamiento caracterizaron a un ciclo de crecimiento poco sustentable y que, dada la pervivencia de las reformas 
estructurales, no logró revertir la elevada concentración del producto social. Los costos sociales de la inminente fase recesiva fueron altos: la escasa absorción de mano de obra se mantuvo y a los altos índices de desempleo se sumó el incremento de la subocupación horaria y la precariedad laboral. El deterioro distributivo de esos años estuvo pues gobernado por el impacto de la desocupación, el desigual reparto de las horas laborales y un notable aumento de la incidencia de la precariedad laboral sobre los niveles de desigualdad salarial. El final de la convertibilidad llegó en el marco de una aguda crisis política con altos niveles de conflictividad social y significó también, como era previsible, un pico distributivo sin precedentes. Sin embargo, la peculiaridad de la crisis distributiva posterior a la devaluación no encuentra paralelo en las anteriores: la mayor concentración de ingresos desatada tras el fin de la convertibilidad estuvo exclusivamente gobernada por la incidencia del desempleo.

En los últimos cuatro años los niveles de desigualdad han registrado algunos síntomas de mejoría. Sin embargo, al observar con mayor detenimiento, el balance distributivo de los primeros años del modelo de dólar alto no es indefectiblemente alentador. Algunas de las características que persisten -y se intensifican- en la forma vigente de la desigualdad ponen serios límites a la profundización del proceso de recomposición: el efecto del desempleo, la precariedad y la subocupación sobre los niveles de inequidad siguen siendo elevados. Más aun, lo ocurrido en los últimos años muestra que eventuales disminuciones en el impacto distributivo de la desocupación parecen estar escoltadas por sensibles incrementos en el efecto distributivo negativo de los empleos de baja calidad (precarios y a jornada parcial). Por su parte, la política de ingresos de los sucesivos gobiernos -necesaria para contribuir a la recomposición del poder de compra de los salarios- en un contexto como el actual -caracterizado por altísimos niveles de precariedad- tiene por efecto no deseado el acentuamiento de la brecha salarial, pues contribuyen a deteriorar en términos relativos los ingresos provistos por posiciones precarias. A todo esto debemos sumar el hecho de que buena parte de la recomposición distributiva está fuertemente atada aún hoy a la vigencia de un plan social compensatorio de características similares a los de los años noventa. ${ }^{22}$

Es posible, sin duda, que con el crecimiento económico sostenido la equidad distributiva vuelva a mostrar síntomas de recuperación.

22 La dependencia de la recomposición de la desigualdad a los efectos distributivos del PJJH es tal que al descontar (en el segundo semestre de 2005) los ingresos que el plan aporta a los hogares de beneficiarios el CG de IPCF se remonta a los niveles de mayo de 2001 (0,517 en el conjunto de aglomerados y 0,521 para el GBA). 
Pero si consideramos que en el marco de los altísimos niveles de crecimiento de los últimos tres años (superiores al $9 \%$ en promedio) solo se observa una mejora en el CG del orden del $2 \%$ anual promedio, resulta difícil pensar que la inequidad se revierta sustancialmente con la bonanza económica como único mecanismo. La complejidad del patrón distributivo actual es tal que la desigualdad tampoco se revierte haciendo uso de diseños de política otrora eficaces: problemas como la fragmentación del mercado laboral, la precariedad en las condiciones de contratación y las todavía elevadas tasas de desempleo y subocupación horaria, todos ellos directamente relacionados con el reparto del producto social, requieren, para su solución, de políticas públicas más reflexivas que la sola intervención en el mercado cambiario, la determinación de los salarios "en blanco" o la implementación de planes compensatorios de transferencia de ingresos. La forma actual de la inequidad impone, mucho más que en otras etapas, la elaboración de diagnósticos claros y precisos, sin los cuales, tarde o temprano, cualquier modalidad de intervención estatal corre el riesgo de perpetuar el deterioro de los últimos treinta años.

\section{Bibliografía}

Abeles, M. 1999 "El proceso de privatizaciones en la Argentina de los noventa: ¿reforma estructural o consolidación hegemónica?" en Época (Buenos Aires) $\mathrm{N}^{\circ} 1$.

Altimir, O. y Beccaria, L. 2001 "El persistente deterioro de la distribución del ingreso en la Argentina" en Desarrollo Económico (Buenos Aires) $\mathrm{N}^{\circ} 160$.

Altimir, O. et al. 2002 "La distribución del ingreso en Argentina, 19742000" en Revista de la CEPAL, (Buenos Aires) $\mathrm{N}^{\circ} 78$, diciembre.

Azpiazu, D. et al. 1986 El nuevo poder económico (Buenos Aires: Hyspamérica).

Azpiazu, D. et al. 2000 La reestructuración y el redimensionamiento de la producción industrial argentina durante las últimas décadas (Buenos Aires: Instituto de Estudios y Formación de la CTA).

Banco Mundial 1993 América Latina y el Caribe: diez años después de la crisis de la deuda (Washington).

Barbeito, A. et al. 2001 Transformar la crisis en una oportunidad. Shock redistributivo y profundización democrática (Buenos Aires: Instituto de Estudios y Formación de la CTA).

Basualdo, E. 2000 Acerca de la naturaleza de la deuda externa y la definición de una estrategia política (Buenos Aires: Editorial La Página).

Basualdo, E. et al. 2002 Las transferencias de recursos a la cúpula económica durante la administración Duhalde (Buenos Aires: Instituto de Estudios y Formación de la CTA). 
Beccaria, L. 1991 "Distribución del ingreso en la Argentina: explorando lo sucedido desde mediados de los setenta" en Desarrollo Económico (Buenos Aires) $\mathrm{N}^{\circ} 123$.

Beccaria, L. 2002 "Empleo, remuneraciones y diferenciación social en el último cuarto del siglo XX" en Beccaria, L. et al. Sociedad y sociabilidad en la Argentina de los 90 (Buenos Aires: Biblos).

Beccaria, L. 2003 "Las vicisitudes del mercado laboral argentino luego de las reformas" en Boletín Informativo Techint (Buenos Aires) $\mathrm{N}^{\circ} 312$.

Beccaria, L. y López, N. 1997 "Notas sobre el comportamiento del mercado de trabajo urbano" en Beccaria L. y López, N. (comps.) Sin trabajo. Las características del desempleo y sus efectos en la sociedad argentina (Buenos Aires: Unicef / Losada).

Beccaria, L. y Galín, P. 2002 Regulaciones laborales en Argentina. Evaluación y propuestas (Argentina: OSDE / CIEPP).

Bekerman, M. y Sirlin, P. 1996 "Patrón de especialización y política comercial en la Argentina de los noventa" en Desarrollo Económico (Buenos Aires) número especial.

Bisang, R. et al. 1996 "La transformación industrial en los noventa. Un proceso con final abierto" en Desarrollo Económico (Buenos Aires) número especial.

Boletín Oficial de la República Argentina de 02/06/2000, 07/01/2002, 12/11/1984, 17/12/1991, 21/05/1976, 24/09/1998, 25/06/2001, 28/03/1995, 28/03/1991, 04/04/2002, 13/09/2002 y 30/01/2003.

Braun, O. 1975 "Desarrollo del capital monopolista en la Argentina" en Braun, O. (comp.) El capitalismo argentino en crisis (Buenos Aires: Siglo XXI).

Calvi, G. y Zibecchi, C. 2004 "El Plan Jefes y Jefas. Cambios y continuidades en materia de programas sociales" en Textos para pensar la realidad (La Plata) $\mathrm{N}^{\circ} 5$.

Calvi, G. y Zibecchi, C. 2006 “¿El epitafio del Plan Jefes y Jefas de Hogar o una nueva orientación de la política social? Evaluando algunos de los escenarios sociolaborales posibles ante la consolidación del Plan Familias" en Revista Laboratorio (Buenos Aires: IIGG) $\mathrm{N}^{\circ} 19$.

Calvi, G. y Benza, G. 2005 "Precariedad laboral y distribución del ingreso en el Gran Buenos Aires (1974-2003)", ponencia presentada en el VII Congreso Nacional de Estudios del Trabajo (Buenos Aires).

Campione, D. y Muñoz, C. 1993 "Concentración capitalista y sistema político" en Realidad Económica (Buenos Aires) № 121.

Canavese, R. y Gerchunoff, P. 1996 "Reformas estructurales, productividad y tipo de cambio” en Desarrollo Económico (Buenos Aires) número especial. 
Canitrot, A. 1980 "La disciplina como objetivo de la política económica" en Desarrollo Económico (Buenos Aires) N 76.

Canitrot, A. 1982 "Teoría y práctica del liberalismo. Política antiinflacionaria y apertura económica en la Argentina, 1976-1981" en Desarrollo Económico (Buenos Aires) $\mathrm{N}^{\circ} 21$.

Carciofi, R. 1990 "La desarticulación del pacto fiscal: una interpretación sobre la evolución del sector público argentino en las dos últimas décadas" en Documentos de Trabajo CEPAL (Buenos Aires) $\mathrm{N}^{\circ} 36$.

CELS 2003 Plan Jefes y Jefas. ¿Derecho social o beneficio sin derechos? (Buenos Aires) mayo.

Cooper, R. 1994 Auge, crisis y auge. La experiencia macroeconómica de los países en desarrollo, 1970-1990 (Washington DC: Banco Mundial).

Cortés, R. y Marshall, A. 1991 "Estrategias económicas, intervención social del Estado y regulación de la fuerza de trabajo. Argentina 18801990" en Revista estudios del Trabajo $\mathrm{N}^{\circ} 1$ (Buenos Aires: ASET).

Damill, M. 2000 El balance de pagos y la deuda externa pública bajo la convertibilidad (Buenos Aires: CEDES).

Damill, M. y Frenkel, R. 1993 "Restauración democrática y política económica: Argentina, 1984-1991" en Morales, J. A. y McMahon, G. (eds.) La política económica en la transición a la democracia. Lecciones de Argentina, Bolivia, Chile, Uruguay (Santiago de Chile: Ediciones CIEPLAN).

Damill, M. et al. 2002 Argentina. Una década de convertibilidad (Santiago de Chile: OIT).

Diamand, M. 1973 Doctrinas económicas, desarrollo e independencia (Buenos Aires: Paidós).

Diéguez, H. y Gerchunoff, P. 1984 "La dinámica del mercado laboral urbano en la Argentina, 1976-1981" en Desarrollo Económico (Buenos Aires: IDES) $\mathrm{N}^{\circ} 93$.

Gasparini, L. et al. 2000 "La distribución del ingreso en la Argentina y en la provincia de Buenos Aires" en Cuadernos de Economía (La Plata) $\mathrm{N}^{\circ} 49$.

Gasparini, L. et al. 2001 La distribución del ingreso en la Argentina (Fundación Arcor) Premio Fulvio Salvador Pagani.

Gerchunoff, P. y Torre, J. C. 1996 "La política de liberación económica en la administración de Menem” en Desarrollo Económico (Buenos Aires) $\mathrm{N}^{\circ} 143$.

Gerchunoff, P. y Llach, L. 2003 El ciclo de la ilusión y el desencanto (Buenos Aires: Ariel).

Giosa Zuazua, N. 1999 "Desempleo y precariedad laboral en la Argentina de los “90” en Epoca. Revista argentina de economía política (Buenos Aires) Año I, No 1. 
Grandes, M. y Gerchunoff, P. 1998 "Distribución del ingreso y mercado de trabajo en el Gran Buenos Aires. 1987-1997" en $4^{\circ}$ Congreso Nacional de Estudios del Trabajo (Buenos Aires: ASET).

Grassi, E. et al. 1994 Políticas sociales, crisis y ajuste estructural (Argentina: Espacio Editorial).

INAP 1997 Organización del Estado y de la Administración Pública Nacional de la República Argentina (Buenos Aires).

INDEC 2002 Comunicado de prensa del 27 de diciembre de 2002 (Buenos Aires).

Kaufman, R. 1994 "Estabilización y ajuste en Argentina, Brasil y México" en Nelson, J. (comp.) Crisis económica y políticas de ajuste (Bogotá: Norma).

Levit, C. y Ortiz, R. 1999 "La hiperinflación argentina: prehistoria de los años noventa" en Época (Buenos Aires) $\mathrm{N}^{\circ} 1$.

Lindemboim, J. et al. 2005 "La distribución funcional del ingreso en Argentina. Ayer y hoy" en Documentos de Trabajo (Buenos Aires: CEPED, Facultad de Ciencias Económicas, UBA) $\mathrm{N}^{\circ} 4$.

Lindemboim, J. et al. 2006 "Distribución, consumo e inversión en la Argentina a comienzos del siglo XXI" en Realidad Económica (Buenos Aires: IADE) $\mathrm{N}^{\circ} 218$.

Lindemboim, J. 2003 "El mercado de trabajo en la Argentina en la transición secular: cada vez menos y peores empleos" en Lindemboim, J. y Danani, C. (coords.) Entre el trabajo y la política. Las reformas de las politicas sociales argentinas en perspectiva comparada (Buenos Aires: Biblos).

Lo Vuolo, R. y Barbeito, A. 1998 La nueva oscuridad de la política social. Del Estado populista al neoconservador (Buenos Aires: Miño y Dávila Editores / Ciepp).

Marticorena, C. 2005 Precariedad laboral y caída salarial. El mercado de trabajo en la post convertibilidad, trabajo presentado en el VII Congreso Nacional de Estudios del Trabajo (Buenos Aires).

Meller, P. 1993 "Ajuste y reformas en América Latina: Problemas y experiencias recientes" en Pensamiento Iberoamericano (Madrid) $\mathrm{N}^{\circ} 22 / 23$, tomo II.

Minujín, A. 1993 "En la rodada" en Cuesta abajo (Buenos Aires: UNICEF / Losada).

Monza, A. 1996 "La situación ocupacional argentina. Diagnóstico y perspectivas" en Minujín, A. (ed.) Desigualdad y exclusión. Desafíos para la política social en la Argentina de fin de siglo (Buenos Aires: UNICEF / Losada).

Nochteff, H. 1994 "Los senderos perdidos del desarrollo" en Azpiazu, D. y Nochteff, H. El desarrollo ausente (Buenos Aires: FLACSO). 
Novick, M. 2004 "Costos laborales en la Argentina 2003. Un análisis comparativo" en Serie de documentos de trabajo (Buenos Aires: Subsecretaría de Programación Técnica y Estudios Laborales, MTESS) $\mathrm{N}^{\circ} 1$.

Oszlak, O. y O’Donnell, G. 1984 "Estado y políticas estatales en América latina: Hacia una estrategia de investigación" en Kliksberg, B. y Sulbrandt, J. (comps.) Para investigar la administración pública (Madrid: INAP).

Pautassi, L. 2000 "El impacto de las reformas estructurales y la nueva legislación laboral sobre la mujer en la Argentina" en Ley, Mercado y Discriminación (Buenos Aires: Editorial Biblos).

Pessino, C. 1996 "La anatomía del desempleo" en Desarrollo Económico, Número especial (Buenos Aires: IDES).

Pok, C. 1992 "Precariedad laboral: personificaciones sociales en la frontera de la estructura del empleo", Documento presentado en el Primer Congreso Nacional de Estudios del Trabajo (Buenos Aires).

Portantiero, J. C. 1977 "Economía y política en la crisis argentina" en Revista Mexicana de Sociología (México) N² 2.

Portantiero, J. C. 1987 "La concertación que no fue" en Nun, J. y Portantiero, J. Ensayos sobre la transición democrática en la Argentina (Buenos Aires: Puntosur).

PREALC 1982 Mercado de trabajo en cifras. 1950-1980 (Chile: OIT).

Pucciarelli, A. 1997 "Los dilemas irresueltos en la historia reciente de la Argentina" en El Taller (Buenos Aires) $\mathrm{N}^{\circ} 4$.

Pucciarelli, A. 1999 “Crisis o decadencia?” en Estudios Sociológicos (Buenos Aires) XVII.

Quiroga, H. 1989 Autoritarismo y Reforma del Estado (Buenos Aires: CEAL).

Salvia, A. et al. 2000 "Análisis de ingreso según su origen. Gran Buenos Aires 1991-1999" en Lavboratorio (Buenos Aires) $N^{\circ} 4$.

Salvia, A. y Donza, E. 2001 "Alcances, cambios en el sesgo estadístico y otras derivaciones de la no declaración de ingresos personales en la EPH (1990-1999). Aplicación de un modelo de regresión múltiple para la estimación de valores faltantes" en Lindenboim, J. (comp.) Cuadernos del CEPED (Buenos Aires: Facultad de Ciencias Económicas, UBA) $\mathrm{N}^{\circ} 5$.

Salvia, A. y Donza, E. 2001 "Cambio estructural y desigualdad social. Ejercicios de simulación sobre la distribución del ingreso 19902000" en Lindenboim, J. (comp.) Cuadernos del CEPED (Buenos Aires: Facultad de Ciencias Económicas, UBA) $\mathrm{N}^{\circ} 5$.

Salvia, A. y Tissera, S. 2000 "Heterogeneidad y precarización de los hogares asalariados en Argentina durante la década del 90" en 
Cuadernos del CEPED (Buenos Aires: Facultad de Ciencias Económicas, UBA) $\mathrm{N}^{\circ} 4$.

Schorr, M. 2002 "Mitos y realidades del pensamiento neoliberal: La evolución de la industria manufacturera argentina durante los años noventa" en Schorr, M. et al. Más allá del pensamiento único. Hacia una renovación de las ideas económicas en América Latina (Buenos Aires: CLACSO).

Schvartzer, J. 1987 "El Estado y su mecanismo de regulación frente a diferentes situaciones macroeconómicas" en Latinoamérica: lo político y lo social ante la crisis (Buenos Aires: CLACSO).

Schvartzer, J. 1988 La política económica de Martínez de Hoz (Buenos Aires: Hyspamérica).

Schvartzer, J. 1996 "Entre la informalidad y el desempleo. Una perspectiva de largo plazo" en Realidad Económica (Buenos Aires) $\mathrm{N}^{\circ}$ 139.

Sidicaro, R. 1996 "El régimen autoritario de 1976: refundación frustrada y contrarrevolución exitosa" en Quiroga, H. (comp.) A veinte años del golpe (Buenos Aires: Homo Sapiens).

Sidicaro, R. 2001 La crisis del Estado y los actores políticos y socioeconómicos en la Argentina (1989-2001) (Buenos Aires: Libros del Rojas).

Tamayo Sáez, M. 1997 "El análisis de las políticas públicas” en Bañón, R. y Carrillo, E. (comps.) La Nueva Administración Pública (Madrid: Alianza).

Tilly, C. 2000 La desigualdad persistente (Buenos Aires: Manantial).

Tokman, V. 1997 "La especificidad y generalidad del problema del empleo en el contexto de América latina" en Beccaria L. y López, N. (comps.) Sin trabajo. Las características del desempleo y sus efectos en la sociedad argentina (Buenos Aires: Unicef / Losada).

Torrado, S. 1994 Estructura social de la Argentina: 1945-1983 (Buenos Aires: Ediciones De la Flor).

Torre, J. C. 1998 El proceso político de las reformas económicas en América Latina (Buenos Aires: Paidós).

Villarreal, J. 1985 “Los hilos sociales del poder" en Jozami, E. (comp.) Crisis de la Dictadura Argentina (Buenos Aires: Siglo XXI). 



\title{
Flavio Gaitán*
}

\section{Crecimiento, desigualdad y POBREZA EN EL CAPITALISMO PERIFÉRICO}

\author{
ANÁLISIS DE LOS PAÍSES LATINOAMERICANOS
}

\author{
"Los filósofos no han hecho más que interpretar de \\ diversos modos el mundo, \\ pero de lo que se trata es de transformarlo" \\ KaRl MarX, \\ Tesis sobre Feuerbach, XI
}

\section{INTRODUCCIÓN}

El presente trabajo de investigación intenta abordar el análisis de las causas de la persistencia de la pobreza en los países de América Latina, centrándose, particularmente, en la relación entre crecimiento, desigualdad y bienestar social. El principal cuestionamiento que guía este proyecto de investigación es: ¿Cuál es la causa de la persistencia de la profunda pobreza en la región?, pregunta que, traducida en un tema de investigación que permita acotar el análisis se traduce en las siguientes: ¿Es posible estudiar la pobreza desligada de la desigualdad? ¿Cuál es la relación entre crecimiento, desigualdad y reducción de la pobreza en América Latina? ¿Genera el crecimiento de la región una reducción de la pobreza? ¿Cuál es la relación entre pobreza y desigualdad?

Abordamos, así, un tema ampliamente estudiado en la economía y las ciencias sociales. El debate sobre la pobreza o la marginalidad no es reciente en el ambiente académico en América Latina ${ }^{1}$ y de modo

* Candidato a Doctor en Ciencia Política, Instituto Universitário de Pesquisas do Rio de Janeiro, Becario CAPES PEC-PG.

1 El debate sobre la pobreza es de antigua data, como afirma Ceceña Martorella (1994) y ha sido documentado, entre otros, por Castels (1994), para el caso francés y, Farah (1991) para la problemática latinoamericana. Véase también Forman (1994) acerca de los diversos enfoques de investigación sobre pobreza. 
particular desde los años setenta, diversas instituciones y centros académicos se han declarado preocupados por abordar alternativas para su superación (Farah, 1991). A pesar de ello, la espantosa magnitud de la pobreza persiste en América Latina. En el momento en que este informe es redactado aproximadamente el $40 \%$ de la población de la región vive bajo la línea de pobreza, es decir, casi 210 millones de personas no accede al ingreso mínimo para no ser considerado pobre.

El interés por estudiar la pobreza en relación al crecimiento económico y la desigualdad se relaciona con un supuesto que subyace implícito en este trabajo: que las diversas manifestaciones de pobreza están históricamente constituidas, por lo que se vuelve necesario quebrar el círculo vicioso de su reproducción. Por ello, nos interesa analizar lo que podría denominarse el núcleo primario de las causas de la pobreza, que es aquel que se establece en torno de la distribución de los recursos al interior de una determinada sociedad.

Los principales objetivos del presente trabajo son los siguientes: i) estudiar las causas de la persistencia de la pobreza en América Latina contemporánea; ii) medir el impacto del crecimiento del producto sobre la pobreza y iii) medir la relación entre pobreza y calidad de la distribución del ingreso. En función de los objetivos planteados, asumimos las siguientes hipótesis principales: i) la pobreza en América Latina es resultado de la desigual concentración del ingreso antes que del bajo producto o la escasez de recursos; ii) la pobreza es poco sensible al crecimiento del producto en períodos de alto crecimiento pero aumenta significativamente en los períodos de crisis. Estos supuestos significan, a nuestro entender, que analizar la pobreza en América Latina implica, en consecuencia, relacionarlo íntimamente con la desigualdad y los factores que la perpetúan, considerando la pobreza como una manifestación de la distribución del ingreso en una determinada sociedad. La pobreza es entendida, así, como una situación de carencia de ingresos en que los individuos no consiguen un padrón mínimo de vida.

El estudio se circunscribe, en términos generales, al período 19702005 y abarca a los países de América del Sur y Central, con excepción de Surinam y Guyana. El corte espacio-temporal se relaciona con un gran condicionante de la elección de países y años de cobertura como es la carencia de datos sistemáticos previos a la década del setenta (Psacharopoulos et al., 1997: 4; WB, 2006; Gangas Peiró, 2003). ${ }^{2}$

2 No existen datos sistemáticos previos a 1978 que cubran el conjunto de países latinoamericanos. Solo es hacia los años ochenta que "la disponibilidad de datos ha ido en aumento" (WDR, 2006: 302) pasando de una cobertura de 13 en 1979 a 100 en 1997. 
En la primera sección presentamos la estrategia metodológica. A continuación, establecemos una aproximación teórico-conceptual sobre pobreza, crecimiento y desigualdad, en el cual presentamos el marco teórico adoptado y de la cual se derivan los objetivos del presente trabajo. Los siguientes apartados plantean la evidencia empírica referente a la relación entre crecimiento y pobreza y sobre el peso de la desigualdad en la persistencia de la pobreza. Finalmente, las conclusiones representan un llamado a la inclusión de mayores niveles de igualdad como factor superador de la pobreza y un planteo de ciertos temas pendientes para una futura investigación.

\section{ESTRATEGIA Y DISCUSIÓN METODOLÓGICA}

Este trabajo constituye un estudio longitudinal, estructurado en diversas etapas, en las cuales prestamos especial atención a la dinámica de las variables analizadas a lo largo de un período significativo de tiempo y en un amplio número de países latinoamericanos. Realizar una investigación sobre la relación entre crecimiento, pobreza y desigualdad presenta riesgos que limitan el alcance, asociados al modo en que es conceptualizada y medida la situación de privación y la disponibilidad y calidad de los datos.

Existen diversos métodos para medir la situación de marginación social (en tanto ausencia de bienestar) en una sociedad. El método más utilizado para dividir a la población en algunos clasificados pobres y otros que no lo son es la Línea de Pobreza, que ha sido definida como el nivel de ingreso necesario para financiar las necesidades básicas (Musgrave, 1982) y consiste en llevar a cabo una comparación del ingreso o del consumo per cápita con una línea mínima que establece el umbral de pobreza. De acuerdo con Boltvinik (1994) "el punto clave de este método consiste en la forma como se define la línea de pobreza, siendo que en América Latina la variante usual es definir una canasta básica alimentaria, calcular su costo y multiplicar este valor". Esta canasta básica varía obviamente de país en país, pero en términos generales incluye una lista de bienes que satisface un conjunto de necesidades consideradas elementales y que incluyen nutrición, vivienda, vestimenta, alimentación y salud. El precio de esta canasta representa, generalmente, la línea de pobreza (Psacharopoulos et al., 1997). La línea de indigencia, por su parte, se refiere principalmente a alimentación. Desde luego, la elección de una línea de pobreza, ese punto sobre el cual se deja de ser pobre, es un valor arbitrario y a menudo causa de polémica (Hoffmann, 1997). Una debilidad es asociar, linealmente, ingresos por encima de la línea de pobreza con satisfacción garantida de las necesidades básicas. En palabras de Altimir (1979: 42), existe el supuesto de que "los hogares que se hallan por encima del umbral 
mínimo de alimentación se hallan también por encima de los murales mínimos para otras necesidades básicas".

El método de necesidades básicas insatisfechas compara la situación de los hogares respecto de una serie de necesidades consideradas esenciales denominadas necesidades básicas, que constituyen un conjunto de indicadores considerados mínimos que deben ser tenidos en cuenta para medir la pobreza absoluta, como son alimentación, calidad de la vivienda (servicios sanitarios, cobertura de agua potable por red, existencia de hacinamiento entendido generalmente como más de tres personas por cuarto, piso de tierra, cobertura de energía eléctrica) y educación (considerando generalmente la población en edad escolar que no asiste a educación formal y los años de educación de la población adulta). Las principales críticas a este método derivan de la confiabilidad de la información como así también de la imposibilidad de considerar necesidades no materiales (Farah, 1991). Por otro lado, existe una relación directa entre la cantidad de indicadores incluidos, que varían en cada país, y las cifras de pobreza. Además, por el hecho de guardar una relación directa con las inversiones en infraestructura, las comparaciones periódicas se dificultan y pueden dar lugar a interpretaciones erróneas. Por lo general la mayoría de los países muestran mejoras (excepto, como veremos, respecto de la alimentación), pese a lo cual no puede afirmarse que este mayor acceso a las obras de infraestructura signifique una menor tasa de pobreza.

Un tercer método, que en realidad representa una variación de las líneas nacionales de pobreza e indigencia, mucho más modesto, es el uso que el Banco Mundial hace de las categorías de 1,08 dólares PPP (paridad de poder de compra, base dólares internacionales de 1993) $)^{3}$ de ingreso personal diario para medir a las personas que se encuentran en la pobreza extrema y de 2,15 dólares estandarizados por PPP al día para calificar a las personas en pobreza moderada. El principal cuestionamiento a este método radica en su pobreza conceptual, tomando un umbral absolutamente mínimo de bienestar. En palabras de Boltvinik (1994: 67), "los datos del Banco Mundial se deben tomar como indicador de personas cuya supervivencia está en peligro y los de pobreza extrema deben, por lo tanto, desecharse". Pese a ello, considerando las dificultades existentes para la comparación, la metodología que el Banco Mundial utiliza para los países periféricos

3 La metodología de dólares PPP (purchasing power parity) considera el ingreso nacional bruto convertido en dólares usando la paridad del poder de compra. Supuestamente, 1 dólar PPP internacional tiene el mismo poder de compra sobre el PBN que un dólar estadounidense sobre el Gini de los Estados Unidos. Los factores de conversión de los PPP derivan de las encuestas de precios. 
(agrupados por la institución bajo el eufemismo "países en vías de desarrollo") tiene, al menos, el modestísimo pero útil mérito de permitir una comparación con un indicador único, deflacionado con los mismos parámetros en la totalidad de los países (Székely y Londoño, 1997; WB, 2006), razón por la que ha sido utilizado en este trabajo.

En este estudio se han utilizado las líneas de pobreza e indigencia provenientes de las Encuestas de Hogares, padronizadas por la CEPAL, los datos de personas viviendo con menos de 1,08 y 2,15 dólares PPP del Banco Mundial y el indicador de subalimentación del conjunto de necesidades básicas insatisfechas. Se debe tener en cuenta que estamos utilizando datos de fuentes secundarias y que, por ello, la comparación dista de ser perfecta. En principio, los cuestionarios varían entre países e incluso en un mismo país a lo largo del tiempo. Así, los datos no serían comparables entre países por usar diferentes metodologías de pobreza. De todos modos, los datos de CEPAL para medir la línea de indigencia recalculan la canasta básica de alimentos incluyendo "los hábitos de consumo, la disponibilidad efectiva de alimentos, sus precios relativos, así como las diferencias de precios entre áreas metropolitanas, de las áreas urbanas y zonas rurales" (CEPAL, 2005: 67). La institución toma el cuidado de actualizar las líneas de pobreza de acuerdo con la variación de precios del consumidor desde la fecha en que la encuesta fue realizada como así también de llevar a cabo correcciones de los datos debido a la falta de respuestas y la subdeclaración. Por otro lado, como hemos dicho, la inclusión de los datos del Banco Mundial, cuyas fuentes de información (Deininger y Squire, 1997) representan amplias bases de datos para un numero abarcador de países, facilitan un cierto tipo (mínimo) de comparación.

En un primer momento, para analizar la relación entre crecimiento del producto y su impacto sobre la pobreza, analizamos el crecimiento del producto bruto interno de los países latinoamericanos y la media de la región, desde 1950 hasta el presente y lo contrastamos con las magnitudes de pobreza e indigencia de la región en su conjunto y en cada país en ciertos puntos determinados de tiempo: 1970 (en los casos disponibles), 1980, 1990, 2000 y el último dato disponible (circa 2005). Privilegiamos el ingreso per cápita porque es útil para contrarrestar el argumento frecuente de que el impacto del crecimiento vertiginoso de la población invalida los efectos positivos del crecimiento, que se esconde bajo el argumento de que aun cuando la economía crece no alcanza a acompañar el aumento poblacional, por lo que se debe trabajar sobre las tasas de fecundidad. Considerar el producto bruto per cápita toma en cuenta la presión poblacional, por lo que se vuelve un mejor indicador a los efectos de comparar las variables. 
El segundo momento de la estrategia metodológica se propone establecer la relación entre desigualdad y pobreza, ateniéndonos para ello a diversas medidas de desigualdad. Del mismo modo que la medición de pobreza, establecer una medida de desigualdad presenta ciertas complejidades. Una cuestión central se relaciona con la conocida pregunta que realiza Sen: ¿desigualdad de qué?, teniendo en cuenta que la desigualdad en diferentes ámbitos (riqueza o felicidad por ejemplo) suelen ser divergentes entre si. Considerando nuestro marco teórico, como así también la disponibilidad de datos, nos referimos aquí a desigualdad de ingresos y/o consumo, es decir, a un factor de desigualdad material. Tomamos para ello dos indicadores: el Índice de Gini y la relación entre los quintiles de distribución.

El Índice de Gini expresa numéricamente la desigual apropiación de la riqueza al interior de una determinada sociedad. En términos técnicos este indicador puede ser expresado gráficamente por la Curva de Lorenz, que representa el consumo o el ingreso de una sociedad dividido en 10 partes iguales, o deciles de apropiación. En el gráfico, el eje horizontal representa el porcentaje de la población, comenzando por los más pobres a la izquierda y ubicando a los más ricos en la derecha. En el eje vertical, por su parte, se ubica el porcentaje de ingresos o gastos que corresponde con la población ubicada en el eje horizontal. Considerando que una distribución igualitaria será aquella en que cada 10\% de la población reciba el 10\% del ingreso, esta situación sería coincidente con la línea que divide en 45 grados el cuadrado. Las sociedades más desiguales (entre ellas las latinoamericanas) presentarán una tendencia hacia un ángulo de 90 grados ubicado hacia el ángulo interior derecho (Gangas Peiró, 2003; Paes de Barros et al., 2005). Expresado numéricamente, el Gini varia entre 0 y 1 , siendo más igualitario al tender a cero. A su vez, el porcentaje de ingresos que apropian los más ricos y los más pobres al interior de una sociedad es una medida más clara sobre la relación entre las diversas clases y fracciones de clase, pues es una muestra más cabal de cómo se distribuye la riqueza en ese país,

Por último, se debe tener en cuenta que las medidas de desigualdad de los diferentes países presentan también un problema de "comparabilidad" que se relaciona con las diferencias en las fuentes de datos: mientras algunos países miden ingresos otros se centran en el consumo (WB, 2006; Paes de Barros et al., 2005) y está afectado a su vez por otros factores como por ejemplo, considerar la fuente de ingresos con o sin impuestos, la inclusión o no de transferencias, si se tienen en cuenta solo los ingresos laborales, si se refiere solo a ciertas áreas (rurales o urbanas) o a todo el país, entre otras. En definitiva, en un tema tan sensible como el de la desigualdad y las condiciones sociales, las bases 
de datos con las que contamos permiten solo una "cuadro tentativo de las diferencias de desigualdad entre países" (WB, 2006: 38), que pueden ayudar a caracterizar un cuadro de diferencias entre países antes que ofrecer una concisa medida de esas diferencias.

Dos son las formas por medio de las cuales buscamos establecer el impacto de la desigualdad sobre la situación de pobreza. Por un lado, llevamos a cabo una comparación de algunos países latinoamericanos con estados con similar ingreso medido en paridad de poder de compra. Teniendo en cuenta que se toman fuentes secundarias de datos que dimensionan la pobreza como insuficiencia de ingresos o de renta, esta solo puede ser resultado de la escasez de recursos de la sociedad analizada o de la calidad de la distribución de estos recursos (Paes de Barros et al. 2005). Tomando como valido este supuesto, si dos países presentan similar ingreso per cápita (anulando así el factor demográfico) y diferencias significativas en la proporción de personas consideradas pobres (medidas por el mismo indicador o padronizando los datos existentes) se entiende que dicha situación solo puede ser causada por las diferencias en la distribución del ingreso. Este ejercicio puede ser complementado comparando a los países de la región con aquellos que presentan similar población. Las diferencias en las tasas de pobreza podrán provenir: i) de disímiles ingresos; ii) de diferencias en la distribución de dichos ingresos.

\section{EL DEBATE SOBRE CRECIMIENTO, DESIGUALDAD Y POBREZA}

Una amplia gama de la bibliografía aborda desde diversas perspectivas la relación crecimiento, desigualdad ${ }^{4}$ y pobreza. Una vertiente, que no analizaremos aquí, estudia el impacto de la desigualdad sobre el crecimiento económico sostenido y se basa en considerar de qué modo la desigualdad influye sobre el escaso crecimiento económico ${ }^{5}$. Nos interesa aquí el debate más directo, que estudia la relación crecimiento-pobreza-desigualdad o, de modo menos directo, la calidad del crecimiento/desarrollo latinoamericano.

El modelo económico neoliberal o neoclásico, dominante pese a la crisis de su hegemonía, concibe como motor fundamental del desarrollo al crecimiento económico y prioriza intervención pública y

\footnotetext{
4 Una razón de orden práctico contribuyó a la difusión de los estudios sobre desigualdad del ingreso: el hecho que las sociedades europeas, acostumbradas a una relativa igualdad en la posguerra, vieran aumentar la desigualdad a partir de las diferencias salariales (Atkinson, 1997). Debemos agregar el caso de las economías latinoamericanas y de la ex órbita soviética, durante los años noventa.
}

5 Para una lista de la profusa bibliografía, veáse Iradian (2005), como así también Barro (1999), Benabaub (1996) y Ferreira (1999), entre otros. 
recursos dirigidos hacia el desempeño económico argumentando que el éxito en el marco de una fase de recomposición del modo de producción capitalista (Montero, 2004) se basa en economías abiertas en competencia global

El argumento de su estrategia de desarrollo es que existiría un efecto rebalse mediante el cual la dinámica del crecimiento generaría mayores fuentes de empleo e ingresos, además de recursos fiscales adicionales para políticas redistributivas y programas de reducción de la pobreza. El pretendido crecimiento económico debe asentarse sobre tres pilares fundamentales que conducirían, a través del crecimiento, a la superación de la pobreza: el sector privado, el mercado y la economía internacional.

La asociación entre crecimiento económico y reducción de la desigualdad está basada en Kuznets (1955) ${ }^{6}$ quien formuló una hipótesis relacionando el crecimiento y la distribución del ingreso según la cual en las fases iniciales del crecimiento económico se intensifica la concentración del ingreso, pero esta disminuye a medida que continúa la expansión. Eso se debería a que al inicio existiría una necesidad de realizar grandes inversiones en infraestructura y en bienes de capital. Al continuar el crecimiento, la generación de empleo y los aumentos en la productividad conducirían a salarios más elevados y a una mejor distribución del ingreso. Teóricamente, a largo plazo (deberíamos preguntarnos aquí: ¿cuán largo?) el desarrollo económico debería conducir a una mayor igualdad, a pesar de no ser inmediato, pues el primer impacto del desarrollo económico bajo ciertas condiciones iniciales debería contribuir a un incremento de la desigualdad para ceder paso a una etapa de desigualdad estable y luego a su reducción.

La posición, que se refleja en una profusa bibliografía producida, es que (considerando correctos los supuestos de Kuznets) podría pensarse que los estudios conocidos sobre crecimiento económico e igualdad en América Latina no registren sino una superposición de esas etapas como resultado de las diversas trayectorias de los países. En otras palabras, la relación directa entre crecimiento y reducción de la pobreza no se invalida, sino que deben esperarse resultados a largo plazo.

Esta relación ha sido abordada a menudo desde la economía y los organismos multilaterales de crédito. Desde los años setenta, el Banco

6 Los trabajos de Kuznets son de la década del cincuenta y posteriores a otros estudios, como los de Lewis (1954) y Kaldor (1956). Para Kaldor la desigualdad del ingreso, concentrando éste en los ricos, que tienen mayor propensión a ahorrar, es necesaria para el crecimiento, porque el ahorro generará acumulación de capital y crecimiento (Iradian, 2005). 
Mundial (cuyo eslogan, tallado incluso en enormes letras en su lujosa sede en Washington, es: "Nuestro sueño es un mundo sin pobreza") presenta la pobreza como un problema social agudo y adhiere a la defensa del crecimiento para superarla.

Entre los estudios elaborados por el Banco Mundial, Morley (1994) encuentra que la pobreza se reduce con el crecimiento económico. Sin embargo, en un artículo posterior (Morley, 2000) introduce la relación con la desigualdad y afirma que difícilmente la distribución irá a mejorar solo con el crecimiento, manteniéndose inalterado el padrón distributivo.

Analizando la primera parte de la década del noventa, Székely y Londoño (1997: 21) afirmaban que la región (ellos consideran solo 13 países que incluyen Jamaica y Haití, pero excluyen por ejemplo a la Argentina) tenía un "exceso" (sic) de pobreza de aproximadamente el 50\% durante los años noventa, refiriéndose a que si la región tuviese un menor grado de desigualdad la pobreza sería también mucho menor o incluso desaparecería; por ejemplo, si la región tuviese la distribución del ingreso equivalente a Europa o el Sudeste asiático, menos del 3\% de la población se encontraría en situación de pobreza moderada.

Unos años más tarde, los mismos autores (Székely y Londoño, 1997: 10) afirmaban que "existe una clara relación positiva entre incrementos en la desigualdad y en la pobreza", pero también consideran la relación entre crecimiento y pobreza afirmando que "existe una fuerte relación inversa entre crecimiento económico y pobreza”. De todos modos, concluyen que "ciertos progresos han sido alcanzados debido al crecimiento económico durante la década del noventa" afirmando, con un dejo de optimismo, que "un contexto macroeconómico como el experimentado por América Latina durante los años noventa crea condiciones favorables para la reducción de la pobreza".

Desde el FMI, Iradian (2005: 8) revisa el impacto de la desigualdad sobre el crecimiento económico y es categórico al relacionar directa y positivamente crecimiento y superación de la pobreza, afirmando que "la relación positiva entre crecimiento económico y reducción de la pobreza es clara" aunque reconoce que existen diferencias significativas entre países sobre la tasa de reducción que ocurre con el crecimiento, considerando que las "desigualdades iniciales" y las "fuentes y calidad del crecimiento" tienen profunda influencia sobre el impacto final del crecimiento sobre la pobreza. Se admite que, en teoría (sic), existiría la posibilidad de que un país tenga crecimiento económico sin beneficiar significativamente a los más pobres. Sin embargo, las conclusiones del artículo confirman la validez de la curva de Kuznets, según la cual la desigualdad primero presenta un incremento y luego un descenso du- 
rante el proceso de desarrollo económico, resaltando que "con otros factores inalterados, el crecimiento conduce a menor reducción de la pobreza en sociedades desiguales que en aquellas igualitarias".

Desde la CEPAL, Ocampo (1998: 13) menciona la alta desigualdad latinoamericana como característica del desarrollo en la región, pero no deja de considerar el crecimiento como benéfico, al afirmar que "la década perdida fue un período de marcado deterioro en materia de pobreza en América Latina. [...] y en los noventa, por el contrario, la recuperación del crecimiento económico ha impulsado una importante mejoría en los indicadores". El trabajo no niega, sin embargo, la heterogeneidad entre países y la desigualdad, pero pone el acento en las diferencias entre remuneraciones según el grado de instrucción y la orientación del gasto y las políticas sociales.

Contrastando la relación lineal entre crecimiento y reducción de la pobreza, los trabajos son variados. Algunos refutan la información de los organismos multilaterales (Robbins, 1996; Berry, 1997) con énfasis en los efectos de los procesos de ajuste estructural llevados a cabo en la región, afirmando que las medidas de liberalización y apertura comercial han sido nocivas para los sectores populares. Otros autores (Uribe López, 2005) afirman que la agudización de las desigualdades de ingreso vuelven el crecimiento un camino tortuoso, que no es seguro que lleve a un alivio de la pobreza, ni siquiera aquella absoluta.

Mayorga (2004) califica a la economía informal como "una de las tendencias principales del desarrollo económico-social del siglo XXI", la cual genera un "patrón de desigualdades y marginación". En definitiva, "el modelo de desarrollo reproduce y profundiza desigualdades inscritas en el desarrollo histórico de nuestras sociedades", obligando a los actores, sean urbanos o rurales, a estrategias de supervivencia. En la misma línea de análisis, Montero (2004) propone que el modelo de acumulación vigente produce, inevitablemente, pobreza e inequidad, considerando que la "reducida y precaria generación de empleo, concentración de ingresos (y) exclusión social [...] son aspectos inherentes a la creciente subordinación de la economía real a la economía financiera".

Puyana (2000) sostiene que en casi todos los países ha habido crecimiento durante los años noventa pero no ha habido reducción en la pobreza o el desempleo, en virtud de que este ha sido bajo (respecto de los parámetros necesarios para reducir la pobreza e incluso para no aumentarla), inestable, concentrado y desigual. Laurell (1999), a su vez, afirma que durante los años noventa, a pesar de existir cierto crecimiento, han crecido la pobreza y la desigualdad.

Gangas Peiró (2003) presenta una serie de indicadores para los años 1960, 1970, 1980 y 1990, comprendiendo a un grupo de países 
latinoamericanos y europeos, teniendo el cuidado de tomar medidas complementarias de desigualdad y pobreza, y llega a la conclusión de que es difícil afirmar, para el caso de América Latina, que ha habido una reducción en la desigualdad y, a pesar de que el núcleo del trabajo no lo constituye la cuestión del crecimiento y la relación que aquí nos ocupa, presenta datos de crecimiento del producto per cápita y ciertos indicadores de (ausencia) de bienestar, para afirmar que no existe una conclusión lineal y univoca y que la región dista de tener efectos positivos del crecimiento.

Una vertiente de la bibliografía no descarta el efecto positivo del crecimiento, pero destaca que en el caso latinoamericano la relación se ve afectada por los ciclos del mismo. En esta línea se encuentra Iglesias (1998) quien resalta el papel de la recesión sobre el nivel de los salarios y el empleo. De Janvry y Saudolet (2002), que llevan a cabo un estudio de doce países latinoamericanos cubriendo el período 19701994, enfatizan también que pobreza y desigualdad son sensibles al crecimiento, ya que caen en períodos de crecimiento y suben en los tiempos de recesión. En este trabajo se destaca la mayor sensibilidad de la pobreza rural frente a los períodos de crecimiento, a diferencia de la pobreza rural, que parece menos afectada por las variaciones del crecimiento. Un factor interesante es que sus efectos positivos se encuentran en directa relación con los grados de desigualdad, pese a lo cual esta crece en los períodos de recesión sin caer en los períodos de crecimiento.

\section{Crecimiento y POBREZA: LA EVIDENCIA EMPíricA}

En esta sección presentaremos el análisis de la serie de datos para poner a prueba la segunda hipótesis planteada: que el crecimiento no conduce a una reducción significativa de la situación de pobreza en que se encuentran amplios sectores de la población en América Latina. Los datos sobre crecimiento comprenden el período 1950-2004 y corresponden al crecimiento del producto bruto interno per cápita a precios constantes, base año 2000 .

En términos generales, como se puede observar en el Cuadro 1, el crecimiento puede ser caracterizado como oscilante, altamente irregular. Si en los años sesenta y setenta el desempeño económico produjo un crecimiento estable y continuo, los años ochenta representarían una regresión en esa tendencia, en parte por los efectos de la crisis fiscal y la correspondiente crisis de la deuda externa. En los años noventa se revertirá el proceso de caída y la mayoría de los países (excepto Colombia y Paraguay) mostraron tasas de crecimiento, con desigual intensidad. 


\section{Cuadro 1}

Tasa de crecimiento del PBI

\begin{tabular}{|c|c|c|c|c|c|c|}
\hline & Promedio 1951-1959 & 1961-1969 & $1971-1979$ & $1981-1989$ & 1991-1999 & 2000-2004 \\
\hline Argentina & 0,6 & 3,1 & 1,3 & $-2,7$ & 3,1 & $-2,6$ \\
\hline Bolivia & $-1,9$ & 0,9 & 2,1 & $-2,4$ & 1,5 & 0,5 \\
\hline Brasil & 3,8 & 3,9 & 5,9 & 0,9 & 0,7 & 1 \\
\hline Chile & 0,9 & 2,8 & 1 & 1,5 & 4,7 & 2,1 \\
\hline Colombia & $-1,4$ & 2 & 3,4 & 1,1 & 0,9 & 0,6 \\
\hline Costa Rica & 3,4 & 1,7 & 3,3 & $-1,1$ & 2,3 & 0,3 \\
\hline Ecuador & 1,9 & 1,4 & 6,5 & $-0,8$ & $-0,2$ & 2 \\
\hline El Salvador & 1,8 & 2,2 & 1,3 & $-2,8$ & 1,9 & 0,4 \\
\hline Guatemala & 0,8 & 2,3 & 3 & -1 & 1,1 & 0,2 \\
\hline Honduras & $-0,2$ & 0,4 & 2,3 & $-0,1$ & $-0,4$ & 0,5 \\
\hline México & 2,7 & 3,5 & 3,2 & $-0,2$ & 1,7 & 0,9 \\
\hline Nicaragua & 2,9 & 4,2 & $-2,3$ & $-3,8$ & $-0,6$ & 0,2 \\
\hline Panamá & 0,8 & 5,6 & 2,2 & 0,6 & 3,1 & 0,5 \\
\hline Paraguay & 0,1 & 1,3 & 4,7 & 0,8 & $-1,1$ & $-2,5$ \\
\hline Perú & 1,8 & 4,3 & 0,8 & $-2,3$ & 1,5 & 1,7 \\
\hline R. Dominicana & & & & 4,7 & 2,7 & $-1,6$ \\
\hline Uruguay & 0,8 & 0,4 & 2,6 & $-0,3$ & 2,6 & $-3,1$ \\
\hline R. B. Venezuela & 3,6 & 2,1 & $-1,6$ & $-2,5$ & $-0,1$ & $-4,5$ \\
\hline A. Latina & 2,1 & 3 & 2,9 & $-0,3$ & 1,4 & 0,2 \\
\hline
\end{tabular}

Fuente: Elaboración propia sobre datos de Penn Table 6.2.

En todo el período analizado solo tres países (Chile, Colombia y Panamá) han tenido tasas de crecimiento per cápita constante a lo largo del tiempo. En el resto de los países el crecimiento y el estancamiento se combinan en ciclos, cuyas características son particulares. Mientras la expansión de los años cincuenta, sesenta y setenta estaba asentada en un modelo de desarrollo endógeno, típico de economías protegidas de dinámicas sustitutivas de importaciones, tras el emergente neoliberal y las transformaciones estructurales de las economías y, el crecimiento de los años noventa se vuelve más inestable en virtud de la mayor sensibilidad a los cambios operados en la economía mundial, como se puede observar en las oscilaciones posteriores a las crisis que tuvieron efectos sobre los mercados internacionales originadas en México, los países asiáticos, Rusia y Brasil. 
En cuanto a la dinámica de la pobreza en relación al crecimiento, en teoría, debería existir una correlación negativa entre pobreza y crecimiento del ingreso per cápita, pero la relación dista de ser lineal. Por el contrario, la sensibilidad de la pobreza frente a las variaciones en el producto es oscilante a lo largo del tiempo y heterogénea entre los diversos países.

\section{Cuadro 2}

Pobreza, Indigencia y Crecimiento del Producto

\begin{tabular}{c|c|c|c}
\hline & \multicolumn{2}{|c|}{ Hogares } & \\
\hline Año & LP & LI & Crecimiento del PPC en la década previa \\
\hline 1970 & 40 & 19 & 2,9 \\
\hline 1980 & 35 & 15 & - \\
\hline 1985 & 37 & 17 & $-0,3$ \\
\hline 1990 & 41 & 18 & - \\
\hline 1995 & 40 & 18 & 1,4 \\
\hline 2000 & 42,5 & 18,1 & 2,3 \\
\hline 2005 & 39,8 & 15,4 & \\
\hline
\end{tabular}

Fuente: Panorama Social de América Latina, 1994, 2004.

PPC: Producto Bruto per cápita a precios constantes, base año 2000.

La década del ochenta, que ha quedado en la historia como la "década perdida”, a pesar de los avances que significó para la región en términos institucionales, fue, sin dudas, un período negativo en términos de distribución del ingreso. Considerando las líneas de pobreza nacionales, encontramos dos situaciones claramente diferentes. Por un lado, excepto en Bolivia (donde pese a la caída del producto se observa una mejora de 2,9 puntos en la línea de pobreza nacional, debido quizá al éxito en el combate a la inflación) en todos los países en que cae el producto (Argentina, Uruguay, Costa Rica, Ecuador, Guatemala, Honduras, México y Venezuela) crece la pobreza, con casos extremos como el de Argentina que, con una caída de $2,7 \%$ anual en promedio, se vio reflejado en un aumento del número de pobres de casi el 100\% (del 13 al 23\%) y México, donde la caída de $0,2 \%$ al año representó un aumento de 5,2\% en el número de personas pobres.

Por su parte, en los países que muestran crecimiento del producto, en todos (Panamá, Brasil, Colombia), excepto en Chile, crece la pobreza. La salvedad en este país es que si bien cae 6\% la pobreza, aumenta en 200.000 personas la cantidad de personas 
que la padecen. En Panamá, el crecimiento de los años ochenta, de $0,6 \%$ anual, no impidió que haya más personas bajo la línea de pobreza, tantos en términos porcentuales como absolutos. Brasil representa el caso típico de crecimiento sin reducción de la pobreza. Pese a que el país creció a tasas altas, a punto de ser considerado como "milagro económico" logrando incluso escapar a la recesión de los años ochenta, no existió un proceso redistributivo. El aumento del producto per cápita en estos años fue de 0,9\%, pese a lo cual el porcentaje (de 47 a $48 \%$ ) y más aun, el número de personas bajo la línea de pobreza aumentó (de 57 a 71 millones). Como se puede ver, la relación esperada se cumple en aquellos países en que cae el producto, pero no en los cuales hay crecimiento. El único caso atípico es Bolivia, donde pese a la caída del producto, cae el porcentaje pero se mantiene constante el número de pobres, probablemente por el descenso en los indicadores de desigualdad y factores demográficos y el mencionado factor de la estabilidad de la moneda.

Ampliando el análisis a las personas viviendo en condición de indigencia el cuadro de situación no varía, pues el número de personas aumenta en Argentina, Colombia, Bolivia, Costa Rica, Ecuador, Guatemala, Honduras y México. Solo Brasil, Chile, Panamá y Uruguay muestran una mejoría de este indicador. Se observa también una relación lineal en los países con caída del producto mientras el crecimiento no se expresa en una disminución significativa de personas viviendo en situación de indigencia.

Entre los factores explicativos del quiebre del ciclo de crecimiento suele mencionarse que el crecimiento de los setenta fue en parte irreal y poco sustentable, asentado en exceso de créditos generando un déficit de la cuenta corriente; la eclosión de los modelos sustitutivos de importaciones; la recesión de los Estados Unidos a inicios de la administración Reagan, en los años 1980-1982, entre otros. También la crisis de la deuda externa que afrontaron los países latinoamericanos ${ }^{7}$ parece tener correlato no solo con los años ochenta sino un impacto bajo la forma de legado que se arrastra hasta nuestros días.

7 La caída del crecimiento, total y per cápita, en los años ochenta, está directamente relacionada con la crisis de la deuda, que se sucedió tras la moratoria unilateral decretada por México en 1982. El costo fiscal de esa crisis representó el 55\% del PBI argentino, el 41\% del producto chileno, el 22\% en Venezuela, el 19,3\% en México y el 13\% del PBI de Brasil y Ecuador (WDR, 2006: 200). 


\section{Cuadro 3}

Crecimiento del Producto y Pobreza, años seleccionados

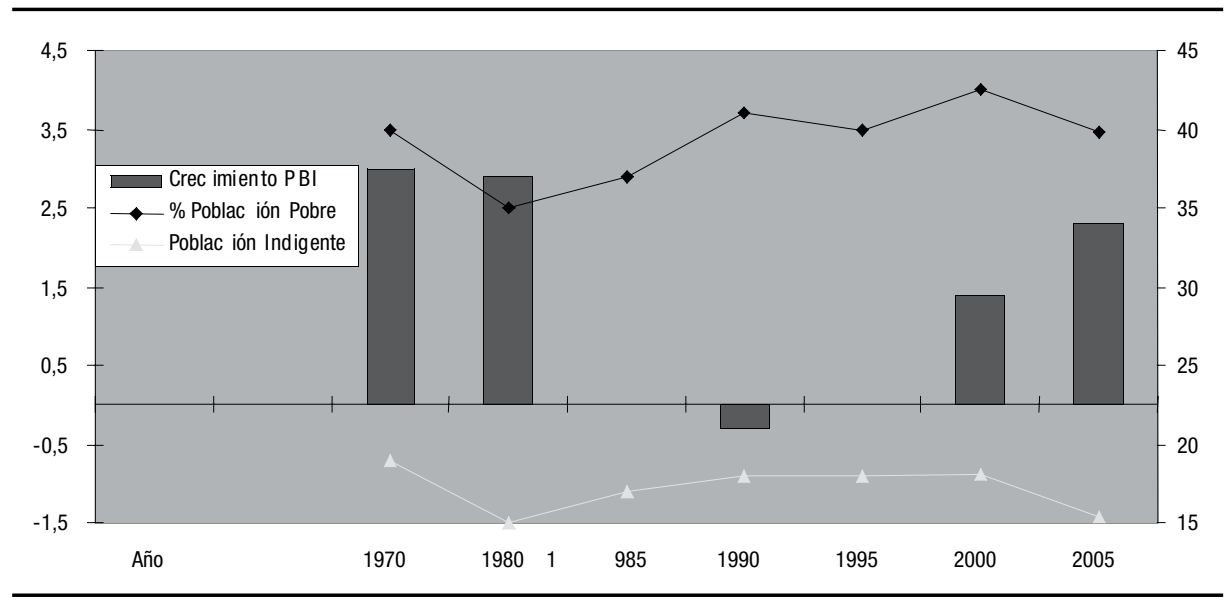

Fuente: Elaboración propia en base a CEPAL, ediciones varias.

La década del noventa representó para un amplio número de países un momento de ajustes económicos estructurales. Estos años presentan una particularidad que los vuelven interesantes para analizar, porque entre economistas, funcionarios políticos y técnicos de los organismos multilaterales de crédito se difundió con fuerza la idea de que las reformas económicas implementadas entre fines de los años ochenta y comienzos de los noventa no solo conducirían a generar y fortalecer el camino del crecimiento económico sino a una mejora social. El discurso dominante escondía, de modo más o menos manifiesto, que solo aquellos países que llevaran a cabo las reformas sectoriales (entre las que se incluían la liberalización financiera, la apertura comercial con el objetivo de generar menores barreras al comercio internacional, la desregulación de las actividades económicas, la privatización de las empresas públicas, la reducción de impuestos personales y a las actividades económicas con el objeto de no desincentivarlas y la disciplina fiscal maximizando el control de gastos del Estado) podrían retomar el camino del crecimiento, negado a América Latina en los años ochenta.

La defensa de las reformas, basada en la estrategia del crecimiento como camino para la superación de la pobreza, respondía a una cuestión de orden práctico: solo el crecimiento del producto o el ingreso per cápita de una sociedad permite la mejora de todos los grupos sociales. La defensa de la teoría del derrame no significaba negar que, 
en teoría, sin crecimiento no pudiese existir una mejora social, sino que, en términos prácticos, eso aparece casi imposible. Solo las tasas sustanciales de crecimiento permitirían mejorar la situación de aquellos ubicados en la base de la distribución del ingreso sin alterar la situación de los no pobres. Dicho de modo sencillo, la copa de los ricos podía llenarse y los pobres disfrutar de las gotas que se derramaran en los períodos de alto crecimiento.

Pese a que, con pocas excepciones (Ecuador, Nicaragua, Honduras, Venezuela y Paraguay), los países muestran expansión del producto, el presupuesto no se cumplió pues el crecimiento de los años noventa no parece tener correlato sustancial sobre los indicadores de pobreza. En aquellos en que hubo caída del producto, la correlación negativa se observa en Ecuador, pero no así en Honduras, donde cae levemente tanto el porcentaje como el número de pobres. Por su parte, en aquellos países que presentan expansión no hay un padrón homogéneo. Por un lado, se encuentra un grupo donde la pobreza crece en cantidad de personas, comprendido por Argentina, Guatemala, Venezuela y Colombia (país donde también hay un aumento porcentual). Por otro lado, los países en que la expansión se expresa en una caída de la pobreza: Brasil, Chile, Panamá y Uruguay. Nuevamente se observa un caso atípico que es Honduras. Los datos parecen confirmar los hallazgos del trabajo ya citado de Hilgert y Székely (1999) que afirman que no se puede afirmar que durante los años noventa haya habido una mejora en la distribución a pesar del crecimiento.

Como se puede observar en el Cuadro 2, el promedio general para los países considerados de América Latina es particular, porque tanto la caída del producto de los años ochenta (de - $0,3 \%$ de promedio anual) como el crecimiento de los años noventa (de 1,4\% anual promedio) generan un aumento sostenido del número de personas viviendo bajo la línea de pobreza (considerando un promedio de las líneas de pobreza nacional), pero el impacto negativo que produce la caída del producto en los años ochenta (del 40,5 al 48,3\% de las personas, con un aumento en el número total de personas de 142 a 207 millones) es más agudo que el impacto positivo que tuvo el crecimiento del PBI per cápita de los años noventa (una baja de 4,5 puntos porcentuales, aunque un aumento de unos 12 millones de personas). Considerando como punto de partida los años setenta, en que las cifras comienzan a estar disponibles permitiéndonos un análisis de la sensibilidad entre ambas variables, se puede ver que el efecto del crecimiento es escaso. Si observamos el Cuadro 3, la población pobre se mantiene casi constante durante 35 años en torno del 40\%, mostrando un descenso en los años setenta, pero un crecimiento considerable en el decenio siguiente, sin que el crecimiento de los años noventa se 
haya expresado en una reversión significativa de esta dinámica. Solo la indigencia ha mostrado una ligera reducción, siendo más sensible a los períodos de crecimiento.

Con el objetivo de ampliar el horizonte temporario de análisis, hemos apelado a dos estimativas para suplir la ausencia de datos oficiales referentes a líneas nacionales de pobreza. Naciones Unidas (1980) alega que, a pesar del crecimiento durante la década del cincuenta en la región fue de 5, 2\% anual para el total de la región (2, 3 por ciento de ingreso per cápita, un poco superiores al 2,1\% que resulta de la estimativa hecha para esta investigación), a comienzos de la década del sesenta, el $20 \%$ más pobre de la población recibía el $3,1 \%$ del producto y el $50 \%$ más pobre, el 13,4; y las personas viviendo en la pobreza alcanzaban el 51 por ciento de la población. Cifras similares son presentadas por Perry et al. (2006), quienes realizan una estimación macroeconómica para el total de la región, sobre la base de aproximación log-normal, en la que calculan que la población bajo la línea de pobreza viviendo con menos de 2 dólares al día representaría el $60 \%$ en 1950, el 50\% en 1960 y aproximadamente el $40 \%$ a inicios de 1970, bajando al $23 \%$ en 1980 . Sobre la base de estas estimaciones, se puede medir el impacto del crecimiento sobre la pobreza en este ciclo de crecimiento económico.

Considerando que la tasa de crecimiento de los años cincuenta fue de $2,1 \%$ anual, representado aproximadamente un $21 \%$ en los diez años de la década, la reducción de la pobreza en 10 puntos es importante, a pesar de continuar siendo alta. En esta primera década parece constatarse los supuestos de asociación entre crecimiento y superación (gradual) de la pobreza, en una tasa de aproximadamente 1:0,5, representando medio punto de caída de la pobreza por cada punto de crecimiento del producto bruto per cápita, acabando la década con el $50 \%$ de la población viviendo con menos de 2,08 dólares al día.

La asociación parece confirmarse también en el crecimiento que se dio en la década del sesenta, que comienza con aproximadamente el $50 \%$ de la población viviendo bajo la línea de pobreza moderada y tras una tasa de promedio anual de crecimiento de 3\% mostró una reducción significativa, también de 10 puntos, aunque la asociación crecimiento-desigualdad se constate en menor proporción, pues ante mayor crecimiento per cápita se obtuvo la misma reducción de la pobreza que la década anterior, con una tasa de 1:0,33, es decir, que cada punto de crecimiento del producto generó una reducción de 0,33 puntos de mejora en la situación de los pobres. Vistos en su conjunto, los años de la segunda posguerra representan un crecimiento aproximado total de más del $50 \%$ del producto y una reducción de las cifras de pobreza de alrededor de 20 puntos porcentuales. 


\section{Cuadro 4}

Relación entre ingreso per cápita y porcentaje de pobreza

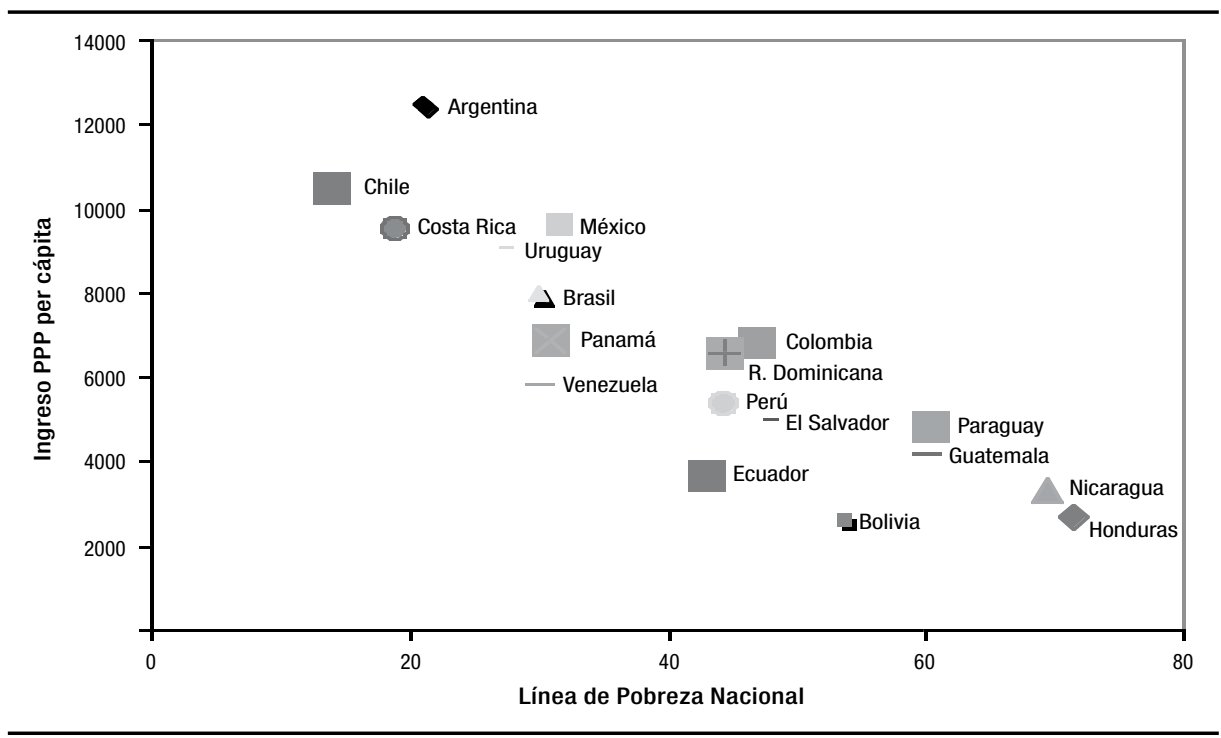

Fuente: Elaboración propia sobre datos de WB (2006), CEPAL $(1994,2006)$.

En los años setenta el crecimiento tuvo, para la mayoría de los países, un efecto en las cifras de pobreza. Pero la particularidad es que esa caída en la pobreza se da en forma paralela al crecimiento y la caída de la desigualdad, al menos, medida por el índice de Gini. Con un crecimiento levemente inferior al de los años sesenta, de 2,9\% anual la caída en la pobreza fue significativa, tomando como válidas las estimativas, pasando del 40\% de las personas en 1970 al 23\% en 1980.

Si consideramos válidos los datos de estas fuentes secundarias, se puede hablar de dos ciclos de crecimiento, con características disímiles. Aceptando que la pobreza bajó a razón de 1 punto porcentual acumulativo anual hasta los años setenta y aun más en los años setenta (pasando del 40 al 23\%), se constata el quiebre de la dinámica descendente, pues a partir de los años ochenta se muestra estancada en torno del 20\%. Dicho de otro modo, el ciclo 1950/1980 parece tener un efecto sobre la reducción de la pobreza que no muestra el ciclo actual 1990-2004, o incluso el período oscilante 1980-2004 (caída y posterior crecimiento).

Como se puede ver, el crecimiento no parece generar un proceso redistributivo y ni siquiera una mejora sustancial de los considerados 
pobres. Incluso analizando la relación entre pobreza y producto per cápita en un momento fijo de tiempo, como se presenta en el Cuadro 4 (datos correspondientes al año 2005) se observa que, si bien en los países pobres se constata la correlación, en aquellos de ingreso medio o alto persisten tasas de pobreza en torno del $20 \%$ de la población. Esto es, en los países de la región de ingreso bajo o medio bajo, la pobreza es alta, pero en los países con ingreso medio alto o alto, las tasas de pobreza, si bien menores, son también altas. La explicación técnica que esgrimen los economistas, descartado el efecto poblacional, es que no todo crecimiento conduce a un beneficio global de la sociedad y existe un tipo de crecimiento que puede aumentar (en teoría) el producto económico de una determinada sociedad sin modificar la distribución: el crecimiento puro, neutro o proporcionalmente distribuido. La alternativa de combate a la pobreza por medio del crecimiento económico exigiría plazos largos y altas tasas de crecimiento, situación que, si volvemos nuevamente la atención hacia las tasas de crecimiento de la región a partir de los años cincuenta parece poco probable.

Incluso considerando una manifestación extrema de la situación de indigencia que coloca a las personas al borde mismo de la subsistencia material, como es el porcentaje de la población que se encuentra por debajo del nivel de energía calórica considerado mínimo para la supervivencia, el crecimiento tampoco es responsable por una baja sustancial en el conjunto de los países analizados, puesto que pasa del 20 al 10 por ciento de la población, en un lapso de 35 años, pero se encuentra en la actualidad en el mismo rango desde mediados de la década del noventa.

Dicha reducción es ligeramente más significativa en el caso de los países de América del Sur, en que pasa del 20 al 9\%, aunque al igual que la región en su conjunto, esta baja se dio en los años setenta y comienzos de los ochenta, manteniéndose inalterada durante los años ochenta y generando una leve reducción durante los primeros años de la década del noventa, sin mostrar desde ese momento avances sustanciales (10\% en 1995-1997 y 9\% en 2002-2003). Traducido: en un período en que la región creció, no ha habido siquiera una reducción significativa de la característica más perversa de la situación de pobreza, como es la subalimentación.

En América Central la situación es aun más alarmante, pues el 19\% de los 40 millones de personas que habitan la región consume menos calorías de las necesarias. También en este caso, la variación más significativa se ha dado en los años sesenta y setenta, un período en que el crecimiento promedio parece reflejarse en una mejora de este indicador. La diferencia es que los años ochenta, que no tienen 
efecto positivo para América del Sur y para la región en general, representan una leve mejoría para los países centroamericanos $(20 \%$ en 1979-1981 y 17\% en 1990-1992) y considerados los seis países en su conjunto ha crecido en los últimos años, por lo que se encuentran peor que una década atrás, teniendo un avance prácticamente nulo en los últimos 25 años (20\% en 1979-1981 a 19\% en la última medición de la FAO, de 2002-2003).

Considerados por países se pueden considerar tres situaciones diferentes. Un primer grupo en que el porcentaje es "bajo", en el cual se consideran Argentina (inalterado en torno del 2,5\% y con una leve suba entre 2001 y 2004 producto de la crisis social tras la "explosión" de la convertibilidad del peso), Uruguay (que muestra el mismo porcentaje que hace 30 años aunque con un pico en los años ochenta, volviendo a caer en los años noventa) y Chile (que crece entre inicios de los años setenta y de los noventa, del 6 al 8\%, bajando a partir de allí, mostrando, en este caso una sensibilidad proporcional al crecimiento, por lo que parece imperar la lógica del crecimiento del producto o efecto derrame).

En un segundo grupo se deberían incluir a los dos países con una tasa "media" de personas bajo el nivel mínimo de consumo calórico a inicios de los años setenta, que muestran trayectorias divergentes. Paraguay empeoró su porcentaje, pasando del 11 al 15\% en todo el período, con la particularidad de tener un comportamiento irregular respecto el crecimiento económico, a pesar de crecer en los años setenta, se mantuvo constante (11\% en 1969-1971 y 12\% en 1979-1981) y aumentó al $18 \%$ en una década en que el país tuvo un crecimiento per cápita del $0,8 \%$ anual. A pesar de la caída del producto en los años noventa, hubo una leve mejora. México mejoró sustancialmente, aunque con la particularidad de que ese avance se produjo en los años setenta, sin cambios en los últimos 25 años. En este caso, la variación del producto tampoco parece contar, ni positivamente (como el crecimiento de 1,7\% de los años noventa y de $0,7 \%$ desde 2000 ) ni negativamente (como la caída anual del $0,2 \%$ que sufrió durante los años ochenta).

Finalmente, se encuentra el amplio grupo de países cuya población con consumo calórico debajo del mínimo necesario era alta a inicios del período y que puede ser subdividido en tres. Aquellos países con una mejora sustancial (en que parece cumplirse la premisa del impacto del crecimiento: Brasil, Colombia, Costa Rica, Ecuador y El Salvador); un segundo grupo en que hubo una mejora leve (Bolivia, Guatemala, Honduras, Perú y República Dominicana) y el último en que la situación empeoró (Nicaragua, Panamá y Venezuela). En este grupo, solo en Nicaragua y Venezuela parece existir una relación con la variación del producto, mientras que Panamá muestra un crecimiento constante que no se traduce en una mejoría de este indicador esencial. 
En cuanto al primer subgrupo el caso más interesante es el de Colombia, que presenta bajo crecimiento y una reducción significativa y prácticamente constante como se puede ver, pasando del 39 al 13\%. La misma situación se encuentra en El Salvador, donde el crecimiento es modesto pero la reducción es importante, pasando del 45 al 11\%. En Brasil y Costa Rica se puede ver no solo un crecimiento del producto per cápita, sino también en PPP.

Por último, el grupo de países que muestra una leve mejoría, solo en los casos de Perú y Guatemala se encuentra una correlación constante entre crecimiento y caída de personas que se encuentran subalimentadas, mientras que en Bolivia y Honduras hay una reducción a pesar de la caída del producto per cápita, aunque en el primer país la reducción se produjo principalmente en el período de crecimiento del producto (los años setenta, con un crecimiento de $2 \%$, en que pasó del 35 al 26\%), manteniéndose casi constante a partir de allí.

En conclusión, si bien existe una correlación en algunos países, no se puede afirmar que exista una relación directa y unívoca entre crecimiento del ingreso per cápita y mejora sustancial de los indicadores de pobreza por ingreso o de personas viviendo por debajo del consumo de energía mínimo como una de las manifestaciones más acuciantes de la pobreza. Por el contrario, la relación es irregular.

\section{CRECIMIENTO CONCENTRADO Y DESIGUALDAD EN AMÉRICA LATINA}

Si el crecimiento no parece ser el camino para la superación de la pobreza y la indigencia en la región, se debe prestar atención a la variable desigualdad. Como hemos afirmado, considerando a la pobreza como ausencia de ingresos necesarios para afrontar las necesidades básicas, su expresión en una determinada sociedad puede deberse a la escasez de recursos o a la calidad de la distribución de dichos recursos.

El índice de Gini es un indicador útil para tener una representación de la distribución de la renta, en que sabemos que más cerca de 1 se encuentran los países más desiguales y que en torno de 0,500 (como los que presentan los países analizados) se trata de regiones altamente desiguales, pero por tratarse de un índice sintético no provee información sobre el porcentaje de renta apropiado por los diferentes grupos, para lo cual debemos apelar a los datos desagregados de distribución. Tomamos para ellos, la distribución del ingreso por quintiles de percepción ${ }^{8}$.

8 Como hemos afirmado, cualquier indicador para medir pobreza y desigualdad presenta falencias. El caso específico de los quintiles de percepción del ingreso no da 
Los datos que se presentan en el Cuadro 5 muestran que ningún país de la región presenta un índice de Gini bajo. Por otro lado, es significativo que de los cuatro países con mayor grado de desarrollo relativo de la región (Argentina, Brasil, México y Chile), solo México muestra una (leve) mejoría y los demás parecen invalidar el principio postulado hace más de 50 años por Kuznets de que en las fases iniciales del crecimiento económico se intensifica la concentración del ingreso, pero esta disminuye a medida que continúa la expansión. Esta idea de que la desigualdad aumenta en los períodos de desarrollo y transformación de la matriz productiva se muestra inservible también para analizar el caso brasileño, la potencia industrial de la región.

\section{Cuadro 5}

Relación entre índice de Gini y personas bajo la línea de pobreza

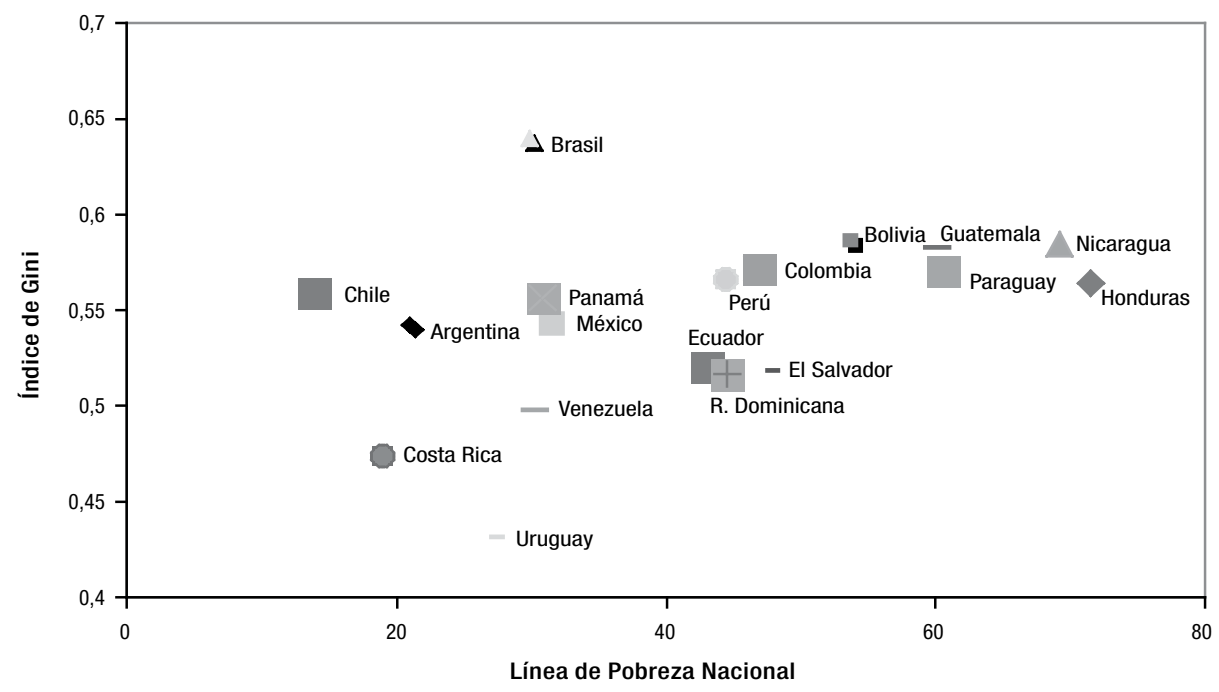

Fuente: Elaboración propia sobre datos de WB (2006), CEPAL (1994, 2006).

En primer lugar, en relación a los ingresos de los países de la región, encontramos que, excepto un reducido núcleo que tiene ingresos muy bajos menores a 3500 dólares PPP per cápita (El Salvador, Bolivia, Honduras), la mayoría de los países cuenta con ingresos per cápita

cuenta de las diferencias que existen al interior de cada subgrupo, debiéndose tomar como supuesto que el ingreso es distribuido equitativamente. 
superiores al 50\% de los países del mundo. El mayor número se encuentra en una media entre 4000 y 9000 dólares PPP y un núcleo no menor tiene ingresos altos o medio altos.

En los países con ingreso bajo para parámetros internacionales, no se observa un padrón respecto de países con ingreso PPP per cápita similar. Así, Honduras presenta mayor porcentaje de pobreza que Georgia pero menos que la India; Bolivia, menos que Camboya y más que Moldavia y Guatemala o Paraguay, más pobreza que Marruecos y menos que Egipto o Sri Lanka.

En los países con ingreso medio o medio alto, la situación es irregular pero, en términos generales, el grado de pobreza de los países de la región es mayor que el de países con ingreso per cápita similar, lo que estaría indicando que la distribución y no la escasez de recursos es la principal causa de la pobreza. Brasil, cuyo ingreso per cápita medido en paridad de poder de compra es de aproximadamente 8800, tiene mayor porcentaje de personas viviendo con menos de dos dólares PPP al día $(21,2 \%)$ que Bielorrusia (menos de $2 \%$ ), Turquía (18\%) y Tunes $(6,6 \%)$. La misma situación se da en Costa Rica $(9,8)$ respecto de Bulgaria $(6,1 \%)$ y, más notable aun, de Argentina (7,1\%) en comparación con Eslovenia (2,9\%), Letonia $(4,7)$ y Polonia (menos de $2 \%$ ), país que tiene ingreso per cápita menor pero cifras sustancialmente menores de pobreza. También se muestra una diferencia notable entre Colombia y Panamá (en torno del 18\%) respecto de Macedonia (menos de $2 \%$ ); Venezuela (40\%) en comparación con Ucrania (4\%); México $(11,6 \%)$ respecto de Malasia $(9,3 \%)$ y Perú $(30,6 \%)$ en relación a Jordania (7\%) y Azerbaiyán (9,1\%).

En todos los casos, se constata que la causa, considerando que el ingreso es constante entre los países analizados, es la calidad de la distribución, pues los países latinoamericanos que presentan mayores porcentajes de pobreza que otros con ingreso similar presentan un mayor valor del índice de Gini y mayor distancia entre el decil más rico y el más pobre de la población. El papel que juega la desigualdad se percibe en la situación contraria: cuando la cantidad de personas pobres del país analizado en América Latina es menor que en un país con ingreso similar al suyo se cumple la regla de que el país en cuestión presenta una mejor distribución del ingreso. En términos generales, el índice de Gini y el ratio entre el decil más rico y el más pobre en los países de la región muestran un padrón inequitatito de distribución. Mientras que el ingreso del decil más pobre en los países europeos o asiáticos es superior al 3\%, en los países de la región se ubica en torno del 1\%. En el extremo opuesto, el decil más rico se apropia en América Latina de al menos el $40 \%$ del ingreso, con casos extremos como Colombia o Brasil, cercano al 50\%. 


\section{Conclusiones}

La principal preocupación de este trabajo fue intentar analizar la relación crecimiento-desigualdad-superación de la pobreza, partiendo de la base que el pensamiento hegemónico defiende la idea del crecimiento sostenido como garantía de mejores indicadores de bienestar social. En primer lugar, hemos visto que los países de América Latina han crecido en el amplio periodo 1950-2004, con diferentes ritmos pero con la característica de no haber generado una reducción significativa y mantenida en el tiempo de la pobreza, sea esta medida por ingresos o por el más acuciante indicador de subalimentación. Un argumento repetido por organismos internacionales, economistas y funcionarios de gobierno, tan responsables como incapaces de enfrentar la problemática de aquellos ubicados en la base de la pirámide de la distribución del ingreso, esgrime la imposibilidad de medir los efectos de los períodos de crecimiento en el corto plazo, (bajo la suposición de que los cambios en la distribución son graduales y se pueden analizar mejor, en el mediano y largo plazo). Este argumento se muestra una falacia si analizamos: i) que en los períodos de crisis la repercusión sobre la pobreza es casi inmediata; ii) que los ricos (aquellos que se encuentran en la cúspide de la curva de Lorenz) muestran rápidas variaciones en los períodos de crecimiento y se ven poco afectados en los períodos de crisis; iii) que 55 años de crecimiento, oscilante y bajo, pero crecimiento al fin, no han significado en las diversas mediciones de pobreza reducción significativa.

Por ello, nos interesamos por la variable desigualdad para intentar medir la relación con la pobreza. Técnicamente, pobreza y desigualdad son dos cosas separadas, pero nosotros, deliberadamente, los hemos ligado, para el análisis, no solo por una convicción ética sino también metodológica: la pobreza se asume como una característica de los segmentos más bajos de la curva de Lorenz. No de otro modo se entiende que el cálculo de pobreza se realiza a través de estimativas de la distribución.

La conclusión más saliente de este trabajo es la persistencia de un núcleo duro de pobreza que parece no ser sensible al crecimiento latinoamericano, asociado a una alta desigualdad. En términos generales y, particularmente en los países de ingreso medio y medio-alto, la calidad de la distribución antes que la escasez de recursos configura la principal característica de la situación social en América Latina. La experiencia en América Latina muestra que la pobreza puede mantenerse e incluso aumentar, mostrando una mayor sensibilidad a la calidad de la distribución que a las tasas de crecimiento.

De este modo, pensar en políticas de reducción de la pobreza en el marco de la continuación de los modelos de desarrollo parece un 
sinsentido. Como hemos visto, la región presenta un padrón distributivo desigual en extremo, con tasas de pobreza superiores a algunos países con menor ingreso. Por ello, desligar la cuestión de la pobreza de la política económica y de toda lógica distributiva no solo implica un freno a las políticas de bienestar, sino también eximir a aquellos históricamente beneficiados de aportar a la sociedad. No debe ser casualidad que la década en que se producen las reformas estructurales (entre ellas la baja de aportes patronales, la reducción de impuestos a las empresas y a los ingresos y la propiedad de los más pudientes) se produce un aumento significativo del índice de Gini y un período de crecimiento que no reporta beneficios sociales al conjunto de la población. Las cifras de ingreso de algunos de los países analizados muestran que no es una cuestión de carencia sino de distribución. Por eso, pobreza y desigualdad en nuestras sociedades están íntimamente ligadas.

Una de las características del capitalismo periférico en su versión latinoamericana es la exclusión como resultado de la concentración de la tierra, recursos, actividades económicas y acceso al poder en pocas manos. La pobreza, en ese sentido, es producto de la desigualdad entre extremos, situación que provoca la exclusión/inclusión diferencial de las mujeres y los hombres pobres. Exclusión si se lo entiende como una situación de marginación del disfrute del producto social. Pero en una versión crítica, la situación de pobreza es expresión misma del modo en que las personas pobres son incluidas en la sociedad y el mercado de cada país.

El único modo posible de solucionar la pobreza es profundizar en las causas, de tipo económico, como la distribución de los factores económicos, el funcionamiento del mercado de trabajo y la tasa de ganancia. Desde luego no estamos negando la importancia del crecimiento para los países, pero incluso si asumimos que este es una variable significativa para la reducción de la pobreza (ceteris paribus todas las demás variables) debemos considerar su efecto lento, comparado con los escasos indicadores que muestra América Latina, lo que significa, en otras palabras, que con los actuales niveles de crecimiento o, incluso retomando tasas superiores como las de los años setenta o noventa, la superación de la pobreza parece una quimera.

Otros factores que no han sido considerados aquí (dado el carácter en cierto sentido descriptivo o exploratorio de este trabajo) podrían haber sido analizados y son quizá interesantes de rescatar en futuros estudios $^{9}$. Por ejemplo, la estructura del comercio internacional que

9 La ONU menciona, en su Informe para el Desarrollo Humano 2003, que existen tres tipos de limitaciones para cumplir los modestos objetivos del milenio, plantea- 
impide que los países en vías del desarrollo pierdan más de $40 \mathrm{mil}$ millones de dólares en exportaciones (Uribe López, 2005), la sesgada política de reducción de deuda de los organismos multilaterales de crédito que condicionan los programas de ayuda a la implementación de programas de ajuste estructural; el sistema tributario y en especial sobre la riqueza y la herencia, teniendo en cuenta que, como hemos visto, la pobreza y la desigualdad provienen de la persistencia de la desigual apropiación del ingreso de la sociedad.

\section{Bibliografía}

Acemoglu, D. y Robinson, J. 1998 Why the West Extended the Franchise: Lessons for Latin America. Presentación en la World Bank Conference on Asset Distribution, Poverty and Economic Growth, Brasilia, Brasil.

Altimir, Oscar 1979 La dimensión de la pobreza en América Latina (Santiago: Cuadernos de la CEPAL) N 27.

Atkinson, A. 1997 "Bringing income distribution in from the cold" en Economic Journal (Londres: Royal Economic Society) Vol. 107, $\mathrm{N}^{\circ} 441$, marzo.

Barro, Robert J. 1999 "Inequality, Growth and Investment" en NBER Working Papers (Cambridge, MA: National Bureau of Economic Research) $\mathrm{N}^{\circ} 7038$.

Becker, Gary 1983 El capital humano (Madrid: Alianza Editorial).

Boltvinik, Julio 1994 "Los organismos multilaterales frente a la pobreza" en IUPERJ\&CROP, mimeo.

Cardoso, Fernando Henrique 1970 "Comentario sobre los conceptos de superpoblación relativa y marginalidad" en Revista Latinoamericana de Ciencias Sociales (Santiago de Chile) $\mathrm{N}^{\circ} 1$.

Castel, Robert 1998 As metamorfoses da questão social: uma crônica do salário (Petrópolis: Vozes).

Ceceña Martorella, Ana Esther 1994 "Los miserables en la teoría social latinoamericana" en La teoría social latinoamericana, subdesarrollo y dependencia (México: Ediciones El Caballito) tomo II.

CEPAL 1994 El gasto social en América Latina: un examen cuantitativo y cualitativo. (Santiago de Chile: Naciones Unidas - Cuadernos de la CEPAL N $\mathrm{N}^{\circ} 73$ ).

CEPAL 2004 Panorama Social 2003 (Santiago de Chile: Naciones Unidas).

CEPAL 2006 Panorama Social 2005 (Santiago de Chile: Naciones Unidas).

dos por dicho organismo: i) el proteccionismo de los países centrales; ii) la deuda de los países pobres y iii) el escaso importe de la cooperación internacional. 
Cortés, Fernando 2006 "Consideraciones sobre la marginación, la marginalidad, marginalidad económica y exclusión social” en $\mathrm{Pa}$ peles de Población (Toluca: Universidad Autónoma del Estado de México) $\mathrm{N}^{\mathrm{o}} 47$.

De Janvry, Alain y Sadoulet, Elisabeth 1995 "Pobreza rural y programas diferenciados de desarrollo rural" en Economía (Lima: PUCP) Vol. 18, julio-diciembre.

De Janvry, Alain y Sadoulet, Elisabeth 2002 "Land Reforms in Latin America: Ten Lessons toward a Contemporary Agenda". Ponencia preparada para el World Bank's Latin American Land Policy Workshop, Pachuca, México, 14 de junio.

Deininger, Klaus y Squire, Lyn 1997 "Measuring income inequality database", disponible en <www.worldbank.org $>$.

Farah, Ivonne 1991 "La Pobreza" en Las transformaciones de la pobre$z a$ (La Paz: UMSA).

Ferreira, Francisco 1999 "Inequality and Economic Performance: A Brief Overview to Theories of Growth and Distribution". Texto para el Banco Mundial, disponible en <http://www.worldbank. org/poverty/inequal/index.htm >.

Ferreira, Francisco y Litchfield, Julie 1996 Growing apart: inequality and the poverty trends in Brazil in the 1980s (Brasilia: IPEA, Serie Seminarios $\mathrm{N}^{\circ} 18 / 96$ ).

Figueroa, Adolfo 2001 "Reformas en sociedades desiguales" (Lima: PUCP).

Forman, Shepard (ed.) 1994 Diagnosing America: Anthropology and Public Engagement (Ann Arbor, MI: University of Michigan Press).

Gangas Peiró, Pilar 2003 "Desigualdad y pobreza: América latina y Europa desde 1950" en Política y Cultura (México DF: Universidad Autónoma Metropolitana, Xochimilco) $N^{\circ} 20$, otoño.

Global Poverty Monitor Database, disponible en <http://iresearch. worldbank.org/PovcalNet/povcalSvy.html >.

Heston, Alan; Summer, Robert y Aton, Bettina 2006 Penn World Table (Pennsylvania: Center for International Comparissons of Production, Income and Prices - University of Pennsylvania) Versión 6.2 .

Hoffmann, Rodolfo 1997 Distribuição de renta, medidas de desigualdade e pobreza (San Pablo: Editora da USP).

Kaldor, N. 1956 "Alternative theories of distribution" en Review of Economic Studies, (Estocolmo) $\mathrm{N}^{\circ} 23$.

Iglesias, E. 1998 "Income distribution and sustainable growth: Latin American perspective" en Tanzi, Vito y Chu, Ke-Young (eds.) Income distribution and high quality growth (Cambridge / Londres: MIT Press). 
Iradian, Garbos 2005 Inequality, Poverty and Growth. Cross Country Evidence (Washington DC) Working paper IFM 05/28.

Kuznets, S. 1955 "Economic growth and income inequality" en American Economic Review (Pittsburg) Vol. 65.

Laurell, Asa Cristina 1999 "Social Policy Issues in Latin America" en Therborn, Goran, Experiences and perspectives of Europe and Latin America (Estocolmo: FRN).

Lewis, W. A. 1954 "Economic development with unlimited supplies of labour" en Manchester School (Manchester) Vol. 22, mayo.

Mayorga, Enoch 2004 "La crisis de las ciencias sociales y los retos de la pobreza y la marginalidad” en Revista Temas (Panamá: Centro de Estudios Latinoamericanos Justo Arosemena) $\mathrm{N}^{\circ} 117$.

Montero, Lourdes 2004 Trabajo y producción de la pobreza en América Latina (La Paz: CEDLA).

Morley, Samuel 1994 "Poverty and Inequality in Latin America. Future Prospects" en Policy Essay (Washington DC: Consejo de Desarrollo de Ultramar) $\mathrm{N}^{\circ} 13$.

Morley, Samuel 2000 "Efectos del crecimiento y las reformas económicas sobre la distribución del ingreso en América Latina" en Revista de la Cepal (Santiago de Chile) $\mathrm{N}^{\circ} 71$.

Musgrave, Philip (ed.) 1982 Ingreso, Desigualdad y Pobreza en América Latina (Río de Janeiro: BID - ECIEL).

Naciones Unidas 1980 ¿Se puede superar la pobreza? Realidad y perspectivas (Santiago de Chile: Naciones Unidas).

Nun, José 1960 "Superpoblación relativa, ejército industrial de reserva y masa marginal" en Revista Latinoamericana de Ciencias Sociales (Santiago de Chile) $\mathrm{N}^{\circ} 1$.

Ocampo, José 1998 "Distribución del ingreso, pobreza y gasto social en América Latina" en Revista de la CEPAL (Santiago de Chile) № 65.

Paes de Barros, Ricardo; De Carvalho, Mirela; Franco, Samuel; Ganuza, Enrique y Mendonça, Rosane 2005 Crecimiento con equidad: el combate contra la pobreza en Centroamérica (Brasilia: PNUD / IPEA).

Perry, G. E., Arias, O. S. et al. 2006 Poverty reduction and growth: virtuous and vicious circles (Washington DC: World Bank Latin American \& Caribbean Studies).

Pinto, Aníbal 1976 "Notas sobre a distribuição da renda e a estratégia da distribuição" en Distribuição da renda na América Latina e desenvolvimento (Río de Janeiro: Zahar Editores).

Psacharopoulos, George; Morley, Samuel; Fiszbein, Ariel; Lee, Haeduck y Wood, Bill 1997 Poverty and Income Distribution in Latin America. The Story of the 1980s (Washington DC: WB) World Bank Technical Paper $\mathrm{N}^{\circ} 351$. 
Puyana, Alicia 2000 Globalización, equidad y pobreza en América Latina. ¿Hay nuevas soluciones para un problema permanente? (México: FLACSO).

Robbins, D. 1996 Evidence on Trade and Wages in the Developing World (París: Organización de Cooperación y Desarrollo Económicos OCDE).

Sader, Emir (comp.) 2001 El ajuste estructural en América Latina. Costos sociales y alternativas (Buenos Aires: CLACSO).

Sen, Amartya

Székely, Miguel y Londoño, Juan Luis 1997 Persistent Poverty and Excess of Inequality: Latin America, 1970-1995 (Washington DC: BID) Working Paper 357.

Uribe López, Mauricio 2005 "Pobreza: escasez o desigualdad" en Cultura y Trabajo. Revista de la Escuela Nacional Sindical (Medellín).

Urmeneta, Roberto 1996 "Exclusión, servicios sociales y pobreza: desafíos para las políticas" en Economía y Trabajo en Chile (informe anual) (Santiago de Chile: PET).

World Bank 2006 World Development Report (Washington DC: World Bank). 



\title{
Mónica L. HeRnández CHÁvez*
}

\section{EXCLUSIÓN LABORAL Y EMIGRACIÓN EN El SALVADOR}

\author{
EFECTOS DE LAS REMESAS FAMILIARES SOBRE LA \\ SITUACIÓN DE POBREZA DE LOS HOGARES \\ DURANTE EL PERÍODO 1990-2004
}

\section{INTRODUCCIÓN}

En El Salvador, a partir de 1989, se realizaron una serie de reformas como resultado de la implementación de los Programas de Ajuste Estructural (PAE) y las Políticas de Estabilización Económica (PEE) ${ }^{1}$. La flexibilización del mercado laboral vinculada con estas políticas, así como la reducción de la capacidad del mercado de trabajo para

* Economista por la Universidad de El Salvador, investigadora junior para el Programa CLACSO-CROP de estudios sobre pobreza. Agradezco a CLACSO y al Programa CLACSO-CROP por la concesión de la beca de investigación que permitió la realización de este trabajo, asimismo a las tutoras metodológicas María Pía Otero y María Mercedes Di Virgilio, así como a todo el equipo de coordinación del programa. Agradezco a FLACSO programa Costa Rica por su respaldo a mi postulación y particularmente a Minor M. Salas, Pablo P. Sáinz y Guillermo Lathrop. Por otro lado, quiero agradecer especialmente a Raúl Moreno por sus valiosos comentarios y aportes a este trabajo. También agradezco a las diferentes personas que me orientaron para la realización de los cálculos presentados, y en general a todas las personas que me apoyaron.

1 Los PAE y PEE han servido como instrumentos que han permitido la continuidad del proceso de acumulación de capital tanto a nivel nacional como transnacional, en el marco de la globalización. Estos programas han estimulado un escenario propicio para el desarrollo de la flexibilidad laboral a través de la desregulación económica (principalmente del mercado de trabajo) y de la liberalización de precios de la economía (incluyendo los salarios). Con el modelo de acumulación generado con la globalización se han consolidado desigualdades estructurales y se han fundado desigualdades de carácter dinámico (Fitoussi y Rosanvallon, 1997: 3) que han permitido, principalmente las últimas, que las personas o los grupos que no encuentran su lugar en el nuevo modelo tiendan a quedar excluidos. 
absorber a un segmento importante de la fuerza laboral en un contexto digno, han contribuido a precarizar las condiciones laborales de las y los trabajadores ${ }^{2}$. Las personas que no pueden acceder a un empleo que les permita garantizar ingresos suficientes para el sostenimiento de sus familias, ven reducido su bienestar y su nivel de vida y en los casos más extremos, esto conlleva a la profundización de su pobreza. De esta manera, la exclusión social ${ }^{3}$-de tipo laboral ${ }^{4}$ - impulsa a muchos trabajadores y trabajadoras a emigrar hacia otros países (por lo menos 700 personas emigran diariamente de El Salvador, según CARECEN Internacional) para tratar de ocuparse en una actividad remunerada y proveerse así de los medios que les permitan garantizar su reproducción y la de sus familias en sus países de origen.

En este sentido, las remesas familiares generadas con el trabajo de los emigrantes han creado, entre otros aspectos, una fuerte dependencia por parte de sus receptores para satisfacer muchas de sus necesidades. Además, las remesas también se han convertido en un sostén importante para la economía salvadoreña; hasta 2004, representan el $16.1 \%$ del PIB y el $106.1 \%$ de las exportaciones totales. En este contexto, el objetivo de este artículo es dar a conocer una aproximación acerca de la influencia de las remesas familiares sobre la situación de pobreza de los hogares de El Salvador, durante el período 1990-2004, considerando a la exclusión laboral como uno de los principales impulsadores de emigración transnacional.

Cabe señalar que el enfoque sobre pobreza utilizado para la realización de este trabajo es el de las capacidades y realizaciones de

2 Cabe señalar que con el proceso de globalización se han perdido los antiguos mecanismos de inclusión desde el mercado de trabajo. Antes y durante la década del ochenta existía una dinámica integradora en dicho mercado, en la que el empleo formal (principalmente público) ocupaba un lugar importante; sin embargo desde hace varios años el paradigma del empleo de masas, estable y previsible ha entrado en crisis, de manera que desde hace algunos años ya no existe la capacidad para absorber formalmente a la mayor parte de los trabajadores y trabajadoras. Esto se ve agudizado por la reducción de la participación económica y social del Estado, lo cual refuerza la acumulación de desventajas para quienes se encuentran excluidos.

3 La interpretación original europea de exclusión social alude a una situación en la que existe un debilitamiento o quiebre de los vínculos que unen al individuo con la sociedad. Esta definición se le atribuía a un proceso que afectaba a grupos o personas que previamente no estaban socialmente excluidos (Weller, 2001). Acá la exclusión social es entendida en un sentido más amplio, ya que alude en general tanto a los que fueron incluidos alguna vez, pero ya no lo son más, como a los que no lo han sido nunca.

4 Inclusión y exclusión laboral forman un mismo concepto con el que se hace referencia, por un lado, al acceso de una parte de la población a empleos productivos de calidad, y por otro, al inacceso de otra parte de la población a dicho tipo de empleo. En este trabajo se hace énfasis en la situación del último grupo. 
Amartya Sen. Según este la pobreza se relaciona con la imposibilidad real de un grupo de personas en una sociedad específica para, con base en la movilización de sus capacidades, generar los recursos que en esa sociedad son fundamentales para garantizar su buen desempeño social, o para funcionar de manera eficiente en dicha sociedad ${ }^{5}$. Una de las principales diferencias entre el enfoque de Sen y los enfoques más tradicionales sobre pobreza es que en el primero se considera al ingreso (y a los bienes) solo como un medio y no como un fin en sí mismo a la hora de medir la pobreza. Según Sen lo realmente importante en relación al ingreso es la oportunidad de convertirlo en capacidades (o habilidades) de funcionamiento social, pero ellas dependen de una variedad de circunstancias personales y del medio social que rodea a la persona (Olavarría, 2001:10). Desde este enfoque se reconoce, entonces, que la pobreza alude a no poder alcanzar ciertas capacidades mínimas (Sen, 1985), y que aunque estas capacidades puedan verse potenciadas por el ingreso, no es necesariamente este en sí mismo el que determina el estado de pobreza de alguna persona.

\section{La Medición de la pobreza en El SALVAdor}

En El Salvador la medición de la pobreza ${ }^{6}$ se realiza principalmente a través del método del ingreso; desde esta perspectiva, pobre es aquella persona o grupo que no cuenta con un ingreso suficiente para adquirir un conjunto determinado de bienes y servicios considerados básicos. Esta forma indirecta ${ }^{7}$ de medir la pobreza se concreta a través de la elaboración de dos líneas de pobreza; una para la pobreza extrema o absoluta y otra para la pobreza relativa. La pobreza absoluta alude a la situación en la que se encuentran personas u hogares que no alcanzan a cubrir el costo de la canasta básica de alimentos (CBA), que según fuentes oficiales es el conjunto de productos considerados básicos en la dieta de la población, en cantidades suficientes para cubrir adecuadamente las necesidades calóricas y proteínicas para que una persona subsista. Por otro lado, la pobreza relativa hace referencia a la situación de aquellas personas u hogares con ingresos suficientes

5 Esta definición se extrajo de la clase $\mathrm{N}^{\circ} 1$ del Curso sobre Pobreza y Desigualdad en América Latina y el Caribe, celebrado entre mayo y agosto de 2005 en el Campus Virtual de CLACSO.

6 La información de medición de la pobreza se obtuvo del Informe sobre Desarrollo Humano, El Salvador, 2003.

7 El método directo de medición de la pobreza hace alusión principalmente a la satisfacción de necesidades básicas, por lo que suele relacionarse más con el análisis del consumo efectivamente realizado; el método indirecto, por otro lado, se basa en los recursos que permiten satisfacer dichas necesidades, por lo que está vinculado con el análisis del ingreso, o sea, con la posibilidad de realizar consumo. 
para adquirir la CBA, pero insuficientes para financiar la satisfacción de otras necesidades (vivienda, salud, educación, etc.) incluidas en lo que se conoce como la canasta básica ampliada (CA).

Cabe señalar que en el país se elaboró una CBA para el área urbana y otra para el área rural según los alimentos más consumidos en cada área y asegurando la cobertura de los requerimientos diarios mínimos de calorías para una persona adulta normal. Por otro lado, uno de los inconvenientes con esta medición de la pobreza está relacionado con el supuesto de que la línea de pobreza relativa equivale al doble de la línea de pobreza absoluta ${ }^{8}$; el problema con esto es que los precios de los otros bienes y servicios, diferentes a los alimenticios, no tienen un comportamiento similar a los precios de los bienes de la CBA, lo que hace de este un supuesto poco pertinente. Otra de las principales deficiencias en la medición de la pobreza en El Salvador está relacionada con la posible subestimación de la línea de pobreza absoluta dadas las diferencias de precios registradas para los alimentos incorporados en la CBA y los precios de los alimentos de la canasta -de mercado-que sustenta al Índice de Precios al Consumidor (IPC) utilizado para medir la inflación. El IPC refleja que el crecimiento de los precios de los alimentos ha sido mucho mayor al reportado a partir de los precios de los bienes en la CBA. Según fuentes oficiales, en la última década la pobreza ha tenido una sensible disminución, pero aunque una parte de este comportamiento puede estar de acuerdo con la realidad, otra parte podría ser el resultado de dicha subestimación.

\section{EMIGRACIÓN Y REMESAS FAMILIARES HACIA EL SALVADOR}

De acuerdo con el Informe sobre Desarrollo Humano para El Salvador (PNUD, 2005) en la historia reciente del país pueden identificarse al menos cuatro etapas migratorias ${ }^{9}$. En el último período, identificado entre

8 Una de las versiones del método de la Línea de Pobreza con mayor aceptación fue la desarrollada por Altimir (1979) en la CEPAL. Esta propuesta se basó en el desarrollo de una estrategia metodológica para elaborar la línea de pobreza absoluta y la línea de pobreza relativa (o indigencia y pobreza respectivamente según el lenguaje cepalino). Altimir propuso que para obtener la línea de pobreza relativa podía multiplicarse la línea de pobreza absoluta por un factor estadístico (el coeficiente de Engel); este es un recurso que fue utilizado en Estados Unidos por Orshansky en la década del sesenta. En el caso de El Salvador, se estableció que aproximadamente el $50 \%$ del ingreso era destinado a alimentos, por lo que la línea de pobreza relativa se obtendría al multiplicar la línea de pobreza absoluta por 2.

9 La primera etapa migratoria (1920-1969) se caracteriza principalmente por la emigración hacia la parte norte de Honduras, donde se encontraban las plantaciones de banano de la United Fruit Company, como consecuencia de la escasez de empleo y de la falta de acceso a tierras para cultivo. La segunda etapa (1970-1979) apareció cuando la falta de acceso a tierras, la falta de empleo, la inseguridad social, las expectativas positivas de trabajo en Estados Unidos así como la relativa facilidad 
1992-2005, la emigración se incrementó, pero esta ya no es de un carácter forzado provocado por el conflicto armado como en la etapa anterior, más bien es de carácter voluntario relacionado principalmente con aspectos de tipo económico. En 1992, con la firma de los Acuerdos de Paz se presentó un escenario más estable para el retorno de miles de salvadoreños que habían emigrado, pero la relativa estabilidad socioeconómica alcanzada duró poco tiempo; al paso de algunos años el país ya se encontraba en un estancamiento económico ${ }^{10}$ que, aunado al deterioro de la calidad de los empleos y oportunidades, así como al incremento de la desigualdad, de la inseguridad y de las expectativas positivas de empleo y de un mejor nivel de vida en Estados Unidos ${ }^{11}$, motivaron a muchos a emigrar nuevamente o a hacerlo por primera vez ${ }^{12}$.

Aunque no hay datos exactos acerca de la cantidad de personas que salen del país para tratar de llegar a Estados Unidos de manera ilegal, según CARECEN Internacional podrían estar saliendo del país por lo menos 700 personas al día a pesar de las dificultades que implica el emigrar ilegalmente ${ }^{13}$. Cabe señalar que pese a las restricciones para emigrar a

para emigrar legal e ilegalmente hacia este, provocó que miles de personas optaran por emprender el viaje hacia el extranjero. La tercera fase migratoria (1980-1991), se caracteriza por haber sido estimulada por la inseguridad e inestabilidad social y económica como resultado de la agudización del conflicto armado en el país.

10 A pesar del crecimiento económico mostrado durante los primeros años de la década del noventa, no hizo falta mucho tiempo para que se manifestaran signos de agotamiento del modelo implementado: dicho crecimiento comenzó a descender para el segundo quinquenio de la misma década. Cabe señalar que la tendencia se mantuvo entre 2001 y 2004 , pues la tasa de crecimiento promedio en este período fue de $1.8 \%$. Uno de los principales factores que más influyó para que se presentara esta situación fue el establecimiento de una política económica restrictiva-generada con los mismos PAE y PEE- cuyo principal objetivo fue la estabilidad financiera y cambiaria. Cabe señalar que el comportamiento decreciente mostrado por la pobreza durante el mismo período, no se corresponde con la anterior situación económica observada, que también afecto la generación de fuentes de trabajo, lo cual podría indicar que la reducción de la pobreza no es el resultado del esfuerzo interno, realizado a partir de las políticas económicas y sociales implementadas por los gobiernos de turno.

11 Desde los años setenta, el principal destino de las y los salvadoreños ha sido Estados Unidos. Hasta 2005, la mayor parte de emigrantes -casi el 90\%- se encuentra en dicho país.

12 Según un informe del PNUD (2005), la emigración tuvo un incremento sin precedentes $(307 \%)$ entre la década del ochenta y la del noventa. Al estimar el balance entre las entradas y salidas de salvadoreños desde 1980 (ver Gráfico 6) se observa que hay pérdida de población nativa durante todo el período, a excepción de los tres años posteriores a la finalización del conflicto armado en 1992. De esta manera, desde 1996 -año en que también comienza a decrecer la economía- vuelve a presentarse pérdida de población, y para los primeros años del nuevo milenio, se estiman pérdidas de entre 220 mil y 300 mil salvadoreños al año (OIM/SIEMCA, 2004: 12).

13 Se estima que entre 350 y 400 personas mueren anualmente tratando de atravesar la frontera México/Estados Unidos (Meneses, 2005). También existen otros peligros como 
Estados Unidos, muchas personas continúan haciéndolo también con el objetivo de encontrarse con sus parientes. Esto se ve relativamente facilitado gracias al apoyo económico y a la permanencia de los vínculos del emigrante con su familia en su país de origen. A pesar de esto, la principal razón para emprender el viaje al extranjero continúa siendo económica; si bien muchos de los que emigran tienen un trabajo en El Salvador, la mayoría decide irse tratando de encontrar mayores ingresos y oportunidades de desarrollo y de bienestar que no han encontrado en su país (PNUD, 2005: 70; CARECEN ${ }^{14}$ ). De esta manera, hasta 2005 según el Ministerio de Relaciones Exteriores, hay aproximadamente 2.8 millones de salvadoreños en Estados Unidos (ver Cuadro 1). Cabe señalar que junto al incremento del flujo de emigrantes también ha aumentado la importancia del flujo de remesas enviadas por los mismos.

Cuadro 1

Número aproximado de salvadoreños en el exterior, 2005

\begin{tabular}{l|c|c}
\hline & Personas & Porcentaje \\
Total & $3,278,192$ & 100.0 \\
\hline Canadá & 157,000 & 4.79 \\
\hline Estados Unidos & $2,868,996$ & 87.52 \\
\hline México & 31,465 & 0.96 \\
\hline Centroamérica y el Caribe & 152,813 & 4.66 \\
\hline Sur América & 3,979 & 0.12 \\
\hline Europa & 44,654 & 1.36 \\
\hline Asia, Africa y Oceanía & 19,285 & 0.59 \\
\hline
\end{tabular}

Fuente: Ministerio de Relaciones Exteriores.

Nota: Las cifras son datos aproximados del número de salvadoreños en el exterior e incluyen salvadreños de segunda generación. La fuente de información proviene de las diferentes Misiones Diplomáticas y Consulares de El Salvador en el mundo. Las cifras tienen un propósito referencial, no son datos consolidados.

caer en manos de "caza inmigrantes" o de la patrulla fronteriza, así como otros riesgos asociados con toda la travesía: los que resultan al tratar de atravesar otros países -como Guatemala- para llegar a México; robos, extorsiones y violaciones por parte de "maras", de la policía o de quienes dirigen el viaje. Los emigrantes también pueden ser abandonados en el camino -en 2004 más de 200 niños y niñas fueron abandonados en Guatemala y México y luego repatriados- y aquellos que realizan una parte del viaje dentro de México en el denominado "tren de la muerte" pueden perder algún miembro del cuerpo. Esta situación podría empeorar al concretarse el contenido de la Ley de Protección Fronteriza, Antiterrorismo y Control de la Inmigración Ilegal, aprobada por la Cámara de Representantes de los Estados Unidos, en la que se promueve, entre otras cosas, la construcción de un muro en la frontera sur a lo largo de los estados de California, Texas, Arizona y Nuevo México.

14 Información extraída de la entrevista realizada a Jesús Aguilar, Director Ejecutivo de CARECEN Internacional, el 19 de mayo de 2006. 


\section{EVOLUCIÓN DE LAS REMESAS DE LOS EMIGRANTES SALVADOREÑOS}

Las remesas familiares pueden definirse como "la parte de los ingresos del migrante internacional que son enviados a sus familiares en su país de origen desde el país que lo ha acogido" (Banco Central de Reserva-BCR-, 2005: 20). En El Salvador, el BCR contabiliza las remesas familiares bajo el rubro remesas de los trabajadores, que se refieren a las transferencias realizadas por los emigrantes que trabajan en otra economía de la que se consideran residentes (permanecen en ella por más de un año) y que son enviadas sin un quid pro quo, usualmente a personas relacionadas (BCR, 2005: 20). Las remesas familiares (que pueden ser individuales o colectivas) se envían para ser utilizadas con diferentes propósitos como consumo, educación, inversión, entre otros. En el siguiente gráfico puede observarse la evolución del monto de las remesas desde 1989.

\section{Gráfico 1}

El Salvador: Monto de las Remesas Familiares 1990-2005 (millones de dólares)

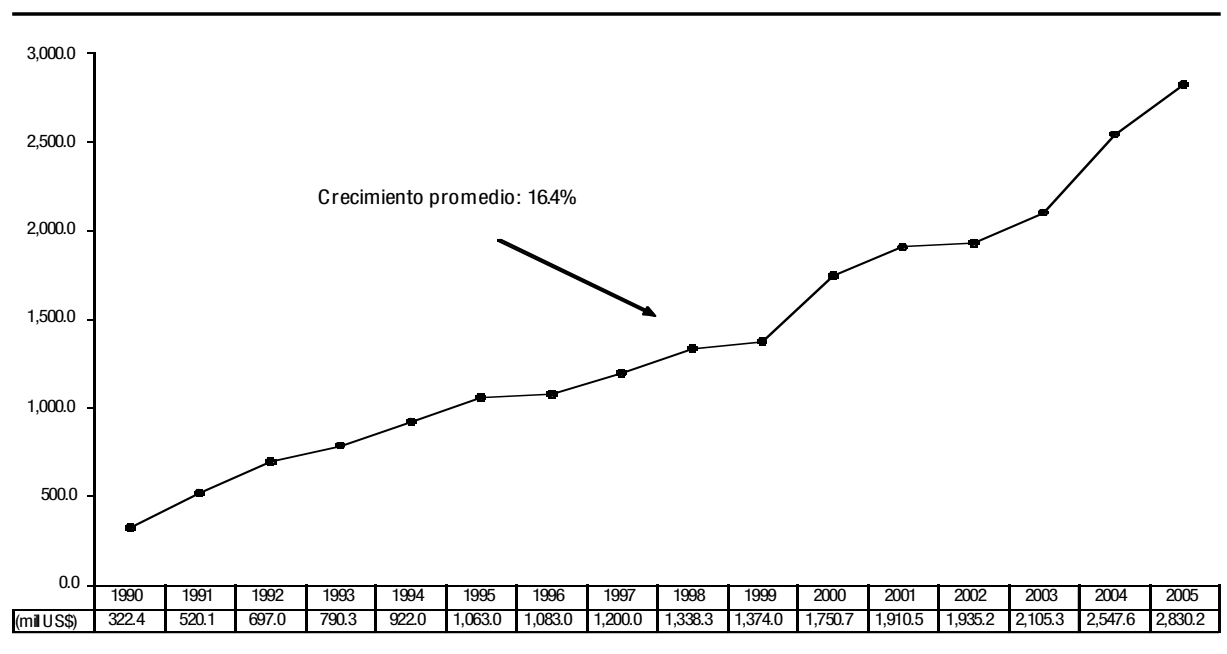

Fuente: Elaborado a partir de datos del Banco Central de Reserva de El Salvador.

A pesar de que el crecimiento de las remesas haya sido mayor en los primeros años del período estudiado (entre 1990 y 1995 crecieron $28.1 \%$ en promedio), los mayores montos se han registrado desde mediados de la década del noventa y han ido aumentando año tras año. De esta manera, puede establecerse que tanto el monto de las remesas como su crecimiento es cada vez más importante; según el 
BCR, para 2005 las remesas familiares ascendieron a $\$ 2.830$ millones (11.1\% más que en 2004); y según la Encuesta de Hogares de Propósitos Múltiples (EHPM), los hogares que reciben remesas obtuvieron en promedio $\$ 160.85$ mensuales para ese año ${ }^{15}$. Cabe señalar que la mayor parte de remesas; es decir, el 31.3\% se envían hacia la capital del país, San Salvador. Por otro lado, a nivel nacional el 22\% de los hogares recibe remesas (aproximadamente 1.5 millones de personas); al desagregar este dato según los catorce departamentos en los que está dividido el país, se observa que los hogares de los departamentos de La Unión, Cabañas, Morazán, San Miguel y Chalatenango dependen más de las remesas. Aunque no hay referencias acerca de los países desde donde se originan estos flujos, puede establecerse que la mayoría de estas provienen de trabajadores en Estados Unidos, dado que la mayor parte de salvadoreños y salvadoreñas en el extranjero residen en ese país ${ }^{16}$.

\section{IMPORTANCIA DE LAS REMESAS EN LA ECONOMÍA SALVADOREÑA}

Las remesas constituyen un importante sostén para numerosas familias en El Salvador, según el PNUD (2003) un tercio de la población en las áreas rurales depende de las remesas enviadas por sus familiares en el extranjero. De esta manera, las remesas generadas con el trabajo de los emigrantes han creado, entre otras cosas, una fuerte dependencia por parte de sus receptores para satisfacer muchas de sus necesidades. Pero no solo sus receptores directos han desarrollado dependencia por las mismas; desde hace años las remesas individuales y colectivas -o comunitarias que están dirigidas a la realización de proyectos- son uno de los principales pilares de la economía salvadoreña. Desde principios de la década del noventa las remesas han contribuido a la estabilidad macroeconómica del país y son su principal fuente de divisas (ver Gráfico 2).

15 Cabe señalar que las cifras de remesas presentadas por las dos principales fuentes de información, el BCR y los resultados de la EHPM, son muy diferentes. Se considera que esto es el resultado, por un lado, del subregistro de ingreso del que adolecen este tipo de encuestas, así como de que el objetivo más importante de estas no sea precisamente la medición de las remesas. Por otro lado, también se considera que es el resultado del sobrerregistro en los datos del BCR (consideración como remesas de otro tipo de operaciones que no lo son: transacciones comerciales, pago de salarios o incluso transacciones de tipo ilegal) -lo cual no indica que no haya subregistro acá también-. A pesar de esto, se considera que los datos más consistentes con la realidad, en cuanto a la recepción anual de remesas, son los del BCR (PNUD, 2005).

16 También debe tomarse en cuenta que no todos los emigrantes salvadoreños envían remesas hacia el país, según el PNUD (2005), aproximadamente solo el 65\% de los y las trabajadoras en el extranjero realizan los envíos de dinero. 
Gráfico 2

El Salvador: Cambios en las fuentes de divisas 1978 y 2004

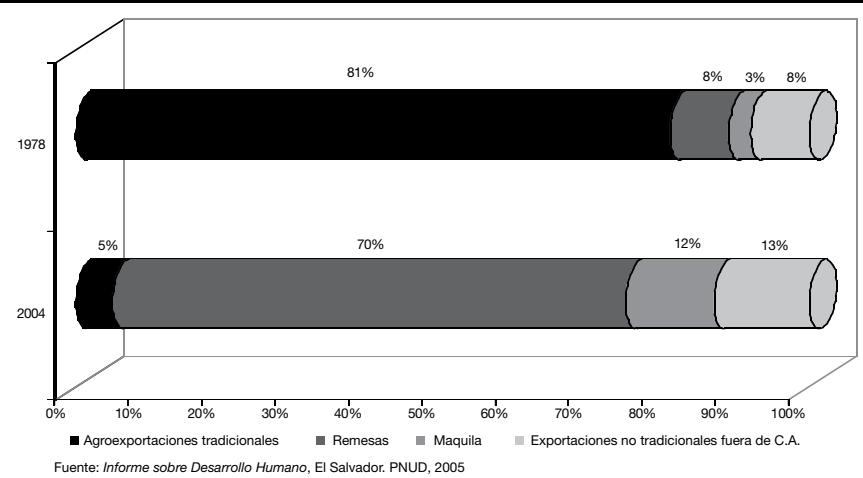

Fuente: Informe sobre Desarrollo Humano, El Salvador. PNUD, 2005.

Al relacionar algunos datos publicados por el BCR, se puede tener una idea de la importancia de las remesas familiares: hasta 2004 estas representan el $16.1 \%$ del PIB; el $106.1 \%$ de las exportaciones totales; el $56.2 \%$ de las importaciones totales (ver Gráfico 3 y 4); el 140\% de los ingresos tributarios y el 546.8\% de la Inversión Extranjera Directa (IED). Puede establecerse que la importancia que han ido ganando las remesas refleja una contradicción entre las supuestas intenciones por parte del gobierno de erradicar las causas que generan la emigración -como las relacionadas con el deterioro de las condiciones laborales como se vera más adelante- y la importancia para la economía de los frutos de dicha emigración, manifestada en las remesas.

\section{Gráfico 3}

El Salvador: porcentaje de las remesas con relación al PBI, 1997-2004

\section{Gráfico 3}

El Salvador: remesas familiares como proporción de las exportaciones e importaciones totales, 2000-2004
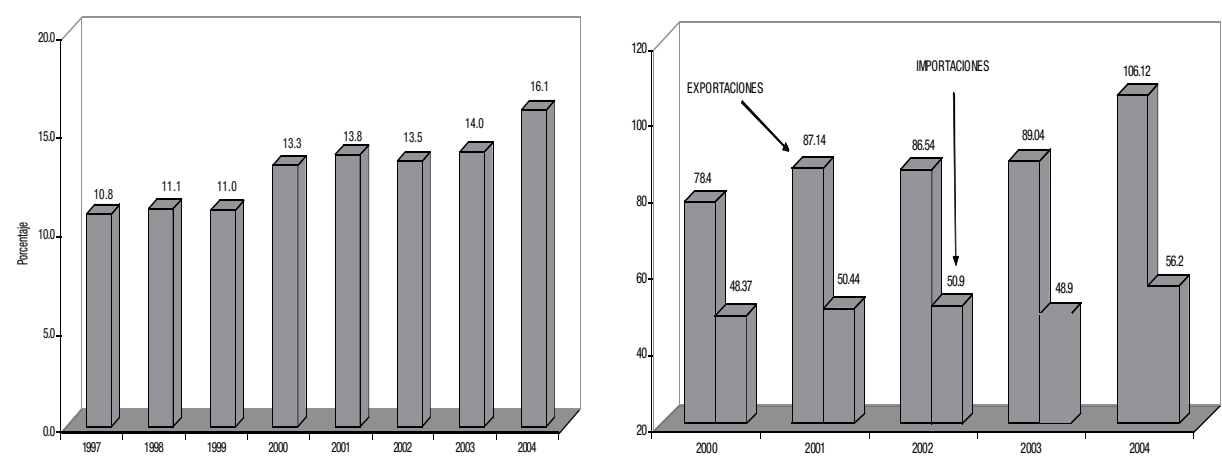

Fuente: Elaborado a partir de datos del Banco Central de Reserva. Fuente: Elaborado a partir de datos del Banco Central de Reserva. 
Finalmente, debe reconocerse, además, que a pesar de la importancia de las remesas y de la relativa estabilidad macroeconómica que brindan, también hay efectos negativos vinculados con dichos flujos: apreciación del tipo de cambio real; aumento de los precios; disminución de la actividad económica -como resultado del estímulo al consumo de bienes importados-; así como un impacto negativo sobre el ahorro. A pesar de esto, los beneficios obtenidos por sus receptores directos opacan en parte estos aspectos negativos, principalmente porque permiten a muchas familias acumular activos (como viviendas); permiten a las personas de mayor edad retirarse con relativa facilidad del mercado de trabajo y además de constituir una entrada extra o única de ingresos para muchas personas, poseen un efecto redistributivo que hace menos sensible los efectos de la desigualdad y la pobreza (PNUD, 2005).

\section{EFECTOS DE LAS REMESAS SOBRE LA POBREZA}

A continuación se presenta una descripción del comportamiento de la pobreza de los hogares salvadoreños, a nivel nacional y según área geográfica (urbana y rural); además, para establecer el efecto de las remesas familiares sobre la pobreza, se realiza la comparación -utilizando las EHPM, 1999-2004- de dos escenarios: la situación de pobreza del total de los hogares -cuando algunos de estos reciben remesasy la situación de pobreza de estos mismos cuando ninguno las recibe -acá la hipótesis es que las remesas familiares tienen una influencia importante en la reducción de la pobreza de los hogares salvadoreños, fundamentalmente en el área rural-; antes de presentar esto se hace alusión de los efectos de la emigración y las remesas sobre el mercado de trabajo.

\section{ALGUNOS EFECTOS DE LA EMIGRACIÓN Y LAS REMESAS SOBRE EL MERCADO DE TRABAJO}

Los efectos sobre el mercado de trabajo pueden analizarse en la forma de un círculo vicioso que comienza y termina con la emigración. En primer lugar, los emigrantes presionan por subir el salario nominal de manera directa, ya que al partir reducen la cantidad de personas que buscan empleo, y de manera indirecta con el envío de remesas, ya que proporcionan una especie de salario de reserva a quienes las reciben $\mathrm{y}$, al mismo tiempo, porque con esto generan expectativas positivas, a quienes se quedan en los países de origen, acerca de los mercados de trabajo en los países receptores. Esta presión ha permitido que el salario mínimo nominal en El Salvador sea mayor que el del resto de países centroamericanos, con excepción de Costa Rica. Esto genera por otra parte, pérdida de competitividad al país en las actividades 
intensivas en el uso de fuerza de trabajo no calificada, generando la reducción de puestos de trabajo. De esta manera, con menores posibilidades para acceder a un puesto de trabajo; salarios nominales más altos, pero inferiores en términos reales al resto de países, y expectativas positivas de mejores oportunidades en el extranjero, las personas optan por emigrar (PNUD, 2005: 141).

Cabe señalar que en este trabajo se ha considerado como supuesto que la exclusión laboral ${ }^{17}$, dada en el marco de la flexibilización del mercado de trabajo ${ }^{18}$, ha profundizado la emigración, y que, a partir de esta las personas se incorporan a actividades remuneradas en otros países $^{19}$, generando así las transferencias o remesas familiares, que tienen efectos sobre la situación de pobreza de los hogares en el área urbana y rural. Otra hipótesis considerada es que la exclusión laboral en El Salvador se manifiesta principalmente a través del empleo de baja productividad y el empleo productivo bajo condiciones precarias: como se verá a continuación una parte importante del empleo se encuentra desde hace años en el sector informal; asimismo, las condiciones laborales salariales y no salariales en general no muestran mejoras significativas por lo menos durante el período estudiado.

\section{DESEMPLEO ABIERTO, EMPLEO DE BAJA PRODUCTIVIDAD, EMPLEO PRODUCTIVO BAJO CONDICIONES PRECARIAS Y SU VÍNCULO CON LA MIGRACIÓN TRANSNACIONAL}

La tasa de desempleo total en El Salvador -volumen de desocupados entre la población económicamente activa- es baja y se ha mantenido relativamente estable desde la década del noventa en alrededor de 7.6\% aproximadamente. A pesar de esto, desde hace años el grupo

17 Exclusión laboral se entiende como el resultado de la contracción de la demanda de trabajo. De dicha exclusión se desprenden: el desempleo abierto; el empleo de baja productividad y el empleo productivo bajo condiciones precarias.

18 La flexibilización se relaciona con la reestructuración productiva, la desregulación laboral y el debilitamiento del actor sindical; de esta manera, puede derivar en la precarización de las relaciones laborales (Mora, 2000) y, por lo tanto, también puede contribuir a aumentar los flujos migratorios. En El Salvador, la flexibilidad ha afectado las formas de contratación al promover la eliminación de los contratos indefinidos en detrimento de la estabilidad laboral; ha afectado la jornada laboral con la institucionalización del empleo parcial; también ha afectado el derecho a la sindicalización y las condiciones de trabajo relacionadas con los espacios físicos, salario, seguro social, entre otros. Cabe señalar además que existe un sistema de salarios mínimos que constituye una rigidez pero que paradójicamente se convierte en una flexibilidad al mantener congelados los salarios por varios años, reduciendo su valor real (Ochoa et al, 2000: 180).

19 Algunos estudios que sustentan este supuesto son PNUD (2005) y FESPAD (2006). 
etáreo más afectado en este sentido es el de los jóvenes entre 15 a 29 años, como se observa en el Gráfico 5.

\section{Gráfico 5}

El Salvador: desempleo abierto nacional y desempleo abierto jóvenes entre 15 a 29 años

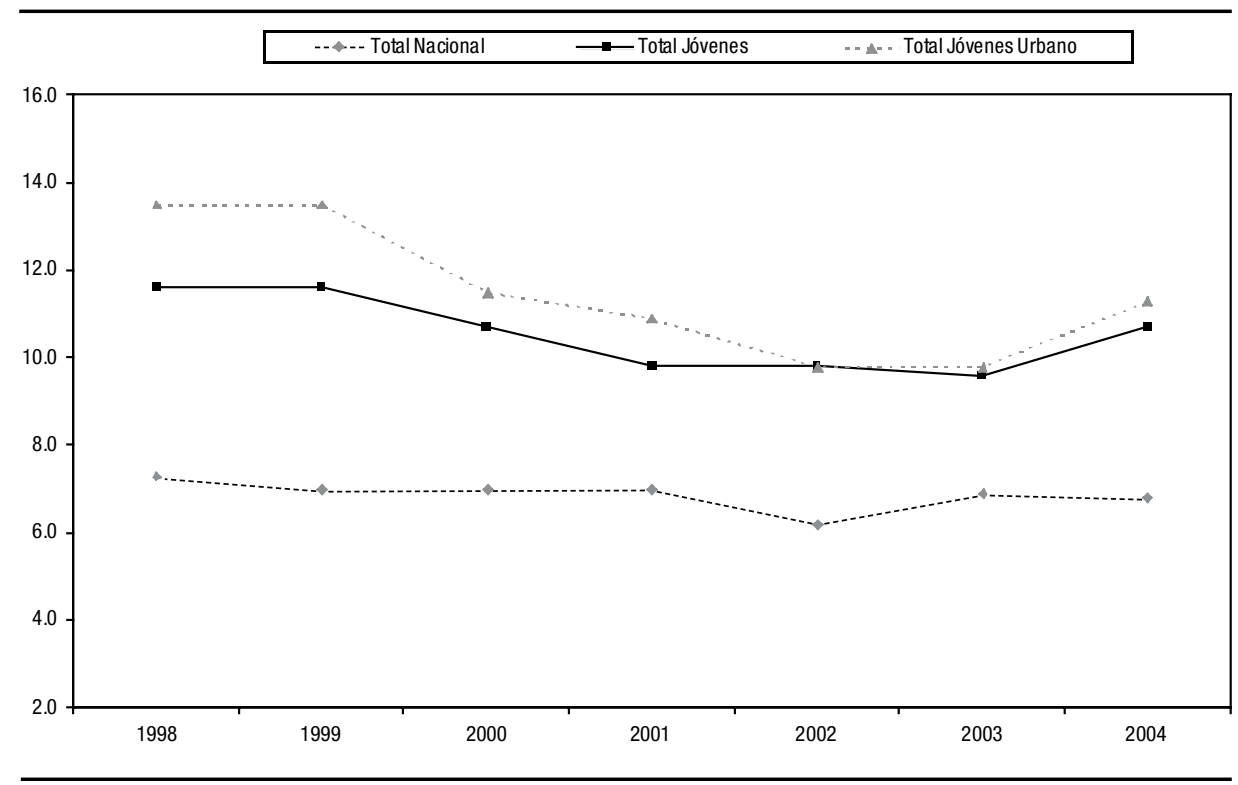

Fuente: Elaborado a partir de datos de Hogares de Propósitos Múltiples, varios años.

La tasa de desempleo para este grupo es superior al 10\% para la mayor parte de años y, a pesar de que ha ido disminuyendo -excepto para 2004-, se encuentra muy por encima de la tasa de desempleo nacional. La situación empeora si se considera solo a los jóvenes del área urbana. Cabe señalar que para este mismo período se registran los mayores saldos migratorios negativos en el país; es decir, para estos años el número de personas que salieron del país fue mayor al número de las que entraron, como se refleja en el Gráfico 6. Durante dicho período, la mayor parte de emigrantes han sido jóvenes en edad productiva $^{20}$, lo cual ha afectado directamente el mercado laboral, al reducir el crecimiento de la oferta de trabajo.

20 Como parte del perfil de los emigrantes salvadoreños puede señalarse que estos son casi en igual proporción tanto hombres como mujeres con responsabilidades familiares. Además, se caracterizan por encontrarse en edad productiva, y por contar con bajos o medios niveles de educación y de ingresos al momento de salir del país. 
Gráfico 6

El Salvador: Evolución de los saldos migratorios de nacionales. 1980-2002

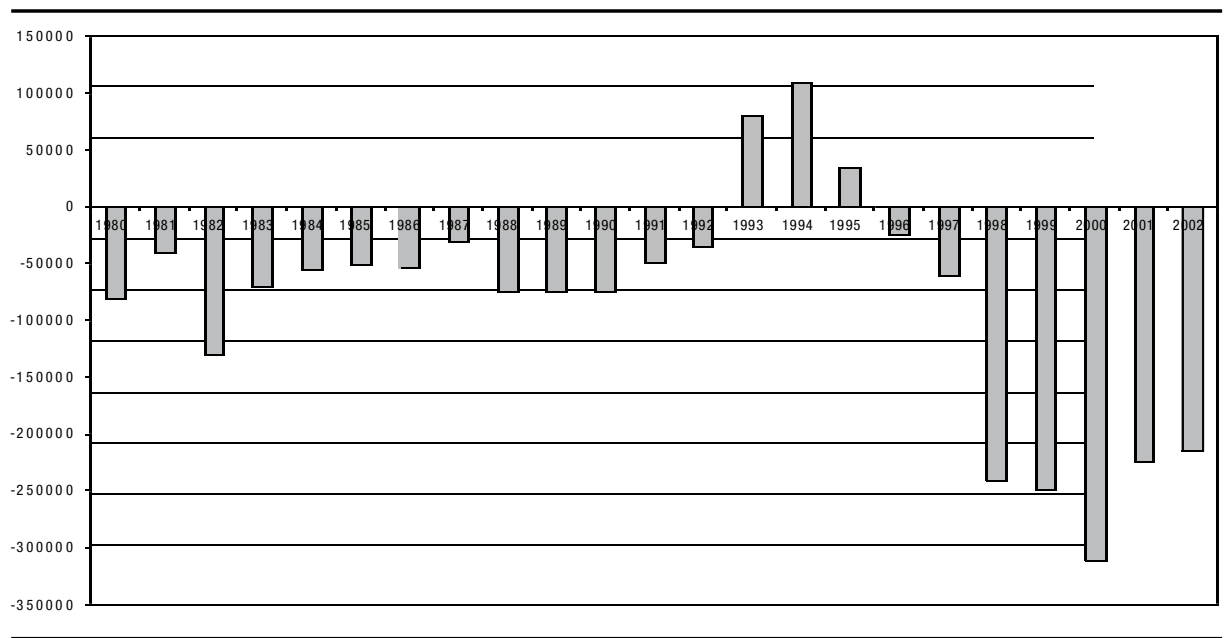

Fuente: Elaborado a partir de datos de OIM/SIEMCA.

A pesar de esto, el desempleo no se considera la principal causa de exclusión laboral, principalmente porque a nivel general ha disminuido en los últimos años. Esto puede deberse, entre otras razones, a mejoras relativas en la actividad económica para determinados años, pero también a la estabilidad y a la caída, en algunos años, de la tasa de participación (relación entre la población económicamente activa -PEA- y la población en edad de trabajar-PET-) principalmente de personas entre 15 a 24 años y los mayores de 50 años. También la reducción de la tasa de desempleo puede estar asociada a la mayor reducción de la oferta laboral, frente a la demanda laboral, como consecuencia de la emigración en los últimos años (OIT, 2002: 17 y 2004). Por otro lado, aunque la tasa de desempleo en El Salvador sea relativamente baja, puede considerarse la presencia de exclusión laboral, que contribuye a aumentar la emigración, debido a que una parte muy importante de los empleos se caracterizan por encontrarse en el sector informal ${ }^{21}$ o de baja productividad; en el período comprendido entre 1998 y 2004 casi el 50\% del total de ocupados laboraba en este sector. Asimismo, aunque para algunos de los años de la década del noventa la tasa de subempleo descendió, esta ha ido incrementándose en los

21 El sector formal e informal constituyen los segmentos básicos del mercado de trabajo urbano. En el área rural, la mayor parte de empleos se desarrolla en condiciones vinculadas a la informalidad. 
últimos años; entre 2002 y 2003 dicha tasa pasó de 29.7\% a 36.4\%, como puede observase en el Cuadro $2^{22}$.

\section{Cuadro 2}

El Salvador: Proporción de personas que trabajan en el sectorinformal y proporción de personas subempleadas

\begin{tabular}{|c|c|c|c|c}
\hline Año & Trabajo Informal & Subempleo Total & Subempleo Visible & $\begin{array}{c}\text { Subempleo Invi- } \\
\text { sible }\end{array}$ \\
\hline 1998 & & & & 2,4 \\
\hline 1999 & 46,6 & 31,5 & 3,1 & 28,8 \\
\hline 2000 & 46,5 & 31,9 & 3,1 & 23,6 \\
\hline 2001 & 47,7 & 27,0 & 3,4 & 24,6 \\
\hline 2002 & 49,4 & 28,1 & 3,5 & 25,6 \\
\hline 2003 & 49,7 & 29,7 & 4,1 & 32,0 \\
\hline 2004 & 47,9 & 36,4 & 4,4 & 32,3 \\
\hline
\end{tabular}

Fuente: Elaboración propia a partir de los datos de la EHPM, 1998-2004.

Aunque el sector informal suele estar asociado con un ambiente laboral y salarial precario e inestable ${ }^{23}$, esto no significa que en el sector formal no existan condiciones laborales y salariales igualmente precarias. La condición de precariedad en los empleos formales está asociada al deterioro de los salarios, así como a aspectos relacionados con la estabilidad y la seguridad laboral de las y los trabajadores. En cuanto al salario mínimo urbano, desde 1990 hasta el año 2000, ha decrecido 1.6\% en promedio (CEPAL, 2001: 229). Para 2004, la mayor parte de las y los ocupados en el sector formal recibieron mensualmente salarios inferiores a los $\$ 500$, como se observa en la segunda y sexta columna del Cuadro 3. El 20\% de las personas que se encuentran laborando en este sector gana entre $\$ 114$ y $\$ 170$; mientras que solo poco más del $5 \%$ gana entre $\$ 800$ y más. Además, en el resto del cuadro puede compararse la situación de hombres y mujeres para cada tramo

22 En algunas partes de este trabajo se utiliza información a partir del año 1998, aproximadamente, debido a limitaciones de acceso a la información y a inconvenientes técnicos relacionados con las encuestas de hogares de años anteriores.

23 Cabe señalar que en los últimos años, las mujeres han venido laborando en las condiciones más precarias, por ejemplo, ganando los peores salarios, y esto las hace más vulnerables a caer en situación de pobreza. Por ejemplo, más del $22 \%$ de los asalariados en el sector informal ganan entre $\$ 46$ y $\$ 113$ mensuales, de los cuales $61 \%$ son mujeres. 
de ingresos; nuevamente, en los tramos de mayores ingresos hay una proporción mucho mayor de hombres que de mujeres.

Cuadro 3

El Salvador: proporción de ocupados del sector formal, por sexo, según tramos de remuneración mensual, 2004

\begin{tabular}{|c|c|c|c|c|c|c|c}
\hline Tramos (US\$) & Ocupados & Hombres & Mujeres & $\begin{array}{c}\text { Tramos } \\
\mathbf{( U S \$ )}\end{array}$ & Ocupados & Hombres & Mujeres \\
\hline Ninguno & 8.8 & 62.0 & 38,0 & $286-342$ & 8,0 & 66,1 & 33,9 \\
\hline Menos de 46 & 0.8 & 58.2 & 41,8 & $343-456$ & 13,1 & 62,7 & 37,3 \\
\hline $46-113$ & 5.5 & 65.5 & 34,5 & $457-570$ & 5,4 & 48,5 & 51,5 \\
\hline $114-170$ & 19.7 & 51.2 & 48,8 & $571-685$ & 4,3 & 59,9 & 40,1 \\
\hline $171-228$ & 20.0 & 65.3 & 34,7 & $686-799$ & 1,2 & 78,0 & 22,0 \\
\hline $229-285$ & 7.6 & 67.5 & 32,5 & 800 y más & 5,4 & 70,3 & 29,7 \\
\hline
\end{tabular}

Fuente: Elaboración propia a partir de los datos de la EHPM, 2004.

De acuerdo con el código de trabajo de El Salvador, el salario mínimo debe ser ajustado por lo menos cada 3 años; no obstante, el último cambio importante en el salario rural y urbano se dio en 1998. Para 2003 se presentó un nuevo ajuste, aunque no muy significativo: el salario mínimo para todos los trabajadores del sector comercio, industria y servicios quedó establecido en poco más de $\$ 5$ por día, o $\$ 154$ al mes aproximadamente. No obstante, a pesar de que los mayores niveles de pobreza se encuentran en el área rural del país y que el trabajo agrícola suele concentrarse en esta zona, no se presentó ningún incremento en los salarios para el sector de la agricultura (el salario diario por jornada se mantuvo en $\$ 2.81$ ). Por otro lado, en lo que respecta a la cobertura de la seguridad social, del total de empleados en el sector informal en 1990 solo el 4.2\% contaban con este tipo de protección; mientras que en el sector formal el 67.8\% estaba asegurado. Para los siguientes años no se observa una mejora significativa, pues durante la mayor parte de años de la década del noventa más del 50\% de los trabajadores no han tenido esta protección. Para 2004 la proporción total de trabajadores sin seguro social es de 56\%; dentro del sector informal el $90 \%$ de los empleados no tienen cobertura y dentro del sector formal más del $26 \%$ no cuentan con esa prestación.

De esta manera, puede considerarse que una parte importante de los empleos generados en el marco de las políticas de ajuste y estabilización no han permitido mejorar las condiciones de vida de la población ocupada en tanto que, además de que casi la mitad de los ocupados labora en sectores de baja productividad, los salarios y otras prestaciones en general no han mejorado significativamente. Muchos de los 
trabajadores no gozan de puestos de trabajo estables, son vulnerables a despidos y a remuneraciones desproporcionada con su jornada de trabajo $^{24}$. Lo anterior evidencia la mala calidad de una parte importante del empleo generado en la economía salvadoreña, la cual se ve reflejada en la informalidad, la inestabilidad laboral y la falta de acceso a seguridad social y a un salario digno; esto permite establecer que en El Salvador se ha incrementado la exclusión laboral en la última década y en los primeros años de 2000, principalmente a través del empleo de baja productividad y del empleo productivo bajo condiciones precarias, lo cual contribuye a estimular el incremento de la migración transnacional, repercutiendo directamente sobre el mercado de trabajo.

No obstante, cabe señalar que aunque generalmente los emigrantes cuentan con mayores ingresos a los que tenían en su país de origen, muchos de ellos, especialmente los no calificados, además de sufrir la desarticulación de la familia en el país de destino están ubicados en los tramos bajos de la distribución del ingreso, generalmente trabajan más pero ganan menos que los nativos, y enfrentan precarias condiciones en cuanto a sus derechos laborales y estatus migratorio. Según datos de 2003, la tasa de desempleo de los inmigrantes en Estados unidos era de $8.7 \%$ frente a solo $6.2 \%$ para los trabajadores nativos; para 2002 la remuneración media de los trabajadores inmigrantes fue de $\$ 28.082$ frente a $\$ 42.575$ de los trabajadores nativos, pero en ambos casos las mujeres son las más afectadas en cuanto a las asimetrías de la tasa de desempleo y del nivel de remuneración (Solimano, 2005: 52). Para la década del noventa el $76.6 \%$ de los emigrantes salvadoreños en Estados Unidos se encontraba en edad productiva, o sea en edades entre 20 a 59 años, lo que refleja, como se ha señalado, la poca atracción que el mercado laboral del país de origen tiene para estas personas. Sin embargo, las posibilidades de encontrar un empleo de calidad en otro país también dependen de la calificación del emigrante ${ }^{25}$; según un informe de la CEPAL (2002) para la misma década más del $21 \%$ de los inmigrantes salvadoreños en Estados Unidos tenían menos de cuatro años de educación; la mayor parte, o sea el $45 \%$ poseía entre cuatro a nueve años, mientras que solo $32 \%$ tenía más de diez años de estudios. Cabe señalar que más del 65\% de los emigrantes se encuentran ocupados en el sector de servicios en puestos que no requieren mucha calificación (camare-

24 Ejemplos de precariedad en la que laboran trabajadoras de la maquila pueden encontrarse en <http://www.rel-uita.org/old/maquilas $>$.

25 Otro factor que influye en la posibilidad de obtener un mejor empleo e ingresos es la capacidad para hablar inglés, así como el estatus migratorio; un salvadoreño y una salvadoreña con la ciudadanía estadounidense ganan respectivamente $12 \%$ y $9 \%$ más que aquellos que no la tienen (PNUD, 2005: 69). 
ras, cocineros, limpiadores y porteros, obreros de construcción, cajeros, cuidadores de niños, etc.); el $31.1 \%$ en el sector secundario y $3.6 \%$ en el sector primario (desarrollando principalmente trabajos agrícolas, pecuarios y forestales); dentro del total solo $2.4 \%$ están ocupados como profesionales o técnicos.

Finalmente, como parte de los efectos directos de la emigración sobre el mercado de trabajo, hasta 2004 puede establecerse que los hogares que reciben remesas tienen una tasa mucho menor de Población Económicamente Activa (PEA) y de participación (41.7\%) que los que no las reciben (54.6\%). Además, la tasa de dependencia de los hogares que reciben remesas es más alta que la de aquellos que no las reciben; por ejemplo, en el área urbana los hogares que reciben remesas tienen $2 \%$ de tasa de dependencia, mientras que los que no las reciben tienen una tasa de $1.4 \%$; en el área rural se observa una tasa de dependencia de $2.8 \%$ y $1.8 \%$ respectivamente. La población económicamente inactiva (PEI) en los hogares receptores de remesas es de 58.3\%, mientras que en aquellos que no las reciben es de $45.4 \%$. La tasa de desempleo entre la población receptora de remesas es de $8.6 \%$, frente a solo $6.4 \%$ de la población no receptora (Pérez Sáinz, 2003 y PNUD, 2005: 89).

Sobre la base de datos como estos se ha especulado acerca de la disponibilidad de trabajar de los receptores de remesas. Por ejemplo, en los últimos años ha comenzado a ingresar a El Salvador una cantidad importante de trabajadores procedentes de Honduras y Nicaragua para laborar en actividades relacionadas con la zafra de la caña de azúcar, la construcción y la recolección de café. Aparentemente hay oportunidades de empleo en el país y poca disposición de las y los salvadoreños que reciben remesas a trabajar. Pero la escasez de fuerza laboral podría deberse a que, ante la precariedad de los salarios reales -principalmente en el área rural- muchos no están dispuestos a trabajar por un salario tan bajo (si se compara con las remesas que reciben) y prefieren dedicarse a otras actividades $u$ optan por emigrar -llegando muchas veces a tener más de un empleo en el país de destino-. Además, la recepción de remesas posibilita que más personas continúen estudiando; dado que la tasa de matriculación de los hogares en que se reciben remesas es más alta, estas contribuyen a reducir la tasa de participación de los mismos en actividades laborales. Por esto, puede considerarse que la entrada de trabajadores extranjeros, lejos de reflejar altas posibilidades de empleo estable en el país, solo estaría contribuyendo a mantener estables los salarios, en detrimento de las condiciones de vida de los trabajadores salvadoreños, los cuales, ante esto, pueden eventualmente optar por emigrar, en lugar de quedarse a recibir un salario inferior al que recibirían si se dedicaran a las mismas actividades en el extranjero. 


\section{EFECTOS DE LAS REMESAS SOBRE LA POBREZA ${ }^{26}$}

La pobreza de ingresos en El Salvador ha descendido considerablemente en los últimos años. Según el Gráfico 7 para 1991 la pobreza total alcanzaba a casi el 60\% de los hogares salvadoreños; mientras que para 2004 la proporción total de hogares pobres es de poco más del 34\%; es decir que de acuerdo con estos datos la pobreza se ha reducido casi a la mitad. Aunque, como se señalaba anteriormente, los datos podrían reflejar alguna subestimación -tomando en cuenta también que las condiciones económicas del país no han sido muy favorables en los últimos años como para suponer que esto hubiera contribuido a la reducción de la pobreza- podría haber otros factores, como las remesas, que contribuyan a reducir la cifra de pobres.

\section{Gráfico 7}

El Salvador: proporción de hogares en condición de pobreza, 1991-2004

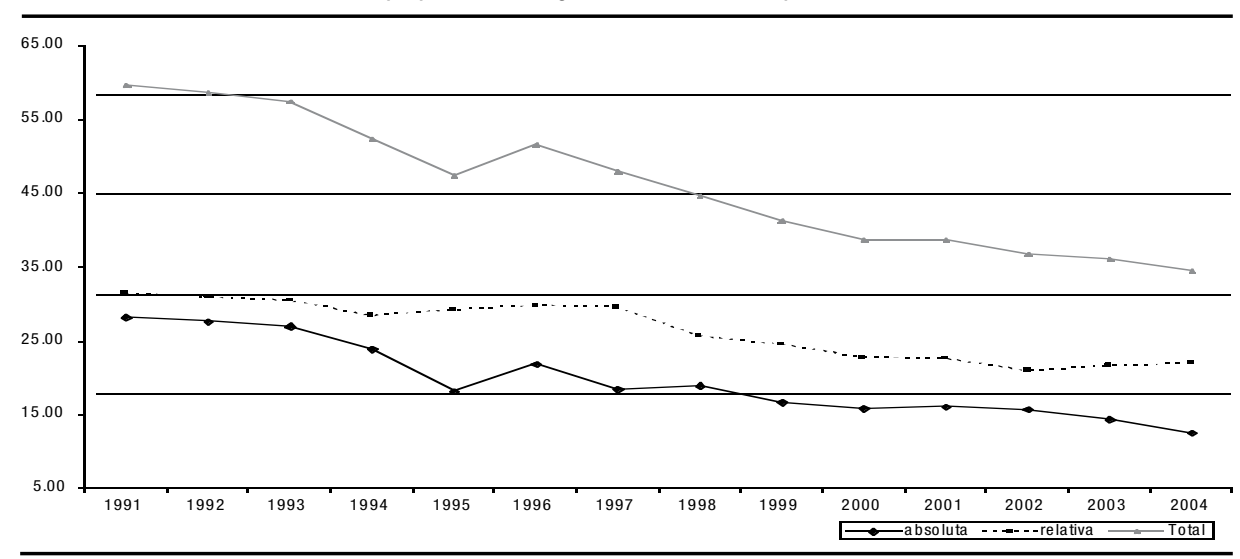

Fuente: Elaborado a partir de datos de la Encuesta de Hogares de Propósitos Múltiples, varios años.

26 Existen dos perspectivas opuestas en la corriente de pensamiento económico en cuanto a los efectos de la emigración y las remesas sobre la pobreza (Taylor y Fletcher, 2002). Una de ellas considera a la emigración como un drenaje de la fuerza de trabajo y de sus habilidades; de esta manera, los ingresos per capita en las regiones desde las que se ha emigrado pueden descender cuando la emigración aumenta, pudiendo generar aumentos en el nivel de pobreza. Así, el ingreso generado por las remesas podría compensar solo parcialmente la pérdida de empleo y de capital. La otra corriente de pensamiento es la denominada Nueva Economía de la Migración Laboral. Según ésta la decisión de emigrar es tomada en conjunto por el grupo familiar o por la comunidad como parte de una estrategia para incrementar los ingresos. De esta manera, las remesas y su potencial pueden contribuir a anular algunas restricciones sobre la producción y la inversión, afectando positivamente a los sectores más pobres, principalmente en las zonas rurales convirtiéndose en verdaderas compensaciones por la pérdida de fuerza de trabajo y de producción generada con la emigración. Además, en este modelo, se reconoce que las personas no rompen sus lazos con su familia cuando han emigrado, lo que contribuye al mantenimiento de la recepción de remesas y de sus efectos multiplicadores beneficiosos para los pobres. 
Cabe señalar que tanto la proporción de hogares en pobreza absoluta como en pobreza relativa se han visto reducidos. Durante el primer quinquenio de la década del noventa la pobreza absoluta estuvo presente en promedio en el $25 \%$ de los hogares, en el siguiente quinquenio en el $18 \%$ de los mismos y entre 2001 y 2004 solo en el $15 \%$. Por otro lado, la pobreza relativa estuvo en promedio en el 30.2\%, 26.5\%; y $21.8 \%$ respectivamente. A nivel departamental, hasta 2004 San Salvador y La Libertad son los únicos departamentos con una proporción de hogares pobres inferior al promedio nacional de 34.6\%; en el otro extremo se encuentra Ahuachapán, Cuscatlán, Cabañas, San Vicente y Morazán con una proporción por encima de dicho promedio ${ }^{27}$.

Aunque a nivel nacional la pobreza se redujo en los últimos años, al desagregar los datos por área geográfica se observa que esta continúa siendo un problema muy grave en el área rural. Para 1991 la proporción de hogares pobres en esta zona superó el $60 \%$, esta tendencia se mantuvo aproximadamente hasta 1997; pero aunque posteriormente hubo una reducción, hasta 2002 la mitad de los hogares en el área rural continuaba en situación de pobreza. Entre 2003 y 2004 dicha proporción se redujo hasta $46.2 \%$ y $43.7 \%$ respectivamente. Cabe señalar que en el caso de esta zona la proporción de hogares en pobreza absoluta y relativa ha sido muy similar, ya que durante casi todo este período la mitad de hogares pobres han sido pobres absolutos y la otra mitad pobres relativos.

En el caso del área urbana, puede establecerse que la proporción de pobres también se ha visto reducida en los últimos años. En 1991 más del 53\% de los hogares eran pobres; mientras que para 2004 solo el $29.2 \%$ se encontraban en dicha situación. A diferencia del área rural, el área urbana se caracteriza por contar con una proporción menor de hogares en pobreza absoluta y con una proporción mayor de hogares en pobreza relativa. Para 2004 el $8.6 \%$ de los hogares pobres en esta zona eran pobres extremos; mientras que el restante $20.7 \%$ se encontraban en pobreza relativa ${ }^{28}$.

27 Como se señaló anteriormente, estos departamentos figuran entre los que tienen una proporción mayor de hogares receptores de remesas: en Cabañas el 37.2\% de los hogares recibe remesas y en Morazán el 34.2\%. Por otro lado, de acuerdo con el Mapa Nacional de Extrema Pobreza elaborado por FLACSO (programa El Salvador) para el Fondo de Inversión Social para el Desarrollo Local (FISDL), estos dos departamentos también forman parte de aquellos con mayor número de municipios en extrema pobreza severa.

28 Según algunas fuentes (FISDL/FLACSO, 2005) la pobreza por el método de las Necesidades Básicas Insatisfechas (NBI) también ha disminuido. Sin embargo, aunque algunos indicadores de satisfacción de necesidades básicas reflejan alguna mejora, esta no es significativa para todos los casos. Cabe señalar que, en cuanto a la cobertura de servicios básicos -como agua y energía eléctrica- también se observa una marcada diferencia entre el área urbana y rural, lo cual evidencia que no solo hay una brecha amplia entre los ingresos de los hogares, sino que también existe una 
La reducción de la pobreza observada puede relacionarse en buena medida con el sacrificio hecho por una parte importante de los miembros de la sociedad salvadoreña, al emigrar, ocuparse en alguna o algunas actividades remuneradas y enviar remesas familiares. Hasta 2004 el 22\% de los hogares salvadoreños recibieron remesas familiares; en el caso de muchos de los hogares pobres, las remesas pueden llegar a representar más del 50\% de sus ingresos. Puede establecerse que muchos hogares no caen en situación de pobreza absoluta o relativa gracias al aporte realizado por sus familiares en el extranjero a través de estos flujos monetarios. Por ejemplo, para 1999 el 41\% del total de hogares era pobre, pero sin remesas esta proporción hubiera podido aumentar a más del $45 \%$; para 2002 dicha proporción se redujo hasta $36.7 \%$, pero sin remesas esta hubiera sido superior al 43\%; luego, para 2004 solo el 34\% de los hogares era pobre, pero si se sustraen las remesas familiares más del $40 \%$ de los mismos se hubiera encontrado en dicha situación ${ }^{29}$. Esto refleja además que el impacto de las remesas en la reducción de la pobreza a nivel nacional ha ido aumentando año con año (ver Gráfico 8). Posteriormente se presenta esta información según área geográfica: urbana y rural.

Gráfico 8

El Salvador: Proporción de los hogares que logran salir de la pobreza en general como resultado de las remesas familiares, 1999-2004

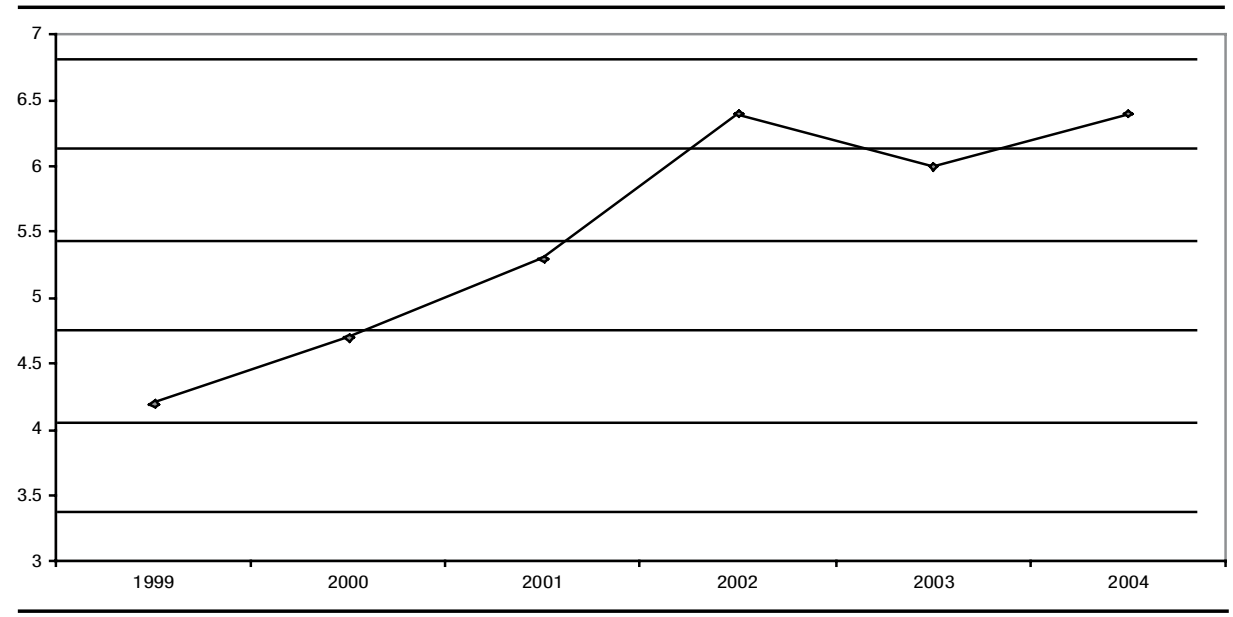

Fuente: Cálculos propios realizados con las bases de datos de la EHPM, varios años.

brecha importante en cuanto a la cobertura de algunos servicios básicos dependiendo del área en la que se encuentren.

29 Cabe señalar que con esto se está suponiendo que en ausencia de las remesas el comportamiento de los hogares sería el mismo; en la práctica existe la posibilidad de que esto sea diferente, pues los hogares pueden eventualmente cambiar sus opciones de oferta laboral (por ejemplo, en cuanto a horas trabajadas, etc.) para tratar de que su ingreso no sea tan bajo. 
En el Cuadro 4 puede observarse el incremento de la pobreza absoluta -y en algunos casos de la relativa ${ }^{30}$ - cuando se sustrae del ingreso de las familias las remesas familiares. En este caso la brecha entre los niveles de pobreza absoluta con remesas y sin remesas también ha ido incrementándose con el paso de los años; para 1999 la proporción de hogares que habían logrado salir de la pobreza como resultado de las remesas era de $4.5 \%$, mientras que para 2004 fue de casi $7 \%$.

\section{Cuadro 4}

El Salvador: Total de hogares en situación de pobreza, con y sin remesas familiares 1999-2004

\begin{tabular}{c|c|c|c|c}
\hline \multirow{2}{*}{ Año } & \multicolumn{2}{|c|}{ Pobreza Absoluta } & \multicolumn{2}{c}{ Pobreza Relativa } \\
\cline { 2 - 4 } & con remesa & sin remesa & con remesa & sin remesa \\
\hline 1999 & 16,8 & 21,3 & 246 & 24,4 \\
\hline 2000 & 16,0 & 21,0 & 228 & 22,5 \\
\hline 2001 & 16,1 & 21,7 & 227 & 22,3 \\
\hline 2002 & 15,8 & 22,0 & 210 & 21,1 \\
\hline 2003 & 14,4 & 20,2 & 217 & 21,9 \\
\hline 2004 & 12,5 & 19,4 & 222 & 21,7 \\
\hline
\end{tabular}

Fuente: Cálculos propios realizados con las bases de datos de la EHPM, varios años.

Puede establecerse que la situación presentada a nivel nacional se reproduce al hacer una clasificación geográfica de los hogares en área urbana y rural, aunque el mayor impacto se manifiesta en esta última área. En el Gráfico 9 puede observarse cómo la proporción de hogares que logran salir de la pobreza como resultado de la recepción de remesas es mayor en el área rural; en el área urbana, aunque esta proporción es cada vez más importante, apenas llegaba al 5\% para 2004; mientras que en el área rural superaba el 8\%.

30 Cabe señalar que el comportamiento casi estable presentado por la pobreza relativa responde a que al sustraer las remesas del ingreso de las familias, muchas de estas pasan a formar parte automáticamente de los pobres absolutos, reduciéndose así la proporción de hogares en pobreza relativa; esto podría indicar que hay muchas familias en pobreza relativa -situación que les es permitida gracias a las remesasque aunque reciban dichos flujos de dinero, poseen una cantidad de ingresos que apenas les alcanza para cubrir el coste de la CA y no aparecer como pobres extremos (al realizar paralelamente el mismo razonamiento en el caso de los hogares no pobres, se constata que al sustraer las remesas de sus ingresos, la proporción de pobres relativos se mantiene más o menos constante o aumenta un poco). 


\section{Gráfico 8}

El Salvador: Proporción de los hogares que logran salir de la pobreza en el área urbana y rural como resultado de las remesas familiares, 1999-2004

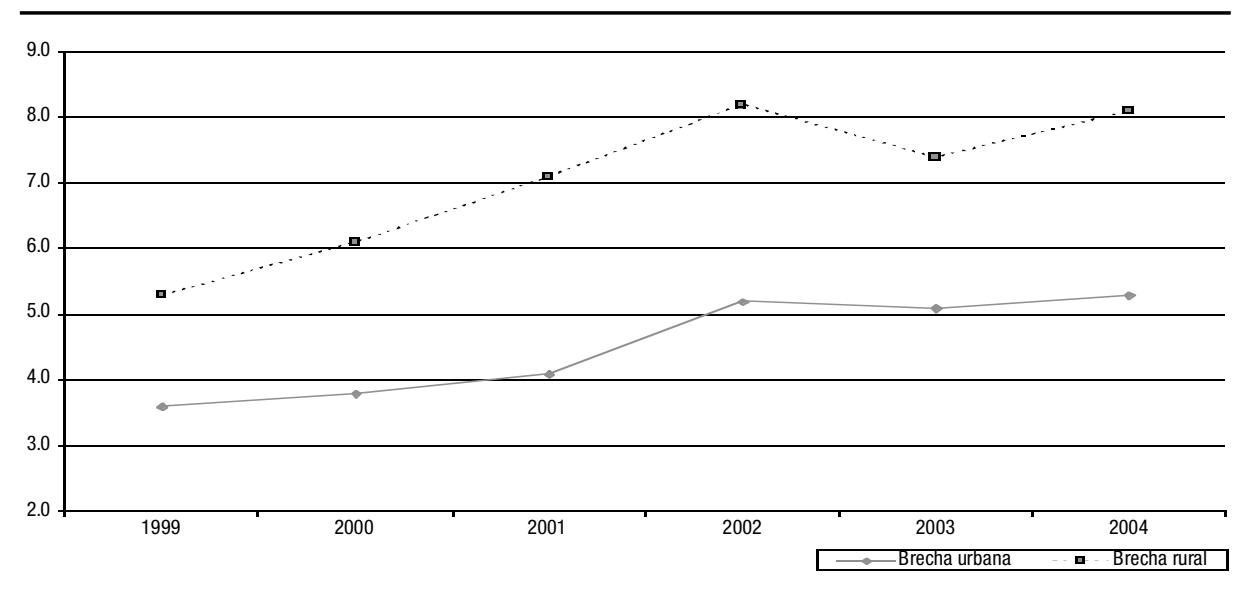

Fuente: Cálculos propios realizados con las bases de datos de la EHPM, varios años.

En cuanto a la pobreza absoluta se presenta la misma situación; en el área urbana la proporción de hogares que logran salir de la pobreza absoluta como resultado de la recepción de remesas fluctúa entre el $3 \%$ y $4 \%$ para la mayor parte del período analizado, aunque para 2004 se incrementa hasta 6\%; mientras que en el área rural dicha proporción se sitúa entre el 6\% y más del $8 \%$. En el Gráfico 10 y 11 puede observarse cómo aumenta la proporción de hogares en situación de pobreza absoluta en el área urbana y rural, cuando se sustraen las remesas del ingreso de los hogares en que las reciben. Aunque la importancia de las remesas en la disminución de la pobreza en ambas áreas es significativa, el área más impactada es el área rural; por esto, puede establecerse que las remesas familiares tienen una influencia importante en la reducción de la pobreza de los hogares salvadoreños en general, pero fundamentalmente en el área rural. 
Gráfico 10

El Salvador: Proporción de hogares urbanos en situación de pobreza absoluta, con y sin remesas familiares, 1999-2004
Gráfico 13

El Salvador: Proporción de hogares rurales en situación de pobreza absoluta, con y sin remesas familiares, 1999-2004

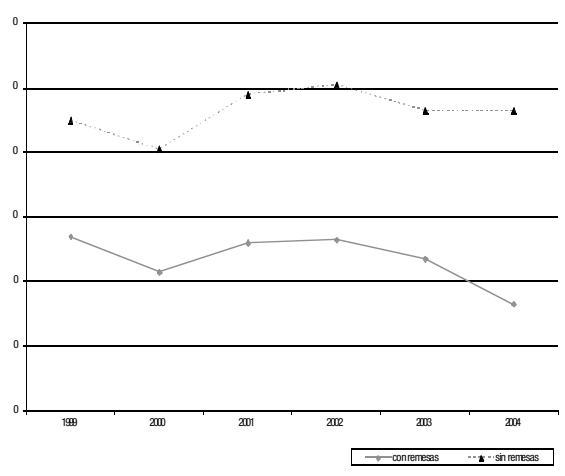

Fuente: Cálculos propios realizados con las bases datos de la EHPM, varios años.

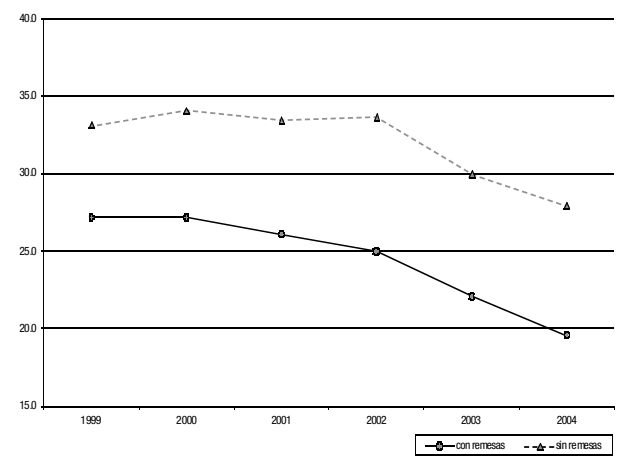

Fuente: Cálculos propios realizados con las bases de datos de la EHPM, varios años..

En lo que respecta al uso que se hace de las remesas familiares, se observa que entre el $79 \%$ y el $80.5 \%$ de estas es utilizado en consumo, como compra de artículos personales y del hogar de consumo frecuente (ver Gráfico 12 y 13). Este es un fenómeno que se observa en ambas áreas, aunque en mayor proporción en el área rural (aproximadamente $84 \%$ para ambos años) donde los salarios son mucho menores. Las remesas también son utilizadas en aspectos relacionados con salud, educación, pago de vivienda y ahorro, pero en una proporción mucho menor que la utilizada para los artículos de consumo frecuente.

Cabe señalar que, al comparar el año 1999 con el año 2004, la proporción del gasto de remesas en educación ha disminuido: para 1999 este era en total de 9.1\%, mientras que para 2004 disminuyó a $6.6 \%$. Esta disminución de la proporción del gasto en educación se ha presentado tanto para hombres como para mujeres de ambas áreas, aunque principalmente para los hombres del área rural; para los que dicho gasto disminuyó de $6.4 \%$ en 1999 a $2.6 \%$ en 2004 . El gasto de remesas en pago de vivienda y salud también ha cedido frente al aumento de la proporción gastada en consumo de artículos frecuentes (a excepción del área rural en lo que respecta al gasto en salud). El gasto de remesas en vivienda a nivel nacional ha disminuido de $2.4 \%$ a $0.7 \%$; esta disminución se presenta principalmente tanto para hombres como para mujeres del área urbana. 
Gráfico 12

El Salvador: Uso de las remesas familiares, 1999
Gráfico 13

El Salvador: Uso de las remesas familiares, 2004
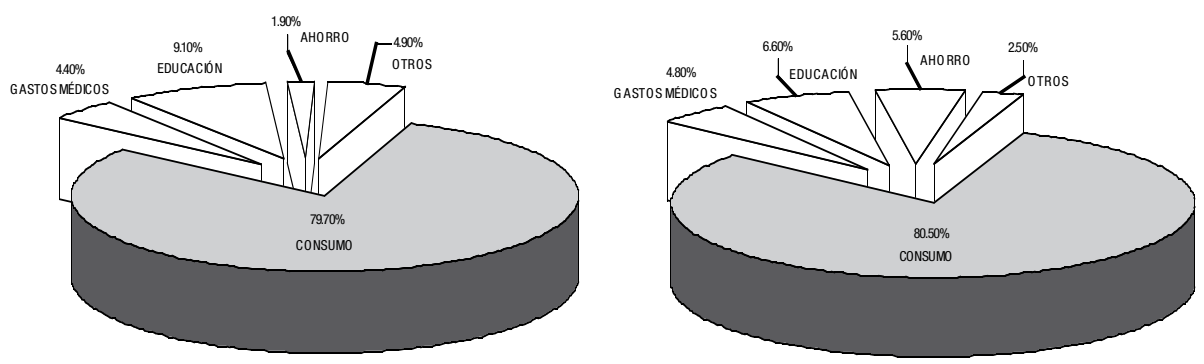

Fuente: Elaborado a partir de la Encuesta de Hogares de Propósitos Múltiples, 1999.

Fuente: Elaborado a partir de la Encuesta de Hogares de Propósitos Múltiples, 2004.

La prevalencia de la mayor proporción de remesas destinada a consumo refleja que aunque en alguna medida las remesas contribuyan a reducir la pobreza de ingresos de los hogares, la pobreza relacionada con las capacidades de las personas no parece muy afectada. Como se ha señalado, la proporción de remesas destinada a educación y salud solo representa una pequeña parte del destino de las remesas si se le compara con la proporción destinada al consumo. Tanto la salud como la educación son aspectos que podrían contribuir a los funcionamientos realizados o a la realización (Sen, 2003) de una persona porque influyen directamente sobre sus capacidades. En este sentido las remesas estarían convirtiéndose únicamente en un paliativo de la situación de pobreza de ingresos de los hogares salvadoreños.

\section{CONSIDERACIONES FINALES}

El propósito principal de este trabajo ha sido conocer en términos generales la influencia de las remesas familiares sobre la situación de pobreza de los hogares salvadoreños, considerando a dichas remesas como parte del fruto de la emigración profundizada con la exclusión laboral. Se ha constatado, entre otros aspectos, que aunque generalmente los emigrantes cuentan con ingresos superiores a los que tenían en El Salvador, muchos de estos están ubicados en los tramos bajos de la distribución del ingreso, generalmente trabajan más pero ganan menos que los nativos, y enfrentan precarias condiciones en cuanto a sus derechos laborales y estatus migratorio. Sin embargo, esto no les restringe a ayudar económicamente a su familia, e indirectamente, 
al país de origen por medio de los ingresos que obtienen al ocuparse en cualquier tipo de actividad remunerada. De esta forma, la permanencia de los emigrantes salvadoreños en Estados Unidos se ha vuelto muy importante tanto para el sostenimiento de su familia en El Salvador, como para el sostenimiento del país en general. Por esto, puede establecerse que la importancia que han ido ganando las remesas refleja una contradicción entre las supuestas intenciones por parte del gobierno acerca de erradicar las causas que generan la emigración -como las relacionadas con el deterioro de las condiciones laborales por ejemplo- y la importancia para la economía de los frutos de dicha emigración, manifestada en las remesas (que opaca algunos de sus aspectos negativos vinculados principalmente con la apreciación del tipo de cambio y con la disminución de la actividad económica).

Se ha identificado que la emigración y las remesas familiares tienen varios efectos ${ }^{31}$, y que dos de los más importantes están vinculados con el mercado de trabajo y con la situación de pobreza de los hogares. En cuanto al mercado de trabajo, uno de los efectos está relacionado con la presión al alza del salario nominal de manera directa, al reducirse el número de trabajadores disponibles, y de manera indirecta con el envío de remesas, fundamentalmente porque generan un salario de reserva para quienes las reciben y expectativas positivas de empleo en otros mercados de trabajo. La presión sobre los salarios produce pérdida de competitividad y generación de pocos puestos de trabajo; esto junto al detrimento de los salarios reales y las expectativas positivas de empleo en los mercados de trabajo en el extranjero motivan a más personas a emigrar. Por otro lado, también se ha identificado que el hecho de que la tasa de participación así como la proporción de personas ocupadas en los hogares en que reciben remesas sea menor, si se le compara con la de aquellos que no las reciben, no significa necesariamente que las personas que reciben remesas no quieran trabajar, sino que gracias a que reciben ese dinero pueden dedicarse a realizar una actividad no laboral -como educarse- o pueden optar eventualmente por emigrar para tratar de acceder a mayores ingresos en otro país.

Por otra parte, según los datos presentados, la pobreza de ingresos en El Salvador se ha reducido casi a la mitad entre 1990 y 2004 , pero aunque haya una reducción tanto de la pobreza absoluta como

31 A partir de este estudio surgen nuevOs interrogantes: un problema que puede ser planteado, para una investigación posterior, está relacionado con la posible desigualdad económica y social que las remesas generan entre personas, familias, comunidades, etc., que reciben remesas y aquellas (de similares características) que no las reciben. 
de la pobreza relativa, es evidente que esta continúa siendo un problema muy grave principalmente en el área rural, donde además, se observa una menor cobertura de servicios básicos importantes. La reducción de la pobreza antes mencionada está relacionada con algunos de los efectos positivos de la emigración y las remesas sobre las condiciones de vida de las personas, pues la recepción de remesas ha permitido que muchos hogares no caigan en situación de pobreza absoluta o relativa (estos resultados positivos pueden vincularse con algunos de los propuestos desde la Nueva Economía de la Migración Laboral). En este sentido, dicha reducción de la pobreza responde en buena medida al sacrificio hecho por una parte importante de los miembros de la sociedad salvadoreña, al emigrar, ocuparse en alguna o algunas actividades remuneradas y enviar remesas familiares. Cabe señalar que la importancia de las remesas se refleja también en que la proporción de hogares que logran salir de la pobreza, como resultado de las mismas ha ido en aumento en los últimos años, tanto en el área urbana como en el área rural. Sin embargo, esta última es el área más impactada, tanto en la reducción de la pobreza en general como en la reducción de la pobreza absoluta. Finalmente, dado que solo una pequeña parte de las remesas es utilizada en educación y salud -aspectos estrechamente relacionados con las capacidades de una persona- $\mathrm{y}$ que la mayor proporción es destinada al consumo, puede establecerse que aunque en alguna medida las remesas contribuyan a reducir la pobreza de ingresos de los hogares, la pobreza relacionada con las capacidades de las personas no parece tan afectada, de manera que las remesas pueden considerarse solo como un paliativo para sobrellevar la situación de pobreza de ingresos de los hogares salvadoreños.

\section{Bibliografía}

Altimir, Óscar 1979 "La dimensión de la pobreza en América Latina" en Cuadernos de la CEPAL (Santiago de Chile: CEPAL) N 27.

BCR 2005 "Características de los remitentes de remesas familiares desde Estados Unidos". Boletín Económico, noviembre-diciembre (San Salvador: BCR).

CARECEN Internacional, disponible en <www.freewebs.com/carecenelsalvador/recursos.htm> (consulta: 31/03/06).

CEPAL 2001 Panorama social de América Latina y el Caribe 2000-2001 (Santiago de Chile: Naciones Unidas).

CEPAL; OIM y BID 2002 Informes nacionales sobre migración internacional en países de Centroamérica (Santiago de Chile: Naciones Unidas).

FESPAD 2006 Políticas Públicas y Derechos Económicos, Sociales y Culturales en El Salvador (San Salvador: FESPAD). 
FISDL/FLACSO 2005 Mapa de Pobreza: Política Social y Focalización (San Salvador: FISDL) Tomo I.

Fitoussi, J. P. y Rosanvallon, P. 1997 La nueva era de las desigualdades (Buenos Aires: Ed. Manantial).

Meneses, Guillermo 2005 "La dimensión femenina del cruce clandestino de la frontera México-Estados Unidos” en Mobilités au féminim. Disponible en <www.mmsh.univ-aix.fr/lames/Papers/Alonso_ES.pdf> (consulta: 16/03/2005).

Mora, Minor 2000 "Tendencias de precarización de empleo en América Latina", ponencia presentada al Seminario Latin American Labor and Globalization: Trends Following a Decade of Economic Adjustment. Organizado por el Social Science Research Council y FLACSO-Costa Rica, San José, Costa Rica, 10 y 11 de julio.

Ochoa, M.; Dada, O. y Montecinos, M. 2000 El Impacto de los Programas de Ajuste Estructural y Estabilización Económica en El Salvador, disponible en <http://www.saprin.org/elsalvador/research/ els_cover_index.html> (consulta: 27/12/2005].

OIM/SIEMCA 2004 "Movimientos internacionales a través de las fronteras centroamericanas. El Salvador 1980-2002" en Serie Flujos Migratorios $N^{o}$ 3, disponible en <http://www.siemca.iom.int/descargas/documentos/siemca03.pdf> (consulta: 08/03/2006).

OIT 2002 Panorama Laboral de América Latina y el Caribe (Lima: OIT).

OIT 2004 Panorama Laboral de América Latina y el Caribe (Lima: OIT).

Olavarría, Mauricio 2001 "Pobreza: conceptos y medidas". Documento de trabajo $\mathrm{N}^{\circ} 76$. Universidad de Chile. Parte del proyecto de investigación "Fighting Poverty in Chile", disponible en <www. inap.uchile.cl/gobierno/publicaciones/Olavarría-pobreza.pdf > (consulta: 16/05/2006).

Pérez Sáinz, Juan Pablo 2003 "Los impactos de la globalización en el mundo laboral centroamericano" en Revista Europea de Estudios Latinoamericanos y del Caribe (Madrid) $\mathrm{N}^{\circ} 74$.

PNUD 2003 Informe sobre Desarrollo Humano, El Salvador 2003: Desafíos y opciones en tiempos de globalización (San Salvador: PNUD).

PNUD 2005 Informe sobre Desarrollo Humano, El Salvador 2005: Una mirada al nuevo nosotros, el Impacto de las Migraciones (San Salvador: PNUD).

Sen, Amartya 1985 "A sociological approach to the measurement of poverty: a reply to professor Peter Townsend" en Oxford Economic papers (Oxford: Oxford University Press) $\mathrm{N}^{\circ} 37$.

Sen, Amartya 2003 "El enfoque de las Capacidades y las Realizaciones" en Comercio Exterior (México DF) Vol. 53, N 5, mayo. 
Solimano, Andrés 2005 "Migraciones internacionales, remesas y mercado laboral: la situación en América Latina y el Caribe" en Panorama Laboral (Lima: OIT).

Taylor, Edward y Fletcher L., Peri 2002: "Remittances and Development in Mexico: Part One; The New Labor Economics of Migration: A Critical Review" en Rural Mexico Research Review (California) Vol. 2.

Weller, Jürgen 2001 "Procesos de exclusión e inclusión laboral: la expansión del empleo del sector terciario" en Serie Macroeconomía del Desarrollo. División de Desarrollo Económico (Santiago de Chile: CEPAL) $\mathrm{N}^{\circ} 6$. 


\title{
JHON ANTón SÁNCHEZ*
}

\section{EXCLUSIÓN, POBREZA Y DISCRIMINACIÓN RACIAL EN LOS AFROECUATORIANOS}

\author{
LAS RESPUESTAS DESDE SUS \\ ORGANIZACIONES SOCIALES
}

\section{INTRODUCCIÓN}

El Ecuador es uno de los países de menor nivel de desarrollo humano de América del Sur (NU, 2004) ${ }^{1}$. Según el Censo del 2001 más del $61 \%$ de sus habitantes están en condiciones de pobreza por necesidades básicas insatisfechas. Sin embargo, este fenómeno en el país tiene connotaciones étnicas y sociorraciales muy acentuadas. Los grupos negros o afroecuatorianos e indígenas son los que presentan los indicadores de pobreza más altos (70,3\% para los primeros y el 89,9\% para los segundos) (STFS, 2005). Documentos de las organizaciones sociales afroecuatorianas coinciden en que la marcada pobreza y mar-

* Afrocolombiano. Antropólogo. Especializado en Desarrollo Comunitario en la Universidad del Chocó (Colombia), magíster en Sociología en la Universidad Nacional de Colombia. Candidato a Doctor en Ciencias Sociales (FLACSO- Ecuador). Actualmente es coordinador del Sistema de Indicadores Sociales del Pueblo Afroecuatoriano (SISPAE) del Gobierno del Ecuador. Pertenece a la Alianza Estratégica Afrodescendiente y Caribeña y a la Fundación Cultural Las Mojarras (Condoto, Colombia).

1 De acuerdo con el Informe de Desarrollo Humano de las Naciones Unidas del 2004, el Ecuador ocupa el puesto 100 de 177 en la escala de países con Índice de Desarrollo Humano (IDH) en el mundo. Este lugar es uno de los más bajos en la escala latinoamericana, apenas por encima de Bolivia (NU, 2004: 140). 
ginalidad en los afro guarda relación con la discriminación racial y el racismo que soportan desde la esclavitud (BID, 2004). Y en efecto, una vez superada la esclavitud en 1854 los descendientes de africanos quedaron sin ninguna garantía de derechos ciudadanos. Más bien, sobre ellos pesó la exclusión social y la dominación racial, factores que los obligó a ocupar el espacio más bajo en la escala social. Como consecuencia de todo esto los afroecuatorianos se vieron envueltos en un proceso histórico de marginación y empobrecimiento sostenido, incluso hasta hoy. Y en efecto, los indicadores sociales así lo demuestran: en Ecuador existen zonas rurales de mayoría afroecuatoriana, tal como los cantones del norte de la provincia de Esmeraldas, donde la pobreza por NBI es superior al 87,63\%. Para el 2006, el desempleo en las mujeres afroecuatorianas superaba el 17\%, mientras que la misma tasa en todas las mujeres era el 10,8\%, siendo el promedio nacional del 7,9\%. (STFS, 2005: 5). Asimismo se registra que para el 2004 un hogar afroecuatoriano promedio recibía ingresos mensuales por debajo de los 378 dólares, mientras que un hogar blanco alcanzaba los $\$ 644,66$, siendo el promedio nacional $\$ 500,82$. (Antón, 2006: 436)

En contraste con este diagnóstico desalentador de las condiciones sociales de los afroecuatorianos, desde los años noventa del siglo $\mathrm{XX}$ estas comunidades han generado interesantes movilizaciones sociales (De la Torre, 2003; Walsh, 2004). Aunque con menos publicidad e intensidad que los indígenas, diez años atrás las organizaciones de la sociedad civil afro generaron acciones con el objetivo de concretar demandas ante el Estado (Antón, 2003). De este modo, y como en ninguna otra parte de la región, se han canalizado varias medidas legislativas e institucionales que demuestran cierto grado de inclusión en las políticas públicas. Pero paradójicamente las condiciones de pobreza no logran ser afectadas positivamente. ¿Qué sucede entonces? ¿Por qué dichas medidas no son suficientes? ¿Qué hace falta? ¿Hacia dónde hay que apuntar con exactitud?

En este ensayo me interesa debatir sobre la relación entre desafío de la pobreza en los afroecuatorianos y las acciones que las organizaciones de estas comunidades emprenden para superarlo. Más concretamente, pretendo analizar las respuestas que las organizaciones afro dan al problema de la marginalidad, la exclusión y la desigualdad socioeconómica que gran parte de la ciudadanía afroecuatoriana experimenta históricamente.

Para el logro del objetivo esta investigación dispuso tanto de técnicas cuantitativas como cualitativas. En primer lugar se hizo un esfuerzo en el análisis de las fuentes estadísticas que expresan el panorama de exclusión social, pobreza y discriminación de los afroecuatorianos. Asimismo, existió el interés en comprender la dinámica política y las 
acciones colectivas de las organizaciones sociales afro que reivindican derechos sociales como una estrategia para superar la pobreza en sus comunidades. Pero además fue necesario realizar un trabajo de campo suficiente a lo largo del país que permitiera acercarnos al debate por parte de las organizaciones respecto a la manera cómo ellas enfrentan la pobreza de sus comunidades.

Dividiremos nuestro ensayo en tres partes: en una primera examinaremos brevemente conceptos relacionados con la exclusión social, discriminación racial y desigualdad. La segunda parte tratará sobre el panorama de pobreza de los afroecuatorianos a partir de los indicadores sociales disponibles. Finalmente se expondrán elementos del proceso organizativo afroecuatoriano y sus estrategias para enfrentar la situación de pobreza de las comunidades que ellos dicen representar.

En términos generales trataremos de demostrar que pese a que las organizaciones aafroecuatorianas han emprendido con éxito algunas acciones para superar la pobreza de sus comunidades, estas aun no logran ser suficientes ni efectivas. Concluiremos que la razón principal para que dichas medidas no logren mejor impacto presumiblemente tenga que ver con la complejidad del problema que se intenta resolver. Esto por cuanto los afroecuatorianos se encuentran envueltos en la encrucijada del racismo estructural, es decir, un fenómeno que se sitúa desde el contexto de las prácticas históricas de discriminación y exclusión que la sociedad ecuatoriana ha ejecutado contra los afroecuatorianos. Se trata de raíces de la desigualdad social que se han cimentado desde la esclavitud. Y este es un desafío que demanda un cambio de actitud, transformación de valores culturales y de ciertas costumbres, pero que consideramos que son posibles de enmendar mediante estrategias pedagógicas y educativas a través de un período de larga duración.

\section{RACISMO, POBREZA Y EXCLUSIÓN SOCIAL: EL DESAFÍO AFRODESCENDIENTE}

La discriminación racial, la desigualdad socioeconómica y la exclusión social retratan una problemática de tipo estructural con profundas raíces históricas que padecen los afrodescendientes en América Latina (García, 2001). Al menos a esta conclusión se llegó en la III Cumbre Mundial contra el Racismo, celebrada por las Naciones Unidas en Durban (Sudáfrica) durante el año 2001. Igualmente así lo determinan los informes sobre pobreza y desigualdad en la región, elaborados por instituciones como CEPAL, Banco Mundial, Naciones Unidas, BID y las mismas redes sociales de afrodescendientes que funcionan en la región.

De acuerdo con Rodríguez Romero (2000) en la mayoría de los países de América Latina la problemática afrodescendiente 
de la pobreza y la exclusión asociada al racismo es un fenómeno preocupante. En Ecuador las organizaciones afroecuatorianas ya son concientes de este fenómeno, y particularmente desde finales de los años noventa plantean una serie de alternativas a la encrucijada.

En Ecuador los afrodescendientes superan el 5\% del total de la población ${ }^{2}$. Según el Censo del 2001 el 70,6\% de ellos viven en la pobreza medida por Necesidades Básicas Insatisfechas (NBI), pero estos son aun más pobres si viven en aquellas zonas rurales donde son mayoría. Ejemplo de ello son los asentamientos de municipalidades de la Provincia de Esmeraldas, como Eloy Alfaro o San Lorenzo, donde la pobreza por NBI supera el $99,6 \%$.

Otros datos afirman la condición marginal y de desigualdad de los afroecuatorianos en relación con otras etnias o grupos sociorraciales. De acuerdo con la Secretaría Técnica del Frente Social del Gobierno del Ecuador (2005), para el 2001 la tasa de analfabetismo en el país fue de $9,2 \%$, mientras en los afroecuatorianos fue superior al 10,3\%. La escolaridad promedio de un afrodescendiente es de 6,1 años, mientras que los blancos registran una media de 9,2 años, siendo el promedio nacional 7,2 años. De la misma manera, los jóvenes afro apenas alcanzan una tasa de asistencia universitaria neta de $4,7 \%$, muy inferior al promedio nacional de $11,2 \%$ y a la tasa de los blancos de $16,5 \%$. Otro problema social que enfrentan los afroecuatorianos es el acceso a puestos de trabajo. De acuerdo con la encuesta de empleo del Instituto Nacional de Estadísticas y Censos del Ecuador (INEC) para el 2005 la tasa de desempleo de la población afro superaba el $11 \%$, indicador más alto que la tasa nacional urbana que bordeaba el $7,9 \%$. Sin embargo la peor parte la llevan las mujeres afroecuatorianas, quienes registraron unas tasa histórica de desempleo del 17,5\% frente al 10,8\% de desempleo de todas las mujeres ecuatorianas.

Ahora bien, las bajas tasas se escolaridad y los altos índices de desempleo en los afroecuatorianos se reflejan en el tipo de actividades que en mayor medida desempeñan. Gran parte de la población afro económicamente activa se ocupan en el sector primario de la economía. Además muchos de ellos apenas logran trabajar como jornaleros, albañiles, domésticos, vigilantes, ayudantes de talleres o vendedores

2 De los cuales el $77,4 \%$ se reconoce como mestizo, el $10,46 \%$ como blanco, el $6,83 \%$ indígena, mientras los afroecuatorianos que se identificaron como tal alcanzaron el 4,97\%, de los cuales el 2,23 se consideró negro y el 2,74 se declaró mulato. En total, según cifras del Instituto Nacional de Estadísticas del Ecuador (INEC), los afroecuatorianos son 604.009 personas (271.327 que se identificaron como negros y 332.632 personas que dijeron ser mulatos) (Secretaría Técnica del Frente Social, 2005). 
callejeros. Empero muy pocos afro se dedican a actividades ejecutivas, profesionales y lucrativas.

Los indicadores sociales que presentan los afroecuatorianos son el reflejo de la condición de desigualdad que padecen estas comunidades. Panorama que se agrava más si tal desigualdad se relaciona con los factores de discriminación racial social que son muy característicos en Ecuador (STFS, 2005). Las investigaciones de Carlos de la Torre (2002) demuestran que en el país, por ejemplo, es muy característico que en la escala social los afroecuatorianos e indígenas aparezcan en situaciones de desventaja frente a otros grupos sociorraciales como los blancos y mestizos. En particular se trata de una geografía racial que presenta dos polos opuestos, los blancos en el extremo de las oportunidades ocupan los mejores niveles de desempeño, mientras que en el otro extremo se sitúan indígenas y afro.

¿Por qué ocurre este fenómeno? A manera de hipótesis consideramos que la situación de marginalidad que rodea a gran parte de los afroecuatorianos es parte del fenómeno de exclusión social arraigada en el país. La exclusión la comprendemos como un proceso en que grupos de personas son total o parcialmente relegados de la plena participación en la sociedad en que viven. Bhalla y Lapeyere la asocian con la limitación de derechos ciudadanos y por tanto tiene que ver con la obstrucción a oportunidades reales para el desarrollo social (Bhalla y Lapeyere, 1997: 5). De modo que nos encontramos frente a una problemática muy compleja que se desagrega en varias tipologías: exclusión socioeconómica, exclusión sociocultural y exclusión sociopolítica. Y estos tres asuntos son muy relevantes en el contexto de los afrodescendientes.

Siguiendo a Jeannette Sutherland (2001) la exclusión social con base en las condiciones étnicas y culturales es un tema prioritario en la agenda del movimiento afrodescendiente. Desde el punto de vista socioeconómico la exclusión en los afroecuatorianos se plasma en la condición de su subordinación en la vida económica y productiva del país. Luego de 1852, en que se declara la abolición de la esclavitud, el Gobierno republicano en lugar de reparar los daños materiales, culturales y espirituales a los libertos, decide más bien indemnizar a la elites esclavistas, dejando al liberto sin tierra y sin oportunidades de inserción social, relegándolos a precarias condiciones sociales (Peñaherrera y Costales, 1964; Savoia, 1992). Desde entonces la vida de los afroecuatorianos ha estado marcada por desafíos estructurantes para su desarrollo, la cual se caracteriza por poco o limitado acceso a los recursos (incluyendo el capital y la propiedad), a los mercados (mano de obra y crédito), a los servicios (salud, educación, agua potable) y a la evidente restricción a tierras productivas, agua para riego, créditos productivos y capacitación. 
La exclusión sociopolítica se refiere al grado de marginación institucional y política que se practica hacia ciertos grupos minoritarios. Uno de los elementos clave para medir su alcance tiene que ver con la capacidad que las instituciones tienen para facilitar o restringir la participación comunitaria de ciertos sectores de la población en diversos asuntos nacionales. Es este caso se mira con preocupación la reducida participación política de los afrodescendientes en distintos escenarios del ámbito democrático.

Otro elemento importante en esta discusión es la exclusión sociocultural que padecen los afroecuatorianos. Los trabajos de Jean Rahier (1999) dan cuenta de cómo el fenómeno se concreta por medio de distintos factores determinantes: los estigmas de peligrosidad, sexismo y delincuencia asociados con las personas afrodescendientes, el racismo psicolingüístico, la ideología del mestizaje y el blanqueamiento ligada al prejuicio racial.

De acuerdo con lo anterior, un aspecto clave para la comprensión del fenómeno de la exclusión social en los afroecuatorianos tiene que ver con la discriminación racial que ellos padecen. La discriminación racial está asociada al racismo, el cual se interpreta tanto como una ideología que incluye aspectos políticos, prejuicios, disposiciones legales y prácticas cotidianas e institucionalizadas que provocan y refuerzan la desigualdad racial. Pero ante todo entendemos el racismo como una estrategia de poder y dominación, la cual se expresa tanto en la conducta como también en las actitudes de los poderosos (Antón, 2005: 16). Del racismo se deriva el prejuicio racial, quien se expresa de distintas maneras tales como en frases o palabras con cargas peyorativas que pretenden inferiorizar a ciertas personas. Asociado al racismo se encuentra la discriminación racial. En sentido amplio remite a un trato diferenciado a las minorías culturales o grupos étnicos basado en aspectos sexuales, raciales, políticos, laborales o religiosos ${ }^{3}$. El trato discriminatorio se puede dar en el plano de las relaciones interpersonales, en el ámbito de la esfera pública y en la esfera privada.

En el caso de los afroecuatorianos, es evidente que sus procesos de desarrollo han estado atravesados por situaciones de racismo estructural y de discriminación enraizadas como prácticas de una so-

3 La Convención Internacional contra todas las Formas de Discriminación Racial de las Naciones Unidas, en su artículo 1 define la discriminación racial como: "[...] toda distinción, exclusión, restricción o preferencia basada por motivos de raza, color, linaje u origen nacional o étnico que tenga por objeto o por resultado anular o menoscabar el reconocimiento, goce o ejercicio, en condiciones de igualdad de derechos humanos y libertades fundamentales en las esferas política, económica, social, cultural o en cualquier otra esfera de la vida pública" (Municipio del Distrito Metropolitano de Quito, 2005). 
ciedad post esclavista. Sobre este punto Carlos de la Torre afirma que a los afroecuatorianos les ha correspondido "vivir en una sociedad que discrimina en lo cotidiano, lo que produce una situación muy costosa para los negros" (De la Torre, 2002: 17). Asimismo, el autor precisa que el racismo y la discriminación se expresan como una estrategia que le permite al sector hegemónico mantener un "sistema de poder que sistemáticamente da privilegios a quienes han sido racializados como miembros de grupos étnicos blancos o como casi blancos o blancos honorarios pero no totalmente blancos como son los mestizos y los mulatos ecuatorianos y que excluyen a los negros y a los indígenas" (ibid.). De este modo el racismo y la discriminación deben explicarse igualmente como un sistema estructural e ideológico que regula y racionaliza las relaciones desiguales de poder de acuerdo con la herencia piramidal colonial que aún subyace. Esta condición permite entender la estrecha conexión entre racismo, discriminación y desigualdad, aspecto último al que nos referimos a continuación.

Según el Banco Mundial (2003: 5) la desigualdad alude a una medida de dispersión en una redistribución económica. De manera específica permite entender los niveles de asimetría en términos de distribución de los ingresos familiares, los cuales se consideran básicos para el bienestar de las familias. El concepto de bienestar aquí tendría que ver con la satisfacción de necesidades de las personas en materia de servicios como educación, salud, empleo, recreación, vivienda, servicios básicos, seguridad, libre circulación y libertad de opinión y credo, entre otros aspectos. Pero además, el bienestar se liga a factores como la política, la participación democrática y el libre desarrollo de la personalidad. De acuerdo con el Banco Mundial sobre las condiciones de desigualdad en América Latina, no es suficiente analizar el fenómeno de la desigualdad solamente desde el ámbito de la distribución de los ingresos, sino que es importante tener en cuenta la distribución de las oportunidades y posibilidades. De este modo factores que inciden en las oportunidades y posibilidades como la participación, la influencia política y el poder están estrechamente relacionados con las diferencias económicas y constituyen elementos clave en el desarrollo personal y social.

\section{LOS AFROECUATORIANOS Y SUS PROCESOS DE MOVILIZACIÓN SOCIAL}

A continuación se explora la dinámica del proceso organizativo afroecuatoriano, como expresión de la sociedad civil, en términos de sus propuestas que se estructuran como respuesta a los desafíos 
de pobreza, discriminación, desigualdad y exclusión social de los afroecuatorianos.

Particularmente desde finales de los años noventa del siglo XX los afroecuatorianos logran un interesante proceso político que les permite fortalecerse como sociedad civil. ${ }^{4}$ En medio de una década caracterizada por grandes movilizaciones sociales de toda índole, en especial de indígenas, los afro crean cientos de organizaciones regionales, locales y de carácter nacional e irrumpen en la esfera pública ${ }^{5}$. Estas organizaciones asumen una agenda política que coloca al Estado como centro catalizador de sus demandas que van desde el reconocimiento de derechos colectivos que exigen la aplicación de políticas públicas garantes de su identidad, de la igualdad de oportunidades, del combate a la discriminación, y sobre todo políticas que les permitan salir de la pobreza.

Referencias institucionales dan cuenta de un catálogo de al menos 310 organizaciones de la sociedad civil afroecuatorianas verificadas $^{6}$. Geográficamente estas se sitúan en mayor medida en la provincia de Esmeraldas, seguidas por Guayas, Pichincha y el Valle del Chota. Solo en Pichincha existe una federación que agrupa un poco más de 41 organizaciones. Se precisa que el mayor porcentaje de organizaciones corresponden a los sectores populares dado el hecho de que el 68,3\% de la población afro de Ecuador es urbana (Ver cuadro 1).

4 La década de los noventa y el comienzo del siglo XXI han demarcado una época de interesantes cambios y transformaciones en la vida del Ecuador, caracterizada por un ambiente de globalización neoliberal y donde se ha canalizado con profundidad una crisis de corte económico y político. Pero igualmente en esta década la irrupción de los movimientos sociales ha sido notoria en tanto planteaban la transformación del modelo de Estado y nación. Dentro de este contexto los afroecuatorianos desde las expresiones organizativas de su sociedad civil han hecho aportes importantes, sobre todo en el marco de la construcción de un nuevo carácter identitario de la nación, el cual merece romper la pirámide racial monolítica en la que se construyó el proyecto nacional, para dar paso al multiculturalismo característico del pueblo ecuatoriano.

5 De acuerdo con Gerardo Maloney (1993) los afroecuatorianos comenzaron a estructurar un concepto moderno de sociedad civil desde finales de los años setenta del siglo XX donde el interés étnico y de clase fueron los rasgos fundamentales distintivos. Pese a lo temprano de esta emergencia su proceso debe analizarse desde la perspectiva sociológica de la larga duración en la cual a los afrodescendientes les correspondió la superación de la dura prueba de la dispersión y deconstrucción cultural que representó el período esclavista, para luego con creatividad reconstruir sus principales rasgos ontológicos e identitarios.

6 Base de Datos de las organizaciones de la sociedad civil afroecuatoriana. Sistema de Indicadores Sociales del Ecuador. Secretaría Técnica del Frente Social, Quito, 2005. 
Cuadro 1

Resumen de organizaciones afroecuatorianas

\begin{tabular}{|c|c|c|c|c|}
\hline \multicolumn{5}{|c|}{ RESUMEN DE ORGANIZACIONES AFROECUATORIANAS REGISTRADAS } \\
\hline AREA & PROVINCIA & NUMERO & $\%$ AREA & \% PROVINCIA \\
\hline \multirow[t]{2}{*}{ COSTA NORTE } & ESMERALDAS & 115 & & $37,10 \%$ \\
\hline & MANABI & 0 & & \\
\hline Sub Total & & 115 & $37,10 \%$ & \\
\hline PICHINCHA & PICHINCHA & 41 & & $13,20 \%$ \\
\hline Sub Total & & 41 & $13,20 \%$ & \\
\hline \multirow[t]{2}{*}{ VALLE DEL CHOTA } & CARCHI & 18 & & $5,80 \%$ \\
\hline & IMBABURA & 41 & & $13,20 \%$ \\
\hline Sub Total & & 59 & $19,00 \%$ & \\
\hline \multirow[t]{4}{*}{ COSTA SUR } & GUAYAS & 71 & & $22 ; 90 \%$ \\
\hline & LOS RIOS & 1 & & $0 ; 30 \%$ \\
\hline & EL ORO & 8 & & $2,60 \%$ \\
\hline & LOJA & 1 & & $0,30 \%$ \\
\hline Sub Total & & 81 & $26 ; 10 \%$ & \\
\hline \multirow[t]{2}{*}{ AMAZONIA NORTE } & SUCUMBIOS & 13 & & $4,20 \%$ \\
\hline & ORELLANA & 1 & & $4,20 \%$ \\
\hline Sub Total & & 14 & $4,50 \%$ & \\
\hline TOTAL & & 310 & $100,00 \%$ & $100,00 \%$ \\
\hline
\end{tabular}

Fuente: CODAE, PRODEPINE, BID, MONUME-BM, DEFENSORIA.

Elaborado por Jhon Antón, 2005.

Uno de los mayores logros de la sociedad civil afrodescendiente lo constituyó la coyuntura de la Asamblea Nacional Constituyente de 1998, la cual expidió una Constitución que instaura una nueva cultura política y la legitimidad de una sociedad civil diferente amparada en la diversidad de sus expresiones culturales ${ }^{7}$. Pero además de ello, las acciones colectivas y las demandas de los afro se han convertido en una serie de medidas que el Estado emprende a favor de este pueblo (Agenda Política de Mujeres Negras, 2000). Un examen a primera vista de estas acciones daría a entender por qué los afroecuatorianos, como en ningún otro país a excepción de Brasil y Colombia, han lo-

7 La Constitución Política de 1998 en primer lugar determina al Ecuador como un Estado Multiétnico y Pluricultural (Art.1) y además reconoce y legitima el carácter de "pueblo" tanto de los afroecuatorianos como indígenas (Art. 83). 
grado tantas reivindicaciones. El cuadro 2 detalla una síntesis de las acciones más relevantes. A continuación se describen algunas medidas importantes.

\section{Cuadro 2}

Acciones del estado a favor de los afroecuatorianos

\begin{tabular}{|c|c|c|c|}
\hline $\mathbf{N}^{0}$ & Tipo de acción & Institución responsable & Logros \\
\hline 1 & \multirow{4}{*}{ Legislativa } & \multirow{4}{*}{ Congreso de la República } & Ley de Derechos Colectivos del pueblo afroecuatoriano \\
\hline 2 & & & Día Nacional del Negro \\
\hline 3 & & & Medalla Nacional de reconocimiento Alonso de Illescas \\
\hline 4 & & & $\begin{array}{c}\text { Plan Nacional de Derechos Humanos del Pueblo } \\
\text { Afroecuatoriano }\end{array}$ \\
\hline 5 & \multirow{3}{*}{ Institucionales } & \multirow[t]{2}{*}{ Gobierno Nacional } & $\begin{array}{c}\text { Consejo Nacional de Desarrollo Afroecuatoriano } \\
\text { CONDAE }\end{array}$ \\
\hline 6 & & & Dirección Nacional de Defensoría del Pueblo Negro \\
\hline 7 & & Gobiernos Locales & $\begin{array}{l}\text { Unidad de Desarrollo del Pueblo Negro de la Alcaldía } \\
\text { de Quito }\end{array}$ \\
\hline 8 & \multirow{3}{*}{$\begin{array}{l}\text { Proyectos de } \\
\text { Inversión }\end{array}$} & BANCO MUNDIAL & PRODEPINE \\
\hline 9 & & \multirow{2}{*}{ BID } & $\begin{array}{l}\text { Diagnóstico de la Problemática Afroecuatoriana y } \\
\text { Propuestas de Acciones Prioritarias }\end{array}$ \\
\hline 10 & & & $\begin{array}{l}\text { Capacitación y fortalecimiento de las organizaciones } \\
\text { afroecuatorianas }\end{array}$ \\
\hline 11 & Visibilidad Estadística & INEC & $\begin{array}{c}\text { Inclusión de la variable afroecuatoriana en los censos y } \\
\text { encuestas nacionales }\end{array}$ \\
\hline 12 & & STFS & $\begin{array}{c}\text { Sistema de Indicadores Sociales del Pueblo } \\
\text { Afroecuatoriano SISPAE }\end{array}$ \\
\hline 13 & Otras acciones & Unión Europea & $\begin{array}{c}\text { Proyecto de consolidación de liderazgo y } \\
\text { empoderamiento de las mujeres negras organizadas } \\
\text { del Ecuador }\end{array}$ \\
\hline
\end{tabular}

Elaborado por John Antón, 2005.

\section{LEY DE DERECHOS COLECTIVOS DEL PUEBLO AFROECUATORIANO}

El 9 de mayo de 2006 el Congreso de la República aprobó el Proyecto de Ley de Derechos Colectivos del Pueblo Negro o Afroecuatoriano ${ }^{8}$. La Ley contiene 27 artículos y dos disposiciones transitorias.

8 La ley fue publicada en el registro oficial $\mathrm{N}^{\circ} 275$ del lunes 22 de mayo de 2006. Sobre esta propuesta de ley se presentaron tres versiones al Congreso, la primera presentada por el diputado Víctor Junior León Luna el 16 de mayo de 1999; la 
Busca concretar una serie de derechos económicos, políticos, sociales, culturales, civiles, territoriales contemplados en los Artículos 83 y 84 de la Constitución.

En esencia, las propuestas de reglamentación de los derechos colectivos del pueblo afroecuatoriano busca darle una posibilidad jurídica a las expresiones organizativas naturales del pueblo afroecuatoriano, a la vez que pretende garantizar y fortalecer espacios de participación social dentro del Estado, propone la institucionalidad de los programas etnoeducativos, y establece un Consejo Nacional de Desarrollo Afroecuatoriano (CONDAE). ${ }^{9}$

\section{La Ley de Plan Nacional sobre los Derechos Humanos}

En cumplimiento del mandato de la Declaración y Plan de Acción de la Conferencia Mundial sobre Derechos Humanos celebrada en Viena en 1993, cuyo Párrafo 71 recomendó a los estados que consideren la posibilidad de elaborar planes de acciones nacionales, en las cuales se determinen las medidas necesarias para que cada estado mejore la promoción y protección de los derechos humanos, el Gobierno Nacional adoptó como política de Estado el Plan Nacional de Derechos Humanos, mediante Decreto Ejecutivo 1527, publicado en el Registro Oficial $\mathrm{N}^{\circ}$ 346, del 24 de junio de 1998.

El Plan Nacional de Derechos Humanos, en sus Artículos 10 y 11 establece "Los derechos de los pueblos afroecuatorianos", donde se plantean como objetivos: i) mejorar la calidad de vida del pueblo afro, ii) fortalecer y consolidar el movimiento social, y iii) lograr el reconocimiento y la protección efectiva de los derechos individuales y colectivos del pueblo afro. Además de ello se traza una serie de compromisos relativos a generar políticas sociales, económicas y culturales que promuevan su desarrollo, la participación en cargos de decisión en los sectores públicos y privados, el establecimiento de programas de educación especial, la promoción y respeto por las formas de organización y propender al reconocimiento de los derechos de propiedad sobre los territorios ancestrales ${ }^{10}$.

segunda presentada por la Confederación Nacional Afroecuatoriana en julio de 2002, y la última iniciativa la tiene actualmente el diputado por Esmeraldas Rafael Erazo (MPD).

9 Asimismo la ley reglamenta aspectos relacionados con el "derecho a la tierra, el territorio y la propiedad", "el derecho a la biodiversidad y los recursos naturales", "el derecho a la propiedad intelectual colectiva, "el derecho a la identidad, educación y cultura", "el derecho a la medicina tradicional y los servicios de salud", y una serie de disposiciones que tiene que ver con instrumentos garantes de los derechos económicos, sociales y culturales (DESC), entre otras disposiciones transitorias.

10 Plan Nacional de Derechos Humanos y Planes Operativos de Derechos Humanos 


\section{El Consejo de Desarrollo Afroecuatoriano (CODAE)}

En 1998 el gobierno nacional crea la Corporación para el Desarrollo del Pueblo Afro Ecuatoriano (CODAE) adscrita a la Presidencia de la República, con el objetivo de proponer políticas de Estado para el fortalecimiento del pueblo afroecuatoriano, la difusión de los derechos, valores, cultura e historia afroecuatoriana y fomentar la etnoeducación

\section{Dirección Nacional de Defensa de los Derechos del Pueblo Afroecuatoriano}

Dentro de la Defensoría de Pueblo el Estado Ecuatoriano crea la Dirección Nacional de Defensa de los Derechos Humanos del Pueblo Afroecuatoriano, como un espacio institucional encargado de tratar las lesiones de los derechos humanos del pueblo afroecuatoriano. Entre sus funciones la oficina contempla promover los derechos de los afroecuatorianos, coordinar con las organizaciones las acciones a seguir para lograr un desarrollo eficiente de las bases sociales para lo cual establece un plan de trabajo coordinado a desarrollarse en las zonas habitadas por esta población ${ }^{11}$.

\section{EL PROYECTO DE DESARROLLO DE LOS PUEBLOS INDÍGENAS Y NEGROS DEL ECUADOR (PRODEPINE)}

Este proyecto fue financiado por el Banco Mundial mediante préstamo reembolsable del 50 millones de dólares. El proyecto PRODEPINE fue una unidad ejecutora del Consejo de Desarrollo de las Nacionalidades y Pueblos del Ecuador (CODENPE). Tuvo una duración de cuatro años y finalizó en el 2003. El proyecto pretendió beneficiar aproximadamente a 815.000 personas ubicadas en 288 parroquias del país de población indígena y afro. Tuvo cuatro áreas fundamentales de trabajo: a) fortalecimiento de las nacionalidades y organizaciones indígenas y negras; b) apoyo a la regularización de la tenencia de tierras y derechos de aguas; c) inversiones rurales y d) fortalecimiento de las oficinas de los indígenas y de los afroecuatorianos ${ }^{12}$.

del Ecuador. Comisión Permanente de Evaluación, Seguimiento y Ajuste a los Planes Operativos. Quito, enero de 2003, pág. 17.

11 La situación de esta dirección es particular. Sus funciones son de carácter nacional, pero apenas funciona en una sala estrecha en la Ciudad de Guayaquil, sin presupuesto alguno, con pocos funcionarios y completamente limitada, situación que la coloca en desventaja frente a la responsabilidad que posee como órgano rector defensor de los derechos humanos del pueblo afroecuatoriano.

12 Para las mismas organizaciones afro el PRODEPINE no ejecutó una política de equidad, pues se cometieron actos de discriminación toda vez que tanto su presupuesto como los funcionarios y la infraestructura se dirigieron al beneficio de los indígenas. 


\section{El Diagnóstico de la Problemática Afroecuatoriana y Propuestas de Acciones Prioritarias y el Proyecto de Fortalecimiento de la Sociedad Civil}

En el año 2003 el Banco Interamericano de Desarrollo mediante cooperación técnica no reembolsable de 150 mil dólares financió el Diagnóstico de la Problemática Afroecuatoriana y Propuestas de Acciones Prioritarias. Resultado de esta consultoría se elaboró una propuesta de plan de desarrollo para el pueblo afroecuatoriano, calculado en 170 millones de dólares para ser invertidos en un plazo de diez años. Este diagnóstico y el plan de desarrollo se han convertido en la primera fuente de información completa y actualizada de la realidad del pueblo afroecuatoriano. De manera específica se realizaron diagnósticos sectoriales en temas de Territorio, Desarrollo Productivo, Género, Derechos Humanos, Participación e Identidad Cultural. Además se logró la identificación de una serie de propuestas de políticas sectoriales.

\section{VISIBILIDAD ESTADÍSTICA}

Desde el año 2001 el Instituto Nacional de Estadísticas y Censos del Ecuador decidió aplicar a todas sus encuestas y censos la variable de autoidentificación étnica a los ecuatorianos. Se trata de cinco categorías: a) blanco, b) mulato, c) negro, d) indígena y e) mestizo. De la combinación de las variables mulato y negro se construye la variable "afroecuatoriano". Esta decisión técnica ha permitido que el Ecuador sea uno de los países de América Latina con mejores estadísticas sociodemográficas y socioeconómicas sobre los afrodescendientes. Resultado de este esfuerzo de visibilidad estadística la Secretaría Técnica del Frente Social (STFS) dentro de su unidad de análisis de datos sociales establece el Sistema de Indicadores Sociales del Pueblo Afroecuatoriano (SISPAE), el cual se construyó con recursos del BID en el 2004 ${ }^{13}$.

\section{OTROS ESPACIOS INSTITUCIONALES Y DE INVERSIÓN}

El Municipio Metropolitano de Quito en el año 2000 creó la Dirección Metropolitana de Desarrollo Social y Económico (DMDSE), hoy Dirección de Desarrollo Sustentable. Al interior de esta dependencia funcio-

13 El Sistema de Indicadores Sociales de la Población Afro Ecuatoriana (SISPAE) es un instrumento objetivo, actualizado y confiable, que permite visualizar la situación sociodemográfica, socioeconómica y cultural del pueblo afroecuatoriano. Su objetivo es proveer a las organizaciones que representan al pueblo afroecuatoriano y a las organizaciones sociales en general; a las instituciones públicas y privadas; a las entidades académicas, de investigación y desarrollo; a las organizaciones no gubernamentales y organismos de cooperación nacional e internacional, de un instrumento de información sistematizado sobre la realidad de la población afrodescendiente del Ecuador. 
na la Unidad Metropolitana de Desarrollo del Pueblo Afroquiteño. Dentro de las prioridades de esta unidad se contempla la formulación de un diagnóstico situacional del pueblo afroquiteño que permita ubicar las condiciones reales en términos demográficos, socioeconómicos y culturales que los caracterizan. Y a partir de allí, diseñar un plan de acción para la política pública en materia de desarrollo de los afroquiteños.

\section{BALANCE DE LAS ACCIONES CONCRETADAS POR LAS ORGANIZACIONES PARA COMBATIR LA POBREZA AFROECUATORIANA}

A lo largo de este ensayo hemos sostenido que la pobreza junto con la discriminación racial y la exclusión social ocupan el centro de la preocupación de las organizaciones afroecuatorianas. Al consultar la opinión de varios líderes afroecuatorianos sobre esta problemática, se reconoce que en el Ecuador se han logrado interesantes acciones públicas a favor de los afroecuatorianos por parte del Estado. Dichas acciones se han asumido gracias a la presión de la sociedad civil que ha demandado mayor atención. Pero la conclusión más evidente es que esas medidas no son suficientes (Antón, 2003).

De acuerdo con Ibsem Hernández, líder del proceso Afroamérica XXI de la ciudad de Guayaquil, las organizaciones han tenido logros importantes en un corto tiempo:

"Ya tenemos indicadores concretos en términos de racismo, en términos de saber cuántos somos y que nuestros indicadores de pobreza son los más altos del país (...). Otro logro es la ley de derechos colectivos, la cual pone nuevas luces para ir combatiendo la pobreza". ${ }^{14}$

Pero este balance, pese a que es satisfactorio, es criticado por Juan Montaño Escobar, un intelectual notable del pueblo afroecuatoriano, quien afirma que tales logros son solo

"[...] atajos, estrategias para acortar distancias con los otros que tienen ya mejores condiciones de vida" ${ }^{15}$.

Asimismo para Pablo de la Torre, vocero de la Confederación Afroecuatoriana del Norte de Esmeraldas (CANE) esas acciones son solo buenas intenciones, pues:

14 Entrevista a Ibsem Hernández, líder del proceso Afroamérica XXI, Quito, 4 de junio de 2006.

15 Entrevista a Juan Montaño Escobar, escritor y columnista del Diario Hoy, Esmeraldas, 13 de mayo de 2006. 
“[...] en más de 12 años hemos logrado cosas importantes, pero lo que hace falta es concretar todo eso". ${ }^{16}$

Pero hay igualmente otros balances más radicales como el de Renán Tadeo, economista de la Federación de Comunidades Negras de Imbabura y Carchi (FECONIC), quien considera que

“[...] el Estado ha hecho muy poco. No ha habido política (concreta) en beneficio del pueblo afroecuatoriano". ${ }^{17}$

¿Pero por qué dichas políticas son insuficientes? ¿En dónde radica la responsabilidad de combatir la pobreza? ¿Qué se propone realmente para enfrentar el problema?

Desde los líderes afroecuatorianos consultados varios son los elementos que habría que explorar en este asunto: a) una equivocada concepción de la pobreza para el pueblo afro, b) los obstáculos que evitan que los instrumentos actuales respondan verdaderamente al desafío de la pobreza, y c) la prioridad del Estado en materia de inversión social. Exploremos estos acercamientos:

\section{UN EQUIVOCADO CONCEPTO DE POBREZA EN EL PUEBLO AFRO}

Para Renán Tadeo muchas acciones políticas se han emprendido para enfrentar la pobreza en el pueblo afroecuatoriano sin que se tenga en cuenta un entendimiento de su verdadera realidad sociocultural. Según él la pobreza está entendida "como la escasez de recursos que le permita a una persona vivir con dignidad". Y en el pueblo afro estos recursos realmente han sido negado desde el mismo proceso de la esclavización que luego en la historia del país perduraron con otras formas de explotación (como el concertaje) y de negación de derechos con la marcada discriminación racial que pesa sobre los afroecuatorianos.

Para Pablo de la Torre esta visión de negación de derechos y de recursos que históricamente ha pesado sobre los afroecuatorianos "más que pobreza ha generado es un proceso de empobrecimiento". Proceso que, si bien tiene raíces históricas, hoy en día se profundiza con las políticas neoliberales que se han implantado en el país. Según De la Torre,

"[...] a causa de eso, nuestras comunidades salen de sus territorios, se van a las periferias de los barrios suburbanos de las grandes ciudades sometiéndose al empobrecimiento".

16 Entrevista a Pablo de la Torre, delegado del presidente de la República ante la CODAE, 6 de junio de 2006.

17 Entrevista a Renán Tadeo, economista líder de la FECONIC, Esmeraldas, 12 de mayo de 2006. 
Pero la visión crítica al concepto de la pobreza es mucho más radical en Douglas Quintero, de Afroamérica XXI y ex Director Nacional de Defensa de los Derechos del Pueblo Negro de la Defensoría del Pueblo. Para Quintero un error ha sido

"[...] definir la pobreza solo desde la dimensión material, pues existe otra pobreza que es más del orden intelectual, la cual impide que los líderes que hacen cabeza en las organizaciones puedan tener un lenguaje adecuado para negociar con el Estado una inserción práctica en el desarrollo"18

Esta visión de la "pobreza intelectual" que identifica Quintero coincide con el criterio de Juan Montaño quien observa que este fenómeno es quizá el primer obstáculo que hay en el mismo pueblo afroecuatoriano para lograr su desarrollo. De allí que considere que se trata de una suerte de colonización mental, una manera de enajenación (de la que habla Franz Fanon) que se expresa en la incapacidad de

“[...] pensar por el pueblo negro, pensar desde nosotros mismos. Esto es porque cada quien tiene en su mente intereses personales, regionales, clasistas".

Pero hay más. Según Renán Tadeo (2003) al pensar en estrategias para superar la pobreza, solo se prioriza suplir bienes materiales o en entregar recursos, pero "no estamos pensando en el ser humano". Para Tadeo,

"[...] en medio de todo esto para superar la pobreza lo fundamental es el ser humano, hay que partir de él con su saber, con su saber hacer y desde allí plantear estrategias para mejorar las condiciones de vida, llámense condiciones de salud, educación y vivienda, las cuales han sido esquivas a la población negra".

\section{LOS OBSTÁCULOS PARA CONCRETAR LAS ACCIONES ACTUALES ENCAMINADAS A COMBATIR LA POBREZA}

Desde la visión de Santander Quiñónez, antiguo líder del proceso organizativo afroecuatoriano, en el país las organizaciones han avanzado mediante la institucionalización de muchas de sus demandas. Según él:

“[...] fundamentalmente tenemos la Corporación de Desarrollo Afroecuatoriana (CODAE), la ley de derechos colectivos, que es un marco

18 Entrevista a Douglas Quinteros, director de la Oficina de Defensa de los Derechos del Pueblo Afroecuatoriano, Esmeraldas, 13 de mayo de 2006. 
jurídico que respalda legalmente las estrategias para superar la pobreza. Se ha hecho un plan maestro para salir de la pobreza (el Diagnóstico de la Problemática Afroecuatoriana y Propuestas de Acciones Prioritarias). Pero con todas esas herramientas doctrinarias hay obstáculos y faltan eslabones". ${ }^{19}$

En efecto, para los líderes afroecuatorianos las acciones públicas que en este ensayo hemos descrito no han llegado a feliz término. Esto quizá por muchos factores que obstaculizan su correcta concreción. Entre estas barreras sobresalen aspectos como debilidad organizativa, dispersión en la sociedad civil, poca difusión de los instrumentos y falta de orientación política de las instituciones públicas como la CODAE.

Desde la perspectiva de Douglas Quintero, el eje de los obstáculos para que estas iniciativas se concreten tiene que ver con

"[...] la desintegración que existe en las organizaciones afro en función de objetivos concretos. No existen objetivos compartidos porque cada una de ellas tiene una visión distinta del desarrollo".

Este criterio es compartido por Pablo de la Torre quien considera que

“[...] si nosotros nos fortaleciéramos como movimiento social podríamos lograr que las leyes se aplicaran y a lo mejor tendríamos otras oportunidades".

¿Qué camino seguir? ¿Cuál es el desafío estratégico de las organizaciones? Según Tadeo, Quiñónez y De la Torre, para encontrar un mejor camino para el cambio de escenario de la pobreza y la exclusión de los afroecuatorianos es importante que el pueblo salga de la productividad para adentrarse en la producción. En palabras de Quiñónez se requiere "imprimir el espíritu empresarial en el pueblo negro". Se trata del eslabón que hace falta: "Desarrollar empresas, desarrollar una cultura de empresa, inyectarle en la cosmovisión una capacidad de desarrollo empresarial, pues sin empresa no hay riqueza “

Para Santander Quiñónez una adecuada inserción de los afroecuatorianos al mundo de la producción y a la lógica del capital debe pasar por la eliminación de barreras que impiden que los afroecuatorianos

19 Entrevista a Santander Quiñónez, promotor de la ley de derechos colectivos del pueblo afroecuatoriano, Esmeraldas, 13 de mayo de 2006. 
sean vistos como sujetos capaces y emprendedores. Se trata de barreras impuestas por el racismo, la discriminación y el estereotipo que "permiten que no seamos sujetos de créditos por parte de la burguesía bancaria". Y agrega que justamente en los bancos radica el problema para que los afro se incorporen al mundo de la producción, toda vez que este sector se resiste a prestarle al afro. Esto por cuanto

“[...] existe una estigmatización financiera que dice que todos los negros no son sujetos de crédito. Se trata de un pretexto de que no tenemos bienes, propiedades. Y qué mas bienes que el aporte que en más de 300 años le hemos hecho a la burguesía para que hoy sean ricos".

De acuerdo con Quiñónez es urgente "cambiar la política crediticia dentro de la normativa para que al negro se le facilite el crédito". $\mathrm{Y}$ en ese cambio de la política crediticia se considera que la Banca Multilateral debe jugar un papel clave. En consecuencia, Quiñónez propone que

“[...] el BID debe traer recursos justos para desarrollar a la gente seria, a desarrollar a los pobres, a los pobres afroecuatorianos. Que esas inversiones ya no vengan a diagnosticar y a diagnosticar sino para invertir".

Pero el asunto no es solo que el pueblo afroecuatoriano se inserte de cualquier forma al mundo de la producción. Al menos esta no es la visión de Renán Tadeo. Para este economista "no se trata de emprender proyectos productivos para mejorar los ingresos de las familias y con esto poder vivir mejor, supuestamente". Desde su perspectiva,

"[...] cuatro son los ejes fundamentales que contribuyen a disminuir la pobreza en los afroecuatorianos: Uno es el desarrollo productivo otro es la investigación, y finalmente la formación y la incidencia política”.

Estos cuatro elementos estratégicos para salir de la pobreza, es lo que Ibsem Hernández denomina inversión en el capital humano del pueblo afroecuatoriano. Según él:

"Lo primero es la educación. Creemos que si invertimos en el tema del capital humano podemos encontrar una salida importante en el tema de la pobreza".

Esta visión estratégica que le apunta a la formación, la educación y el fortalecimiento de las capacidades organizativas es compartida por Catherine Chalá, lidereza del Movimiento Nacional de Mujeres Negras del Ecuador (MOMUNE). De acuerdo con ella, 
“[...] para superar la pobreza primero debe haber un proceso organizativo. La fuerza está en las organizaciones. Si las mujeres negras no estamos organizadas vamos a seguir siendo manipuladas, vamos a seguir de beneficiarias y no de protagonistas de nuestros procesos". 20

En suma, los líderes y liderezas afroecuatorianas consideran que en Ecuador las organizaciones han dado pasos vitales para acortar distancia en el camino para superar la pobreza. Para Ibsem Hernández son logros importantes que abren procesos de inclusión pero que no son suficientes. Hay que implementar herramientas que le permitan al pueblo afro salir de la fase de la producción para insertarse en la fase de la productividad. Para ello las organizaciones deben ser protagonistas en la implementación de las herramientas hasta ahora existentes. Por su parte al Estado se le exigen propuestas concretas en términos de aplicar políticas públicas consistentes con los logros obtenidos por medio de las leyes y las recomendaciones emanadas de distintas instituciones y de propuesta de planes de desarrollo. Mientras que al sector privado se le pide un cambio de actitud frente a la población afroecuatoriana que hasta el momento no es sujeta de crédito productivo dado los estereotipos y los imaginarios racistas que hasta ahora prevalecen en la mentalidad colonial de los ricos. Para concretar todo lo anterior, los líderes consideran dos pasos previos: la inversión en el capital humano y el papel activo y protagónico de las instituciones encargadas de la política pública hacia los afroecuatorianos.

\section{LA PRIORIDAD DEL ESTADO EN MATERIA DE INVERSIÓN SOCIAL}

Hasta aquí hemos analizado que en el Ecuador se han dado avances institucionales para atender demandas de los afroecuatorianos, y al mismo tiempo las organizaciones han abonado un terreno fértil en materia de participación y movilización. Pero paradójicamente todo lo anterior no ayuda a mejorar las condiciones sociales de los afroecuatorianos, ni mucho menos está contribuyendo a superar los indicadores de pobreza que hemos demostrado. Y esta paradoja al menos es evidenciada por Mauricio León (2003), coordinador del Sistema Integrado de Indicadores Sociales del Ecuador (SIISE), adscrito a la Secretaría Técnica del Frente Social. Para León, en los últimos años se ha avanzado mucho en la transformación de la institucionalidad y en la adopción de políticas públicas, pero menos en términos de que estos grupos puedan superar realmente la pobreza; allí todavía existe un esfuerzo tanto para las organizaciones como

20 Entrevista a Catherine Chalá Angulo, Quito, 8 de junio de 2006. 
para las instituciones en función de lograr mejor inversión social por parte del Estado y una necesaria distribución de recursos existentes en infraestructura, crédito, asistencia técnica, en educación y salud hacia las personas afro ${ }^{21}$.

Desde la visión de León, lo que el Estado y las Organizaciones deben enfatizar es la necesidad de "redistribuir el gasto social con miras a obtener mejores oportunidades para los grupos étnicos indígenas y afro", que son quienes más altos índices de pobreza registran en el país. Y desde este acuerdo poder concretar varias cosas: en educación es clave que el Ministerio de Educación tenga prioridad en los sitios de asentamiento de los afroecuatorianos. Eso implica redistribuir los recursos económicos que ahora están dirigiéndose realmente hacia otros sitios, hacia otros grupos que tienen mejores resultados en términos de desarrollo social. Lo mismo en salud, es necesario invertir fuertemente en este sector.

Existe entonces una coincidencia de criterios entre León, como experto de programas sociales del Estado, y los líderes de las organizaciones: Se hace necesario invertir más y de manera focalizada en salud y educación, pues estos dos aspectos son clave para al menos intentar interrumpir los mecanismos de transmisión intergeneracional de la pobreza.

Pero igualmente se concluye que esto solo no es suficiente. Pues al mismo tiempo se requiere inversión en términos de redistribuir el capital físico tanto en las zonas rurales como urbanas. Esto por cuanto el fenómeno de la pobreza logra sus diferenciaciones de acuerdo a las condiciones regionales. Por ejemplo en la zona rural es importante invertir en canales de riego, carreteras, caminos, etcétera; mientras que en las zonas urbanas habrá que hacer énfasis en invertir en generación de empleo, asistencia técnica, capacitación laboral, pero sobre todo en esfuerzos en eliminar las barreras de discriminación dentro del mercado laboral.

En esta estrategia global para enfrentar la pobreza se estima que también es importante la inversión de los gobiernos locales en los barrios donde predominan los afroecuatorianos. Sobre todo en acciones que propendan al mejoramiento de sus asentamientos, de sus calles, de su infraestructura en agua potable, al saneamiento y a la vez a mejores oportunidades de empleo local.

Finalmente, no se podría descuidar el sector de los jóvenes afroecuatorianos, quienes requieren programas de inserción laboral y de nivelación en términos de educación y de destreza para ubicar-

21 Entrevista con Mauricio León, coordinador del SIISE- STFS, Quito, 9 de junio de 2006. 
los en el mercado. Pero al mismo tiempo hay otros grupos que no les interesa tener empleo en el sector formal, sino que para ellos es suficiente tener su propia iniciativa productiva. Se considera que es necesario apoyar estos grupos en la capacidad de emprender sus propios negocios en asistencia técnica y crédito con el fin de obtener el capital para lograr progresar. Además de ello es importante incentivar la asociación de grupos de personas que permitan tener escalas de ingresos mucho más grandes, de modo que se les facilite obtener no solo ganancias para su sostenimiento medio sino también para obtener un mejor nivel de productividad.

\section{CONCLUSIONES: VISIONES PARA SUPERAR LA POBREZA, EL RACISMO Y LA EXCLUSIÓN}

En menos de doce años las organizaciones han logrado acciones importantes para superar la pobreza, la exclusión y las desigualdades en los afroecuatorianos. Se tiene una ley de derechos colectivos del pueblo afroecuatoriano que busca garantizar los derechos culturales específicos consignados en los Artículos 83 y 84 de la Constitución de 1998. Asimismo existen medidas legislativas como el Plan Nacional de Derechos Humanos del Pueblo Afroecuatoriano, y una serie de leyes que amparan derechos territoriales, de participación y consulta. De otra parte se ha ganado en la creación de instituciones públicas dedicadas exclusivamente a la atención de las demandas afroecuatorianas: La Corporación de Desarrollo Afroecuatoriana (CODAE) y la Dirección de Defensa de los Derechos del Pueblo Afroecuatoriano adscrita a la Defensoría del Pueblo. Asimismo la Secretaría Técnica del Frente Social ha creado el Sistema de Indicadores Sociales del Pueblo Afroecuatoriano (SISPAE) y en coordinación con el Instituto Nacional de Estadísticas y Censos ha ejecutado una encuesta nacional sobre discriminación racial. De otra parte el Banco Interamericano de Desarrollo ha hecho inversiones en la construcción de un Diagnóstico de la Problemática Afroecuatoriana y Propuestas de Acciones Prioritarias, documento que sirve de base para que el Gobierno pueda adoptarlo como una política pública en términos de un futuro plan nacional de desarrollo a ejecutarse en diez años.

Pero según el criterio de los líderes sociales consultados, dichas acciones solo son un modo de acortar distancia en el desafío de superar la pobreza, un conjunto de buenas intenciones que no se han concretado. No tanto porque sea el Estado quien no le preste mayor atención a dichas acciones, sino porque el camino está lleno de obstáculos. Siendo el principal de ellos la condición de dispersión, de falta de unidad y sinergia de las mismas organizaciones, quienes aún son débiles y no logran aprehender con suficiente fuerza la importancia de 
dichos instrumentos, de modo que sean capaces de exigirle al Estado mayor seriedad en los compromisos adquiridos.

Otro aspecto que limita las acciones emprendidas para superar la pobreza tiene que ver con que, tanto en Ecuador como en otras naciones de la Región, la adopción de políticas públicas a favor de los afrodescendientes no ha sido fácil, e incluso han sido limitadas. Pues en el terreno de lo práctico la instauración de un estado multiétnico garante de los derechos humanos y colectivos de los indígenas y afrodescendientes ha encontrado la barrera de posiciones dominantes, tradicionales y hegemónicas que se resisten al rompimiento del orden jurídico y político imperante. Por tanto, muchas veces la adopción de políticas públicas incluyentes han quedado solo en el plano de la formulación, dejando enormes vacíos entre la expedición de la norma y la concreción de la misma.

En suma, para las organizaciones de la sociedad civil afroecuatoriana, pese a que el Estado ha venido implementando medidas garantes del reconocimiento de sus derechos colectivos, estas "solo representan simbólicamente un reconocimiento legal"22. El ejemplo de esta denuncia lo demuestra lo que sucede con dos espacios institucionales que el Estado ha implementado a favor de los afroecuatorianos: La Corporación de Desarrollo Afroecuatoriana (CODAE) y la Dirección Nacional de Defensa de los Derechos de los Pueblos Afroecuatorianos adscrita a la Defensoría del Pueblo, los cuales se han caracterizado por ser, en el caso de la primera, "inoperante, sin financiamiento", mientras que la segunda "se convierte en una Dirección de carácter provisional y no nacional, donde su acción es limitada y no cuenta con recursos suficientes "23.

Otro asunto es el incumplimiento por parte del Estado con medidas más eficaces que permitan superar la condición de marginalidad y discriminación que vive el pueblo afro. Particularmente las organizaciones demandan la aplicación de instrumentos legales como la Convención Internacional sobre la Eliminación de Discriminación Racial, la Declaración de Durban, y el Artículo 11, Ítem 3 del Plan Nacional de Derechos Humanos del Ecuador ${ }^{24}$ donde se consagra la adopción de

22 Informe Alternativo de las organizaciones afroecuatorianas al comité para la eliminación de la discriminación racial, Ecuador, 2002, pág. 4.

23 Informe Alternativo, Ibíd. pág. 6.

24 Artículo 11, Ítem 3: "Velar por la participación de los afroecuatorianos en cargos de decisión en los sectores públicos y privados, en adecuadas proporción al número de sus habitantes". Plan Nacional de Derechos Humanos adoptado como política de Estado, mediante Decreto Ejecutivo $\mathrm{N}^{\circ} 1527$, siendo presidente Fabián Alarcón Rivera, y publicado en el Registro Oficial No 346 el 24 de julio de 1998. 
medidas de acción afirmativa que sirvan como instrumentos garantes de promoción de políticas públicas, de inclusión y de reconocimiento para el pueblo afroecuatoriano.

Como parte del paquete de medidas de políticas públicas o de acción afirmativa, la sociedad civil recomienda que el Estado adecue su aparato institucional, dé cumplimiento a los derechos de participación y representación, reglamente los derechos colectivos constitucionales y demás acciones legales que penalicen la discriminación racial. Se exige la visibilidad en las estadísticas sociales de modo que respalden las inversiones focalizadas; asimismo se debería procurar que los medios de comunicación y el sector privado incorporen una cultura política incluyente y equitativa frente al trato desigual que ordinariamente le han dado a los afroecuatorianos.

\section{Bibliografía}

Agenda Política de las Mujeres Negras del Ecuador 2000 (Quito) abril. Antón Sánchez, Jhon 2003 Organizaciones de la sociedad civil. Consultoría sobre Diagnóstico de la Problemática Afroecuatoriana y Propuestas de Acciones Prioritarias. CT BID ATN SF 573 (Quito: Consejo de Coordinación de la Sociedad Civil Afroecuatoriana).

Antón Sánchez, Jhon 2005 "Afroecuatorianos: invisibilidad, racismo, exclusión y pobreza” en Secretaría Técnica del Frente Social del Gobierno del Ecuador Racismo y Discriminación Racial en Ecuador. Los Afroecuatorianos en Cifras (Quito: Zenitram Editores).

Antón Sánchez, Jhon 2006 "Afroecuatorianos: exclusión social, pobreza y discriminación racial” en CEPAL Pueblos indígenas y afrodescendientes en América Latina y el Caribe: Información sociodemográfica para políticas y programas (Santiago de Chile: CEPAL).

Banco Interamericano de Desarrollo (BID) y Consejo de Coordinación de la Sociedad Civil Afroecuatoriana 2004 Diagnóstico de la problemática afroecuatoriana y propuestas de acciones prioritarias (Quito: Láser Editores).

Banco Mundial 2003 "Desigualdad en América Latina y el Caribe. ¿Ruptura con la Historia?” (Washington) edición de conferencia.

Bhalla, Ajit y Lapeyere, Frédéric 1997 "El caso económico para combatir la exclusión racial y étnica en los países de América Latina y el Caribe" en Zoninsein, Jonas 2001 Documentos BID (Washington) junio.

Comisión Permanente de Evaluación, Seguimiento y Ajuste a los Planes Operativos 2003 Plan Nacional de Derechos Humanos y Planes Operativos de Derechos Humanos del Ecuador (Quito) enero.

De la Torre, Carlos 2002 Afroquiteños, ciudadanía y racismo (Quito: Centro Andino de Acción Popular). 
De la Torre, Carlos 2003 "Movimientos étnicos y cultura política en Ecuador" en Revista ICONOS (Quito: FLACSO) No 13, enero.

García, Jesús 2001 "Reconstrucción, transformación y construcción de nuevos escenarios de las prácticas de la Afroamericanicidad" en Cultura y transformaciones sociales en tiempos de la Globalización 2 (Caracas: CLACSO - Colección Grupo de Trabajo).

Informe Alternativo de las organizaciones afroecuatorianas al comité para la eliminación de la discriminación racial 2002 (Quito) Documento mimeografiado.

León Guzmán, Mauricio 2003 Etnicidad y exclusión en el Ecuador: una mirada a partir del Censo de Población de 2001 (Quito: Sistema Integrado de Indicadores Sociales del Ecuador-SIISE).

Maloney, Gerardo 1993 "El negro y la cuestión nacional” en Ayala, Enrique (ed.) La Nueva Historia del Ecuador (Quito: Corporación Editora Nacional / Editorial Grijalbo) Vol. 13.

Municipio del Distrito Metropolitano de Quito, Secretaría de Desarrollo Social 2005 Instrumentos Internacionales contra la Discriminación Racial (Quito: Imprenta Municipal).

Naciones Unidas 2004 Informe sobre Desarrollo Humano 2004. La libertad cultural en el mundo diverso de hoy (México DF: PNUD / Ediciones Mundi Prensa).

Peñaherrera de Costales, Piedad y Costales, Alfredo 1964 "Historia social del Ecuador. Tomo I: Concertaje de Indios y Manumisión de esclavos" en Llacta (Quito) $\mathrm{N}^{\circ} 17$.

Rahier, Jean 1999 “¿Mami: qué será lo quiere el negro?” en Ecuador Racista. Imágenes e Identidades (Quito: FLACSO).

Rodríguez Romero, Jorge 2000 "Breve resumen del proceso de generación de políticas públicas de las organizaciones afroamericanas en la Raza y la Pobreza" en Consulta Interagencias sobre Afroamericanos. Mesa Redonda (Washington) 19 de junio.

Savoia, Rafael 1992 El Negro en la Historia. Raíces africanas en la nacionalidad afroecuatoriana (Quito: Centro Cultural Afroecuatoriano).

Secretaría Técnica del Frente Social del Gobierno del Ecuador 2005 Los afroecuatorianos en cifras (Quito: Zenitram Editores).

Sutherland, Jeannette 2001 "El desarrollo económico frente a la exclusión social: El costo del desarrollo en Brasil" en El desarrollo económico en las comunidades latinoamericanas de ascendencia africana (Washington: Fundación Interamericana de Desarrollo).

Tadeo, Renán 2003 Desarrollo productivo en el pueblo afroecuatoriano. Consultoría sobre Diagnóstico de la Problemática Afroecuatoriana y Propuestas de Acciones Prioritarias. CT BID ATN SF 573 (Quito: Consejo de Coordinación de la Sociedad Civil Afroecuatoriana). 
Walsh, Catherine 2004 "Colonialidad, conocimiento y diáspora AfroAndina” en Rojas, Alejandro y Restrepo, Eduardo (eds.) Conflicto e (in)visibilidad. Retos en los estudios de la gente negra en Colombia (Popayán: Universidad del Cauca). 



\title{
NeLSON ANTEQUera D.*
}

\author{
EL SISTEMA DE ORGANIZACIÓN \\ ORIGINARIO Y EL CICLO \\ AGRÍCOLA-COMERCIAL-LABORAL \\ COMO ESTRATEGIAS DE RESISTENCIA \\ A LA POBREZA EN EL CONTEXTO \\ DE LA MUNICIPALIZACIÓN
}

\section{EL CASO DE LAS COMUNIDADES INDÍGENAS DEL AYLLU KIRKYAWI (BOLIVIA)}

\begin{abstract}
INTRODUCCIÓN
El presente proyecto se enmarca en el análisis de la dinámica política como base del sistema productivo y la dinámica social entendida como itinerancia cíclica anual como estrategia económica de los indígenas campesinos de los ayllus del sur de Cochabamba y su relación con las políticas sociales estatales implementadas desde la promulgación de la Ley de Participación Popular en 1994. En el trabajo mostraremos que las políticas sociales se articulan débilmente a la dinámica productiva y laboral de las comunidades indígenas campesinas, razón por la cual no tienen el efecto deseado en cuanto a reducción de la pobreza en la región. Proponemos que la incorporación en las políticas sociales de las formas productivas y de circuitos laborales y productivos que tienen un componente cultural fundado en la cosmovisión andina y en las redes sociales comunitarias (en el caso de la organización política)

* Estudiante de Doctorado en Antropología del Instituto de investigaciones antropológicas de la UNAM.
\end{abstract}


y amplias redes sociales extra regionales e interétnicas supondrían un cambio sustancial en la efectividad de dichas políticas en cuanto a reducción de la pobreza y de los niveles de desigualdad persistentes en la sociedad boliviana.

El objetivo de la investigación ha sido analizar la articulación entre las formas de organización tradicional, la itinerancia cíclica anual como estrategia económica de los campesinos indígenas del ayllu Kirkyawi, (provincia Bolívar, Cochabamba, Bolivia) y las políticas sociales derivadas del proceso de implementación de la Ley de Participación Popular.

Para alcanzarlo partimos de la descripción de las formas de organización tradicional como la base del sistema productivo, el cual es presentado en el primer apartado.

En el segundo apartado describiremos y examinaremos la dinámica de itinerancia cíclica anual como estrategia económica de los campesinos indígenas del ayllu Kirkyawi.

En el apartado final examinaremos cómo estas características organizativas y económicas se articulan con las políticas sociales derivadas de la implementación de la Ley de Participación Popular y en consecuencia las mismas han tenido escasa incidencia en la reducción de la pobreza en la región.

\section{METOdOLOgía DE LA INVESTigaCión}

La investigación se desarrolló en tres ámbitos: el ayllu Kirkyawi, los circuitos comerciales-laborales y las políticas sociales-municipales.

Para comprender y dar cuenta de la lógica del ayllu y de los circuitos comerciales y sus relaciones con las políticas sociales se utilizó el método etnográfico. En el ayllu esta aproximación nos ha permitido una descripción y análisis de las formas de organización tradicional como base del manejo del recurso tierra. En este ámbito también se llevaron a cabo entrevistas a profundidad con autoridades originarias y sindicales.

En el caso de los circuitos comerciales-laborales se aplicó el método etnográfico, pero en este caso en los centros urbanos donde se llevan a cabo las actividades comerciales y laborales de los campesinos provenientes del ayllu Kirkyawi. Se tomaron como referentes las ciudades de Cochabamba y Oruro. Asimismo se realizaron entrevistas semiestructuradas tanto a quienes provienen de las comunidades indígenas de Kirkyawi como a quienes forman parte de las redes sociales en los lugares de destino.

El tercer ámbito, que es el de las políticas sociales municipales, se estudió a partir de la asistencia a reuniones de comunidad, subcentrales y provinciales. Se realizaron entrevistas semiestructuradas a 
autoridades municipales y autoridades originarias del ayllu Kirkyawi. Asimismo se hará un recorrido de observación y entrevistas en diversas comunidades para conocer las características y alcances de los proyectos ejecutados.

\section{MARCO CONTEXTUAL Y TEÓRICO}

La realidad social y cultural boliviana está marcada por fuertes rasgos pluriculturales y multilingües. Bolivia es probablemente el tercer país con mayor número de hablantes de lenguas indígenas, después de México y Perú: el quechua (con aproximadamente un tercio de la población total) y el aymara (un cuarto de la población total). Los otros más de treinta idiomas originarios son hablados por grupos minoritarios que suman un $2 \%$ del total de la población (Albó, 2002: 21-22). La convivencia en un mismo país y en un mismo territorio de personas pertenecientes a grupos culturalmente diversos todavía se caracteriza por su carácter neocolonial, en el que los grupos indígenas han quedado en una situación de subordinación económica, cultural y política (Albó, 2002 y Stavenhagen, 2001: 67).

Gran parte de la población indígena tanto aymara como quechua vive en el área rural y ha mantenido o está en proceso de reconstitución de sus antiguos ayllus. Los ayllus bolivianos representan un tipo de organización sociocultural particularmente rico. La misma está basada en prácticas y costumbres que tienen sus raíces en la cosmovisión andina, en los sistemas organizativos, en las estrategias económico-ecológicas prehispánicas. Por otra parte han sabido adaptarse a las diversas circunstancias económicas y políticas de su historia.

La situación de dominación colonial durante la conquista y el colonialismo interno de la República (Platt, 1988; Stavenhagen, 2001: 34) han despojado gradualmente a los ayllus de sus territorios, los cuales han quedado en las zonas de altura, donde la práctica de la agricultura y la ganadería se hace más difícil y menos productiva. Estos procesos históricos han determinado que los ayllus se cuenten hoy en día entre las zonas más pobres del país. Los índices de pobreza en estas regiones son los más altos de Bolivia. Los indicadores reflejan solo parte de una situación económica de pobreza, que se traduce en una mayor marginación de los sectores indígenas y campesinos ${ }^{1}$.

1 Los datos estadísticos muestran que en las provincias de los departamentos de Oruro, norte de Potosí y suroeste de Cochabamba, donde se encuentran los ayllus, la pobreza afecta entre el 96 y 100 por ciento de la población. En el norte de Potosí, la indigencia afecta a más del 72 por ciento de la población y la marginalidad o pobreza extrema a más del 16 por ciento (INE, 2001). 


\section{MARCo TEÓRICO. El ENFOQUe RELACIONAL Y CULTURAL}

Para el estudio de la pobreza y la desigualdad retomaremos el enfoque relacional propuesto por Tilly. El análisis relacional permite el tratamiento de las categorías como "invenciones sociales que solucionan problemas y/o subproductos de la interacción social". Estos modelos de análisis permiten una descripción de la forma en que "las transacciones se aglutinan en lazos sociales, estos se concatenan en redes y las redes existentes fuerzan soluciones de los problemas organizacionales", este tipo de descripción "aclara la creación, el mantenimiento y el cambio de la desigualdad" (Tilly, 2000: 34).

El tipo de análisis relacional permite comprender el peso de la cultura en la vida social. Entendida la cultura como un conjunto de nociones compartidas y sus representaciones, de esta forma podemos imaginar a la cultura ya no como una esfera autónoma, sino como parte de la estructura de las relaciones sociales (Tilly, 2000: 33).

En nuestro caso de estudio, la desigualdad tiene un fuerte componente étnico, cuya base no es tanto la diferencia racial sino la diferencia cultural. La diferencia étnica, si bien tiene una base cultural, es también una construcción social (o una "invención", en palabras de Tilly). Esta forma de incorporar el ámbito cultural en las relaciones de desigualdad nos permitirá situar la diferencia social y la diferencia étnica como parte constitutiva de la sociedad boliviana y analizar las relaciones entre las categorías indígena-mestizo.

El análisis de la formación cotidiana del Estado de Roseberry nos permite una lectura menos polarizada que la del análisis categorial de Tilly. Roseberry plantea una comprensión de los campos de fuerza sociales "en términos más complejos y procesuales". A partir de la crítica de Scott al concepto de hegemonía como "consenso ideológico" (Scott, 2000: 97-124) y de Sayer, quien hace hincapié en la materialidad de las formas cotidianas de la formación del estado (Sayer, 2002: 237), propone utilizar un concepto de hegemonía "más material, político y problemático" (Roseberry, 2002: 216), que permita entender no el consenso sino la lucha: "Lo que la hegemonía construye no es, entonces, una ideología compartida, sino un marco común material y significativo para vivir a través de los órdenes sociales caracterizados por la dominación, hablar de ellos y actuar sobre ellos" (Roseberry, 2002: 220). En nuestro caso las diferencias sociales basadas en la diferencia étnica no son aceptadas consensualmente por quienes las sufren; sin embargo, son aceptadas como el marco material significativo en el que se desarrollan las estrategias políticas y económicas que permiten la sobrevivencia material y cultural de los grupos indígenas.

El enfoque mencionado permite analizar el problema de la desigualdad social en Bolivia desde las categorías basadas en la dife- 
rencia étnica. La etnicidad tiene en este contexto dos atributos fundamentales, su carácter construido y la diferencia cultural. En este punto, tomaremos el concepto de etnicidad desarrollado por Barth y por autores como Stavenhagen, Gilberto Giménez y Figueroa, de la antropología mexicana.

Barth es quien inaugura la tradición del análisis relacional de la etnicidad, analizando la misma a partir de los límites: "La persistencia de los grupos étnicos en contacto implica no solo criterios y señales de identificación, sino también estructura de interacción que permita la persistencia de las diferencias culturales" (Barth, 1976: 18). Las estructuras sociales, en este caso las diferencias étnicas, "no son elementos fundamentales de la vida social, sino subproductos variables de principios generativos" (Tilly, 2000, citando a Barth, 1981). La etnicidad es entendida así como la "organización social de la diferencia cultural" (Barth, 2000: 13), entendida la cultura no como un inventario fijo de sus manifestaciones sino como un continuo flujo contradictorio, incoherente y distribuido diferenciadamente entre las personas que pertenecen a ella (Barth, 2000: 14-15).

Stavenhagen da cuenta del carácter eminentemente político y relacional de la etnicidad: "Es la sociedad la que define la etnicidad del individuo, la del miembro tanto como la del extraño, y no al contrario" (Stavenhagen, 2001: 29). En este sentido, la etnicidad solo puede comprenderse en el marco de una sociedad más amplia y como parte de un proceso histórico concreto. En el caso de Bolivia, el estado poscolonial ha quedado en manos de los descendientes de los colonos españoles, y los grupos indígenas, a pesar de ser la mayoría, han quedado en una situación de subordinación económica, cultural y política. Esta situación es definida como colonialismo interno (Stavenhagen, 2001: 67-69).

Figueroa plantea que los símbolos de identidad no remiten únicamente a la cultura objetivada (instituciones y significados socialmente codificados), sino que remiten también a la cultura subjetivada, a la que se interioriza como habitus, y que es más difícil de cambiar, o por lo menos sus transformaciones son más lentas y se presentan como fenómenos de larga duración (1994: 38).

Asumiremos la identidad étnica en su carácter dinámico y conflictivo: determinada por las relaciones sociales conflictivas y por los procesos históricos. Sin embargo, las identidades étnicas se componen de otro elemento: la persistencia cultural. La persistencia cultural supone un núcleo de cultura propia a partir del cual se integran las transformaciones. Este núcleo está compuesto por elementos de la cultura subjetivada o habitus, los cuales se expresan en el sistema de valores, el ethos, y la cosmovisión. Existe un límite social determinado 
por la diferencia cultural, el vínculo entre los miembros de ambos lados de ese límite son asimétricos. De este modo se puede entender la diferencia étnica como desigualdad categorial, como la creación de un orden social basado en la cultura, el cual reproduce una situación de desigualdad.

En esta misma línea de análisis relacional, retomaré los conceptos de capital cultural y capital social de Bourdieu para describir y examinar las configuraciones de las redes sociales (Bourdieu, 2002b: 13-21). Según el enfoque de Bourdieu, el capital cultural consiste en maneras arbitrarias pero legitimadas de valorar determinadas prácticas y bienes culturales, definidas por lo general por las clases dominantes (Bourdieu, 2002a). En nuestro análisis mostraremos que los elementos culturales de los grupos indígenas son también "capital cultural", en el sentido que, aunque no sean elementos valorados por la sociedad dominante, son la base del desarrollo de formas organizativas, productivas, laborales o comerciales que hacen posible su subsistencia y el desarrollo de una dinámica política fundada en prácticas y valores propios.

El concepto de capital social es entendido por Bourdieu como "la suma de los recursos, actuales o potenciales, correspondientes a un individuo o grupo, en virtud de que estos poseen una red duradera de relaciones, conocimientos y reconocimientos mutuos más o menos institucionalizados, esto es la suma de los capitales y poderes que esta red permite movilizar" (Bourdieu y Wacquant, 1995: 82). Este concepto permite examinar las redes sociales que los campesinos indígenas tienen a su disposición y que posibilitan la organización política local y el funcionamiento de los circuitos comerciales y laborales extracomunitarios.

Par una lectura de las políticas estatales dirigidas a la reducción de la pobreza, retomaremos la relación que hace Nancy Fraser entre injusticia económica e injusticia cultural. La injusticia económica se expresa como explotación laboral, marginación económica, y la privación (deprivation) del acceso a un adecuado estándar material de vida. La injusticia cultural se expresa como dominación cultural, el no reconocimiento (la invisibilización de la cultura propia) y el irrespeto (ser sistemáticamente discriminado y despreciado por los estereotipos de las representaciones culturales y en las interacciones cotidianas). Las demandas de reconocimiento atienden a la injusticia cultural, mientras que las demandas de redistribución atienden a la injusticia económica y social. El problema que apunta la autora es que las demandas de reconocimiento, que buscan afirmar el valor del grupo y su cultura, promueven la diferenciación. Mientras que las demandas de redistribución promueven la igualdad. El dilema surge en que ambas, si bien son necesarias, aparecen como contradictorias (Fraser, 2001: 286-287). 
Una posible salida a este dilema es distinguir entre dos aproximaciones al problema de la injusticia: la afirmación y la transformación. La aproximación afirmativa tiende a la corrección de los resultados de las desigualdades sociales sin afectar a las estructuras que las generan. La aproximación transformativa de la justicia tiene como objeto corregir los resultados de las inequidades sociales transformando precisamente las estructuras que las generan (Fraser, 2001: 291).

La aproximación transformativa de la política cultural apunta más bien a la deconstrucción de las estructuras que generan la valoración cultural. Se trata no solo de que los grupos dominantes "reconozcan" a los grupos étnicamente subordinados, sino de cambiar la autopercepción que se tiene en ambos grupos. Mientras que las políticas afirmativas promueven las diferencias, las políticas transformativas tienden a desestabilizar la estructura que las generan (Fraser, 2001: 291).

La transformación de las estructuras en ambos casos implica que la justicia pasa no por reafirmar las diferencias sino por borrar esas diferencias. Mientras que la aproximación afirmativa tiende a la estigmatización de los empobrecidos o discriminados, la aproximación transformativa tiende a promover la solidaridad para la consecución de la justicia (Fraser, 2001: 293).

\section{EL AYLLU KIRKYAWI Y EL MUNICIPIO DE BOLÍVAR}

\section{LOS AYLLUS}

El ayllu es un tipo de organización política con base territorial, cuyos lazos están fundados en la idea de un antepasado común, sea real o ficticio. El ayllu es un tipo de organización segmentaria, esto es que comprende diversos niveles organizativos cada vez más abarcativos.

Podemos anotar las características de los ayllus en tres ámbitos: el espacial, el temporal y el sociopolítico.

\section{Organización espacial}

Los ayllus tienen la característica de una organización dual, la división entre el arriba y el abajo. División que responde en parte a una realidad geográfica de la distribución de las comunidades de acuerdo a la altura en que se encuentran, pero también a un tipo de orden social y simbólico de organización. El arriba significa lo masculino, seco, etcétera, y el abajo es la parte femenina, húmeda, etcétera (Bouysse-Cassagne, 1978). Cabe señalar que la dualidad en el mundo andino responde a una visión en la que los opuestos siempre son complementarios. En el sistema de cargos tradicional quien asume el cargo es la pareja, a la que se considera la persona "completa" (chacha warmi: marido mujer), concepto difícil de entender para la mentalidad individualista. 
Otra característica de la organización de los ayllus es la discontinuidad territorial que responde a la lógica del acceso a la mayor diversidad de pisos ecológicos posible. Murra da cuenta de este tipo de manejo del territorio en la época incaica y a principios de la colonia. Los ayllus tenían acceso a tierras de puna y también tenían tierras en los valles y en la costa. Diversos procesos históricos hicieron que se reduzca el acceso de los ayllus a esta diversidad de pisos ecológicos y en la actualidad la mayoría solo tiene acceso a tierras en la puna (Murra, 1975; Condarco y Murra, 1987).

\section{Organización temporal}

En el ámbito temporal, el ritmo de la vida en el ayllu está marcado por el ciclo agrícola-laboral-comercial y el ciclo festivo. El ciclo agrícola tiene dos momentos de trabajo fuerte, la siembra y la cosecha, y entre estas dos etapas existen meses de menor intensidad en el trabajo agrícola durante los cuales la gente se desplaza a otros lugares a comerciar o trabajar. Por eso el ciclo de vida en las comunidades lo hemos denominado agrícola-laboral-comercial.

En la época incaica y colonial, entre la cosecha y la siembra en la puna (aproximadamente entre fines de junio y principios de septiembre), la gente se desplaza a sus tierras en los valles a realizar también labores agrícolas (Platt, 1986). Actualmente las tierras de los valles ya no están en manos de la gente de los ayllus. Sin embargo, entre julio y septiembre es común que los hombres hagan viajes largos hacia los valles llevando productos de la puna como sal, cueros de oveja y llama, lana y principalmente $c h u \tilde{n} o^{2}$. Hasta hace pocos años se realizaban estos viajes con grandes caravanas de llamas. Un viaje de tres o cuatro días a pie duraba tres semanas con llamas. En la actualidad la mayoría se traslada en camiones o colectivos. Los productos llevados a los valles se intercambian principalmente con maíz (Platt, 1986: 231). Mayormente la producción en la puna no es lo suficientemente grande como para tener excedentes para la venta. La gente prefiere siempre el trueque.

Quienes no tienen productos para intercambiar en los valles optan por irse a trabajar o por la mendicidad en las ciudades durante los meses en que no hay labores en el campo.

Esta dinámica del "doble domicilio" de la familia o de los prolongados viajes del jefe de familia a trabajar es una de las característi-

2 El chuño es la papa deshidratada. Este producto tiene gran valor porque puede ser conservado por años. Constituye la reserva alimenticia de la familia en la puna, que durante todo el año se alimenta de chuño y papa. Por ser un producto deshidratado es más fácil de transportar y por su alto valor es un producto importante para intercambiar en los valles. 
cas más antiguas de los ayllus y tiene que ser considerada seriamente (Platt, 1981).

El ciclo festivo-ritual es parte fundamental del ciclo agrícola y de la vida comunitaria. Las diversas fiestas religiosas del año coinciden con los momentos importantes del trabajo agropecuario, los cuales se convierten en celebraciones comunitarias, en honor a la pachamama (el concepto de pachamama es especialmente complejo, por el momento diremos que es la tierra, pero también es la naturaleza, la fuerza que da los frutos, etcétera).

\section{Organización sociopolítica}

Otra característica de los ayllus es su sistema político (sistema de cargos), el cual tiene en general estas características: es jerárquico, escalafonado, rotativo y obligatorio. Además, el sistema funciona sobre la base del ciclo agrícola-ritual de la comunidad o el ayllu.

Es jerárquico, en cuanto el grupo de familias que forma la comunidad elige a sus autoridades comunitarias. Es escalafonado, puesto que para ocupar cargos de mayor responsabilidad es necesario seguir el escalafón de cargos establecido por la tradición comunitaria. El sistema de cargos en los ayllus es rotativo en todos sus niveles. En el nivel mínimo, el grupo de familias que conforman la comunidad tiene establecidos los turnos de cada familia para ocupar los cargos. El cargo no recae solo sobre el individuo, o sobre la pareja, sino es a la familia (entendida la familia como linaje) a la que le "toca" el cargo.

En este sentido, podemos decir que no existe un sistema de "elección" de autoridades, sino de "selección" de las mismas de acuerdo al turno correspondiente. Considero que el sistema rotativo ayuda a evitar o aminorar los conflictos de poder entre los diversos grupos en que está dividido el ayllu.

La obligación de cumplir los cargos se refiere a dos niveles: el del individuo, a quien le toca desempeñar un cargo, y el de la comunidad, cuando a esta le toca designar a uno de sus miembros para ocupar un cargo en la jerarquía intercomunitaria. La obligatoriedad se puede explicar como condición para que el sistema rotativo funcione, como retribución del individuo a su posibilidad de acceso a la tierra y como una forma de adquirir prestigio, es decir un determinado lugar de mayor privilegio simbólico y de mayores derechos en la comunidad.

\section{LA ORGANIZACIÓN TRADICIONAL DEL AYLLU KIRKYAWI}

\section{El complejo organizativo regional}

El ayllu Kirkyawi coincide con la Provincia Bolívar y con el municipio del mismo nombre. En la mayoría de los casos, las provincias 
abarcan varios municipios, pero en este caso la provincia comprende solo un municipio, del mismo nombre. Tanto la provincia como el municipio fueron creados sobre la base territorial del antiguo ayllu Kirkyawi. La provincia ${ }^{3}$ Bolívar se encuentra al sudoeste del Departamento de Cochabamba. Tiene una superficie aproximada de $735 \mathrm{~km}^{2}$ y una población de 8635 habitantes. La población habita dispersa en aproximadamente 60 comunidades. La máxima autoridad política de la provincia es el subprefecto.

También existe una organización campesina sindical. Debemos anotar que en el contexto rural boliviano, el sindicato no es un tipo de organización gremial que atañe solo a los afiliados, sino un tipo de organización social que comprende a toda la comunidad.

La organización sindical es jerárquica. En la base están los sindicatos de cada comunidad. Luego están las 14 subcentrales, que aglutinan a los sindicatos comunales. En el nivel provincial la Central Sindical Única de Trabajadores Campesinos de la Provincia Bolívar (CSUTCPB).

La máxima autoridad sindical de la central provincial es el secretario ejecutivo al que se denomina "tata provincial" (señor provincial). El resto de la directiva está compuesto por los dirigentes de las subcentrales. Los dirigentes de la subcentral se eligen de forma rotativa entre las comunidades que la componen.

En cada comunidad se eligen también un secretario general y una directiva. La función principal del sindicato campesino es la relación con las instituciones externas a la comunidad y la toma de decisiones en lo que concierne a las mismas. Desde la implementación de la participación popular, el sindicato cumple la función de velar por que el municipio ejecute las obras planificadas para la comunidad.

\section{El ayllu Kirkyawi}

La organización del ayllu se vincula fundamentalmente a la producción agrícola, es decir a la tierra, a la economía y la sobrevivencia de la gente. Esta es la diferencia fundamental entre este tipo de organización y la organización sindical.

3 Bolivia se divide políticamente en nueve departamentos. La autoridad política de cada departamento es el Prefecto. Cada departamento se divide en provincias, donde la autoridad política es el subprefecto.

Según la legislación, cada prefecto es elegido directamente por el Presidente de la República. A su vez, el prefecto designa a los subprefectos de cada provincia. Cada provincia se divide políticamente en cantones, donde la autoridad política es el corregidor, designado por el subprefecto.

Cada provincia se divide administrativamente en municipios. En cada municipio, se eligen las autoridades municipales por voto, cada cinco años. En el caso de Bolívar, la provincia coincide con el municipio. 
El territorio del ayllu está dividido en dos mitades, aransaya o wichay peraño y urinsaya o uray peraño ${ }^{4}$. Lo que significa la parcialidad de arriba y la parcialidad de abajo.

Cada parcialidad se subdivide en 10 jap'iy $^{5}$. Cada jap'iy abarca a su vez de cinco a seis comunidades. La autoridad originaria de cada jap'iy es el kuraq tata. Los diez kuraq tatas del ayllu conforman una especie de junta de gobierno presidida por el cacique. Este cargo fue restituido a mediados de la década de los noventa por la acción de instituciones estatales. Actualmente el cacique es una autoridad que tiene la función de llevar a cabo los trámites del saneamiento de tierras y de la obtención del título de TCO.

El cargo de kuraq tata es asumido en pareja, no recae solo sobre el varón. Cuando la pareja asume el cargo encarna al cerro protector del jap'iy. La pareja debe vestir la indumentaria propia de su cargo.

En el nivel de las comunidades, la figura central es la de hilanco. El hilanco es la autoridad comunitaria que tiene que ver esencialmente con la producción agropecuaria.

\section{INSTANCIAS DE PARTICIPACIÓN POLÍTICA Y TOMA DE DECISIONES}

Las instancias de participación se dan en círculos concéntricos y van desde las reuniones de comunidad hasta las asambleas. La periodicidad de las reuniones y asambleas permite un flujo de información constante entre las instancias comunales y las supracomunitarias.

\section{Las asambleas}

Las asambleas son una de las instancias fundamentales del sistema organizativo. Desde la implementación de la participación popular, los sindicatos se han reactivado, pues han adquirido la función de procurar las obras del municipio y las ONG para sus comunidades. De esta forma se ha establecido un ciclo de asambleas comunales y regionales.

A las reuniones de la comunidad deben asistir los jefes de familia. A las reuniones de la subcentral asisten los secretarios generales y hilancos de las comunidades. Y a la reunión de la central asisten tanto

4 En Kirkyawi se utilizan ambos tipos de denominación. Los términos urinsaya y aransaya se utilizan en otros ayllus para denominar a las dos parcialidades en que siempre está dividido un ayllu. En cambio los términos uray peraño y wichay peraño son propios del ayllu Kirkyawi, hasta donde tenemos noticia.

5 Jap'iy" en quechua quiere decir "agarrar", "asir", y también hace referencia a "lo agarrado". Agarrar en este sentido tiene varias connotaciones. Cuando decimos que alguien "agarra" algo, significa que lo tiene bajo su poder, pero también bajo su cargo. Jap'iy en este sentido es difícil de traducir, quiere decir un conjunto de cosas agarradas, que están en el poder de, o bajo la responsabilidad de. Jap'iy evoca también a un amarro, un conjunto de cosas que se mantienen unidas por un lazo. 
los secretarios generales y hilancos de las comunidades como de las subcentrales. A todas las reuniones asisten las dirigentas de las organizaciones de mujeres.

\section{ITINERANCIA CÍCLICA ANUAL Y “DOBLE DOMICILIO”}

El propósito de este apartado es escribir y examinar la dinámica de itinerancia cíclica anual como estrategia económica de los campesinos indígenas del ayllu Kirkyawi. Previamente, es necesario distinguir esquemáticamente dos tipos de familias, aquellas que tienen residencia en el campo y que parte de sus miembros se traslada a la ciudad temporalmente y aquellas que tienen residencia en la ciudad y que parte de sus miembros se traslada al campo en época de labores agrícolas.

Constatamos así que la dinámica económica y social es eminentemente desterritorializada. La itinerancia permite mitigar la pobreza de la población indígena y campesina que reside tanto en las comunidades como en las ciudades. La misma requiere de un capital social, esto es una serie de recursos basados en redes de relaciones y reconocimientos mutuos que, tanto en el campo como en la ciudad se transforman en capital económico. En el campo, las redes sociales permiten disponer de mano de obra en las periodos agrícolas donde el trabajo es más intenso, en las ciudades posibilitan la inserción laboral, y en el caso de los viajes de intercambio a los valles la relación con otros grupos étnicos en zonas alejadas de su comunidad son fundamentales en las relaciones comerciales y laborales.

Quienes residen en las ciudades se encuentran en una situación de mayor vulnerabilidad pues no cuentan con el mismo capital social, por lo menos en el ámbito laboral. A esto se suma la precariedad en cuanto a condiciones laborales, económicas, habitacionales, etcétera.

El vínculo con la comunidad les permite a los que viven en la ciudad complementar su economía y el vínculo con la ciudad permite, a los que viven en la comunidad, complementar también su economía familiar. En ambos casos el capital social es el que posibilita la generación y flujo de recursos.

\section{EL CICLO AGRÍCOLA-LABORAL-COMERCIAL}

El ciclo laboral y comercial anual está determinado fundamentalmente por el ciclo agrícola.

La producción principal de la zona es la papa. La papa dulce es para el consumo, mientras que la papa amarga es para la elaboración del chuño. El segundo producto en importancia es la cebada. La siembra de la papa y de la cebada, según el lugar, es entre septiembre y noviembre. La siembra demanda la mano de obra de toda la familia y el trabajo en colaboración mutua entre parientes y vecinos, puesto que 
se debe realizar en las fechas adecuadas. En esta época las familias que residen en el campo no se trasladan a las ciudades bajo ninguna circunstancia. Por su parte, las familias que viven en las ciudades llegan a la comunidad, por lo menos los hombres y los jóvenes, para realizar las labores agrícolas. Una vez terminadas las mismas retornan a la ciudad.

Durante el mes de diciembre la demanda de mano de obra disminuye y es la época en que la gente que residen en el campo se traslada a las ciudades, especialmente las mujeres y ancianos para dedicarse a la mendicidad masiva.

Entre los meses de marzo y abril tiene lugar la cosecha de la papa. Este trabajo también demanda la mayor cantidad posible de mano de obra, por lo que se recurre a la ayuda mutua. El mes de mayo es la época de corte de la cebada. Durante el mes de junio la gente se dedica a la elaboración del chuño, por ser la época en que las temperaturas son más bajas. Durante este tiempo quienes viven en las ciudades se trasladan temporalmente al campo para realizar las labores de cosecha de papa y elaboración del chuño.

Pasado este tiempo, para quienes residen permanentemente en el campo viene la época de migración hacia los valles y a las ciudades, entre julio y septiembre, en otras regiones la gente viaja hacia los valles ya desde mayo. En esta ocasión son generalmente los hombres ya sean casados o solteros quienes se ausentan durante semanas o meses.

Podemos dividir entonces el ciclo de trabajo anual, tanto de quienes residen en la ciudad como de quienes residen en el campo, en dos etapas: la vida en el campo y la vida en la ciudad. Describiremos ambas situaciones para comprender mejor el ciclo agrícola-laboral-comercial.

\section{La vida en el campo}

Las condiciones de vida en el campo son muy difíciles. La economía familiar es sumamente precaria. La producción agrícola está destinada en un ochenta por ciento al consumo doméstico. Los viajes hacia los valles tienen como objetivo el intercambio de productos que permitan complementar la dieta familiar. Además de esta labor comercial, permanecen en las ciudades durante semanas o meses trabajando como jornaleros.

Tanto en el intercambio de productos como en el trabajo asalariado entran en juego las redes sociales (capital social), tanto para conseguir alojamiento como para conseguir trabajo. Normalmente se tienen "conocidos" en los valles quienes además de intercambiar productos les ofrecen alojamiento. Igualmente en las ciudades, cuentan con redes de familiares y "conocidos" quienes les ofrecen alojamiento y posibilidades de trabajo. 


\section{La vida en las ciudades}

En el caso de Kirkyawi y de las comunidades andinas en general, debemos entender la migración a la ciudad no como un traslado definitivo y un abandono de la comunidad de origen sino en el contexto de lo que hemos llamado la "doble residencia", que es una característica inherente a la cultura andina. De esta manera podemos decir que la migración a las ciudades debe ser entendida como un cambio de la residencia principal que implica un vínculo con la comunidad de origen. Este vínculo tiene razones tanto culturales como económicas.

Una de las explicaciones que ofrecen los entrevistados para la migración de las familias a las ciudades es la escasez de tierras y/o la insuficiente producción de las mismas. Sin embargo, las condiciones de vida de los migrantes en las ciudades son mucho más duras que en el campo, como veremos más abajo. La explicación de la migración debe buscarse más bien en las oportunidades a futuro que ofrece la vida en las ciudades. Para las familias que tienen hijos pequeños, el factor que define el cambio de residencia es la educación. En las comunidades los niños no pueden hacer más que tres o cuatro cursos de primaria y luego se quedan sin estudiar. Cuando pueden elegir, los padres prefieren establecerse en las ciudades para que sus hijos puedan asistir a la escuela. Para los jóvenes, la ciudad ofrece mayores oportunidades laborales.

Lo que determina el lugar de residencia no son tanto las condiciones laborales sino el lugar donde los hijos estudian.

La economía familiar de quienes están establecidos en las ciudades es complementada por el trabajo agrícola en la comunidad. El cambio de residencia a la ciudad implica la movilización del capital social tanto para establecerse en la ciudad como para mantener los vínculos con la comunidad.

Otra de las condiciones para mantener el derecho sobre la tierra es asumir los cargos. Quienes tienen tierras en la comunidad tienen la obligación de pasar los cargos así vivan en las ciudades. Cuando a una persona (sería más apropiado decir a una familia, porque los cargos recaen sobre el varón y la mujer) le toca pasar el cargo debe asumirlo y retornar a la comunidad mientras dure el cargo.

El vínculo con la comunidad, además de las razones económicas expuestas, es fundamental en la identidad de la persona. Los migrantes en las ciudades no tienen referentes sociales, no tienen vínculos sino los laborales o vecinales.

Otra forma de establecer redes sociales en las ciudades y de mantener vínculos con la comunidad son las asociaciones de residentes. Otro espacio de encuentro entre quienes migraron a la ciudad son los campeonatos deportivos que se desarrollan en los barrios periurbanos donde residen. Los equipos de fútbol de estos campeonatos se organi- 
zan de acuerdo al lugar de procedencia. En el caso de los residentes, se organizan también para recaudar fondos para hacer alguna donación de materiales a las escuelas o alguna obra en el pueblo. Estos eventos son una ocasión de encuentro y de reafirmación de los vínculos de los residentes entre sí y con la comunidad.

La experiencia en la ciudad, ya sea como migrante estacional o definitivo, y en la relación entre indígenas y pueblerinos, se ponen en evidencia las desigualdades categoriales (Tilly, 2000) fundadas en la diferencia cultural. En las ciudades los indígenas sufren no solo la injusticia económica sino también la injusticia cultural. La diferencia étnica se vive también como desigualdad social. Para los indígenas están reservadas las escuelas de menor calidad, se les niegan los servicios básicos, no tienen atención de salud, no cuentan con ningún tipo de seguridad social, etcétera. Las relaciones sociales marcadas por la diferencia étnica y la desigualdad, que actúan visiblemente en el contexto urbano, son incorporadas en la experiencia personal generando así un sentido de "naturalización" de las mismas.

El resultado de esta incorporación es que se intenta superar esta diferencia categorial no mediante el cambio de relaciones entre los actores de ambos lados del límite social cultural, sino mediante la asimilación al grupo dominante. Hemos mencionado que una de las motivaciones fundamentales de la migración es la educación de los hijos. Esto implica que los hijos deben "dejar de ser indios" y "campesinos" para asimilarse al grupo "mestizo" y "profesional". Se asocia el "cambio cultural" con el cambio de las condiciones económicas que viven. Esto explica cómo, por ejemplo en el caso de la educación, los padres de familia no aceptan la educación intercultural bilingüe, quieren que en la escuela sus hijos aprendan el español y la cultura dominante para que puedan tener acceso a los bienes económicos del sector dominante. Es esta situación dramática la que se refleja en la entrevista que dice que "los jóvenes se avergüenzan de su propia gente, no nos quieren saludar". El análisis de la desigualdad categorial nos muestra cómo la cultura, en este caso la diferencia cultural, forma parte de las relaciones sociales, y que el cambio cultural es percibido por los indígenas como una posibilidad de un cambio en sus relaciones sociales y en su situación económica.

\section{Políticas Sociales MUNiCipales Y REDUCCIÓN DE LA POBREZA}

El objetivo de este capítulo será examinar las políticas sociales derivadas de la implementación de la Ley de Participación Popular, las acciones tomadas en concreto por el municipio de Bolívar y su incidencia en la reducción de la pobreza en la región. 
Hasta antes de la Ley de Participación Municipal (1994), el municipio de Bolívar era una instancia cuyas acciones se limitaban a los centros urbanos, y en este caso al pueblo (capital provincial). Desde el punto de vista del Estado, el cambio fundamental es que amplía su jurisdicción mediante el municipio a una parte importante de la población excluida de las instituciones estatales, especialmente en el área rural. Desde el punto de vista de las comunidades, como desarrollaremos con mayor amplitud adelante, la posibilidad de participar de los recursos provenientes del estado reconfigura la dinámica política local.

La principal función del municipio es la administración de los recursos municipales, lo que se traduce en la ejecución de obras en las comunidades, de acuerdo al Plan de Desarrollo Municipal y al Plan Operativo Anual (POA).

Administrativamente el municipio se divide en agencias municipales, las cuales en el caso presente coinciden con los "cantones". En cada cantón existe un agente cantonal. La función del agente cantonal es la de intermediación entre el cantón y el municipio. Debe velar por que las obras sean ejecutadas en su jurisdicción, informar a las comunidades acerca de la gestión municipal y llevar al municipio las necesidades y demandas de las comunidades. El agente cantonal se elige en la misma plancha de candidatos municipales a alcalde y concejales, en las elecciones municipales.

\section{EL PROCESO DE MUNICIPALIZACIÓN}

El proceso comenzó en 1994 con la promulgación. Hasta ese entonces la alcaldía (actualmente llamado el municipio o gobierno municipal) limitaba sus funciones al pueblo y no tenía jurisdicción en las comunidades. El cargo de alcalde era ad honorem. La alcaldía tenía escasos ingresos por concepto de impuestos a las panaderías, matanza de chanchos, impuesto a la chicha, impuesto a las viviendas, a las tiendas, etcétera. Estos escasos recursos se destinaban a mejoras en el pueblo.

En su primera etapa la Ley se encontró con muchas resistencias y susceptibilidades de parte de la población. La Federación de Sindicatos Campesinos había rechazado la Ley y en las comunidades existían una serie de rumores acerca de la razón por la que se querían hacer las obras. Se decía que el diagnóstico que se estaba haciendo era para cobrar impuestos, que una vez que se hicieran las obras iban a venir los q'aras (blancos) a quitarles sus tierras, etcétera. Sin embargo, cuando se vieron las primeras obras en las comunidades los sindicatos se fueron reorganizando para exigir obras al municipio.

La Ley de Participación Popular ha movilizado más bien a los sindicatos. Los mismos se han visto en la necesidad de fortalecerse en 
cuanto a su organización para solicitar y ejecutar las obras que vienen de parte de los municipios y en algunos casos de las ONG.

En este punto podemos decir que la dinámica organizativa es producto de las políticas estatales generadas a partir del proceso de municipalización. Si bien la Ley "reconocía" a las organizaciones ya existentes, en el caso de Bolívar hasta cierto punto tuvieron que crearse.

En cuanto a la organización de las autoridades originarias hemos constatado que el proceso ha sido diferente. El proceso de restitución de los ayllus y sus autoridades originarias surgió a partir de las políticas estatales de titulación de tierras que se inició a fines de la década del noventa, como hemos mencionado en el apartado sobre el ayllu.

La dramática situación de marginación y abandono que vivía la región hace que la Participación Popular sea vista en una primera instancia como beneficiosa para la región. Sin embargo, la etapa de las "obras" está llegando a su fin y ya los comunarios empiezan a cuestionar los alcances de la Ley y de las políticas municipales, como lo veremos en el siguiente apartado.

\section{LAS POLÍTICAS MUNICIPALES}

En este apartado se analizarán los principales supuestos y premisas de las políticas municipales, las cuales determinan la planificación de la inversión de los recursos municipales. Veremos también qué tipo de acciones y "obras" realizó el municipio en las últimas gestiones y en qué medida inciden en la reducción de la pobreza.

Durante los más de diez años desde que se inició la municipalización, la gestión del municipio ha estado y está actualmente centrada en la ejecución de obras de infraestructura en las comunidades.

Una de las principales obras que se ha ejecutado es la instalación de redes de agua "potable" en las comunidades. Aunque técnicamente el agua no es tratada para su potabilización, el hecho de ser distribuida en cañerías a las casas de alguna manera ha mejorado la calidad del agua para consumo humano.

Otro tipo de obras son los "microrriegos", que básicamente consisten en canales de riego sencillos que permiten abastecer de agua algunos terrenos en las comunidades. La falta de planificación a largo plazo y a mayor escala ha derivado en que estos sistemas en pocos años quedaran sin uso, pues los terrenos no se pueden cultivar cada año: después de un ciclo de cultivo de tres años los terrenos deben "descansar" por al menos diez años. Durante este tiempo el sistema de riego queda inutilizado. Por otra parte ha generado conflictos entre comunidades pues el riego en unas ha ocasionado que el agua ya no llegue a otras vecinas.

Otro gran rubro de la infraestructura son las escuelas. La infraestructura escolar ha mejorado notablemente en las comunidades. 
Sin embargo, este hecho no ha traído consigo mejoras en la calidad de la educación, que sigue teniendo limitaciones muy grandes en la zona. La infraestructura escolar también comprende la construcción de "canchas multifuncionales" y baterías de letrinas.

También se constató que en varias comunidades se construyeron "letrinas ecológicas" y "duchas solares". Lamentablemente en ninguna comunidad se vio que las duchas fueran utilizadas, sino que están en completo estado de abandono y deterioro. Este tipo de obras responde más a la necesidad de ejecución presupuestaria de las contrapartes (ONG) que a las necesidades reales de la población.

Parte del presupuesto se destina también al mejoramiento y conservación de los caminos vecinales. Estos caminos son utilizados principalmente por los vehículos del mismo municipio o de las ONG que trabajan en la zona. Lamentablemente no existen medios de transporte motorizado que vinculen a las comunidades con los centros urbanos.

La ejecución de obras en las comunidades ha generado una lógica de competencia entre ellas. Las obras no son valoradas solo por su función concreta sino porque la comunidad que tiene mayor infraestructura es vista como de mayor prestigio ante las demás.

Después de estos años de implementación de la Ley de Participación Popular las comunidades perciben que las pequeñas obras, si bien han mejorado algunos aspectos en cuanto a infraestructura básica, no han impactado en su economía familiar, no han logrado superar la pobreza de la región. Sin embargo, este cuestionamiento no logra la transformación de las políticas municipales puesto que no se ve una salida viable. La respuesta que se plantea ante esta situación es que se hagan obras de mayor impacto, pero ni el presupuesto del municipio ni el de las ONG es suficiente para lograr este objetivo.

Las políticas municipales están enmarcadas dentro de lo que Fraser llama políticas afirmativas. El municipio de Bolívar ha sido uno de los primeros en implementar la Participación Popular por su situación de pobreza. La municipalización, no solo en Bolívar, sino en el país en su conjunto, no logra revertir la pobreza y la marginación de las mayorías. Las políticas se han abocado a mitigar algunos efectos de las desigualdades sociales dejando intactas las estructuras de injusticia económica y social y las condiciones laborales de los campesinos, en este caso de Bolívar.

La percepción que empieza a tenerse es que las políticas estatales no han logrado revertir la situación de pobreza de las familias. Al contrario, la municipalización ha sido parte de las reformas neoliberales implementadas en la década del noventa, que apunta a crear entornos favorables para el buen desempeño económico, de manera tal de garantizar la gobernabilidad: 
Para el Banco Mundial la agenda del Buen Gobierno se refiere a la relación que permita establecer entornos favorables para el mercado. [...] Para el Banco Interamericano de Desarrollo (BID), la agenda del Buen Gobierno se entiende por "el ejercicio de la autoridad política de forma democrática, inclusiva de todos los sectores de la población, eficiente, observadora de reglas y derechos, transparente y responsable frente a la sociedad civil" (Morales, 2003: 13)

La municipalización amplía el rol de las instituciones hacia el rol de los actores, para promover el avance económico de los pobres, de modo que puedan vincularse al mercado.

\section{LA PARTICIPACIÓN DE LAS ORGANIZACIONES EN EL GOBIERNO MUNICIPAL}

Las organizaciones sindicales así como las originarias de los ayllus se han ido fortaleciendo hasta tal punto que, como vimos arriba, en las elecciones del 2004 se plantearon seriamente la posibilidad de acceder al municipio presentando sus propios candidatos. La idea que subyacía en las elecciones era que "debemos gobernarnos a nosotros mismos". El triunfo fue arrasador, ninguno de los candidatos mestizos pudo acceder siquiera a una concejalía.

El hecho de que los mismos campesinos hayan accedido al municipio representa para la organización sindical así como para quienes están en los cargos un reto mucho más grande que para las anteriores autoridades mestizas. El control sobre las acciones del municipio se ha hecho más agudo, tanto de parte de los mestizos del pueblo como de parte de los mismos comunarios.

En cuanto a la participación de las comunidades y sus autoridades en la gestión municipal podemos decir que tiene tres momentos: la planificación, la ejecución y la fiscalización.

La planificación tiene lugar a fin de año. En la asamblea de la CPPP las comunidades deben presentar ante el municipio sus demandas, que, como vimos arriba, se reducen a las obras que se solicitan para la comunidad. Las demandas se discuten previamente en las reuniones de comunidad y se las presenta al municipio para ser incluidas en el Plan Operativo Anual. Si bien el proceso es participativo y logra el consenso de las comunidades la elaboración del Plan no responde a una visión regional de desarrollo sino a la satisfacción inmediata de las peticiones de la comunidad, por lo que su alcance siempre se ve reducido a ejecución de pequeñas obras en cada una de ellas.

La comunidad también participa en la ejecución de las obras. Normalmente la comunidad debe poner una "contraparte" en mano de obra. La disposición de las comunidades a poner su fuerza de trabajo en las obras que se construyen responde por una parte al anhelo de ver 
ejecutada la misma en su comunidad. Sin embargo, también responde a la idea de que las obras son una "dádiva" del Estado, un "regalo" de las autoridades, puesto que ellos no se consideran parte del Estado y por tanto los recursos que llegan a la comunidad son vistos no como un derecho sino como una merced del Estado o de las ONG.

En cuanto a la fiscalización, la instancia máxima es el CPPP, en la cual el alcalde, las instituciones y los concejales deben informar a la población acerca de la ejecución de las obras, de la ejecución presupuestaria del municipio, de los problemas que surgen en las comunidades, del desarrollo de las actividades en las escuelas y en las postas de salud, etcétera. Podemos decir que si bien la fiscalización en apariencia es activa y participativa en cuanto a las obras, su ejecución y aspectos puntuales de la gestión municipal, sus alcances son limitados en cuanto a una visión de desarrollo de la región o a políticas a mediano plazo que pueda adoptar el municipio.

Morales muestra que en general las personas con menores niveles de ingresos tienden a participar más de los procesos de planificación y fiscalización municipales, a este hecho lo denomina selección adversa. El mismo, según la autora, "se ha constituido en una institución formal exitosa" (Morales, 2003: 41), pero entraña riesgos en la "calidad" del diseño de las políticas, debido al problema de selección adversa, donde la mayor parte de las personas involucradas en actividades de la comunidad tiene bajos niveles de instrucción y condiciones laborales negativas, reflejadas en los bajos niveles de ingresos (Morales, 2003: 41). La falta de información y conocimientos técnicos, así como factores culturales (la competencia entre comunidades) limitan a las comunidades elaborar políticas de mayor alcance. La mayor participación no es de por sí garantía de una mejor gestión: "No por mucho participar van a dejar de ser pobres” (Morales, 2003: 15).

\section{Conclusiones}

Hemos descrito y analizado tres ámbitos de la vida en las comunidades campesinas del ayllu Kirkyawi: la dinámica económica, la dinámica organizativa y las políticas municipales. En este apartado se analizarán los puntos de convergencia y divergencia entre estos tres ámbitos para llegar a algunas conclusiones sobre el tema planteado.

Tenemos por una parte que la dinámica económica basada en la producción agropecuaria tiene en la organización originaria uno de sus pilares fundamentales. La organización originaria está concebida desde la relación que tiene la comunidad con la tierra y el territorio. Esta relación está mediada a la vez por una determinada cosmovisión fundada en una concepción de la tierra no como medio de producción a explotar sino como la dadora de vida con la que se convive. Los siste- 
mas de cultivo responden a prácticas ancestrales de aprovechamiento de distintos pisos ecológicos, de aprovechamiento de distintos microclimas, de la ocupación discontinua del territorio, etcétera. Esta cosmovisión y estas prácticas comprenden también un sistema de cargos comunitarios y supracomunitarios que permiten la organización del trabajo agrícola y de la vida ritual, la resolución de los permanentes conflictos por tierras, etcétera. En este contexto son fundamentales la figura del hilanco en cada comunidad y de los kuraq tatas en los jap'iy. Podemos decir que las autoridades originarias están orientadas hacia dentro de la comunidad y hacia los aspectos fundamentales de la misma: la reproducción de la vida.

En este contexto surge la municipalización que dinamiza otro tipo de organización, el de los sindicatos agrarios. Los sindicatos que habían surgido con la Revolución de 1952 no tenían mayores funciones más que las de esporádicamente hacer algunas gestiones ante las autoridades estatales. Con la Ley de Participación Popular se revitalizan y adquieren una función importante en cuanto a la gestión municipal. Podemos decir que el sindicato es la instancia de relación hacia afuera de la comunidad.

Si enfocamos la mirada hacia el municipio y la gestión municipal, hacia el proceso de municipalización, hacia la planificación y ejecución de obras, hacia el desarrollo de la organización sindical que ha logrado hacerse de la administración misma del municipio, puede parecer que el proceso de municipalización ha generado grandes logros en cuanto a organización de las comunidades y en cuanto a las obras que se han hecho en las mismas. De hecho, todos los estudios realizados en lo que respecta a la municipalización tienen este enfoque.

Pero ¿por qué la municipalización no ha revertido la situación de pobreza en la región? Una posible respuesta, más allá de los factores técnicos del proceso de municipalización, puede encontrarse mirando el proceso de municipalización desde la perspectiva de las comunidades. Esta perspectiva no ha sido lo suficientemente estudiada y es uno de los aportes del presente trabajo. Desde este enfoque vemos que para la comunidad aquello que le permite la reproducción de la vida no son las obras que se ejecutan desde el municipio sino la producción agropecuaria y el trabajo en las ciudades. Para la comunidad la construcción de duchas solares, microrriegos, escuelas, etcétera es visto como un logro, incluso como un elemento de prestigio ante otras comunidades, pero no es un factor fundamental para su subsistencia. Incluso en términos de inversión de tiempo y recursos, la comunidad puede participar en la construcción de las obras y enviar a sus representantes a las reuniones, pero son momentos puntuales en el ciclo laboral anual, generalmente fuera de las épocas de mayor trabajo en el 
campo. La comunidad puede invertir algunos días de trabajo al año en la construcción de la escuela o la canchita para mejorar así la infraestructura de la comunidad, pero las obras no representan un elemento vital en la comunidad, son un elemento incluso marginal en la vida de las familias.

En la cotidianidad de la comunidad tiene más peso y más importancia la organización originaria que permite la reproducción de la vida, que el municipio y la organización sindical en que se sustenta.

El proceso de municipalización, en la letra de la Ley, reconoce a las organizaciones existentes en las comunidades campesinas e intenta incorporarlas a la lógica municipal. En la práctica, las comunidades han potenciado el tipo de organización que les permita articularse con el Estado, el sindicato campesino, manteniéndose intacta la organización que rige la vida al interior de la comunidad. Es cierto que, en otros ayllus, el proceso de municipalización en vez de potenciar los sindicatos, se ha articulado con la organización originaria. Pero en estos casos los resultados son similares.

El problema de fondo radica en que la municipalización ha seguido su propia lógica y ha obligado a las comunidades a adaptar sus sistemas organizativos a la misma. Las políticas municipales ignoran la dinámica económica (productiva, laboral, migratoria) de las comunidades y la dinámica organizativa que la sustenta (el sistema de cargos originario). Para la comunidad, así como para el Estado, este hecho es de "sentido común". Desde siempre ha habido un "pacto" entre el ayllu y el Estado, que consistía en que el Estado respeta el derecho sobre la tierra de los ayllus y el derecho a su autonomía a cambio del tributo (Platt, 1982). A pesar de que en la década del sesenta este tributo fue abolido, los ayllus lo seguían pagando (y aún en la actualidad en algunos ayllus se sigue cobrando), pues era la garantía de su derecho a la tierra. El Estado boliviano siempre se ha considerado como ajeno al ayllu. Es esta lógica la que subsiste y la municipalización no ha podido revertir esta situación.

Por otra parte, hemos analizado el ciclo anual de migraciones hacia los valles y las ciudades. La investigación nos ha mostrado que en la lógica de los ayllus persiste la concepción de una territorialidad discontinua en la que se desarrollan las actividades de subsistencia. Los estudios históricos muestran que desde épocas remotas los habitantes de los ayllus se trasladaban estacionalmente a los valles y a la costa donde tenían tierras y podían acceder a una mayor variedad de productos. La mayoría de los ayllus ha perdido hace tiempo esos vínculos con sus tierras de los valles, sin embargo se mantiene esa lógica de acceder a otros espacios que les permitan subsistir. Este es el sentido de los viajes a los valles, de la migración temporal a las ciudades 
y de la migración temporal a la comunidad en el caso de las familias que residen en las ciudades.

El proceso de municipalización implicó una "territorialización" de la jurisdicción del Estado mediante los municipios hasta sus niveles mínimos, ignorando completamente esta dinámica económica de las familias andinas que se funda en la "doble residencia" y la itinerancia cíclica anual. Esta característica implica que las familias se mueven en varios ámbitos espaciales, económicos, sociales y culturales. Implica también la movilización de capitales sociales y culturales que les permiten acceder y desenvolverse en estos ámbitos. Las políticas municipales son "territorializadas" mientras que la dinámica de la gente de los ayllus es "desterritorializada". Este es otro de los aspectos que no se ha estudiado en absoluto en las evaluaciones que se hacen acerca de la municipalización.

El problema de fondo no radica solo en la asignación presupuestaria sino en la discordancia entre los supuestos de las instituciones estatales y sus políticas y la dinámica social y económica de la gente de los ayllus y de las zonas suburbanas donde habitan. Las políticas estatales siempre se plantean en los límites de la jurisdicción municipal y no con una perspectiva más amplia. Por ejemplo, atendiendo a la dinámica migratoria estacional o definitiva, se podrían desarrollar proyectos educativos que entrenen a los jóvenes en oficios útiles en las ciudades. Considerando que no pierden sus vínculos con la comunidad, el obtener mejores condiciones laborales en la ciudad incidiría a mediano plazo en la economía del municipio. En el caso de las familias que viven en las ciudades y tienen tierras en la comunidad, se puede pensar en proyectos productivos que vinculen campo y ciudad, por ejemplo proyectos de comercialización o transformación de productos. Otro tipo de proyectos podría atender la dinámica migratoria estacional buscando convenios con municipios o empresas en las ciudades para canalizar fuentes de trabajo temporales en mejores condiciones, etcétera. Estas son solo algunas de las posibilidades que tendría el pensar las políticas públicas más allá de las jurisdicciones establecidas. Esto implicaría la transformación de las normas y prácticas de los gobiernos municipales y abriría las posibilidades más allá de la mera ejecución de "obras" en las comunidades.

Ciertamente la superación de la pobreza, la exclusión social y cultural está muy lejos de alcanzarse por el camino de la profundización de las políticas de redistribución (vía municipalización de la administración de los recursos estatales) y de reconocimiento (vía reetnización de los ayllus por las políticas de tierras) tal como están planteadas puesto que las mismas mantienen las desigualdades categoriales fundadas en la diferencia étnica. El proceso de recons- 
titución de los ayllus no logra la justicia cultural puesto que ha entrado en la lógica de la afirmación de las diferencias culturales sin cuestionar el colonialismo interno propio de la sociedad boliviana. La municipalización no promueve la justicia económica puesto que las políticas remediales de carácter afirmativo (o de "alivio a la pobreza" en términos gubernamentales) dejan intactas las estructuras que generan la desigualdad. De todas maneras, ambos procesos han generado nuevos escenarios y una nueva dinámica social y cultural en el país. El desafío pendiente es que esta dinámica se encamine hacia la transformación de las estructuras sociales y culturales de manera que se genere un verdadero respeto de las diferencias culturales y una transformación en las condiciones de vida de los pueblos indígenas. Mientras tanto, seguirán itinerando en busca de mejores días, como hace cientos de años.

\section{Bibliografía}

Albó, Xavier 1997 "Alcaldes y concejales campesinos-indígenas: la lógica tras las cifras” en SNPP Indígenas en el poder local (La Paz: Ministerio de Desarrollo Humano / SNPP).

Albó, Xavier 2002 Pueblos indios en la política (Bolivia: CIPCA).

Antezana, Fernando 2003 "Participación y poder popular en los municipios de Bolívar y Tacopaya" en Participación popular: vivencias y perspectivas (Cochabamba: CEPLAG, UMSS).

Arratia, Miguel 2002 "La participación de las organizaciones campesino-indígenas en el proceso de participación popular en el municipio de Bolívar-ayllu Kirkyawi (1994-2000)", Tesis de maestría, (Cochabamba: CESU, UMSS).

Barth, Fredrik (comp.) 1976 Los grupos étnicos y sus fronteras. Organización social de las diferencias culturales (México: Fondo de Cultura Económica).

Barth, Fredrik 1981 Process and form in social life (Londres: Routledge / Kegan Paul).

Barth, Fredrik 2000 "Enduring and emerging issues in the analysis of ethnicity" en Vermeulen, Hans y Govers, Cora The Anthropology of Ethnicity (Amsterdam: Het Spinhuis).

Bourdieu, Pierre y Wacquant, Loïc 1995 Respuestas por una antropología reflexiva (México: Grijalbo).

Bourdieu, Pierre 2002a La distinción (México: Taurus).

Bourdieu, Pierre 2002b Razones prácticas (Barcelona: Anagrama).

Bouysse-Cassagne, T. 1978 "Urco and Uma: Aymara Concepts of Space" en Murra, John et al. (eds.) Anthropological history of Andean Politics (Cambridge: Cambridge University Press). 
Calla, Ricardo 1999 “Indígenas, Ley de Participación Popular y cambios de gobierno en Bolivia (1994-1998)" en Assies, W.; Van der Haar, G. y Hoekema, A. (eds.) El reto de la diversidad (Michoacán: El Colegio de Michoacán, Zamora).

Condarco, Ramiro y Murra, John 1987 La teoría de la complementariedad vertical eco-simbiótica (La Paz: Imp. Papiro).

Corrigan, Philip y Sayer, Derek 1985 Introduction: The Great Arch. English State formation as cultural revolution (Oxford: Oxford University Press).

De Vries, A. 1999 “Municipios y territorios indígenas: una comparación geográfica" en CEJIS Municipio y pueblos indígenas. Problemas del modelo municipal y propuesta social de creación de municipios especiales (Santa Cruz: CEJIS).

Figueroa, Alejandro 1994 Por la tierra y por los santos. Identidad y persistencia cultural entre yaquis y mayos (México: CONACULTA).

Fraser, Nancy 2001 "From redistribution to recognition?" en Seidman, Steven y Alexander, Jeffrey The new social theory reader (Nueva York: Routledge).

Gilbert, Joseph y Nugent, Daniel (comps.) 2002 Aspectos cotidianos de la formación del Estado (México: Ediciones Era).

Giménez, Gilberto 2000 "Identidades étnicas: estado de la cuestión" en Reina, Leticia (coord.) Los retos de la etnicidad en los estadosnación del siglo XXI (México: CIESAS / INI / Miguel Ángel Porrúa Editores).

Gobierno Municipal de Bolívar 1997 Plan de desarrollo municipal (Cochabamba).

INE (Instituto Nacional de Estadística) 2001 Censo Nacional de Población y Vivienda 2001 (Bolivia).

Morales, Natacha 2003 "Un rompecabezas no resuelto: La estrategia boliviana de reducción de la pobreza y el rol del estado", Informe final del Concurso 2002 CLACSO/CROP-Junior, El rol del estado en la reducción de la pobreza (ms.).

Murra, John 1975 Formaciones económicas y políticas en el mundo andino (Lima: IEP).

Orellana, René 1999 “Municipalización de pueblos indígenas en Bolivia: impactos y perspectivas" en Assies, Willem et al. (eds.) El reto de la diversidad (Michoacán: El colegio de Michoacán, Zamora).

Platt, Tristan 1981 "El papel del ayllu andino en la reproducción del régimen mercantil simple en el norte de Potosí" en América Indígena, Vol. 41, octubre-diciembre.

Platt, Tristan 1982 Estado boliviano y ayllu andino (Lima: IEP). 
Platt, Tristan 1986 "Mirrors and maize: the concept of yanantin among the Macha of Bolivia" en Murra, J.; Wachtel, N. y Revel, J. Anthropological History of Andean Politics (Londres: Cambridge University Press).

Platt, Tristan 1988 "Pensamiento político aymara" en Albó, Xavier (comp.) Raíces de América. El mundo aymara (Madrid: Alianza Editorial / UNESCO).

Roseberry, William 2002 "Hegemonía y lenguaje contencioso" en Gilbert, Joseph y Nugent, Daniel (comp.) Aspectos cotidianos de la formación del Estado (México: Ediciones Era).

Sayer, Derek 2002 "Formas cotidianas de formación del estado: algunos comentarios disidentes acerca de 'hegemonía”' en Gilbert, Joseph y Nugent, Daniel (comps.) Aspectos cotidianos de la formación del Estado (México: Ediciones Era).

Scott, James 2000 Los dominados y el arte de la resistencia (México: Ediciones Era).

Stavenhagen, Rodolfo 1992 "La cuestión étnica: algunos problemas teórico-metodológicos" en Estudios del Colegio de México (México) Vol. X, $\mathrm{N}^{\circ} 28$, enero-abril.

Stavenhagen, Rodolfo 2001 La cuestión étnica (México: El Colegio de México).

Tilly, Charles 2000 La desigualdad persistente (Buenos Aires: Manantial). Zicardi, Alicia (coord.) 1996 La tarea de gobernar: Gobiernos locales y demandas ciudadanas (México: UNAM / Porrúa).

Zicardi, Alicia (comp.) 2003 Pobreza, desigualdad social y ciudadanía (Buenos Aires: CLACSO). 


\title{
Osvaldo Blanco*
}

\section{MiCROCRÉdito Y EMPRENDIMIENTO EN CHILE}

\section{UN ANÁLISIS DESDE LA IDEOLOGÍA Y EL ANÁLISIS DE DISCURSO}

\author{
- ¿Qué es la lucha de clases? \\ -El proceso antagonista que constituye \\ las clases y determina su relación. \\ -iPero en nuestra sociedad no hay luchas de clases! \\ - ¡Ya ves cómo funciona! \\ Alfred Hitchcock \\ (Citado por S. Žižek)
}

\section{RESUMEN}

La presente investigación tiene como objetivo dar cuenta de la relación discursiva entre "emprendimiento" y el "microcrédito" dentro de un proceso ideológico de definición de una nueva concepción de pobreza y del "sujeto-pobre". Este objeto de estudio se encuentra constituido tanto por discursos de representantes de instituciones oferentes de crédito privadas como por los discursos de microempresarios estudiados. Todo esto en el marco de lo que se ha denominado "políticas de segunda generación” en América Latina (post-ajuste estructural) sugeridas, en especial, por el Banco Mundial y el CGAP.

* Sociólogo, 28 años, profesor de la Universidad ARCIS, sede Valparaíso, carrera de Sociología. Agradezco a la socióloga Luz María Montero por toda su ayuda y compañía. También a María J. Guevara, Hilda Hernández, Álvaro Neira y Felipe Leiva, por sus aportes a la presente investigación. Por último, este trabajo se lo dedico con todo mi amor a Vicente. 


\section{ELEMENTOS TEÓRICOS FUNDAMENTALES}

\section{¿Por QUÉ ESTUdiAR EL MICROCRÉDITO A LA MICROEMPRESA?}

Se hace necesario advertir que aquello que entendemos por "microcrédito" necesita una aclaración terminológica de entrada, pues en Chile las microempresas pueden llegar a recibir préstamos por montos muchísimo más altos que lo que comúnmente se entiende por "microcrédito", vale decir, una cosa sería el microcrédito y otra el crédito a la microempresa (Herrera, 2003). Sin embargo, nosotros aquí evadiremos las distinciones técnicas para referirnos al crédito o microcrédito desde un sentido amplio, como un préstamo de determinado monto a unidades económicas de subsistencia que si no es por este servicio estarían fuera del sistema financiero convencional (principalmente bancos). En la actual oferta financiera no todas las microempresas han recibido microcréditos y no todos ellos están dirigidos a la microempresa ${ }^{1}$. A eso se agrega que "el promedio de los montos de los créditos entregados por los distintos operadores chilenos se alejaría cuantitativa y cualitativamente de lo que se puede entender por microcrédito" (Ibíd.: 31$)^{2}$.

Lo que nos importa a nosotros es que si bien el crédito a la microempresa es un fenómeno estudiado, el tema del emprendimiento como "discurso ideológico" no había sido analizado nunca antes. Y esto es significativo pues, al menos en Chile, la irrupción del discurso del "emprendimiento" en la vida cotidiana es cada vez más acentuada. La televisión, secciones y suplementos de periódicos, programas de radio, en fin, diversos espacios en los medios de comunicación ya hablan de las microempresas ligándolas al "emprendimiento". El co-

1 La microempresa -al menos en su rama "formal"- ha mejorado su acceso al crédito en los últimos años. Así lo confirman las cifras de la Superintendencia de Bancos e Instituciones Financieras (SBIF) y del Servicio de Impuestos Internos (SII), utilizando como indicador la proporción de microempresas que tienen deudas vigentes en el sistema financiero respecto al total de ellas. Sin embargo, estas cifras se refieren solo a aquellas microempresas formales (que pagan impuestos), es decir, aquellas que estarían en una categoría superior, con lógicas muy distintas a la lógica de subsistencia. De 1999 a 2003, estas microempresas formales que acceden a un sistema de crédito crecieron desde 190.318 (representando un total de 36,1\% del total de micro y pequeñas empresas, MYPE) a 217.970 (38,2\% del total de MYPE), lo que representaría una "tasa de crecimiento" de 14\%.

2 El crédito a la microempresa llega hasta un máximo de US $\$ 10$ mil, por tanto, completamente alejado a los créditos de la institución oferente más conocida en el mundo, el Grameen Bank. Al operar en los países más pobres del mundo, cuyo Producto Nacional per-cápita asciende a alrededor de US $\$ 350$, es decir, 14 veces menos que el promedio chileno, el impacto de un préstamo de US $\$ 25$ es significativamente más importante en los países del Grameen Bank que en un país como Chile (Herrera, op. cit.: 30-31). 
rolario de esto llegó el año 2006, cuando el BancoEstado de Chile implantó un concurso a nivel nacional dirigido de manera explícita a los "microempresarios-emprendedores".

Esto no es una simple casualidad; los términos de microempresa y emprendimiento tienen que ver con una nueva disposición para enfrentar la pobreza. Esto pasa por nuevas definiciones acerca del papel de las instituciones y, por sobre todo, del propio "sujeto-pobre". Este último viene a ser garante de su propio camino, pasa a ser un "microempresario", donde un nuevo marco de instituciones financieras es enunciado como una forma de integración para que la gente que tiene capacidades pueda "salir de la pobreza".

La presente investigación es un análisis de discurso del emprendimiento dentro de lo que aquí llamaremos el "campo de microcrédito a la microempresa", constituido por: a) un sistema de ideas que generan una política sobre microcrédito; b) unas instituciones oferentes que prestan sus servicios; c) la masa cada vez más amplia de clientes o microempresas que acceden al sistema. De esta forma, nos hemos enfrentarnos al desafío de un análisis del emprendimiento para así entender al lenguaje como un lazo social entre estos tres niveles esenciales del campo de microcrédito a la microempresa.

\section{CONCEPTOS BÁSICOS PARA UNA TEORÍA DE LA IDEOLOGÍA Y DEL DISCURSO APLICADOS AL EMPRENDIMIENTO Y LA POBREZA}

El marco teórico recoge aportes del psicoanálisis lacaniano, el que ha sido sociológicamente adaptado a fin de analizar un objeto surgido de un campo de estudio tradicionalmente ligado a la economía. De esta manera, el discurso del emprendimiento será entendido como la ficción simbólica que trata de atenuar la crisis y de administrar el "espectral" antagonismo social. Dicho antagonismo es constitutivo de la sociedad, donde el pobre se enfrenta a ella y en donde la política social -entendida como lenguaje "simbólico" lacaniano- pretende hacer desaparecer mediante la integración, aunque siempre con el destino de la "falla". Desde nuestra perspectiva, la ideología del emprendimiento se enfrenta a lo "Real" de la lucha de clases, la cual simbólicamente se ha desplazado hegemónicamente hacia el discurso de la lucha contra la pobreza.

Por otro lado, entendemos al discurso del emprendimiento como una ideología no por sus premisas falsas que interpela a los pobres engañándolos, mostrándoles razonamientos viciosos y/o mentiras hipócritas. Muy por el contrario, el discurso del emprendimiento es una forma imaginaria de concebir la "realidad". Esta última no se oculta "debajo" de la ideología, sino que, en tanto lenguaje que se cierra semióticamente, continuamente rechaza las fuerzas desorganizadoras 
y descentradas en nombre de una unidad imaginaria, impidiendo la aparición de un espacio para la crítica (Eagleton, 2005).

Sin embargo, de forma algo paradójica, este cierre no implica necesariamente una homogeneidad del discurso. La ideología siempre debe ser lo suficientemente flexible como para incorporar motivaciones, creencias y prescripciones de las clases y/o grupos dominados. En nuestro caso, la ideología del emprendimiento se vuelve efectiva al proporcionar al "sujeto-pobre" un mínimo de sentido a su experiencia de vida. Pero este sentido, contradictoriamente, no puede definirse en cuanto tal de manera consciente pues el emprendimiento es un "significante sin significado", muy propio de la interpelación ideológica, por tanto, es un sentido que solo se define a partir de su referencia metonímica con otros significantes y no en sí mismo (Žižek, 2003b).

A su vez, si decimos que el discurso del emprendimiento -así como toda ideología que pretenda ser efectiva- logra ajustarse hasta cierto grado a lo que los sujetos-pobres saben de la realidad social es porque se trata de un discurso eminentemente práctico que se instituye desde la interacción de dominantes y dominados con la realidad social. Es decir, no es solo que las ideologías dominantes impongan externamente (desde arriba hacia abajo) las necesidades y deseos de las personas sometidas a ellas; deben también "implicarse significativamente con las necesidades genuinas, modulando estas en su propia jerga particular y realimentando con ellas a sus súbditos de una manera que vuelva a estas ideologías plausibles y atractivas" (Eagleton, op. cit.: 36). En suma, las ideologías deben ser bastante reales y creíbles para proporcionar la base sobre la que las personas puedan forjar una identidad coherente. Se trata de un proceso dialógico más que monológico que obliga a reconocer el interés del súbdito.

Esto último no significa que se trate de una especie de discurso democrático construido sin mediación de poder. Un espacio ideológico se caracteriza también porque el contenido de lo enunciado es funcional respecto de alguna relación de dominación social -poder, explotación o gobernabilidad- de un modo no transparente (Žižek, 2003a; 2005; Eagleton, op. cit.). No se trata solamente de analizar la "verdad" o "falsedad" empírica de los enunciados; es la lógica misma de la legitimación de la relación de dominación la que debe permanecer oculta para ser efectiva. Por tanto, lo que hace ideológico a un argumento no tiene tanto que ver con que si este hace o no referencia a sistemas de creencias verdaderas o falsas, sino más bien con que si hace o no referencia a cuestiones de poder ${ }^{3}$.

3 Eagleton separa el aspecto epistemológico de la ideología como falsedad que oculta la verdadera realidad (la falsa conciencia de Marx y Engels en la "Ideología Ale- 
En suma, en el presente artículo el discurso del emprendimiento lo consideramos como ideológico pues logra ser lo suficientemente flexible como para incorporar los intereses de los propios pobres, legitimándose como el discurso más importante en la actual "lucha contra la pobreza" en Chile. No obstante, en un segundo nivel, es ideológico también porque con él se "simboliza" (en sentido lacaniano del término) el proceso de recrudecimiento de la pobreza a fin de lograr la idealizada cohesión de la comunidad. De esta forma, el discurso del emprendimiento esconde, bajo una nueva forma de definición de la pobreza, el poder del saber burocrático que busca una pobreza administrable, basada en la premisa de enfrentarla por medio de la equidad en los accesos al sistema financiero. Este proceso se materializa mediante la interpelación ideológica que busca de manera performativa hacer que los individuos actúen como sujetos (Althusser, 2003), en este caso, que actúen como "microempresarios". Mediante enunciados "performativos" que constituyen la forma de actuar en prácticas y ritos específicamente determinados se interpela al sujeto-pobre a seguir un patrón de acciones de tipo inter-pasivo ${ }^{4}$, logrando la sujeción con la realidad social del orden simbólico imperante (Žižek, 2003b: 201-293; 2005: $100-101)^{5}$.

mana") del aspecto funcional de la ideología que se remite a servir el dominio de un grupo sobre los otros (Eagleton, op. cit.: 57-91). Ambos aspectos casi siempre están juntos, pero no necesariamente.

4 La "inter-pasividad" es el complemento sombrío de un clásico concepto sociológico: la interactividad. Se trata de aceptar que el goce mismo no es un estado espontáneo inmediato proveniente del "interior" de los sujetos, sino que un "imperativo del superyó" (Žižek, 2005: 100). Tal y como señala este autor: “¿No es la inter-pasividad la otra cara de la interactividad? ¿No es la contraparte necesaria de mi interacción con el objeto esta situación en la que el propio objeto toma mi reacción pasiva de satisfacción? [...] [Acaso] ¿no somos testigos de una gran cantidad de inter-pasividad en los anuncios publicitarios en los que el producto, pasivamente, goza en vez de nosotros?”. Žižek, con sus particulares ejemplos de la cultura popular, señala: “Por ejemplo, las latas de Cola Cola con inscripciones de tipo ¡Ooh! ¡Ohh! ¡Qué sabor!, ya simulan por adelantado la reacción ideal del consumidor" (Ibíd.: 98).

5 El mejor ejemplo de un discurso inter-pasivo lo encontramos en los "perfiles" de las categorías dadas por el concurso al "Emprendedor. Muhamad Yunnus" realizado en el año 2006 por el BancoEstado y ampliamente promovido en medios de comunicación de masas (BancoEstado de Chile sacó una fuerte campaña para este concurso, incluso meses antes de que Yunnus fuera premiado con el Nobel de la Paz ese mismo año del 2006). Las siguientes definiciones son textuales de folletos y propaganda escrita que el BancoEstado ha dispuesto como las categorías del concurso. Vemos en ellas el "goce" por adelantado propio de este término, donde el enunciado es claramente de tipo performativo: a) Mujer Emprendedora: "Mujer microempresaria que con su trabajo diario logra llevar el sustento a la familia y puede orgullosamente mostrar los logros que con su actividad han obtenido sus hijos o más cercanos, venciendo los obstáculos que la sociedad le impone"; b) Innovación y Tec- 


\section{MICROEMPRESA Y MICROCRÉDITO: HACIA UNA NUEVA SUBJETIVIDAD DE LA POBREZA}

\section{LA POBREZA COMO “OBJETO” Y LA INTERPELACIÓN AL “SUJETO-POBRE” PARA DESENVOLVERSE EN EL MERCADO}

Sea cual fuese el enfoque de pobreza del cual hablemos, los pobres son vistos como un "otro" y socialmente son regulados de manera especial con instituciones específicas. Precisamente esta característica común marca toda concepción que los distintos sectores ideológico-políticos de la sociedad tienen del pobre ${ }^{6}$.

La idea del pobre como el "otro" en directo antagonismo con el cuerpo social "sano" ya la podemos encontrar en uno de los fundadores de la sociología moderna, el alemán Georg Simmel. Es este quien señala que la pobreza es un grupo de individuos que tienen como característica especial constituir "una constelación única: un número de individuos que, por destino puramente individual, ocupan un puesto orgánico específico dentro del todo; pero este puesto no está determinado por el destino y manera de ser propia, sino por el hecho de que otros (individuos, asociaciones, comunidades) intenten corregir esta manera de ser" (Simmel, citado por Murillo et al., 2006b). Es decir, la propia sociedad se establece a partir de exteriorizar y volver población-objeto al pobre, pero este apartamiento "no significa una exclusión absoluta, sino que envuelve una relación perfectamente determinada con el todo" (Ibíd.).

En la actualidad, la sociedad capitalista-democrática levanta una saga de políticas sociales donde el pobre está siendo un sujeto/objeto de medidas, pero, además, está adquiriendo performativamente una figura discursiva "participativa", apareciendo en escena significantes ligados a la proactividad de los pobres, tales como empoderamiento, asociatividad, capital social, accountability, ente los más importantes.

nología: "Microempresario/a destacado/a por tener la capacidad de incorporar a su sistema de trabajo alguna herramienta tecnológica y/o procedimiento novedoso, que lo ha llevado a diferenciarse en su rubro. Se entiende como una persona que tiene alta disposición a los cambios y a la innovación. Es reconocido/a por su inventiva y competencia para desarrollar su negocio y su capacidad para asumir el cambio"; c) Mundo Rural: "microempresario/a rural, destacado/a por su labor, constancia y esfuerzo en el difícil mundo de la agricultura o de la pesca que ha enfrentado con éxito los cambios y modernizaciones que el sector le ha exigido"; y d) Mundo Joven: "Emprendedores/as entre 19 y 35 años que han logrado levantar una microempresa con éxito, a pesar de los pocos años de experiencia”.

6 Nos basamos en la tipología de las tres visiones que alimentan los modelos de regulación y gobernabilidad de la pobreza en América Latina: a) visión "modernistatecnocrática", b) visión "asistencial-represiva”, c) visión "caritativa” (Lo Vuolo et al., 1999: 102-118). 
Una de las tesis principales de esta investigación es que el "emprendimiento" puede comenzar a entenderse como parte de este conjunto de significantes de corte proactivo. De esta forma, lo que aquí llamaremos ideología del emprendimiento nos habla de una acción capacitada para desenvolverse adecuadamente en el mercado, proceso incorporado en las actuales orientaciones de la política social.

Para poder desarrollar esta idea, en este primer nivel de análisis vincularemos el término de emprendimiento con los conceptos de "capacidades" y "funcionamientos" desarrollados por el economista y premio Nobel de origen indio Amartya Sen. Como es bien sabido, la influencia de Sen en la medición del bienestar humano -en particular por su trabajo en el PNUD- ha sido muy importante, y es en torno a él donde uno puede encontrar conceptos transversales en el desarrollo teórico y operativo de la política social moderna. A partir de ambas nociones vamos a sostener que el pobre ya no será definido por su "carencia" (de ingresos, de acceso a mercancías y servicios), sino por la incapacidad para desenvolverse en el mercado y de proveerse de determinados bienes y servicios que le permitan salir de este estado. Con Sen, los pobres -en realidad, todos los seres humanos- tienen diferentes grados de capacidad, siendo la labor de la economía y de la política el diseñar un marco contextual para que desarrollen por sí mismos estas capacidades que les permitan alcanzar estándares decentes de calidad de vida.

Para Sen el término "capacidad" es el factor para obtener "funcionamientos" de calidad. Las capacidades de las personas para lograr la realización y articulación de funcionamientos valiosos determinan un conjunto de estados que estas alcanzan al ser y al actuar. Los funcionamientos se definen como "estados de ser" y aquellos que hacen que las personas no sean pobres varían desde aspectos tales como alimentarse adecuadamente, gozar de buena salud, prevenir riesgos evitables de morbilidad y mortalidad prematura, hasta funcionamientos más complejos tales como ser feliz, respetarse a sí mismo, participar políticamente, etcétera (Sen, 2000). En otras palabras, "cuando se aplica el enfoque sobre la capacidad a la ventaja de una persona, lo que interesa es evaluarla en términos de su habilidad real para lograr funcionamientos valiosos como parte de la vida" (Ibíd.: 55). Este planteamiento de los funcionamientos como resultado de las capacidades/actividades redefine profundamente la concepción de pobreza, pues esta ya no será vista como una carencia de bienes $\mathrm{y}$ servicios frente a necesidades fundamentales por satisfacer, sino en términos de un bajo desarrollo de las capacidades que están en potencia y que permitirían alcanzar funcionamientos de calidad. Se alcanzan funcionamientos relativos a la pobreza -es decir, se alcan- 
zan funcionamientos de baja calidad- en función de la inadecuación de los medios económicos con respecto a poder convertirlos en capacidades para su propio desarrollo.

Un punto importante en este asunto es el hecho de que Sen se encuentra dentro de la frontera de los pensadores no neoliberales, pues la disponibilidad de un bien general se relaciona con la posibilidad que tienen ciertos grupos sociales para procurárselos, conjuntamente con aspectos como la creación de empleos, el sistema de precios y la constitución de reservas públicas, etcétera (Salama y Destremau, 2002: 59-65). En otros términos, las capacidades son tanto individuales como competencia del Estado y, por extensión, de las políticas sociales que buscan el bienestar.

Aplicando estas ideas a nuestro tema, podemos decir que una política social moderna como la política microfinanciera no solo provee mercancías y servicios, sino que también utiliza lo que los sujetospobres son y hacen -sus funcionamientos y capacidades- para aprovecharlos en la solución de sus propios problemas. En otras palabras, podemos tender un puente de analogía entre el emprendimiento, la capacidad y el funcionamiento en la medida en que los pobres que acceden a microcrédito no son cualquier tipo de pobre, sino aquellos que son suficientemente capaces para desenvolverse en el mercado y poder pedir, pagar y volver a pedir un nuevo crédito.

\section{LA ESTRATEgia de Las Microfinanzas Como PARTE DE LA "NUEVA POLÍTICA SOCIAL"}

Nos interesa ahora conectar las ideas de Sen con las del Consultive Group to Assist the Poorest (CGAP), una iniciativa creada y promovida por el Banco Mundial y que tiene actualmente una fuerte relación con el BID ${ }^{7}$. En sus inicios (junio de 1995) contó con la participación de diez miembros donantes: Canadá, Francia, Países Bajos, Estados Unidos, el Banco de Desarrollo Africano, el Fondo Internacional de Desarrollo Agrícola, el PNUD, el Fondo de Desarrollo de Capital de las Naciones Unidas y el Banco Mundial. El objetivo del CGAP es dirigirse a los más pobres para que estos se beneficien de una mejora en el acceso a los servicios financieros, capacitando a las personas para que progresen económicamente con la expectativa de que algunos de ellos puedan llegar a utilizar servicios bancarios formales (Carpintero, 1998: 114-116). En uno de sus informes, se sostiene que la forma en que es vista la función de las microfinanzas resulta ser clave en el

7 Tanto el CGAP como el propio BID han sido dos de los más importantes protagonistas de créditos a ONG para la consolidación del sistema de microfinanzas tal y como lo conocemos hoy en ALC. 
contexto de la superación de la pobreza y de los desafíos del milenio. Así, la microfinanciación promete reducir la pobreza sin subvenciones y utilizar el mercado para obtener un bien social, valiéndose de ser un servicio para las capacidades de los microempresarios (CGAP, 2001).

De esta manera, el microfinanciamiento no puede remitirse a la vieja concepción de la política social estatista, pues incorpora elementos públicos y privados, "sirviendo a los pobres y en general a las personas que están fuera del alcance del mercado financiero formal, pero con la necesidad de seguir siendo instituciones sustentables" (Ibíd.). Las microfinanzas aparecen en el medio de un proceso de desplazamiento especial que ha sufrido la política social durante las últimas décadas, destinado a socavar los viejos paradigmas del rol del Estado, donde este aparece como el único responsable de determinar las políticas a seguir y debiendo además ser su único ejecutor. El campo del microcrédito posee estas características, pues, en su inmensa mayoría, son instituciones privadas las que han encontrado en el sector informal un nicho para desarrollar su tarea (ONG, Cooperativas y, por supuesto, Bancos). Esto hace que, para el propio CGAP, las instituciones financieras que conceden microcrédito tengan por obligación la sostenibilidad económica como criterio fundamental.

Paralelo a este cambio en los agentes que actúan en las políticas sociales, también es importante volver a señalar que el propio concepto de pobreza ha sufrido una profunda modificación. No se puede entender la creciente importancia que mundialmente se le está concediendo al microcrédito sin entender que la pobreza misma -y en particular, el sujeto pobre- ha sido radicalmente modificado. Desde el discurso de la política social, el "pobre" tal y como se le concibe en la política "asistencialista" no es el mismo pobre "proactivo" que monta un microempresa y recibe un préstamo de dinero para prosperar en el mercado. En otros términos, mientras el primero espera una satisfacción externa de sus carencias de bienes y/o servicios, el segundo actuaría bajo las leyes propias de la sociedad de mercado.

Como es bien sabido, la nueva política social, dentro de la cual podemos insertar al microcrédito, tiene su origen en ALC a partir del fracaso que significaron las medidas de "ajuste estructural" instaladas en la década de los ochenta a instancia del Fondo Monetario Internacional y el Banco Mundial. Esta nueva política social, conocida también como "reforma de segunda generación" o "ajustes del ajuste", se fue consolidando a mediados de los noventa hasta la actualidad a medida que el problema de la pobreza se profundizó, en especial en temas como el empleo y la distribución del ingreso. Lo importante es que la reconceptualización de la pobreza pasa por una crisis del paradigma neoliberal del "chorreo" ("derrame"), supuesto efecto directo 
del crecimiento económico y liberación del mercado (Salama y Valier, 1996; Lo Vuolo et al., op. cit.). Esta idea deja de ser una propuesta creíble incluso por los más acérrimos neoliberales, pasándose a una propuesta donde la liberalización de la economía ya no es la panacea, sino que un régimen que debe estar acompañado por medidas destinadas a erradicar la "verdadera" causa de la pobreza: la desigualdad (Murillo et al., 2006b). En otras palabras, el nuevo diagnóstico es el problema de la desigualdad y, en particular, la desigualdad de acceso a las instituciones y servicios como causa de la pobreza (Banco Mundial, 2002; Murillo et al., op. cit.).

Asimismo, la nueva política social se vuelve una especie de sistema de ideas que flotan en un campo de discurso común. Este sistema de ideas se basa en una gama de términos directamente relacionados a la necesidad de incluir y hacer partícipes a los pobres-excluidos de las "bondades" del desarrollo capitalista. La política de segunda generación pasa a ser una propuesta de reformulación de las estructuras inmediatas del Estado respecto de la sociedad civil, bajo nuevas formulaciones de integración y asistencialismo que se basan en la propia capacidad de la personas y, en este caso, de los pobres. Resulta entonces que el acceso al sistema financiero también comienza a ser visto como uno de esos servicios que deben abrirse a los sectores populares.

\section{GÉNESIS Y ACTUALIDAD DEL TÉRMINO MICROEMPRESA}

Pero vayamos hacia atrás en el tiempo para así encontrar la génesis de todo este proceso de apertura del sistema financiero a los pobres con capacidad para desenvolverse en los mercados.

Podemos decir que, al menos desde la década del sesenta, se viene señalando al capitalismo latinoamericano como el culpable de un proceso de quiebre social, donde se observarían dos sectores claramente diferenciados: el sector moderno e industrial de la sociedad y el pre-moderno, pre-industrial y, por tanto, pre-capitalista. Esta "dualidad estructural" incentivó al desarrollismo latinoamericano a apurar la modernización de los sectores más atrasados, suponiéndose que la producción masiva e industrial era la base para el desarrollo social, donde el Estado al estilo keynesiano debía asegurar la relación positiva entre crecimiento económico y crecimiento del empleo. Fueron precisamente las dificultades del desarrollismo para absorber la fuerza de trabajo excedente el detonante para la aparición en la época de una serie de teorías desde las ciencias sociales.

Una de estas teorías críticas aparece en 1969. Ese año, el politólogo argentino José Nun observó la persistencia de la precarización, 
terciarización e informalización de nuestras sociedades en un marco de desempleo formal y autoempleo creciente. La tendencia de las sociedades latinoamericanas hizo que Nun tomara al desempleo estructural como cuadro para señalar no solo la existencia de actividades de subsistencia, sino también la serie de relaciones entre estas poblaciones y el sistema social y económico que las origina (Nun, 2003). En suma, cuanto mayor era el afán industrializador de un país, menor era su capacidad para incorporar la mano de obra excedente, siendo esta fuerza de trabajo sobrante aquello que Nun llamó "masa marginal". El concepto de masa marginal describe a los agentes marginales a partir de las relaciones sociales que los reproducen, por lo que es un fenómeno social inserto dentro de la lógica de reproducción del antagonismo y desigualdad.

Pese a su aporte, la teoría de Nun comenzó progresivamente a perder vigencia, al tiempo que la "marginalidad" comenzó a homologarse con otro término preparado ahora por otra institución (PREALC-OIT ${ }^{8}$ ): la "informalidad". Sin duda, este último organismo ha sido uno de los más importantes, cumpliendo un destacado papel en la instalación del concepto de "economía informal". El PREALC postula por primera vez un modelo dualista basado en la separación entre empleo y autoempleo (Carpintero, 1998; Portes, 2000), cosa que Nun no apartaba tan tajantemente, sino más bien tendía a matizar mediante la idea del desplazamiento continuo de lo marginal dentro y fuera del sector hegemónico de la economía.

Además, es a partir de la noción de la informalidad que se opera un cambio radical con respecto a la teoría de la marginalidad en tanto comienza a hablarse de una analogía con una "economía de la empresa”, denominándose a las unidades del sector informal bajo el término de "empresas informales" o lisa y llanamente "microempresas". Todo ello se inscribe en un examen predominantemente economicista que prohíbe la reflexión de otras perspectivas de las ciencias sociales fuertemente estigmatizadas, como era el caso de las marxistas. Al hablar de sus características, los investigadores que trabajaron en uno u otro momento en PREALC -entre los cuales se cuentan a los destacadísimos Raúl Prebisch, Aníbal Pinto y Víctor Tokman- definen a la empresa informal sobre la particularidad de una racionalidad de producción diferente de la usual en la economía capitalista, la cual se caracterizaría por el afán de lucro y el solipsismo acumulativo (Carpintero, op. cit.: 34-37). Sin embargo, el enfoque de la "economía informal" del PREALC tiene en común con el concepto de la masa marginal de

8 Programa Regional de Empleo para América Latina y el Caribe de la Organización Internacional del Trabajo. 
Nun precisamente en el énfasis estructural de la economía hegemónica respecto de las masas marginales?.

La respuesta crítica más importante a este enfoque fue la elaborada por el economista peruano Hernando De Soto, especialmente a partir de su libro El otro sendero, publicado en 1986. Ahí cuestiona la propuesta del PREALC justamente por su énfasis estatista-keynesiano y señala explícitamente que el sector informal se origina (y queda estancado ahí) por la excesiva regulación de la economía por parte del Estado, el cual pasa a ser un garante de la injusticia y desigualdad que no hace sino asegurar a unos pocos la participación legal en la economía. Para De Soto, la informalidad es la respuesta popular a las trabas legales estatalmente impuestas, por lo que las actividades informales son el verdadero espíritu capitalista latinoamericano. En resumidas cuentas, "donde el PREALC ve actividades de supervivencia que emplea excedente de mano de obra, De Soto ve producción eficiente y comercio organizado por parte de pequeños empresarios" (Carpintero, op. cit.: 38). De esta forma, es De Soto uno de los pioneros de un enfoque propiamente "microempresarial" que, en vez de pura negatividad (marginalidad, pobreza y exclusión), ve en él una potencialidad de genuinas fuerzas de mercado que resultan fundamentales para el desarrollo de nuestras economías y de las poblaciones pobres (Portes, op. cit.: 26).

El enfoque de De Soto se entronca con el punto de vista más reciente promovido hoy por el Banco Mundial, caracterizado por la creación de un marco institucional que promueva -y no obstruya- a la fuerza y motor de las sociedades de mercado latinoamericanas: las empresas, entre las cuales se cuentan las de tamaño "micro". Una vez que este enfoque se convierte en hegemónico, la microempresa será la figura que la política oficial define, esto es, el ideal o "deber ser" que toda actividad económica marginal debería seguir. Por esto mismo, vamos a entender a la microempresa como una figura enunciada desde políticas, programas e instituciones que se caracterizaría por tener unas capacidades mínimas de acumulación, de gestión, de ahorro, de capitalización, así como para tener un comportamiento financiero intachable.

9 Por oto lado, partiendo de un punto que José Nun también toca (a saber, que el origen del sector informal está en la mano de obra excedente), el PREALC propuso tanto una política macroeconómica que pusiera el énfasis en la expansión del empleo y la renta del sector moderno. Se sostuvo que había que desarrollar medidas directas que incidieran en la creación de puestos de trabajo, la productividad y los ingresos, lo que es una responsabilidad que le cabe al Estado, de manera tal que esta perspectiva fue incluso calificada como correspondiente a una posición keynesiana propia del mundo de posguerra. 
A la aparición del término microempresa le siguió un período de elaboración de las primeras tipologías (principalmente la década de los noventa), buscando apoyar por medio de indicadores cuantitativos las políticas y programas de apoyo para el sector que fueron apareciendo. Entre las más conocidas están las que ponen el acento en la capacidad de acumulación, aunque no llegan a referirse a variables más cualitativas como, por ejemplo, el grado de racionalidad empresarial. En Chile, un buen ejemplo de esto es la tipología de Van Hemelryck, con tres niveles de acumulación que varían según la capacidad de ahorro e inserción en la economía ${ }^{10}$.

La inmensa mayoría de las definiciones de microempresa estarán dadas sobre la base de tres variables: a) el promedio de ventas en un período de tiempo (por lo general ventas anuales); b) el monto de su capital (activos); c) el número de trabajadores ${ }^{11}$. Además, tales indicadores permiten representaciones de la microempresa más operativas que caracterizaciones de tipo cualitativo, principalmente debido a que parten de lo evidente, de lo directamente observable, es decir, resultan ser de fácil medición como parámetros de evaluación y seguimiento de programas y políticas (Márquez y Van Hemelryck, 1996). El resultado de esto ha sido que no existe restricción de rubro ni de rama de actividad, tampoco de género ni de sector de la economía, pudiendo ser "microempresarios" tanto profesionales por cuenta propia, como feriantes, comerciantes ambulantes, costureras, mueblistas, artesanos, agricultores, campesinos, reparadores de calzado, taxistas, etc. (Ibíd.). A su vez, los microempresarios pueden ser formales, semi-formales o informales, es decir, pueden tener patente municipal, haber

10 La tipología de Van Hemelryck a la cual aludimos comprende los siguientes estratos: A) Microempresa con capacidad de acumulación ampliada: son las que generan una cierta capacidad de ahorro, por lo que son cercanas a las unidades económicas denominadas pequeñas y medianas empresas (pyme). Se señalaba que su principal obstáculo era su dificultad para acceder al sistema financiero, lo que no le dejaba posibilidad para innovar en tecnología o bien realizar inversiones a mediano-largo plazo. B) Microempresa con capacidad de reproducción simple: sin mucha capacidad de ahorro, pero que de todas formas logran mantenerse en el tiempo. Tampoco logran innovar en tecnología y/o herramientas, lo que tiende a estancar su capacidad. C) Microempresas de subsistencia: aquellas que tienden a una descapitalización continua, es decir, se van consumiendo a sí mismas dada su incapacidad de ahorro y baja generación de ingresos (Van Hemelryck, 1993).

11 En América Latina las definiciones en torno al empleo se presentan en ocho países, las centradas en la relación ventas/ingresos en seis y la de los activos en cuatro (Zevallos, 2003). En Chile, la definición del Fondo de Solidaridad e Inversión Social (Fosis) entiende por microempresario al dueño de una pequeña unidad productiva que tiene un monto promedio de ventas anuales de 0 hasta $2.400 \mathrm{U}$. F. (aproximadamente US\$ 82.062) y un rango de trabajadores de 1 a 9 (incluidos los casos de trabajadores por cuenta propia). 
iniciado actividades en el Servicio de Impuestos Internos (SII) o no haber hecho ningún trámite legal respecto de su actividad.

En suma, la microempresa es una terminología existente al nivel de política, donde ya existen leyes y programas destinados a su crecimiento. Lo que nos falta por dilucidar es el espíritu de estas, lo que ideológicamente se enuncia como una capacidad intrínseca para "emprender". Para ello, a continuación trataremos de exponer las líneas principales del discurso del emprendimiento que fuimos descubriendo a lo largo de la investigación, tanto en instituciones oferentes como en los casos de microempresas estudiados.

\section{EL DISCURSO IDEOLÓGICO EN LAS INSTITUCIONES OFERENTES}

\section{EMPRENDIMIENTO COMO CAPACIDAD DE “CLIENTES", NO DE "BENEFICIARIOS"}

Para las instituciones oferentes estudiadas las microempresas son "clientes" que asumen una deuda con las mismas condiciones que se enfrentan si estuvieran trabajando con otra entidad financiera. Esto nos confirma que la separación entre cliente y beneficiario (poniendo énfasis en el primer término por sobre el segundo) es clave para entender al emprendimiento como "capacidad" de la microempresa para desenvolverse en el mercado propio de una política de "segunda generación". Gabriela Hidalgo, Jefa de la Oficina del Fondo Esperanza (FE) en la ciudad de Valparaíso señaló al respecto:

"La primera distinción que nosotros hacemos es que no son beneficiarios, sino clientes o socios, porque en realidad ellos no están optando por un beneficio, sino que por un servicio microfinanciero."

De estas palabras se desprenden dos cosas: hay una idea de que el pobre "opta" por un servicio, a la manera de "cliente". En segundo lugar, el ser "cliente" y ser "socio" -pese a tener definiciones distintas- se juntan como unidad en el afán de una connotación de separación respecto al término "beneficiario". Por "socio", el diccionario de la Real Academia Española de la Lengua entiende a aquella persona asociada con otra(s), ya sea aportando capital o algún tipo de pericia con el objeto de compartir ganancias o pérdidas. El significante "socio" es usado por el FE de forma explícita en la interpelación con sus clientes al tener un carácter integrador, pues denota una relación de mayor compromiso y acercamiento con la persona, precisamente lo que debe hacer cualquier institución oferente si quiere fortalecer sus ciclos de crédito.

Pero la separación ente beneficiarios y clientes no solo fue enunciada por funcionarios del FE, sino que también por Raúl Perry, di- 
rector ejecutivo de la Fundación Contigo (FC), organismo que opera en la región metropolitana. Respecto de la misma pregunta, Perry nos aclara:

“A nosotros 'nos carga' [expresión que en Chile significa una profunda molestia hacia algo] la palabra beneficiario porque establece una relación de asistencia desde la fundación hacia los clientes. Para nosotros son derechamente clientes. Ellos pagan por su crédito y pagan bastante dinero, no es una tasa subsidiada [...] así que nosotros abortamos hace varios años la palabra beneficiario de nuestro discurso y se instaló el tema cliente, con los elementos negativos que, para mucha gente que está abocada al concepto caritativo del desarrollo social, la palabra cliente les produce."

En primer lugar, llama la atención la última frase enunciada por Perry. Habría, según sus propios dichos, una concepción "caritativa" del desarrollo social que estaría definida por ver al prestatario del crédito como un beneficiario, a diferencia de una concepción propiamente crediticia. Sin embargo, recordemos que por definición técnica el microcrédito, efectivamente, no es un beneficio, ni un regalo, por tanto, el hecho de que las instituciones oferentes separen las categorías de "cliente/socio" respecto del "beneficiario" no debe llevarnos a mayor sorpresa. Lo que sí es interesante analizar es la inmediata relación que los oferentes entrevistados realizan respecto de otro significante: la responsabilidad. Para poder profundizar en esto analicemos el siguiente enunciado que Raúl Perry señaló en una de las dos entrevistas que tuvimos con él:

"Los clientes pagan y, cuando lo hacen, se sienten contentos de haber pagado por haber cumplido un compromiso. Pueden sentirse a veces molestos, pero estas molestias fueron porque hicieron algo que es importante para ellos, en el sentido de que cumplieron a cabalidad con algo y tienen el derecho a exigir que ese algo sea lo mejor."

Es decir, la responsabilidad en el pago permite que el cliente exija de la institución oferente un mejor servicio, eso no cabe dudas. A diario nosotros mismos, en nuestro desenvolvimiento como compradores de mercancías y/o servicios, tenemos la facultad para exigir que lo que se nos ofrece sea el equivalente al dinero que desembolsamos. El derecho a exigir las "cuentas claras" pasa a ser también una mercancía que podemos ejercer en la medida en que cumplamos con las responsabilidades de compra. En otras palabras, el derecho a exigir es una garantía simbólica que solo obtenemos si nos ponemos en el papel de compradores, esto es, de clientes, pero responsables. Es interesante ver 
cómo el pago de las cuotas del crédito permite al individuo tener la responsabilidad, el derecho, de exigir mejores ofertas. Gabriela Hidalgo, la funcionaria del FE en Valparaíso señaló:

"[...] Lo importante es que ellos pagan por este servicio una comisión
que no tiene fines de lucro, cantidad bastante acotada a las caracterís-
ticas de nuestros microempresarios y de sus negocios, pero que tiene
justamente la finalidad de que ellos las asuman como un servicio,
como una oportunidad en la cual ellos toman toda la responsabilidad,
responsabilidad muy similar a la que obtendría una persona en un sis-
tema formal de préstamo, solamente que el diseño de los montos y las
condiciones del crédito se adaptan a las condiciones generales de ellos,
pero no dejan de tener las condiciones generales que ellos tendrían
que enfrentar si estuviesen trabajando con otra entidad de finanzas o
microfinanzas."

Acá aparecen varios elementos determinantes en el discurso del emprendimiento que se configura desde las instituciones oferentes estudiadas. Entiéndase bien lo que decimos: en los discursos de las instituciones oferentes, diversos significantes se desplazan y se conectan en una sola categoría que los "acolcha": el ser cliente. El carácter fetichista del término "cliente" consiste en el hecho de que al enunciarlo no solo se designa la definición convencional del diccionario (acceso a determinados bienes o servicios por medio del desembolso de un equivalente en dinero), sino que conlleva a un "plus-metafórico", muy propio de los significantes ideológicos (Žižek, 2003b). En efecto, este plus-metafórico hace que el significante "cliente" vaya más allá de su propio significado convencional (el del diccionario) para hacer referencia también a la responsabilidad, la dignidad y la capacidad. En efecto, inmediatamente después de enunciar el relato que acabamos de ver, Gabriela Hidalgo del FE sede Valparaíso nos señaló:

"Y eso es, a juicio nuestro, mirar a la persona en la totalidad de su dignidad, como un ser humano completo, igual a nosotros, que está en una situación o condición económica diferenciada, pero no por eso menos capaz, no por eso hay que subestimar su potencial de hacerse cargo de un compromiso y una responsabilidad como cualquier otra persona."

Observemos que, dentro de la interesante frase de la funcionaria del FE que estamos analizando, en un momento ella señala que tratar a los prestatarios como clientes y no como beneficiarios implica "mirar a la persona en la totalidad de su dignidad, como un ser humano completo, igual a nosotros". Más allá de que la condición de "ser cliente" 
concede un rango de dignidad, el "pobre-digno", responsable y con capacidad para desenvolverse en el mercado (y, lo que es más importante, una persona "igual que todos nosotros") pasa a ser el sujeto tácito que yace como referencia durante toda la enunciación. Aquí la interpelación se dirige directamente a la capacidad adquirida al ser cliente de un crédito, el cual, dejando de lado su carácter de "otro-pobre" que hay que asistir (beneficiario) para pasar a ser incluido dentro de un "nosotros", los que nos desenvolvemos como ciudadanos-clientes en el mercado y tenemos las capacidades para hacerlo.

Ahora bien, debemos entender que este discurso del emprendimiento (al ser desarrollado en lugares externos a los clientes) es eminentemente "inter-pasivo", lo que en esta investigación se entenderá como aludiendo a un "deber ser", un "goce", definido institucionalmente que trata de interpelar en una relación estratégica, una relación particular de crédito. La "inter-pasividad" la entenderemos entonces como la interpelación que hace la institución oferente respecto del "otro", el sujeto-pobre. Al ser una interpelación, pasamos directamente a la práctica del sujeto, esto es, en el rito y la práctica "emprendedora" misma, la cual consiste en el hecho de ser capaz de actuar como cliente, vale decir, pagar las cuotas del crédito. Podemos decir incluso que el discurso del emprendimiento se convierte en interactivo en sentido sociológico tradicional, es decir, diseñando la estrategia de mi acción en relación a las posiciones y al grado de poder que demuestran los demás. No obstante, detrás de esta acción libre e ideológicamente "espontánea" la otra cara de la moneda la encontramos en el llamamiento hecho por la institución oferente. De ahí que, más allá del concepto de interacción que implica la noción de capacidad casi solipsista de la microempresa de desenvolverse en el mercado, sostenemos que la interpelación hecha por la institución oferente es eminentemente inter-pasiva. Nótese que la inter-pasividad no solo radica en una interpelación del "emisor" (la institución oferente), sino que más precisamente consiste en la forma cómo el discurso del emprendimiento llega hasta el cliente enunciando performativamente las características intrínsecas del receptor.

\section{LA CAPACIDAD Y EL EMPRENDIMIENTO VISTA DESDE EL "RETORNO"}

El "retorno" es cuando el cliente devuelve el dinero y, junto a ello, un interés en un plazo convenido de tiempo. Esto tiene relación con que el emprendimiento debe estar considerado como un a priori por la institución oferente si quiere la sustentabilidad financiera de la institución.

Del análisis del discurso de las instituciones oferentes se puede sostener que si ser "cliente" equivale a dar por supuesta una capacidad 
mínima para desenvolverse en el mercado, eso implica que necesariamente existiría una mínima cuota de emprendimiento para ingresar al sistema microfinanciero. De aquí que podemos decir que el crédito no genera el emprendimiento, sino más bien supone que el emprendimiento está ahí, siendo esto una cuestión que iremos desarrollando a medida que avancemos en nuestra exposición.

Por ahora digamos que suponer al emprendimiento como algo dado a priori tiene relación con un proceso de lenta maduración que tuvieron que vivir las instituciones oferentes, y en especial las que provienen del mundo de las ONG. Al respecto, Raúl Perry de FC señala de manera clara:

"Si hablamos de crédito entonces tenemos que poner condiciones para que ese crédito se devuelva. Suena obvio, pero no es para nada obvio. Nos costó mucho entender como organización que debíamos definir cosas distintas, diferenciar entre crédito y donación, y esa definición cuajó básicamente por la variable de la necesidad trascendental de retorno."

El término al que recurre Perry es clave: el "retorno" es una "necesidad trascendental" desde el punto de vista de la institución oferente, es su verdadero quid. Recordemos que estas instituciones saben que sus clientes son, por lo general, "informales", es decir, que no presentan las garantías que pueden presentar, por ejemplo, las empresas tradicionales a los bancos. De esta forma, las instituciones oferentes son obligadas a reflexionar sobre las razones de por qué un crédito a este tipo de actividades se devuelve, esto es, acerca de cómo ocurre la condición trascendental del "retorno". Esto se observa en la siguiente frase enunciada por Raúl Perry de FC:

"[Un crédito se devuelve] básicamente por dos razones. Primero porque existe capacidad de pago y segundo porque hay voluntad de pago. Los indicadores de la capacidad de pago son por ejemplo las ventas de hoy o las ventas a futuro y la voluntad de pago tiene como indicadores a la moral, la transparencia, la veracidad en torno a lo que la persona me dice al evaluar su proyecto, la constancia en venir a las reuniones [...] El tema de la voluntad de pago no era conflictivo para nosotros, pero con lo que comenzamos a chocar fue con el concepto de la capacidad de pago [...] Dábamos crédito a gente moral y éticamente calificada como muy buena, pero que no pagaba o que tenía enormes dificultades para hacerlo."

La "venta actual" se mide de manera relativamente fácil, pero en el caso de las "ventas a futuro" (indicadores evidentemente necesarios para proyectar al cliente en los ciclos de crédito) es imposible 
construir modelos predictivos. Es precisamente en este punto donde aparece el tema del "emprendimiento", ya que este se asociará con la "capacidad de pago". Aparecía entonces la idea de que bastaba con predecir los casos de emprendimiento para conceder créditos a actividades informales, pero esta ecuación no resultó fácil de resolver. Tal y como lo reveló Perry:

"Creíamos que en este punto ya teníamos resuelto el problema. Había que diagnosticar el emprendimiento, pero apareció otro problema: es extremadamente difícil diagnosticar emprendimiento [...] Dentro del tema de la capacidad de pago, el emprendimiento era vital porque necesitábamos condiciones que aseguraran el resultado, pero el problema era que no teníamos cómo medir el emprendimiento."

En resumen, las instituciones oferentes dejaron de abordar el modelo generador por uno potenciador del emprendimiento, es decir, dejaron de pensar que eran ellos los que generaban el emprendimiento de las personas, para pasar a una convicción de que solo son entes que potencian las "capacidades" ya existentes de sus "clientes". Así es como debieron empezar trabajar con "lo dado", suponiendo que el emprendimiento "está ahí". En otos términos, como no se podía prever si la microempresa era emprendedora o no, entonces tuvieron que asumir que, si la microempresa existía, era porque un mínimo de emprendimiento o capacidad debía haber. Otra vez citamos a Raúl Perry:

"El emprendimiento que tiene una microempresa en funcionamiento y la capacidad de pago van de la mano porque tú eres capaz de diagnosticar que existe emprendimiento porque existe microempresa. Ese zapato chino no ha podido ser desabrochado aún por nadie de los que trabajamos en microfinanzas."

Este "zapato chino" no es sino una enmarañada tautología discursiva. Opera aquí lo más profundo de la prescripción de la nueva política social, a saber, que la pobreza de redefine en torno al concepto de "capacidad" que vimos con Amartya Sen. Toda microempresa tiene una capacidad emprendedora básica, dada como supuesto; por lo tanto, la institución oferente debe dar solo condiciones para que ese emprendimiento se "potencie"12. El hecho de que microempresa y emprendimiento sean análogos es porque yace implícita la convicción de que este sujeto-pobre es, en realidad, un nuevo pobre, un pobre con capacidad, por tanto, un pobre confiable para prestarle dinero,

12 Recordemos precisamente que en Sen las capacidades están también "en potencia" (Sen, op. cit.). 
un pobre "digno" y "responsable". Nótese que ello indica que no fue necesario en realidad descubrir ni mucho menos medir la capacidad, ni el emprendimiento del "nuevo pobre". Este último surge simplemente a partir de las propias inconsistencias del discurso-técnico, lo que termina provocando que se asuma la existencia de capacidad y emprendimiento simplemente por la incapacidad de poder generar indicadores para ello. Los obstáculos que pueden surgir a las metodologías de crédito para medir y clasificar las actividades marginales lleva a asumir como verdad la tautología de que "la microempresa tiene capacidad porque tiene emprendimiento en tanto es microempresa".

Con este tipo de argumentos se evaden problemas técnicos, pero de pasada se estructuran corpus discursivos tejidos a partir de conexiones de argumentos que conducen a callejones sin salida, recursos tautológicos, demostraciones circulares, accidentes externos que se sistematizan como el discurso que percibimos como "verdad" (Foucault, 2002: 105-116). La ideología es una percepción que reifica estos resultados de los procedimientos discursivos en propiedades de la "cosa en sí", discursos construidos sobre la base de vacíos no explicados que reifican un argumento presentándolo como la explicación legítima, universal y natural que fundamenta todo un discurso. Es decir, en el nivel de las instituciones oferentes el "emprendimiento" es aquello que Lacan llamaba el "significante sin significado", el "Uno-lacaniano" que no significa nada pues no puede ser definido por nadie, sino solo a partir de ser el término "nodal" que acolcha una multiplicidad de significantes que constituyen el discurso propio de la interpelación ideológica (Žižek, 2003b: 125-147, passim).

\section{LA “CAPTURA"}

Tal y como lo hemos apuntado, la institución oferente -que es casi siempre un organismo privado- también tiene una necesidad: ser sustentables en el tiempo. En su intento por ser instituciones financieramente sustentables, las instituciones oferentes deben exigir además ciertas condiciones como la "moral de pago" y la "capacidad de pago". Como este tema no se resuelve en términos lógicos (lo que afecta directamente en las metodologías institucionales), el emprendimiento surge como una condición que debe existir con anterioridad, es decir, debe asumirse como algo "ya dado". De hecho, las instituciones oferentes exigen un mínimo de tiempo de la microempresa funcionando, siendo este el más claro indicador de lo que estamos explicando ${ }^{13}$. Tal

13 Las otras condiciones son los boletines comerciales (Dicom y/o Bic). Además, FC tiene la exigencia del aval, tal y como nos lo señaló su director ejecutivo: "Les pedimos un aval que no es calificado, ojala sea un pariente con un vínculo muy estrecho 
y como lo explicó uno de los funcionarios de una de las instituciones estudiadas:

"Nuestros clientes deben tener al menos 6 meses de antigüedad en el trabajo que desarrollan, no 6 meses formalizados, o sea, con su iniciación de actividades. No es necesario que sean formales. Nos interesa es que la persona conozca lo que va a hacer y a través de ese conocimiento disminuyamos la morosidad."

El solo hecho de que la microempresa tenga un determinado tiempo funcionando induce la idea de cierta capacidad mínima para desenvolverse en el mercado, por tanto, ya está implícita la capacidad, pues si no fuera así peligraría el "retorno" o devolución de dinero. El servicio de crédito por parte de prácticamente toda institución oferente va hacia aquellos que ya cuentan con un supuesto básico: un cierto grado de capacidad de haber sobrevivido al mercado, es decir, un grado de "capacidad" por el solo hecho de "existir". Nuevamente, de manera performativa, la capacidad aparece. Pero, lo interesante es que esta "capacidad supuesta" respecto del microempresario le da sentido a la propia "labor social" que tiene la institución respecto de sí misma en relación al impacto en sus clientes.

"[...] la devolución adecuada del crédito es lo que te permite generar impacto social y, a la vez, es lo que te permite generar impacto económico. Entonces uno tiene una responsabilidad con el crédito y con el cliente en torno a entregar aquellos créditos que puedan beneficiar a las personas al mismo tiempo que recuperar la plata."

La "captura" es entonces esta capacidad que tiene la institución oferente de presentarse como un agente "potenciador" del emprendimiento ya existente (dado como supuesto). De ello depende que la microempresa siga en su "ciclo de crédito", esto es, que vuelva a pedir un segundo, tercer, cuarto crédito y más. Esta capacidad institucional tiene que ver, en términos gruesos, en elevar la cobertura y en que los que ya estén en su "ciclo de crédito" sigan estándolo. A su vez, la eficiencia del proceso de "captura" de la institución oferente radica en el "retorno", lo que implica que las instituciones enuncian performativamente las características del emprendimiento (dignidad, capacidad, responsabilidad). La "captura" se logra cuando el cliente paga, es decir, satisface la necesidad de ser clientes (consumidores) de

entre el microempresario y el aval para que el cliente piense cuatro veces antes de solicitar un monto que ponga en riesgo al aval. Lo hijos y las hijas, por sobre todo, son los mejores avales por lejos". 
crédito y permiten a las instituciones oferentes ir logrando sostenibilidad económica.

Pero, además, las instituciones oferentes no serían un simple negocio: según ellas, cumplen una función social de forma económicamente sustentable. El propio CGAP señala que

"[...] mundialmente existen muchas instituciones de microfinanciamiento bien administradas que proveen servicios financieros en forma sostenible, sin el apoyo de donantes. En consecuencia, el microfinanciamiento presenta el potencial de un ciclo retroalimentado de sostenibilidad y crecimiento masivo, ejerciendo un profundo impacto en la vida de los pobres, incluso de los extremadamente pobres" (CGAP, op. cit.).

El discurso ideológico desde el punto de vista de las instituciones hace que estas se vean a sí mismas como agentes potenciadores de las capacidades naturales (a priori) de las microempresas y, al mismo tiempo, como entidades privadas que conformarían una nueva camada dentro de la política social contra la pobreza.

\section{EL DISCURSO IDEOLÓGICO DE LAS MICROEMPRESAS}

\section{LA INTERPELACIÓN IDEOLÓGICA DEL EMPRENDIMIENTO MICROEMPRESARIAL COMO "EFECTO RETROACTIVO"}

De los casos con los cuales conversamos, una de las categorías más "saturadas" fue la existencia de un discurso de emprendimiento ligada a su propia condición de trabajo independiente, donde el emprendimiento es percibido como una característica relativamente autónoma del crédito (por tanto, de las instituciones oferentes). En otras palabras, algunos de los relatos estudiados revelan que las personas no se ven influenciadas en cuanto al emprendimiento en el momento de entrar a los "ciclos de crédito", principalmente porque el emprendimiento es más bien visto como las simples "ganas de salir adelante", sumado a una cuota importante de "viveza" y "pillería". Al respecto, dos relatos de casos distintos nos confirman esto:

"Esa cuestión de partir y emprender y todo lo demás lo tengo de antes de Fondo Esperanza [...] hay gente que tiene la mejor intención del mundo, pero no tiene... le falta esa chispa para emprender negocios. [...] Todas las personas que partimos trabajando y que somos comerciantes queremos emprender y tener algo más allá. Pa' mí el emprendimiento es progresar, el emprendimiento es emprender (sic) y tener otro local. Si tengo un uno, tener dos o tener tres." 
Existiría lo que podríamos llamar un "espíritu emprendedor" por sí mismo, con independencia de la ayuda del oferente, en especial en los casos de varios años de experiencia en el rubro y de al menos dos años como clientes. Esto se condice con la idea vista más arriba acerca de que las instituciones oferentes dan por supuesto el emprendimiento y la capacidad de los microempresarios como una cuestión a priori (natural). La pregunta que surge es sobre quién "instala" el término emprendimiento, ¿la política social y las instituciones microfinancieras para atraer ("capturar") a sus clientes o fueron los microempresarios que ya contaban a priori con dicha cualidad?

Para explicar esto vamos a presentar la hipótesis del "efecto retroactivo" del significado del emprendimiento en los sujetos de la interpelación microcrediticia. Es decir, tenemos que remitirnos a la tesis de la "retroactividad del significado" desarrollada por Lacan y retomada por Žižek para el estudio de la ideología (Žižek, 2003b: 125-150). La interpretación retroactiva del efecto de significación con respecto al significante se basa en el principio de que mientras el significado es el mismo, los significantes abundan, se reproducen por montones, proliferan bajo formas siempre impredecibles, siempre nuevas. De esta manera, los espacios ideológicos se van diseñando a partir de elementos sin ligar, sin amarrar, significantes flotantes "cuya identidad está 'abierta', sobredeterminada por la articulación de los mismos en una cadena con otros elementos, es decir, su significación 'literal' depende de su plus de significación metafórico" (Ibíd.: 125). El ejercicio que debemos organizar es de encontrar el significante que actúa como "punto nodal" del deslizamiento infinito de significantes, es decir, "aquel término que los 'acolcha', detiene su deslizamiento y fija su significado" (Ibíd.).

Esto lo vemos en la multiplicidad de frases que pudimos rescatar de las entrevistas (indistintamente de los años como clientas). Lo más interesante de todo este ejercicio fue que mientras los significantes se reproducían bajo muchas formas distintas, subtendidamente había un significado que "se quedaba atrás" con respecto a la progresión de la cadena de significantes. Las frases saturadas de siete conversaciones grabadas manifiestan lo que aquí decimos:

"Hay gente que [...] le falta esa chispa para emprender negocios."

"Todas las personas que somos comerciantes queremos emprender y tener algo más allá."

"El emprendimiento es progresar."

"Poco a poco he ido subiendo."

"El emprendimiento es crecer con mi negocio."

"He debido trabajar durante toda mi vida, claro que estoy orgullosa."

"Yo tenía eso de emprender de siempre." 
"Siempre he surgido por mí misma."

"No sabría explicarle bien, pero como que siempre he sido buena pa' los negocios."

"Soy luchadora."

Estas pocas frases demuestran que los significantes pueden deslizarse perpetuamente, pero habría un significado especial, el significante-amo que "aterriza" esta volatilidad de los significantes. En tanto existan muchas frases enunciadas por los casos estudiados que nos remitan a la misma idea, el efecto ideológico de lo que aquí hemos llamado discurso del emprendimiento es mucho más potente y eficaz, pues este no hace sino "acolchar" estos significantes que flotan y se reproducen infinitamente. Precisamente, el emprendimiento sería el significante-amo y tendría como principal función el ser un punto específico que atraviesa la cadena de significantes que hasta dicho momento de irrupción permanecían flotando, logrando sentar una significación específica. Lo importante es que esta significación no implica "nada nuevo" para el individuo, es decir, el significado siempre estuvo, aunque en un principio obscurecido por la nube de significantes contingentes enunciados por el individuo. No se trata entonces de que la institución oferente haya instalado externamente el discurso del emprendimiento y con ello haya otorgado a sus socias o clientas "una luz" que las convierta en personas nuevas. El significante del emprendimiento es el término de referencia principal para "lo mismo" que ya venían enunciando sobre sí, pero con otras palabras, otros significantes.

Como se puede apreciar, esto se encuentra directamente relacionado con lo dicho más arriba acerca de las instituciones oferentes y su convencimiento de que no "generan" sino que simplemente "potencian" el emprendimiento ya existente. Recordemos que una de las premisas centrales de la "teoría de la ideología" es que aquella ideología que no se articula con la experiencia viva de los sujetos simplemente estará destinada al fracaso. La efectividad del significante-amo del emprendimiento radica en que cuando este aparece "todo se esclarece" y las personas pueden sentir que, en realidad, "siempre fueron emprendedoras". No es que ahora lo sean pues antes no lo fueron, sino que siempre lo han sido y ahora "lo saben concientemente".

\section{EL “EMPRENDIMIENTO VALORATIVO"}

En este punto es donde podemos seguir mostrando una nueva tesis: el emprendimiento es claramente valorativo desde el punto de vista de los microempresarios estudiados, es decir, no sería solo una propiedad de la microempresa de tipo racional, sino también de aquellas 
de subsistencia. En especial en los casos de mujeres jefas de hogar, el emprendimiento está fuertemente vinculado a significantes tales como "familia", "hijos", el "estar sola", el de la "responsabilidad de salir adelante por los tuyos", etc. Un ejemplo de esto fue lo que nos señaló una jefa de hogar (comerciante ambulante):

"Imagínate, quedar sola con dos niños y te embargaron tu casa, saliste adelante, no pediste ayuda, entonces eso [el emprendimiento] ya lo tengo arraigado."

En primer lugar, nótese que el emprendimiento valorativo es una actitud "orgullosa" de "no pedir ayuda" a nadie y de "salir sola adelante". Ahora bien, esta categoría del "emprendimiento valorativo" no es racional en el sentido economista del homooeconomicus. Una persona que se decía a sí misma "emprendedora" nos relató que no se proyectaba vendiendo otras mercancías que no fuesen las mismas que ha vendido durante más de quince años, aun cuando ella misma confesó que el negocio no crece y solo le sirve para subsistir. Es decir, pese a que le iba mal, no quería cambiarse de rubro. Tal y como ella misma lo dice:

“-¿Ha pensado instalarse formalmente?

-No, no conviene por el pirateao, el pirateao [copia ilegal] mató al libro y la fotocopia lo remató [...]

$-\dot{-} Y$ siempre va a seguir con los libros?

-No, es que no me cambiaría de rubro porque me gustan los libros, en eso no transo.

-¿Y por qué?

-Es que te da otro nivel, vender libros no es como vender zapatillas o un pantalón. Para vender libros tú tienes que saber, tienes que leerte el libro. Yo no puedo recomendarte a ti, por ejemplo, un libro de la Isabel Allende sin haberla leído."

De esta forma, la supuesta racionalidad microempresarial basada en un modelo homoeconómicus o de rational action muchas veces no existe, pues los agentes toman decisiones sistemáticamente distintas de las que pueden preverse a partir del modelo de acción económica especulativa. Es decir, "las disposiciones económicas más fundamentales, necesidades, preferencias, propensiones, no son exógenas, esto es, dependientes de una naturaleza humana universal (la racionalidad o instrumentalidad de la acción), sino endógenas y dependientes de una historia, la historia del campo que envuelve al agente". Es así como "los agentes se orientan en función de intuiciones y previsiones del sentido práctico", una "experiencia adquirida en la práctica" 
(Bourdieu, 2005: 22). La lección que debemos aprender de esto es que si el emprendimiento se enuncia solo como pura y simple racionalidad instrumental economicista, entonces se aboga una definición distante del sentido de emprendimiento que tienen algunas personas. Así, el emprendimiento como capacidad instrumental sería un atributo de una pequeñísima elite, una vanguardia de microempresarios completamente racionales. Muy lejos de esto, la ideología del emprendimiento se construye por personas que no cumplen con este tipo de racionalidad. La pregunta que se nos presenta aquí es saber si este enfoque del "emprendimiento valorativo" es "capturado" por las instituciones oferentes en tanto, como ya hemos dicho mas arriba, la ideología que pretende ser efectiva se basa en lo vivido por las personas, esto es, las ideologías son eminentemente verdades prácticas (Althusser, op. cit.; Eagleton, op. cit.).

\section{EMPRENDIMIENTO VALORATIVO, LA EXCLUSIÓN Y VIGILANCIA DE LOS “IRRESPONSABLES"}

No obstante, el "emprendimiento valorativo" también se relaciona con la exclusión y la vigilancia. Esto se da especialmente en las metodologías de los bancos comunales. La separación entre los "buenos" y los "malos" se reactualiza en la separación entre los "responsables y los "irresponsables", pero lo interesante es que esta disociación es hecha por los propios clientes. El siguiente relato aclara lo que queremos decir:

“- ¿Han incluido a alguien en su banco comunal o han sido los mismos desde el primer ciclo?

-Incluimos como cinco personas cuando estábamos en el tercer ciclo, pero después a la cuarta fase las desechamos porque eran demasiado irresponsables, [...] queremos gente conocida y que paguen. Como somos co-avales de cada uno de los del banco entonces es difícil poner gente nueva."

Nuevamente resulta asombroso ver aquí los mismos argumentos que revisábamos cuando dábamos cuenta de que las instituciones oferentes necesitan el sacrosanto "retorno". Es como si los propios clientes también consideraran al retorno un tema altamente valorativo, pero ahora resignificado bajo sus propios intereses. El no pagar (retorno), sea por las razones que sea, tiene para estas personas una connotación de "irresponsabilidad", es decir, un valor. Puesta desde un punto de vista del consumo, la irresponsabilidad en el pago de la deuda impide pertenecer a la comunidad de consumidores/clientes.

Por otro lado, nótese que se asocian como si fuesen la misma cosa dos elementos que no necesariamente pueden estar articula- 
dos. Es decir, ser un "emprendedor" no implica necesariamente tener "moral de pago", pues se puede tener importantes formas de emprendimiento que no radican en "ganas" o "disposición" a pagar ${ }^{14}$. Ligar ambas nociones implica pensar que el retorno y el mantenimiento en el ciclo de crédito es en sí mismo una acción emprendedora. Esta ideológica articulación entre emprendimiento y moral de pago es reforzada en contextos dados por metodologías de vigilancia y exclusión tales como los bancos comunales (BC). En otras palabras, la efectividad de las metodologías como la de los BC está en que la vigilancia y la evaluación entre los miembros de la comunidad de consumidores de crédito es una práctica que deja de ser responsabilidad de la institución oferente, pasando al lado de los propios clientes los que se aseguran de que todos los miembros avancen en el ciclo de crédito ${ }^{15}$. La violencia de la ley representada por Dicom y el BIC no desaparece; sin embargo, en estos casos es reforzada por un verdadero esquema de panoptismo llevado a cabo por los ojos de los propios socios.

Esta "confianza mutua" fundada en la pertenencia a un grupo común de co-avales es el único recurso para el "retorno". En las transacciones informales, la confianza se genera tanto a partir de las identidades y sentimientos como por estos verdaderos "ritos", donde cualquier acción fraudulenta será penada con la exclusión del "infractor" de la red social. Este mecanismo responde a los que Portes denomina "confianza cumplimentable" de los círculos de prestamistas y de actividades informales. Es un grupo "donde la confianza mutua respecto de la observancia de los acuerdos está fundada en algo más que la simple convicción moral" y donde "el poder de sanción de la comunidad, su capacidad de conferir status a los individuos o excluirlos, es la fuerza clave que garantiza el cumplimiento individual" (Portes, op. cit.: 30).

14 Por ejemplo, en una conversación con uno de los ejecutivos de las dos instituciones estudiadas se nos comentó la anécdota de unos microempresarios con capacidades de emprendimiento por sobre el promedio pues eran extremadamente "diestros en los negocios", pero que, sin embargo, estafaron a la institución oferente con el pago de las cuotas.

15 Obviamente, las instituciones oferentes se informan de los antecedentes comerciales del solicitante. En Chile, hay dos organismos para ello: i) la Cámara de Comercio, la que emite información oficial de protestos y morosidades de los sistemas financieros y comercial por medio de su boletín de informaciones comerciales (BIC); ii) la empresa privada de servicios de información Dicom, la cual provee a quien lo requiera información oficial sobre morosidad, domicilios, protestos de cheques, deudas impagas, etc. (PET, 2002). Insistimos en el hecho de que tanto la Cámara de Comercio como la empresa Dicom son instituciones a las cuales recurren cualquiera de los oferentes (bancos, cooperativas, ONG). 


\section{Conclusiones}

Con todo lo visto en el presente artículo, podemos decir que el discurso del emprendimiento lo encontramos en dos vertientes principales: como un aspecto valorativo y, segundo, como capacidad (hacer) y funcionamiento (estados de ser). Estas interpretaciones del emprendimiento se pueden encontrar en un campo discursivo que en el presente artículo fue estudiado a partir de tres grandes niveles: a) un sistema de ideas que generan una política sobre microcrédito dada por la nueva política social post-ajuste estructural; b) unas instituciones oferentes que prestan sus servicios microcrediticios; c) la masa cada vez más amplia de clientes o microempresas que acceden al sistema.

Mientras la vertiente del emprendimiento como "capacidad/funcionamiento" está más cercana a las orientaciones técnico-teóricas de la política social moderna, la vertiente "valorativa" tiene la función de la interpelación directa con las personas en tanto es un significado contingente, es decir, que nace "retroactivamente" (Lacan) de la experiencia de los microempresarios. Sin embargo, ambas nociones de emprendimiento cumplen la misma función en tanto son formas de racionalización en distintos planos del discurso, es decir, forman parte de una estrategia donde instituciones y sujetos presentan a sí mismos una explicación de su quehacer que es tanto lógicamente congruente como éticamente aceptable. Esta racionalización legitima al discurso del emprendimiento, convirtiéndose así en orientaciones, valores y prescripciones para la acción de los agentes.

Es importante recalcar que el emprendimiento, como todo discurso ideológico, se basa en su carácter "natural", es decir, algo dado como a priori, lo que se traduce en que el emprendimiento es en sí mismo un término o significante que "no tiene significado" (el "Unolacaniano"). Esto se confirmó con el análisis de discurso, donde vimos que las instituciones oferentes se ocupan de clientes que "ya cuentan" con emprendimiento, por lo que les cuesta muchísimo definir el emprendimiento sin tener que recurrir a otros significantes (dignidad, responsabilidad, capacidad). Es decir, les es imposible definir el emprendimiento en cuanto tal, en sí mismo y mucho menos pueden emplearlo como indicador de sus modelos de gestión. Por ello, pese a todos sus esfuerzos, para las instituciones oferentes el término del emprendimiento es un "significante sin significado" que "acolcha" el desplazamiento de significantes. Paralelamente, los casos de microempresas estudiadas por lo general vieron al emprendimiento como un significante-amo (igualmente un "significante sin significado") que "acolchó" las ideas que tenían de sí mismas y de su propia experiencia (valerse por sí mismo, tener chispa para los negocios, querer salir para adelante, etcétera). 
Por tanto, el emprendimiento no es un "saber" porque, simplemente, no es conocimiento a interiorizar ni mucho menos una especie de "doctrina". Parafraseando a Althusser, diremos que tanto para las instituciones como para los casos estudiados, los microempresarios son "siempre-ya" emprendedores. Aquí reside la efectividad de la interpelación ideológica; en el "goce" mismo, irracional y sin significado del término emprendimiento. De esta forma, la efectividad del discurso del emprendimiento tiene menos relación con la capacidad economicista a potenciar externamente que con el aspecto interno, vivido, práctico y valorativo en relación a la forma en que las personas/instituciones ven imaginariamente la realidad social. Así, pretender que la microempresa sea un agente emprendedor en tanto extensión del homoeconómicus (es decir, una racionalización basada en un sujeto conscientemente "evaluador" objetivo de sus circunstancias) es una visión ingenua que a esta altura debe comenzar a complejizarse.

\section{Bibliografía}

Althusser, Louis 2003 [1969] "Ideología y aparatos ideológicos de Estado" en Žižek, Slavoj (comp.) Ideología. Un mapa de la cuestión (Buenos Aires: Fondo de Cultura Económica).

Banco Mundial 2002 Instituciones para los mercados. Informe sobre el desarrollo mundial 2002. Panorama general. (Washington D. C.).

Bourdieu, Pierre 2005 [2000] Las estructuras sociales de la economía (Buenos Aires: Manantial).

Carpintero, Samuel 1998 Los programas de apoyo a la microempresa en América Latina. El microcrédito como la gran esperanza del siglo $X X I$ (Bilbao: Deusto).

CGAP 2001 "Microfinanzas, donaciones y respuestas no financieras para la reducción de la pobreza: ¿dónde encaja el microcrédito?” en Enfoques (Nueva York) No 20.

Eagleton, Terry 2005 [1995] Ideología. Una introducción (Barcelona: Paidós).

Foucault, Michel 2002 [1969] "La formación de las estrategias" en La arqueología del saber (Buenos Aires: Siglo XXI).

Herrera, José 2003 Crédito a la microempresa en Chile. Una revisión cualitativa, 1991-2001 (Santiago de Chile: PET).

Lo Vuolo, Rubén; Barbeito, A.; Pautassi, L. y Rodríguez, C. 1999 “La pobreza en la visión de algunas agencias internacionales" en $L a$ pobreza... de la política contra la pobreza (Madrid: Miño y Dávila).

Márquez, Francisca y Van Hemelryck, Libero 1996 Fenomenología y génesis de un concepto: la microempresa en América Latina (Santiago de Chile: SUR). 
Murillo, Susana; Aguilar, A.; Grondona, L. y Motto, E. 2006a "El valor del concepto Ideología. La materialidad del discurso" en Murillo, Susana (coord.) La interpelación del Banco Mundial a América Latina y el Caribe. La ideología de la inseguridad como condición de posibilidad de la naturalización de la desigualdad y la excepcionalidad, Clase 1 del curso Campus-Virtual CLACSO, Aula 575.

Murillo, Susana; Aguilar, A.; Grondona, L. y Motto, E. (2006b) “La interpelación ideológica a reformular los significantes pobreza, desigualdad, vulnerabilidad y riesgo social" en Murillo, Susana (coord.) La interpelación del Banco Mundial a América Latina y el Caribe. La ideología de la inseguridad como condición de posibilidad de la naturalización de la desigualdad y la excepcionalidad, Clase 1 del curso Campus-Virtual CLACSO, Aula 575.

Nun, José 2003 [2001] Marginalidad y exclusión social (Buenos Aires: Fondo de Cultura Económica).

Portes, Alejandro 2000 "La economía informal y sus paradojas" en Carpio, J.; Klein, E. y Novacovsky, I. (eds.) Informalidad y exclusión social (Buenos Aires: OIT / Secretaría de desarrollo social de la Nación / Fondo de Cultura Económica).

Salama, Pierre y Valier, J. J. 1996 "La vía liberal de lucha contra la pobreza" en Neoliberalismo, pobreza y desigualdades en el Tercer Mundo (Buenos Aires: Miño y Dávila Editores / CIEPP).

Salama, Pierre y Destremau, Blandine 2002 "Medidas de la pobreza humana" en Medidas de la pobreza desmedida. Economía política de la distribución del ingreso (Santiago de Chile: Lom).

Sen, Amartya 2000 [1993] "Capacidad y bienestar" en Nussbaum, Martha y Sen, Amartya (comps.) La calidad de vida (México DF: Fondo de Cultura Económica).

Van Hemelryck, Libero 1993 "Los tipos de asociatividad microempresariales y sus limitaciones" en González, Raúl (editor) Microempresa y asociatividad (Santiago de Chile: PET).

Zevallos, Emilio 2003 "Micro, pequeñas y medianas empresas en América Latina" en Revista de la Cepal (Santiago de Chile) $\mathrm{N}^{\circ} 79$.

Žižek, Slavoj 2003a "El espectro de la ideología” en Žižek, S. (comp.) Ideología. Un mapa de la cuestión (Buenos Aires: Fondo de Cultura Económica).

Žižek, Slavoj 2003b [1989] El sublime objeto de la ideología (Buenos Aires: Siglo XXI).

Žižek, Slavoj 2005 "El malestar en el fetichismo" en Actuel Marx (Santiago de Chile) $\mathrm{N}^{\circ} 3$. 


\title{
LORENA M. SCALA*
}

\section{Trabajo, pobreza y políticas SOCIALES DE EMPLEO}

\author{
UN ACERCAMIENTO A LOS EMPRENDIMIENTOS DEL \\ Plan de Desarrollo local \\ Y ECONOMía Social Manos \\ A LA OBRA EN LA PROVINCIA DE MENDOZA
}

\section{INTRODUCCIÓN. EN BUSCA DE UNA NUEVA POLÍTICA SOCIAL}

El presente trabajo se funda en una preocupación central por el aumento sostenido de la pobreza e indigencia en la Argentina y por las políticas sociales ensayadas. Nos proponemos analizar la aplicación en la provincia de Mendoza de un plan social, el Plan de Desarrollo Local y Economía Social Manos a la Obra, a partir de las experiencias de quienes lo percibieron.

En los últimos años, tras una década de aplicación de las políticas de ajuste recomendadas por los organismos financieros internacionales de crédito y plasmadas en el Consenso de Washington, las condiciones de vida de la clase que vive de su trabajo (Antunes, 2003) han sufrido un fuerte deterioro. Ante el aumento de las problemáticas sociales relacionadas con el trabajo, desde el Estado se pusieron en práctica dos modalidades de intervención: por un lado modificaciones en las leyes laborales (las llamadas desregulación y flexibilización) y por otro la aplicación de planes y programas sociales de empleo; ambas resultaron ineficaces para lograr la inclusión de los desocupados al mercado de trabajo. La novedad de estos planes y programas sociales fue que incorporaron la obligación a los/as llamados/as beneficiarios/

\footnotetext{
* Licenciada en Sociología (Universidad Nacional de Cuyo).
} 
as de realizar una contraprestación a cambio de la prestación recibida. Dicha contraprestación consistía en la realización de actividades laborales (Plan Trabajar) o de capacitación (Plan Jefas y Jefes de Hogar Desocupados) a fin de demostrar que los/as perceptores de las prestaciones estatales se encontraban ocupados en alguna actividad que les brindaría herramientas a fin de volverlos "empleables". Esta obligación invierte la responsabilidad de la exclusión, ya que según esta lógica los excluídos del mercado de trabajo se encuentran en esa situación por su falta de capacitación o experiencia, y con esto deja de analizar las causas estructurales de la pobreza y las problemáticas vinculadas con el trabajo. Por eso a medida que estos planes se extendieron en el tiempo, se hizo cada vez más evidente que en el actual modelo de acumulación el capital ya no requiere de gran cantidad de población trabajadora. Los/as beneficiarios/as de los planes de empleo, lejos de lograr insertarse en el mercado laboral, continúan dependiendo de la percepción de los mismos para su sobrevivencia, por lo que el Estado se ve obligado a renovarlos constantemente. Por esto los planes sociales más que promover la inclusión funcionan como un eficaz instrumento político, ya que han sido utilizados para aplacar el conflicto social.

La evidencia de la prescindencia que el capital tiene de gran parte de quienes viven de la venta de su fuerza de trabajo, la paradoja de proponer contraprestaciones laborales que no los capacitan y la proliferación de experiencias productivas que conforman verdaderas estrategias de supervivencia generadoras de autoempleo, provocaron un cambio en las políticas sociales que se reflejó en la implementación de un plan social con una nueva modalidad de contraprestación. Nos referimos al Plan de Desarrollo Local y Economía Social Manos a la Obra. Este Plan marca un viraje respecto de los planes sociales anteriores ya que promueve el autoempleo de sus perceptores mediante la conformación de emprendimientos de economía social. Para esto el Estado entrega una suma inicial de dinero para la adquisición de maquinarias, materias primas y demás insumos necesarios, a fin de permitir a personas reunidas en grupos asociativos, llevar adelante actividades productivas o comunitarias.

Nuestro objetivo es analizar, en la provincia de Mendoza, el modo en que se aplicó el Plan Nacional Manos a la Obra a partir de indagar las formas de organización de los emprendimientos socioproductivos que recibieron el subsidio del mismo, tomando en consideración los principios de la Economía Social, base sobre la que se asienta. Para esto utilizamos técnicas cualitativas de investigación, específicamente la observación participante y entrevistas en 
profundidad con preguntas abiertas, ya que nos interesaba rescatar los relatos de quienes participan en estos emprendimientos y conocer sus experiencias. Elegimos nueve emprendimientos ubicados en distintos departamentos de la provincia de Mendoza. Con el uso de estas técnicas centramos nuestro análisis en el funcionamiento de los emprendimientos en términos del modo como los mismos organizan la producción, las vinculaciones que establecen con los actores que intervienen en la implementación del Plan, como también el acercamiento con otros emprendimientos. Por último, nos interesaba conocer el impacto en las condiciones de vida de sus miembros, no solo en cuanto a la posibilidad que tienen de permitirles la reproducción de sus vidas, si no también a ampliar los espacios de participación y ejercer los derechos de ciudadanía.

El artículo parte de realizar un recorrido en torno a los que consideramos los pilares del Plan: la economía social y el desarrollo local. Luego presentamos el Plan Nacional Manos a la Obra y señalamos sus lineamientos principales. A continuación exponemos el análisis del trabajo de campo.

\section{CONCEPTOS Y DISCUSIONES ACTUALES EN TORNO A la EConomía Social y el DeSARrollo Local}

El carácter estructural de la sobreoferta de fuerza de trabajo respecto de los requerimientos del capital es un problema de larga data. El mismo fue analizado en los años setenta por José Nun, quien creó la categoría población marginal para referirse a la oferta que excede la demanda de mano de obra (sobrepoblación relativa), población que nunca entró ni entrará en contacto con el sector productivo, y por lo tanto no cumple la función del ejército de reserva ya que no es funcional al capital (Supervielle y Quiñones, 2005). En los ochenta, por el contrario, esta problemática fue abordada desde otra perspectiva por la Organización Internacional del Trabajo (OIT) que destacaba las múltiples actividades económicas que estaban surgiendo entre la población de los países subdesarrollados y que denominó sector informal urbano. A pesar de la heterogeneidad de experiencias productivas que comprende la categoría sector informal urbano, es posible detectar algunas similitudes:

"La facilidad de entrada al sector, el uso de tecnologías simples y mano de obra poco calificada, unidades productivas de tamaño reducido y escasa separación entre el trabajo y el capital, la posibilidad de coexistencia de relaciones de producción diferentes en el interior del sector, restricción a aquellos mercados donde existe fuerte competencia o bien en algunos mercados oligopólicos o concentrados" (Supervielle y Quiñones, 2005: 107). 
Carbonetto (1997) por su parte propone considerar dos características principales para identificar las unidades que conforman el sector informal urbano: escasez de capital (y por tanto baja productividad) y autogeneración de empleo. La importancia de este sector es que se trata de experiencias productivas generadoras de autoempleo, razón por la cual se remarca la necesidad de que el Estado le brinde apoyo mediante políticas públicas. Las experiencias tomadas en consideración por el Plan que nos proponemos analizar presentan rasgos en común con las que contempla esta categoría.

La Economía Social por su parte toma como punto de partida la conformación de experiencias organizativas de producción, que revalorizan el trabajo humano pensándolo como mecanismo privilegiado de inclusión social. Las unidades domésticas son consideradas el sujeto privilegiado para llevar adelante experiencias de este tipo en la medida que es allí donde se crean las condiciones de generación y valoración del trabajo para la producción y reproducción de la vida de sus miembros. Para esta concepción la unidad doméstica no se reduce a relaciones de parentesco entre los miembros ya que puede incluir también relaciones de proximidad (de vecindad, ideológica, afectiva, etc.), según destaca Coraggio (1998). Para este autor la economía social

“[...] existe como un sector agregado de actividades socioeconómicas, compuesta por el conjunto de recursos subjetivos y materiales, privados o públicos que comandan las unidades o grupos domésticos [...], las actividades que realizan para satisfacer sus necesidades de manera inmediata o mediata [...], las reglas, valores, saberes y conocimientos que orientan tales actividades, y los agrupamientos, redes y relaciones que instituyen a través de la organización formal o de la repetición de esas actividades" (Coraggio citado en Hintze, 2003: 39)

La principal característica de esta economía es la valoración del trabajo humano en detrimento del capital y la importancia que se otorga a los conocimientos y experiencias organizativas de los sujetos que participan en las mismas. Esta valoración se vislumbra en la finalidad que estas unidades persiguen, que, lejos de ser la acumulación, es la reproducción de la vida entendida en su doble acepción: reproducción simple, que implica garantizar, en un determinado contexto histórico, las condiciones de vida consideradas mínimas y la reproducción ampliada, que permite a las personas realizarse más allá del mínimo de sobrevivencia. Es por esto que plantean una nueva unión entre producción y reproducción.

Otro rasgo que caracteriza a este sector es la importancia que se atribuye a la solidaridad y cooperación entre los miembros de los 
emprendimientos, condición de posibilidad para la continuidad de sus actividades, ya que las limitaciones a las que se enfrentan tornan indispensable el trabajo asociado. Además las vinculaciones con otros emprendimientos y organizaciones sociales son fundamentales para lograr el fortalecimiento del sector. Como Coraggio lo expone:

"Tal cambio cualitativo solo podrá alcanzarse si se actúa conscientemente para constituir un sistema, es decir no un conjunto agregado mecánicamente de personas, organizaciones, comunidades y recursos, sino una red auto-sostenida de redes interdependientes [...]" (Coraggio citado en Forni, 2004: 25).

La construcción de una economía social también implica la autogestión de los emprendimientos, en la medida que son los propios sujetos que integran las unidades económicas los que realizan la gestión de las actividades por sí mismos, lo que lleva a una mayor democratización del poder y de los recursos económicos. De allí el planteo político que esta propuesta encierra, en la medida que cuenta con un fuerte componente democratizante y pluralista vinculado a la construcción de nuevas formas de poder, promoviendo la asociación horizontal y sin jerarquías entre sus miembros y evitando vínculos que impliquen generar relaciones de dependencia. La participación de los trabajadores en la gestión, lleva a que sean ellos mismos quienes puedan organizar y decidir, viéndose implicados en la coordinación y ejecución de las tareas. Esto forma parte de las transformaciones culturales y políticas que se vuelven necesarias para hacer viable la propuesta de la economía social.

Lo expuesto hasta aquí muestra que la vinculación entre producción y reproducción, la valoración del trabajo humano, el rescate de los lazos de solidaridad y cooperación, como también las concepciones de trabajo asociativo y autogestionario, presentan a esta economía con una lógica propia que se opone o al menos, se muestra como alternativa a la racionalidad capitalista que está basada en el individualismo, la división entre producción y reproducción de la vida, el cálculo racional de los beneficios, la explotación del trabajo humano y la acumulación de capital. Por esto la relación entre economía social y de mercado acarrea discusiones entre los autores. Algunos consideran que el sector de la economía social no se opone al capitalismo, sino que más bien de lo que se trata es de lograr una articulación entre ambos sectores en la medida que es el mercado es el que posibilitará su subsistencia y crecimiento, pero siempre que exista una fuerte intermediación del Estado (Coraggio, 1998). Para otros autores es necesario prescindir del mercado capitalista ya que las lógicas de funcionamiento y los valores en juego son 
contrarios entre sí y por tanto las experiencias de economía social conforman una alternativa con modalidades de trabajo opuestas al capital (Mance, 2004 y Singer, 2002). Autores como Razeto (2004a) y Singer (2002) destacan que es necesario que las unidades de producción tengan por objetivo la reproducción ampliada de la vida y que su funcionamiento esté regido por principios solidarios, y que esto debería vincularse con un comercio solidario (la red de comercio justo por ejemplo), un sistema financiero solidario y un consumo solidario. Sin embargo consideran que es la etapa de la producción la que conlleva el mayor desafío y que los cambios promovidos en esta posibilitarán la extensión de los principios de solidaridad a las demás etapas.

De acuerdo a algunos autores entonces

“[...] la Economía Social es un posible marco estratégico -concertado en un espacio pluralista- para hacer converger sinérgicamente la acción de múltiples organizaciones sociales, económicas y culturales de instancias del Estado, y está orientada por objetivos de reproducción social ampliada de la vida" (Hintze, Sabaté y Coraggio en Hintze, 2003: 40).

Los sujetos que dan vida a esta economía son para Razeto (2004a) las múltiples experiencias organizativas desarrolladas por los sectores populares, que conforman lo que denomina Economía Popular; ya que son organizaciones socioproductivas en las que la solidaridad se hace presente, porque es un valor propio de las culturas populares debido a la escasez de recursos de los que disponen (Razeto, 2004b). Los aspectos que estas diferentes experiencias tienen en común, que son los que permiten incluirlas dentro de este sector de la economía, son señaladas por Razeto (2004a): se trata de experiencias asociativas de pequeños grupos o comunidades, formadas por escaso número de personas; con predominio del factor trabajo; conforman una organización propiamente dicha en la medida que tienen objetivos, organización y administración de medios y recursos; tienen contenido económico aunque sus actividades estén extendidas a otras dimensiones de la vida social; buscan satisfacer necesidades y solucionar problemas mediante la acción directa, con el esfuerzo propio y utilizando recursos mediante la ayuda mutua y el auto desarrollo; implican relaciones $\mathrm{y}$ valores solidarios, elemento esencial de estas experiencias; quieren ser participativas, democráticas, autogestionarias y autónomas; pretenden ser alternativas a las formas organizativas predominantes (capitalistas, individualistas, consumistas, autoritarias) y aportan a un cambio social; porque uno de sus objetivos es superar la marginación y el aislamiento, para lo cual propenden a una conexión entre ellas de 
manera horizontal y buscan también colaboración de Organizaciones No Gubernamentales (ONG) y de otras instituciones.

$\mathrm{El} \mathrm{mismo} \mathrm{autor} \mathrm{se} \mathrm{refiere} \mathrm{a} \mathrm{las} \mathrm{limitaciones} \mathrm{que} \mathrm{estas} \mathrm{experiencias}$ encuentran en el desarrollo de sus actividades: falta de financiamiento y de acceso al crédito, deficiencia tecnológica, dificultades en la comercialización (falta de centros de venta, carencia de contactos), deficiencia en la gestión por la inexperiencia de sus miembros, carencia de integración y coordinación con otras organizaciones (Razeto, 1997). Es por esto que considera que la posibilidad de autosustentarse de este sector es escasa, de allí la necesidad de contar con instituciones y entidades que presten apoyo a estas experiencias, ya que es esto lo que garantiza la permanencia de estas organizaciones (Razeto, 2004a). De esto se derivan algunas críticas a la propuesta de la economía social ya que se piensa que promueve relaciones de dependencia entre las organizaciones (Coraggio, 1999). Además, algunos autores (Mercau, 1991) consideran que estas experiencias, lejos de promover la generación de empleo, conforman nuevas modalidades de asistencia, que precisan permanentemente de subsidios externos e internos (trabajo voluntario o remuneraciones inferiores a los salarios vigentes) para desarrollar sus actividades.

Como señalamos, las formas que pueden adoptar las organizaciones de la economía social son múltiples. Para Coraggio el sujeto propio de esta economía es la unidad doméstica, organizada en la microempresa familiar. En este caso el grupo familiar extendido es considerado como unidad de trabajo y gestión que organiza la producción de bienes y servicios y escasamente se valen de mano de obra asalariada. Estas experiencias se consideran una prolongación de la economía doméstica y por ello la familia se convierte en una unidad de producción y consumo, aspectos escindidos en el capitalismo. Para Razeto las microempresas familiares son

“[...] auténticas formas alternativas de empresa, no basadas en el capital sino en el trabajo, no fundadas en el individualismo sino en la familia, no orientadas al lucro injustificado sino a la búsqueda sana y legítima de los medios de subsistencia, de mejoramiento de la calidad de vida y de colaboración al desarrollo de la comunidad" (Razeto, 1990: 32).

Las microempresas familiares se rigen por una racionalidad diferente de la economía formal ya que

“[...] su desempeño se orienta más por la necesidad de conservar la fuente de trabajo que le permite subsistir que por criterios objetivos de maximización de ganancias. Su doble condición de pequeño productor marginal y de proveedor de la subsistencia básica familiar determina 
ese perfil. [...]; lo que está en juego en el funcionamiento de la unidad informal es la subsistencia familiar y esto tiñe toda su racionalidad y desempeño." (Mizrahi citado en Cohen, 1988).

Esto hace que las relaciones que establecen con el mercado formal, con el que están en estrecha vinculación, presenten dificultades por su situación de desventaja en la comercialización (falta de lugares donde comercializar, altos costos, dificultad para ingresar a un mercado que funciona en condiciones oligopólicas) y en la producción (escaso capital, uso de tecnologías simples y escasa capacidad de gestión); lo que lleva a que se establezcan relaciones de dependencia con instituciones que les posibilitan la continuidad de sus actividades. Para Mizrahi, la articulación entre las microempresas y el mercado formal es de subordinación de la primera al segundo y por tanto resultan funcionales a los fines de la acumulación

“[...] en la medida que le asegure el aprovisionamiento de un insumo o de un servicio, le reduce el costo laboral y de administración de la producción y, en particular, le permite desplazar las incertidumbres del mercado" (Mizrahi en Martínez Nogueira, 1988: 140)

De allí se presentan dos alternativas: producir de manera independiente asumiendo los riesgos comerciales o fabricar a pedido y perder el control de la producción y la comercialización.

Otro sujeto de la economía social son los emprendimientos productivos. Según Gaiger se conforman por un grupo de personas que pueden ser parte de la unidad doméstica, trabajadores asociados o contratados, que con su trabajo buscan producir y comercializar bienes o prestar servicios en el mercado. Se basan en la libre asociación de los trabajadores y siguen los principios de autogestión, cooperación, eficiencia y viabilidad. La finalidad que persiguen es la generación de empleo y la reproducción de la vida, como modos de propender a la inclusión social. También contempla la vinculación con organizaciones intermedias e instituciones que prestan apoyo en diferentes aspectos. Conforman experiencias de economía alternativa a la lógica mercantil capitalista por dos rasgos: la socialización de los medios de producción y la democratización del poder económico. Además, sus objetivos exceden lo meramente económico ya que se proponen la reproducción de la vida de sus miembros y la autogeneración de empleo, y también contemplan actividades relacionadas con el desarrollo comunitario, la capacitación de sus miembros, etcétera:

"Se presentan en forma de grupos de producción, asociaciones, cooperativas y emprendimientos de autogestión y combinan actividades 
económicas con acciones de índole educativa y cultural, valorando el sentido de la comunidad de trabajo y el compromiso con la colectividad social en la cual se insertan" (Gaiger, 2004: 229).

Como un tipo especial de emprendimiento están los talleres autogestionados. Este taller es considerado desde tres dimensiones: como un grupo solidario en tanto la confianza y cooperación entre sus miembros es un factor fundamental para su funcionamiento, un colectivo de trabajo ya que la conformación del grupo consta de más de dos participantes que comparten situaciones similares y una unidad de gestión en tanto tienen objetivos y un proyecto en común. El rasgo diferencial es que el taller está conformado íntegramente por sus miembros, sin contratar personal externo, excepto la recepción de trabajo de tipo voluntario, por lo cual la propiedad y gestión es del colectivo de trabajadores que participan (Singer, 2002). Otro aspecto importante es la vinculación con la comunidad, con la que mantiene relaciones de reciprocidad que consisten en la entrega de parte de lo que producen a fin de aprovisionarse en el futuro de medios que por sí solos no pueden obtener. De allí que se destaca el aspecto relacional que se establece con la comunidad más que la posibilidad de obtener un beneficio económico de ella.

La importancia de estas experiencias en una economía fuertemente expulsora de fuerza de trabajo reside en que las mismas son generadoras de empleos. Es por ello que en los últimos años hemos asistido a una proliferación de subsidios y financiamientos tendientes al desarrollo y fortalecimiento de estas modalidades organizativas como el caso del Plan Nacional Manos a la Obra que analizaremos más adelante.

\section{APUNTES SOBRE EL DESARROLLO LOCAL}

Nos enfrentamos actualmente a un hecho que a primera instancia aparece como paradójico. La exaltación de un proceso de globalización que se presenta como inevitable y homogeneizador se da conjuntamente con una apelación al desarrollo de lo local. Sin embargo, tal y como lo explica Boaventura de Sousa Santos (2003) la paradoja no es tal ya que nos encontramos ante dos procesos simultáneos: una globalización que se localiza y un localismo que se globaliza. Lo primero se produce porque los efectos de la globalización hegemónica afectan a la mayor parte de las localidades de los países que terminan subsumiéndose a los imperativos del mercado. Lo segundo se presenta según el autor porque la globalización es un proyecto local que se vuelve hegemónico y por tanto se hace global:

"Es el proceso mediante el cual una condición o instancia local logra extender su radio de influencia a lo largo del globo y, al desplegar esta 
acción, desarrolla la capacidad de designar como local a la instancia o condición social con la cual compite" (De Sousa Santos, 2003: 86).

En este sentido Yamandú Acosta (2005) considera que el capitalismo implica un proceso de apertura y totalización a la vez, por el cual se intentan obtener nuevos espacios a fin de imponerles una misma lógica: la lógica del capital. Lo que para Wallerstein (1988) se relaciona con la necesidad de imponer la mercantilización a cada vez más procesos sociales y es considerada como la autoexpansión propia del capitalismo. Vemos entonces que conjuntamente con un proceso de intensa globalización y apertura de los mercados, que pareciera a primera vista tendiente a la homogeneización del planeta bajo iguales pautas de consumo y bajo la lógica imperante del capital; surge, en un movimiento contrario pero a la vez complementario, una valoración de lo regional y lo local, una visibilización de las heterogeneidades y diferencias existentes y por tanto una emergencia de nuevos actores que irrumpen en el espacio público. Consideramos para el presente trabajo que la visibilización e importancia otorgada al territorio se manifiesta, en términos políticos y económicos, en lo que se denomina estrategias de desarrollo local. En la propuesta del PNMO este componente territorial se hace presente en la medida que toma como punto de partida la acción comunitaria y busca que posteriormente se expanda. El territorio es visto como un eje que organiza los procesos de desarrollo asociado a una estrategia económica distributiva y a la búsqueda de una mayor equidad (Rofman y Merlinsky, 2004).

El desarrollo local es entendido como un proceso que promueve la participación y movilización de los actores e instituciones presentes en una comunidad, a fin de comprometerlos en la búsqueda de un desarrollo que resulte ecológicamente sustentado (procurando el cuidado del medio ambiente) y capaz de generar trabajo y mejorar el ingreso de sus habitantes. Para esto se precisa la participación efectiva de los distintos actores locales en la elaboración de un diagnóstico capaz de detectar los recursos reales y potenciales de la comunidad, a fin de diseñar proyectos estratégicos que permitan una mejora en el territorio. Para esto se precisa atender al perfil de la localidad, su gente, los recursos de las comunidades, y también las prácticas culturales, las instancias educativas, las características de la población, su historia, sus tradiciones. Esto hace que este proceso incluye una articulación de aspectos políticos, sociales, económicos y también culturales y educativos, en la medida que las estrategias de acción delineadas para el logro de una producción económicamente sustentable en el territorio deben contemplar la conformación de una red de relaciones entre los diferentes actores involucrados y promover su efectiva participación en las decisiones. 
Siguiendo a Albuquerque diremos que el desarrollo local es el

“[...] proceso por el cual los actores o instituciones locales se movilizan para apoyar las diferentes acciones, tratando de crear, reforzar y preservar actividades y empleo, utilizando los medios y recursos del territorio" (Albuquerque citado en Di Pietro Paolo, 2003: 25).

Pero además, la propuesta de desarrollo local promueve la vinculación entre diferentes comunidades, articulación que busca un mayor fortalecimiento en el escenario nacional y global (Heras y Burín, 2003). Arocena (1998) considera que lo local y lo global son las dos dimensiones de lo social y que por ello todo proceso de desarrollo local deberá referirse a la sociedad global en que se inscribe. La importancia de lo local, subraya, es que tiende a otorgar un mayor poder a los municipios, ya que son estos los que están en posibilidad de percibir y considerar las múltiples diferencias existentes en su territorio. En efecto la propuesta de desarrollo local implica para los gobiernos municipales el desafío de tomar a su cargo nuevas responsabilidades, ya que deben convocar y concertar los espacios de encuentro y articulación entre distintos actores para tomar decisiones de manera participativa sobre las estrategias de desarrollo a implementar, en función de los recursos con los que cuentan (Arroyo, 2003); gestionar los recursos provenientes del Estado nacional y de organismos de crédito internacional.

La noción de desarrollo local a su vez nos lleva a preguntarnos qué entendemos por desarrollo. Este término ha sido equiparado al crecimiento económico, ya que el logro de uno traería aparejado casi mecánicamente el otro. Sin embargo a partir de los años setenta, el crecimiento con estancamiento en la creación de puestos de trabajo mostró que crecimiento y desarrollo no van de la mano. El aumento de la pobreza y la exclusión en épocas de crecimiento económico son un ejemplo de la insuficiencia de este para lograr una mejora en las condiciones de vida de la población y con ello de promover el desarrollo (Hinkelammert y Duchrow, 2003).

Desde otra perspectiva, Paulo de Jesús (2004) considera que el auge del desarrollo local se vincula con los procesos de descentralización y focalización propios de las exigencias de ajuste estructural impuestas a las sociedades latinoamericanas en la década del noventa. El autor considera que la globalización es uno de los factores que han intervenido en el auge del proceso de desarrollo local. En esto incide la reforma del Estado y la descentralización que

"[...] han puesto en primer plano a las instancias regionales (provincias) y locales (municipios), que han recibido del nivel central la ad- 
ministración y ejecución de nuevas competencias y servicios sociales, obligándoles a modificar el sentido y la modalidad de la gestión, incorporar tecnología, desarrollar liderazgos innovadores, racionalizar las plantas de agentes públicos y capacitar sus recursos humanos" (De Jesús, 2004: 20).

En opinión de Marcos Arruda los procesos de desarrollo local que se están aplicando en América Latina buscan comprometer a las comunidades locales en la búsqueda de soluciones a los problemas que el mercado no se plantea resolver:

"Ellos [el Estado] ven al desarrollo comunitario como una 'cuestión necesaria', o una 'política compensatoria' para que el sector privado continúe haciendo lucros como siempre" (Arruda, 2000: 162, traducción propia).

De este modo, objetivos como tornar a las comunidades más competitivas o reintegrar a los excluidos al mercado de trabajo, no se presentan como verdaderas alternativas, sino más bien, como una vuelta a un modelo cuyos límites se han tornado evidentes. Propone por esto un desarrollo alternativo, que denomina desarrollo emancipatorio, que busca la construcción de relaciones integralmente humanas ya que parte de considerar al ser humano como un ser racional, emocional e intuitivo. El sujeto de este desarrollo es la comunidad, entendida como el "conjunto de personas que comparten un proyecto en común, valores, ideas y prácticas en común" (Arruda, 2000: 162). Este modelo de desarrollo no busca insertar lo local en lo global, sino imponer en lo global una lógica diferente que valorice la diversidad, y que plantee relaciones de cooperación, reciprocidad y solidaridad entre los seres humanos. La revalorización del trabajo humano se torna indispensable, por ello propone una nueva organización de la economía y el mercado, a fin de devolver al trabajo su potencial emancipador. Para lograr esto es imprescindible dotar de autonomía a los sujetos, lo que se logra superando la dependencia propia del asistencialismo que ha caracterizado las relaciones del Estado con la comunidad.

Podríamos decir entonces que la noción de desarrollo local no tiene un sentido unívoco ya que supone por un lado la aplicación de los procesos de descentralización propios del ajuste estructural neoliberal llevado a cabo en las sociedades latinoamericanas en los noventa y que conlleva a una transferencia de responsabilidades del sector estatal nacional a los gobiernos provinciales y municipales, sin la dotación de recursos correspondientes y sin las herramientas de decisión necesarias para hacer frente a las acciones y reclamos sociales que se les formulan. En estos procesos reconocemos que si bien el discurso 
se tiñe de nociones que plantean propender a una mayor participación de los gobiernos locales y demás actores sociales en la gestión de recursos y en la toma de decisiones que hacen a los asuntos de la comunidad y aprovechar la cercanía de las instancias municipales con la gente y el reconocimiento de los particularismos, lo que subyace a este planteo son las teorías de gerencia social que proponen la descentralización, participación y mayor flexibilización tendientes al logro de la eficiencia empresarial, por lo cual se impregna al Estado de la lógica empresaria. Lo que esto produce es una delegación de responsabilidades y un abandono y desfinanciamiento de actividades consideradas imprescindibles para el efectivo ejercicio de los derechos ciudadanos y la satisfacción de las necesidades de la comunidad. Sin embargo, desde un planteo diferente que le otorga otro significado a la noción de desarrollo, encontramos un potencial proceso de construcción alternativa de formas de relacionarse dentro de la comunidad y de esta con su entorno, que implica dotarla de mayor poder para pensar en nuevas formas de acción política, de producción económica y de prácticas culturales, en el cual subyace un alto contenido emancipador.

\section{LA ECONOMía SOCIAL Y EL DESARROLlO LOCAL COMO EJES de Política social: el Plan Nacional Manos a la Obra} En este apartado proponemos analizar los lineamientos del Plan de Desarrollo Local y Economía Social Manos a la Obra y vincularlo con los postulados de la Economía Social y el Desarrollo Local recién expuestos. Intentaremos destacar la presencia en el Plan de los rasgos que definen a esta economía como social, para analizar más adelante si estos efectivamente se ponen en práctica en los emprendimientos creados.

\section{LAS POLÍTICAS SOCIALES EN EL CONTEXTO DE APLICACIÓN del Plan Nacional Manos a la Obra}

En Argentina, al igual que en el resto de América Latina, en la década del noventa se aplicaron las políticas de ajuste estructural contenidas en el Consenso de Washington.

La aplicación de estas medidas demostraron gran eficacia en el disciplinamiento impuesto por el mercado a la clase que vive del trabajo, que implicaba, ante cualquier reclamo por el efectivo cumplimiento de los derechos vinculados con el trabajo, la posible pérdida del empleo por tiempo indefinido. Como parte del ajuste se implementan cambios en las condiciones y relaciones laborales, la pérdida de los derechos de los trabajadores bajo el paradójico término de "desregulación" y un aumento de las tasas de desempleo, subempleo y sobreocupación. Estas transformaciones provocaron un deterioro de las 
condiciones laborales, constatándose el aumento de la precarización, un incremento de las actividades que se enmarcan dentro de lo que se denomina economía informal y de subsistencia y consecuentemente un aumento de los niveles de pobreza e indigencia, ya que la cantidad de personas (con o sin empleo) que contaban con ingresos que no les permitían cubrir la canasta básica de bienes y servicios era cada vez mayor $^{1}$. Las problemáticas vinculadas al trabajo adquirieron tal relevancia que el mismo pasó a ser considerado un verdadero problema social. Como consecuencia de esto la desocupación creció al máximo histórico en el año 1995 según mostraron los índices proporcionados por el gobierno: $18,4 \%$ el desempleo abierto y $29,7 \%$ si consideramos el subempleo (Rapoport, 2000). Las consecuencias de estas políticas se hacen explícitas en los índices de pobreza e indigencia. Según la Encuesta Permanente de Hogares en octubre de 2001 la pobreza trepaba al 35,4\% y la indigencia al 12,2\% (de acuerdo al método de medición de la línea de pobreza).

Por esto en la década del noventa se produce una proliferación de experiencias que podrían encuadrarse en el amplio concepto de Economía Informal, ya que quienes resultaban excluidos del mercado de trabajo (según las nuevas categorías sociales utilizadas para explicar este fenómeno) debían recurrir a diferentes estrategias para lograr la sobrevivencia. Clubes de trueque, actividades por cuenta propia, talleres familiares, emprendimientos productivos y fábricas recuperadas son algunos de los ejemplos de las múltiples experiencias puestas en práctica.

Ante el creciente descontento social, desde el Estado comenzaron a implementarse dos modalidades de intervención tendientes a atender la situación de los trabajadores. Por un lado a nivel legislativo, promoviendo cambios en las leyes laborales, y por otro implementando políticas sociales de empleo que buscaban contener el creciente descontento social y aliviar la pobreza (Grassi, 2003). Esta segunda modalidad se tradujo en una sumatoria de planes y programas sociales tendientes a resolver los "costos sociales del ajuste", según la terminología impuesta por los organismos internacionales de crédito².

1 Es importante destacar que dentro de las filas de los considerados pobres se encontraban no solo trabajadores desocupados, sino también aquellos que, aun teniendo un empleo o más (ya que también la sobreocupación comenzó a hacerse visible) sus salarios reales quedaban muy por debajo de lo que se precisaba para la reproducción de la vida.

2 De acuerdo a los objetivos que se planteaban las políticas sociales, estas se implementaron para disminuir los costos sociales del ajuste y aliviar la pobreza. Es decir que las mismas buscaban mantener la legitimidad de las instituciones políticas a los ojos de la sociedad y frenar el descontento de quienes más sufrieron las políticas de 
Los planes sociales de empleo resultaron de gran eficacia para profundizar el disciplinamiento económico impuesto a los trabajadores. Estos planes cumplen con una doble función: disciplinar a quienes se encuentran excluidos del mercado de trabajo, resultando un poderoso instrumento de contención frente al descontento social creciente; e imponen un disciplinamiento a los trabajadores que tienen empleo, en la medida que quienes los reciben pujan por su ingreso al mercado de trabajo y de este modo permiten al capital implementar nuevas condiciones de precariedad y desprotección que afectan a quienes se encuentran ocupados. De allí que estos planes finalmente favorecen la acumulación de capital (Féliz, 2005), ya que al promover la realización de actividades a cambio de magras prestaciones, junto con el incentivo que se da a las empresas de ocupar esta mano de obra (con las exenciones del pago de aportes durante un período de tiempo) funciona claramente como un factor de disciplinamiento de los trabajadores ocupados porque termina favoreciendo la creación de puestos de trabajo en condiciones cada vez más degradantes, sin derechos sociales y obteniendo como salario las prestaciones de los planes, que no alcanzan siquiera a cubrir la canasta de bienes necesaria para superar la situación de indigencia. Por ello, lejos de favorecer la inclusión social, los planes sociales promovieron un "plan canje" de trabajo: flexibilizaban, precarizaban y tornaban más inseguro el empleo de quienes se encontraban ocupados, mientras que por otro lado decían brindar capacitación y experiencia laboral a quienes a su juicio carecían de calificaciones necesarias para insertarse en el mercado laboral. El monto entregado a los perceptores de los planes funciona además como piso mínimo de las remuneraciones abonadas por el capital a la fuerza de trabajo ocupada. Por su parte, las contraprestaciones propuestas como condición para la percepción de los mismos, que versan en la realización de algún trabajo, capacitación o acceso a la educación formal, no tiene implicancias en las posibilidades concretas de acceder a empleos formales (Scala, 2005).

El fracaso de estos planes para el logro de la inclusión social está dado porque las posibilidades de inserción en el mercado de trabajo, lejos están de depender de las capacitaciones propuestas, del capital cultural de sus beneficiarios o de aspectos que puedan adjudicarles

ajuste, pero de ninguna manera implicaban un desafío al sistema económico. De esta manera los planes profundizan el divorcio entre políticas sociales y políticas económicas ya que entre sus objetivos no se contempla el logro de una más justa distribución del ingreso y por tanto no suponen modificaciones en materia económica. Es este otro ejemplo que muestra cómo el Estado neoliberal se encarga de dejar intactos los intereses de los sectores que continúan acumulando capital y concentrando riqueza. 
la carga de la responsabilidad de su situación a ellos mismos. Esto muestra que cualquier política social que no implemente cambios en las políticas económicas está destinada a un ineludible fracaso.

Vemos entonces cómo las políticas implementadas en torno al trabajo, lejos de promover la inclusión social buscaron disciplinar a los trabajadores, promoviendo a su vez mejores condiciones para la valorización y acumulación de capital (Féliz, 2005). Por ello el Estado se encuentra continuamente ante la situación de generar y entregar nuevos planes sociales, ya que quienes los percibían no lograron, en su mayor parte, ingresar al mercado laboral y así dejar de depender de los mismos. Actualmente para gran parte de la población es este el único ingreso.

En el año 2003 las políticas sociales dieron un nuevo viraje en los criterios rectores de los noventa. El Plan de Desarrollo Local y Economía Social Manos a la Obra, objeto de nuestro trabajo, es un ejemplo de estas nuevas políticas sociales.

\section{Lineamientos del Plan de Desarkollo Social Y ECONOMía SOCIAL MaNOS A LA OBRA}

El Plan de Desarrollo Local y Economía Social Manos a la Obra (PNMO) se pone en vigencia en agosto del año 2003. Este Plan marca un viraje respecto de las políticas sociales de la década anterior. Elimina la focalización ya que

"Manos a la Obra está destinado a aquellas personas que tengan una alternativa laboral que ya están llevando adelante o necesiten apoyo para empezar. [...]; es abierto a todas las personas que quieran presentar proyectos que ofrezcan la elaboración de algún producto o un servicio"3.

El mismo propone superar las escisiones entre políticas sociales y políticas económicas: “articular 'lo social' y 'lo económico' desde el comienzo buscando generar condiciones para que las familias tengan mayores ingresos" (Arroyo, s/f). Asimismo marca un giro de la descentralización al desarrollo local:

"El Programa "Manos a la Obra" se propone consolidar los vínculos entre las organizaciones gubernamentales y las organizaciones sociales, integrando el capital social y el económico. Se trata de darle sentido a la Economía Social para fortalecer las economías regionales, anudando el compromiso y la participación".

3 En este aparatado, las transcripciones acerca del Plan Nacional Manos a la Obra, salvo indicación expresa, han sido obtenidas de <www.desarrollosocial.gov.ar/planes/ dles>. 
La contraprestación también muestra rasgos novedosos ya que consiste en conformar emprendimientos socioproductivos de economía social. Para esto promueve la realización de experiencias asociativas de producción generadoras de autoempleo, a fin de permitir la búsqueda de alternativas a la falta de empleo.

"Hacer políticas sociales en la Argentina actual significa generar las condiciones para que las familias tengan más recursos, puedan acceder al menos a los bienes y servicios básicos, y de esta manera puedan vivir mejor. Las familias solo pueden acceder a una renta extra produciendo y vendiendo, lo cual nos lleva al campo de la economía social“ (Arroyo, s/f).

El Plan se basa en dos pilares fundamentales: un aspecto institucional o político, vinculado al Desarrollo Local y un aspecto económico con énfasis en la Economía Social. Para esto el Plan busca articular las distintas organizaciones que funcionan en la comunidad: municipio, organizaciones no gubernamentales, sindicatos, cámaras, empresarios e instituciones educativas, muchas de ellas nucleadas en los llamados Consejos Consultivos ${ }^{4}$. Según el Plan:

“[estos] asumirán el rol de acompañantes de los proyectos socioproductivos [...], evaluarán la calidad y variedad de los proyectos, propiciando la complementariedad y articulación entre las distintas iniciativas y fomentando la utilización de los recursos y capacidades locales".

En el Plan el desarrollo local se presenta como una instancia política con fuertes connotaciones en lo económico:

"Manos a la obra' es un plan de desarrollo local y economía social, en ese orden. Esto se debe a que primero es necesario tener en claro el perfil de una ciudad y el perfil de la gente de esa localidad, cómo se compone el PBI de esa ciudad, qué condiciones existen y en función de estos y otros elementos, diseñar una estrategia que oriente el desarrollo para los próximos años. En cada lugar se articula con los actores locales en un proceso hasta constituir lo que se llama la 'agen-

4 Un antecedente de los Consejos Consultivos fue la Mesa de Diálogo concertada durante el gobierno de Duhalde (2002/2003) para la implementación del Plan Jefas y Jefes de Hogar Desocupados. A la misma concurrieron diferentes actores: empresarios, sindicatos, ONG, organizaciones piqueteras, gobierno e Iglesia Católica Argentina. Posteriormente, y para la implementación del Plan, se crean los Consejos Consultivos, con la finalidad de participar en el proceso de implementación y ejecución, a fin de dotarlo de mayor transparencia (Golbert, 2004). 
da de desarrollo local'. En esta agenda queda determinado el perfil local, dado que un proyecto estratégico está necesariamente relacionado con el perfil de cada localidad. [...] Se pretende que dichos microemprendimientos y las microempresas o cualquiera de las distintas modalidades socioproductivas asociativas posibles, formen parte de la estrategia de cada territorio. Y como quienes realmente saben lo que pasa en el territorio son quienes viven y trabajan en el mismo, los actores locales, la única opción que se configura como válida es la de trabajar con ellos" (Arroyo, s/f).

El PNMO intenta potenciar los vínculos presentes en la comunidad, para lo cual aprovecha los lazos de solidaridad y las estrategias de supervivencia que se ponen en práctica "[...] recuperando la comunicación y el encuentro entre las personas a partir del apoyo a los espacios de trabajo asociativo y productivo". El punto de partida del Plan son las prácticas y valores, conocimientos y capacidades de un sujeto: los vecinos "[...] para que junt[o]s puedan construir alternativas de trabajo y mejorar las condiciones en que viven", erigiendo a la comunidad como instancia de articulación entre distintos actores y de trabajo solidario, como espacio de encuentro en la búsqueda de soluciones comunes. De allí que el financiamiento es entregado a "grupos de personas organizadas en forma asociada que necesiten trabajo y tengan una alternativa laboral que estén llevando adelante o necesiten apoyo para empezar".

Para el Plan los emprendimientos son considerados una pieza clave ya que son creadores de fuentes de empleo. Con esto pretende generar mejores condiciones de vida para la población ya que su finalidad, de acuerdo a la economía social, es la reproducción de sus miembros mediante la realización de trabajos asociativos. De este modo rescata y aprovecha las experiencias y recursos que los sectores populares ponen en práctica para lograr su propia supervivencia, y busca que eso sea reutilizado por ellos, a fin de lograr una mejora en su situación de pobreza. El PNMO pone de este modo en el espacio público formas alternativas de organizar la producción (Rofman y Merlinsky, 2004) y a los/as sujetos que realizan estas actividades, a fin de lograr su propia reproducción, administrando su propia escasez de recursos. Toma en consideración prácticas comunitarias en las que se rescatan los lazos de solidaridad, y brinda a estas (y nuevas) experiencias un incentivo económico que les permita continuar (o comenzar) con actividades productivas y comunitarias, a fin de "desarrollar nuevas formas de vida, recuperando las capacidades de trabajo desde su lugar y con sus propios recursos".

El Plan propone "financia[r] proyectos productivos que favorezcan la inclusión social a partir de las distintas experiencias, oficios, 
recursos y habilidades de la gente y de las características propias de cada municipio y localidad. Está destinado a grupos de personas organizadas en forma asociada que necesiten trabajo y tengan una alternativa laboral". Para esto entrega maquinarias, herramientas y materias primas a proyectos productivos "destinados a la producción agroindustrial, la elaboración de manufacturas, servicios y comercio" que pueden ser unipersonales y familiares, asociativos de autoconsumo, emprendimientos productivos comerciales y cadenas productivas "cuya finalidad es fortalecer actividades conjuntas entre diferentes emprendimientos para mejorar la calidad de lo producido, aumentar su cantidad, disminuir costos y mejorar la comercialización". Además reconoce la importancia de brindar servicios de apoyo a los emprendimientos, como microcréditos, apoyo técnico, capacitación y creación de cadenas de valor. La propuesta de conformar cadenas de valor implica articular las experiencias de economía social entre sí y con el mercado formal, con el fin de vincular los distintos sectores de la economía y no crear unidades productivas separadas entre sí, en las que los emprendimientos quedarían como una economía de pobres para pobres:

"El último punto es la construcción de cadenas de valor y la articulación con las empresas. La responsabilidad social empresaria y la articulación entre los grandes y los pequeños productores" (Arroyo, s/f).

Por último, queremos destacar que este viraje se explicita también en los objetivos del PNMO que enfatizan el logro de la inclusión social mediante la construcción de alternativas de trabajo, promoviendo la cultura del trabajo ("como eje liberador, como derecho universal") mientras que a la vez remarca la necesidad de redistribuir la riqueza y propiciar la equidad: "Generar puestos de trabajo, mejorar los ingresos por hogar, disminuir los problemas de pobreza y exclusión y aprovechar los recursos y la capacidad institucional existente [...]".

\section{Los emprendimientos del Plan. Aspectos METODOLÓGICOS Y ANÁLISIS DEL TRABAJO DE CAMPO.}

En el presente apartado exponemos los resultados del trabajo de campo realizado, en el cual utilizamos las técnicas de investigación basadas en la observación participante y la realización de entrevistas en profundidad con preguntas abiertas, ya que nos interesaba rescatar las experiencias de los/as emprendedores/as según sus relatos, expresados con sus propias palabras. Realizamos también entrevistas a dos personas que trabajan en vinculación con los emprendimientos desde un municipio (encargada de la confección de los proyectos), y a través de una ONG (tutor que realiza tareas de acompañamiento). 
A continuación presentamos los emprendimientos visitados, destacamos sus características principales y nos adentramos luego en el análisis de los datos que surgen de las entrevistas y de las observaciones realizadas entre los meses de enero a agosto de 2006. Buscamos mostrar el modo en que se implementó el Plan Nacional Manos a la Obra a partir del funcionamiento de los emprendimientos visitados y de las experiencias de los/as emprendedores/as.

\section{BREVE PRESENTACIÓN DE LOS EMPRENDIMIENTOS}

Para realizar este trabajo elegimos como unidad de observación los emprendimientos productivos que recibieron el subsidio del PNMO, ya sea que en el momento de la presentación al Plan hayan comenzado su actividad o que se encontraran en funcionamiento. Para esto buscamos emprendimientos con diversas características en cuanto al número y género de miembros, actividades, ubicación, relaciones con otros emprendimientos u organizaciones, etcétera.

El total de emprendimientos visitados son nueve y se ubican en cuatro departamentos del norte de la provincia de Mendoza: Capital, Guaymallén, Las Heras y Lavalle. Su actividad está relacionada con diferentes rubros de producción: cría de conejos, elaboración de dulces y conservas, vivero dedicado a la producción de almácigos de tomate, chacra, elaboración de salsa de tomate, confección de ropa para bebés y niños, serigrafía, gráfica y un gimnasio. Algunos de estos emprendimientos se ubican en ámbitos rurales y otros en zonas urbanas.

Al momento del trabajo de campo no todos los emprendimientos se encontraban en actividad; por este motivo la observación participante no pudo ser realizada en todos los casos. La situación que presentan los emprendimientos es sumamente diversa, ya que en algunos casos las actividades están suspendidas temporariamente por diferentes motivos relacionados con la estacionalidad de la materia prima (dulces), con la falta de entrega de maquinarias y materiales para la producción (confección de ropa) o por no haber resultado rentable la actividad o carecer de una clientela suficiente para sostenerla (gimnasio y serigrafía). En aquellos casos en los cuales el grupo no se encontraba en actividad, realizamos entrevistas en profundidad a algunos de sus miembros.

Esta diversidad también se refleja en la vinculación con otras organizaciones, ya que mientras algunos de los emprendimientos cuentan con apoyo de ONG, en otros los proyectos se presentaron vía municipios, y no están vinculados a ninguna institución.

Acerca de las características de los miembros de los emprendimientos, podemos decir que en algunos de ellos hay presencia única 
de mujeres (conejos, elaboración de dulces, confección de ropa), en otros solo de varones (vivero, gimnasio, chacra y serigrafía) y en el resto participan varones y mujeres (producción de salsa y gráfica). Algunos emprendimientos son trabajados de manera individual, tal el caso del vivero, la chacra y el gimnasio; y en otros hay un fuerte componente familiar (gráfica, serigrafía), aunque también participan personas que no son de la familia. En algunos emprendimientos se contratan personas para las épocas de mayor trabajo (vivero, chacra y elaboración de salsa) mientras que en el resto de los casos esto no ocurre.

De acuerdo a las características que presentan los emprendimientos visitados, los mismos no pueden incluirse dentro de algún sujeto de la economía social, ya que presentan rasgos comunes a los tres tipos de organización analizados. De allí que creemos que estas modalidades no se dan en la realidad de forma pura, sino que más bien se trata de tipos ideales, en sentido weberiano (Gaiger, 2004). Lo que encontramos es un grupo de personas, familiares y/o asociados, que producen bienes y servicios para comercializarlos en el mercado (aunque en un caso la finalidad principal es el autoconsumo), cuyo objetivo es lograr la reproducción de la vida de sus miembros. El régimen de propiedad de los bienes es colectivo y las decisiones buscan tomarse de manera grupal. Por su parte la confianza y solidaridad entre los miembros es un rasgo que está muy presente para el logro de las actividades y que es lo que permite que estas experiencias puedan seguir adelante. Asimismo las relaciones con la comunidad no se plantean como un objetivo explícito en todos los emprendimientos, pero sí en algunos de ellos está muy presente y se considera prioritario. Los casos excepcionales están dados por los emprendimientos unipersonales en los que eventualmente contratan personal.

Proponemos a continuación analizar los diferentes aspectos a partir de lo que surgió del trabajo de campo realizado.

\section{ANÁLISIS DEL TRABAJO DE CAMPO}

\section{El Plan Nacional Manos a la Obra. Implementación en la provincia de Mendoza.}

A partir de los emprendimientos visitados constatamos que en la etapa de confección y presentación de proyectos algunos emprendedores lograron proponer actividades acordes a sus propios intereses y capacidades, de acuerdo a las habilidades y conocimientos que poseían. En otros casos por el contrario, fue el municipio el cual, atento a sus propios intereses, confeccionó los proyectos y los presentó sin intervención de los actores. En estos casos el proyecto fue elaborado 
sin tener en cuenta sus intereses y habilidades, como tampoco las características del lugar donde desarrollarían sus actividades (distancia con el lugar para comercializar, acceso al agua, materiales de los emprendedores para aportar, necesidades). Esto es lo que sucedió en el caso del emprendimiento de cría de conejos. De esto se derivaron posteriormente algunos problemas, ya que las mujeres carecen del agua necesaria para la producción y limpieza del lugar, porque el pozo del que disponen se ubica alejado del lugar donde residen.

Según las nociones del Desarrollo Local, pilar sobre el que reposa el PNMO, los municipios deberían generar las instancias para la participación de los actores sociales. En la práctica sin embargo, estos criterios no se aplicaron ya que estas instancias no se promovieron. Los miembros de los emprendimientos visitados nos manifestaban que no fueron convocados a reunirse con otros actores de la comunidad, y sí en cambio fueron llamados para participar en reuniones informativas sobre los aspectos tributarios y legales de los emprendimientos.

La participación de los municipios en la implementación del Plan estuvo limitada a las tareas relacionadas con la elaboración de proyectos, asistencia a quienes deseaban presentarse y entrega de proyectos al Ministerio de Desarrollo Social de la Nación:

"Yo entré entre los primeros proyectos que se presentaron en la municipalidad, la municipalidad no tenía infraestructura, no tenía personal capacitado ni demás para darle agilidad al tramite entonces por eso se demoró muchísimo. Ahora [...] están tratando de organizar mucho mejor la cosa para que en la tanda de los que presentaron después no suceda lo mismo, sea mas ágil..." (Entrevista a Silvia. Taller Gráfico).

La heterogeneidad de situaciones con la que nos encontramos nos hace pensar que el Plan, tal y como ha sido aplicado en la Provincia, cuenta con escasa organización y control sobre la marcha de los emprendimientos. En algunos emprendimientos los proyectos se presentaron teniendo como organización intermedia al municipio. La entrega de los materiales en estos casos tardó aproximadamente un año y medio (desde mediados de 2004 a fines de 2005) siendo un caso extremo el del emprendimiento textil que aún no logra obtener todos los materiales y máquinas que precisan para comenzar con la actividad. Al parecer, la demora se produce por los mecanismos que utiliza ese municipio para la compra de los materiales:

"[...] la demora exagerada que hubo fue responsabilidad de la burocracia de la municipalidad porque cuando la Municipalidad mandó todos los proyectos a Buenos Aires allá cumplieron en tiempo y forma con la aprobación, allá dijeron que era cuatro a cinco meses lo que ellos de- 
moran en hacer todo el proceso de evaluación correcciones y demás y eso fue tal cual, después volvió a la municipalidad, hicieron el depósito del dinero de todos los proyectos que en total eran 42 y después fue un tramiterío de la municipalidad. Cada cosa que compraban tenía que ir con su respectivo decreto, y se equivocaban un numerito y tenían que hacerlo de nuevo y pasar por todas las oficinas para la firma y sello..." (Entrevista a Silvia. Taller Gráfico)

“[...] nosotras tenemos que esperar que ellos saquen una licitación, llaman a licitación. A las personas les cobran $\$ 150$ para presentarse a la licitación y ellos hacen una orden de compra y ellos pagan a quince, veinte hasta cuarenta y cinco días, entonces nadie quiere vender. [...] La licitación viene porque en el caso nuestro el expediente se perdió porque lo tomó una concejal que supuestamente iba a apurar todo iba a sacar todo pronto, y ahí se perdió." (Entrevista a Fernanda. Taller textil)

En los emprendimientos en los que la entrega de los materiales tardó mayor tiempo del estipulado, encontraron que no tenían posibilidad de reclamo. Tal el caso del emprendimiento textil en el que se desconoce quién ha quedado a cargo de la responsabilidad del Plan por parte del gobierno. Es el único caso en el que un tutor de una organización administradora las visita, pero no tiene posibilidad de solucionarles el problema:

"Nosotras queremos saber adónde poder ir, adónde reclamar esto por qué estamos, o sea, si nosotras queremos trabajar adónde podemos ir a reclamar para poder trabajar, y no hay. Acá no hay un representante de... una vez que entró al municipio ya no se puede ir a otro lado, solo queda pelear con ellos y estar ahí, esperando." (Entrevista a Iride. Taller textil)

Los municipios brindaron en algunos casos capacitación para la producción, sin embargo, una vez obtenido el Plan ni el municipio ni las instituciones intermedias, en la mayor parte de los casos visitados, llevaron adelante tareas de seguimiento o control. Existen casos en los que una vez que se presentaron las boletas de las compras realizadas finalizó la relación con la entidad. Los talleres de serigrafía y de conservas son los únicos que recibieron la visita de una persona del gobierno que controlaba que el emprendimiento se encontrara en funcionamiento y que las máquinas o materiales adquiridos estuvieran en el lugar. En el caso del emprendimiento de serigrafía, las instancias de seguimiento y control, pero también de apoyo, fueron enfáticamente reclamadas:

“[...] nos vimos un poco solos, nos sentimos dejados de lado, llegó un momento que no sabíamos si estábamos a cargo de alguien, quién era 
y por qué no lo hacía. Porque yo recuerdo que Manos a la Obra hasta el momento inmediato que nosotros habíamos completado más del $70 \%$ del dinero y materiales comprados llegó una especie de inspección sorpresa que quería ver si habíamos comprado las cosas [...]. A nosotros nos pareció bien, porque era una manera de auditoria para ver si los materiales se habían usado según lo que habíamos estipulado en el proyecto [...]; nos dijeron que iban a haber más auditorias, inspecciones, un seguimiento y después no pasó más nada [...] [la entidad intermedia] se cambió de lugar, no supimos más el teléfono y no vimos más a nadie. [Necesitábamos contar con gente] en un nivel de cómo organizar la producción, de qué pasa, por qué pasa, que sobra un material y falta otro y eso lo hacía el capacitador, pero porque excedió de lejos lo que tenía que hacer, él tenía que capacitarnos durante cuatro meses y nos capacitó durante un año [...]. También de ver el taller como una institución, de cómo hacer, alguien que nos dijera si nosotros queremos ser esto, y no queremos ser patrones, y queremos trabajar todos con estas reglas y no hubo nadie de ninguna fundación o parte del Estado que nos dijera en qué nos equivocábamos o nos mostrara un ejemplo o un caso que nos dijera hicieron esto y les salió..." (Entrevista a Daniel. Taller de serigrafía).

En otros casos, al estar vinculados con ONG, son estas las que les brindaron el apoyo necesario en términos de capacitación, financiamiento para la producción, comercialización, pago de salarios, etcétera. Además, la intervención de asociaciones o fundaciones en la presentación de los proyectos para su evaluación permitió la obtención más ágil del subsidio para comenzar con las actividades. En algunos de estos casos los proyectos tardaron menos de tres meses en ser aprobados. Estos aspectos serán abordados en detalle más adelante. A continuación analizamos los emprendimientos tomando en cuenta lo desarrollado sobre la economía social.

\section{Características de los emprendimientos}

Las experiencias visitadas presentan características comunes con lo que los autores distinguen como microempresas familiares, emprendimientos o talleres autogestionados, aunque, como dijimos, no pueden enmarcarse en ninguna de estas tipologías. También existen tres experiencias que funcionan como proyectos individuales.

Constatamos que si bien el PNMO financia proyectos asociativos (de tres a ocho personas) aunque se contemplan también experiencias unipersonales, algunos proyectos se presentaron de manera asociada (figuraban más de tres personas) pero al obtener el subsidio, el trabajo era realizado por cuenta propia, sin la intervención de quienes figuraban en el proyecto. La participación de terceras personas se produce, en algunos casos, en las épocas de mayor trabajo. En el caso de la 
chacra, al comenzar sus actividades contrataron a una persona del lugar. Se estipuló un contrato de mediero, característico de las zonas rurales de la provincia, según el cual una parte aporta la inversión y la otra parte el trabajo, y luego se reparten las ganancias en diferentes porcentajes. En este caso el trabajador contratado realiza sus actividades con su familia.

Por el contrario en otros casos el proyecto fue presentado de manera unipersonal, pero al recibir el dinero se repartió en partes iguales entre los integrantes del grupo que se hallaban trabajando en forma conjunta. En el caso de la producción de salsa de tomate, si bien el proyecto se presentó de manera asociativa, posteriormente se trabajó de modo unipersonal, contratando gente del barrio durante la producción pero sin mantener actividades conjuntas el resto del año. A partir de este año intentaban mantener el grupo de trabajo durante todo el año, por lo cual buscaban diversificar la producción a fin de darle continuidad al proyecto. Decidieron también invitar a tres personas más para que se asocien al proyecto, con la propuesta de incorporarlas para la producción y luego repartir lo elaborado por partes iguales (anteriormente a las familias que participaban en el proyecto productivo se les entregaba el $30 \%$ de la producción). Además contrataron a dos personas para las semanas de mayor producción, a las que les abonaban un salario.

En el resto de los casos el trabajo se realiza de manera asociativa, tal como fue presentado el proyecto en su momento. Sin embargo la instancia asociativa presenta numerosas dificultades relacionadas con las experiencias y aprendizajes anteriores de los miembros de los emprendimientos. De allí que parte de los grupos se han disuelto, han cambiado sus miembros o se ha reducido el número de participantes. Los motivos están relacionados con desacuerdos por las responsabilidades asignadas, los modos de trabajar, las prácticas para tomar decisiones que han implementado, aunque la mayor limitación se debe al hecho de que el Plan no permite la reproducción de sus miembros.

En algunos grupos los/as integrantes han cambiado casi completamente por el tiempo que medió entre la presentación del proyecto y la entrega efectiva de las maquinarias y materiales, por razones vinculadas con la necesidad de trabajar y obtener un ingreso, etc. En el caso de confección de ropa algunos miembros abandonaron por el desaliento debido al tiempo transcurrido, o por haber obtenido un empleo:

"El grupo anterior se divide porque estábamos siempre en lo mismo: que esto no salía, nunca salía. Presentamos con ellos el proyecto pero nunca salía, entonces llamábamos y preguntábamos y las chicas estaban muy expectantes a eso y entonces cuando ya no salió entonces 
ya tenían menos ganas de trabajar y ya mucho no les gustaba y entonces las reuní para decirles que teníamos que esperar, invertir para comprar telas y ver qué vamos a hacer, pero en el grupo la idea fue que si salía lo teníamos que dividir, que repartir, ya no tenían el interés porque se empezaron a cansar cuando no salía el proyecto pero porque tampoco había interés propio de cada persona." (Entrevista a Fernanda. Taller textil).

Sin embargo, como dijimos, la mayor limitación es que al ser insuficiente la producción o el ingreso que se obtiene de la comercialización, solo realizar las tareas individualmente garantiza obtener lo necesario para la reproducción. Es esto lo que nos planteaban en el emprendimiento de salsa de tomate, ya que según nos explicaban, el monto entregado para los proyectos no era suficiente para obtener excedentes si trabajan tres personas o más. De allí la necesidad de presentarse en grupo para obtener el plan, pero luego se tornó indispensable trabajar de manera individual para continuar con la actividad. Algo similar ocurrió en el caso del taller de serigrafía donde si bien el grupo estaba conformado por cuatro personas, finalmente los trabajos se tomaban individualmente y en caso de ser necesario, se convocaba a otro miembro. Por esto, más que un trabajo asociativo que implique una organización con reparto de tareas y ganancias entre todos los miembros, lo que encontramos en este caso es que comparten un espacio y los materiales, mas la producción se realiza individualmente:

"Al faltar un seguimiento del Manos a la Obra, vos quedás solo y decís: 'Tengo que empezar a competir de la misma manera que lo hace el serigrafista de la cuadra' y ahí empezamos a hacer lo mismo [...], los costos los tuvimos que manejar de la misma manera porque si no, no se podía competir [...], dentro del grupo cambiamos la visión del tipo cooperativista y fue más bien una especie de cooperativa en cuanto a las herramientas y a las máquinas pero un trabajo individual con respecto a la producción, porque las máquinas, la computadora, la impresora, la tinta eran de todos pero yo encontraba un trabajo y lo que hacía era ir, hacer el trabajo y dejar el costo, y la ganancia era toda mía, si el trabajo era muy grande llamaba a alguno de mis compañeros [...] y eso a la larga fue llevando a un individualismo extremo porque con tal de quedarte con más ganancias vos decías: 'Bueno me demoro tres días trabajando pero toda la ganancia es para mí'. Cuando bueno, el grupo para nosotros fue un intento, y pensamos que eso si nos iba bien a la larga iba a llamar a una cooperativa obligatoria porque si nos iba muy bien íbamos a necesitar cuatro trabajando todo el tiempo. Y nos fue bien y no pasó eso, preferíamos trabajar de a dos y no llamar a los otros, porque ya tenías que trabajar compitiendo con una empresa serigráfica en donde los costos son más bajos, donde nosotros 
tenemos que igualar el precio y esto implica que el margen de ganancia se nos reducía, si lo repartíamos entre cuatro personas la ganancia era miserable entonces preferíamos quedarnos trabajando más horas, pero al final nos terminábamos sobreexplotando nosotros mismos por querer competir con un negocio o una empresa que está dentro del sistema."(Entrevista a Daniel. Taller de serigrafía).

Acerca de la etapa de producción, nos interesaba conocer por un lado los modos cómo los grupos se organizan en términos de división del trabajo, reparto de responsabilidades y ganancias y toma de decisiones. A partir del trabajo de campo realizado encontramos que existen dificultades para la organización del grupo, aunque también en este aspecto se presentan importantes diferencias.

En la mayor parte de los casos la producción se encuentra limitada por las posibilidades de reproducción de sus miembros. Para los emprendimientos de invernadero, chacra y elaboración de salsa de tomates, que conforman una cadena productiva, la posibilidad de permanecer en esta actividad está dada porque reciben una remuneración mensual de la asociación para la cual trabajan, que se dedica al fomento de emprendimientos de economía solidaria. De este modo al tener su reproducción asegurada, los emprendedores pueden trabajar de manera exclusiva en los emprendimientos del Plan. En el resto de los casos se presenta una constante: solo logran continuar los grupos en los cuales sus miembros tienen asegurados sus ingresos por otros medios (reciben un plan social, no son el sostén del hogar, reciben un ingreso por otra actividad), ya que de lo contrario lo que producen en los emprendimientos no logra ser comercializado o lo que obtienen no alcanza para la reproducción de la vida de sus miembros. En algunos casos lo percibido ha sido reinvertido en su totalidad en el emprendimiento para continuar con la producción. En el caso de las mujeres de las conejeras, la posibilidad de continuar con sus actividades está dada porque las mismas cobran mensualmente un plan social. Dos de los miembros del emprendimiento de serigrafía se encuentran trabajando en relación de dependencia en otra actividad y mantienen el proyecto como un ingreso extra, de allí que es una actividad que pueden realizar solo los fines de semana o durante las noches. Las mujeres del emprendimiento de dulces y conservas nos comentaban que para ellas el Plan es una "ayudita", ya que cuentan con empleos estacionales, por lo que cuando quedan sin trabajo, tener dulces y conservas les resulta de gran ayuda. Quien trabaja en el invernadero nos comentaba a propósito de este tema que si bien el Plan entrega un dinero inicial para comenzar o continuar con una actividad, por sí solo no da la posibilidad de subsistir ya que media un lapso prolongado de tiempo hasta comenzar a comercializar los productos, por lo 
tanto si bien los emprendedores logran una dotación inicial, después se les hace imposible sobrevivir si no cuentan con otro ingreso. De allí el fracaso gran parte de los emprendimientos que comenzaron sus actividades conjuntamente en el mismo lugar.

La organización de la producción también presenta algunas diferencias. Acerca de la división del trabajo en algunos emprendimientos el trabajo es unipersonal pero se contratan personas en determinadas épocas del año, según la estacionalidad de la producción. En aquellos donde el trabajo se realiza asociativamente, la división del trabajo no se estipula formalmente, aunque al llevar adelante las tareas se asumen diferentes responsabilidades en relación a la necesidad del momento y no a una verdadera división del trabajo organizada. En la producción de salsa de tomates notamos un reparto de las tareas en función del género, ya que las mujeres se encargaban en su mayoría de las tareas relacionadas con la manipulación de la verdura (lavado, corte, extracción de semillas, triturado, llenado de las botellas) mientras que los varones se encargaban de las tareas vinculadas con la organización de la actividad (conseguir botellas, trasladar el tomate desde la finca, encender y cuidar el fuego, etc.). En el caso del emprendimiento gráfico las tareas se han repartido atendiendo al conocimiento y experiencia de cada miembro. El caso del emprendimiento textil es bastante particular ya que cuentan con un reglamento escrito, confeccionado por una de ellas y puesto a consideración del grupo, donde se estipula el reparto de tareas en función de las habilidades y gustos de cada una. Sin embargo no se han contemplado las tareas de comercialización. Este grupo no obstante no ha puesto en práctica esta organización ya que aún no comienza a trabajar en tareas productivas.

Respecto del tiempo de trabajo, en algunos casos se reúnen diariamente y en otros solo lo hacen los fines de semana, en función de los trabajos encargados. En otros se reúnen para las épocas en las que cuentan con materias primas para producir, sin lograr una continuidad de sus actividades.

Acerca de la toma de decisiones, nos interesa destacar que son instancias en las que se reúne la totalidad del grupo. En la mayor parte de los emprendimientos visitados se realizan reuniones periódicas para poner en discusión las decisiones que deben tomar. Algunos emprendimientos, por las características del producto o del grupo, trabajan de manera individual pero cuentan con instancias de reunión para discutir distintos aspectos que hacen a su funcionamiento. En el caso de los emprendimientos que conforman una cadena productiva, se reúnen para discutir los aspectos vinculados con la actividad en su totalidad. Nos interesa destacar en este sentido lo que nos decía quien trabaja en el invernadero acerca de la diferencia importante entre el 
trabajo que realizaba anteriormente como empleado en un vivero, en el cual las reuniones le parecían una pérdida de tiempo; y cómo en esta actividad que realiza actualmente ha comenzado a valorar la importancia que las mismas tienen, en la medida que su palabra tiene un valor ya que puede incidir en las decisiones que se toman. La instancia de aprendizaje que las reuniones tienen, fue también destacada por él. Consideramos que esta participación en las decisiones entraña un aspecto político que se vincula a las propuestas de economía social y desarrollo local. No obstante percibimos en los grupos la presencia de fuertes liderazgos vinculados con características personales, tales como la capacidad de organizar e impulsar nuevas ideas y propuestas, el compromiso que los miembros tienen con el proyecto y sus objetivos, las experiencias de participación comunitaria anteriores y también en algunos casos con poseer el saber técnico.

"Las cosas se hacían entre todos aunque no todas las ideas eran de todos, pero no se imponía porque el grupo no nació con esa idea." (Entrevista a Daniel. Taller de serigrafía.).

Por último, en relación al reparto del remanente, encontramos que en los casos donde la tarea se realiza grupalmente, estas han sido repartidas por partes iguales entre quienes han participado en la producción. En el caso del emprendimiento gráfico se estipuló una distribución diferencial basada en las responsabilidades y en la dedicación horaria de cada uno/a al proyecto. Por último, en el caso de la producción de dulces y conservas, la misma se realiza con fines de autoconsumo, por lo cual en los casos que han comercializado algo, lo obtenido ha sido destinado a la compra de frascos y tapas para la producción de la próxima temporada. Lo mismo ocurre en la cría de conejos, donde lo obtenido por la comercialización ha debido ser reinvertido íntegramente.

Esto nos remite a analizar la etapa de la comercialización. Como se ha traslucido de lo expuesto hasta acá, esta etapa presenta serios inconvenientes ya que en la mayor parte de los casos la comercialización presenta dificultades, ya que se desconoce dónde y cómo vender lo producido debido a que los/as emprendedores/as carecen de la capacitación necesaria:

"Nosotras aprendimos algunas cosas en un estudio de mercado que hicimos [por nuestra cuenta] porque lo primero que hicimos fue hacer de todo un poco, que es una cosa que no te resulta porque en cualquier cosa que emprendas necesitás primero que nada el estudio de mercado, sin lugar a dudas. Eso no nos dio resultado, el hacer un poquito de cada cosa porque no sabíamos después a quién le íbamos a vender 
[...]. La comercialización es lo más flojo que tenemos, nos cuesta salir y vender, y además hay mucha competencia con las marcas, con la ropa que traen de otros lugares. Además hay gente que no sabe el costo [...]. Entonces hay mucha gente que cree que lo que vos vendés es ganancia, y no es ganancia sino que hay que cubrir los gastos y reinvertir para capitalizarse. El costo no nos permite que haya un buen margen de ganancia para vender en los negocios, porque entonces tendríamos que trabajar para el negocio nomás, por eso queremos ver si podemos vender nosotros por nuestra cuenta. [...]. Por eso también pensamos en achicar el grupo porque si no la ganancia que nos queda es muy poca, no da para muchas personas, para poder salir con las prendas da para poco" (Entrevista a Fernanda. Taller textil).

No encontramos que el Plan haya brindado alguna capacitación en este sentido y tampoco se ha previsto la conformación de redes de comercialización que permitan la ubicación de los productos de los distintos emprendimientos. Por eso los emprendedores precisan contar con lugares donde comercializar sus productos, teniendo en cuenta que el intento de colocar lo que producen en el mercado les ha resultado imposible, ya que se ven obligados a competir con precios de venta que son, en muchos casos menores a los costos de lo que han producido. Lo que encontramos en los casos visitados es que la propuesta del Plan de vincularse y competir con el mercado se torna imposible para los emprendimientos, que finalmente se encuentran ante la decisión de ofrecer sus productos en la comunidad que presenta severas limitaciones dada la escasez de recursos que las caracteriza, o autoexplotarse (como nos decían algunos de los emprendedores entrevistados) para intentar vender los productos en el mercado, que implica ofrecerlos sin obtener ganancia alguna o reducir la cantidad de miembros del emprendimiento para lograr obtener algún remanente. La posibilidad de comercializar los productos plantea la necesidad de adoptar ciertas decisiones a nivel grupal: continuar trabajando de manera autónoma y autogestionada o comenzar a hacerlo en una relación que podríamos denominar de dependencia con una institución o empresa. Esto nos decía un emprendedor:

"[La organización que les alquilaba un local para trabajar] nos estaban obligando a maternos en algún proyecto, mandaban el palito de que va a venir un proyecto de textil y entonces tenían pensado hacer un proyecto de textil y que impriman porque si no este lugar lo pueden ocupar para una cámara frigorífica [...] como diciendo 'Mirá, nos tienen que servir a nosotros o si no se tienen que ir'. Y pasó a ser eso, pasó a ser lo que nosotros temíamos: tener que trabajar para ellos con la condición de estar ahí, o sea, vivir y trabajar ahí con la condición de trabajar para ellos. Por lo que nos decían ellos íbamos a estar trabajando mínimo 8 horas 
a un costo, un precio menor que lo que trabajábamos en la calle y ahí nosotros nos habíamos acostumbrado a trabajar así, particularmente. Dentro del grupo se planteó, [otro integrante del grupo] dice 'Vamos a estar diez horas trabajando para ellos, bueno pero entonces ¿lo que queremos es trabajar o no?' Pero tenía razón, no de esta manera, porque íbamos a tener que bajar los costos y bajar las ganancias por trabajar $8 \mathrm{o}$ 10 horas, según el planteo que nos hicieron. [...] Y nosotros queríamos trabajar, la idea nuestra era mas allá de todas las instituciones, mas allá de la fundación, del plan, que era dejar de ser explotados y de última explotémonos nosotros mismos pero sin que caiga todo en un patrón y no se logró nunca" (Entrevista a Daniel. Taller de serigrafía.)

Los emprendimientos de servicios (serigrafía y gráfica) son los que han tenido mayor posibilidad de comercializar, sin embargo ya apuntamos anteriormente las limitaciones que el grupo de serigrafía debió enfrentar en este sentido.

También Fernanda comentaba algo al respecto:

"[Acerca de la posibilidad de formar un grupo con otros emprendimientos textiles] Lo que nosotros planteábamos es que era buena la idea [de juntarlos] por un lado, pero yo no estoy de acuerdo de trabajarle a otra persona porque la idea era conseguir trabajos en un negocio para que los hiciéramos los emprendimientos. Entonces bueno, nosotras armamos esto y las chicas de otro lugar hacen los ojales, pero qué pasa, obvio que la ganancia es más que mínima y entonces nosotras decíamos eso ya sufre un desgaste que vos no lo llegás a recuperar con lo que vos ganás. Entonces la idea es buena de agrupar a todos los textiles pero hacer nuestra marca, nosotras todas agruparnos y vamos a sacar la marca y nosotras en el mercado esa marca trabajamos, no trabajar para otra persona porque caemos en lo mismo." (Entrevista a Fernanda. Taller textil.)

Un aspecto que queremos destacar relacionado con esto, es la importancia de las experiencias personales de quienes conforman los emprendimientos. En algunos de los casos visitados nos encontramos con personas que tienen experiencias anteriores en trabajos comunitarios y cuentan por esto con una red de relaciones sociales que se torna de enorme importancia para permitirles vender los productos u ofrecer los servicios entre las personas conocidas. En estos casos el territorio donde están ubicados funciona como un entorno favorable para potenciar sus ventas. Pero para la mayor parte de los emprendimientos, el estar ubicados en zonas empobrecidas o marginales, los limita para ofrecer sus productos o servicios en la comunidad. La vinculación con las organizaciones es también un factor importante al momento de facilitar la venta de los productos, según veremos más adelante. 
Encontramos entonces que la comercialización es, como nos comentaba un emprendedor, "el cuello de botella de estos planes" (Oscar, emprendimiento salsa de tomate) ya que la imposibilidad de ubicar los productos genera límites importantes para proyectar cierta continuidad de las actividades. Este aspecto no ha sido contemplado debidamente en el PNMO ya que, aun cuando en sus lineamientos se establece la importancia de brindar servicios más allá de lo productivo, en las experiencias recopiladas aparece que los otros aspectos indispensables para la continuidad de las actividades de los emprendimientos (incluido el financiamiento y entrega de créditos), no han sido atendidos. Hasta el momento de realizar nuestro trabajo, el Plan se ha limitado a la entrega de una suma de dinero para comenzar con las actividades, mas no ha habido otro tipo de apoyo, o no de manera formal. Encontramos sí algunos emprendimientos que han logrado obtener alguna ayuda posterior por parte del municipio o asociación con la que se hallan vinculados, mas esto ha sido realizado de manera informal, no como parte del plan. Veremos esto más adelante, al analizar las vinculaciones de las instituciones.

Para finalizar con la caracterización de los emprendimientos en función de los lineamientos de la economía social, queremos destacar un último aspecto relacionado con la instancia comunitaria. En algunos casos la dimensión comunitaria cobra gran importancia, mas esto se debe a las experiencias de sus miembros y no al énfasis, seguimiento o capacitación realizada por parte del Plan. Algunos emprendedores contaban con experiencias en proyectos comunitarios (salsa de tomates, chacra y gimnasio), en otros la lucha conjunta por la propiedad de la tierra (cría de conejos) o la participación en instancias de trabajos grupales por formar parte de una fundación o partido político (serigrafía, gráfica y conservas) favorecieron la realización de un trabajo conjunto, con un fuerte énfasis en la promoción de la comunidad a la que se buscaba implicar de algún modo en el proyecto. Sin embargo, esta instancia que es resaltada en los lineamientos del Plan no es posteriormente promovida, sino más bien se la deja librada a cada experiencia concreta. De acuerdo a nuestro análisis, es la propia experiencia de los/as emprendedores/as lo que determina finalmente la participación y vinculación con la comunidad, en cada caso.

\section{Papel de las instituciones intervinientes. Vinculaciones con los emprendimientos}

Lo manifestado anteriormente nos permite esbozar algunas ideas acerca de la importancia de las organizaciones que intervienen en la aplicación del Plan. Hacíamos referencia antes a la participación que las organizaciones no gubernamentales (ONG) y los municipios tuvie- 
ron al momento de presentación de los proyectos, ya que mientras en algunos casos la intervención de ciertas ONG facilitaron y agilizaron la presentación y obtención de los recursos, en otros se presentaron numerosos problemas que más tarde han sido difíciles de superar. En los casos con mayores inconvenientes la presentación de los proyectos estuvo a cargo de los municipios.

También hicimos referencia al papel que las organizaciones tienen en términos de posibilitar la reproducción de los miembros de los emprendimientos, y con esto, permitir la continuidad del proyecto. En el caso de los emprendimientos que se hallaban vinculados con las ONG, estas prestaron servicios diversos: algunas pagan salarios mensuales a quienes se encuentran trabajando en los emprendimientos, otras brindan financiación (chacra y producción de salsa), ofrecen lugares para trabajar (serigrafía), les brindan apoyo institucional para presentarse a proyectos y subsidios y en un caso también conformaron un fondo rotatorio que les permitió adquirir lo necesario para la producción y vincularse con otros grupos de la zona (conservas).

En el caso de los emprendimientos de chacra y producción de salsa de tomate, la asociación con la que trabajan cuenta con una comercializadora. De este modo alivia a los emprendedores de la obligación de encargarse de la comercialización, aunque según nos comentaban, el precio al que les compran los productos es muy bajo en relación con lo que pueden obtener vendiendo por su cuenta. Esto cobra mayor relevancia en la medida que al ser dificultosa la etapa de la venta y ser el "cuello de botella" de estas experiencias, se genera una relación de dependencia con las organizaciones con las cuales están articulados.

En la relación de los emprendimientos con las organizaciones, se manifiesta la dependencia aun cuando las mismas se vincularon con los municipios, ya que algunos de ellos adquieren los productos que fabrican los/as emprendedores/as. El caso de la cría de conejos es un ejemplo en el que además, es este el que les provee algunos insumos necesarios para continuar con la producción. Este municipio, a fin de permitir la comercialización de la producción, inauguró un frigorífico recientemente. Sin embargo los precios que propone pagar para la compra de conejos, según manifestaban las mujeres, no les resultan convenientes ya que no alcanzan a cubrir los costos de la producción.

"Hay tres proyectos de conejos [en la zona, el marido participa en uno], ¿pero dónde los vendemos? En la cooperativa de la municipalidad los pagan muy poco, hay que comprar y todavía debés, porque vas y cambiás por alimento. Yo tenía una vecina que hizo el proyecto de la municipalidad y ella iba, llevaba conejos, traía alimentos y además quedaba debiendo. Porque [...] el municipio inauguró un frigorífico antes de las elecciones de diputado, las últimas que hubo, el intendente 
lo inauguró, pero por ejemplo ya hay mucha gente que no, que ya se ha dado cuenta, por ejemplo yo fui a una reunión que nos conversaron eso de Chile, que supuestamente nosotros tenemos que hacer los contratos, pero tenemos que hacer un contrato por 5 años ¿y si te sale otra cosa mejor? Pero también el pago es el alimento hasta que sale el conejo" (Entrevista a Gabriela. Emprendimiento de conservas y dulces.)

A partir de lo analizado y siguiendo a Razeto, podríamos decir que la mayor parte de los emprendimientos visitados son talleres incompletos, en la medida que mantienen relaciones de dependencia con las instituciones que los presentaron: ya sea para obtener créditos o financiación, alimentos, pago de salarios, personería jurídica para presentarse en nuevos subsidios, etc. Lo que notamos es que lejos de lograr una autonomía, la mayor parte de los emprendimientos visitados precisan de las organizaciones para continuar con sus actividades. Esto muestra los límites que existen para la construcción del sector de la economía social, en la medida que los emprendimientos no logran ser autosustentables.

Además, esta situación genera límites en cuanto a la posibilidad de autogestionarse, otra de las características que se considera debe poseer una organización de economía social. En algunos casos son las organizaciones con las que se hallan vinculados las que toman las decisiones en torno al proceso productivo (incluyendo la comercialización y distribución). En los casos como el municipio que inaugura un frigorífico, las asociaciones que buscan articular a los emprendimientos con empresas para que trabajen por encargo, o la que posee la comercializadora; percibimos la imposibilidad que los emprendedores tienen de llevar a la práctica sus propias ideas y decisiones acerca de la totalidad del proceso que están realizando.

El único emprendimiento que ha logrado mantener sus actividades sin relaciones de dependencia es el emprendimiento de gráfica, cuyos miembros, si bien cuentan con otras fuentes de ingresos (familiares y otras actividades laborales) tenían experiencia y conocimientos sobre el tema: conocían el oficio, ya que ambos emprendedores habían ya trabajado en esa actividad y cuentan con una clientela. Pero además, hay otros factores que inciden en la posibilidad de continuar con la actividad. La misma situación podemos encontrar en el grupo de jóvenes de serigrafía. Podríamos decir que los participantes de ambos grupos corresponden a una clase media, empobrecida en la década del noventa, que hace que dispongan de un capital social y una capacitación previa que les permiten llevar adelante la producción en condiciones diferentes al resto de los grupos visitados. La comunidad donde están ubicados estos emprendimientos marca también una diferencia, ya que trabajan en zonas urbanas donde pueden ofrecer sus servicios y donde hay una mayor capacidad para adquirirlos que la 
que se presenta en el resto de los casos. Además de estos factores, encontramos que al tratarse de personas que contaban con experiencias previas en la actividad, conocen todo lo relacionado con la producción, los posibles clientes, las formas de comercialización, etc. Por otro lado, también creemos que el rubro en el que se especializaron les permitió contar con mejores condiciones de comercialización, ya que se trata de servicios que escasamente son ofrecidos por otros emprendimientos. La diferencia de resultados en función de los rubros que trabajan los emprendimientos era señalada por quien realiza tutorías a diferentes grupos, quien planteaba que quienes realizan prestación de servicios se encuentran en mejores condiciones que el resto, factor que debería haberse atendido al momento de aprobar los proyectos, muchos de los cuales no contemplaron la posible colocación del bien (entrevista a tutor de una ONG de proyectos del PNMO). Observamos que las organizaciones que intervienen tienen un rol protagónico, en lo que hace a favorecer el desarrollo y la continuidad de los emprendimientos. Sin embargo las relaciones entre estas presentan rasgos de fuerte dependencia más que de acompañamiento y capacitación.

Existe un caso interesante que es el de una asociación que cuenta con una Escuela de Emprendedores. Quien participó en el emprendimiento del gimnasio, asistió a la capacitación que brinda la escuela, en la cual les daban herramientas para llevar a la práctica esta actividad. Los contenidos que brindan están referidos a los diferentes aspectos que deben tener en cuenta en la producción, organización, comercialización, marketing y publicidad, administración, nociones básicas de economía social, y posteriormente los prepara para la presentación de proyectos. Sin embargo esta capacitación es insuficiente para lograr los objetivos del Plan, según nos comentaba el emprendedor, en la medida que se vuelve necesario contar con apoyos de la organización una vez iniciada la actividad, referidos a la comercialización, financiación, organización, factores que actúan como posibilitadores de la continuidad de la actividad (entrevista a emprendedor de gimnasio, febrero de 2006). Los emprendimientos vinculados a esta Escuela mantienen relaciones de tipo paternalistas, nos decía un emprendedor, en la medida que no pueden por sí solos tomar decisiones de todo el proceso en su conjunto, ya que solo pueden decidir acerca de la producción.

Queremos hacer referencia a un aspecto que en el marco de la economía social se presenta como de gran importancia para posibilitar la permanencia de estas organizaciones. Nos referimos a la conformación de redes entre emprendimientos. Algunos de los emprendimientos visitados establecieron contactos con otras experiencias similares y han tenido la posibilidad de participar en reuniones con asociaciones. Esto les permitió conocer a otras organizaciones y verificar que se encontraban 
en situaciones similares: dificultad en la recepción de los materiales, en la producción y las ventas. Sin embargo en la mayor parte de los casos, para la conformación de una red, las asociaciones les imponían condiciones para la compra de los bienes o servicios o para la producción, que implicaban una subordinación completa a las reglas establecidas por ellas. Estas reglas implicaban en la mayor parte de los casos, que el trabajo se realizara en condiciones de autoexplotación, según lo definieron algunos emprendedores, ya que consistía en trabajar por encargo para empresas. Por esto consideramos que si bien para la mayor parte de los emprendedores la posibilidad de realizar una actividad productiva tiene una enorme importancia, ya que es lo que les permite trabajar y lograr la reproducción, en los dos casos en los que esta situación se presentó (taller de serigrafía y textil) la importancia de la actividad radica también en que este trabajo les permita la reproducción, y sea realizado en condiciones de autonomía, "sin un patrón que se apropie de lo que producimos" (Entrevista a Daniel. Taller de serigrafía.).

Queremos resaltar a partir de estas narraciones, que la red de instituciones y emprendimientos que se consideran necesarias para el desarrollo de este sector de la economía no se encuentra en funcionamiento de acuerdo a los criterios de autogestión, asociación, valoración del trabajo humano, horizontalidad, participación y ampliación de la democracia, que son algunos de los requisitos para pensar en la construcción de una economía social. Vislumbramos por un lado una dificultad para articular a las diferentes instituciones entre sí y con los emprendimientos. Pero además, en los casos que esto es posible, los emprendimientos aparecen como subordinados a las actividades propuestas por las primeras, debiendo someterse a sus lógicas de funcionamiento, que muchas veces no son ajenas a las que impone el mercado. Por esto pensamos, de acuerdo a algunos autores analizados, que la construcción de un sector de economía social, en caso de ser posible, solo lo será si incluye transformaciones en lo político, en lo cultural, en lo social y en lo económico. De otra manera el cambio propuesto por el Plan, lejos de promover una transformación, resulta más bien una política social más que, aunque se presente con visos innovadores, produce finalmente los mismos efectos que las anteriores.

\section{A Modo de Conclusión}

A lo largo del trabajo hemos intentado vincular las nociones de Economía Social y Desarrollo Local con los modos como se organizan los emprendimientos que recibieron el subsidio del Plan Nacional de Desarrollo Local y Economía Social Manos a la Obra.

Si bien la literatura sobre economía social la presenta como una propuesta capaz de plantear alternativas al capitalismo (en relación a 
los modos de producción y relación entre las personas, el concepto de democracia y desarrollo hoy imperantes) consideramos que la construcción de la misma resulta en la actualidad una expresión de deseo más que una posibilidad concreta. Por un lado a partir de lo analizado sobre la implementación y puesta en funcionamiento del PNMO podemos constatar la insuficiencia de lo que el mismo promueve para la construcción de un sector económico alternativo. No solo el modo como el mismo se implementó, sino también las formas de organizar la producción o la exigencia de competir en el mercado, hace que percibamos una tensión entre los planteos de la economía social y el desarrollo local y lo que efectivamente ocurre en la puesta en práctica del Plan.

La construcción de un nuevo sector de la economía debe tender a propiciar los distintos aspectos que permiten la efectiva realización de actividades alternativas, lo que consideramos que en el caso del Plan no ha sido realizado. No obstante, consideramos necesario tomar en consideración que las experiencias de los emprendimientos son muy recientes, vale recordar que el Plan tiene tres años desde su implementación y que gran parte de los emprendimientos visitados recién han recibido sus materiales hace menos de un año, y algunos incluso no los han recibido en forma completa; de allí que estimamos prudente considerar que todo abordaje del mismo debe plantearlo en términos de proceso y prestar atención al hecho de que los emprendimientos están en una etapa inicial de su actividad.

Planteamos algunas cuestiones relacionadas con los sujetos a los que el Plan interpela: los vecinos y al énfasis otorgado al trabajo comunitario y asociado. Si bien el Plan busca rescatar los valores relacionados con el trabajo asociativo y comunitario, en la práctica promueve la construcción de otro sujeto, un sujeto microempresario, con lógicas similares a las que rigen en el mercado capitalista y que los equipara a los propietarios de los medios de producción instándolos a competir en el mercado. Esto implica por un lado desconocer las limitaciones que estas experiencias presentan, que analizamos a lo largo del trabajo y que son numerosas y constituyen verdaderos problemas para dar continuidad a la actividad. Pero además, implica desconocer los planteos de la economía social, que promueve la existencia de otra lógica alternativa a la del capital, y la importancia de que la misma se extienda al resto de la economía y no viceversa. En el caso del Plan pareciera no haberse atendido este aspecto. Avalan esto algunos ejemplos expuestos a lo largo del análisis del trabajo de campo, pero además, quien trabaja como tutor de emprendimientos nos planteaba que el enfoque sobre los emprendimientos es un enfoque neoliberal, en la medida que busca asimilarlos a una empresa pequeña y que por lo tanto su tarea de tutor consiste en gran medida en asesorarlos para que se inserten en el 
mercado (Notas tomadas en junio de 2006). El ser emprendedor lleva implícita para este Plan la idea de empresario o microempresario por lo que intenta imprimir a estas experiencias comunitarias y solidarias la lógica de funcionamiento de los mismos. Por esto, lejos de plantearse una búsqueda de alternativas, lo que resulta es que expande los valores económicos dominantes a las diferentes organizaciones que se dan los sectores populares para la sobrevivencia y que escapan en su mayoría a la lógica dominante. Constatamos así que el Plan por un lado rescata y coloca en el espacio público las distintas experiencias comunitarias que se dan los sectores excluidos del mercado de trabajo, pero finalmente propone una creciente mercantilización de vínculos y estrategias de supervivencia que escapaban al cálculo racional y a la lógica del mercado, desarticulando estas experiencias organizativas, en la medida que les proponen un desafío que resulta imposible: producir para competir en el mercado. Además, el discurso que proponen presenta ciertas contradicciones en la medida que por un lado apela a valores comunitarios y solidarios pero en un contexto en el cual los valores hegemónicos son fuertemente individualistas y basados en la competencia. El resultado pareciera ser que se imponen valores diferenciales para los distintos sectores sociales: para los sectores desfavorecidos se apela a la voluntad, el compromiso social, la solidaridad y la participación para encontrar soluciones a la situación en la que se hallan, mientras que para el resto de la sociedad los valores imperantes están vinculados al individualismo extremo: la búsqueda de beneficio, la eficiencia, la competencia.

Constatamos una vez más cómo, siguiendo los planteos de los organismos internacionales y la lógica de las políticas sociales de los noventa, la salida de las situaciones de exclusión recaen en la responsabilidad de los sectores desfavorecidos, que deben comprometerse en llevar adelante tareas que promuevan su inclusión. Esto permite tomar en consideración el modo como las instancias gubernamentales dejan de lado los motivos por los cuales la pobreza y la exclusión se producen y reproducen, y se apela al voluntarismo y el esfuerzo propio y compartido para superar estas situaciones. Esta lógica produce una curiosa inversión: se responsabiliza a las personas de su situación y hace recaer en ellas las tareas y responsabilidades necesarias para la salida de la pobreza y la indigencia, comprometiéndolos en la solución a sus problemas y desatendiendo las causas estructurales que hicieron posible que se encuentren excluidos.

Además pareciera que reina un total desconocimiento de la calidad de empleo que se está creando; que en las actuales condiciones, en este contexto, este tampoco permite la inclusión social, en la medida que se trata de empleos precarios, que no otorgan derechos y no garantizan la reproducción. Decimos esto porque el Plan, al igual que las 
políticas sociales de empleo implementadas, enfatiza al empleo como necesario para el logro de la inclusión social. Esto se agrava en el caso de los emprendimientos del Plan que logran mantener a las personas ocupadas, pero de ninguna manera podemos decir que se encuentran "trabajando", si por esto entendemos todas aquellas actividades que se realizan para el logro de la reproducción de la vida del trabajador y su familia y que permite el ejercicio de ciertos derechos vinculados con el mismo. Es por esto que estas políticas promueven la ocupación de las personas en actividades que pueden propiciar cambios en cuanto a la participación, la adquisición de la noción de derechos de ciudadanía (cuya garantía es avasallada por el mercado), la capacitación y aprendizaje de habilidades; aspectos que no pretendemos desmerecer en ningún caso, pero que finalmente no logran modificar las condiciones materiales de vida de quienes son considerados beneficiados, demostrándose, una vez más, las limitaciones que las políticas sociales presentan en tanto se dejen intactos los intereses del capital y permanezcan inmodificables las políticas económicas.

En relación a esto queremos recalcar el valor del trabajo humano, que es uno de los pilares de la economía social y del PNMO. Consideramos que valorar el trabajo humano implica retribuirlo de manera tal que permita la reproducción ampliada de la vida. Lo que encontramos es que por el contrario, son pocos los emprendimientos que logran obtener lo necesario siquiera para la reproducción simple, y que cuando estos se vinculan con organizaciones, las mismas comercializan los productos, pero a precios que no alcanzan siquiera para cubrir los costos que deben afrontar. Por esto nos preguntamos por la supuesta valoración que se propone del trabajo. Consideramos entonces que si la propuesta del Plan es construir una economía social y con esto revalorizar el trabajo y promover la cultura del trabajo, deberían darse las condiciones para que esto efectivamente se cumpla. Con esto el Plan logra efectivamente mantener ocupadas a las personas pero de ningún modo lo que hacen puede ser considerado como trabajo, en la medida que no garantiza siquiera la subsistencia.

Consideramos entonces que lo que se promueve con este Plan es brindar apoyo a estas experiencias de trabajo informal y economía de subsistencia, pero que carece de un marco que verdaderamente brinde a quienes conforman los emprendimientos la posibilidad de lograr la inclusión social que, según dice, es el objetivo que persigue. Mientras se siga promoviendo una articulación entre economía social y economía de mercado, lo único que se logrará será la subordinación de la primera a la segunda y la autoexplotación de quienes participan en estas experiencias. Los emprendimientos del sector de la economía social terminan de este modo siendo útiles y funcionales al sistema en 
la medida que permiten una mayor acumulación del capital por parte de los sectores dominantes y las políticas sociales continúan sirviendo a los intereses del capital. Tal como plantea Borón:

"En la medida en que sigamos escuchando que hay propuestas de resolver o mejorar la cuestión social en el marco doctrinario del neoliberalismo, debemos saber que las mismas están irremisiblemente condenadas al fracaso" (Borón, 2000: 379).

\section{Bibliografía}

Acosta, Yamandú 2005 Sujeto y democratización en el contexto de la globalización. Perspectivas críticas desde América Latina (Montevideo: Universidad de la República y Cooperativa Comunidad del Sur).

Antunes, Ricardo 2003 (1999) ¿Adiós al trabajo? Ensayo sobre las metamorfosis y el rol central del mundo del trabajo (Buenos Aires: Herramientas).

Arocena, José 1998 "Discutiendo la Dimensión Local. Las coordenadas del debate" en Descentralización y desarrollo local. Análisis, experiencias y propuestas (Montevideo: Revista Uruguaya de Ciencias Sociales, CLAEH 45/46)

Arroyo, Daniel s/f "Desarrollo local y economía social: aportes para su discusión" en Foro Federal de Investigadores y Docentes: La Universidad y la Economía Social en el Desarrollo Local. Disponible en <www.desarrollosocial.gov.ar>.

Arroyo, Daniel 2003 "Políticas sociales municipales y modelos de planificación en la Argentina" en Burín, David y Heras, Ana Inés (comps.) Desarrollo Local. Una respuesta a escala humana a la globalización (Buenos Aires: Ciccus / La Crujía).

Arruda, Marcos 2000 "Globalização e desenvolvimento comunitário autogestionário" en Arruda, Marcos y Boff, Leonardo Globalização: Desafios socioeconômicos, éticos e educativos (Petropolis: Vozes).

Borón, Atilio 2000 "El lugar de la desigualdad en el paradigma neoliberal" en Lozano, Claudio (comp.) Democracia, estado y desigualdad (Buenos Aires: Ed. Universitaria).

Carbonetto, Daniel 1997 "El sector informal y la exclusión social" en Villanueva, Ernesto (coord.) Empleo y globalización. La nueva cuestión social en la Argentina (Buenos Aires: Universidad Nacional de Quilmes).

Cohen, Ernesto 1988 "La microempresa: notas para su análisis" en Rofman, A. y Moreno, G. (comps.) Generación de empleo. La microempresa como alternativa (Buenos Aires: CEUR). 
Coraggio, José Luis 1998 Bases para una nueva generación de políticas socioeconómicas: la economía del trabajo o economía popular (Porto Alegre: Enc. Cultura y Socioeconomía Social).

Coraggio, José Luis 1999 Política social y economía del trabajo. Alternativas a la política neoliberal para la ciudad (Madrid: Miño y Dávila).

Coraggio, José Luis 2003 "La economía social como vía para otro desarrollo social", disponible en <www.urbared.ungs.edu.ar>.

De Jesús, Paulo 2004 "Desarrollo local” en Catani, A. La otra economía (Buenos Aires: Altamira).

De Sousa Santos, Boaventura 2003 La caída del Angelus Novus: ensayos para una nueva teoría social y una nueva práctica política (Bogotá: ILSA / Universidad Nacional de Colombia).

Di Pietro Paolo, Luis José 2003 "Hacia un desarrollo integrador y equitativo: una introducción al desarrollo local" en Burín, David y Heras, Ana Inés (comps.) Desarrollo Local. Una respuesta a escala humana a la globalización (Buenos Aires: Ciccus / La Crujía).

Féliz, Mariano 2005 "La reforma económica como instrumento de disciplinamiento social: la economía política de las políticas contra la pobreza y la desigualdad en Argentina en los '90" en Álvarez Leguizamón, Sonia (comp.) Trabajo y producción de la pobreza en Latinoamérica y el Caribe (Buenos Aires: CLACSO).

Forni, Floreal H. (comp.) 2004 Caminos solidarios de la economía argentina. Redes innovadoras para la integración (Buenos Aires: Ciccus).

Gaiger, Luiz Inácio 2004 “Emprendimientos productivos solidarios” en Catani, Antonio David La otra economía (Buenos Aires: Altamira).

Golbert, Laura 2004 ¿Derecho a la inclusión social o paz social? Plan Jefas y Jefes de Hogar Desocupados (Santiago de Chile: Naciones Unidas).

Grassi, Estela 2003 Políticas y problemas sociales en la sociedad neoliberal (Buenos Aires: Espacio).

Heras, Ana Inés y Burín, David (comps.) 2003 Desarrollo Local. Una respuesta a escala humana a la globalización (Buenos Aires: Ciccus / La Crujía).

Hinkelammert, Franz y Duchrow, Ullrich 2003 La vida o el capital. Alternativas a la dictadura global del capital (San José de Costa Rica: DEI).

Hintze, Susana (ed.) 2003 Trueque y economía solidaria (Buenos Aires: Prometeo).

Hintze, Susana; Federico Sabaté, Alberto y Coraggio, José Luis 2003 "Documento Base de la Jornada Nacional sobre Trueque y Economía Solidaria" en Hintze, Susana (ed.) Trueque y economía solidaria (Buenos Aires: Prometeo).

Mance, Euclides André 2004 “Cadenas Productivas Solidarias" en Cattani, Antonio David (org.) La otra economía (Argentina: Altamira). 
Martínez Nogueira, Roberto 1988 "Racionalidad, riesgo y viabilidad de la microempresa" en Rofman, Alejandro y Moreno, Guillermo (comps.) Generación de empleo. La microempresa como alternativa (Buenos Aires: CEUR).

Mercau, Fernando 1991 Las experiencias económicas populares, ¿un espacio alternativo? (Buenos Aires: CEDEYEP).

Rapoport, Mario 2000 Historia económica, politica y social de la Argentina (1880-2000) (Buenos Aires: Macchi).

Razeto, Luis 1990 Modelos organizativos de talleres laborales (Santiago de Chile: Programa de economía del trabajo).

Razeto, Luis 1997 Los caminos de la economía de la solidaridad (Buenos Aires: Lumen Humanitas).

Razeto, Luis 2002 "La economía solidaria como radicalización de la democracia" en II Foro Social Mundial de Porto Alegre, seminario Economía de Solidaridad. Disponible en <www. economiasolidaria.net $>$.

Razeto, Luis 2004a “¿Qué es la economía de la Solidaridad?” en Forni, Floreal (comp.) Caminos solidarios de la economía argentina. Redes innovadoras para la integración (Buenos Aires: Ciccus).

Razeto, Luis 2004b "El camino de los pobres y de la economía popular" en Forni, Floreal (comp.) Caminos solidarios de la economía argentina. Redes innovadoras para la integración (Buenos Aires: Ciccus).

Rofman, Adriana y Merlinsky Gabriela 2004 “Los programas de promoción de la economía social: ¿una nueva agenda para las políticas sociales?” en Forni, F. (comp.) Caminos solidarios de la economía argentina. Redes innovadoras para la integración (Buenos Aires: Ciccus).

Scala, Lorena 2005 La constitución de un 'nosotras' a partir de experiencias compartidas. Mujeres de sectores populares en el Plan Jefas de Hogar (Mendoza: inédito).

Singer, Paul 2002 Introdução à Economia Solidaria. (San Pablo: Fundação Perseu Abramo).

Supervielle, Marcos y Quiñones, Mariela 2005 "De la marginalidad a la exclusión social: cuando el empleo desaparece" en Álvarez Leguizamón, Sonia (comp.) Trabajo y producción de la pobreza en Latinoamérica y el Caribe (Buenos Aires: CLACSO).

Wallerstein, Emmanuel 1988 El capitalismo histórico (Madrid: Siglo XXI). 


\title{
Gleidys Martínez Alonso*
}

\section{INTER(DES)CONEXIONES DEL ESTADO Y LA SOCIEDAD CIVIL EN LAS POLÍTICAS Y ESTRATEGIAS DE SUPERACIÓN DE LA POBREZA EN CUBA ${ }^{1}$}

\begin{abstract}
INTRODUCCIÓN
Este artículo tiene como objetivo analizar la relación Estado-sociedad civil en la lucha contra la pobreza contextualizada en un estudio de tres experiencias comunitarias en el ámbito local cubano. Específicamente se inquiere sobre las articulaciones de las políticas y estrategias de ambos actores, así como sobre las nociones de pobreza y desigualdad que se tienen en cada una de estas esferas de la política. Se abordan las metodologías de implementación de cada uno de ellos en vías de valorar los espacios existentes en la institucionalidad cubana para potenciar esta relación y se reconocen los elementos de la cultura política cubana que podrían obstaculizarla o favorecerla, así como sus políticas y estrategias en materia de bienestar.

En un primer momento haremos una breve descripción de la relación Estado-sociedad civil en Cuba más allá de la temática de pobreza y del panorama pobre del país, haciendo énfasis en la políticas de

* Licenciada en Comunicación Social (2005). Maestrante en Sociología por la Universidad de La Habana. Investigadora del Grupo de Políticas Culturales en el Instituto Cubano de Investigación Cultural Juan Marinello (Cuba).
\end{abstract}

1 Para obtener más información sobre este tema, se debe revisar la investigación con el mismo nombre, realizada en el marco de la beca CLACSO-CROP, 2005. 
superación de esta condición. Después abordaremos concretamente las prácticas de transformación social, objetos de investigación.

\section{EL ESTADO Y LA SOCIEDAD CIVIL EN EL SOCIALISMO CUBANO. CONCEPCIONES HISTÓRICAS Y POSICIONES EPISTEMOLÓGICAS}

Pensar la relación Estado-sociedad en sus momentos de articulación y desconexión en el marco de un estudio sobre las políticas, metodologías y estrategias de superación de la pobreza en Cuba, implica relacionarse con algunos asuntos esenciales: uno, que esta relación tiene un carácter histórico, segundo que esta reflexión debe corresponderse con un posicionamiento específico sobre su preocupación en el pensamiento marxista y en su propuesta socialista; y por último, ubicarse en el debate cubano sobre la importancia y existencia de una sociedad civil en el contexto específico del socialismo.

Los primeros años de la Revolución se caracterizan por un diálogo orgánico entre Estado-sociedad civil mientras la agenda social tuvo que resolver problemas acumulados, muchos de los cuales habían sido ya enunciados por Fidel en su célebre programa revolucionario La Historia me absolverá.

Se apuntan como características de la sociedad civil cubana de entonces la existencia de seis organizaciones de masas ${ }^{2}$ que agruparon a casi todo el pueblo cubano (exceptuando a los campesinos) bajo la denominación de trabajadores. Esta había quedado reducida a espacios muy formales potenciados por el Estado a razón de una homogeneización clasista, y a la existencia de instituciones y roles tributarios a la política en las primeras tres décadas desde 1959 y 1989 (Azcuy, 1995: 106). De esta manera se estructuraba la participación, movilización y el consenso del pueblo en la construcción del proyecto socialista.

La historia más reciente da cuenta de que durante los noventa, a raíz del Período Especial ${ }^{3}$, la activación de la economía y la sociedad civil trajo consigo un "pluralismo" (Azcuy, 1995: 107) que se contextualiza en el surgimiento de nuevos espacios en la comunidad, la existencia de organizaciones privadas, la formación de nuevos gru-

2 Hugo Azcuy comenta que estas seis organizaciones de masas (Central de Trabajadores de Cuba [CTC], Federación de Mujeres Cubanas [FMC], Comité de Defensa de la Revolución [CDR], Asociación Nacional de Agricultores Pequeños [ANAP], Federación de Estudiantes Universitarios [FEU], Federación de Estudiantes de Enseñanza Media [FEEM]) agruparon a casi toda la población joven y adulta del país.

3 Proceso político-social que la mayoría sitúa a partir de los noventa hasta hoy caracterizada por una situación de crisis y por tanto, con medidas para enfrentarla. 
pos, actores sociales y económicos y la transformación a nivel de las relaciones sociales, lo cual tuvo su correlato en el panorama de las desigualdades sociales y el proceso general de reestratificación social (Espina, 2000).

Estas situaciones críticas como la desigualdad y la pobreza que se daban en el seno de muchos ámbitos locales, eran realidades sociales incoherentes con el proyecto social y amenazaban la continuidad del consenso en la Revolución, un consenso que en todo momento trató de ser activo con la participación dialógica del pueblo en las decisiones estatales que los afectaban, sobre todo aquellas que se introducían en el campo de las relaciones económicas y las garantías sociales.

En este contexto algunas alternativas para construir un mejor socialismo partían del principio de la crítica al marxismo dogmático y de entender la existencia de una fase de transición socialista que se construía como proyecto y no como modelo. Estas ideas vinieron aparejadas al rescate de algunos elementos del pensamiento marxista crítico -sobre todo del pensamiento de Gramsci ${ }^{4}$ y del Che Guevaracon el fin de rearticular las relaciones entre Estado y sociedad civil en pos de mantener el proyecto socialista nacional.

En los momentos más tensos del reacomodo social de los noventa "los criterios predominantes en el país reflejaban que las relaciones entre Estado y Sociedad Civil no se percibían como irreconciliablemente conflictuales" (Lechner en Azcuy, 1995: 110)5. El estereotipo de desestabilización del sistema o de "proyecto antisocialista" que signaba algún uso de la noción de sociedad civil parecía decaer por lo menos en el seno de las reflexiones en el país ${ }^{6}$.

4 De acuerdo con Jorge Luis Acanda (2003) el momento más importante de la recepción de Gramsci en los noventa empieza en 1994 con los conocidos artículos de Rafael Hernández sobre la sociedad civil cubana: "Mirar a Cuba" y "La sociedad civil y sus alrededores".

5 Azcuy se refiere específicamente a la obra "La (problemática) invocación de la sociedad civil" en Perfiles latinoamericanos, No 5, diciembre, 1994.

6 Hay un conjunto de trabajos sobre sociedad civil que le dieron un hilo conductor al debate cubano, más allá de que su actualización sea hoy un imperativo. Se citan: Hernández, Rafael 1994 "La sociedad civil y sus alrededores" en La Gaceta de Cuba, $\mathrm{N}^{\mathrm{o}} 1$ (La Habana) y “EEl turno de la sociedad civil?” en Cuba hoy: desafío de fin de siglo (Santiago de Chile: LOM Ediciones); Hart, Armando 1995 "Lo jurídico y lo ético. Nuestra sociedad civil (I)" en Granma 9 de agosto, 1995 "Lo jurídico y lo ético. Responsabilidad individual, conciencia social (II)" en Granma, 10 de agosto y 1996 "Sociedad civil y Organizaciones No Gubernamentales (I) y (II)" en Granma, 23 y 24 de agosto de 1996; Lavastida, Octavio 1996 "Existen más de 22000 sociedades inscritas en Cuba" en Granma Internacional (La Habana) 19 de junio; Valdés Vivó, Raúl 1996 “¿Sociedad civil o gato por liebre?” en Granma, 4 de enero; Acanda González, Jorge Luis 1996 “Sociedad civil y hegemonía” en Revista Temas, № 6 (La Habana) abril- 
La sociedad civil cubana, apostillada sociedad civil socialista de Cuba, para evitar contradicciones con una visión de la sociedad civil en el mundo capitalista, y particularmente el discurso anticastrista de las organizaciones disidentes y el gobierno norteamericano (Friedman, 2006: 64), es reconocida como tal en la Constitución de la República de Cuba.

Nos ubicamos en una posición que reconoce que la sociedad civil socialista cubana se da a partir de un campo de fuerzas específico, propio de una hegemonía revolucionaria, y proyectivamente se la concibe para que potencie tanto la formación de un sujeto a la altura de la transición socialista, como para que focalice e intervenga en procesos microsociales que escapan a las políticas de desarrollo no atentas en su totalidad a las nuevas dinámicas y pobreza que se han visualizado en Cuba. Empíricamente nos apropiamos de un concepto de sociedad civil que tiene en cuenta la organicidad entre lo social, lo cultural y lo político, donde la sociedad civil es solo separable metodológicamente del Estado. En este sentido nos identificamos con la noción que reconoce a la sociedad civil como un espacio de acción simbólica y comunicativa donde se fortalece una trama asociativa, en la cual dichos sujetos constituyen el núcleo protagónico en la construcción y conformación del sentido de ciudadanía, de la ética y de lo nacional, en constante interconexión con el Estado (Acanda, 2003: 133).

\section{Pobreza y POLíticas Sociales EN EL SOCIALISMo CUBANo}

En Cuba, las políticas y estrategias sociales llevadas a cabo a partir de la Revolución han colocado al hombre y su bienestar en el foco de atención. Entre 1959 y 1989 la sociedad cubana llegó a constituir una de las sociedades más equitativas del mundo y se llegó a asegurar la erradicación de la pobreza como mal social a partir de la consecusión de niveles de vida bastante similares para las mayorías (Rodríguez y Carriazo, 1983).

Pero esta situación no siguió el curso esperado. El cambio geopolítico que trajo consigo la debacle del socialismo soviético y sus filiales esteeuropeas significó para la mayor isla de las Antillas una crisis económica sin precedentes en la historia de la Revolución que se tradujo

\footnotetext{
junio; Azcuy, Hugo 1995 “Estado y sociedad civil en Cuba”, en Revista Temas, N ${ }^{\circ}$ (La Habana) octubre-diciembre; Dilla, Haroldo 1995 "Sociedad civil, pueblo y participación" en Mensaje de Cuba (La Habana: Centro de Estudios Europeos), No 19-20, agosto-septiembre; y al Taller "Reflexiones sobre la sociedad civil", convocado por la Escuela Superior del Partido "Nico López" del 14 al 15 de marzo de 1996. Puede revisarse también: Limia, Miguel 2005 "Retomando el debate sobre la sociedad civil" en Filosofía.cu (La Habana). Disponible en <http://www.filosofia.cu/contemp/index. htm\#A>, consulta: 24-08-2005.
} 
en un cese de las relaciones comerciales con más del 75\% de sus socios tradicionales (González, 1997: 7). A esto se agregan las medidas anticubanas de la administración norteamericana para recrudecer el bloqueo económico impuesto desde 1961. En este escenario de cambio socioeconómico las condiciones de vida de la mayoría de los cubanos empezaron a deteriorarse. El fuerte Estado no cedía terreno a la privatización y los programas sociales fueron mantenidos, al tiempo que dejaba claro su intención de salvaguardar las conquistas del socialismo. De hecho, en toda la plataforma programática del Estado revolucionario, la llamada cuestión social ha estado presente a partir de su interés de consolidar mejores condiciones de vida como racionalidad misma del consenso.

Mayra Espina refiere que en nuestro país se da una identificación de política de pobreza con una estrategia más general de desarrollo social (Espina, 2004: 113), que supone como fin su erradicación. En este escenario, se destaca que ha sido una prioridad de Estado dentro de su proceso de institucionalización estatal, una concepción amplia de enfrentamiento a la pobreza, no identificada solo con la cuestión de los ingresos y las necesidades básicas. Así, pudiera hablarse de una concepción más global que no se desentiende del problema de la familia, las políticas de empleo, el medio ambiente, la salud, la cultura, la educación y la ciencia.

Dentro de este diapasón de políticas sociales se puede decir -de manera resumida- que el modelo estatal de atención a la pobreza se particulariza en una fuerte actuación sobre la matriz productiva y de propiedad como presupuesto para actuar sobre las relaciones de distribución; propiedad social estatal como base del hegemonismo de los sectores populares, centralidad de la igualdad y la justicia social en la formulación de las políticas; protagonismo del Estado en el diseño y puesta en práctica de las políticas sociales y de la planificación centralizada como mecanismo para su ordenamiento; una política social única y centralizada considerada como garantía de los niveles más extendidos posibles de servicios sociales básicos universales; centralidad de la distribución como instrumento de la justicia social; combinación del consumo individual y social, con un alto peso de este último en la justicia distributiva; presencia de mecanismos de participación popular en las acciones transformativas; desconcentración y homogenización progresiva de los ingresos; acceso masivo al empleo; racionalidad del consumo y de las necesidades como modelo de vida social general; masificación del acceso a los bienes culturales; promoción de procesos de desestratificación y homogenización social; orientación hacia la satisfacción de necesidades básicas y racionales, otorgando protagonismo a la esfera educacional y espiritual-cultural; debilita- 
miento progresivo del papel de los ingresos personales y familiares en el consumo y la satisfacción de las necesidades; mantenimiento de estos principios y de la responsabilidad inalienable e indelegable del Estado como centros rectores de la política social, cualquiera sea la disponibilidad de recursos económicos y la cuantía de los bienes a distribuir; la existencia de un Estado como productor, distribuidor y asignador de bienes por excelencia y papel secundario y subordinado del mercado (Espina, 2004: 136-137).

Aun en medio de esta intencionalidad política la existencia de la pobreza en Cuba ha resultado un tema reconocido -si bien no recurrente en el discurso público-; incluso a nivel de gobierno se insiste en que no se ha pretendido "presentar a nuestra patria como modelo perfecto de igualdad y justicia. [...] Hay zonas marginales, hay cientos de miles de personas que viven en zonas marginales, pero no solo negros y mestizos, sino también blancos" (Fidel Castro, 2000).

Para contextualizar brevemente el panorama pobre de Cuba se pueden mencionar un conjunto de estudios que describen la pobreza cubana desde varias dimensiones de esta. Por solo citar algunos ejemplos podemos encontrar posturas que se refieren a una diferenciación de condiciones de vida de determinados grupos en los espacios poblacionales del país apuntando a una distinción territorial; desde un análisis estructural se ha advertido una reconfiguración de la estructura socioclasista cubana que ha generado desigualdad. Otro enfoque ha tomado por foco la dimensión familiar y comunitaria mientras analiza experiencias comunitarias de atención a la pobreza, y los impactos de situaciones socioeconómicas específicas en los núcleos familiares cubanos. Pensando en términos raciales, se ha abordado el fenómeno de una persistencia de las desigualdades raciales y de una refuncionalización de las formas de racismo en Cuba.

Un posicionamiento cultural ha señalado la necesidad de atender un enfoque integral de la pobreza y de redimensionar el concepto de cultura en vías de diseñar políticas culturales que atiendan explícitamente este tema dentro de su agenda pública. En este sentido, desde el punto de vista politológico, se ha apuntado la importancia del desarrollo de la sociedad civil en un sentido socializador y desenajenante, como ámbito legitimado para superar formas de subjetividad social que pueden estar perpetuando la cultura de la pobreza en nuestro país. ${ }^{7}$

7 Los estudios comentados se refieren a un conjunto de autores y trabajos como son -en orden de aparición en el texto- Iñíguez, Luisa y Ravenet, Mariana 2005 “Desigualdades espaciales del bienestar en Cuba. Aproximaciones a los efectos de los nuevos procesos en las realidades sociales" en Iñíguez, Luisa y Pérez, Omar E. (comps.) Het- 


\section{SOCIEDAD CIVIL: LAS EXPERIENCIAS DE TRANSFORMACIÓN SOCIAL. ESTRATEGIAS Y POLÍTICAS DE SUPERACIÓN DE LA POBREZA}

Las experiencias de estudio se eligieron por la diversidad estructural y conceptual de sus propuestas, el sentido de transformación de barrios en desventaja y la solución de problemas y necesidades de contextos o situaciones de vulnerabilidad. La mayoría de ellas se asientan en barrios con situaciones de desventaja social, cuyas necesidades requieren ser atendidas. Además poseen características especiales en cuanto a los actores que intervienen y sus dinámicas participativas.

Fueron intencionadamente ubicadas en tres contextos diferentes de la región occidental: un proyecto lidereado por una institución religiosa en Matanzas, el Centro Kairós, que promueve un proyecto de transformación sociocultural en un barrio marginal: La Marina; un taller de transformación integral del barrio ${ }^{8}$ (TTIB), espacio dentro de la institu-

erogeneidad social en la Cuba actual (La Habana: Centro de Estudio de Salud y Bienestar Humano), Zabala, María del Carmen y Morales, Elaine 2005 "Desigualdades sociales: dimensión subjetiva en el escenario comunitario capitalino" en Iñíguez, Luisa y Pérez, Omar E. (comps.) Heterogeneidad social en la Cuba actual (La Habana: Centro de Estudio de Salud y Bienestar Humano). Rodríguez, Pablo y Estévez, Claudio s/f Algunas reflexiones en torno al tema de la pobreza y la marginalidad, a manera de introducción (La Habana: Centro de Antropología, Papeles de investigación); Espina, Mayra s/f "Efectos sociales del reajuste económico: igualdad, desigualdad y procesos de complejización en la sociedad cubana” en Pérez, Omar Reflexiones sobre economía cubana (La Habana: Editorial de Ciencias Sociales) pp. 385-419. "Reestratificación y desigualdad” en Iñíguez, Luisa y Pérez, Omar E. 2005 (comps.) Heterogeneidad social en la Cuba actual (La Habana: Centro de Estudio de Salud y Bienestar Humano). Morales, Esteban 2005 "Cuba, los retos del color" en Iñíguez, Luisa y Pérez, Omar E. 2005 (comps.) Heterogeneidad social en la Cuba actual (La Habana: Centro de Estudio de Salud y Bienestar Humano). Rodríguez, Lázaro Israel “¿Todos los negros toman café? Políticas públicas de cultura, equidad, raza y pobreza como condición cultural" en Pobreza, exclusión social y discriminación étnico-racial en América Latina y el Caribe, Memorias del Taller (Cali: Consejo Latinoamericano de Ciencias Sociales (CLACSO)/ Programa de Investigaciones Comparativas sobre Pobreza (CROP) / Centro de Investigaciones y Documentación Socioeconómica (CIDSE)), 2006 "Las políticas públicas de cultura y la cuestión del acceso: algunas consideraciones desde la pobreza como matriz cultural" Informe de investigación (La Habana: Centro de Investigación y Desarrollo de la Cultura Cubana Juan Marinello) y Acanda, Jorge Luis 2005 "Sociedad civil y superación de la pobreza" en Iñíguez, Luisa y Pérez, Omar E. (comps.) Heterogeneidad social en la Cuba actual (La Habana: Centro de Estudio de Salud y Bienestar Humano).

8 Los Talleres de Transformación Integral son estructuras creadas, asesores técnicos de los Consejos Populares (véase nota siguiente) en el trabajo comunitario. Estos TTIB tienen el objeto social de promover la integración de las instituciones y otros actores en la comunidad para la transformación integral y el "mejoramiento de la calidad de vida" de sus habitantes a través de un proceso de planeamiento participativo (TTIB Pogolotti s.a.: 1-2) 
cionalidad de los Consejos Populares ${ }^{9}$ que promueve proyectos físicos y socioculturales en un barrio pobre habanero: Pogolotti; y por último una iniciativa de desarrollo sostenible en Pinar del Río, que apuesta por la intervención comunitaria en localidades rurales y urbanas a partir de proyectos de impacto medioambiental y cultura agroecológica. Estos proyectos son acompañados por una ONG de la sociedad civil socialista cubana, el Centro Memorial Martin Luther King Jr. ${ }^{10}$ (CMMLK), que promueve espacios de movimiento social y trata de subvertir situaciones de pobreza desde sus variadas dimensiones.

Sin embargo, en los análisis de los documentos del CMMLK no hay una definición evidente de lucha contra la pobreza. Su coordinador Joel Suárez insiste en que los objetivos estratégicos del Centro no son de desarrollo comunitario ni local, aunque reconoce que sus intenciones por aplicar la concepción y metodología de la educación popular y las nociones de desarrollo comunitario no son excluyentes. Se prefiere dejarlo abierto a la denominación de experiencias locales porque las que se vinculan con el Centro son diversas entre sí por sus ámbitos geográficos o territoriales, temáticos y sectoriales, por el tipo, carácter y finalidad de las acciones que despliegan (Roselló Reina, 2005: 42).

De hecho, entre los expertos prima el criterio de que se utilizan otras palabras para referirse al tema de la pobreza como "resolver necesidades apremiantes", "atender problemas sociales", "elevar la calidad de vida". Lo cierto es que también coinciden en afirmar que la mayoría de las experiencias de este movimiento comunitario ha sido

9 Los Consejos Populares son un eslabón de la dirección estatal, que realizan su labor con la participación activa del pueblo, en interés de la comunidad y de toda la sociedad. "Sus funciones son entre otras trabajar activamente para que se satisfagan las necesidades asistenciales, económicas, educacionales, culturales y sociales de la población y la búsqueda de soluciones a los problemas planteados; así como exigir la eficiencia en el desarrollo de las actividades de producción y de servicios a las entidades enclavadas en su área de acción y apoyar, en lo posible, su realización. Se ocupan también de coordinar, cuando resulte necesario, las acciones de las entidades existentes en su área de acción y promover la cooperación entre ellas, así como controlar y fiscalizar las actividades de las entidades existentes en la demarcación, independientemente de su nivel de subordinación." (Asamblea Nacional del Poder Popular, en lo adelante ANPP por sus siglas, 2000)

10 No coincidimos, desde el punto de vista teórico metodológico, con entender la sociedad civil cubana solamente con las ONG, concordamos con Jorge Luis Acanda en que existen un conjunto de instituciones cubanas, como los medios masivos [ICRT], las instituciones culturales, el sistema educacional, que también se pueden analizar como parte de ella en tanto son estructuras que difunden valores que legitiman la hegemonía que existe, o la desafían (Acanda, 1999: 161-162). Sin embargo, para ajustarnos al tema de subversión de la pobreza, nos resultaban más conveniente estos espacios por su propuesta específica de intervención social en este sentido. 
para subvertir determinadas situaciones de carencia, ya sean materiales o espirituales. Se asegura que los movimientos comunitarios son alternativas de superación de la pobreza en el ámbito más local de la sociedad, aunque muchas veces no se reconozca como tal (entrevistas a expertos, 2006)

La apuesta radica del CMMLK radica en dinamizar los espacios de participación desde una perspectiva innovadora de los sujetos y grupos en procesos sociales. Aun cuando la mayoría de esos "procesos" tienen que ver con situaciones de desventaja social, generalmente están localizados en barrios marginales, y buscan una incidencia en el cambio de prácticas de los habitantes de esos barrios para la identificación y enfrentamiento de problemas y el mejoramiento de la calidad de vida de los más preteridos ante la crisis económica del Período Especial. A través de sus dos modos de acompañamientos: los puntuales (generalmente dedicados a capacitar y/o asesorar a equipos de trabajo); y los globales: asesoramiento a diversos momentos de un proyecto o proceso comunitario (CMMLK, 2000), se diseñan acciones que contribuyen a la búsqueda de soluciones a situaciones de desventaja como: construcción de vivienda, asistencia a adultos mayores, dinámicas de inclusión social de la mujer, atención a problemas que presentan los jóvenes y ancianos; proyectos comunitarios; programas de generación de alimentos, y sobre todo, programas culturales de transformación de prácticas y estructuras de poder verticalistas, enajenantes y reproductoras de la dominación (CMMLK, 2000; 2006; entrevistas).

El énfasis en el carácter político del trabajo social del CMMLK se sustenta en la apuesta por la educación popular como herramienta y en el trabajo coordinado con las estructuras políticas y sociales, en un país donde hay un predominio del actor estatal en el contexto comunitario. Tanto de los análisis de las entrevistas, como de la lectura de los documentos de trabajo de los diferentes programas del centro, se confirma su intención de trabajar en los procesos de despolitización y desocialización (Suárez; Figueredo y Romero, 2006). Estos procesos se han acrecentado en el contexto de la crisis de los noventa que se traduce en un desinterés por lo marcadamente político que "cohabita con las capacidades de aprendizaje, el nivel educativo y cultural y del conocimiento de la política que tiene el cubano", y que atentan cada vez más contra la búsqueda de soluciones individuales y/o familiares a la crisis cuando "el proyecto colectivo" deja de ser "el centro de su interés y su proyecto de vida que se vuelve cada vez más individual". El trabajo social y comunitario, por tanto, es el canal del CMMLK para contribuir a la resocialización y a la repolitización, en consecuencia a la recreación de lo político. 
En los estudios de casos de experiencias concretas de acompañamiento las estrategias de atención a problemas relacionados con la pobreza pueden vislumbrarse a través de sus actividades específicas de intervención en la comunidad.

En el caso del TTIB de Pogolotti se trata de una agenda que interviene en una de las zonas más deterioradas de Ciudad de La Habana desde la dimensión física, social y ambiental. Las agendas de intervención del TTIB de Pogolotti ("26.283 habitantes en 5,28 km². 80,6\% composición obrera, una fuerza laboral que se traslada a otros municipios, existencia de 'asentamientos espontáneos', prima raza negra y sectas abakuás ${ }^{11}$ y religión predominantemente negra") implican el mejoramiento del hábitat y su entorno; proyectos de reducción de la vulnerabilidad a las inundaciones de alto riego; estrategias de trabajo educativo urbano con niños y jóvenes -por ejemplo, la identificación de niños de 2 a 4 años para insertarlos en el plan de vías no formales de educación preescolar y el seguimiento a los casos de niños y jóvenes con desajuste de conducta y la enseñanza especial; de igual forma tienen una prioridad la captación de jóvenes desvinculados del trabajo para su posibles ubicación laboral-; el mantenimiento de la atención a madres solteras, actividades de asistencia social con adultos mayores desvalidos, el fortalecimiento de la identidad barrial; la integración de los actores locales; la educación ambiental; la construcción de 60 viviendas de bajo costo y la rehabilitación de otras 23 , un proyecto de alumbrado público y el saneamiento del territorio; la prevención social así como el desarrollo de una economía local. Cada uno de estos proyectos del TTIB ha tenido desarrollos diversos a partir de los límites que imponen el propio contexto y la disponibilidad de recursos.

Si analizamos la experiencia del barrio La Marina (posee 6.078 viviendas, "más de 3000 viviendas clasifican en estado de mal y regular. La densidad poblacional es superior a la media del municipio. Posee 165 ciudadelas, existen familias completas integradas por entre 5 y 11 personas -la mayoría niños- que viven en una sola habitación, con las instalaciones sanitarias y suministro de agua colectivos, en áreas externas a la vivienda. Población mayoritariamente negra, era un barrio de prostitutas y vicio antes del triunfo de la Revolución, que hoy sigue siendo percibido negativamente por su "mala fama"12), podemos advertir que su intervención social enfoca de manera más explícita la cuestión de la marginalidad, sin desentenderse de los fac-

11 Sociedad secreta afrocubana integrada solo por hombres.

12 Hoy se reconoce que los proyectos implementados en La Marina han contribuido al conocimiento de la representación del barrio en el municipio y la autopercepción de sus habitantes. 
tores materiales de base. Sus propósitos en este sentido son "lograr que se reconozcan, respeten y resalten los aportes, la idiosincrasia y los valores de los/las vecinos/vecinas del barrio La Marina, a través de estrategias de educación, animación sociocultural, comunicación y mejoramiento de la vivienda y el entorno, con sentido profundamente participativo y de compromiso" (Williams, 2006).

Las estrategias de intervención en el barrio del proyecto entre el Centro Kairós que es la institución que representa, administra y dirige según las decisiones del Grupo Gestor y el barrio La Marina, partieron de la construcción y reparación de viviendas con métodos participativos, el mejoramiento de la alimentación mediante un proyecto de organopónicos -huertos en solares y terrenos baldíos-, proyectos de saneamiento, de educación ambiental y embellecimiento de las calles; el rescate de las tradiciones del barrio a través del desempeño de la comparsa La Imaliana; según comenta Laydis Daniel, especialista del Grupo Gestor "después de 20 años de silenciada" (Kairós, 2003). Se incluye la conformación de equipos deportivos para implicar a niños, jóvenes y adultos en una dinámica grupal de pertenencia al barrio con la condición de que tienen que estudiar o trabajar.

Como estrategia para resolver situaciones y problemáticas ligadas a la pobreza como condición cultural y combinando la dimensión educativa se han realizado talleres de mediación de conflictos, programas de trabajo con la familia en su estrecha relación con el barrio como medio de convivencia, debates sobre las temáticas de género (imagen de la mujer negra, la violencia en la familia y de la mujer -teniendo en cuenta que en el barrio son comunes las referencias a la "mujer abusada", según comentan las mujeres entrevistadas del barrio-), comunicación y solidaridad. Se hacen actividades artísticas con niños, niñas y adolescentes (canto coral, pintura, artesanía, oralidad, teatro, danza) y otros eventos culturales con contenidos afrocubanos de las religiones predominantes en el barrio matancero.

Desde otro ámbito de incidencia, las prácticas del Centro de Educación y Promoción para el Desarrollo Sostenible (CEPRODESO) en Pinar del Río promueven una experiencia protagonizada por educadores populares ambientales que implica el fortalecimiento de capacidades para la gestión ambiental participativa y la promoción del desarrollo sostenible. Esto, a partir de un escenario predominantemente rural donde, según un diagnóstico institucional del Ministerio de Ciencia, Tecnología y Medio Ambiente en la provincia, se estaban dando situaciones de degradación y pérdida de los suelos, causados tanto por factores naturales como antrópicos.

Dichos problemas atentan contra la calidad de vida de los ciudadanos en tanto coexiste una insuficiente aprehensión de la adecuada 
relación hombre-naturaleza. Además, es notable la reducción de la capacidad productiva de las tierras confinadas a producir alimentos, y de las más vulnerables en particular. Existe un deterioro del saneamiento y las condiciones ambientales en asentamientos humanos, que se traduce en las limitaciones del servicio de suministro de agua potable que ha sufrido limitaciones en cantidad y calidad por la falta de recursos para su tratamiento, el deterioro de las redes de distribución y las instalaciones. A este factor se suman los problemas con la recolección y el tratamiento de los desechos sólidos urbanos que tributan a la proliferación de microvertederos, así como la contaminación de las aguas interiores y marinas. El estado crítico de los sistemas de tratamiento de residuales, el deficiente aprovechamiento y reutilización de residuales líquidos y el insuficiente monitoreo y control sobre la calidad del agua inciden notablemente en esta situación ${ }^{13}$.

Los focos de incidencia de CEPRODESO consisten en un proyecto enfocado al mejoramiento de la calidad de los habitantes de las comunidades insertadas en la cuenca del Río Cuyaguateje (Guaní-Ciencia) mediante el rescate de prácticas agroecológicas en función del desarrollo de una agricultura sostenible en la zona, un programa de Agroecología de Campesino a Campesino para rescatar tradiciones de prácticas agroecológicas en función del desarrollo de una agricultura sostenible. Este movimiento resulta de una importancia inestimable porque se proponen extender las técnicas de sostenibilidad con un enfoque popular en el desarrollo rural mediante la transformación de los conceptos tradicionales de cultivar la tierra y abarca la capacitación para solucionar los problemas de alimentación, una de las esferas más golpeadas por el período especial.

Se cuenta con otros programas de capacitación social: programa CREA ("Cómo Realizo la Educación Ambiental") que consiste en proyectos de desarrollo y en acompañamiento a experiencias de educación popular ambiental, comunicación popular ambiental y la sensibilización comunitaria para el uso racional de los recursos en escuelas y comunidades del municipio San Cristóbal; y PEASEP (Educación Ambiental en el Sector Empresarial y Productivo) que capacita a los cuadros y funcionarios de las unidades de la Empresa de Trans-

13 De las 114 fuentes contaminantes principales de la provincia (40 industriales, 34 agropecuarias y 40 domésticas), solo cuentan con sistemas de tratamiento 54 , de ellas 22 funcionan deficientemente, 13 lo hacen satisfactoriamente y las restantes 47 no cuentan con sistemas. Los principales sectores con fuentes de contaminación son el Ministerio de la Agricultura (MINAGRI) con 31, el Poder Popular (núcleos urbanos) con 24, el Ministerio de la Industria Alimentaria (MINAL) con 11, el Ministerio de Salud Pública (MINSAP) con 9, el Ministerio de la Industria Básica (MINBAS) con 7 y el Ministerio del Azúcar (MINAZ) con 5. 
porte Agropecuario y al resto de las instituciones y organizaciones de las comunidades donde se encuentran insertadas estas unidades en temáticas relacionadas con la gestión ambiental. A estos se suma la iniciativa de la articulación de actores sociales vinculada a la gestión ambiental participativa en una comunidad costera en La Coloma, un puerto sureño en Pinar del Río, donde dan apoyo metodológico al grupo gestor del proyecto de La Marina y hacen diagnósticos, planificación y evaluación participativos de las prácticas socio ambientales, perspectivas del desarrollo sostenible y trabajo grupal.

Como parte de su agenda también están los encuentros anuales de experiencias de educación popular ambiental donde comparten críticamente una mirada a las prácticas socio-ambientales en curso y propician niveles y recursos de articulación óptimos entre los actores sociales del territorio y del país, socializando los avances y retrocesos de sus respectivos proyectos comunitarios, entre otras instituciones afines de la sociedad civil.

En sentido general en estas experiencias se advierte la conexión con instituciones y entidades estatales y de la sociedad civil. Para poner algunos ejemplos, en proyectos específicos se aprecia la integración entre las escuelas de las comunidades, los centros deportivos del INDER (Instituto Nacional de Deporte y Recreación), la Policía Nacional Revolucionaria (PNR), Los Comité de Defensa de la Revolución (CDR), los delegados de circunscripción del Poder Popular, el Poder Popular Municipal, los Consejos Populares, el Médico de la Familia, apoyo de diversas ONG e instituciones internacionales como Pan para el Mundo y Oxfam-América, la Agencia de Colaboración Holandesa NOVIB en Cuba, la Unidad Municipal de Vivienda, el Ministerio de la Agricultura, el Ministerio de Cultura y las Casas de Cultura, el Ministerio de Ciencias, Tecnología y Medio Ambiente, la Asociación de Artesanos y Ceramistas, la Iglesia Bautista Ebenézer de Marianao, el Centro Kairós, la Universidad de Pinar del Río, la Asociación Nacional de Agricultores Pequeños (ANAP). Esto da una idea de las condiciones que el contexto cubano trae consigo para plantear posibilidades de integración de manera horizontal, en toda la estructura social para la atención a la pobreza.

\section{Criterios metodológicos Y MECANISMOS DE PARTICIPACIÓN}

Según las sistematizaciones que hace a partir de Monreal y Carranza (1997), Mayra Espina refiere tres planos reservados más generales en los que se podrían incluir a la regulación planificadora estatal las metodologías de la atención a la pobreza. Estos tienen que ver con una planificación estratégica, concebida como proyección de desarrollo a 
largo plazo; la planificación directiva en áreas centralizadas (sobre las empresas estatales centralizadas, las instituciones de servicios presupuestadas por el Estado, la inversión en infraestructura física y productiva de alta prioridad) y descentralizadas (empresas estatales, cooperativas y empresas privadas, a través de pedidos estatales bajo contrato); y la planificación indirecta macroeconómica (ejercida sobre toda la economía nacional como manejo de política económica externa, tasa de cambio, aranceles, subsidios, política monetaria y fiscal, control de precios y salarios, etc.) y microeconómica (ejercida sobre las entidades económicas particulares como política monetaria, fiscal, de precios, laboral, comercial y ambiental) (Carranza y otros, 1997: 60-61). Así, el cómo de las estrategias cubanas está en contar con un sistema político e institucional amplio, encargado de la organización e identificación de la agenda social, la participación en la agregación de demandas y el diseño, puesta en práctica y control de los programas de acción específicos, y mecanismos de redistribución a través de la jerarquización de los gastos sociales (Espina, 2004: 135-138). Los instrumentos de estas estrategias son los mecanismos de distribución y redistribución de los bienes a partir de un sistema normado y un cuerpo institucional de garantías de servicios básicos como salud y educación.

El sistema participativo estatal ha quedado descrito en varios trabajos de autores cubanos, pero concisamente han sido sistematizados por Mayra Espina y Cecilia Linares, una enfocada desde el estudio de las políticas de atención a la pobreza y la otra desde las maneras en que son implementadas y recibidas las políticas sociales en el ámbito municipal. El criterio de ambas autoras se puede resumir en que estas políticas se caracterizan por: "la preeminencia jerárquica de las definiciones estratégicas políticas y toma de decisiones, sobre todo en la distribución y uso de los recursos materiales; la especialización tecnoburocrática; un estilo de relaciones sociales verticales que no pueden abarcar la heterogeneidad de sus bases y desarrollar relaciones horizontales; el sectorialismo en las relaciones institucionales, la carencia de estrategias de desarrollo local y limitaciones de los actores a esta escala para la identificación y el ejercicio de acciones autónomas autotransformativas; limitaciones de las instituciones municipales de gobierno para ejercer el control real sobre las empresas e instituciones enclavadas en su territorio, subordinadas al gobierno central; extendidos métodos autoritarios en la conducción de acciones comunitarias y una concepción de la participación que la entiende más como movilización de apoyo a objetivos estratégicos definidos centralmente por decisores de la política y de la técnica y como aseguramiento de canales que para la expresión del criterio y la discusión sobre dichos objetivos y sobre las acciones que los concretan; la no explotación 
de la creatividad de los actores sociales, así como la no generación de espacios de expresión, entorpecimiento la emergencia de nuevos actores y el incremento de niveles de participación y protagonismo popular. Se suma a estos criterios el que la gente se sienta beneficiaria de las acciones del Estado quien es responsable y estructurador de las acciones (2004: 139).

Específicamente en el ámbito municipal los Consejos Populares contienen en sus estatutos las estrategias de participación "como la vía fundamental para realizar su labor". Ella debe estar presente desde la identificación de los problemas y necesidades y sus posibles soluciones, hasta la adopción de las decisiones, así como en la planificación, desarrollo y evaluación de las principales acciones que se ejecutan en la demarcación" (Art. 35). Se asegura que "mediante métodos participativos de trabajo", el Consejo Popular coordina e integra a los delegados, las organizaciones de masas, instituciones, entidades y vecinos en general, para la identificación sistemática de "problemas y necesidades que afectan la comunidad y sus posibles soluciones"; la organización y promoción de los vecinos para "la solución de sus propias necesidades, mejorar la convivencia y la calidad de vida"; la decisión de la "estrategia de trabajo para desarrollar, en un período determinado, las actividades que se propongan", así como la realización de la "evaluación y control de los resultados de las acciones desarrolladas" (ANPP, 2000).

Se deja ver claro en el artículo 24 de la ley que les da origen, que estos "reciben para su labor indicaciones e instrucciones de los órganos representativos del Poder Popular y de sus autoridades competentes". Los órganos y los organismos administrativos, sus entidades y otras instituciones no están facultados para impartir indicaciones, instrucciones o asignar tareas a los Consejos Populares, con lo cual subordinan las decisiones del Consejo Popular a una instancia superior y no a la decisión de quienes lo integran. Quizás este sea un elemento a superar si se quiere sumar personas al proyecto revolucionario y a la propia gestión del Poder Popular para realizar la política social a partir de la satisfacción de las necesidades de la población, mediante el recurso a la participación.

Por otro lado, las metodologías de trabajo de las experiencias estudiadas parecen aprovechar mejor las posibilidades de los canales formales e informales creados para la participación en el contexto cubano en función de los procesos de transformación social al amparo de la legislación vigente y en franca conexión con actores que son estatales en sus territorios.

El CMMLK define como "acompañamiento" su política de relación con estas otras instituciones de la sociedad civil, o sea, estas ex- 
periencias comunitarias. La idea del acompañamiento, es un término que viene de la misión del Centro de "acompañar al pueblo cubano" y expresa su voluntad diacónica, una opción llamada a dar testimonio de fe en la sociedad cubana, particularmente en los procesos barriales concretos en los ámbitos nacionales, territoriales, municipales, institucionales y sectores educativo, cultural, eclesial, salud, agricultura, etcétera (CMMLK, 2006: 3).

Como metodología de trabajo, según se analiza en los documentos del Programa de Educación Popular y Acompañamiento de Experiencias Locales (EPAEL): se expresa en el principio de que el Centro y el programa no sustituye a nadie, sea comunidad, organización o grupo; se trabaja articuladamente (es decir, se está junto a una persona o grupo en igualdad de condiciones, respetando los diversos procesos que implementan y desarrollan, desde sus experiencias de trabajo); propicia y apoya procesos innovadores respecto a la participación de las personas y que resultan de la formación de sus actores al participar en el diagnóstico de la realidad, diseño de estrategias y acciones para solucionar los problemas que esa realidad plantea, uso y control de los recursos y evaluación de los procesos; presupone la apropiación de concepciones y metodologías de trabajo que favorezcan la elevación del diálogo, el protagonismo popular, respeto al semejante y diferente, uso contextualizado del trabajo grupal, construcción colectiva de conocimiento, desarrollo de valores como la equidad, solidaridad y justicia social; se pretende transformar al mundo y no adaptarse a él, transformación que parte de los cambios de las personas mismas, para transformar las relaciones sociales en que estas personas está inmersas. De esta manera, aunque no se desestima la necesidad de acciones asistenciales, las supera, entendiendo que las personas son sujetos activos en la transformación de sus condiciones materiales y espirituales de vida; la actividad de acompañamiento expresa la relación práctica-teoría-práctica transformada.

Este trabajo comunitario debe expresarse en un trabajo social de base. Se construye una relación fraterna entre el CMMLK y esas experiencias. En un sentido educativo; constituye una manera de asociarse, articularse y afirmar una experiencia con apoyo de orden metodológico, teórico o financiero, o todos; acompaña experiencias, procesos, acciones, que pueden estar vinculadas o no a instituciones, organizaciones, gobiernos locales, que formen sujetos sociales comprometidos, que sean capaces de continuar el desarrollo de sus experiencias de una manera autogestionada y autoconducida, cuidando no reproducir actitudes asistencialistas, paternalistas y dependientes que obstaculicen el desarrollo de estas capacidades (CMMLK, 2006: 3-6).

Se destaca en los análisis de documentos, entrevistas y visitas a estas experiencias el carácter único y diferente de cada una de ellas, 
sus dinámicas específicas y las diferentes actitudes y actividades que el CMMLK les reserva en función de las relaciones específicas de cada una, aunque debe hablarse de denominadores comunes de los acompañamientos que son: los procesos educativo-comunicativoparticipativos; la participación de promotores que han participado en los talleres de transformación del CMMLK con quienes se comparten referentes teórico-metodológicos y ético-políticos que facilitan el diálogo y el trabajo conjunto; se ejecutan a escalas territoriales y locales; todas tienen algún tipo de dificultad con los recursos materiales; solicitan asesoría metodológica; requieren superación y capacitación permanente; tienen una dimensión social; han creado grupos gestores que coordinan estos procesos colectivamente; articulan actores de diversos sectores en el territorio; parten de un presupuesto común que unifica la educación popular con una participación popular activa y consciente (CMMLK, 2006: 5, 26). Otro aspecto en común muy interesante es el hecho de trabajar con líderes naturales de las comunidades, lo que conlleva a la legitimación de autoconducción y sostenibilidad de los procesos de intervención ${ }^{14}$.

En sentido general las experiencias de base asumen la misma metodología y concepción que el CMMLK, que consiste en la utilización de la educación popular y educación popular ambiental (caso de CEPRODESO) para diagnosticar las problemáticas de las comunidades, confeccionar sus agendas de intervención y solucionar los problemas del barrio, mientras se revelan prácticas participativas diferentes. CEPRODESO, por ejemplo, se ha convertido en una organización con determinada autonomía, que a su vez, como ya se ha visto, brinda apoyo metodológico a otras experiencias en Pinar del Río y en el país.

En cuanto al tema participativo, varios criterios de los acompañantes miembros del programa EPAEL coinciden en afirmar que "la apropiación del sentido de la participación en Pogolotti se avala de manera más instrumental". Si bien les interesa incorporar a diferentes actores del barrio a la ejecución de las actividades, todavía no logran una estrategia a seguir, responsabilidades que quedan en el TTIBP. Se le da prioridad en este proyecto a la ayuda material del CMMLK, en detrimento de un conjunto de acciones de capacitación, que no favorecen un cambio en las concepciones de trabajo en las personas que integran el TTIB, para lograr desterrar toda posible

14 En La Marina se tiene una experiencia peculiar con un líder barrial, Kimbo, que confesó una vez que este Proyecto había "cambiado su vida". Él es santero, abakuá, dice ser ex presidiario y "jinetero". Hoy es promotor de Cultura del Consejo Popular citado, director y coreógrafo de la comparsa La Imaliana, "orgullo y escuela para el barrio" (2003). 
visión asistencialista del intercambio (Roselló Reina, 2005: 67). En comparación con las otras dos experiencias, CEPRODESO y La Marina, se advierte que la participación es más sustantiva, de acuerdo a los diagnósticos del CMMLK.

En este sentido las sistematizaciones críticas realizadas apuntan a un conjunto de factores que vienen obstaculizando el sentido político de la participación, que tiene que ver con a) la aplicación solo metodológica e instrumental del concepto de participación; b) la centralización de funciones en los grupos gestores y su impacto en la fragmentación y pérdida del sentido participativo de la experiencia a mediano plazo, cuando no se cuenta con una estrategia de formación de líderes que garantice la sostenibilidad; c) la existencia de diversas visiones en el CMMLK acerca de la actividad de acompañamiento y de su rol en ella. No haber programado, ni priorizado espacios para debatir para unificar visiones; d) el impulso, a través de las actividades de acompañamiento, de procesos que sobrepasan las capacidades de formación en gestión de proyectos que tienen los miembros del equipo. Eso dificulta el paso de las acciones puntuales hacia el acompañamiento desde la visión integral; e) la ausencia de un diagnóstico real de las fortalezas y debilidades de las instituciones y personas promotoras de la experiencia (Roselló Reina, 2005: 79). La misma autora plantea otros problemas que nos remiten directamente a las inter(des) conexiones que buscamos. Son situaciones que se relacionan, sobre todo, con el hecho de que en muchos casos las articulaciones son tomadas como "simples prestaciones mutuas de servicios o como la incorporación formal de instituciones legitimadas en el contexto social cubano (CDR, FMC, Poder Popular)"; que no se trabaja lo suficiente en los sentidos estratégicos y políticos de las articulaciones a nivel barrial, con vista a que la experiencia acompañada alcance mayor legitimidad; el peligro de lo afectivo como obstáculo a la intencionalidad política: al tiempo que se valora la importancia de rescatar la necesidad de lo afectivo, romper el paternalismo y la centralización, y no se implementa la planeación estratégica como elemento de selección del acompañamiento por parte del CMMLK, para evitar apoyar acciones puntuales y favorecer con su contribución sostenibilidad y éxito en la estrategia (2005: 77).

En las experiencias de trabajo específicas como Pogolotti (entrevistas) y La Marina (Williams, 2006) hubo siempre una sospecha inicial a la hora de plantear espacios comunitarios conjuntos con el CMMLK, hecho heredado de la demonización de lo religioso que la etapa más ortodoxa del socialismo dejó como herencia en Cuba. De hecho el centro, al ser una institución asociada en su fundación a la Iglesia Bautista Ebenezer de Marianao, pudo haber levantado no 
pocas suspicacias entre las instituciones estatales con respecto a su intervención en procesos de transformación social en el barrio, sin embargo, su propuesta de compromiso social se ha impuesto en las comunidades con las cuales se relacionan.

Raúl Suárez, director del CMMLK, comenta que en la génesis del Centro confluyeron dos esquemas ortodoxos y excluyentes, el concepto tradicional de la iglesia de evangelizar, que suponía esencialmente no tocar el sistema político, sacarlos del mundo y meterlos en la comunidad religiosa. El otro dogma venía del modelo soviético: la iglesia no puede tener un espacio en la sociedad, ya que el Estado lo hace todo. "Nosotros estábamos inconformes con ambas visiones y su aplicación en Cuba. Para él el Centro fue una experiencia completamente distinta, otro modelo" (Roselló Reina, 2005: 31).

En estos contextos se plantean límites y fortalezas tanto de parte del Estado como de la sociedad civil que ayudan a entender mejor el acercamiento al tema de la pobreza respectivamente y en su relación contribuyen tanto a la implementación de estrategias, como a la credibilidad misma de los compromisos. En este caso, es útil proceder al análisis de las condiciones de institucionalidad que el ámbito cubano trae consigo para plantear posibilidades de interrelación entre actores diversos en el espacio de la comunidad en la atención a la pobreza.

\section{INSTITUCIONALIDAD}

El Estado cubano ha desarrollado una compleja estructura institucional para la realización de la política social, que abarca las más diversas esferas de la sociedad, dada la dimensión integral de su propuesta. Cada una de las esferas en que se divide lo social: la salud, la educación, el trabajo, la alimentación, etc., tiene una estructura creada a todo lo largo y ancho de la división político administrativa del país (nación, provincia, municipio, consejo popular, circunscripción), pero de alguna manera es en el municipio donde se realizan los vínculos más directos entre el pueblo y su gobierno, que como se ha indicado, es el responsable en Cuba de garantizar protección y atención social. En una escala menor y más próxima a la gente, están los llamados Consejos populares, los órganos del Poder Popular, local, de carácter representativo, investido de la más alta autoridad para el desempeño de sus funciones. El hecho de que el Consejo Popular comprenda una demarcación territorial dada, que apoye a la Asamblea Municipal del Poder Popular en el ejercicio de sus atribuciones y le ofrezca un mejor conocimiento y atención de las necesidades e intereses de los pobladores de su área de acción (ANPP, 2000: Artículo 2) lo coloca ante los ojos del buen entendedor en una estructura privilegiada para una interlocución efectiva. 
El Consejo Popular tiene en su concepción, ser canal la de participación popular que en legislación se reconoce como un principio esencial de la democracia socialista "que se manifiesta en la acción de los diputados y delegados a las Asambleas del Poder Popular, las organizaciones de masas, sociales, instituciones, entidades y demás integrantes de la sociedad, al intervenir de manera activa y coordinada en las decisiones que tienen que ver con la vida de la comunidad, el territorio y el país" (ANPP, 2000). Tiene como tarea controlar y fiscalizar (actividades de las entidades existentes en la demarcación, independientemente de su nivel de subordinación); de la misma manera que apoya el trabajo de prevención y atención social (ANPP, 2000). Desde su concepción, los consejos no serían "una instancia administrativa, se quiere allí una autoridad política y popular", comenta Ernesto Suárez, especialista de la ANPP, haciéndose eco de las palabras de Fidel (Mayoral, 2006: 5), lo cual puede ser tenido como una fortaleza del sistema, que existen estas estructuras institucionales como canales que están creados ya y "solo" hay que potenciarlos.

En el artículo 21 de esa ley del Consejo se marca dentro de su competencia, las funciones de trabajar para la satisfacción de las necesidades "asistenciales (sic), económicas, educacionales, culturales y sociales de la población y en la búsqueda de soluciones a los problemas planteados" en la comunidad, así como en exigir la eficiencia en el desarrollo de las actividades de producción y servicios a las entidades enclavadas en su área de acción. Según la ley, tendrían que hacerlo sobre: a) unidades de servicios; b) entidades de producción, principalmente en lo referido al cabal cumplimiento de sus obligaciones y el control de los recursos; c) distribución de materiales para la reparación y mantenimiento de las viviendas de la población d) realización de las acciones necesarias por las entidades dirigidas a prevenir y enfrentar la actividad delictiva y antisocial; e) el cumplimiento de las medidas necesarias para evitar construcciones ilegales, violaciones de las normas de arquitectura y urbanismo, entre otras; $f$ ) las actividades realizadas por trabajadores por cuenta propia, en lo referido al cumplimiento de las disposiciones legales vigentes; g) cualquier entidad en que resulte necesario; h) el cumplimiento de las leyes vigentes (ANPP, 2000). Estos factores confirman su potencial para la integración en la comunidad.

Claro, que estas estructuras no están exentas de obstáculos. El diputado secretario del Parlamento Ernesto Suárez plantea como unas de las principales dificultades de que no se solucionen los problemas planteados reiteradamente por la población en la rendición de cuenta lo que conlleva a una pérdida de confianza en el Sistema del Poder Popular; la falta de atención de los delegados por las direcciones de las asambleas; la falta de control y fiscalización de los Consejos de Admi- 
nistración sobre las respuestas que ofrecen los organismos, la demora, la negligencia y la apatía con que actúan; el exceso de tiempo detrás de las administraciones para lograr la atención a los planteamientos de los electores y la adopción de decisiones que no son consultadas con el Consejo Popular y con los delegados, que conocen de ellas cuando ya son realidades.(Mayoral, 2006: 4).

Por otra parte, él mismo ha reconocido públicamente la problemática de la burocracia que según refiere puede incentivar a que algunas personas busquen caminos inapropiados para resolver sus necesidades, pues donde pueden resolver el servicio resultan víctimas del "peloteo" y de respuestas superficiales (Mayoral, 2006: 4).

Ante este universo, las relaciones Estados y Movimientos Asociativos se caracterizan por: la fluctuación debido a múltiples factores; en muchos casos no logran armonizar con los interlocutores estatales con los que tienen que negociar; falta de comprensión y apoyo, imposición de criterios privilegiando objetivos de desarrollo de carácter sectorial; las asociaciones se aprovechan de determinados espacios que los proyectos institucionales brindan, para, de manera indirecta, tratar de satisfacer una amplia gama de necesidades; las dificultades materiales y pocas posibilidades de resolver, por ellos mismos, las barreras que se levantan ante sus proyectos sin ayuda del Estado, contribuyen al debilitamiento de sus propuestas, al agotamiento de sus miembros, y su disolución en muchos casos; la propia vocación autogestionaria que forma parte de la filosofía de base de gran parte de estos movimientos contra ciertos estereotipos de accionar político y con una estructura de organización social centralizada en exceso; la preocupación por parte de las instancias políticas sobre la manipulación de que pueden ser objeto en el terreno político estos grupos (Linares, 2004: 136-137).

Desde el punto de vista normativo existen regulaciones de la relación entre el Estado a través de los organismos de su administración central y las asociaciones. Las disposiciones de la Ley 54 de 1985 que regulan las relaciones de coordinación y colaboración entre las asociaciones y los órganos, organismos y dependencias estatales se establecen de común acuerdo teniendo en cuenta los objetivos que se propongan, las actividades que se desarrollen y lo dispuesto en el reglamento de esta ley (Art. 13); en ella tiene un peso la dimensión de control y fiscalización de estas asociaciones por parte de los órganos, organismos y dependencias estatales que realizarán inspecciones a las asociaciones con las que tienen relaciones para comprobar el cumplimiento de las normas acordadas y velar por que estas utilicen los recursos en beneficio social y en cumplimiento de la finalidad y objetivo que determinaron su constitución (Art. 15). Una esfera de interconexión entre el 
movimiento asociativo y las estructuras del Estado es el marco relacional que propicia el Ministerio de Justicia, sobre todo en el ejercicio de la dirección técnica normativa y metodológica de la actividad registral de asociaciones; el hecho de brindar asesoramiento técnico y la función de asesorar, inspeccionar y controlar el trabajo de las direcciones de justicia de los órganos provinciales del Poder Popular (ANPP, 1985). Se conoce de la constitución y habilitación de un Registro Público, encargado de la inscripción de sociedades civiles creadas al amparo de la legislación vigente (Ministerio de Justicia, 2006).

Para el caso específico de los acompañamientos, que dependen de la colaboración internacional para su financiamiento, el marco legal donde se deben mover son las regulaciones más generales de la ley que abarca las disposiciones generales de relación con las ONG. El Ministerio de Cultura, que "atiende" al CMMLK, dictó la Resolución no.88 que actualiza las funciones de un grupo de trabajo para la atención a las ONG en el Ministerio de Cultura. Dicho grupo, en el marco de esta resolución, vela por el estricto cumplimiento de los parámetros y disposiciones legales establecidas para la constitución, funcionamiento y control de las ONG; ejecuta visitas sistemáticas a las ONG vinculadas al MINCULT, las asesora y supervisa en materias relativas a su régimen jurídico, económico, laboral; atiende su proyección internacional; entre otras. La atención a las ONG se realiza en correspondencia directa con el objeto social y los fines de cada una de las organizaciones (Rimbau, entrevista, 2006).

La reciente Resolución $\mathrm{N}^{\circ}$ 15/2006 del Ministerio para la inversión extranjera y la colaboración económica deja en claro los principios que rigen la colaboración económica que recibe Cuba. Así, no se aceptan condicionamientos de tipo económico, político o social que conlleven una injerencia en los asuntos internos o que estén contra los principios de la Revolución; debe estar dirigida, fundamentalmente, a las prioridades establecidas por el Gobierno y en ningún caso favorecer a sectores de la población por razones étnicas, religiosas o de nacionalidad; no se permite la creación de sistemas de servicios sociales o de distribución de los recursos recibidos por la vía de la Colaboración Económica; las contrapartes cubanas garantizan el cumplimiento de los compromisos asumidos en materia de recursos humanos, materiales y financieros durante la ejecución del proyecto y su sostenibilidad después que cese el financiamiento externo; y por último que las entidades cubanas, las organizaciones de masas y sociales, asociaciones, fundaciones y sociedades civiles, legalmente constituidas, sólo podrán desarrollar Proyectos de Colaboración en correspondencia con su objeto social o actividad fundamental para la cual están autorizadas, entre otras (MINVEC, 2006: Art. 3). 
Una mediación del Estado en los proyectos de colaboración y por tanto, en cualquier experiencia de acompañamiento que tenga fondos provenientes del extranjero es el hecho de que la aprobación de todo proyecto tiene que pasar por las manos del MINVEC, previa coordinación con el organismo de la Administración Central del Estado que le corresponda -en el caso de los proyectos del CMMLK, es el Ministerio de Cultura-; otra, que se consigna en el artículo 13 son algunas formas de control de los proyectos: 1) autocontrol ejercido por las propias Partes del Proyecto en correspondencia con la Guía de Autocontrol que forma parte integrante de la Resolución; 2) las visitas de Control realizadas por las Áreas Políticas y las Delegaciones Territoriales, ambas del MINVEC, los Organismos de la Administración Central del Estado o Entidades responsables del Proyecto; las auditorías realizadas por el Ministerio de Auditoría y Control u otra entidad integrante del Sistema Nacional de Auditoria, o por entidades extranjeras en correspondencia con lo previsto en el documento rector del Proyecto, previo el cumplimiento de las regulaciones establecidas en el país (MINVEC, 2006).

En el marco de las estructuras de la comunidad, la existencia de Grupos gestores de proyectos puede ser tenida como un elemento de potencialidad para negociar con el Estado. De hecho, se ha corroborado por las experiencias que cuando se comenzaban a preocupar por "muchas problemáticas del barrio que no se tocaban de cerca", y en la medida que este grupo gestor comenzó a funcionar, el gobierno comenzó a mirarlo de una manera diferente. Se empieza a gestar un nivel de articulación más institucional, más allá que el nivel de articulación personal (Jesús Figueredo, acompañante del proyecto por el CMMLK, entrevista 2006).

Entre los expertos, los criterios que son coincidientes con respecto a la articulación entre actores son: la propensión a la subjetividad de un funcionario para decidir si una asociación es o no de "objetivo social”, el no respaldo como normativa a los movimientos comunitarios, lo que deslegitima su perfil asociativo y limita su autogestión y otras. El hecho de la no existencia de espacios de concertación en los cuales se integren visiones de trabajo de las asociaciones, de los movimientos comunitarios, está afectando la dinámica de atención a situaciones de pobreza o empobrecimiento en el barrio. Estas experiencias sirven de referente en el sentido que apuntan a maneras de articular estrategias y metodologías sobre todo si se trata de estrategias de superación de la pobreza ${ }^{15}$. Para esa óptima articulación se hacen imprescindibles in-

15 Sería necesario estudiar otras metodologías de intervención social como la gestión de proyectos o la animación cultural, que actualmente se utilizan en Cuba por otras organizaciones civiles y políticas. 
dicadores coincidentes en el tema de la pobreza porque aunque existe una perspectiva de la pobreza identificada con el bienestar, su atención debe ser puntual como han explicado tanto los expertos, como autores como Espina (2004), Zabala (1999), Ferriol (1999) y Alonso (2002).

Las iniciativas de los TTIB (como las otras) "son alternativas válidas, pero que si no buscan sus propias formas de autogestión dependen de otros fondos, que muchas veces pudieran ser estatales o no (entrevista a experto, 2006). Este factor choca con las limitaciones reales para desarrollar la economía local en un contexto de centralización reeditado. Las experiencias analizadas de alguna manera socializan relaciones de poder, dinamizan formatos participativos, pero quedan cruzadas de brazos en cuanto al tema de la generación de una economía local que tribute al autosostenimiento de los proyectos.

En resumen, en Cuba ningún esfuerzo de la sociedad civil en el campo de la superación o erradicación de la pobreza se divorcia de la mediación estatal. El rol centralizador del Estado en cuanto al diseño de las políticas sociales acentua el sentido universal y "masivo" de estos servicios (Martínez et al., 2000) y la exclusión de todo proceso de privatización de los sectores relacionados con la prestación de los servicios básicos de salud y educación, así como la seguridad y la asistencia social. Las intervenciones estatales en el barrio y la política social no cuentan con un marco jurídico que regule la relación estadosociedad civil en torno a la pobreza que siente pautas que puedan ser modificadas por experiencias puntuales de enfrentamiento, teniendo en cuenta que hay zonas de mayor vulnerabilidad social, y que las políticas tienen un alcance macrosocial y universal.

\section{CONCLUSIONES Y RECOMENDACIONES}

Deteniéndonos en las implicaciones empíricas de las posturas conceptuales alrededor de la relación Estado - sociedad civil se puede decir que en la amplia bibliografía consultada sobre esta problemática en el contexto de estudio, se advierte una lectura reduccionista de qué entender por sociedad civil -tanto en Cuba, como fuera de Cuba- que está afectando: 1) la delimitación de espacios y competencias en la esfera de la sociedad civil; 2) la integración de sujetos locales dentro de esa sociedad civil para una lucha más efectiva contra la pobreza y las expresiones de desigualdad que han venido apareciendo en Cuba.

De un lado, muchas veces la sociedad civil queda reducida a lo opuesto de la sociedad política y el Estado, identificándose, como advierte Acanda, con "un espacio antiestatal y antipolítico" (2004: 351). Esta es la visión con que trabaja el grupo de disidentes y el gobierno norteamericano en afán de promover una sociedad civil en activa oposición al socialismo (Friedman, 2006: 68). Esos grupos internos, por 
tanto, serían a los ojos norteamericanos los acreedores exclusivos de la asistencia del exterior. El hecho de que del exterior se conciba a la sociedad civil de esta forma se pudiera apuntar como un obstáculo que prejuzga al Estado cubano y que limita las posibilidades que puede tener el movimiento asociativo a partir de su temor a "los efectos denigradores de tal ayuda en la solidaridad interna, la igualdad y la moral colectivista" (ídem) y a la amenaza real de desestabilización interna que tienen estos grupos denominados disidentes.

Por otro lado se reducen sus componentes a lo que se llama "solo un puñado de organizaciones políticas y de masas ya existentes (Acanda, 2004: 354). La sociedad civil se identifica con las organizaciones políticas integradas, aunque a nivel discursivo y legal se incluyen las más de dos mil asociaciones que abarcan las más variadas temáticas; en la práctica estas condicionan en la mayoría de los casos las intervenciones en la comunidad en materia de pobreza. Específicamente en el marco de nuestro estudio de casos, ambas concepciones han afectado las diferentes posiciones con respecto a la superación de la pobreza y al trabajo por un desarrollo integral y socialista del bienestar social.

Por otra parte, pudiéramos concluir que ni el Estado cubano, ni las estrategias de la sociedad civil estudiadas se reconocen explícitamente como políticas de reducción de pobreza, sino que incluyen la superación de esta condición dentro de una estrategia más amplia de transformación social: en el caso del Estado, identificándolo con las políticas sociales y de bienestar; en el caso de la sociedad civil con el trabajo comunitario o el desarrollo comunitario indistintamente. Se asegura que los movimientos comunitarios son alternativas de superación de la pobreza en el ámbito más local de la sociedad, aunque muchas veces no se reconozca como tal (entrevistas a expertos, 2006).

La reticencia de todas las experiencias a hablar explícitamente de pobreza y a trabajar con un enfoque de políticas de pobreza, y el aprovechamiento del marco más integral de atención al bienestar -sin desestimar la atención particularizada a situaciones de pobreza- pudiera sospecharse como una estrategia -fructífera hasta ahora al parecer- de articulación con el Estado cubano que es, a fin de cuentas, el actor hegemónico a través de sus canales formales y sus aparatos ideológicos. Si en algún lugar parece imposible separar la sociedad civil del Estado es en Cuba, por la comprensión práctica y la complejidad que toman los procesos de la sociedad civil en la construcción socialista. Por otro lado, esta reticencia puede entenderse en un contexto donde existe una alta politización de la cuestión social que muchas veces limita las posibilidades de autogestión, sobre todo por las carencias económicas devenidas de la centralización de recursos. Politización que se explica, sobre todo en el discurso y el imaginario político, a partir de las condiciones de 
Cuba frente a su aislamiento económico y su coyuntura subalterna con respecto al orden social vigente encabezado por los Estados Unidos, el enemigo histórico número uno de la Revolución Cubana.

Puede concluirse que cuando se analizan en profundidad las dimensiones cualitativas de expresión de la pobreza, la desigualdad, la vulnerabilidad y la actual disposición de las políticas sociales en el contexto cubano, no parecen suficientes aún las estrategias, articulaciones y metodologías interventoras para la superación de manera irreversible de estas situaciones, muy a pesar de la voluntad política, centralizada, a nivel de proyecto político que este problema tiene y su rol en la creación del consenso.

Desde el punto de vista institucional se puede corroborar la hipótesis inicial de que las políticas y estrategias de estas instituciones funcionaban per se, en franca desconexión con las de sus similares, de alguna manera contribuyendo a la dispersión de fuerzas y a una descentralización que respondía a sus visiones y misiones con respecto a la cuestión del desarrollo local, deben ser replanteadas, matizando la dinámica de interconexión al nivel de que aunque no funcionan de manera óptima los canales y formatos existentes, y a veces no existe la voluntad de las partes de coolaborar, en estas experiencias concretas la relación está dada a niveles específicos y atendiendo a las características de cada proyecto.

Por otro lado, el nivel de "autonomía" y de "objeto social" de las instituciones de la sociedad civil está muchas veces mediado por su rol ideológico legitimante de la sociedad civil socialista y pocas veces se integra a una transformación integral de la vida de las personas en desventaja, a pesar de las experiencias concretas de ONG como estas que estudiamos que sí tienen un planteamiento de desarrollo sostenible desde una modificación de las prácticas culturales que contribuyen a reproducir la pobreza. De hecho, como acierta un experto entrevistado: "Un Estado fuerte, con pasos de centralización, corre el peligro de ignorar o no tomar en cuenta la capacidad que tienen instituciones de menor tamaño de complementar a estos esfuerzos del estado, o coadyuvar en estrategias trazadas por el estado, en su implementación en estos niveles porque tienen capacidades para ello". Del lado de la sociedad civil, estas experiencias dinamizan el sentido de lo político en contextos de fragilidad del tejido social. Contribuyen al ejercicio de deconstrucción de las relaciones sociales, sobre todo las predominantemente estatales, a partir del anuncio-denuncia de concepciones que naturalizan relaciones de poderes desiguales y enajenantes en el propio proceso cubano actual, de las que el socialismo no está exento como proceso social.

La generación y el potenciamiento de espacios microsociales, mejor "aterrizados en el contexto cubano", parece ser una condición de 
posibilidad muy fructífera para evaluar las necesidades reales de la gente en su medio de vida, sus situaciones sentidas de la pobreza, de lo que es estar excluido, que muchas veces son expresiones, incluso, de relaciones sociales heredadas de la cultura de la dominación esclavista y del modo de vida capitalista, sin por esto desestimar el rol también que puedan tener los procesos de diferenciación y distinción que generan exclusión dentro del socialismo como proceso social emergente.

Desde una perspectiva de actuación política y estratégica, sería pertinente el reconocimiento por parte de las instituciones estatales de una mayor atención a los procesos comunitarios más allá de lo normativo, el control y la fiscalización, y reconsiderar políticas y estrategias de intervención comunitaria para la superación de situaciones de pobreza y vulnerabilidad incorporando metodologías que puedan engrasar los mecanismos institucionales creados en su estructura para la atención a los problemas sociales. En este sentido, puntualmente, según sugieren los expertos entrevistados, sería necesario crear espacios de diálogo, evaluación y articulación, y potenciar los pocos existentes dentro de las relaciones ya establecidas, sobre la base de un mutuo entendimiento que supere la metodología de la sospecha que parece provenir de unos y otros en el diálogo.

A partir de los resultados de esta investigación sería recomendable dar seguimiento al estudio de la relación entre el Estado y la sociedad civil a partir de la profundización de estas experiencias de acompañamiento del CMMLK, al igual que se sugiere el estudio comparativo del resto de las experiencias de acompañamiento del Centro y de nuevas estrategias de superación de la pobreza de otro conjunto de ONG dentro de la sociedad civil socialista cubana. Para potenciar la dimensión comparativa tan necesaria en los estudios de pobreza, los datos resultantes de estas investigaciones contribuirían al mejor conocimiento de la problemática en Cuba, en el Caribe y en América Latina.

Por último y no menos relevante, sería importante retomar el debate sobre la sociedad civil desarrollado en la esfera pública por intelectuales y políticos cubanos en los noventa, para de ese modo avanzar en el mejor conocimiento conceptual y práctico de lo que se ha dado en llamar la sociedad civil socialista cubana. Retomar el debate que implica, sobre todo, pensar en roles, en posibilidades articulatorias, en esferas de competencia y en metodologías alternativas que contribuyan al mejoramiento de los formatos y dinámicas en los que se realiza la concepción socialista del proyecto social cubano y su irreversibilidad.

\section{Bibliografía}

Acanda, Jorge Luis 2003 "Amor y poder. La relación imposible (Homenaje a Foucault)” en Temas (La Habana), no. 32, pp. 118. 
Acanda, Jorge Luis 2004 Sociedad civil y superación de la pobreza", en Iñiguez, Luisa y Omar E. Pérez (comps.) Heterogeneidad social en la Cuba actual (La Habana: Centro de Estudio de Salud y Bienestar Humano).

Alonso, Aurelio 2002 "La pobreza vista en tres escalas. Reflexiones sobre el Caribe Hispano". Ponencia presentada al Seminario Internacional Estrategias de reducción de la pobreza en el Caribe. Los actores externos y su impacto en la reducción de la pobreza en el área (La Habana: CLACSO-CROP).

Asamblea Nacional del Poder Popular 1985 "Ley no. 54. Ley de Asociaciones, en La Gaceta Oficial de la República de Cuba, La Habana, 27 de diciembre de 1985, número 19, p. 119.

Asamblea Nacional del Poder Popular, 2000. Ley 91 de los Consejos Populares. Disponible en http://www.parlamentocubano.cu/espanol/ley91.htm

Azcuy, Hugo 1995 "Estado y sociedad civil en Cuba”, en Temas, (La Habana), no.4, octubre-diciembre.

Carranza, Julio et al. 1997 Cuba: la reestructuración de la economía. Una propuesta para el debate. Ed. Nueva Sociedad, Caracas.

Castro, Fidel. 2000 Discurso pronunciado por Fidel Castro en el acto de solidaridad con Cuba, efectuado en la Iglesia Riverside Harlem, Nueva York, 8 de septiembre de 2000. Disponible en: http: // www.cuba.cu/gobierno/discursos/2000/esp//f080900e.html.

CMMLK 2000 Programa General. Informe de Actividades Centro Memorial Dr. Martin Luther King jr. La Habana, documento interno.

CMMLK 2006 Programa Educación Popular. Centro Memorial Dr. Martin Luther King jr. La Habana, documento interno.

Declaraciones de Ernesto Suárez, Diputado, Secretario del Parlamento de la Asamblea Nacional, 2006.

Espina Prieto, Mayra 2004 Efectos sociales del reajuste económico: igualdad, desigualdad y procesos de complejización en la sociedad cubana. En, Omar Pérez. Reflexiones sobre economía cubana. La Habana, Editorial de Ciencias Sociales, pp. 385-419.

Espina, Mayra 2000 "Transición y dinámica de los procesos socioestructurales" en Monereo et al. (coords.) Cuba construyendo futuro. Reestructuración económica y transformaciones sociales. (España: El Viejo Topo/Fundación de Investigaciones Marxistas).

Espina, Mayra Paula 2004. Políticas de atención a la pobreza y la desigualdad. Examinando el rol del estado en la experiencia cubana. La Habana, CLACSO/CROP/CIPS 
Ferriol, Ángela 1999 "Política social cubana: situación y transformaciones", en Temas (La Habana), No. 11, julio-septiembre;

Friedman, Douglas 2006 "La sociedad civil en la Cuba contemporánea: la política estadounidense y la realidad cubana", en Temas (La Habana), no. 46: abril-junio.

González, Alfredo 1997 "Economía y sociedad: los retos del modelo económico", en Temas (La Habana), No. 11, julio-septiembre. Pp. 4.

KAIRÓS 2003 El barrio "La Marina": un proceso de desarrollo sustentable para la elevación de la autoestima y revalorización de sus costumbres y cultura. Matanzas, Proyecto de trabajo.

Linares (comp.) La participación: diálogo y debate en el contexto cubano. (La Habana: Centro de Investigación y Desarrollo de la Cultura Cubana Juan Marinello).

Martínez, Osvaldo, et al 2000 Investigación sobre Desarrollo Humano y Equidad en Cuba 1999. (La Habana: CIEM-PNUD- Ed. Caguayo).

Mayoral, María Julia, 2006. Declaraciones de Ernesto Suárez, Diputado, Secretario del Parlamento de la Asamblea Nacional, en Granma, 24 de mayo, p. 4.

Ministerio de Justicia, 2006, Resolución 296. Archivos Ministerio de Cultura: La Habana)

Ministerio para la Inversión Extranjera y la Colaboración Económica. MINVEC, 2006 RESOLUCIÓN No. 15 /2006 Documento electrónico.

Monreal Pedro y Julio Carranza 1997 "Problemas del desarrollo en Cuba: realidades y conceptos”, en Temas (La Habana), no. 11, julio-septiembre

Rodríguez José Luis y Carriazo George 1983 La erradicación de la pobreza en Cuba (La Habana: Editorial de Ciencias Sociales).

Roselló, Tamara 2005 El tren de la vida. Sistematización de los acompañamientos a experiencias locales. (La Habana: Editorial Caminos).

Williams, Marta Beatriz 2006 Caracterización del Consejo Popular Matanzas Este. Matanzas, Asamblea Municipal del Poder Popular, Documento de trabajo.

Zabala. María del Carmen 1999 "Alternativas de estrategias comunitarias para la atención a la pobreza”, en Caminos (La Habana), No. 15-16. 
